





\section{OEUVRES}

G.OMTI,TES

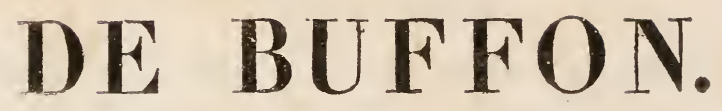

TOME X VII.

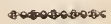

MA MMIFERES.

I V. 



\section{OEUVRES}

(C) NPLETSS
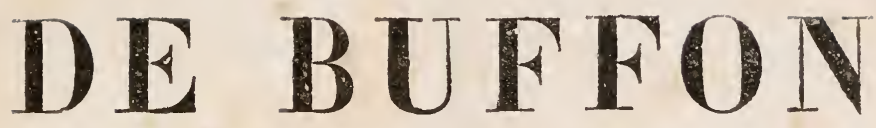

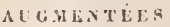

PAR M. F. CUVIER,

NEMBRE DE L'INSTITUT,

Acidicuie des Sciences

\section{DE DEUX VOLUMES}

\section{supplementaites}

OFFRANT LA DRSCRIPTION DES MAHUEERLS LT DES OISEAUX L JS PLUS REMARQUABLES DECOUVERTS JUS!U’A CE JOUK,

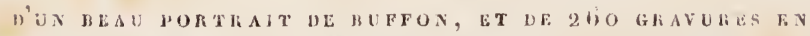

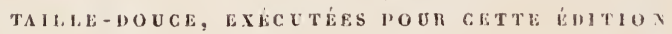

TAR LEG NEITLEUGS A UTISTES.

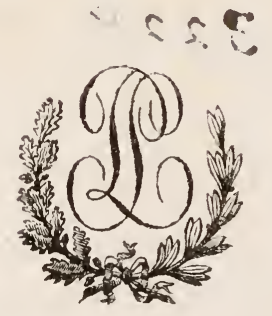

\section{A PARIS,}

CHEZ F. D. PILLOT, FUITEUR.

BUE HB SELAE-SAINT-GEHAIN, N 49

\$othos on

1830. 
3229 


\section{MAMMIFÉRE. \\ I V.}





\section{ANIMAUX SAUVAGES.}

\section{LE MOUFFLON ${ }^{1}$}

Ovis Ammon. L.

\section{ET LES AUTRES BREBIS ETTRANGËES.}

Lrs espèces les plus foibles des animaux utiles ont été réduites les premières en domesticité. L'on a soumis la brebis et la chèvre avant d'avoir dompté le cheval, le bœuf ou le chameau: on les a aussi transportées plus aisément de climats en climats; de là le grand nombre de variétés qui se trouvent dans ces deux espèces, et la difficulté de reconnoître quelle est la vraie souche de chacune. Il est certain, comme nous l'avons prouvé, que notre brebis domestique, telle qu'elle existe aujourd'hui, ne pourroit subsister d'elle-même, c'est-à-dire sans le secours de l'homme : il est donc également certain que la

1. Mot dérivé de l'italien mufione, nom de cet animal dans les iles de Corse et de Sardaigne : en grec, mousmon, selon Strabon; en latin, musmon ou musimon; en Sibérie, stepnie-barani, c'est-à-dire mouton sauvage, selon Gmelin; dans la Tartarie, chez les Monguls, argali, sclon le même Gmelin. 
nature ne l'a pas produile telle qu'elle est, mais que c'est entre nos nuains qu'elle a dégénéré. Il faut par conséquent chercher parmi les animaux sauvages ceux dont elle approche le plus; il faut la comparer avec les brebis domestiques des pays étrangers; exposer en même temps les différentes causes d'altération, de changement, et de dégénération, qui ont dû influer sur l'espèce, et voir enfin si nous ne pourrons pas, comme dans celle du bouf, en rapporter toutes les variétés, toutes les espèces prétendues, à une race primitive.

Notre brebis, telle que nous la connoissons, ne se trouve qu'en Europe et dans quelques provinces tempérées de l'Asie. Transportée dans les pays plus chauds, comme en Guinée, elle perd sa laine et se couvre de poil; elle y multiplie peu, et sa chair n'a plus le même goût. Dans les pays très froids, elle ne peut subsister; mais on trouve dans ces mêmes pays froids, et surtout en Islande, une race de brebis à plusieurs cornes, à queue courte, à laine dure et épaisse, au dessous de laquelle, comme dans presque tous les animanx du Nord, se trouve une seconde fourrure d'une laine plus donce, plus fine, et plus touffue : dans les pays chauds, au contraire, on ne voit ordiuairement que des brebis à cornes courtes et à queue longue, dont les unes sont couvertes de laine, les autres de poil, et d'autres encore de poil mêlé de laine. La première de ces brebis des pays chauds est celle que l'on appelle communément mouton de Barbarie, mouton d'Arabie, laquelle ressemble entièrement à notre brebis domestique, à l'exception de la queue, qui est si fort chargée de graisse, 
que souvent elle est large de plus d'un pied, et pèse plus de vingt livres. Au reste, cette brebis n'a rien de remarquable que sa queue, qu'elle porte comme si on lui avoit attaché un coussin sur les fesses. Dans cette race de brebis à grosse queue, il s'en trouve qui l'ont si courte et si pesante, qu'on leur donne une petite brouette pour la soutenir en marchant. Dans le Levant, cette brebis est couverte d'une très belle laine; dans les pays plus chauds, comme à Madagascar et aux Indes, elle est couverte de poils. La surabondance de la graisse, qui, dans nos moutons, se fixe sur les reins, descend dans ces brebis sous les vertèbres de la queue; les autres parties du corps en sont moins chargées que dans nos moutons gras. C'est au climat, à la nourriture, et aux soins de l'homme, qu'on doit rapporter cette variété; car ces brebis à large ou longue queue sont domestiques comme les nôtres, et même elles demandent beaucoup plus de soin et de ménagement. La race en est beaucoup plus répandue que celle de nos brebis : on la trouve communément en Tartarie, en Perse, en Syrie, en Égypte, en Barbarie, en Éthiopie, au Mozambique, à Madagascar, et jusqu'au cap de BonneEspérance.

On voit dans les îles de l'Archipel, et principalement dans l'île de Candie, une race de brebis domestiques, de laquelle Belon a donné la figure et la description sous le nom de strepsicheros. Cette brebis est de la taille de nos brebis ordinaires; elle est, comme celles-ci, couverte de laine, et elle n'en diffère que par les cornes, qu'elle a droites et cannelées en spirale. 
Enfin dans les contrées les plus chaudes de l'Afrique et des Indes, on trouve une race de grandes brebis à poil rude, à cornes courtes, à oreilles pendantes, avec une espèce de fanon et des pendants sous le cou. Léon l'Africain et Marmol la nomment adimain, et les naturalistes la connoissent sous les noms de belier du Sénégat, belier de Guinée, brebis d'Angola, etc. Elle est domestique comme les autres, et sujette de même à des variétés. Nous donnons ici la figure de ces deux brebis, qui, quoique différentes entre elles par des caractères particuliers, se ressemblent à tant d'autres égards, qu'on ne peut guère douter qu'elles ne soient de la même race. C'est de toutes les brebis domestiques celle qui paroît approcher le plus de l'état de nature; elle est plus grande, plus forte, plus légère, et par conséquent plus capable qu'aucune autre de subsister par elle-même. Mais comme on ne la trouve que dans les pays plus chauds, qu'elle ne peit souffrir le froid, et que dans son propre climat elle n'existe pas par elle-même comme un animal sauvage, qu'au contraire elle ne subsiste que par le soin de l'homme, qu'elle n'est qu'animal domestique, on ne peut pas la regarder comme la souche première ou la race primitive, de laquelle toutes les autres auroient tiré leur origine.

En considérant done, dans l'ordre du climat, les brebis qui sont purement domestiques, nous avons, $1^{\circ}$. Ia brebis du Nord à plusieurs cornes, dont la laine est rude et fort grossière. Les brebis d'Islande, de Gothlande, de Moscovie, et de plusieurs autres endroits du nord de l'Europe, ont toutes la laine grosse, et paroissent ồre de cette même race. 
LE IIOUFFLON, ele.

$2^{\circ}$ Notre brebis, dont la laine eșt très belle et fort fine dans les climats doux de l'Espagne et de la Perse, mais qui, dans les pays très chauds, se change en un poil assez rude. Nous avons déjà observé celte conformité de l'influence desclimats de l'Espagne et du Chorason, province de Perse, sur le poil des chèvres, des chats, des lapins, et elle agit de même sur la laine des brebis, qui est trìs belle en Espagne, et plus belle encore dans cette partie de la Perse.

$3^{\circ}$ La brebis à grosse queue, dont la laine est aussi fort belle dans les pays tempérés, tels que la Perse, la Syrie, l'Égypte; mais qui, dans des climats plus chauds, se change en poil plus ou moins rude.

$4^{\circ}$ La brebis strepsicheros ou mouton de Crète, qui porte de la laine comme les nôtres et leur ressemble, à l'exception des cornes, qui sont droites et cannelées en vis.

$5^{\circ}$ L'adimain, ou la grande brebis du Sénégal et des Indes, qui nulle part n'est couverte de laine, et porte au contraire un poil plus ou moins court et plus ou moins rude, suivant la chaleur du climat. Toutes ces brebis ne sont que des variétés d'une seule et même espèce, et produiroient certainement toutes les unes avec les autres, puisque le bouc, dont l'espèce est bien plus éloignée, produit avec nos brebis, comme nous nous en sommes assurés par l'expérience. Mais quoique ces cinq ou six races de brebis domestiques soient toutes des variétés de la même espèce, entièrement dépendantes de la différence du climat, du traitement, et de la nourriture, aucune de ces races ne paroît être la souche primitive et commune de toutes; aucune n'est assez forte, assez légère, assez vive, pour ré- 
sister aux animaux carnassiers, pour les éviter, pour les fuir : toutes ont également besoin d'abri, de soin, de protection; toutes doivent donc être regardées comme des races dégénérées, formées des mains de l'homme, et par lui propagées pour son utilité. En même temps qu'il aura nourri, cultivé, multiplié ces races domestiques, il aura négligé, chassé, détruit la race sauvage, plus forte, moins traitable, et par conséquent plus incommode et moins utile : elle ne se trouvera donc plus qu'en petit nombre dans quelques endroits moins habités où elle aura pu se maintenir. Or on trouve dans les montagnes de Grèce, dans les îles de Chypre, de Sardaigne, de Corse, et dans les déserts de la Tartarie, l'animal que nous avons nommé mouflon, et qui nous paroît être la souche primitive de toutes les brebis. Il existe dans l'état de nature, il subsiste et se multiplie sans le secours de l'homme; il ressemble, plus qu'aucun autre animal sauvage, à toutes les brebis domestiques; il est plus vif, plus fort, et plus léger qu'aucune d'entre elles; il a la tête, le front, les yeux et toute la face du belier; il lui ressemble aussi par la forme des cornes et par l'habitude entière du corps; enfin il produit avec la brebis domestique, ce qui seul suffiroit pour démontrer qu'il est de la même espèce, et qu'il en est la souche. La seule disconvenance qu'il y ait entre le mouflon et nos brebis, c'est qu'il est couvert de poil, et non de laine : mais nous avons vu que, même dans les brebis domestiques, la laine n'est pas un caractère essentiel; que c'est une production du climat tempéré, puisque dans les pays chauds ces mêmes brebis n'ont point de laine et sont toutes couvertes de poil, et que dans les 
pays très froids leur laine est encore aussi grossière, aussi rude que le poil. Dès lors il n'est pas étonnant que la brebis originaire, la brebis primitive et sauvage, qui a dû souffrir le froid et le chaud, vivre et se multiplier sans abri dans les bois, ne soit pas couverte d'une laine qu'elle auroit bientôt perdue dans les broussailles, d'une laine que l'exposition continuelle à l'air et l'intempérie des saisons auroient en peu de temps altérée et changée de nature. D'ailleurs, lorsqu'on fait accoupler le bouc avec la brebis domestique, le produit est une espèce de mouflon; car c'est un agneau couvert de poil. Ce n'est point un mulet infécond; c'est un métis qui remonte à l'espèce originaire, et qui paroît indiquer que nos chèvres et nos brebis domestiques ont quelque chose de commun dans leur origine; et comme nous avons reconnu par l'expérience que le bouc produit aisément avec la brebis, mais que le belier ne produit point avec la chèvre, il n'est pas douteux que dans ces animaux, toujours considérés dans leur état de génération et de domesticité, la chèvre ne soit l'espèce dominante, et la brebis l'espèce subordonnée, puisque le bouc agit avec puissance sur la brebis, et que le belier est impuissant à produire avec la chèvre. Ainsi notre brebis domestique est une espèce bien plus dégénérée que celle de la chèvre, et il y a tout lieu de croire que si l'on donnoit à la chèvre le mouflon au lieu du belier domestique, elle produiroit des chevreaux qui remonteroient à l'espèce de la chèvre, comme les agneaux produits par le bouc et la brebis remontent à l'espèce du belier.

Je sens que les naturalistes qui ont établi leurs méa 
thodes, et, j'ose dire, fondé tout es leurs connoissances en histoire naturelle, sur la distinction de quelques caractères particuliers, pourront faire ici des objections, et je vais tâcher d'y répondre d'avance. Le premier caractère des moutons, diront-ils, est de porter de la laine, et le premier caractère des chèvres est d'être couvertes de poil : le second caractère des beliers est d'avoir les cornes courbées en cercle et tournées en arrière; celui des boucs est de les avoir plus droites et tournées en haut. Ce sont là, dirontils, les marques distinctives et les signes infaillibles auxquels on reconnoîtra toujours les brebis et les chèvres; car ils ne pourront se dispenser d'avouẹr en même temps que tout le reste leur est commun : les unes et les autres n'ont point de dents incisives à la mâchoire supérieure, et en ont huit à l'inférieure; les unes et les autres n'ont point de dents canines : ces deux espèces ont également le pied fourchu; elles ont des cornes simples et permanentes, toutes deux ont les mamelles dans la même région du ventre, toutes deux vivent d'herbes et ruminent. Leur organisation intérieure est encore bien plus semblable, car elle paroît être absolument la même dans ces deux animaux; le même nombre et la même forme pour les estomacs, la même disposition de viscères et d'intestins, la même substance dans la chair, la même qualité particulière dans la graisse et dans la liqueur séminale, le même temps pour la gestation, le même temps encore pour l'accroissement et pour la durée de la vie. Il ne reste donc que la laine et les cornes par lesquelles on puisse différencier ces espèces. Mais, comme nous l'avons déjà fait sentir, la 
laine est moins une substance de la nature qu'une production du climat, aidé des soins de l'homme, et cela est démontré par le fait. La brebis des pays chauds, la brebis des pays froids, la brebis sauvage, n'ont point de laine, mais du poil; d'autre côté, les chèvres dans des climats très doux ont plutôt de la laine que du poil, car celui de la chèvre d'Angora est plus beau et plus fin que la laine de nos moutons. Ce caractère n'est donc pas essentiel; il est purement accidentel et même équivoque, puisqu'il peut également appartenir ou manquer à ces deux espèces, suivant les différents clinats. Celui des cornes paroît être encore moins certain; elles varient pour le nombre, pour la grandeur, pour la forme, et pour la direction. Dans nos brebis domestiques, les beliers ont ordinairement des cornes et les brebis n'en ont point. Cependant j'ai souvent vu dans nos troupeaux des beliers sans cornes et des brebis avec des cornes; j'ai non seulement vu des brebis avec deux cornes, mais même avec quatre. Les brebis du Nord et d'Islande en ont quelquefois jusqu'à huit. Dans les pays chauds, les beliers n'en ont que deux très courtes, et souvent ils en manquent ainsi que les brebis. Dans les uns, les cornes sont lisses et rondes; dans les autres, elles sont cannelées et aplaties : la pointe, au lieu d'être tournée en arrière, est quelquefois tournée en dehors ou en devant, etc. Ce caractère n'est donc pas plus constant que le premier, et par conséquent il ne suffit pas pour établir des espèces différentes ${ }^{1}$. La gros-

1. M. Linnæus a fait avec raison six variétés et non pas six espèces dans la brebis domestique : $2^{\circ}$ Ovis rustica cornut $; 2^{\circ}$ Anglica mutica; cauda serotoque ad genua pendulis; $5^{\circ}$ Hispanica cornuta, spiru extror- 
seur et la longueur de la queue ne suffisent pas non plus pour constituer des espèces, puisque cette queue est, pour ainsi dire, un membre artificiel qu'on fait grossir plus ou moins par l'assiduité des soins et l'abondance de la bonne nourriture, et que d'ailleurs nous voyons, dans nos brebis domestiques, des races, telles que certaines brebis angloises, qui ont la queue très longue en comparaison des brebis ordinaires. Cependant les naturalistes modernes, uniquement appuyés sur ces différences des cornes, de la laine, et de la grosseur de la queue, ont établi sept ou huit espèces différentes dans le genre des brebis. Nous les avons toutes réduites à une; du genre entier nous ne faisons qu'une espèce; et cette réduction nous paroît si bien fondée, que nous ne craignons pas qu'elle soit démentie par des observations ultérieures. Autant il nous a paru nécessaire, en composant l'histoire des animaux sauvages, de les considérer en eux-mêmes un à un et indépendamment d'aucun genre, autant sum tracta; $4^{\circ}$ polycerata e Gothlandia; $5^{\circ}$ A fricana pro lana pilis brevibus hirta; $6^{\circ}$ laticauda platyura Arabica. (Linn. Syst. nat., edit. X, pag. 70.) Toutes ces brebis ne sont en effet que des variétés, auxquelles cet auteur auroit dû joindre l'adimain ou belier de Guinée, et le strepsicheros de Candie, dont il fait deux espèces différentes entre elles et diffẻrentes de nos brebis; et de même, s'il eût vu le mouflon, et qu'il eût été informé qu'il produit avec la brebis, ou qu'il ê̂t seulement consulté le passage de Pline au sujet du musimon, il ne l'auroit pas mis dans le genre des chèrres, mais dans celui des brebis. M. Brisson a non sculement placé de même le mouflon parmi les chèvres, mais il y a encore placé le strepsicheros, qu'il appelle Hircus laniger; et de plus, il a fait quatre espèces distinctes de la brebis domestique couverte de laine, de la brebis domestique couverte de poil dans les pays chauds, de la brebis à large queue, et de la brebis à longue queue. Nous réduisons, comme l'on voit, quatre espèces selon M. Linnæus, et sept espèces suivant M. Brisson, à une seule. 
croyons-nous, au contraire, quill faut adopter, étendre les genres dans les animaux domestiques, et cela parce que dans la nature il n'existe que des individus et des suites d'individus, c'est-à-dire des espèces; que nous n'avons pas influé sur celles des animaux indépendants, et qu'au contraire nous avons altéré, modifié, changé celles des animaux domestiques. Nous avons donc fail des genres physiques et réels, bien différents de ces genres métaphysiques et arbitraires qui n'ont. jamais existé qu'en idée. Ces genres physiques sont réellement composés de toutes les espèces que nous avons maniées, modifiées et changées; et comme toutes ces espèces, différemment altérées par la main de l'homme, n'ont cependant qu'une origine commune et unique dans la nature, le genre entier ne doit former qu'une espèce. En écrivant, par exemple, l'histoire des tigres, nous avons admis autant d'espèces différentes de tigres qu'il s'en trouve en effet dans toutes les parties de la terre, parce que nous sommes très certains que l'homme n'a jaınais manié ni changé les espèces de ces animaux intraitables, qui subsistent loutes telles que la nature les a produites. Il en est de même de tous les autres animaux libres et indépendants. Mais en faisant l'histoire des bœufs ou des moutons, nous avons réduit tous les bœufs à un seul bœuf, et tous les moutons à un seul mouton, parce qu'il est également certain que c'est l'homme, et non pas la nature, qui a produit les différentes races dont nous avons fait l'énumération. Tout concourt à appuyer cette idée, qui, quoique lumineuse par elle-même, ne sera peut-être pas assez sentie. Tous les bœufs produisent ensemble; les ex- 
périences de M. de La Nux et les témoignages de MM. Mentzelius et Kalm nous en ont assurés. Toutes les brebis produisent entre elles, avec le mouflon et même avec le bouc; mes propres expériences me l'ont appris. Tous les bœufs ne font qu'une espèce, et toutes les brebis n'en font qu'une autre, quelque étendu qu'en soit le genre.

Je ne me lasserai jamais de répéter ( vu l'importance de la chose) que ce n est pas par de petits caractères particuliers que l'on peut juger la nature, et qu'on doit en différencier les espèces; que les méthodes, loin d'avoir éclairci l'histoire des animaux, n'ont au contraire servi qu'à l'obscurcir, en multipliant les dénominations, et les espèces autant que les dénonninations, sans aucune nécessité, en faisant des genres arbitraires que la nature ne connoît pas, en confondant perpétuellement les êtres réels avec des êtres de raison, en ne nous donnant que de fausses idées de l'essence des espèces, en les mêlant ou les séparant sans fondement, sans connoissance, souvent sans avoir observé ni même vu les individus, et que c'est par cette raison que nos nomenclateurs se trompent à tout moment, et écrivent presque autant d'erreurs que de lignes : nous en avons déjà donné un si grand nombre d'exemples, qu'il faudroit une prévention bien aveugle pour pouvoir en douter. M. Gmelin parle très sensément sur ce sujet, et à l'occasion même de l'animal dont il est question ${ }^{1}$.

1. "Les argali ou stepnie-barani, qui óccupent, dit-il, les montagnes n de la Sibérie méridionale, depuis le fleuve Irtisch jusqu'au Kamts" chatka, sont des animaux extrêmement vifs, et cette vivacité semble - Les exclure de la classe des moutons, et les ranger plutôt dans la 
Nous sommes convaincus, comme le dit M. Gmelin, qu'on ne peut acquérir des connoissances de la

* classe des cerfs. J'en joindrai ici une courte description, qui fera - voir que ni la vivacité ni la lenteur, ui la laine ni le poil dont l'ani- mal est couvert, ni les cornes courbes ni les droites, ni les cornes - permanentes, ni celles que l'animal jette tous les ans, ne sont des - marques suffisamment caractéristiques par lesquelles la nature dis- tingue ses classes; elle aime la variété; et je suis persuadé que si - nous savions bien gouverner nos sens, ils nous conduiroient sou*. vent à des marques beoucoup plus essentielles touchant la différence * des animanx, que ne nous les apprennent communément les lu" mières de notre raison, qui presciue toujours ne touchent ces mar" ques distinclives que très superficiellement. La forme extérieure de - l'animal, quant à la tête, au cou, aux pattes et à la quene courte, - s'accorde avec celle du cerf, à qui cet animal ressemble aussi, - comme je l'ai déjà dit, par sa vivaeité, si bien qu'on diroit volontiers " qu'il est encore plus sauvage. L'animal que j’ai vu étoit réputé d'a* voir trois ans, et cependant dix hommes n'osèrent l'attaquer pour " le dompter. Le plus gros de cette espèce approche de la taille d'un n daim : celui que j'ai vu avoit, de la terre jusqqu'au haut de la tête, n une aune et demie de Russie de haut; sa longueur, depuis l'endroit "d'où naissent les cornes, étoit d'une aune trois quarts. Les cornes n naissent au dessus et tout près des yeux, droit devant les oreilles; " elles se courbent d'abord en arrière, et ensuite en avant, comme " un cercle; l'extrémité est tournée un peu en haut el en dehors : de* puis leur naissance jusquà peu près de la moitié, elles sont fort " ridées; plus haut elles sont plus unies, sans cependant l'être tout" à-fait. C'est vraisemblablement de cette forme đes cornes que les - Russes ont pris occasion de donner à cet animal le nom de mouton "sauvage. Si l'on peut s'en rapporter aux récits des habitants de ces " cantons, toute sa force consiste dans ses cornes. On dit que les be- liers de cetle espèce se battent souvent en se poussant les uns les " autres avec les cornes, et se les abattent quelquefois; en sorte qu'on " trouve souvent, sur la steppe, de ces cornes dont l'ouverture auprès " de la tête est assez grande pour que les petits renards des steppes - se servent souvent de ces cavités pour s'y retirer. Il est aisé de cal" culer la force quil faut pour abattre une pareille corne, puisque n ces cornes, tant que l'animal est vivant, augmentent continuelle- ment d'épaisseur et de longueur, et que l'endroit de leur naissance 
nature qu'en faisant un usage réfléchi de ses sens, en voyant, en observant, en comparant, et en se refu-

" au crâne acquiert toujours une plus grande dureté. On prétend " qu'une corne bien venue, en prenant la mesure selon sa courbure, " a jusqu'à deux aunes de long, qu'elle pèse entre trente et quarante n livres de Russie, et qu'à sa naissance elle est de l'épaisseur du poing. "Les cornes de celui que j'ai vu étoient d'un jaune blanchâtre : mais "plus l'animal vieillit, plus ses cornes tirent vers le brun et le noi" râtre. Il porte ses oreilles extrêmement droites; elles sont pointues " et passablement larges. Les pieds ont des sabots fendus, et les pattes " de devant ont trois quarts d'aune de haut; celles de derrière en ont "davantage; quand l'animal se tient debout dans la plaine, ses pattes " de devant sont toujours étendues et droites; celles de derrière sont „ courbées, et cette courbure semble diminuer, plus les endroits par n où l'animal passe sont escarpés. Le cou a quelques plis pendants. "La couleur de tout le corps est grisâtre mêlé de brun : le long du " dos il y a une raie jaunâtre, ou plutôt roussâtre, ou couleur de re" nard, et l'on voit cette même couleur au derrière, en dedans des " pattes et au ventre, où elle est un peu plus pále. Cette couleur dure " depuis le commencement d'août, pendant l'automne et l'hiver, jus" qu'au printemps, à l'approche duquel ces animaux muent, et de" viennent partout plus roussâtres. La deuxième mue arrive vers la fin n de juillet : telle est la figure des beliers. Les chèvres ou femelles sont n toujours plus petites; et quoiqu'elles aient pareillement des cornes, ces " cornes sont très petites et minces en comparaison de celles que je " viens de décrire, et même ne grossissent guère avec l'âge. Elles sont " toujours à peu ,près droites, n'ont presque point de rides, et ont à " peu près la forme de celles de nos boucs privés.

"Les parties intérieures, dans ces animaux, sont conformées comme " dans les autres bêtes qui ruminent : l'estomac est composé de quatre " cavités particulières, et la vessie du fiel est très considérable. Leur * chair est bonne à manger, et a à peu près le goût du chevreuil; la " graisse surtout a un goût délicieux, comme je l'ai dẻjà remarqué " ci-dessus, sur le témoignage des nations du Kamtschatka. La nour"riture de l'animal est de l'herbe. Ils s'accouplent en automne et au "printemps : ils font un ou deux petits.

„Par le poil, le goût de la chair, la forme, et la vivacité, l'animal n appartient à la classe des cerfs et des biches; les cornes permanentes, " qui ne tombent pas, l'excluent de cette classe : les cornes courbées 
sant en même temps la liberté téméraire de faire des méthodes, de petits systèmes nouveaux, dans lesquels on classe des êtres que l'on n'a jamais vus, et dont on ne connoît que le nom; nom souvent équivoque, obscur, mal appliqué, et dont le faux emploi confond les idées dans le vague des mots, et noie la vérité dans le courant de l'erreur. Nous sommes aussi très convaincus, après avoir vu des moullons vivants, et après les avoir comparés à la description ci-dessus de M. Gmelin, que l'argali est le même animal. Nous avons dit qu'on 'e trouve en Europe, dans des pays assez chauds, tels que la Grèce ${ }^{1}$, les îles de Chypre, de Sardaigne, et de Co rse : néanmoins il se trouve aussi, et même en plus grand nombre, dans toutes les montagnes de la partie méridionale de la Sibérie,

" en eerele lui donnent quelque ressemblance avec les moutons; le " défaut de laine et la vivacité l'en distinguent absolument : le poil, le " séjour sur des rochers et hauteurs, et les fréquents eombats, rap" prochent assez cet aninial de la classe des eaprieornes; le défaut de " barbe et les eornes courbes leur refusent eette classe. Ne pourroit" on pas plutôt regarder eet animal eomme formant une elasse parti" eulière, et le reeonnoître pour le musimon des anciens? En effet, " il ressemble singulièrement à la description qu'en donne Pline, et " encore micux le savant Gesner. .

Ge passage est tiré de la version rnsse, imprimée à Pétersbourg en ${ }_{17} 75$, en deux volumes in- $4^{\circ}$, de la Relation d'un voyage par terre an Kantschatka, par MM. Nuller, de La Croière, et Gmelin, auteur de l'ouvrage, dont l'original est en allemand. La traduetion françoise ma été eommuniquée par M. de l'Isle, de l'Académie des Scienees. Il est à désirer quïl la doune bientôt au public. Celte relation, eurieuse par elle-mème, est en même temps écrite par un homme de bon sens, et très versé dans l'histoire naturelle:

1. On ne peut pas douter que le tragelaphus de Belon ne soit notre mouflon; et l'un voit, par les indications de cet auteur, qu'il a vu, déerit, et dessiné eet animal en Grèce, et qu'il se trouve daus les montagnes qui sont entre la Macédoine et la Servie. 
sous un climat plutôt froid que tempéré; il paroît même y être plus grand, plus fort, et plus vigourenx. Il a donc pu peupler également le Nord et le Midi, et sa postérité, devenue domestique après avoir longtemps subi les maux de cet état, aura dégénéré, et pris, suivant les différents traitements et les climats divers, des caractères relatifs, de nouvelles habitudes de corps, qui, s'étant ensuite perpétués par les générations, ont formé notre brebis domestique et loutes les autres races de brebis dont nous avons parlé.

Sur les chèrres ètrangères, grandes et petites.

* Pontoppidan rapporte que les chèvres sont en Norwége en si grande quantité, que, dans le seul port de Berghen, on embarque tous les ans jusqu’à quatre-vingt mille peaux de boues non apprêtées, sans compter celles auxquelles on a déjà donné la facon. Les chèvres conviennent, en effet, beaucoup à la nature de ce pays; elles vont chercher leur nourriture jusque sur les inontagnes les plus escarpées. Les mâles sont fort courageux, ils ne craignent pas un loup seul, et ils aident même les chiens à défendre le troupeau.

Nous avons parlé des chèvres de Syrie à oreilles pendantes, qui sont à peu près de la grandeur de nos chèvres, et qui peuvent produire avec elles, même dans notre climat: mais il existe à Madagascar une chèvre considérablement plus grande, et qui a aussi les oreilles pendantes, et si longues que, lorsqu'elle descend, les oreilles lui couvrent les yeux; ce qui 
l'oblige à un mouvement de tête presque continuel pour les jeter en arrière, en sorte que, quand on la poursuit, elle cherche toujours à grimper et jamais à descendre. Cette indication, qui nous a été donnée par M. Commerson, est trop succincte pour qu'on puisse dire si cette chèrre est de la même race que celle de Syrie, ou si c'est une race différente qui auroit également les oreilles pendantes.

M. le vicomte de Querhoent nous a communiqué la note suivante :

"Les chèvres et les cabris qu'on a lâchés à l'île de l'Ascension y ont beaucoup multiplié; mais ils sont fort maigres, surtout dans la saison sèche. Toute l'île est battue des sentiers qu'ils ont faits; ils se retirent la nuit dans les excavations des montagnes; ils ne sont pas tout-à-fait aussi grands que les chèvres et les cabris ordinaires; ils sont si peu vigoureux, qu'on les prend quelquefois à la course; ils ont presque tous le poil d'un brun foncé."

\section{LE BELIER ET LA BREBIS}

DE VALACHIE.

Nous donnons aussi la figure (planche 2) d'un belier et d'une brebis dont le dessin m'a été envoyé par feu M. Collinson, de la Société royale de Londres, sous les noms de Valachian ram et Valachian ewc, c'est-d̀-dire belier et brebis de Valachie. Comme cet habile naturaliste est décédé peu de temps après, je n'ai pu savoir si cette race de brebis, dont les cornes sont d'une forme assez différente de celle des autres, 
est commune en Valachie, ou si ce ne sont que deux individus qui se sont trouvés par hasard différer de l'espèce commune des beliers et des brebis de ce même pays.

\section{B BLIER DE TUNIS.}

Nous donnons aussi la figure (planche /) d'un belier que l'on montroit à la foire Saint-Germain, en 1774 , sous le nom de belier du cap de Bonne-Espérance. Ce même belier avoit été présenté au public, l'année précédente, sous le nom de belier du mogol à grosse queue; mais nous avons su qu'il avoit été acheté à Tunis, et nous avons jugé que c'éloit, en effet, un belier de Barbarie, qui ne diffère de celui dont nous avons donné la figure que par la queue, qui est beaucoup plus courte, et en même temps plus plate et plus large à la partie supérieure. La tête est aussi proportionnellement plus grosse, et tient de celle du belier des Indes; le corps est bien couvert se laine, et les jambes sont courtes, même en comparaison de nos moutons; les cornes sont aussi de forme et de grandeur un peu différentes de celles du mouton de Barbarie. Nous l'avons nommé belier de Tunis, pour le distinguer de l'autre; mais nous sommes persuadés que tous deux sont du même pays de la Barbarie, et de races très voisines ${ }^{1}$.

1. Le belier de Tunis diffère de ceux de notre pays non seulement par sa grosse et large quene, mais encore par ses proportions : il est plus bas de jambes, et sa tête paroit forte et plus arrquée que celle de nos beliers; sa léve inferieure descend en pointe au bout de la mâchoire, et fait le bee de lièvre. Ses cornes, qui font la volute, vont 


\section{LE MORVANT DE LA CHINE.}

Enfin nous donnons aussi la description d'un belier que l'on montroit de même à la foire Saint-Germain,

en arrière; elles ont six pouces mesurées en ligne droite, et dix pouces une ligne de cireonvolution, sur deux pouces deux lignes de grosseur à l'origine; elles sont blanches et annelées de rides, comme dans les autres beliers. Les eornes qui passent par dessus les oreilles les rendent pendantes; elles sont larges, et finissent en pointe. Cet animal domestique est fort laineux, surtout sur le ventre, les cuisses, le cou, et la queue. Sa laine a plus de six pouces de long en bien des endroits; elle est blanche en général, à l'exeeption qüil y a du fauve foneé sur les oreilles, et que la plus grande partie de la tête et les pieds sont aussi d'un fauve foncé tirant sur le brun. Ge que ee belier a de singulier, c'est la queue, qui lui eouvre tout le derrière : elle a onze pouces de large, sur treize pouees neuf lignes de long; son épaissear est de trois pouces onze lignes; cette partie charnue est ronde, et finit en pointe ( par une petite vertèbre, qui a quatre pouees trois lignes de longueur), en passant sous le ventre, entre les jambes ou tombant tout droit : pour lors, le floc de laine du bout de la queue semble toueher à terre. Cette queue est comme méplate dessus comme dessous, s'enfonce dans le milieu, et y forme comme une foible gouttière : le dessus de eette queue, et la plus grande partie de son épaisseur, sont eouverts de grande laine blanche; mais le dessous de eette même queue est sans poil et d'une ehair fraiehe, de sorte que, quand on lève ectte queue, on croiroit voir une partie des fesses d'un enfant.

La longueur de son corps, mesuré en ligne droite depuis le bout du museau jusqu'à l'anus, est de 3

Longueur de la tête depuis le bout du museau jusqu'à l'origine des cornes. ......... . . 7 11

Longueur de l'ceil d'un angle à l'autre. . . . . " 112

Distance entre les angles antérieurs des yeux. . " " 59

Distanee entre l'angle antérieur et le bout des

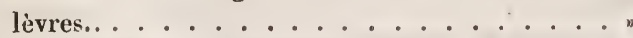

Longueur des oreilles. .

51 
en 1774 , sous le nom de morvant de la Chine. Ce belier est singulier en ce qu'il porte sur le cou une espèce de crinière, et qu'il a sur le poitrail et sous le cou de très grands poils, qui pendent et forment une espèce de longue cravate, mêlée de poils roux el de poils gris, longs d'environ dix pouces, et rudes au toucher. Il porte sur le cou une crinière de poils droits, assez peu épaisse, mais qui s'étend jusque sur

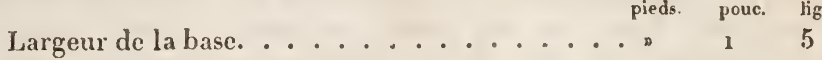

Distance entre les oreill es et les cornes. . . . . . 1

Distance entre les deux oreilles, prise en bas. . . $4 \quad 4 \quad 6$

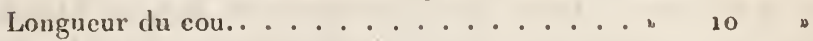

Circonférence près de la tête. . . . . . . 1164

Hauteur du train de devant. . . . . . . 2 "

Hanteur du train de derrière. . . . . . . . $22_{2}$

Circonférence du corps, prise derrière les jambes

de devant. ........................ $3{ }_{2} 6$

Circonférence à l'en droit le plus gros. . . . . $\begin{array}{llll}3 & 8 & 2\end{array}$

Circ onférence devant les jambes de derrière.. . . 3444

Longuenr du tronçon de la queue. . . . . . 1 1 19

Sa largeur. . . . . . . . . . . . . 11 "

Longueur du bras depuis le coude jusqu'au genou. ^ $\quad \begin{array}{lll}7 & 9\end{array}$

Longueur du canon............. . . 5 . 6

Longueur du paturon. . . . . . . . . 16

Circonférence de la couronne............ 4 1

Hanteur depuis le bas du pied jusqu'au genou. . . 1 $4 \quad 4 \quad 6$

Longueur de la cuisse depuis la rotule jusqu'au jarret. .................. „5

Lungueur du canon depu is le jarret jusqu'au boulet. " $6 \quad 6 \quad 8$

Longueur des ergots. ........... . . $2{ }_{2}{ }_{1}$

Hauteur des sabots. .................. 18

Longueur depuis la pince jusqu'au talon, dans les

pieds de devant. ..................... 32

Longueur dans les pieds de derrière. . . . . . 2 24

longueur des deux sabots priz ensemble dans les

pieds de devant. . . . . . . . . . . 1 10

Iargeur dans les pieds de derrière. . . . . . . 18 
le milieu du dos. Cies poils sont de la même couleur et consistance que ceux de la cravate; seulement ils sont plus courts et mêlés de poils bruns et noirs. La laine dont le corps est couvert est un peu frisée, et douce au toucher à son extrémité; mais elle est droite et rude dans la partie qui avoisine la peau de l'animal : en général, elle est longue d'environ trois porices, et d'un jaune clair. Les jambes sunt d'un roux foncé; la tête est tachetée de teintes plus ou moins fauves; la queue est fauve et blanche en plus grande partie, et, pour la forme, elle ressemble assez à la queue d'une vache, étant bien fournie de poil vers l'extrémité. Ce belier est plus bas de jambes que les autres beliers auxquels on pourroit le comparer. C'est a celui des Indes qu'il ressemble plus qu'à aucun autre. Son ventre est fort gros et n'est élevé de terre que de quatorze pouces neuf lignes ${ }^{1}$. M. de Sève, qui a pris

pieds. pouc. lign.

1. Longueur du corps mesuré en ligne droite du museau à l'anus. . . . . . . . . . . 37 . 7

Longueur du corps en ligne superficielle. . . 4 43 "

Hauteur du train de devant. . . . . . . . 2 299

Hauteur du train de derrière. . . . . . . . . . 28

Longueur de la tête depuis le bout du museau jus.

qu’à l'origine des cornes. ........... 8 ". . .

Longueur de l'œil d'un angìc à l'autre. . . . . . " 13

Distance entre les angles antérieurs des yeux. . . " 310

Distance entre l'angle antérieur et le bout des

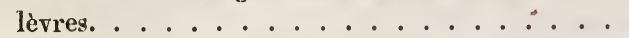

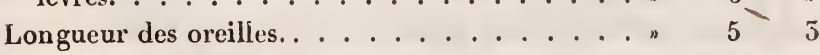

Largeur de la base. . . . . . . . . . . 16

Distance entre les oreilles et les cornes. .... " " 7

Distance entre les oreilles, prise en bas. . . . . 114

Longueur du cou. . . . . . . . . . . . . . $55_{5}$

Circonférence près de la tête......... $15_{2}$ 
les mesures et donné la description de cet animal, ajoule que la grosseur de son ventre le faisoit prendre pour une brebis pleine. Les cornes sont á peu près comme celles de nos beliers; mais les sabots des pieds ne sont point élevés, et sont plus longs que ceux du belier des Indes.

Nous avons dit, et nous le répétons ici, que le mouflon est la tige unique et primordiale de toutes les autres brebis, et qu'il est d'une nature assez ro-

Circonférence du corps, prise derrière les jambes

de devant. . . . . . . . . . . . $3 \quad 3 \quad 3$

Circonférence à l'endroit le plus gros. . . . . 3 3 39

Cireonférence devant les jambes de derrière.. . . $3 \quad 2 \quad 4 \quad 4$

Longucur du troncon de la queue. . . . . . . 1 $22_{7} 7$

Sa largeur. . . . . . . . . . . . . 123

Longueur du bras depuis le eoude jusqu'au genou. " 9

Longueur du eanon. . . . . . . . . . . . . . . 7 . 7

Longueur du paturon............. . . . 206

Circonférence du paluron. ......... . . 53

Circonférence de la eouronne.. . . . . . . 5.10

Hauteur depuis le bas du pied jusqu'au genou. . " $\quad 9 \quad 7$

Lonģueur de la cuisse depuis la rotule jusqu'au jarret. ....................... 10 10

Longueur du eanon depuis le jarret jusqu'au

boulet. .................. 7 "

Longueur du pied de devant. . . . . . . . . . $4 \quad 40$

Longueur des ergots. . . . . . . . . . . 2

Hauteur des sabots. ............ 1...

Longueur depuis la pinee jusqu'au talon dans les

pieds de devaut. . . . . . . . . . . 4 \$

Longuear dans lus pieds de clerrière. . . . . . . . . . . 58

Largenr des mêmes pieds. . . . . . . . . . . . . . 110

Distance entre les deux sábots. . . . . . . „ 3

Circonférenee des deux sabots réunis, prise sur

les picds de devant. . . . . . . . . . 114

Circunférence prise sur les pieds de derrière. . . " g s) 
buste pour subsister dans les climats froids, tempérés, et chauds; son poil est seulement plus ou moins épais, plus ou moins long, suivant les différents climats. Les beliers sauvages du Kamischatka, dit M. Steller, ont l'allure de la chèvre et le poil du renne. Leurs cornes sont si grandes et si grosses, qu'il y en a quelques unes qui pèsent jusqu'à vingt-cinq à trente livres. On en fait des vases, des cuillers, et d'autres ustensiles. Ils sont aussi vifs et aussi légers que les chevreuils; ils habitent les montagnes les plus escarpées au milieu des précipices. Leur chair est délicate, ainsi que la graisse qu'ils ont sur le dos; mais c'est pour avoir leurs fourrures qu'on se donne la peine de les chasser.

Je crois qu'il reste actuellement très peu, ou plutôt qu'il ne reste point du tout de vrais mouflons dans l'île de Corse; les grands mouvements de guerre qui se sont passés dans cette île auront probablement amené leur destruclion : mais on y trouve encore des indices de leur ancienne existence, par la forme même des races de brebis qui y subsistent actuellement. II y avoit, au mois d'août 1774 , un belier de Corse appartenant à M. le duc de La Vrillière. Il n'étoit pas grand, même en comparaison d'une belle brebis de France qu'on lui avoit donnée pour compagne. Ce belier étoit tout blanc, petit et bas de jambes, la laine longue et par flocons. Il portoit quatre cornes larges et fort longues, dont les deux supérieures étoient les plus considérables, et ces cornes avoient des rides comme celles du mouflon.

Dans les pays du nord de l'Europe, comme en Danemarck et en Norwége, les brebis ne sont pas belles; 
et pour en améliorer l'espèce, on fait de temps en temps venir des beliers d'Angleterre. Dans les îles qui avoisinent la Norwége, on laisse les beliers en pleine campagne pendant toute l'année. Ils deviennent plus grands et plus gros, et ont la laine meilleure et plus belle que ceux qui sont soignés par les hommes. On prétend que ces beliers qui sont en pleine liberté passent toujours la nuit au côté de l'île d'où le vent doit venir le lendemain; ce qui sert d'avertissement aux mariniers, qui ont grand soin d'en faire l'observation.

En Islande, les beliers, les brebis, et les moutons diffèrent principalement des nôtres, en ce qu'ils ont presque tous les cornes plus grandes et plus grosses. Il s'en trouve plusieurs qui ont trois cornes, et quelques uns qui en ont quatre, cinq, et même davantage. Cependant il ne faut pas croire que cette particularité soit commune à toute la race des beliers d'Islande, et que tous y aient plus de deux cornes; car, dans un troupeau de quatre ou cinq cents moutons, on en trouve à peine trois ou quatre qui aient quatre ou cinq cornes. On envoie ceux-ci à Copenhague comme une rareté, et on les achète en Islande bien plus cher que les autres; ce qui seul sulfit. pour prouver qu'ils y sont très rares.

\section{LE BOUC A LONGS SABOTS.}

Nous donnons ici la description d'un bouc dont les sabots avoient pris un accroissement extraordinaire; ce défaut, ou plutôt cet excès, est assez commun dans 
les boucs et les chèvres qui habitent les plaines et les terrains humides.

Il y a des chèvres beaucoup plus féc ondes que les autres, selon leur race et leur climat. M. Secretary, chevalier de Saint-Louis, étant à Lille en Flandre en 1773 et 1774 , a vu, chez madame Denizet, six beaux chevreaux, qu'une chèvre avoit produits d'une seule portée; cette même chève en avoit produit dix dans deux autres portées, et douze dans trois portées précédentes.

Feu M. de La Nux, mon correspondant à l'île de Bourbon, m'a écrit qu'il y a aussi dans cette île des races subsistantes depuis plus de quinze ans, provenant des chèvres de France et des boucs des Indes; que nouvellement on s'étoit procuré des chèvres de Goa très petites et très fécondes, qu'on a mêlées avec celles de France, et qu'elles se sont perpéluées et fort multipliées. Je rapporterai dans l'article des $m u$ lets les essais que j'ai faits sur le mélange des boucs et des brebis; et ces essais démontrent qu'on en obtient aisément dẹs métis, qui ne diffèrent guère des agneaux que par la toịson, qui est plutôt de poil que de laine. M. Roume de Saint-Laurent fait à ce sujet une observation qui est peut-être fondée. "Cornme l'espèce des chèvres, dit-il, et celle des brebis, produisent ensemble des métis nommés chabins, qui se reproduisent, il se pourroit que ce mélange eût influé sur la masse de l'espèce, et fût la cause de l'effet que l'on a attribué au climat des îles, où l'espèce de la chèvre a dominé sur celle de la brebis."

On sait que les grandes brebis de Flandre produisent communément quatre agneaux chaque année: 
ces grandes brebis de Flandre viennent originairement des Indes orientales, d'où elles ont été apportées par les Hollandois il y a plus de cent ans; et l'on prétend avoir remarqué qu'en général les animaux ruminants qu'on a amenés des Indes en Lurope ont plus de fécondité que les races européennes.

M. le baron de Bock a cu la bonté de m'informer de quelques particularités que j’ignorois sur les variétés de l'espèce de la brebis en Europe. Il m'écrit qu'il y en a trois espèces en Moldavie, celle dè montagne, celle de plaine, et celle de bois.

"Il est fort difficile de se figurer, dit-il, la quantité innombrable de ces animaux qu'on y rencontre. Les marchands grecs, pourvoyeurs du grand-seigneur, en achetoient, au commencement de ce siècle, plus de seize mille tous les ans, qu'ils menoient à Constantinople, uniquement pour l'usage de la cuisine de sa hautesse. Ces brebis sont préférées à toutes les autres, à cause du bon goût et de la délicatesse de leur chair. Dans les plaines, elles deviennent beaucoup plus grandes que sur les montagnes; mais elles y multiplient moins. Ces deux premières espèces sont réduites en servitude. La troisième, 'qu'on appelle brebis des bois, est entièrement sauvage; elle est aussi très différente de toutes les brebis que nous connoissons : sa lèvre supérieure dépasse l'inférieure de deux pouces, ce qui la force à paître en reculant; le peu de longueur et le défaut de flexibilité dans son cou l'empêchent de tourner la tête de côté et d'autre; d'ailleurs, quoiqu'elle ait les jambes frès courtes, elle ne laisse pas de courir fort vite, et ce n'est qu'avec grande peine que les chiens peuvent 
l'atteindre; elle a l'odorat si fin, qu'elle évente, à la distance d'un mille d'Allemagne, le chasseur ou l'animal 'qui la poursuit, et prend aussitôt la fuite. Cette espèce se trouve sur les frontières de la Transylvanie, comme dans les forêts de Moldavie : ce sont des animaux très sauvages, et qu'on n'a pas réduits en domesticité; cependant on peut apprivoiser les petits. Les naturels du pays en mangent la chair; et sa laine, mêlée de poil, ressemble à ces fourrures qui nous viennent d'Astracan. "

Il me paroît que celle troisième brebis dont M. le baron de Bock donne ici la description d'après le prince Cantemir est le même animal que j’ai indiqué sous le noin de saiga, et qui se trouve par conséquent. en Moldavie et en Transylvanie, comme dans la Tartarie et dans la Sibérie.

Et à l'égard des deux premières brebis, savoir celle de plaine et celle de montagne, je soupconne qu'elles ont beaucoup de rapport avec les brebis valachiennes, dont j’ai donné les figures; d'antant plus que M. le baron de Bock m'écrit qu'ayant comparé les figures de ces brebis valachiennes avec sa description de la brebis des bois (saiga), elles ne lui ont paru avoir aucun rapport; mais qu'il est très possible que ces brebis valachiennes soient les mêmes que celles qui se trouvent sur les montagnes ou dans les plaines de la Moldavie.

A l'égard des brebis d'Afrique et du cap de BonneEspérance, M. Forster a observé les particularités suivantes.

"Les brebis du cap de Bonne-Espérance ressemblent, dit-il, pour la plupart, au belier de Barbarie; 
néanmoins les Hottentots avoient des brebis, lorsque les Hollandois s'y établirent : ces brebis ont, pour ainsi dire, une masse de graisse au lieu de queue. Les Hollandois amenèrent au Cap des brebis de Perse, dont la queue est longue et très grosse jusquà une certaine distance de l'origine, et ensuite mince jusqu'à l'extrémité. Les brebis que les Hollandois du Cap élèvent à présent sont d'une race moyenne entre les brebis de Perse et celles des Hottentots : on doit présumer que la graisse de la queue de ces animaux vient principalement de la nature ou qualité de la pâture; après avoir été fondue, elle ne prend jamais de la consistance comme celle de nos brebis d'Europe, et reste au contraire toujours liquide comme l'huile. Les habitants du Cap ne laissent pas néanmoins d'en tirer parti, en ajoutant quatre parties de cette graisse de queue avec une partie de graisse prise aux rognons; ce qui compose une sorte de malière qui a de la consistance et le goût même du saindoux que l'on tire des cochons : les gens du commun la mangent avec du pain, et l'emploient aussi aux mêmes usages que le saindoux et le beurre. Tous les environs du Cap sont des terres arides et élevées, remplies de particules salines qui, étant entrainées par les eaux des pluies dans des espèces de petits lacs, en rendent les eaux plus ou moins saumâtres. Les habitants n'ont pas d'autre sel que celui qu'ils ramassent dans ces mares et salines naturelles. On sait combien les brebis aiment le sel, et combien il contribue à les engraisser; le sel excite la soif qu'elles étanchent en mangeant les plantes grasses et succulentes qui sont abondantes dans ces déserts élevés, 
telles que le sedum, l'euphorbe, le cotylédon, etc., et ce sont apparemment ces plantes grasses qui donnent à leur graisse une qualité différente de celle qu'elle prend par la pâture des herbes ordinaires; car ces brebis passent tout l'été sur les montagnes qui sont couvertes de ces plantes succulentes; mais en aufomne on les ramène dans les plaines basses pour $y$ passer l'hiver et le printemps : ainsi les brebis, étant loujours abondamment nourries, ne perdent rien de leur embonpoint pendant l'hiver. Dans les montagnes, surtout dans celles du canton qu'on appelle Bockenland, ou pays des chèvres, ce sont des esclaves tirés de Madagascar et des Hottentots, avec quelques grands chiens, qui prennent soin de ces troupeaux, et les défendent contre les hyènes et les lions. Ces troupeaux sont très nombreux; et les vaisseaux qui vont aux Indes ou en Europe font leurs provisions de ces brebis : on en nourrit aussi les équipages de tous les navires pendant leur séjour au Cap. La graisse de ces animaux est si copieuse, qu'elle occupe tout le croupion et les deux fesses, ainsi que la queue : mais il semble que les plantes grasses, succulentes et salines qu'elles mangent sur les montagnes pendant l'été, et les plantes aromatiques et arides dont elles se nourrissent dans les plaines pendant l'hiver, servent ì former deux différentes graisses; ces deux dernières plantes ne doivent donner qu'une graisse solide et ferme, comme celle de nos brebis qui se dépose dans l'omentum, le mésentère, et le voisinage des rognons, tandis que la nourriture qui provient des plantes grasses forme cette graisse huileuse qui se dépose sur le croupion, les fesses, et la queue. II semble aussi que 
cette masse de graisse huileuse empêche l'accroissement de la queue, qui, de génération en génération, deviendroit plus courte et plus mince, et se réduiroit peut-être à n'avoir plus que trois ou quatre articulations, comme cela se voit dans les brebis des Calmoucks, des Mogols, et des Kirghises, lesquelles n'ont absolument qu'un tronçon de trois ou quatre articulations : mais comme le pays du Cap a beaucoup d'étendue, et que les pâturages ne sont pas tous de la nature de ceux que nous venons de décrire, et que, de plus, les brebis de Perse à queue grosse et courte, y ont été autrefois introduites et se sont mêlíes avec celles des Hottentots, la race bâtarde a conserví une queue aussi longue que celle des brebis d'Angleterre, avec cette différence que la partie qui est attenante an corps est déjà renflée de graisse, tandis que l'extrémité est mince comme dans les brebis ordinaires. Les pâturages à l'est du Cap, n'étant pas exactement de la nature de ceux qui sont au nord, il est naturel que cela influe sur la constitution des brebis, qui restent dans quelques endroits sans dégénération, et avec la queue longue et une bonne quantité de graisse aux fesses et au croupion, sans cependant atteindre cette monstrueuse masse de graisse par laquelle les brebis des Calmoucks sont remarquables; et comme ces brebis changent souvent de maître, et sont menées d'un pâturage au nord du Cap à un autre à l'est, ou même dans le voisinage de la ville, et que les différentes races se mêlent ensemble, il s'ensuit que les brebis du Cap ont plus ou moins conservé la longueur de leur queue. Dans notre trajel du cap de Bonne-Espérance à la Nouvelle- 
Zélande, en 1772 et 1773 , nous trouvâmes que ces brebis du Cap ne peuvent guère être transportées vivantes dans des climats très éloignés; car elles n'aiment pas à manger de l'orge ni du blé, n'y étant pas accoutumées, ni même du foin, qui n'est pas de bonne qualité aı Cap : par conséquent ces animaux dépérissoient de jour en jour: ils furent attaqués du scorbut; leurs dents n'étoient plus fixes, et ne pouvoient pius broyer la nourriture; deux beliers et quatre brebis moururent, et il n'échappa que trois moutons du troupeau que nous avions embarqué. Après notre arrivée à la Nouvelle-Zélande, on leur offrit toutes sortes de verdures: mais ils les refusèrent, et ce ne fut qu'après deux ou trois jours que je proposai d'examiner leurs dents; je conseillai de les fixer avec du vinaigre, et de les nourrir de farine et de son trempés d'eau chaude. On préserva de cette manière les trois moutons qu'on amena à Taïti, où on en fit présent au roi; ils reprirent leur graisse dans ce nouveau climat en moins de sept ou huit mois. Pendant leur abstinence dans la traversée du Cap à la NouvelleZélande, leur queue s'étoil non seulement dégraissée, mais décharnée et comme desséchée, ainsi que le croupion et les fesses."

M. de La Nux, habitant de lîle de Bourbon, m'a écrit qu'il y a dans cette île une race existante de ces brebis du cap de Bonne-Espérance, qu'on a mêlée avec des brebis venues de Surate, qui ont de grandes oreilles et la queue très courte. Cette dernic̀re race s'est aussi mêlée avec celle des brebis à grande queue du sud de Madagascar, dont la laine n'est que foiblement ondée. La plupart des caractères de ces races 
primitives sont effacés, et on ne reconnoît gù̀re leurs variétés qu'à la longueur de la queue : mais il est certain que, dans les îles de France et de Bourbon, toutes les brebis transporlées d'Europe, de l'Inde, de Madagascar, et du Cap, s'y sont mêlées et également perpétuées, et qu’il en est de même des bœuls grands et petits. Tous ces animaux ont été amenés de différentes parties du monde; car il n'y avoit dans ces deux îles de France et de Bourbon, ni hommes, ni aucuns animaux terrestres, quadrupèdes ou reptiles, ni même aucuns oiseaux que ceux de mer: le bœuf, le cheval, le cerf, le cochon, les singes, les perroquets, etc., y ont été apportés. A la vérité, les singes n'ont pas encore passé (en 1770) à l'île de Bourbon, et l'on a grand intérêt d'en interdire l'introduction pour se garantir des mêmes dommages qu'ils causent à l'lle-de-France. Les lièvres, les perdrix, et les pintades y ont été apportés de la Chine, de l'Inde, ou de Madagascar: les pigeons, les ramiers, les tourterelles, sont pareillement venus de dehors. Les martins, ces oiseaux utiles, auxquels les deux îles doivent la conservation de leurs récoltes par la destruction des sauterelles, n'y sont que depuis vingt ans, quoiqu'il y ait peut-être déjà plusieurs centaines de millier's de ces oiseaux sur les deux îles. Les oiseaux jaunes sont venus du Cap, et les bengalis de Bengale. On pourroit encore nommer aujourd'hui les personnes auxquelles est due l'importation de la plupart de ces espèces dans l'île de Bourbon, en sorte qu'excepté les oiseaux d'eat, qui, comme l'on sait, font des émigrations considérables, on ne reconnoît aucun être vivant qu'on puisse assigner pour ancien 
habitant des îles de France et de Bourbon. Les rats qui s'y sont prodigieusement multipliés sont des espèces européennes venues dans les vaisseaux.

\section{L'AX IS.}

\section{Cervus Axis. L.}

CET animal n'étant connu que sous les noms vagues de biche de Sardaigne et de cerf du Gange, nous avons cru devoir lui conserver le nom que lui a donné BeIon, et qu'il avoit emprunté de Pline, parce qu'en effet les caractères de l'axis de Pline peuvent convenir à l'animal dont il est ici question, et que le nom même n'a jamais été appliqué à quelque autre animal. Ainsi nous ne craignons pas de faire confusion ni de tomber dans l'erreur, en adoptant cet ancien nom, et l'appliquant à un animal qui n'en avoit point parmi nous; car une dénomination générique, jointe à l'épithète du climat, n'est point un nom, mais une phrase par laquelle on confond un animal avec ceux de son genre, comme celui-ci avec le cerf, quoique peut-être il en soit réellement distinct tant par l'espèce que par le climat. L'axis est, à la vérité, du petit nombre des animaux ruminants qui portent un bois, coinme le cerf; il a la taille et la légèreté du daim : mais ce qui le distingue du cerf et du daim, c'est qu'il a le bois d'un cerf et la forme d'un daim; que tout son corps est marqué de taches blanches, 
élégamment disposées el séparées les unes des antres, et qu'enfin il habite les climats chauds; au lieu que le cerf et le daim ont ordinairement le pelage d'une couleur uniforme, et se trouvent en plus grand nombre dans les pays froids et dans les régions tempérées que dans les climats chauds.

MM. de l'Académie des Sciences, en nous donnant la figure et la description des parties antérieures de cet animal, ont dit peu de chose de sa forme extérieure, et rien du tout de ce qui a rapport à son histoire; ils l'ont seulement appelé biche de Sardaigne, parce que probablement il leur étoit venu sous ce nom de la Ménagerie du Roi : mais rien n’indique que cet animal soit originaire de Sardaigne; aucun auteur n'a dit qu'il existe dans cette île comme animal sauvage, et l'on voit, au contraire, par les passages que nous avons cités, qu'il se trouve dans les contrées les plus chaudes de l'Asie. Ainsi la dénomination de biche de Sardaigne avoit été faussement appliquée : celle de cerf du Gange lui conviendroit micux, s'il étoit, en effet, de la même espèce que le cerf, puisque la partie de l'Inde qu'arrose le Gange paroît être son pays natal. Cependant il paroît aussi qu'il se trouve en Barbarie, et il est probable que le daim moucheté du cap de Bonne-Espérance est encore le même que celui-ci.

Nous avons dit qu'aucune espèce n'est plus voisine d'une autre que celle du daim ne l'est de celle du cerf; cependant l'axis parôit encore faire une nuance intermédiaire entre les deux : il ressemble au daim par la grandeur du corps, par la longueur de la quene, par l'espice de livrée qu'il porte toute la vie; 
et il n'en diffère essentiellement que par le bois, qui est sans empaumure, et qui ressemble à celui du cerf. Il se pourroit donc que l'axis ne fût qu'une variété dépendante du climat, et non pas une espèce différente de celle du daim ; car, quoiqu'il soit originaire des pays les plus chands de l'Asie, il subsiste et se multiplie aisément en Europe. Il y en a des trompeanx à la ménagerie de Versailles. Ils produisent entre eux aussi facilement que les daims : néanmoins on n'a jamais remarqué qu'ils se soient mêlés ni avec les daims, ni avec les cerf's, et c'est ce qui nous a fait présumer que ce n'étoit point une variété de l'un ou de l'autre, mais une espèce particulière et moyenne entre les deux. Cependant, comme l'on n'a pas fait des expériences directes et décisives à ce sujet, et que l'on n'a pas employé les moyens nécessaires pour obliger ces animaux à se joindre, nous n'assurcrons pas positivement qu'ils soient d'espèces différentes.

L'on a déjà vu, dans les articles du cerf et du daim, combien ces animaux éprouvent de variétés, surtout par les couleurs du poil. L'espèce du daim et celle du cerf, sans être très nombreuses en individus, sont fort répandues : toutes deux se trouvent dans l'un et dans l'autre continent, et toutes deux sont sujettes à un assez grand nombre de variétés qui paroissent former des races constantes. Les cerfs blancs, dont la race est très ancienne, puisque les Grecs et les Romains en ont fait mention, les petits cerfs bruns, que nous avons appelés cerfs de Corse, ne sont pas les seules variétés de cette espèce : il y a en Allemagne une autre race de cerfs qui est connue dans le pays sous le nom de brandhirtz, et de nos chasseurs 
sous celui de cerf des Ardennes. Ce cerf est plus grand que le cerf commun, et il diffère des autres cerfs non seulement par le pelage, qu'il a d'une couleur plus foncée et presque noire, mais encore par un long poil qu'il porte sur les épaules et sous le cou. Cette espèce de crinière et de barbe lui donnant quelque rapport, la première avec le cheval, et la seconde avec le bouc, les anciens ont donné à ce cerf les noms composés d'hippélaphe et de tragélaphe. Comme ces dénominations ont occasioné de grandes discussions critiques; que les plus savants naturalistes ne sont pas d'accord à cet égard, et que Gesner, Caïus, et d'autres ont dit que l'hippélaphe étoit l'élan, nous croyons devoir donner ici les raisons qui nous ont fait penser différemment, et qui nous ont portés à croire que l'hippélaphe d'Aristote est le même animal que Je tragélaphe de Pline, et que ces deux noms désignent également et uniquement le cerf des Ardennes.

Aristote donne à son hippélaphe une espèce de crinière sur le cou et sur le dessus des épaules, une espèce de barbe sous la gorge, un bois au mâle assez semblable à celui du chevreuil, point de cornes à la femelle. Il dit que l'hippélaphe est de la grandeur dn cerf, et naît chez les Arachotas (aux Indes), où l'on trouve aussi des boufs sauvages, dont le corps est. robuste, la peau noire, le mufle relevé, les cornes plus courbées en arrière que celles des bœufs domestiques. Il faut avouer que ces caractères de l'hippélaphe d'Aristote conviennent à peu près également à l'ćlan et au cerf des Ardennes; ils ont tous deux de longs poils sur le cou et les épaules, et d'autres longs 
L'A X Is.

poils sous la gorge, qui leur font une espèce de barbe au gosier, et non pas au menton : mais l'hippélaphe u'étant que de la grandeur du cerf, diflère en cela de l'élan qui est beaucoup plus grand; et ce qui me paroît décider la question, c'est que l'élan, étant un animal des pays froids, n'a jamais existé chez les Aracholas. Ce pays des Arachotas est une des provinces qu'Alexandre parcourut dans son expédition des Indes: il est situé au delà du mont Caucase, entre la Perse et l'Inde. Ce climat chaud n'a jamais produit des élans, puisqu'ils peuvent à peine subsister dans les contrées tempérées, et qu'on ne les trouve que dans le nord de l'un et de l'autre continent. Les cerfs, au contraire, n'affectent pas particulièrement les terres du nord: on les trouve en grand nombre dans les climats tempérés et chauds. Ainsi nous ne pouvons douter que cet hippélaphe d'Aristote, qui se trouve chez les Arachotas, et dans le même pays où se trouve le buffle, ne soit le cerf des Ardennes, et non pas l'élan.

Si l'on compare maintenant Pline sur le tragélaphe avec Aristote sur l'hippélaphe, et tous deux avec la nature, on verra que le tragélaphe est le même animal que l'hippélaphe, le même que notre cerf des Ardennes. Pline dit que le tragélaphe est de l'espèce du cerf, et qu'il n'en diffère que par la barbe, et aussi par le poil qu’il a sur les épaules. Ces caractères sont. positifs, et ne peuvent s'appliquer qu'au cerf des Ardennes; car Pline parle ailleurs de l'élan sous le nom d'alce. Il ajoute que le tragélaphe se trouve auprès du Phase; ce qui convient encore au cerf, et non pas à l'élan. Nous croyons donc être fondés à prononcer 
que te tragélaphe de Pline et l'hippélaphe d'Aristote désignent tous deux le cerf que nous appelons cerfdes Ardennes; et nous croyons aussi que l'axis de Pline indique l'animal que l'on appelle vulgairement cerf dı Gange. Quoique les noms ne fassent rien à la nalure, c'est cependant rendre service à eeux qui l'étudient que de les leur interpréter.

- MI. le duc de Richmond avoit dans son parc, en 1765 , une grande quantité de cette espèce de daims qu'on appelle vulgairement cerfs du Gange, et que j’ai nommés axis. M. Collinson m'a écrit qu'on lui avoit assuré qu'ils engendroient avec les autres daims.

aIs vivent volontiers avec eux, dit-il, et ne forment pas de troupes séparées. Il y a plus de soixante ans que l'on a cette espèce en Angleterre : elle y existe avec celle des daims noirs et des daims blancs, et même avant celle du cerf, qui sont plus nouvelles dans l'île de la Grande-Bretagne, et que je crois avoir été envoyées de France; car il n'y avoit auparavant en Angleterre que le daim commun (fallowdeer), et le chevreuil en Écosse : mais, indépendamment de cette première espèce de daim, il y a maintenant le daim axis, le daim noir, le daim fauve, et le daim blanc. Le mélange de toutes ces couleurs fait que dans les parcs il se trouve de très belles variétés."

II y avoit en 1764 , à la ménagerie de Versailles, deux daims chinois, l'un mâle et l'autre femelle : ils n'avoient que deux pieds trois ou quatre pouces de liauteur; le corps et la queue étoient d'un brun minime; le ventre et les jambes, fauve clair; les jambes courtes; le bois large, étendu, et garni d'andouillers. Colle aspèce, plus petite que celle des daims ordi- 


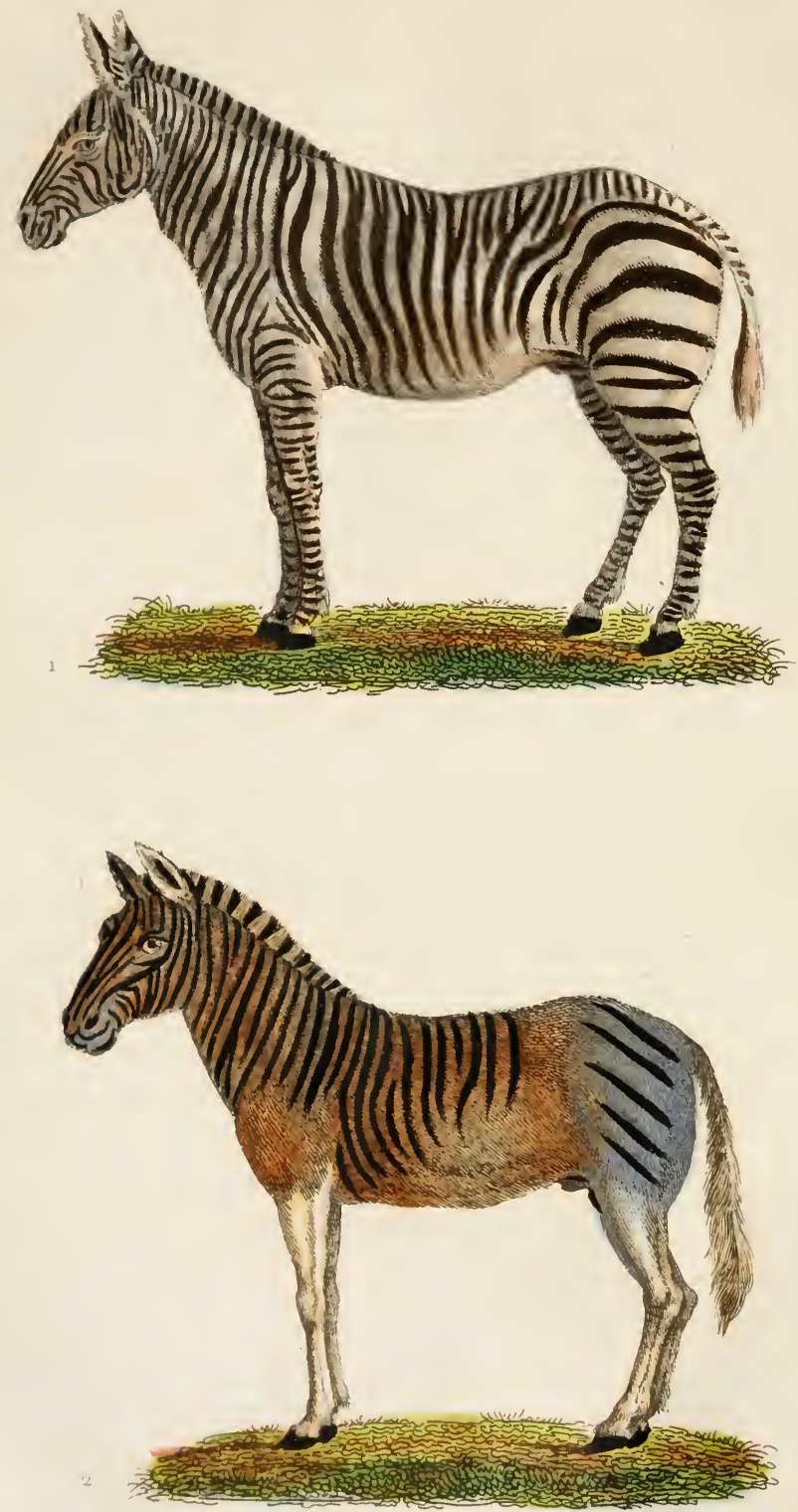
naires, et même que celle de l'axis, n'est peut-être néanmoins qu'une variété de celui-ci, quoiqu'il en diffère en ce qu'il n'a pas de taches blanches; mais on a observé qu'au lieu des ces taches blanches, il avoit en plusieurs endroits quelques grands poils fauves qui tranchoient visiblement sur le brun du corps. Au reste, la femelle étoit de la même couleur que le mâle, et je présume que la race pourroit non seulement se perpétuer en France, mais peut-être même se mêler avec celle de l'axis, d'autant que ces animaux sont également originaires de l'orient de l'Asie.

\section{LE ZÈBRE ${ }^{1}$.}

\section{Equus Zebra. L.}

LE zèbre est pent-être de tous les animaux quadrupèdes le mieux fait et le plus élégamment vêtu. Il a la figure et les grâces du cheval, la légèreté du cerf, et la robe rayée de rubans noirs et blancs, disposés alternativement avec tant de régularité et de symétrie, qu'il semble que la nature ait employé la règle et le compas pour le peindre : ces bandes alternatives de noir et de blanc sont d'autant plus singulières; qu'elles sont étroites, parallèles, et très exactement séparées, comme dans une étoffe rayée; que d'ailleurs elles s'étendent non seulement sur le corps, mais sur la tête, sur les cuisses et les jambes, et jusque sur les oreilles et la queue; en sorte que de loin

1. Zebra, zevera, sebra, nom de cet animal an Congo, et cue nous lui avons conservé. Esvre à $\Lambda$ ngola, selon Pyrard. 
cet animal paroît comme s'il étoit environné partou t de bandelettes qu'on auroit pris plaisir et employé beaucoup d'art à disposer régulièrement sur toutes les parties de son corps; elles en suivent les contours et en marquent si avantageusement la forme, qu'elles en dessinent les muscles en s'élargissant plus ou moins sur les parties plus ou moins charnues et plus ou moins arrondies. Dans la femelle, ces bandes sont alternativement noires et blanches; dans le mâle, elles sont noires et jaunes, mais toujours d'une nuance vive et brillante sur un poil court, fin et fourni, dont le lustre augmente encore la beauté des couleurs. Le zèbre est en général plus petit que le cheval et plus grand que l'âne; et quoiqu'on l'ait souvent comparé à ces deux animaux, qu'on l'ait même appelé cheval sauvage et ane rayé, il n'est la copie ni de l'un ni de l'autre, et seroit plutôt leur modèle, si dans la nature tout n'étoit pas également original, et si chaque espèce n'avoit pas un druit égal à la création.

Le zèbre n'est donc ni un cheval ni un âne, il est de son espèce; car nous n'avons pas appris qu'il se mêle et produise avec l'un ou l'autre, quoique l'on ait souvent essayé de les approcher. On a présenté des ânesses en chaleur à celui qui existoit encore en 1 -61 à la ménagerie de Versailles; il les a dédaignées, ou plutôt il n'en a été nullement ému; du moins le signe extérieur de l'émotion n'a point paru : cependant il jounit avec elles et les montoit, mais sans érection ni hennissement, et on ne peut guère attribuer cetle froideur à une autre cause qu'à la disconvenance de nature; car ce zèbre, âgé de quatre ans, étoit, à tout autre exercice, fort vif et très léger. 
Le zèbre n'est pas l'animal que les anciens ont indiqué sous le nom d'onagre. Il existe dans le Levant, dans l'orient de l'Asie, et dans les parties septentrionales de l'Afrique, une très belle race d'ânes qui, comme celle des plus beaux chevaux, est originaire d'Arabie : cette race diffère de la race commune par la grandeur du corps, la légèreté des jambes, et le lustre du poil ; ils sont de couleur uniforme, ordinairement d'un beau gris de souris, avec une croix noire sur le dos et sur les épaules; quelquefois ils sont d'un gris plus clair avec une croix blonde. Ces ânes d'Afrique et d'Asie, quoique plus beaux que ceux d'Europe, sortent également des onagres ou ânes sauvages, qu'on trouve encore en assez grande quantité dans la Tartarie orientale et méridionale, la Perse, la Syrie, les îles de l'Archipel, et toute la Mauritanie. Les onagres ne diffèrent des ânes domestiques que par les attributs de l'indépendance et de la liberté; ils sont plus forts et plus légers, ils ont plus de courage et de vivacité : mais ils sont les mêmes pour la forme du corps; ils ont seulement le poil beaucoup plus long, et cette différence tient encore à leur état; car nos ânes auroient également le poil long, si l'on n'avoit pas soin de les tondre à l'âge de quatre ou cinq mois : les ânons ont, dans les premiers temps, le poil long, à peu près comme les jeunes ours. Le cuir des ânes sauvages est aussi plus dur que celui des ânes domestiques : on assure qu'il est chargé partout de petits tubercules, et que c'est avec cette peau des onagres qu'on fait dans le Levant le cuir ferme et grenu qu'on appelle chagrin, et que nous employons à différents usages. Mais ni les oulagres ni les beaux 
ânes d'Arabie ne peuvent être regardés comme la souche de l'espèce du zèbre, quoiqu'ils en approchent. par la forme du corps et par la légèreté : jamais on n'a vı ni sur les uns ni sur les autres, la variété régulière des couleurs du zèbre: celte belle espèce est singulière et unique dans son genre. Elle est aussi d'un climat différent de celui des onagres, et ne se trouve que dans les parties les plus orientales et les plus méridionales de l'Afrique, depuis l'Éthiopie jusqu'au cap de Bonne-Espérance, et de là jusqu'au Congo : elle n'existe ni en Europe, ni en Asie, ni en Amérique, ni même dans toutes les parties septentrionales de l'Afrique. Ceux que quelques voyageurs disent avoir trouvés au Brésil y avoient été transportés d'Afrique; ceux que d'autres racontent avoir vus en Perse el en Turquie y avoient été amenés d'Ćthiopie : et enfin ceux que nous avons vus en Europe sont presque tous venus du cap de Bonne-Espérance : cette pointe de l'Afrique est leur vrai climat, leur pays natal, où ils sont en grande quantité, et où les Hollandois ont employé tous leurs soins pour les dompter et pour les rendre domestiques, sans avoir jusqu'ici pleinement. réussi. Celui que nous avons vu, et qui a servi de sujet pour notre description, étoit très sauvage lorsqu'il arriva à la Ménagerie du Roi, et il ne s'est jamais entièrement apprivoisé : cependant on est parvenu à le monter; mais il falloit des précautions; deux hommes tenoient la bride pendant qu'un troisième étoit dessus : il avoit la bouche très dure, les oreilles si sensibles, qu'il ruoit dès qu'on vouloit les toucher. Il étoit rélif comme un cheval vicieux, et têtu comme un mulel. Mais peut-être le cheval sauvage et l'onagre: 
sont aussi peu traitables, et il y a toute apparence que si l'on accoutumoit dès le premier âge le zèbre à l'obéissance et à la domesticité, il deviendroit aussi doux que l'âne et le cheval, et pourroit les remplacer tous deux.

*L'âne domestique ou sauvage s'est trouvé dans presque tous les climats chauds et tempérés de l'ancien continent, et n'existoit pas dans le nouveau lorsquion en fit la découverte. Mais maintenant l'espèce y subsiste avec fruit, et s'est même fort multipliée depuis plus de deux siècles qu’elle y a été transportée d'Europe; en sorte qu'elle est aujourd'hui répandue à peu près également dans les quatre parties du monde. Au contraire, le zèbre, qui nous est. venu du cap de Bonne-Espérance, semble être une espèce confinée dans les terres méridionales de l'Afrique, et surtout dans celles de la pointe de cette presqu'île, quoique J_opez dise qu'on trouve le zèbre plus souvent en Barbarie qu'au Congo, et que Dapper rapporte qu'on en rencontre des troupes dans les forêts d'Angola.

Ce bel animal qui, tant par la variété de ses couleurs que par l'élégance de sa figure, est si supérieur à l'âne, paroît néanmoins lui tenir d'assez près pour l'espèce, puisque la plupart des voyageurs lui ont donné le nom d'ane rayé, parce qu'ils ont été frappés de la ressemblance de sa taille et de sa forme, qui semble au premier coup d'oil avoir plus de rapport avec l'âne qu'avec le cheval : car ce n'est pas avec les petits ânes communs qu'ils ont fait la comparaison du zèbre, mais avec les plus grands et les plus beaux de l'espèce. Cependant je serois porté à croire que le 
zèbre tient de plus près au cheval qu'à l'âne; car il est d'une figure si élégante, que, quoiqu’il soit en général plus petit que le cheval, il n'en est pas moins voisin de cette espèce à plusieurs égards; et ce qui paroît confirmer mon opinion, c'est que dans les terres du cap de Bonne-Espérance, qui paroissent être le pays naturel et la vraie patrie du zèbre, on a remarqué avec quelque étonnement qu'il y a des chevaux tachelés, sur le dos et sous le ventre, de jaune, de noir, de rouge et d'azur; et cette raison particulière est encore appuyée sur un fait général, qui est que dans tous les climats les chevaux varient beaucoup plus que les ânes par la couleur du poil. Néanmoins nous ne déciderons pas si le zèbre est plus près de l'espèce du cheval que de celle de l'âne; nous espérons seulement qu'on ne tardera pas à le savoir. Comme les Hollandois ont fait venir dans ces dernières années un assez grand nombre de ces beaux animaux, et qu'ils en ont même faits des attelages pour le prince stathouder, il est probable que nous serons bientôt mieux informés de tout ce qui peut avoir rapport à leur nature. Sans doute on n'aura pas manqué de les unir entre eux, et probablement avec les chevaux et les ânes pour en tirer une race directe ou des races bâtardes. Il y a en Hollande plusieurs personnes habiles qui cultivent l'histoire naturelle avec succès; ils réussiront peut-être mieux que nous à tirer du produit de ces animaux, sur lesquels on n'a fait qu'un essai à la ménagerie de Versailles en 1761 . Le zèbre mâle, âgé de quatre ans, qui y étoit alors, ayant dédaigné toutes les ânesses en chaleur, n'a pas été présenté à des juments; peut-être aussiétoit-il trop jeune : 
d'ailleurs il lui manquoit d'être habitué avec les femelles qu'on lui présentoit; préliminaire d'autant plus nécessaire pour le succès de l'union des espèces diverses, que la nature semble même l'exiger dans l'union des individus de même espèce.

Le mulet fécond de Tartarie, que l'on y appelle czigithai, pourroit bien être un animal de la même espèce, ou tout au moins de l'espèce la plus voisine de celle du zèbre; car il n'en diffère évidemment que par les couleurs du poil. Or l'on sait que la différence de la couleur du poil ou des plumes est de toutes les différences la plus légère et la plus dépendante de l'impression du climat. Le czigithai se trouve dans la Sibérie méridionale, au Thibet, dans la Daourie et en Tartarie. Gerbillon dit qu'on trouve ces animaux dans le pays des Mongols et des Kakas, qu'ils diffèrent des mulets domestiques, et qu'on ne peut les accoutumer à porter des fardeaux. Muller et Gmelin assurent qu'ils se trouvent en grand nombre chez les Tunguses, où on les chasse comme d'autre gibier; qu'en Sibérie, vers Borsja, dans les années sèches, on en voit un grand nombre; et ils ajoutent qu'ils sont comparables, pour la figure, la grosseur, et la couleur, à un cheval bai clair, excepté la queue, qui est comme celle d'une vache, et les oreilles qui sont fort longues. Si ces voyageurs, qui ont observé le czigithai, avoient pu le comparer en même temps au zèbre, ils y auroient peut-être trouvé plus de rapports que nous n'en supposons. Il existe, dans le cabinet de Pétersbourg, des peaux bourrées de czigithai et de zèbre : quelque différentes que paroissent ces deux peaux par les couleurs, elles pourroient ap- 
partenir également à des animaux de même espèce, ou du moins d'espèces très voisines; le temps seul peut sur cela détruire ou confirmier nos doutes. Mais ce qui paroìt fonder la présomption que le czigithai et le zèbre pourroient bien être de la même espèce, c'est que tous les autres animaux de l'Aŕrique se tronvent également en Asie, et qu'il n'y auroit que le zèbre seul qui léroit exception à ce fait général.

Au reste, si le czigithai n'est pas le même que le zìbre, il pourroit être encore le même animal que l'onagre ou âne sauvage de l'Asie. J'ai dit qu'il ne falloit pas confondre l'onagre avec le zèhre: mais je ne sais si l'on peut dire la même chose de l'onagre el du czigithai; car il paroît, en comparant les relations des voyageurs, qu'il y a différentes sortes d'ânes sauvages, dont l'onagre est la plus remarquable, et il se pourroit bien aussi que le cheval, l'âne, le zèbre, et le czigithai constituassent quatre espèces; et, dans le cas où ils n'en feroient que trois, il est encore incertain si le czigithai est plutôt un onagre qu'un zèbre, d'autant que quelques voyageurs parlent de la légèreté de ces onagres, et disent qu'ils courent avec assez de rapidité pour échapper à la poursuite des chasseurs à cheval, ce qu'ils ont également assuré du czigithai. Quoi qu'il en soit, le cheval, l'âne, le zèbre, et le czigithai sont tous du même genre, et forment trois ou quatre branches de la même familie, dont les denx premières sont, de temps immémorial, réduites en domesticité; ce qui doit faire espérer qu'on pourra de même y réduire les deux dernières, et en tirer peut-être beaucoup d'utilité. 


\section{Sur le Zèbre, le Czigithai, et l'Onagre.}

* On peut voir, dans l'article précédent, les doutes qui me restoient encore sur la différence ou sur l'identité d'espèce de ces trois animaux. M. Forster a bien voulu me communiquer quelques éclaircissements qui semblent prouver que ce sont réellement trois animaux différents, et qu'il y a même dans l'espèce du zèbre une variété constante; voici l'extrait de ce qu'il m'a écrit sur ce sujet.

"On trouve dans le pays des Tartares Mongols une grande quantité de chevaux sauvages ou tarpans, et un autre animal appelé czigithai; ce qui, dans la langue mongole, signifie longue oreille. Ces animaux vont par troupes : on en voit quelques uns dans les déserts voisins de l'empire de Russie et dans le grand désert Gobée (ou Cobi); ils sont en troupes de vingt, trente, et même cent. La vitesse de cet animal surpasse de beaucoup celle du meilleur coursier parmi les chevaux; toutes les nations tartares en conviennent : une mauvaise qualité de cet animal, c'est qu'il reste toujours indomptable. Un Cosaque, ayant attrapé un de ces jeunes czigithais, et l'ayant nourri pendant plusieurs mois, ne put le conserver; car il se tua luimême par les efforts qu'il fit pour s'échapper ou se soustraire à l'obéissance.

"Chaque troupe de czigithais a son chef, comme dans les tarpans ou chevaux sauvages. Si le czigithai chef décourre ou sent de loin quelques chasseurs, il quitte sa troupe, et va seul reconnoître le danger; et dès qu'il s'en est assuré il donne le signal de la fuite, BUFFOX̃. XVII. 
et s'enfuit en eflet, suivi de sa troupe : mais si malheureusement ce chef est tué, la troupe, n'étant plus conduite, se disperse, et les chasseurs sont sûrs d'en tuer plusieurs autres.

"Les czigithais se trouvent principalement dans les déserts des Mongols, et dans celui qu'on appelle Gobée : c'est une espèce moyenne entre l'âne et le cheval; ce qui a donné occasion au docteur Messerschmid d'appeler cet animal mulet fécond de Daourie ${ }^{1}$, parce qu'il a quelque ressemblance avec le mulet, quoique réellement il soit infiniment plus beau. Il est de la grandeur d'un mulet de moyenne taille; la tête est un peu lourde ; les oreilles sont droites, plus longues qu'aux chevaux, mais plus courtes qu'aux mulets; le poitrail est grand, carré en bas, et un peu comprimé. La crinière est courte et hérissée, et la queue est entièrement semblable à celle de l'âne; les cornes des pieds sont petites : ainsi le czigithai ressemble à I'âne par la crinière, la queue, et les sabots. Il a aussi les jambes moins charnues que le cheval, et l'encolure encore plus légère et plus leste. Les pieds et la partie inférieure des jambes sont minces et bien faits. L'épine du dos est droite et formée comme celle d'un âne, mais cependant un peu plate. La couleur dominante dans ces animaux est le brun jaunâtre. La tête, depuis les yeux jusqu'au mufle, est d'un fauve jaunâtre; l'intérieur des jambes est de cette même couleur; la crinière et la queue sont presque noires, et il y a le longr du dos une bande de brun noirâtre qui s'é-

1. La Daourie est une province russe en Sibérie, vers les frontières de la Tartarie chinoise. On ne doit pas la confondre avec la Dorie des anciens. 
LE ZíBRE, IE GZIGITHAI, ctc.

largit sur le train de derrière et se rétrécit vers la queue. En hiver, leur poil devient fort long et ondoyé; mais en été il est ras et poli. Ces animaux portent la tête haute, et présentent, en courant, le nez au vent. Les Tunguses et d'autres nations voisines du grand désert regardent leur chair comme une viande délicieuse.

"Outre les tarpans, ou chevanx sauvages, et les czigithais ou mulets féconds de Daourie, on trouve dans les grands déserts au delà du Jaik, du Yemba, du Sarason, et dans le voisinage du lac Aral, une troisième espèce d'animal que les Kirghises et les Calmoucks appellent koulan ou khoulan, qui paroît être l'onager ou l'onagre des auteurs, et qui sembie faire une nuance entre le czigithai et l'âne. Les Koulans vivent en été dans les grands déserts dont nous venons de parler, et vers les montagnes de Tamanda, et ils se retirent, à l'approche de l'hiver, vers les confins de la Perse et des Indes. Ils courent avec une vitesse incroyable; on n'a jamais pu venir à bout d'en dompter un seul, et il y en a des troupeaux de plusieurs mille ensemble. Ils sont plus grands que les tarpans, mais moins que les czigithais. Leur poil est d'un beau gris, quelquefois avec une nuance légèrement bleuâtre, et d'autres fois avec un mélange de fauve; ils portent le long du dos une bande noire, et une autre bande de même couleur traverse le garrot et descend sur les épaules. Leur queue est parfaitement semblable à celle de l'âne; mais les oreilles sont moins grandes tt moins amples.

"A l'égard des zèbres, j’ai eu occasion de les bien examiner dans mes séjours au cap de Bonne-Espé- 
rance, et jai connu dans cette espèce une variété qui diffère du zèbre ordinaire, en ce qu'au lieu de handes ou raies brunes et noires dont le fond de son poil blanc est rayé, celui-ci, au contraire, est d'un brun roussâtre, avec très peu de bandes larges, et d'une teinte foible et blanchâtre; on a même peine à reconnoître et distinguer ces bandes blanchâtres darıs quelques individus qui ont une couleur uniforme de brun roussâtre, et dont les bandes ne sont que des nuances peu distinctes d'une teinte un peu pâle; ils ont, comme les autres zèbres, le bout du museau et les pieds blanchâtres, et ils leur ressemblent en tout, à l'exception des belles raies de la robe. On seroit donc fondé à prononcer que ce n'est qu'une variété dans cette espèce du zèbre : cependant ils semblent différer de ce dernier par le naturel, ils sont plus doux et plus obéissants; car on n'a pas d'exemple qu'on ait janais pu apprivoiser assez le zèbre rayé pour l'atteler à une voiture, tandis que ces zèbres à poil uniforme et brun sont moins revêches, et s'accoutument aisément à la domesticité. J'en ai vu un dans les campagnes du Cap, qui étoit attelé avec des chevaux à une voiture; et on m'assura qu'on élevoit un assez grand nombre de ces animaux pour s'en servir à l'attelage, parce qu'on a trouvé quils sont, à proportion, plus forts qu'un cheval de même taille. "

J'avois dit qu'on avoit fait des attelages de zèbres pour le prince stathouder; ce fait, qui m'avoit été assuré par plus d'une personue, n'est cependant pas vrai. M. Allamand, que j'ai eu si souvent occasion de citer avec reconnoissance et avec des éloges bien mé- 
LE ZEBHE, LE CZIGITHAI, etc.

rités, m'a fait savoir que j'avois été bien mal informé sur ce fait; le prince stathouder n'a eu qu'un seul zèbre : mais M. Allamand ajoute dans sa lettre au sujet de ces animaux, un fait aussi singulier qu'intéressant. Milord Clive, dit-il, en revenant de l'Inde, a amené avec lui une femelle zèbre dont on lui avoit lait présent au cap de Bonne-Espérance; après l'avoir gardée quelque temps dans son parc en Angleterre, il lui donna un âne pour essayer s'il n'y auroit point d'accouplement entre ces animaux : mais cette femelle zèbre ne voulut point s'en laisser approcher. Milord s'avisa de faire peindre cet âne comme un zèbre: la femelle, dit-il, en fut la dupe, l'accouplement se fit, et il en est né un poulain parlaitement semblable à sa mère, et qui, peut-être, vit encore. La chose a été rapportée à M. Allamand par le général Carnat, ami particulier de milord Clive, et lui a été confirmée par milord Clive fils. Milord Pitt a eu aussi la bonté de m'en écrire dans les termes suivants :

"Feu milord Clive avoit une très belle femelle de zèbre que j’ai vue à Glemnom, l'une de ses maisons de campagne, avec un poulain mâle (foal), provenant d'elle, qui n'avoit pas encore un an d'àge, et qui avoit été produit par le stratagème suivant. Lorsque la femelle zèbre fut en chaleur, on essaya de lui présenter un âne, qu'elle refusa constamment d'admettre : milord Clive pensa qu'en faisant peindre cet âne, qui étoit de couleur ordinaire, et en imitant les couleurs du zèbre mâle, on pourroit tromper la fèmelle; ce qui réussit si bien, qu'elle produisit le poulain dont on vient de parler. 
"J'ai été dernièrement, c'est-à-dire cet été 1778 , à Clemnom, pour m'informer de ce qu'étoient devenus la femelle zèbre et son poulain, et on m'a dit que la mère étoit morte, et que le poulain avoit été envoyé à une terre assez éloignée de milord Clive, où l'on a souvent essayé de le faire accoupler avec des ânesses, mais qu'il n'en est jamais rien résulté."

Je ferai cependant sur ces faits une légère observation, c'est que j'ai de la peine à croire que la femelle zèbre ait reçu l'âne uniquement à cause de son bel habit, et qu'il y a toute apparence qu'on le lui a présenté dans un moment où elle étoit en meilleure disposition que les autres fois. 11 faudroit d'ailleurs un grand nombre d'expériences, tant avec le cheval qu'avec l'âne, pour décider si le zèbre est plus près de l'un que de l'autre. Sa production avec l'âne indiqueroit qu'il est aussi près que le cheval de l'espèce de l'âne; car on sait que le cheval produit avec l'ânesse, et que l'âne produit avec la jument : mais il reste à reconnoître, par l'expérience, si le cheval ne produiroit pas aussi bien que l'âne avec la femnelle zèbre, et si le zèbre mâle ne produiroit pas avec la jument et arec l'ânesse. C'est au cap de Bonne-Lispérance que l'on pourroit tenter ces accouplements avec succès. 


\section{LE GOUAGGA.}

\section{Equus Quagga. Gmel.}

CET animal, dont je n'ai eu aucune connoissance qu'après l'impression des feuilles précédentes où il est question de l'onagre et du zèbre, me paroît être une espèce bâtarde ou intermédiaire entre le cheval et le zèbre, ou peut-être entre le zèbre et l'onagre. Voici ce que M. le professeur Allamand en a publié nouvellement dans un supplément à l'édition de mes ouvrages, imprimée en Hollande.

"Jusqu'à présent, dit ce savant naturaliste, on ne connoissoit que le nom de cet animal, et même encore très imparfaitement, sans savoir quel quadrupède ce nom indiquoit. Dans le journal d'un voyage entrepris dans l'intérieur de l'Afrique par ordre du gouverneur du cap de Bonne-Espérance, il est dit que les voyageurs virent, entre autres animaux, des chevaux sauvages, des ânes, et des quacchas. La signification de ce dernier mot m'étoit absolument inconnue, lorsque M. Gordon m'a appris que le nom de quacchas étoit celui de kwagga, que les Hottentots donnent à l'animal dont il s'agit, et que j'ai cru devoir retenir, parce que, n'ayant jaunais été décrit ni même connu en Europe, il ne peut être désigné que par le nom qu'il porte dans le pays dont il est originaire. Les raies dont sa peau est ornéc le font 
d'abord regarder comme nne variété dans l'espèce du zèbre, dont il diffère cependant à divers é gards : sa couleur est d'un brun foncé, et, comme le zèbre, il est rayé très régulièrenıent de noir, depuis le bout du musean jusqu'au dessus des épaules, et cette même couleur des raies passe sur une jolie crinière qu'il porte sur le con. Depuis les épaules, les raies commencent à perdre de leur longueur, et, allant en diminuant, e!les disparoissent à la région du ventre, avant d'avoir atteint les cuisses. L'entre-deux de ces raies est d'un brun plus clair, et il est presque blanc aux oreilles. Le dessous du corps, les cuisses, et les jambes sont blanches; sa queue, qui est un peu plate, est aussi garnie de crins ou de poils de la même couleur : la corne des pieds est noire; sa forme ressemble beaucoup plus à celle du pied du cheval qu'à la forme du pied du zèbre. On s'en convaincra en comparant la figure que j'en donne avec celle de ce dernier animal. Ajoutez à cela que le caractère de ces animaux est aussi fort différent; celui des couagrgas est plus docile : car il n'a pas encore été possible d'apprivoiser les zèbres assez pour pouvoir les employer à des usages domestiques; au lieu que les paysans de la colonie du Cap attellent les couaggas à leurs charrettes, quilis tirent très bien; ils sont robustes et forts : il est vrai qu'ils sont méchants, ils mordent et ruent; quand un chien les approche de trop prìs, ils le repoussent à grands coups de pied, et quelquefois ils le saisissent avec les dents; les hyènes mêmes, que l'on nomme loups an Cap, n'osent pas les attaquer : ils marchent en troupes, souvent au nombre de cent; mais jamais on ne voil guère un 
zèbre parmi eux, quoiqu'ils vivent dans les mêmes endroits.

"Tout cela semble indiquer que ces animaux sont d'espèces différentes; cependant ils ne difièrent pas plus entre eux que les mulets diffèrent des chevaux ou des ânes. Les couaggas ne seroient-ils point une race bâtarde de zèbres? Il y a en Afrique des chevaux sauvages blancs; Léon l'Africain et Marmol l'assurent positivement; et ce qui est plus authentique encore, c'est le témoignage de ces voyageurs dont j'ai cité le journal : ils ont vu de ces chevaux blancs; ils ont vu aussi des ânes sauvages. Ces animaux ne peuvent-ils pas se mêler avec les zèbres, et produire une race qui participera des deux espèces? J'ai rapporté ci-devant un fait qui prouve qu'une femelle zèbre, couverte par un âne, a eu un poulain. On ne peut guère douter que l'accouplement d'un cheval avec un zèbre ne fût aussi prolifique. Si celni des chevaux avec des ânesses ne produit, pour l'ordinaire, que des mulets stériles, cela n'est pas constant; on a vu des mules avoir des poulains, et il est fort naturel de supposer que les chevaux, ayant plus d'affinité avec les zèbres qu'avec les ânes, il peut résulter du mélange de ces animaux d'autres animaux féconds capables de faire souche; et ceci est également applicable aux ânes, puisque les zèbres sont une espèce mitoyenne entre les chevaux et les ânes. Ainsi je suis fort porté à croire que les couaggas ne sont qu'une race bâtarde de zèbres, qui, pour la figure et les caractères, tiennent quelque chose des deux espèces dont ils tirent leur origine.

"Quoi qu'it en soit, on a heaucoup d'obliggation à 
M. Gordon de nous les avoir fait connoître; car c'est lui qui m'en a envoyé le dessin et la description. II en vit un jour deux troupes, l'une d'une dizaine de couagras adultes, et l'autre composée uniquement de poulains qui couroient après leurs mères : il poussa son cheval entre ces deux troupes; et un des poulains ayant perdu de vue celle qui précédoit, suivit aussitôt de lui-même le cheval, comme s'il eût été sa mère. Les jeunes zèbres en font autant en pareil cas. M. Gordon étoit alors dans le pays des Bosjemants, et fort éloigné de toute habitation : ainsi il fut obligé d'abandonner ce poulain le lendemain, faute de lait pour le nourrir, et il le laissa courir où il voulut. Il en a actuellement un autre qu'il réserve pour la ménagerie de monseigneur le prince d'Orange. N'ayant pas pu se procurer un couagga adulte, il n'a pu m'envoyer que le dessin d'un poulain; wais il me mande qu'il n'y a aucune différence entre un poulain et un couagga qui a fait toute sa crue, si ce n'est dans sa grandeur, qui égale celle d'un zèbre, et dans la tête, qui est, a proportion, un peu plus grosse dans le couagga adulte. La différence qu'il y a entre les mâles et les femelles est aussi très petite.

"Depuis que le Cap est habité, ces animaux en ont quitté les environs, et ils ne se trouvent plus que fort avant dans l'intérieur du pays. Leur cri est une espèce d'aboiement très précipité, où l'on distingue souvent la répétition de la syllabe kwah, kwah. Les Hottentots trouvent leur chair fort bonne; mais elle déplaît aux paysans hollandois par son goût fade.

"Le poulain qui est ici représenté avoit, depuis le bout du museau jusqu'à la queue, trois pieds sept 



$$
\frac{18}{27}
$$


pouces et trois lignes; le train de devant étoit haut de deux pieds et dix pouces, et celui de derrière étoit plus bas d'un pouce; sa queue étoit longue de quatorze pouces.

Voici tout ce que M. Allamand a pu recueillir sur l'histoire de cet animal; mais je ne puis m'empêcher d'observer qu'il paroît y avoir deux faits coutraires dans le récit de M. Gordon : il dit, en premier lieu, que "les paysans des terres du Cap attellent les " couaggas à la charrette, et qu'ils tirent très bien," et ensuite il avoue qu'il n'a pu se procurer un couggga adulte pour en faire le dessin; il paroît donc que ces animaux sont rares dans ces mêmes terres du Cap, puisqu'il n'a pu faire dessiner qu'un poulain. Si l'espèce étoit réduite en domesticité, il lui auroit été facile de se procurer un de ces animaux adulte. Nous espérons que ce naturaliste voyageur voudra bien nous donner de plus amples informations sur cet animal, qui me paroît tenir au zèbre de plus près qu'aucun autre.

Q0 w000050

\section{L'ÉLAN ${ }^{1}$ ET LE RENNE².}

Cervus Alces. L. - Cervus Tarandus. L.

QuorQue l'élan et le renne soient deux animaux d'espèces différentes, nous avons cru devoir les réu-

1. En langue celtique, elch; en latin, alce; en allemand, hellend ou ellend; en anglois, elk.

2. Le renne n'étoit pas connu des Grees : il aroit, en vicux françois, 
nir, parce qu'il n'est guère possible de faire l'histoire de l'un sans emprunter beaucoup de celle de l'autre; la plupart des anciens auteurs, et même des modernes, les ayant confondus ou désignés par des dénominations équivoques qu'on pourroit appliquer à tous deux. Les Grecs ne connoissoient ni l'élan, ni le renne; Aristote 1 n'en fait aucune mention; et chez les Latins, Jules-César est le premier qui ait employé le nom alce. Pausanias, qui a écrit environ cent ans après Jules-César, est aussi le premier auteur grec dans lequel on trouve ce même nom alcé; et Pline ${ }^{2}$,

le nom de rangier ou ranglier; tarandus, en latin; en Norwége, rehen; en Laponie, boetsoi, selon Frédéric Hoffberg (Collection de différents morceaux, etc., par M. de Keralio; Paris, 1763; tome premier, page 240); en allemand, reenthier; en Suède, rhen; en anglois, raindeer; en Canada, caribou; en latin moderne, rangifer. - "In " partibus magna: Laponiæ bestia est de genere cervorum.... Rangifer " duplici ratione dicta : una quod in capite ferat alta cornua velut " quos quercinarum arborum ramos; alia quod instrumenta cornibus "pectorique, quibus hiemalia plaustra trahit imposita, rancha et "locha patrio sermone vocantur." (Olai Magni Hist. de gent. sept. Antuerpia, 1558, page 135.)

1. L'hippélaphe d'Aristote n'est pas l'élan, comme l'ont cru nos plus savants naturalistes. Nous avons discuté dans l'article de l'axis ce que c'est que l'hippélaphe et le tragélaphe.

2. " Septentrio fert et equorum greges ferorum, sicut asinornm Asia " et $\Lambda$ frica; præterea alcem, ni proceritas aurium et cervicis distin" guat, jumento similem; item notam in Scandinavia iusula, nec " unquam risam in hoc orbe, multis tamen narratam machlin, haud " dissimilem illi, sed nullo suffraginum flexu, ideoque non cubanw tem, sed acclivem arbori in somno, eaque incisa ad insidias, capi ; " velocitatis memoratx. Labrum ei superius prægrande : ob id retro"graditur in pascendo, ne in priora tendess, involvatur. " (Plin., IIist. nat., lib. VIII, cap. 15.) - " Mutal culores et Scytharum tarann dus......... Tarando magnitudo qua bovi; caput majus cervino, " nec absimile; cornua ramosa; ungula bilida : villus magnitudine 
qui étoit à peu près contemporain de Pausanias, a indiqué assez obscurément l'élan et le renne sous les noms alce, machlis, et tarandus. On ne peut donc pas dire que le nom alce soit proprement. grec ou latin; et il paroît avoir été tiré de la langue celtique, dans laquelle l'élan se nommoit elch ou elk. Le nom latin du renne est encore plus incertain que celui de l'élan; plusieurs naturalistes ont pensé que c'étoit le machlis de Pline, parce que cet auteur, en parlant des animaux du Nord, cite en mềne temps l'alce et le machlis, et qu'il dit de ce dernier qu'il est particulier à la Scandinavie, et qu'on ne l'a jamais vu à Rome, ni même dans toute l'étendue de l'empire romain : cependant on trouve encore dans les Commentaires de César ${ }^{1}$ un passage qu'on ne peut guère

" ursorum ; sed, cum libuit sui coloris esse, asini similis est : tergoris "tanta duritia, ut thoraces ex eo faciant...... Metuens latet, ideoque "raro capitur. "( Plin., Hist. nat., lib. VIII, cap. 34.)

Jai cru devoir citer ensemble ces deux passages de Pline, dans lesquels, sous les noms d'alce, de machlis et de tarandus, il paroît indiquer trois animaux différents : mais l'on verra, par les raisons que je vais en donner, que les noms machlis et alce doivent tous deux s'appliquer au même animal, c'est-à-dire à l'élan ; et quoique la plupart des naturalistes aient cru que le tarandus de Pline étoit l'élan, il est beancoup plus vraisemblable que c'est le renne qu'il a voulu désigner par ce nom. J'avoue cependant que ces indications de Pline sont si peu précises, et même si fausses à de certains égards, qu'il est assez difficile de se déterminer et de prononcer nettement sur cette question. Les commentateurs de Pline, quoique très savants et très érudits, éloient très peu versés dans l'histoire naturelle, et c'est par cette raison qu'on trouve dans cet auteur tant de passages obscurs et mal interprétés. Il en est de même des traducteurs et des commentateurs d'Aristote. Nous tâcherons, à mesure que l'occasion s'en présentera, de rétablir le vrai sens de plusieurs mots altérés et de passages corrompus dans ces deux auteurs.

1. "Est hos (in Hercynia syira), cervi figura, cujus a media fronte 
appliquer à un autre animal qu'au renne, et qui semble pronver qu'il existoit alors dans les forêts de la Germanie ; et, quinze siècles après Jules-César, Gaston Phœbus semble parler du renne sous le nom de

n inter aures unum cornu existit excelsius, magisque directum his " qua nobis nota sunt cornibus : ab ejus summo, sicut palmæ, rami n quam late diffunduntur. Eadem est feminæ marisque natura ; eadem "forma magnitudoque cornuum. (Jul. Cæsar. De bello Gallico, lib. VI. )

Ce passage est assez précis; le renne a en effet des andouillers en avant, et qui paroissent former un bois intermédiaire. Son bois est divisé en plusieurs branches, terminées par de larges empaumures, et la femelle porte un bois comme le mâle; au lieu que les femelles de l'élan, du cerf, du daim et du chevreuil, ne portent point de bois : ainsi l'on ne peut guère douter que l'animal qu'indique ici César ne soit le renne, et non pas l'élan; d'autant plus que dans un autre endroit de ses Commentaires il indique l'élan par le nom d'alce, et en parle en ces termes:

"Sunt item (in Hercynia sylva) quæ appellantur alces : harum est n consimilis capris (capreis) figura et varietas pellium : sed magnitu" dine paulo antecedunt, mutilæque sunt cornibus, et crura sine " notis articulisque habent, neque quietis causa procumbunt......... "His sunt arbores pro cubilibus; ad eas se applicant, atque jta pau" lum modo reclinatæ quietem capiunt : quarum ex vestigiis cum est n animadversum a venatoribus quo se recipere consueverint, omnes " eo loco aut a radicibus subruunt, aut accidunt arbores tantum, ut n summa species earum stantium relinquatur. Huc cum se ex consuen tudine reclinaverint, infirmas arbores pondere affligunt atque una "ipsæ concidunt." ( De bello Gallico, lib. VI.)

J'arque que ce second passage n'a rien de précis que le nom alce, et que pour l'appliquer à l'élan, il faut substituer le mot capreis à celui de capris, et supposer en même temps que César n’avoit vu que des élaas femelles, lesquelles en effet n'ont point de cornes : le reste peut s'entendre; car l'élan a les jambes fort roides, c'est-à-dire les articulations très fermes; et comme les anciens étoient persuadés qu'il y avoit des animaux, tels que l'éléphant, qui ne pouvoient ni plier les jambes, ni se coucher, il n'est pas étonnant qu'ils aient attribué à l'élan cette partie de la fable de l'éléphant. 
rangier, comme d'un animal qui auroit existé de son temps dans nos forêts de France ; il en fait même une assez bonne description, et il donne la manière de le prendrę et de le chasser. Comme sa description ne peut pas s'appliquer à l'élan, et qu'il donne en même temps la manière de chasser le cerf, le daim, le chevreuil, le bouquetin, le chamois, etc., on ne peut pas dire que, dans l'article du rangier, il ait voulu parler d'aucun de ces animaux, ni qu'il se soit trompé dans l'application du nom. Il sembleroit donc, par ces témoignages positifs, qu'il existoit jadis en France des rennes, du moins dans les hautes montagnes, telles que les Pyrénées, dont Gaston Phœbus étoit voisin, comme seigneur et habitant du comté de Foix, et que, depuis ce temps, ils ont été détruits comme les cerfs, qui autrefois étoient communs dans cette contrée, et qui cependant n'existent plus aujourd'hui dans le Bigorre, le Couserans, ni dans les provinces adjacentes. Il est certain que le renne ne se trouve actuellement que dans les pays les plus septentrionaux; mais l'on sait aussi que le climat de la France étoit autrefois beaucoup plus humide et plus froid, par la quantité des bois et des marais, qu’il ne l'est aujourd'hui. On voit, par la lettre de l'empereur Julien, quelle étoit de son temps la rigueur du froid à Paris : la description des glaces de la Seine ressemble parfaitement à celle que nos Carıadiens font de celles du fleuve de Quebec. Les Gaules, sous la même latitude que le Canada, étoient, il y a deux mille ans, ce que le Canada est de nos jours, c'est-à-dire un climat assez froid pour nourrir les animaux qu'on ne tronve aujourd'hui que dans les provinces du Nord. 
En comparant les témoignages et combinant les indications que je viens de citer, il ine paroît donc qu'il existoit autrefois dans les forêts des Gaules et de la Germanie des élans el des rennes, et que les passages de César ne peuvent s'appliquer qu'à ces deux animaux. A mesure que l'on a défriché les terres et desséché les eaux, la température du climat sera devenue plus donce, et ces mêmes animaux, qui n'aiment que le froid, auront d'abord abandonné le plat pays, et se seront retirés dans la région des neiges sur les hautes montagnes, où ils subsistoient encore $\mathrm{du}$ temps de Gaston de Foix ; et s'il ne s'y en trouve plus arjourd'hui, c'est que cette même température a toujours été en augmentant de chaleur par la destruction presque entière des forêts, par l'abaissement successif des montagnes, par la diminution des eaux, par la multiplication des hommes, et par la succession de leurs travaux et de l'augmentation de leur consommation en tout genre. Il me paroît de wême que Pline a emprunté de Jules-César presque tout ce qu'il a écrit de ces deux animaux, el qu'il est le premier auteur de la confusion des noms; il cite en même temps l'alce et le machlis, et naturellement on devroit en conclure que ces deux noms désignent deux animanx dilférents ${ }^{1}$ : cependant, si l'on remarque, $1^{\circ}$ qu'il nomme simplement l'alce sans autre in-

1. I'lusieurs naturalistes, et même quelques uns des plus savants, tels que M. Ray, out en effet pensé que le machlis de Pline, se trouvant dans cet auteur a côté de l'alce, ne pouroit être autre que le renne. Cervus rungifer, the raindeer: Plinio machlis. (Ray. Syn. quadr. pag. 89. ) C'est parce que je ne suis pas de centiment que $j$ ai cru devoir donner ici le détail de mes raisons. 
dication ni description, qu'il ne le nomme qu'une fois, et que nulle part il n'en dit un mot de plus; $2^{\circ}$ que lui seul a écrit le nom machlis, et qu'aucun autre auteur latin ou grec n'a employé ce mot, qui même paroît factice ${ }^{1}$, et qui, selon les commentateurs de Pline, est remplacé par celui d'alce dans plusieurs anciens manuscrits; $5^{\circ}$ qu'il attribue au machlis tout ce que Jules-César dit de l'alce; on ne pourra douter que le passage de Pline ne soit corrompu, et que ces deux noms ne désignent le même animal, c'està-dire l'élan. Cette question une fois décidée en décideroit une autre; le machlis étant l'élan, le tarandus sera le renne: ce mot tarandus est encore un mot qui ne se trouve dans aucun auteur avant Pline, et sur l'interprétation duquel les naturalistes ont beaucoup varié; cependant Agricola et Éliot n'ont pas hésité de l'appliquer au renne; et par les raisons que nous venons de déduire, nous souscrivons à leur avis. Au reste, on ne doit pas être surpris du silence des Grecs au sujet de ces deux animaux, ni de l'incertitude avec laquelle les Latins en ont parlé, puisque les climats septentrionaux étoient absolument inconnus aux premiers, et n'étoient connus des seconds que par relation.

Or, l'élan et le renne ne se trouvent tous deux que

1. On lit à la marge de ce passage de Pline, achlin, au lieu de machlin. Fortassis achlin, quod non cubet, disent les commentateurs: ainsi ce nom paroît être factice, et ajusté à la supposition que cet animal ne peut se coucher. D'autre côté, en transposant l'l dans alce, on fait acle, qui ne diffère pas beaucoup d'achlis : ainsi l'on peut penser encore que ce mot a été corrompu par les copistes, d'aulant plus que l'on trouve alcem au lieu de machlin dans quelques anciens manuscrits. 
dans les pays du Nord; l'élan en deçà et le renne au delà du cercle polaire en Europe et en Asie : on les retrouve en Amérique à de moindres latitudes, parce que le froid y est plus grand qu'en Europe; le. renne n'en craint pas la rigueur, mêne la plus excessive; on en voit an Spitzberg; il est commun en Groenland ${ }^{4}$ et dans la laponie la plus boréale, ainsi que dans les

1. Le capitaine Craycolt amena de Groenland, en 1758 , un mâle et une femelle à Londres. Voyez l'Histoire des Oiseaux d'Edwards, page 51 , où l'on trouve la description et la figure de cet animal sous le nom de daim de Groenland. Ce daim de Groenland de M. Edwards, aussi bien que le chevreuil de Groenland, ou caprea Groenlendica, dont parle M. Grew dans la description du Cabinet de la Société royale, ne sont autre chose que le renne. Ges auteurs, en décrivant les cornes ou plutôl le bois de ces animaux, semblent tous deux donner comme un caractère particulier le duvet dont le bois étoit recourert dans l'un et l'autre de ces animaux : cela cependant est commun au renne, au cerf, au daim, et à tous les animaux qui portent du bois. Pendant tout le temps que ce bois croît, il est couvert de poil ; et comme l'été est la saison de cet accroissement, et que c'est aussi le seul temps de l'année où l'on puisse voyager en Groenland, il n'est pas étonnant que les bois de ces animaux pris dans cette saison soient couverts de duvet. Ainsi ce caractère est nul dans la description de ces auteurs.

"On trouve sur les côtes, au détroit de Forbisher, des cerfs à peu "près de la couleur de nos ânes, et dont le bois est beaucoup plus " large et plus élevé qu'aux nôtres. Leur pied a sept ou huit pouces " de tour, et ressemble à celui de nos bœufs. " (Voyage de Lade, tome II, page 297.)

Ceci paroît avoir été copié par Robert Lade, d'une ancienne relation qui a pour titre, la Navigation du capitaine Martin, Anglois, es régions d'West et de Nord-West; Paris, ${ }_{1} 578$; où il est dit, page 17 : - Bien qu'il y ait des cerfs dans Jes terres à la rade de Warwick en s grande quantité, la peau desquels ressemble à celle de nos ânes, "leurs tête et cornes surpassent, tant en grandeur qu'en largeur, " celles des nôtres de par-deçá ; leurs pieds sont aussi gros que ceux de n nos baufs, el ont de largeur, comme je vous puis assurer pour les "avoir mesurés, huit pouces." 
parties les plus septentrionales de l'Asie. L'élan ne s'approche pas si près du pôle; il habite en Norwége, en Suède, en Pologne, en Lithuanie, en Russie, et dans les provinces de la Sibérie et de la Tartarie, jusqu'au nord de la Chine. On le retrouve sous le nom d'orignal, et le renne sous celui de caribou, en Canada et dans toute la partie septentrionale de l'Amérique. Les naturalistes qui ont douté que l'orignal fût l'élan, et le caribou le renne, n'avoient pas assez conparé la nature avec les témoignages des voyageurs : ce sont certainement les mêmes animaux qui, comme tous les autres, dans ce nouveau monde, sont seulement plus petits que dans l'ancien continent.

On peut prendre des idées assez justes de la forme de l'élan et de celle du renne, en les comparant tous deux avec le cerf. L'élan est plus grand, plus gros, plus élevé sur ses jambes; il a le cou plus court, le poil plus long, le bois beaucoup plus large et plus massif que le cerf : le renne est plus bas, plus trapu; il a les jambes plus courtes, plus grosses, et les pieds bien plus larges; le poil très fourni; le bois beaucoup plus long et divisé en un grand nombre de rameaux terminés par des empaumures, au lieu que celui de l'élan n'est, pour ainsi dire, que découpé et chevillé sur la tranche. Tous deux ont de longs poils sous. le cou, et tous denx ont la queue courte et les oreilles beaucoup plus longues que le cerf. Ils ne vont pas par bonds et par sauts, comme le chevreuil ou le cerf : leur marche est une espèce de trot, mais si prompt et si aisé, qu'ils font dans le même temps presque autant de chemin qu'eux, sans se fatiguer autant; car ils peuvent trolter ainsi sans s'arrêter pendant un jour ou 
deux. Le renne se tient sur les montagneş l'élan n'habite que les terres basses et les forêts humides. Tous deux se mettent en troupe, comme le cerf, et vont de compagnie; tous deux peuvent s'apprivoiser, mais le renne beaucoup plus que l'élan : celui-ci, comme le cerf, n'a nulle part perdu sa liberté, au lieu que le renne est devenu domestique chez le dernier des peuples; les Lapons n'ont pas d'autre bétail. Dans ce climat glacé, qui ne reçoit du soleil que des rayons obliques, où la nuit a sa saison comme le jour, où la neige couvre la terre dès le commencement de l'automne jusqu'à la fin du printemps, nù la ronce, le genièvre, et la mousse, sont seuls la verdure de l'été, l'homme pouvoit-il espérer de nourrir des troupeaux? Le cheval, le bœuf, la brebis, tous nos autres animaux utiles ne pouvant y trouver leur subsistance, ni résister à la rigueur du froid, il a fallu chercher parmi les hôtes des forêts l'espèce la moins sauvage et la plus profitable : les Lapons ont fait ce que nous ferions nous-mêmes si nous venions à perdre notre bétail; il faudroit bien alors, pour y suppléer, apprivoiser les cerfs, les chevreuils de nos bois, et les rendre animaux domestiques; et je suis persuadé qu'on en vịendroit à bout, et qu'on sauroit bientôt en tirer autant d'utilité que les Lapons en tirent de leurs rennes. Nous devons sentir par cet exemple jusqu'où s'étend pour nous la libéralité de la nature; nous n'usons pas, à beaucoup près, de toutes les richesses qu'elle nous offre; le fonds en est bien plus immense que nous ne l'imaginons : elle nous a donné le cheval, le bœuf, la brebis, tous nos autres animaux domestiques, pour nous servir, nous nourrir, nous vêtir; et elle a en- 
core des espèces de réserve qui pourroient suppléer à leur défaut, et qu'il ne tiendroit qu'à nous d'assujettir et de faire servir à nos besoins. L'homme ne sait pas assez ce que peut la nature, ni ce qu'il peut sur elle : au lieu de la rechercher dans ce qu'il ne connoît pas, il aime mieux en abuser dans tout ce qu'il en connoît.

En comparant les avantages que les Lapons tirent du renne apprivoisć avec ceux que nous retirons de nos animaux domestiques, on verra que cet animal en vaut seul deux ou trois. On s'en sert comme du cheval, pour tirer des traîneaux, des voitures; il marche avec bien plus de diligence et de légèreté, fait aisément trente lieues par jour, et court avec autant d'assurance sur la neige gelée que sur une pelouse. La femelle donne du lait plus substantiel et plus nourrissant que celui de la vache; la chair de cet animal est très bonne à manger; son poil fait une excellente fourrure, et la peau passée devient un cuir. très souple et très durable : ainsi le renne donne seul tout ce que nous tirons du cheval, du bœuf, et de la brebis.

La manière dont les Lapons élèvent et conduisent ces animaux mérite une attention particulière. Olaüs, Scheffer, Regnard, nous ont donné sur cela des détails intéressants que nous croyons devoir présenter ici par extrait, en réformant ou supprimant les faits sur lesquels ils se sont trompés. Le bois du renne, beaucoup plus grand, plus étendu et divisé en un bien plus grand nombre de rameaux que celui du cerf, disent ces auteurs, est une espèce de singularité admirable et monstrueuse. La nourriture de cet animal pendant l'hiver est une mousse blanche qu'il sait trouver sous les neiges épaisses, en les fouillaut 
avec son bois et les détournant avec ses pieds; en été, il vit de boutons et de feuilles d'arbre, plutôt que d'herbes, que les rameaux de son bois avancés en avant ne lui permettent pas de brouter aisément. II court sur la neige, et enfonce peu à cause de la largeur de ses pieds... Ces animaux sont doux; on en fait des troupeaux, qui rapportent beaucoup de profit à leur maître. Le lait la, peau, les nerfs, les os, les cornes des pieds, les bois, le poil, la chair, tout en est bon et utile. Les plus riches Lapons ont des troupeaux de quatre ou cinq cents rennes; les plus pauvres en ont dix ou douze : on les mène au pâturage, on les ramène à l'étable, ou bien on les enferme dans des parcs pendant la nuit, pour les mettre à l'abri de l'insulte des loups. Lorsqu'on leur fait changer de climat, ils meurent en peu de temps. Autrefois Stenon, prince de Suède, en envoya six à Frédéric, duc de Holstein ; et moins anciennement, en 1553, Gustave, roi de Suède, en fit passer dix en Prusse, mâles et femelles, qu'on lâcha dans Jes bois : tous périrent sans avoir produit, ni dans l'état de domesticité, ni dans celui de liberté. "J'aurois bien voulu, dit " M. Regnard, mener en France quelques rennes en " vie; plusieurs gens l'ont tenté inutilement, et l'on " en conduisit l'année passée trois ou quatre à Dantnzick, oì ils moururent, ne pouvant s'accommoder "à ce climat, qui est trop chaud pour eux."

II y a en Laponie des rennes sauvages et des rennes domestiques. Dans le temps de la chaleur, on lâche les femelles dans les bois, on les laisse rechercher les mâles sauvages; et comme ces rennes sauvages sont plus robustes et plus forts que les domestiques, 
on préfère ceux qui sont issus de ce mélange pour les atteler au traîneau. Ces rennes sont moins doux que les autres; car non seulement ils refusent quelquefois d'obéir à celui qui les guide, mais ils se retournent brusquement contre lui, l'attaquent à coups de pied, en sorte qu'il n'a d'autre ressource que de se couvrir de son traîneau, jusqu'à ce que la colère de sa bête soil apaisée. Au reste, cette voiture est si légère, qu'on la manie et la retourne aisément sur soi; elle est garnie par dessous de peaux de jeunes rennes, le poil tourné contre la neige et couché en arrière, pour que le traîneau glisse plus facilement en avan $t$ et recule moins aisément dans la montagne. Le renne attelé n'a pour collier qu'un morceau de peau où la poil est resté, d'où descend vers le poitrail un trait qui lui passe sous le ventre, entre les jambes, et va s'attacher à un trou qui est sur le devant du traîneau. Le Lapon n'a pour guides qu'une seule cordé, attachée à la racine du bois de l'animal, qu'il jette diversement sur le dos de la bête, tantôt d'un côté et tantôt de l'autre, selon qu'il veut la diriger à droite ou à gauche. Elle peut faire quatre ou cinq lieues par heure : mais plus cette manière de voyager est prompte, plus elle est incommode; il faut y être habitué, et travailler continuellement pour maintenir son traîneau et l'empêcher de verser.

Les rennes ont à l'extérieur beaucoup de choses communes avec les cerfs, et la conformation des parties intérieures est, pour ainsi dire, la même. De cette conformité de nature résultent des habitudes analogues et des effets semblables. Le renne jette son. 
bois tous les ans, comme le cerf, et se charge comme lui de venaison : il est en rut dans la même saison, c'est-à-dire vers la fin de septembre. Les femelles, dans l'une et dans l'autre espèce, portent huit mois, et ne produisent qu'un petit : les mâles ont de même une très mauvaise odeur dans ce temps de chaleur; et parmi les femelles comme parmi les biches, il s'en trouve quelques unes qui ne produisent pas. Les jeunes rennes ont aussi, comme les faons, dans le premier âge, le poil d'une couleur variée: il est d'abord d'un roux mêlé de jaune, et devient avec l'âge d'un brun presque noir. Chaque petit suit sa mère pendant deux ou trois ans, et ce n'est qu'à l'âge de quatre ans révolus que ces animaux ont acquis leur plein accroissement. C'est aussi à cet âge qu'on commence à les dresser et les exercer au travail : pour les rendre plus souples, on leur fait subir d'avance la castration; et. c'est avec les dents que les Lapons font cette opération. Les rennes entiers sont fiers et trop difficiles à manier : on ne se sert donc que de hongres, parmi lesquels on choisit les plus vifs et les plus légers pour courir au traîneau, et les plus pesants pour voiturer à pas plus lents les provisions et les bagages. On ne garde qu'un mâle entier pour cinq ou six femelles, et c'est à l'âge d'un an que se fait la castration. Ils sont encore, comme les cerfs, sujets aux vers dans la mauvaise saison; il s'en engendre, sur la fin de l'hiver, une si grande quantité sous leur peau, qu'elle en est alors toute criblée : ces trous de vers se referment en été, et aussi ce n'est qu'en automne que l'on tue les rennes pour en avoir la fourrure ou le cuir. 
Les troupeaux de cette espèce demandent beaucoup de soin : les rennes sont sujets à s'écarter, et reprennent volontiers leur liberté naturelle; il faut les suivre et les veiller de près: on ne peut les mener paître que dans des lieux découverts; et, pour peu que le troupeau soit nombreux, on a besoin de plusieurs personnes pour les garder, pour les contenir, pour les rappeler, pour courir après ceux qui s'éloignent. Ils sont tous marqués, afin qu'on puisse les reconnoître; car il arrive souvent, ou qu'ils s'égarent. dans les bois, ou qu'ils passent à un autre troupeau. Enfin les Lapons sont continuellement occupés à ces soins; les rennes font toutes leurs richesses, et ils savent en tirer toutes les commodités, ou, pour mieux dire, les nécessités de la vie : ils se couvrent, depuis les pieds jusqu’à la tête, de ces fourrures, qui sont impénétrables au froid el à l'eau; c'est leur habit d'hiver : l'été ils se servent des peaux dont le poil est tombé : ils savent aussi filer ce poil; ils en recouvrent les nerfs qu'ils tirent du corps de l'animal, et qui leur servent de cordes et de fil; ils en mangent la chair, en boivent le lait, et en font des fromages très gras. Ce lait, épuré et battu, donne, au lieu de beurre, une espèce de suif. Cette particularité, aussi bien que la grande étendue du bois dans cet animal', et l'abondante venaison dont il est chargé dans le temps du rut, sont autant d'indices de la surabondance de nourriture; et ce 'qui prouve encore que cette surabondance est excessive ou du moins plus grande que dans aucune espèce, c'est que le renne-est le seul dont la femelle ait un bois comme le mâle, et le seul encore dont le bois tombe et se renouvelle mal- 
gré la castration ${ }^{1}$; car dans les cerfs, les daims, et les chevreuils qui ont subi cette opération, la tête de l'animal reste pour toujours dans le mêrne état où elle étoit au moment de la castration. Ainsi le reune est, de lous les animaux, celui où le superflu de la matière nutritive est le plus apparent : et cela tient peut-être moins à la nature de l'animal qu'à la qualité de la nourriture ${ }^{2}$; car cette mousse blanche, qui fait, surtout pendant l'hiver, son unique aliment, est un lichen dont la substance, semblable à celle de la morille ou de la barbe de chèvre, est très nourris-

1. " Cterque sexus cornutus est..... Gastralus quotannis cornua de"ponit. "( Linn. Syst. nat. edit. X, pag. 67.)

C'est sur cette seule autorité de Linnans que nous avançons ce fait, dnquel nous ne voulons pas douter, parce qu'ayant voyagé dans le Nord, et demeurant en Suède, il a été à portée d'être bien informé de tout ce qui concerne le renne. J'avoue cependant que cette exception doit paroître singulière, attendu que dans tous les autres animaux de ce genre l'effet de la castration empêche la chute ou le renouvellement du bois, et que d'ailleurs on peut opposer à M. Linnæus un témoignage contraire et positif.

"Castratis rangiferis Lappones utuntur. Cornua castratorum non " decidunt; et cum hirsuta sunt semper pilis luxuriant." (Hulden, Rangifer. Ienæ, 1697•)

Mais M. IIulden n'avoit peut-être d'autre raison que l'analogie pour avancer ce fait; et l'antorité d'nn habile naturaliste, tel que 11 . Linnaus, vant seule plus que le témoignage de plusieurs gens moins instruits. Le fait très certain que la femelle porte un bois comme le mâle est une autre exception qui appuie la première. Liusage où sont les Lapons de ne pas amputer les testicules au renne, mais seulement de le bistourner, en comprimant avec les dents les vaisseaux qui y aboutissent, la farorise encore : car l'action des testicules, qui paroît nécessaire à la production du bois, n'est pas ici totalement détruite; elle n'est qu'affoiblie, et peut bien s'exercer dans le mâle bistourné, puisqu'elle a son effet inême clans les femelles.

2. Voyez ce que j’ai dit à ce sujet dans cette IIistoire naturelle, article du Crkf. 
sante, et beaucoup plus chargée de molécules organiques que les herbes, les feuilles, ou les boutons des arbres; et c'est par cette raison que le renne a plus de bois et plus de venaison que le cerf, et que les femelles ou les hongres n'en sont pas dépourvus. C'est encore de là que vient la grande variété qui se trouve dans la grandeur, dans la figure, et dans le nombre des andouillers et des rameaux du bois des rennes : les mâles qui n'ont été ni chassés ni contraints, et qui se nourrissent largement et à souhait de cet aliment substantiel, ont un bois prodigieux; il s'étend en arrière presque sur leur croupe, et en avant au delà du museau : celui des hongres est moindre, quoique souvent il soit encore plus grand que le bois de nos cerfs; enfin celui que portent les femelles est encore plus petit. Ainsi ces bois varient non seulement comme les autres par l'âge, mais encore par le sexe et par la mutilation des mâles : ces bois sont donc si différents les uns des autres, qu'il n'est pas surprenant que les auteurs qui ont voulu les décrire soient si peu d'accord entre eux.

Une autre singularité que nous ne devons pas omettre, et qui est commune au renne et à l'élan, c'est que quand ces animaux courent, ou seulement précipitent leurs pas, les cornes de leurs pieds font, à chaque mouvement, un bruit de craquement si fort, qu'il semble que toutes les jointures des jambes se déboîtent: les loups, avertis par ce bruit ou par l'odeur de la bête, courent au devant, la saisissent, et en viennent à bout s'ils sont en nombre; car le renne se défend d'un loup seul : ce n'est point avec son bois, lequel en tout lui nuit plus qu'il ne lui sert; 
c'est avec les pieds de devant, qu'il a très forts : il en frappe le loup avec assez de violence pour l'étourdir ou l'écarter, et fuit ensuite avec assez de vitesse pour n’être plus atteint. Un ennemi plus dangereux pour lui, quoique moins fréquent et moins nombreux, c'est le rosomack ou glouton : cet animal, encore plus vorace, mais plus lourd que le loup, ne poursuit pas le renne; il grimpe et se cache sur un arbre pour l'attendre au passage : dès qu'il le voit à portée, il se lance dessus, s'attache sur son dos en y enfonçant les ongles, et, lui entamant la tête ou le cou avec les dents, ne l'abandonne pas qu'il ne l'ail égorgé. Il fait la même guerre et emploie les mêmes ruses contre l'élan, qui est encore plus puissant et plus fort que le renne. Ce rosomack ou glouton du Nord est le même animal que le carcajou ou quinquajou de l'Amérique septentrionale : ses combats avec l'orignal sont fameux; et, comme nous l'avons dit, l'orignal dı Canada est le même que l'élan d'Europe. Il est singulier que cet animal, qui n'est guère plus gros qu'un blaireau, vienne à bout d'un élan, dont la taille excède celle d'un grand cheval, et dont la force est telle que d'un seul coup de pied il peut tuer un loup; mais le fait est attesté par tant de témoins, que l'on ne peut en donter.

L'élan et le renne sont tous deux du nombre des animaux ruminants ; leur manière de se nourrir l'indique, et l'inspection des parties intérieures le démontre : cependant Tornæus, Scheffer, Regnard, Hulden, et plusieurs autres, ont écrit que le renne ne ruminoit pas: Ray a eu raison de dire que cela Jui paroissoit incroyable; et en effet, le renne ru- 
mine comme le cerf, et comme tous les autres animaux qui ont plusieurs estomacs. La durée de la vie dans le renne domestique n'est que de quinze ou seize ans : mais il est à présumer que, dans le renne sauvage, elle est plus longue; cet animal étant quatre ans à crôtre doit vivre vingt-huit ou trente ans lorsqu'il est dans son état de nature. Les Lapons chassent les rennes sauvages de différentes façons, suivant les différentes saisons : ils se servent des fcmelles domestiques pour attirer les mâles sauvages dans le temps du rut; ils les tuent à coups de mousquet, ou les tirent avec l'arc, et décochent leurs flèches avec tant de roideur, que, malgré la prodigieuse épaisseur du poil et la fermeté du cuir, il n'en faut souvent qu'une pour tuer la bête.

Nous avons recueilli les faits de l'histoire du renne avec d'autant plus de soin, et nous les avons présentés avec d'autant plus de circonspection, que nous ne pouvions pas par nous-mêrnes nous assurer de tous, et qu'il n'est pas possible d'avoir ici cet animal vivant. Ayant témoigné mes regrets à cet égard à quelques uns de mes amis, M. Collinson, membre de la Société royale de Londres, homme aussi recommandable par ses vertus que par son mérite littéraire, et avec lequel je suis lié d'amitié depuis plus de vingt ans, a eu la bonté.de m'envoyer un dessin du squelette du renne, et j’ai reçu du Canada un fœtus de caribou; au moyen de ces deux pièces, et de plusieurs bois de rennes qui nous sont venus de différents endroits, nous avons été en état de vérifier les ressemblances généraleṣ et les différences principales du renne avec le cerf, comme on le verra dans la 
description du foetus, du squelette, et des bois de cel animal.

A l'égard de l'élan, j'en ai vu un vivant, il y a environ quinze ans, que je voulus faire dessiner: mais comme il resta peu de jours à Paris, on n'eut pas le temps d'achever le dessin, et je n'eus moi-même que celui de vérifier la description que MM. de l'Académie des Sciences ont autrefois donnée de ce même animal, et de m’assurer qu'elle est exacte et très conforme à la nature.

"L'élan, dit le rédacteur de ces Memoires de l' $A$ ` cadémie, est remarquable par la longueur du poil, "la grandeur des oreilles, la petitesse de la queue, et "la forme de l'oil, dont le grand angle est beaucoup "fendu, de même que la gueule, qui l'est bien plus " qu'aux bœufs, qu'aux cerfs, et qu'aux autres ani" maux qui ont le pied fourchu... L'élan que nous " avons disséqué étoit à peu près de la grandeur "d'un cerf; la longueur de son corps étoit de cinq " pieds et demi, depuis le bout du museau jusqu'au " commencement de la queue, qui n'étoit longue " que de deux pouces; sa têle n'avoit point de " bois, parce que c'étoit une femelle, et le cou étoit " court, n'ayant que neuf pouces de long et autant " de large; les oreilles avoient neuf pouces de long "sur quatre de large... La couleur du poil n'étoit pas " fort éloignée de celle du poil de l'âne, dont le gris " approche quelquefois de celui du chameau... Mais " ce poil étoit d'ailleurs fort diffé rent de celui de "l'âne, qui est beaucoup plus court, et de celui du " chameau, qui l'a beaucoup plus délié; la longueur - de ce poil étoit de trois pouces, et sa grosseur éga- 
"Loit celle du plus gros crin de cheval : cette gros" seur alloit toujours en diminuant vers l'extrémité, " qui étoit fort pointue, et vers la racine elle dimi"nuoit aussi, mais tout à coup, faisant comme la " poignée d'une lance : cette poignée étoit d'une autre " couleur que le reste du poil, étant blanche et dia"phane comme de la soie de pourceau... Ce poil " étoit long comme à l'ours, mais plus droil, plus "gros, et plus couché, et tout d'une même espèce. " La lèvre supérieure étoit grande et clétachée des "gencives, mais non pas si grande que Solin l'a dé" crit, et que Pline l'a fait à l'animal qu'il appelle " machlis. Ces auteurs disent que cette bête est con" trainte de paître à reculons, afin d'empêcher que " sa lèvre ne s'engage entre ses dents. Nous avons ob" servé dans la dissection que la nature a autrement " pourvu à cet inconvénient par la grandeur et la force " des muscles, qui sont particulièrement destinés à " élever celte lèvre supérieure. Nous avons aussi trouvé "les articulations de la jambe fort serrées par des li"gaments dont la dureté et l'épaisseur peut avoir "donné lieu à l'opinion qu'on a eue que l'alce ne peut " se relever quand il est une fois tombé... Ses pieds " étoient semblables à ceux du cerf, mais beaucoup " plus gros, et n'avoient d'ailleurs rien d'extraordi" naire... Nous avons observé que le grand coin de "l'œil étoit fendu en cn-bas beaucoup plus qu'il ne " l'est aux cerfs, aux daims, et aux chevreuils, mais "d'une façon particulière, qui est que cetle fente " n'étoit pas selon la direction de l'ouverture de l'œil, " mais faisoit un angle avec la ligne qui va d'un des " coins de l'oil à l'autre; la glande lacrymale infé- 
" rieure avoit un pouce et demi de long sur sept lignes " de large... Nous avons trouvé dans le cerveau une " partie dont la grandeur avoit aussi rapport avec l'o" dorat, qui est plus exquis dans l'élan que dans au" cun autre animal, suivant le témoignage de Pausa" nias; car les nerfs olfactifs, appelés communément "les apophyses mamillaires, étoient sans comparaison "plus grands qu'en aucun autre animal que nous " ayons disséqué, ayant plus de quatre lignes de dia" mètre... Pour ce qui est du morceau de chair que " quelques auteurs lui mettent sur le dos, et les autres " sous le menton, on peut dire que s'ils ne se sont " point trompés, ou n'ont point été trop crédules, ces " choses étoient particulières aux élans dont ils par"lent."

Nous pouvons, à cet égard, ajouter notre propre témoignage à celui de MM. de l'Académie, dans l'élan que nous avons vu vivant, et qui étoit femelle. Nous n'avons pas remarqué qu'il y eût une loupe sous le menton ni sur la gorge : cependant M. Linnæus, qui doit connoître les élans mieux que nous, puisqu'il habite leur pays, fait mention de cette loupe sur la gorge, et la donne même comme un caractère essentiel à l'élan : Alces, cervus cornibus acaulibus palmatis carunculagutturali. Il n'y a d'autre moyen de concilier cette assertion de M. Linnæus avec notre négation, qu'en supposant cette loupe ou caroncule gutturale à l'élan mâle, que nous n'avons pas vu; et, si cela est, cet auteur n'auroit pas dû en faire un caractère essentiel à l'espèce, puisque la femelle ne l'a pas. Peut-être aussi cette caroncule est-elle une maIadie commune parmi les élans, une espèce de goître: 
car dans les deux figures que Gesner donne de cet animal, la première, qui n'a point de bois, porte une grosse caroncule sous le cou; et à la seconde, qui représente un élan mâle avec son bois, il n'y a point de caroncule.

En général, l'élan est un animal beaucoup plus grand et bien plus fort que le cerf et le renne; il a le poil si rude et le cuir si dur, que la balle du mousquet peut à peine y pénétrer; il a les jambes très fermes, avec tant de mouvement et de force, surtout dans les pieds de devant, que d'un seul coup il peut tuer un homme, un loup, et même casser un arbre. Cependant on le chasse à peu près comme nous chassons le cerf, c'est-à-dire à force d'homınes et de chiens : on assure que lorsqu'il est lancé ou poursuivi, il lui arrive souvent de tomber tout à coup, sans avoir élé ni tiré ni blessé; de là on a présumé qu'il étoit sujet à l'épilepsie, et de cette présomption ( qui n'est pas bien fondée, puisque la peur senle pourroit produire le même effet) on a tiré cette conséquence absurde, que la corne de ses pieds devoit guérir de l'épilepsie, et même en préserver; et ce préjugé grossier a été si généralement répandu, qu'on voit encore aujourd'hui quantité de gens du peuple porter des bagues dont le chaton renferme un petit morceau de corne d'élan.

Comme il y a très peu d'hommes dans les parties septentrionales de l'Amérique, tous les animaux, et en particulier les élans, y sont en plus grand nombre que dans le nord de l'Europe. Les sauvages n'ignorent pas l'art de les chasser et de les prendre; ils les suivent à la piste, quelquefois pendant plusieurs jours de BEFFON. XVII. 
suite, et à force de constance et d'adresse ils en viennent à bout. La chasse en hiver est surtout singulière. "On se sert, dit Denys, de raquettes par le moyen " desquelles on marche sur la neige sans enfoncer..... "L'orignal ne fait pas grand chemin, parce qu'il en"fonce dans la neige, ce qui le fatigue beaucoup à " cheminer; il ne mange que le jet du bois de l'an" née : là où les sauvages trouvoient le bois mangé, ") ils rencontroient bientòt les bêtes, qui n'en étoient "pas loin, et les approchoient facilement, ne pou"vant aller vite; ils leur lançoient un dard, qui est " un grand bâton, au bout duquel est emmanché un "grand os pointu qui perce comme une épée. S'il y " avoit plusieurs orignaux d'une bande, ils les fai" soient fuir; alors les orignaux se mettoient tous " queue à queue, faisant un grand cercle d'une lieue " et demie ou deux lieues, el quelquefois plus, et "battoient si bien la neige à force de tourner, qu'ils " n'enfonçoient plus; celui de devant étant las se met "derrière. Les sauvages en embuscade les altendoient "passer, et là les dardoient : il y en avoit un qui les "poursuivoit toujours; à chaque tour il en demeuroit "un, mais à la fin ils s'écartoient dans le bois. "En comparant cette relation avec celles que nous avons déjà citées, on voit que l'homme sauvage et l'orignal de l'Amérique copient le Lapon et l'élan d'Europe aussi exactement l'un que l'autre.

\section{Sur l'Élan.}

*Nous donnons ici la figure de l'élan mâle que l'on a vu vivant à la foire Saint-Germain en 1784 ; il n'a- 
voit pas encore trois ans. Les dagues de son bois n'avoient que deux pouces; les dernières étoient tombées dans le commencement de janvier de la même année; et comme il m'a paru nécessaire de donner une idée de ce même bois, lorsque l'animal est adulte, j'ai fait représenter sa tête surmontée du bois figuré dans la planche vir du tome XII de l'édition in-4\%. Ce jeune animal avoit été pris à cinquante lieues au delà de Moscou; et, au rapport de son conducteur, sa mère étoit une ou deux fois plus grande qu'il ne l'étoit à cet âge de trois ans. Il étoit déjà plus grand qu'un cerf, et beaucoup plus haut monté sur ses jambes; mais il n'a point la forme élégante du cerf, ni la position noble et élevée de sa tête. Il semble que ce qui oblige l'élan à porter la tête basse, c'est qu'indépendamment de la pesanteur de son large bois il a le cou fort court. Dans le cerf, le train de derrière est plus haut que celui de devant : dans l'élan, au contraire, le train de devant est le plus élevé; et ce qui paroît encore augmenter la hauteur du devant du corps, c'est une grosse partie charnue qu'il a sur le dos; au dessus des épaules, et qui est couverte de poils noirs.

Les jambes sont longues et d'une forme légère; les' boulets larges, surtout ceux de derrière; les pieds sont très forts, et les sabots, qui sont noirs, se touchent par leur extrémité, qui est menue et arrondie. Les deux ergots des pieds de devant ont deux pouces neuf lignes de longueur : ils sont longs, droits, et plats, et ne se touchent point; mais leur extrémité touche presque à terre. Ceux des pieds de derrière ont de longueur en ligne droite deux pouces neuf 
lignes; ils sont plats, courbes, élevés au dessus de terre de deux pouces cinq lignes, et se touchent derrière le boulet. La queue est très courte, et ne forme qu'un tronçon couvert de poils.

La tête est d'une forme longue, un peu aplatie sur les côtés; l'os frontal forme un creux entre les yeux; le nez est un peu bombé en dessus; le bout du nez est large, aplati, et faisant un peu gouttière au milieu; le nez et les naseaux sont grisâtres. La bouche a d'ouverture en ligne droite quatre pouces trois lignes; il y a huit incisives dans la inâchoire inférieure, et il n'y en a point dans la supérieure.

L'œil est saillant, l'iris d'un brun marron; la prunelle, lorsqu'elle est à demi fermée, forme une ligne horizontale; la paupière supérieure est arquée et garnie de poils noirs. L'angle antérieur de l'œil est ouvert; il forme, en se prolongearit, une espèce de larmier. L'oreille est grande, élevée, et finit en pointe arrondie; elle est d'un brun noirâtre en dessus, et garnie en dedans de grands poils grisâtres à la partie supérieure, et brun noirâtre à l'inférieure.

On reunarque au dessous des mâchoires un gránd flocon de poil noir; le cou est large, court, et couvert de grands poils noirâtres sur la partie supérieure, et gris roussâtre à l'inférieure.

La couleur du corps de ce jeune animal étoit d'un brưn foncé unêlé de fauve et de gris; elle étoit presque noire sur les pieds et le paturon, ainsi que sur le con et la partie charnue au dessus des épaules. Les plus longs poils avoient cinq pouces dix lignes; sur le cou, ils avoient six pouces six lignes; sur le dos, trois pouces : ceux du corps étoient gris à leur racine, 
bruns dans leur longueur, et fauves ì leur extrémité. Les dimensions suivantes sont celles qu'avoit ce jeune élan à la fin de mars 1784 .

Longueur du corps mesuré en ligne droite, depuis

le hout du museau jusqu'à l'anus. . . . . . . 6 6 4 4

Longueur suivant la courbure du corps.... $7 \quad 8$ ఎ

Hauteur du train de devant. . . . . . . . 4 109

Hauteur du train de derrière. . . . . . . . $4 \quad 9 \quad 2$

Longueur de la tête, depuis le bout du museau jusqu'à l'origine du bois. . . . . . . . . 1443

Longueur du bout du museau jusqu'à l'occiput. . 110496

Longueur du bout du museau à l'ocil. . . . . . 113

Circonférence du museau prise derrière les naseaux...................... $6{ }_{1}$

Contour de la bouche. . . . . . . . . . $12_{2} 2$

Distance entre les angles de la mâchoire inférieure, $\quad 11 \quad 3$

Distance entre les naseaux en has.. ....... 34

Distance entre les deux paupières lorsqu'elles sont ouvertes................., 11

Distance entre l'angle antérieur et le bout des lèvres. $\begin{array}{llll} & 1 & 2 & 8\end{array}$

Longueur de l'œil, d'un angle à l'autre. . . . . . 146

Distance entre l'angle postérieur el l'oreille. . . . 34

Distance entre les angles antérieurs des yeux, me. surée en ligne droite............. 6 . 10

Circonférence de la tête, prise au devant du bois. $\begin{array}{llll}2 & 2 & 4\end{array}$

Distance entre les deux dagues du bois. ...... 47

Distance entre le bois et les oreilles....... I 1 1.

Longueur des oreilles.. . . . . . . . 10 ,

Longueur de la base, mesurée sur la courbure

extérieure......................... 76

Distance entre les deux oreilles. ........ 48

Longueur du cou. . . . . . . . . . . . 1 1 . 18

Circonférence près de la tête. . ..... 2 „ 5

Circonférence près des épaules. . . . . . . 2 929

Hauteur des épaules.. . . . . . . . . 5 10 9

Girconférence du corps, prise derrière les jambes de devant...................... 4 4 8

Circonférence à l'endroit le plus gros. . . . . . 5 115

Circonférerce devant les jambes de derrière. . . $4 \quad 9 \quad 3$ 
Distance du dessous dú ventre à terre. . . . . 2775

Longueur du tronçon de la queue.. . . . . . 118

Circonférence de la queue à son origine.. . . . „ 36

Longueur du canon dans les jambes de devant. . ^ $10 \quad 9$

Circonférence à l'endroit le plus mince. . . . „ 49

Circonférence du boulet. ........... 93

Longueur du paturon............. 510

Circonférence du paturon. . . . . . . " 89

Longueur de la jambe depuis la rotule jusqu'au jarret........................... 57

Circonférence de la cuisse près du ventre..... 1443

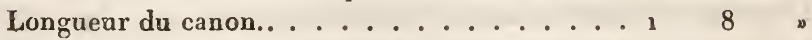

Circonférence du canon. .......... 993

Longueur des ergots. ......... . . . 39

Hauteur des sabots.. ............. 23

Longueur, depuis la pince jusqu'au talon, dans

les pieds de devant. . . . . . . . . . 76

Longueur dans les pieds de derrière.. . . . . 73

Largeur des deux sabots pris ensemble dans les pieds de devant....................... 4

Largeur dans les pieds de derrière.. ...... 34

Distance entre les deux sabots......... „. „ 6

Circonférence des deux sabots réunis, prise sur

les pieds de devant. ................. 1010

Circonférence prise sur les pieds de derrière. . . 996

* Plusieurs voyageurs ont prétendu qu'il existe dans l'Amérique septentrionale des élans d'une taille beaucoup plus considérable que celle des élans d'Europe, et même de ceux qu'on trouve le plus communément en Amérique. M. Dudley, qui a envoyé à la Société royale de Londres une très bonne description de l'orignal, dit que ses chasseurs en tuèrent un qui étoit haut de plus de dix pieds.

Josselyn assure qu'on a trouvé dans l'Amérique septentrionale des élans de douze pieds de haut. Les voyageurs qui ont parlé de ces élans gigantesques 
donnent six pieds de longueur à leur bois; et, suivant Josselyn, les extrémités des deux perches sont éloignées l'une de l'autre de deux brasses, ou de dix à onze pieds. La Hontan dit qu'il y a des bois d'élan d'Amérique quipèsent jusqu’à trois et quatre cents livres. Tous ces récits peuvent être exagérés, ou n'être fondés que sur les rapports infidèles des sauvages, qui prétendent qu'il existe à sept ou huit cents milles au sud-ouest du fort d'York une espèce d'élan beaucoup plus grande que l'espèce ordinaire, et qu'ils appellent waskesser: mais ce qui cependant pourroit faire présumer que ces récits ne sont pas absolument faux, c'est qu'on a trouvé en Irlande une grande quantité d'énormes bois fossiles que l'on a attribués aux grands élans de l'Amérique septentrionale dont Josselyn a parlé, parce que aucun autre animal connu ne peut être supposé avoir porté des bois aussi grands et aussi pesants. Ces bois diffèrent de ceux des élans d'Europe ou des élans ordinaires d'Amérique, en ce que les perches sont en proportion plus longues; elles sont garnies d'andonillers plus larges el plus gros, surtout dans les parties supérieures. Un de ces bois fossiles, composé de deux perches, avoit cinq pieds cinq pouces de longueur, depuis son insertion dans le crâne jusqu'à la pointe; les andouillers avoient onze pouces de longueur; l'empaumure, dix-huit pouces de largeur, et la distance entre les deux extrémités étoit de sept pied neuf pouces : mais cet énorme hois étoit cependant très petit en comparaison des autres qui ont été trouvés également en Irlande. M. Wright a donné la figure d'un de ces bois qui avoit huit pieds de long, et dont les extrémités étoient disłantes de quatorze 
pieds. Cies très grands bois fossiles ont peut-être appartenu à une espèce qui ne subsiste plus depuis longtemps, ni dans l'ancien ni dans le nouveau monde: mais s'il existe encore des individus semblables à ceux qui portoient ces énormes bois, l'on peut croire que ce sont les élans que les Indiens ont nornmés waskesser; et dès lors les récits de M. Dudley, de Josselyn, et de La Hontan, seroient entièrement confirmés.

\section{Sur le Renne.}

* Nous n'avons pu jusqu'alors nous procurer cet animal vivant, ou assez bier conservé pour le faire dessiner; nous donnons la figure d'une femelle renne qui étoit vivante à Chantilly, dans les parcs de S. A. $\mathrm{S}$. Mgr. le prince de Condé, auquel le roi de Suède l'avoit envoyée avec deux mâles de même espèce, dont l'un mourut en chemin, et le second ne vécut que très peu de temps après son arrivée en France. La femelle a résisté plus long-temps; elle étoit de la grandeur d'une biche, mais moins haute de jambes et plus épaisse de corps : elle portoit un bois comme les unâles, divisé de même par andouillers, dont les uns pointoient en devant et les autres en arrière; mais ce bois étoit plus court que celui des mâles. Voici la description détaillée avec les dimensions de cet animal, telles que $M$. de Sève me les a données.

La hauteur du train de devant est de deux pieds onze pouces, et celle du train de derrière, de deux pieds onze pouces neuf lignes. Son poil est épais et uni comme celui du cerf; les plus courts sur le corps ont an moins quinze lignes de longueur. Il est plus 
long sous le ventre, fort court sur les jambes, et très long sur le boulet jusqu'aux ergols. La couleur du poil qui couvre le corps est d'un brun roússâtre, plas ou moins foncé dans différents endroits du corps, et mélangé ou jaspé plus ou moins d'un blanc jaunâtre; sur une partie du dos, les cuisses, le dessus de la tête et le chanfrein, le poil est plus foncé, surtout au dessus du larmier, que le renne a comme le cerf. Le tour de l'œil est noir. Le museau est d'un brun foncé, et le tour des naseaux noir; le bout dı museau jusqu'aux naseaux est d'un blanc vif, ainsi que le bout de la mâchoire inférieure. L'oreille est couverte en dessus d'un poil épais, blanc, tirant sur le fauve, mêlé de poil brun; le dedans de l'oreille est garui de grands poils blancs. Le cou et la partie supérieure du corps sont d'un blanc jaunâtre ou fauve très clair, ainsi que les grands poils qui lui pendent sur la poitrine au bas du cou. Le dessous du ventre est blanc. Sur les côtés au dessus du ventre, est une bande large et brune comme à la gazelle. Les jambes sont fort menues pour le corps : elles sont, ainsi que les cuisses, d'un brun foncé, et d'un blanc sale en dedans, de même que l'extrémité du poil qui couvre les sabots. Les pieds sont fendus comme ceux du cerf. Les deux ergots de. devant sont larges et minces; les deux petits de derrière sont longs, assez minces et plats en dedans; ces quatre ergots sont très noirs.

$$
\text { pieds. pouc. lign, }
$$

Longueur du corps depuis le museau jusquà l'anus,

en ligne superticielle. . . . . . . . . 5 $1{ }_{2}$

La mêne longueur mesurée en ligne droite. . . $4 \quad 7$ "

Longueur de la tête jusqu'à l'origine des cornes. . 1 1

Circonférence du museau, prise derrière les na- 
pieds. pouc. lign.

seaux.................. . . . 1

Ouverture des narines. ........... . . . 14

Contour de la bouche. . . . . . . . . . 78

Distance entre les angles de la mâchoire inférieure. „ 18

Distance entre les angles de la mâchoire supérieure. „ $\quad 2 \quad 2 \quad 9$

Distance entre l'angle postérieur et l'oreille. . . • 999

Distance entre les angles antérieurs des yeux. . . $\quad 5 \quad 3$

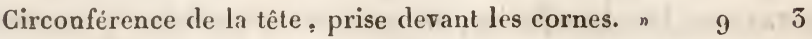

Longueur des oreilles.. . . . . . . . . . 4 1

Largeur de la base, mesurée sur la courbure ex-

térieure.. . . . . . . . . . . . 4

Distance entre les oreilles, prise en bas, suivant

la courbure du chignon. .........

Longueur du cou. . . . . . . . . . . .

Circonférence près la tête.. . . . . . . . .

Circonférence près les épaules.. . . . . . . . 2

Hauteur du train de derant. . . . . . . . 2

Hauteur du train de derrière. . . . . . . . 2

Circonférence du corps derrière les jambes de

devant. . . . . . . . . . . 3

Même circonférence devant les jambes de derrière. 3

Longueur du tronçon de la queue. . . . . . .

Circonférence à son origine.. . . . . . . .

Longueur du bras depuis le coude jusqu'au genou.

Circonférence à l'endroit le plus gros. . . . . . I

Circonférence du genou.. . . . . . . . . ”

Longueur du canon. . . . . . . . . . . 6

Circonférence à l'endroit le plus mince. . . . . n 3

Circonférence du boulet.. . . . . . . . .

Longueur du paturon.. . . . . . . . .

Circonférence du paturon. . . . . . . . .

Circonférence de la couronne........ . . 76

Hauteur depuis le bas du pied jusqu'au genou. . „ „ 10 "

Lorgueur de la cuisse depuis la rotule jusqu'au jarret.

5

Circonférence près le ventre.......... 1 . 105

Longueur du canon depuis le jarret jusqu'au

boulet.

Circonférence. ............. . . . . 5

Longueur des ergots. 
Hauteur des sabots.

Longueur depuis la pince jusqu'au talon, dans les pieds de devant. . . . . . . . . . .

Longueur dans les pieds de derrière. . . . . . .

Largeur des deux sabots dans les pieds de devant. . "

La mêrne largeur daus ceux de derrière. . . . . .

Circonférence des deux sabots dans les pieds de

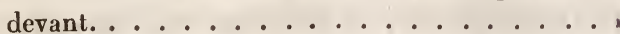

Circonférence des deux sabots dans les pieds de

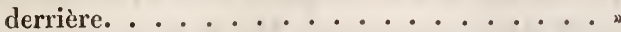

Longueur du bois mesuré en ligne droite. . . . .

Et de l'origine à la branche plus courte et plus large............................. 76

Circonférence à son origine.. ........ 5 . 510

Au reste, il ne faut pas juger, par la figure que nous donnons du renne, de l'étendue en longueur. et en grosseur de son bois. Il y a de ces bois qui s'étendent en arrière, depuis la tête de l'animal jusqu'à sa croupe, et qui pointent en avant par de grands andouillers de plus d'un pied de longueur. Les grandes cornes ou bois fossiles que l'on a trouvés dans plusieurs endroits, et notamment en Irlande, paroissent avoir appartenu à l'espèce du renne. J'ai été informé par M. Collinson qu'il avoit vu de ces grands bois fossiles qui avoient dix pieds d'intervalle entre leurs extrémités, avec des andouillers qui s'étendent en avant de la face de l'animal, comme dans le bois dı renne.

C'est donc à cette espèce, et non pas à celle de l'élan, que l'on doit rapporter les bois ou cornes fossiles de l'animal que les Anglois ont appelé moosedeer; mais il faut néanmoins convenir qu'actuellement il n'existe pas de rennes assez grands et assez puissants pour porter des bois aussi gros et aussi longs que ceux 
qu'on a trouvés sous terre en Irlande, ainsi que dans quelques antres endroits de l'Europe, et même dans l'Auérique septentrionale.

Au resle, je ne connoissois qu'une seule espèce de renue, auquel j’ai rapporté Je caribon d'Amérique, et le daim de Groenland, dont M. Edwards a donné la figure et la description; et ce n'est que depuis peu d'années que j’ai été informé qu'il y en avoit deux espèces ou plutôt deux variélés, l'une beaucoup plus grande que l'autre. Le renne dont nous donnons ici la figure et la description est de la petite espèce, et probablement le inême que le daiın du Groenland de II. Edwards.

Quelques voyageurs disent que le renne est le daim du Nord, qu'il est sauvage en Groenland, et que les plus forts n'y sont que de la grosseur d'une génisse de deux ans.

Pontoppidan assure que les rennes périssent dans tous les pays du monde, à l'exception de ceux du Nord, où il faut même qu'ils habitent les montagnes; mais il ajoute des choses moins croyables, en disant que leur bois est mobile, de façon que l'animal peut le plier en avant ou en arrière, et qu'il a au dessus des paupières une petite ouverlure dans la peau, par laquelle il voit un per, quand une neige trop abondante l'empêche d'ouvrir les yeux. Ce dernier fiait ine paroît imaginé d'après l'usage des Lapons, qui se couvrent les yeux d'un morceau de bois fendu, pour éviter le trop grand éclat de la neige, qui les rend aveugles en peu d'années, lorsqu'ils n'ont pas l'attention de diminuer par cette précaution le reflet de cette limière Irop blanche, qui fait grand mal aux yeux. 
Une chose remarquable dans ces animaux, c'est le craquement qui se fait entendre dans tous leurs mouvements : il n'est pas même nécessaire pour cela que leurs jambes soient en mouvement; il suffit de leur causer quelque surprise ou quelque crainte en les touchant, pour que ce craquement se fasse entendre. On assure que la même chose arrive à l'élan : mais nous n'avons pas été à portée de le vérifies.

* Nous ajouterons à ce que nous avons dit au sujet du craquement qui se fail entendre dans tous les mouvements du renne, une observation que M. le marquis d'Amezaga a eu la bonté de nous communiquer. "On pourroit croire, dit-il, que ce bruit ou craquement vient des pinces du pied, qui se frapperoient l'une contre l'autre comme des castagnettes, d'autant que les reunes ont le pied long et plat. Je cherchai à reconnoître d'où provenoit ce bruit dans les rennes que le roi de Suède avoit envoyés à S. A. S. Mgr. le prince de Condé; je le demandai aux Lapons qui les avoient amenés. Ils tonchèrent assez légèrement l'un de ces rennes, et jentendis le craquement sans pouvoir distinguer d'où il venoit. L'animal avoit été touclıé si foiblement, qu’il n'avoit pas même changé de place. Je jugeai dès lors que le bruit ne venoit pas de ses pinces. Je me mis sur le ventre, et, sans faire marcher le renne, je guettai le moment où il leveroit son pied. Dès qu'il fit ce mouvement, j’entendis l'articulation du pied faire le bruit que j'avois entendu d'abord, mais plus fort, parce que ce mouvement avoit été plus grand. Je restai dans la même attitude, pour massurer du craquement dans les pieds de derrière comme dans ceux de devant; j’en- 
tendis aussi celui du genou, mais bien moins fort que celui du pied; celui du jarret ne s'entend presque pas."

Ces rennes sont morts tous deux à Chantilly, de la même maladie; c'est une inflammation à la gorge, depuis la langue jusqu'aux bronches du poumon. On auroit peut-être pu les guérir en leur donnant des breuvages rafraîchissants ; car ils se portoient très bien, étoient même assez gras jusqu'au jour où ils ont été atteints de cette inflammation. Ils paissoient comme des vaches, et ils étoient très avides de la mousse grise qui s'attache aux arbres.

Il est done certain, par les observations de M. le marquis d'Amezaga, que, dans les rennes, ce n'est qu'aux articulations des os des jambes que se fait le craquement, et il est plus que probable qu'il en est de même dans l'élan et dans les autres animaux qui font entendre ce bruit.

En Laponie et dans les provinces septentrionales de l'Asie, il y a peut-être plus de rennes domestiques que de rennes sauvages; mais, dans le Groenland, les voyageurs disent qu'ils sont tous sauvages.

Ces animaux sont timides et fuyards, et sentent les hommes de loin. Les plus forts de ces rennes du Groenland ne sont pas plus gros qu'une génisse de deux ans, et c'est ce qui me fait présumer qu'ils sont la petite espèce qu'Edwards appelle daims de Groenland, moins grunds de pius d'un tiers que ceux de la grunde espèce. Les uns et les autres perdent leur bois au printemps, et leur poil tombe presque en même temps : ils maigrissent alors, et leur peau devient mince; mais en automne ils engraissent, et leur peau 
s'épaissit. C'est par cette alternative, dit M. Anderson, que tous les animaux du Nord supportent mieux les extrêmes du froid et du chaud; gras et fourrés en hiver, légers et secs durant l'été. Dans cette dernière saison, ils broutent l'herbe tendre des vallons; dans l'autre, ils fouillent sous la neige et cherchent la mousse des rochers.

\section{SUR LE RENNE.}

Extrait de la lettre de M. le comte de Mellin, chambellan du roi de Prusse, datée du château d'Anizow, près Stettin, le 15 novembre 1784 .

* J'ai encore l'honneur de communiquer à M. le comte la gravure d'un renne mâle, que j'ai peint d'après nature : celle de la femelle et du faon, je l'attends tous les jonrs de mon graveur; j'aurai l'honneur de vous en envoyer un exemplaire, si vous le désirez. Le renne, lorsque je l'ai peint, n'avoit que deux ans, et portoit son second bois; c'est pourquoi il n'est pas encore si large d'empaumure, et chargé de tant de chevilles ou de cornichons que ceux que ces mêmes rennes portent présentement. II faut aussi remarquer que le graveur a fait une faute en donnant à la barbe pendante du renne la figure d'une crinière qu'on diroit descendre du côté opposé. Si je puis, monsieur, vous faire plaisir par des miniatures, peintes en couleur d'après nature, de ces animaux, que j'ai faites avec beaucoup de soin, je vous les enverrai avec bien de la satisfaction.... S. A. S. monseigneur le margrave de Brandebourg Schwedt Frédéric-Henri, cousin du roi de Prusse, en a fait venir de 
la Suède et de la Russie, et m'a donné la permission de les dessiner, de les mesurer, et de les observer. J'ai publić dans les Mémoires de la Société de Berlin, en allemand, les observations que j'ai faites, et $j$ 'ai l'honneur de vous en communiquer la substance. 11 y a. comme vous le remarquez, M. le comte, deux espèces, ou plutôt deux variétés, l'une beaucoup plus grande que l'autre, du renne; je les comnois loutes les deux. La différence entre ces deux espèces est aussi remarquable qu'entre le cerf et le daim. Les grands rennes, qui sont de la taille de nos cerfs, furent envoyés de la province Mezeu, dans le gouvernement d'Archangel, province renommée pour avoir les plus beaux et les plus grands rennes de toute la Russie : ce sont deux mâles et dewx femelles. Deux femelles et un mâle vinrent de la Suède, qui n'étoient guère plus grands que nos daims, c'est-à-dire, les rennes femelles; car le mâle n'est pas parvenu jusqu'ici, étant mort sur le vaisseau. Voici quelques dimensions principales qui vous feront voir d'un coup d'weil combien les rennes de Russie surpassent en grandeur ceux de Suède. 


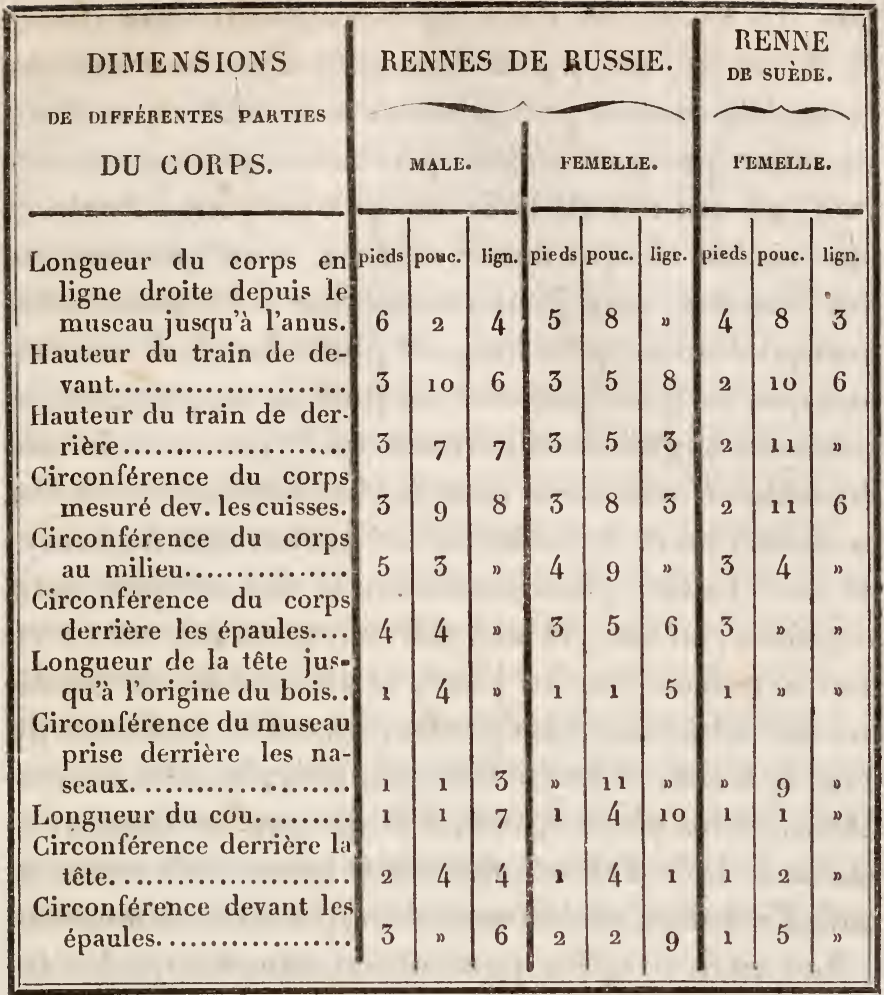

Ce qui est très remarquable, et dont cependant aucun naturaliste ne fait mention, c'est que les faons des rennes ont d'abord en naissant des bossettes, et qu'âgés de quinze jours, ils ont déjà de petites dagues longues d'un pouce, de manière qu'ils touchent au bois peu de temps après leur mère. Les faons des rennes de Russie avoient le bois long d'un pied, et chaque perche avoit trois andonillers, au lieu que ceux de Suède ne portoient que des dagues moins longues, qui se séparoient au bout en deux andouil- 
lers. La figure du daim de Groenland, que donne M. Edwards, me paroît être celle d'un faon de trois mois, à la couleur près, qui est loute différente. Il est singulier que les femelles qui étoient pleines en arrivant, et qui depuis trois ans qu'elles sont à Schwedt ont mis bas chaque année un faon, n'ont produit que des femelles : ainsi je ne saurois dire si les faons mâles portent des bois plus longs et plus chargés d'andouillers que les femelles; mais on peut le supposer en jugeant de la grande différence qu'il y a entre le bois du mâle et celui de la femelle. Les faons naissent aux mois de juin et de juillet, et ne portent pas de livrée; ils sont bruns, plus foncés sur le dos, et plus roux aux pieds, au cou, et au ventre : cependant cette couleur se noircit tous les jours, et au bout de six semaines ils ont le dos, les épaules, les côtés, le dessus du cou, le front, et le nez d'un gris noir; le reste est jaunâtre, et les pieds fauves. J'ai dit que les faons touchent au bois d'abord après leur mère; cela arrive au moisd'octobre, et c'est aussi alors que le rut cómmence.

Les rennes mâles poursuivent long-temps les femelles avant d'en pouvoir jouir. Les femelles russes entroient en rut quinze jours plus tôt que les femelles de Suède; il y eut mème une femelle des faons russes qui, quoique âgrée à peine de cinq mois, souffrit au commencement de novembre les approches du mâle, et mit bas l'année suivante un faon aussi grand que les autres. Cela prouve que le développement des parties de la génération du renne est plus prompt que dans aucun autre animal de cette grandeur : peutétre aussi la plus grande chaleur de notre climat, êt la nourriture abondante dont ils jouissent, ont hâté 
l'accroissement de ces rennes. Cependant le bois que portent les rennes femelles à l'âge de cinq mois n'indiqueroit-il pas une surabondance de molécules organiques, qui peut occasioner un développement plus prompt des parties de la génération? il se peut même que les faons mâles soient en état d'engendrer au mème âge. Le comportement du rerne mâle que jobservois pendant le rut ressembloit plus à celui du daim qu'à celui du cerf. En s'approchant de la femelle, il la caressoit de sa langue, haussoit la tête, et rayoit comme le daim, mais d'une voix moins forte, quoique plus rauque. Il gonfloit en même temps ses grosses lèvres, et, en faisant échapper l'air, il les faisoit trembloter contre les gencives; alors il baissoit les jarrets des pieds de derrière, et je crus qu'il couvriroit ainsi la femelle, qui sembloit aussi l'attendre: mais, au lieu de cela, il fit jaillir beaucoup de semence sans bouger; après quoi il étoit pendant quelques minutes comme perclus des pieds de derrière, et marchoit avec peinc. Jamais je ne l'ai vu couvrir de jour, mais c'étoit toujours la nuit; il s'y prêtoit lentement et point en fuyant, comme les cerfs et les daims, qui, ainsi que je l'ai souvent observé dans mes bois et dans mon parc, sautent sur les biches tout en courant, en les arrêtant et les serrant quelquefois si rudement des pieds de devant, qu'ils leur enfoncent les ergots à travers la peau, et mettent leurs côtés en sang. Le rut commence à la mi-octobre, et finit à la fin du mois de novembre. Les rennes mâles ont pendant ce temps une odeur de bouc extrêmement forte.

On a fait des tentatives infructueuses pour faire couvrir des biches ou des daims par le renne. Le pre- 
mier renne qui vint à Schwedt fut pendant plusieurs années sans femelles; et comme il parut ressentir les impressions du rut, on l'enferma avec deux biches et deux daines dans un parc, mais il n'en approchoit pas. On lui présenta des vaches l'année suivante, qu'il refusa constamment, quoiqu'il attaquât des femmes, et que plus il avançoit en âge, plus il devenoit furieux pendant le rut. Il donne non seulement des coups violents du haut de son bois, mais il frappe plus dangereusement des pieds de devant. Je me souviens qu'un jour le renne étant sorti de la ville de Schwedt, et se promenant par les champs, il fut attaqué par un gros chien de boucher; mais lui, sans s'épouvanter, se cabra et donna des pieds de devant un coup si violent au chien, qu'il l'assomma sur la place. Il n'avoit pas de bois dans ce temps là. Le bois tombe aux mâles vers Noël et au commencement de l'année, selon qu'ils sont plus ou moins vieux, et ils l'out refait au moins d'août : les femelles, au contraire, muent au mois de mai, et elles touchent au bois au mois d'octobre; elles ont donc leur bois tout refait au bout de cinq mois; au lieu que les mâles y emploient huit mois : aussi les mâles, passé cinq ans, ont des bois d'une longueur prodigieuse; les suranchouillers ont des empaumures larges, ainsi que le haut des perches; mais il est moins gros et plus cassant que celui du cerf ou du daim. C'est peut-être aussi pour le garantir d'autant plus lorsqu'il est encore tendre, que la nature l'a recouvert d'une peau beaucoup plus grosse que celle du refait du cerf; car le refait du renne est beaucoup plus gros que celui du cerf; et cependant, lorsqu'il a touché au bois, les 
perches en sont bien plus minces. Le renne ne peut guère blesser des andouillers comme le cerf; mais il frappe des empaumures du haut en bas; ce que Gaston Phœbus a déjà très bien observé dans la description qu'il donne du rangier (page 97 de la $V \dot{e}$ nerie de Dufouilloux ).... Tous ceux qui ont donné l'histoire du renne prétendent que le lait qu'on tire des femelles ne donne pas de beurre; cela dépend, je crois, ou de la nourriture, ou de la manière de traiter le lait. Je fis traire à Schwedt les rennes, et trouvai le lait excellent, ayant un goût de noix; j’en pris avec moi dans une bouteille pour en donner à goùter chez moi, et fus très surpris de voir, à mon arrivée, que le cahotement de ma voiture, pendant trois heures de chemin qu'il faut faire pour venir de Schwedt à mon château, avoit changé ce lait en beurre; il étoit blanc comme celui de brebis, et d'un groût admirable. Je crois donc, fondé sur cette expérience, pouvoir assurer que le lait de renne donne de très bon beurre s'il est battu d'abord après avoir été tiré; car ce n'est que de la crême toute pure. En Suède, on prétend que le lait de renne a un goût rance et désagréable; ici, i’ai éprouvé le contraire. Mais, en Suède, la pâture est très inférieure à celle d'Allemagne : ici, les rennes paissent sur des prairies de trèfles, et on les nourrit d'orge; car l'avoine, ils l'ont constamment refusée; ce n'est que rarement qu'on leur donne du lichen rangiferinus, qui croît ici en petite quantilé dans nos bois, et ils le mangent avidement. J'ai remarqué que le craquement que les rennes font entendre en marchant n'est formé que par les pinces des sabots qui se choquent, et 
par les ergots qui frappent contre les sabots. Or peut s'en convaincre aisément en mettant un linge entre les pinces des sabots, et en enveloppant les ergois de même : alors tout craquement cesse. Je crus, comme tout le monde, que ce craquement se formoit entre le boulet et le genou, quoique cela ne me parût guère possible; mais un cerf apprivoisé que j'ai dans mon parc me fit entendre un craquement pareil, quoique plus sourd, lorsqu'il me suivoit sur la pelouse ou sur le gravier, et je vis très distinctement, en l'observant de près, que c'étoient les pinces des sabots qui, en claquant l'une contre l'autre, formoient ce craquement. En réitérant cette observation sur les rennes, je me suis convaincu qu'il en est tout de même avec eux. Je remarque aussi que, sans marcher, ils font entendre le même craquement lorsqu'on leur cause quelque surprise ou quelque crainte en les touchant subitement; mais cela provient de ce qu'en se tenant debout ils ont toujours les sabots éloignés et distinctement séparés, et que, dès qu'ils s'effraient ou qu'ils lèvent le pied pour marcher, ils joignent subitement les pinces du sabot et craquent. Au reste, c'est un événement très remarquable pour un naturaliste, que ces rennes se conservent et se multiplient dans un pays où la température du climat est bien plus douce que dans leur patrie; dans un pays où les neiges ne sont pas fréquentes et les hivers bièn moins rudes, tandis qu’on a déjà tenté inutilement, depuis le seizième siècle, de les naturalisèr en Allemagne, quoique alors le climat fût bien plus rude et les hivers plus rigoureux. Le roi Frédéric $\mathrm{I}^{\mathrm{ex}}$ de Prusse en reçut de Suède, qui moururent quelques 
mois après leur arrivée, et cependant dans ce temps là il y avoit dans la Poméranie et dans la Marche, ainsi qu'aux environs de Berlin, beaucoup plus de marais et bien plus de bois, et il y faisoit, par cette raison, beaucoup plus froid qu'à présent. Il y a présentement cinq ans que ces rennes subsistent et se multiplient à Schwedt : étant voisin de celte petite ville, et S. A. S. me permettant de venir souvent chez elle, j'ai eu de fréquentes occasions de les voir et de les observer, et tout ce que j'ai eu l'honneur de vous dire au sujet de ces rennes est le fruit de ces observations fréquemment réitérées.

\section{SUR LE RENNE.}

Extrait d'une lettre de M. le chevalier de BuffoN

à M. le comte de Burfon.

Lille, 3o mai 3785 .

* Il vient d'arriver ici trois rennes, dont un mâle âgé de six ans, une femelle âgée de trois ans, et une petite femelle âgée d'un an. L'homme qui les conduit et qui les montre pour de l'argent assure qu'il les a achetés dans une peuplade de Lapons, nommée en suédois Deger Forth Capel, dans la province de $W$ ertu bollo, à quatre-vingt-dix milles (deux cent soixante-dix lieues de France) de Stockholm, et huit milles (vingt-quatre lieues) d'Uma. Il les a débarqués à Lubeck au mois de novembre de l'année dernière. Ces trois jolis animaux son très familiers; le jeune surtout joue comme un chien avec ceux qui le caressent. Ils sont gras, fort gais, et se portent très bien. 
J'ai comparé, le livre à la main, ces rennes à la description que vous en faites; elle est parfaite sur tous les points. Le mâle a un bois couvert de duvet, comme le refait du cerf; ce bois est très chaud au toucher : chaque branche a dix-sept pouces de longueur, depuis la naissance jusqu'à l'extrémité où l'on comınence à reconnoître deux andouillers qui se forment à tête ronde et non pointue comme ceux du cerf. Ces deux branches se séparent dans la forme que je vous présente; leur courbure est en avant : elles sont uniformes et de la plus belle venue. Les deux andouillers qui sont près de la tête croissent en avant en se rapprochant du nez de l'animal, deviennent plats el larges avec six petits andouillers, le tout imitant la forme d'une main qui auroit six doigts écartés, et le reste du bois produisant beaucoup de rameaux qui croissent presque tous en avant, autant que j'ai pu en juger par un dessin très mal fait que le maître de ces rennes m’a présenté du dernier bois du renne qu'il a vendu en Allemagne. Ce bois avoit quatre pieds de hauteur, et pesoit vingt-sept livres. L'extrémité de chaque branche se termine par de larges palettes qui portent de petits andouillers comme celles, qui sont près de la tête. La régularité du jeune bois que ¡'ai vu, et sa belle venue, annoncent qu'il sera superbe.

Ils mangent du foin, dont ils choisissent les brins qui portent la graine. La chicorée sauvage, les fruits et le pain de seigle, sont la nourriture qu'ils préfèrent à toute autre. Quand ils veulent boire, ils mettent un pied dans le seau et cherchent à troubler l'eau en la battant. Ils ont tous trois le même usage, et laissent 
presque toujours leur pied dans le seau en buvant.

La femelle a deux proéminences qui annoncent la naissance du refait; le petit en a de même. J'ai vu le bois de la femelle de l'année dernière; il n'est pas plus grand qu'un bois de chevreuil : il est tortueux, noueux, et chaque branche est d'une forme très irrégulière.

J'y ai reconnu tous les caractères que vous désignez: le craquement des pieds lorsqu'ils marchent, et surtout après le repos; le poil long et blanchâtre sous le cou; leur forme, qui tient de celle du bœuf et du cerf; la tête semblable à celle du bœuf, ainsi que les yeux; la queue très courte et semblable à celle du cerf; le derrière de la croupe blanchâtre comme sur le cerf. Ce renne n'a dans ses mouvements ni la pesanteur du bœuf ni la légèreté du cerf, mais il a la vivacité de ce dernier, tempérée par sa forme, qui n'est pas aussi svelte. Je les ai vus ruminants; ils se mettent à genoux pour se coucher. Ils ont horreur des chiens; ils les fuient avec frayeur, ou cherchent à les frapper avec les pieds de devant. Leur poil est d'un brun fauve; ce fauve se dégrade jusqu'au blanchâtre sous le ventre, aux deux côtés du cou et derrière la croupe.

On remarque au dessous de l'angle intérieur de chaque œil une ouverture longitudinale où il seroit aisé de faire entrer un gros tuyau de plume; c'est sans doute le larmier de ces animaux.

Les deux éperons qu'ils ont à chaque jambe en arrière sont gros, et assez longs pour que la corne pointue dont ils sont armés pose à terre lorsque l'animal marche; les éperons s'écartent dans celte po- 
sition, et l'animal marque toujours quatre pointes en marchant, dont les deux de derrière entrent de quatre à cinq lignes dans le sable. Cette conformation doit leur être fort utile pour se cramponner dans la neige.

Le mâle a cinq pieds six pouces de longueur depuis le bout du museau jusqu'à la naissance de la queue, et trois pieds quatre pouces de hauteur depuis la sole jusqu'au garrot ;

La femelle, quatre pieds six pouces de longueur, et trois pieds de hauteur;

Le petit, quatre pieds un pouce de longueur, et deux pieds sept pouces de hauteur; il croît d̀ vue d'œil.

Ils ont huit petites dents incisives du plus bel émail, et rangées à merveille à l'extrémité antérieure de la mâchoire inférieure, cinq molaires de chaque côté au fond de la bouche. Il y a un espace de quatre doigts entre les molaires et les incisives de chaque côté, dans lequel espace il n'y a point de dents. La mâchoire supérieure a de même et seulement cinq molaires de chaque côté au fond de la bouche; mais elle n'a aucune incisive.

Le temps du rut est le même que celui du cerf. La femelle a été couverte au mois de novembre de l'année dernière, à quatre lieues d'Upsal.

En voilà bien long, et peut-être beaucoup trop sur des animaux que vous connoissez mieux que moi sans les avoir vus; mais, comme il n'en a pas paru jusqu'ici de vivants en France, j'ai pensé que mes observations pourroient vous être agréables, etc. 


\section{DESCRIPTION DU RENNE,}

Par. M. le professeur Alramaid.

* Le renne qui est représenté ici étoit un mâle ${ }^{1}$. La couleur de son poil étoit d'un gris cendré à l'extrémité, mais blanche vers sa racine. Tout son corps étoit eouvert d'un duvet fort épais, d'où sortoient en divers endroits quelques poils assez roides, dont la pointe étoit brune. La partie inférieure de son cou se faisoit remarquer par des poils de huit à neuf pouces, dont elle étoit toute couverte, et qui étoient beaucoup plus fins que des crins, et d'un beau blanc. Le bout de son museau étoit noir et velu. Chacune des perches de son bois étoit chargée de trois andouillers : ceux qui sortoient de la partie inférieure étoient dirigés en avant sur le front; ils se terminoient tous en pointe, et ce n'étoit qu'à l'extrémité supérieure de chaque perche qu'on remarquoit des empaumures; mais vraisemblablement il en auroit paru d'autres, si l'animal avoit vécu plus long-temps. Je vois par un dessin que M. Camper a fait de cet animal, lorsqu'il étoit plus âgé de quatre mois, et qu'il a eu la bonté de me communiquer, que les empaumures du haut du bois s'étoient élargies, qu'elles commençoient à former de nouveaux andouillers, et que ceux qui sont représentés pointus dans notre planche avoient acquis plus de largeur.

Ce renne avoit les jambes plus courtes, mais plus

1. Tome XV, page 52 , édition de Hollande. 
fortes et plus grosses que celles du cerf. Ses sabots étoient aussi beaucoup plus larges, et par là même plus propres à le soutenir sur la neige; le bout de l'un étoit placé sur l'extrémité de l'autre. Voici les dimensions de ses principales parties.

Longueur du corps, mesuré en ligne droite, depuis le bout du museau jusqu'à l'anus. . . . 4 4

Llauteur du train de derant. . . . . . . . . 2 8

Hauteur du train de derrière. . . . . . . . $3 \quad 2$

Longueur de la tête, depuis le bout du museau

jusqu'à l'origine des cornes. ........

Longueur des cornes. . . . . . . . .

Longueur de l'andouiller qui est dirigé au devant

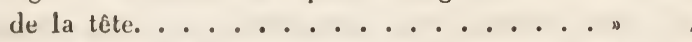

Distance entre les cornes. ........ 2 6

Distance entre les deux naseaux. . . . . . . 112

Distance d'un œil à l'autre. . . . . . . . . 5 ,

Longueur de l'œil d'un angle à l'autre. . . . . . . 1306

Hauteur des jambes de derrière jusqu'à l'abdomen. 3 ( 1 ,

Longueur de la queue. ............. 6 "

Circonférence du corps, prise autour du ventre. 4 2 "

Ce renne n'est pas le seul qui ait paru dans nos provinces : M. le professeur Camper en a reçu un qui malheureusement n'a vécu chez lui que vingt-quatre heures; sa prompte mort est une perte pour l'histoire naturelle. Si cet animal avoit pu être observé pendant quelque temps par un homme aussi exact et pénétrant que M. Camper, nous serions parfaitement instruits de tout ce qui le regarde; cependant nous avons lieu de nous féliciter qu'il soit tombé en si bonnes mains. M. Camper l'a anatomisé avec soin, et il m'en a envoyé une description très intéressante, qui le fera connoître mieux qu'il ne nous est connu par tout ce que les autres en ont dit jusquà présent; on la lira 
ici avec plaisir : la voici donc telle quil a bien voulu me la communiquer.

\section{OBSERVATIONS SUR LE RENNE,}

Faites à Groningue par M. le professeur P. Camper.

Le renne qu'on m'avoit envoyé de la Laponie par Drontheim et Amsterdam arriva à Groningue le 2 เ juin 1771 . Il étoit fort foible, non seulement à cause de la fatigue du voyage et de la chaleur du climat, mais probablement surtout à cause d'un ulcère entre le bonnet ou deuxième estomac et le diaphragme, dont il mourut le lendemain. Dès qu'il fut chez moi, il mangea avec appétit de l'herbe, di pain et autres choses qu'on lui présenta, et il but assez copieusement. Il ne mourut point faute de nourriture; car, en l'ouvrant, je trouvai ses estomacs et ses boyaux remplis. Sa mort fut lente et accompagnée de convulsions qui étoient tantôt universelles et tantôt uniquement visibles ̀̀ la tête : les yeux surtout en souffrirent beaucoup.

C'étoit un mâle âgé de quatre ans: tous les os de son squelette offroient encore les épiphyses; ce qui prouve qu'il n'avoit pas atteint son plein accroissement; auquel il ne seroit parvenu qu'à l'âge de cinq ans. Ainsi on en peut conclure que cet animal peut vivre au moins vingt ans.

La couleur du corps étoit brune et mêlée de noir, de jaune, et de blanc: le poil du ventre, et surtout desflancs, étoit blanc avec des pointes brunes, comme dans les autres bêtes fauves; celui des jambes étoit 
d'un jaune foncé; celui de la tête tiroit sur le noir; celui des flancs étoit très touffu; celui du cou et du poitrail étoit aussi fort épais et très long.

Le poil qui couvroit le corps étoit si fragile, qu'il se cassoit transversalement dès qu'on le tiroit un peu : il étoit d'une figure ondoyée, et d'une substance assez semblable à celle de la moelle des joncs dont on fait les nattes; sa partie fragile étoit blanche. Le poil de la tête, du dessous du cou, et des jambes jusqu'aux ongles, n'avoit point cette fragilité; il étoit au contraire aussi fort que celui d'une vache.

La couronne des sabots étoit reconverte de tous côtés d'un poil fort long. Les pieds de derrière avoient entre les doigts une pellicule assez large, faite de la peau qui couvroit le corps 3 mais parsemée de petites glandes.

A la hauteur des couronnes des sabots, il y avoit une espèce de canal qui pénétroit jusqu'à l'articulation du canon avec les osselets des doigts : il étoit de la largeur du tuyau d'une plume à écrire, et rempli de fort longs poils. Je n'ai pas pu découvrir un semblable canal aux pieds de devant, et j'en ignore l'usage.

La figure de cet animal différoit beaucoup de celle qui a été décrite par les auteurs qui en ont parlé, et de celle que j'ai dessinée il y a deux ans, et cela parce qu'il étoit extrêmement maigre. MM. Linnæus, les auteurs de l'Encyclopédie, et Edwards; le dépeignent tous fort gras, et par conséquent plus rond et plus épais.

Voici les dimensions de ses principales parties, prises avec le pied de Groningue, qui est un peu moins long que celui de France. 
pieds. pouc. lign.

Longueur de la tête, depuis le bout du museau jusquà la nuque du cou. . . . . . . . 1 2 2

Hauteur verticale de la tête, là où elle est plus

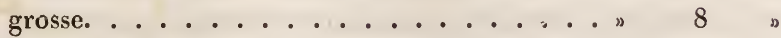

Longueur des oreilles............ 5 . 5 ,

Longueur des vertèbres du cou, entre la tête et la première côte............. " n

Longueur du eorps, depuis l'épaule jusqu'à l'extré-

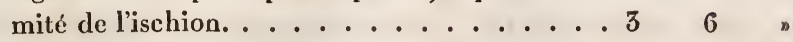

Longueur de l'omoplate. ........ 1 . "

Longueur de l'os du bras. .......... 11 "

Longueur du eanon. .............. 9

Longueur des doigts du pied de devant avee les sabots...................... 56

Longueur de l'os de la jambe. ....... \

Longueur du eanon. .............. 1 n

Longueur des doigts du pied de derrière avec les sabots................... 6 . 6

Hanteur du train de devant. . . . . . . o " . "

Longueur depuis le bout du museau jusqu'à l'anus. 5 n "

Distanee entre l'os des îles et la rotule. .... 1 4 n

Distance entre l'extrémité de l'isehion et la rotule. 14 " Hauteur de la partie inférieure du corps par dessus terre........................ 6

Distance entre le poitrail et le pénis. ..... „

Longueur de l'espace qu'oecupent les eôtes dans les flanes du squelette............

Les yeux ne diffèrent pas de ceux du daim ou du cerf; la prunelle est transversale, et l'iris brun tirant sur le noir; ses larmiers, semblables à ceux des cerfs, sont remplis d'une matière blanchâtre, résineuse, et plus ou moins transparente. Il y a deux points lacrymaux et deux canaux, comme dans le daim. La paupière supérieure a des cils fort longs et noirs : elle n'est pas percée, comme l'ont prétendu quelques auteurs; elle est entière. L'évêque Pontoppidan, et, 
sur son autorité, M. Haller, ont même voulu rendre raison de cetle perforation de la paupière; ils l'ont jugée nécessaire dans un pays presque toujours couvert de neige, dont la blancheur auroit pu nuire par son éclat aux yeux de ces animaux sans ce secours. Les hommes, faits pour polivoir vivre dans tous les climats, préviennent, autant qu'ils peuvent, la cécité par des voiles ou de petites machines trouées, qui affoiblissent. l'éclat de la lumière. Le renne, fait pour ce seul climat, n'avoit pas besoin de ce mécanisme; mais il a cette membrane ou paupière interne si visible dans les oiseaux, et qui se trouve dans plusieurs quadrupèdes, sans y être mobile que dans un petit nombre. Cette membrane n'est pas non plus percée dans le renne; elle peut couvrir toute la cornée, jusqu'au petit angle de l'œil.

Son nez est fort large, comme dans les vaches, et le inuseau est plus ou moins plat, couvert d'un poil long grisâtre, et qui s'étend jusqu'à l'intérieur des narines. Les lèvres sont aussi revêtues de poils, excepté un petit bord qui est noirâtre, dur, et très poreux. Les narines sont fort éloignées l'une de l'autre. La lèvre inférieure est étroite, et la bouche très fendue, comme dans la brebis.

Il y a huit dents incisives à la mâchoire inférieure, mais très petites, et très lâchement attachées; il n'en a point à la mâchoire supérieure, non plus que les autres ruminants : mais j'ai cru y remarquer des crochets, quoiqu'ils ne paroissent pas encore hors des giencives; dans la mâchoire inférieure, je n'en ai vu aucun indice. Les chevaux en ont aux deux mâchoires, mais il est rare que les juments en aient. Les 
daims, tant mâles que femelles, n'en ont presque jamais; mais j’ai préparé cet été la tête d'une biche nouvellement née, qui a un très grand crochet à la mâchoire supérieure du côté gauche. La nature varie trop dans celte partie pour qu'on puisse y déterminer rien de constant. 11 y a six dents mâchelières à chaque côté des deux mâchoires, c'est-à-dire qu'il y en a vingt-quatre en tout.

Je n'ai rien à remarquer au sujet des cornes : elles ne faisoient que de naître. L'une avoit un pouce, et l'autre un pouce et demi de hauteur; leur base étoit située entre l'orbite et l'occiput, un peu plus près de ce dernier. Le poil qui les couvroit étoit joliment contourné, et d'un gris tirant sur le noir; en le voyant d'une certaine distance, on auroit pris les deux touffes de ce poil pour deux grandes souris posées sur la tête de l'animal.

Le cou est court et un peu plus arqué que celui de la brebis, mais moins que celui du chameau. Le corps paroît robuste; le dos est un peu élevé vers les épaules, et assez droit partout ailleurs, quoique les vertèbres soient un peu formées en arc.

La queue est fort petite, recourbée en bas, et très garnie de poils.

Les testicules sont très petits, et ne paroissent point hors du corps. La verge n'est pas grande : le prépuce est sans poil, comme un nombril; il est fort ridé en dedans, et chargé ou couvert d'une croûte pierreuse.

Les sabots sont grands, longs, et convexes en dehors; mais ils n'avoient pas les bouts placés les uns sur les autres, comme ceux du renne que j’ai dessiné if y a deux ans. Les ergots sont aussi fort longs, et 
ceux des pieds antérieurs louchoient à terre quand l'animal étoit debout : mais ceux des pieds postérieurs étoient placés plus haut, et ne descendoient pas si bas : aussi les os des doigts en sont-ils plus courts.

Ces huit ergots étoient creux, apparemment parce que l'animal ne les usoit pas.

Les intestins étoient exactement semblables à ceux du daim. Il n'y avoit point de vésicule du fiel; les reins étoient lisses $\epsilon$ sans division; les poumons étoient grands; la trachée-arı̀re étoient extrêmement large.

Le cœur étoit d'une grandenr médiocre, et, comme celui du daim, ne contenoit qu'un seul osselet. Cet osselet soutient la base de la valvule semi-lunaire de l'aorte, qui est opposée aux deux autres, sur lesquelles les artères coronaires du cœur prennent leur origine. Ce même osselet donne de la fermeté à la cloison membraneuse qui est entre les deux sinus du cour, et à la base de la valvule triglochine du ventricule droit.

Ce qui m'a para de plus remarquable dans cet animal est une poche membraneuse et fort large, placée sous la peau du cou, et qui prenoit son origine entre l'os hyoïde et le cartilage thyroide par un canal conique. Ce canal alloit en s'élargissant, et se changeoit en une espèce de sac membraneux, soutenu par deux muscles oblongs. Ces muscles tirent leur origine de la partie inférieure de l'os hyoïde, précisément là où la base, l'os graniforme, et les cornes se réunissent.

Ces muscles sont plats, minces, larges d'un demipouce, et descendent des deux côtés de la poche 
jusqu'au milieu du sac, où les fibres se séparent et. se perdent dans la membrane extérieure et musculeuse de la poche; ils relèvent et soutiennent cette partie à peu près comme les crémastères soutiennent et élèvent le péritoine, qui est autour des testicules dans les singes et autres animaux semblables.

Cette poche s'ouvre dans le Tarynx, sous la racine de l'épiglotte, par un large orifice qui admettoit mon doigt très aisément.

Lorsque l'animal fait sortir arec force l'air des poumons, comme quand il fait des mugissements, l'air tombe dans cette poche, l'enfle. et cause nécessairement une tumeur considérable à l'endroit indiqué; le son doit aussi nécessairement changer beaucoup par là : les deux muscles vident la poche de l'air quand l'animal cesse de mugir.

J'ai démontré, il y a vingt ans, une semblable poche dans plusieurs papions et guenons; et, l'année passée, j'ai eu occasion de faire voir à mes auditeurs qu'il y en avoit une double dans l'orang-outang. J'en donnerai la description et la figure dans un mémoire que je me propose de publier sur la voix de l'homme et de plusieurs animaux. Je ne saurois déterminer si la femelle renne a cette poche comme le mâle. Dans les singes, les deux sexes en sont pourvus. Je ne me souviens pas de l'avoir trouvée dans le daim; la biche né l'a pas. 


\section{LE BOUQUETIN ${ }^{1}$, LE CHAMOIS ${ }^{2}$,}

Capra Ibex. L. - Antilope Rupicapra. L.

\section{ET LES AUTRES GHÈVES.}

Quoigu'il y ait apparence que les Grecs connoissoient le bouquetin et le chamois, ils ne les ont pas désignés par des dénominations particulières, ni mème par des caractères assez précis pour qu'on puisse les reconnoître: ils ne les ont indiqués que sous le nom générique de chèvres sauvages. Vraisemblablement ils présumoient que ces animaux étoient de la même espèce que les chèvres domestiques, puisqu'ils ne leur ont point appliqué de noms propres, comme ils l'ont fait à tous les animaux d'espèces différentes. Au contraire, nos naturalistes modernes ont cous regardé le bouquetin et le chamois comme deux espèces réellement distinctes, et toutes deux différentes de celles de nos chèvres. Il y a des faits et des raisons pour et contre ces deux opinions; et nous allons les exposer, en attendant que l'expérience nous apprenne si ces animaux peuvent se mêler et produire ensemble des individus féconds et qui re-

1. Autrefois bouc estain, boucstein; c'est-à-dire bouc de rocher. Stein signific pierre dans la langue teutonique. En latin, ibex; en allemand et en suisse, steinbock.

2. En latin, rupicapra; en italien, camuza; en aliemand, gemss。 


$$
5
$$



montent à l'espèce originaire; ce qui seul peut décider la question.

Le bouquetin mâle diffère du chamois par la longueur, la grosseur, et la forme des cornes; il est aussi beaucoup plus grand de corps, et il est plus vigoureux et plus fort : cependant le bouquetin femelle a les cornes différentes de celles du mâle, beaucoup plus petites, et assez ressemblantes à celles du cha-

.. D'ailleurs ces animaux ont tous deux les mêmes habitudes, les mêmes mœurs, et la même patrie : seulement le bouquetin, comme plus agile et plus fort, s'élève jusqu'au sommet des plus hautes montagnes, au lieu que le chamois n'en habite que le second étage : mais ni l'un ni l'autre ne se trouvent dans les plaines. Tous deux se fraient des chemins dans les neiges; tous deux franchissent les précipices en bondissant de rocher en rocher; tous deux sont couverts d'une peau ferme et solide, et vêtus en hiver d'une double fourrure, d'un poil extérieur assez rude, et d'un poil intérieur plus fin et plus fourni; tous deux ont une raie noire sur le dos; ils ont aussi la queue à peu près de la même grandeur : le nombre des ressemblances extérieures est si grand en comparaison des différences, et la conformité des parties intérieures est si complète, qu'en raisonnant en conséquence de tous ces rapports de similitude, on seroit porté à conclure que ces deux animanx ne sont pas d'une espèce réellement différente, mais que ce sont simplement des variétés constantes d'une seule et même espèce. D'ailleurs les bouquetins, aussi bien que les chamois, lorsqu'on les prend jeunes et qu'on les élève avec les chèvres domestiques, 
s'apprivoisent aisément, s'accoutument à la domesticilé, prennent les mêmes mœurs, vont conme elles en troupeaux, reviennent de même à l'étable, et vraisemblablement s'accouplent et produisent ensemble. J'avoue cependant que ce fait, le plus important de tous, et qui seul décideroit la question, ne nous est pas connu. Nous n'avons pu savoir ${ }^{1}$, ni par nous ni par d'autres, si les bouquetins et les chamois produisent avec nos chèvres; seulement nous le soupconnons: nous sommes à cet égard de l'avis des anciens; et de plus notre présomption nous paroît fondée sur des analogies que l'expérience a rarement démenties.

Cependant (et voici les raisons contre) l'espèce du bouquetin et celle du chamois sont toutes deux subsistantes dans l'état de nature, et toutes deux constamment distinctes. Le chamois vient quelquefois de lui-même se mêler au troupeau des chèvres domestiques; le bouquetin ne s'y mêle jamais, à moins qu'on ne l'ait apprivoisé. Le bouquetin et le

x. Dans la compilation que MM. Arrault de Nobleville et Salerne ont faite sur l'histoire des animaux, il est dit (tome $1 V$, page 264) que les chamois sont en rut presque tout le mois de septembre, que les femelles portent neuf mois, et qu'elles mettent bas, pour l'ordinaire, en juin. Si ces faits étoient vrais, ils indiqueroient très clairement que le chamois n'est pas de la même espèce que la chèrre, qui ne porte qu'environ cinq mois : mais je les crois suspeets, pour ne pas dire faux. Les chasseurs, eomme on le peut roir par les passages que je eiterai, assurent, au eontraire, que le ehamois et le bouquetin ne sont en rut que dans le mois de novembre, et que les femelles mettent bas au mois de mai : ainsi le temps de la gestation, au lieu de s'étendre à neuf mois, doit se réduire à peu près à cinc, comme dans les chèvres domestiques. Au reste, nous en appelons à l'expérience, et. wous ne croyons pas qu'elle nou. démente. 
bouc ont une très longue barbe, et le chamois n'en a point. Les cornes du chamois mâle et femelle sont très petites; celles du bouquetin mâle sont si grosses et si longues, qu'on n'imagineroit pas qu'elles pus sent appartenir à un animal de cette taille; et le chamois paroît différer du bouquetin et du bouc par la direction de ses cornes, qui sont un peu inclinées en avant dans leur partie inférieure, et courbées en arrière à la pointe en forme d'hameçon : mais, comme nous l'avons déjà dit en parlant des boufs et des brebis, les cornes varient prodigieusement dans les animaux domestiques; elles varient beaucoup aussi dans les animaux sauvages, suivant les différents climats. La femelle dans nos chèvres n'a pas les cornes absolument semblables à celles de son mâle : les cornes du bouquetin mâle ne sont pas fort différentes de celles du bouc; et comme la femelle du bouquetin se rapproche de nos chèvres, et même du chamois, par la taille et par la petitesse des cornes, ne pourroit-on pas en conclure que ces trois animaux, le bouquetin, le chamois, et le bouc domestique, ne font, en effet, qu'une seule et même espèce, mais dans laquelle les femelles sont d'une nature constante, et semblables entre elles, au lieu que les mâles subissent des variétés qui les rendent différents les uns des autres? Dans ce point de vue, qui n'est peut-être pas aussi éloigné de la nature que l'on pourroit l'imaginer, le bouquetin seroit le mâle dans la race originaire des chèvres, et le chamois en seroit la femelle ${ }^{1}$. Je dis que ce point de vue n'est pas

1. Le défaut de barbe dans le chamois est un caractère féminin quïl faut rékinir avec les autres. Le chamois wâle paroit, ainsi qque 
imaginaire, puisque l'on peut prouver par l'expérience qu'il y a des espèces dans la nature où la femelle peut égralement servir à des mâles d'espèces différentes, et produire de tous deux : la brebis produit arec le bonc aussi bien qu'avec le belier, et produit toujours des agneaux, des individus de son espèce; le belier, au contraire, ne produit point avec la chève : on peut donc regarder la brebis comme une femelle commune à deux mâles différents, et, par conséquent, elle constitue l'espèce indépendamment du mâle. Il en sera de même dans celle du bouquetin; la femelle seule y représente l'espèce primitive, parce qu'elle est d'une nature constante: les mâles, au contraire, ont varié, et il y a grrande apparence que la chèvre domestique, qui ne fait, pour ainsi dire, qu'une seule et même femelle avec celle du chamois et du bouquetin, produiroit également avec ces trois différents mâles, lesquels seuls font variété dans l'espèce, et qui, par conséquent, n'en altèrent pas l'identité, quoiqu'ils paroissent en changer l'unité.

Ces rapports, comme tous les autres rapports possibles, doivent se trouver dans la nature des choses: il paroît même qu'en général les femelles contribuen plus que les mâles au maintien des espèces; car quoique tous deux concourent à la prenière formation de l'animal, la femelle, qui seule fournit ensuite

sa fomelle, participer aux qualités fóminines de la chèvre : ainsi on peut présumer que le bouc domestique: engendreroit avec la femelle du chamois, et qu'au contraire le chamnis mâle ne pourroit engendrer avec la chivre domestique. Le temps confirmera ou détruira cette çujecture. 
tout ce qui est nécessaire à son développement et à sa nutrition, le modifie et l'assimile plus à sa nature; ce qui ne peut manquer d'effacer en beaucoup de parties les empreintes de la nature du mâle: ainsi, lorsqu'on veut juger sainement une espèce, ce sont les femelles qu'il faut examiner. Le mâle donne la moitié de la substance vivante; la femelle en donne autant, et fournit de plus toute la matière nécessaire pour le développement de la forme : une belle femme a presque toujours de beaux enfants; un bel homme avec une femme laide ne produit ordinairement que des enfants encore plus laids.

Ainsi dans la même espèce il peut y avoir quelquefois deux races, l'une masculine et l'autre féminine, qui toutes deux subsistant et se perpétuant avec leurs caractères distinctifs, paroissent constituer deux espèces différentes; et c'est là le cas où il est, pour ainsi dire, impossible de fixer le terme entre ce que les naturalistes appellent espèce et varièté. Supposons, par exemple, qu'on ne donnât constamment que dẹ boucs à des brebis, et des beliers à d'autres, il est certain qu'après un certain nombre de générations il s'établiroit, dans l'espèce de la brebis, une race qui tiendroit beancoup du bouc, et pourroit ensuite se maintenir par elle-même; car, quoique le premier produit du bouc avec la brebis remonte presque entièrement à l'espèce de la mère, et que ce soit un agneau, et non pas un chevreau, cependant cet agneau a déjà le poil et quelques autres caractères de son père. Que l'on donne ensuite le même mâle, c'est-à-dire le bouc, à ces femelles bâtardes, leur produit dans cette seconde génération approchera 
davantage de l'espèce du père, et encore plus dans la troisième, etc. ; lientôt les caractères étrangers l'emporteront sur les caractères naturels, et cette race factice pourra se sontenir par elle-même, et former dans l'espèce une variété dont l'origine sera très difficile à reconnoître. Or ce qui se peut d'une espèce à une autre se peut encore mieux dans la même espèce : si des femelles très vigoureuses n'ont constamment que des mâles foibles, il s'établira avec le temps une race f'éminine; et si en même temps des mâles très forts n'ont que des femelles trop inférieures en force et en vigueur, il en résultera une iace masculine, qui paroîtra si différente de la première, qu'on ne voudra pas leur accorder une origine commune, et qu'on vieudra par conséquent à les regarder comme des espèces réeliement distinctes et séparées.

Nous pouvons ajouter à ces réflexions générales quel ques observations particulières. M. Linnæus ${ }^{1}$ as-

1. a Capra cornibus depressis, incurvis, minimis, cranio incumben๑ tibus; magnitudine hædi hirci ; pili longi, penduli ; cornua lunata, " crassa, vis digitum longa adpressa ut fere cutem perforent. Habitai "in America. $n$

Je doute que M. Linnæus ait été bien informé au sujet du pays natal de cet animal, et je le crois originaire d'Afrique. Les raisons sur lesquelles je fonde ce doute et cette présomption, sont : $1^{\circ}$ qu'aucun auleur n'a dil que cette espèce de chèvre, non plus que la chèvre commune, se soit trouvée en Amérique $; 2^{\circ}$ que tous les voyageurs s'accordent, au contraire, à assurer quïl se trouve en Afrique des chèrres grandes, moyennes et petites, toutes différentes les unes des autres; $3^{\circ}$ parce que nous avons vu un animal qui nous est parvenu sous le nom de bouc d' A frique, lequel ressemble si fort à la description tłu capra cornibus depressis, etc., de M. Linnæus, que nous le regardons conme le même animal, $\Lambda$ insi nous nous croyons fondés à assurer que cette petite espèce de chèvre est originaire d'Afrique, ct non pas d'Amérique. 
LE BOUQUETIN, LE CHAHOIS, etc.

sure avoir vu en Hollande deux animaux du genre des chèvres, dont le premier avoit les cornes très courtes, très rabattues, presque appliquées sur le crâne, et le poil long; le second avoit les cornes droites, recourbées en arrière au sommet, et le poil court. Ces animaux, qui paroissoient être d'espèces plus éloignées que le chamois et la chèvre commune, ont néanmoins produit ensemble; ce qui démontre que ces différences de la forme des cornes et de la longneur du poil ne sont pas des caractères spécifiques el. essentiels, puisque ces animaux n'ont pas laissé de produire ensemble, et que par conséquent ils doivent être regardés comme étant de la même espèce. L'on peut donc tirer de cet exemple l'induction très vraisemblable que le chamois et notre chèvre, dont les principales différences consistent de même dans la forme des cornes et la longueur du poil, ne laissent pas d'être de ia même espèce.

Nous avons, au Cabinet du Roi, le squelette d'un animal qui fut donné à la Ménagerie, sous le nom de capricorne. Il ressemble parfaitement au bouc domestique par la charpente du corps et la proportion des os, et particulièrement au bouquetin par la forme de la mâchoire inférieure; mais il diffère de l'un et de l'autre par les cornes : celles du bouquetin ont des tubercules proéminents et deux arêtes longitudinales, entre lesquelles est une face antérieure bien marquée; celles du bouc n'ont qu'une arête et point de tubercules : les cornes du capricorne n'ont qu'une arête, point de face antérieure, et ont en même temps des rugosités sans tubercules, mais plus fortes que celles $d u$ bouc : elles indiquent done une race in- 
termédiaire entre le bouquetin et le bouc domestique. De plus', les cornes du capricorne sont courtes et recourbées à la pointe, comme celles du chamois, et en même temps elles sont comprimées et annelées : ainsi elles tiennent à la fois du bouc, du bouquetin, et du chamois.

M. Browne, dans son Histoire de la Jamaique, rapporte qu'on trouve actuellemeni dans cette île, $1^{\circ}$ la chèvre commune domestique en Europe; $2^{\circ}$ le chamois; $5^{\circ}$ le bouquetin. 11 assure que ces trois animaux ne sont point originaires d'Amérique, qu'ils y ont été transportés d'Europe; qu'ils ont, ainsi que la brebis, dégénéré dans cette terre nouvelle, qu'ils y sont devenus plus petits; que la laine des brebis s'est changée en poil rude comme celui de la chèvre; que le bouquetin paroît être d'une race bâtarde, etc. Nous croyons donc que la petite chèvre à cornes droites et recourbées au sommet, que M. Linnæus a vue en Hollande, et qu'il dit être venue d'Amérique, est le chamois de la Jamaique, c'est-à-dire le chamois d'Europe, dégénéré et devenu plus petit en Amérique; et que le bouquetin de la Jamaique, que M. Browne appelle bouquetin batard, est notre capricorne, qui ne paroît être en effet qu'un bouquetin dégénéré devenu plus petit, et dont les cornes auront varié sous le climat d'Amérique.

M. Daubenton, après avoir examiné scrupuleusement les rapports du chamois au bouc et au belier, dit qu'en général il ressemble plus au bouc qu'au belier. Les principales disconvenances sont, après les cornes, la forme et la grandeur du front, qui est moins élevé et plus court dans le chamois que dans 
le bouc; et la position du nez, qui est moins reculé que celui du bouc: en sorte que par ces deux rapports le chamois ressemble plus au belier qu'au bouc. Mais en supposant, comme il y a tout lieu de le présumer, que le chamois est une variété constante de l'espèce du bouc, comme le dogue ou le lévrier sont des variétés constantes dans l'espèce du chien, on verra que ces différences dans la grandeur du front et dans la position du nez ne sont pas, à beaucoup près, si grandes dans le chamois, relativement au bouc, que dans le dogue, relativement au lévrier, lesquels cependant produisent ensemble et sont certainement de la même espèce. D'ailleurs, comme le chamois ressemble au bouc par un grand nombre et au belier par un moindre nombre de caractères, si l'on veut en faire une espèce particulière, cette espèce sera nécessairement intermédiaire entre le bouc et le belier. Or nous avons vu que le bouc et la brebis produisent ensemble; donc le chamois, qui est intermédiaire entre les leux, et qui en même temps est beaucoup plus près du bouc que du belier par le nombre des ressemblances, doit produire avec la chèvre, et ne doit par conséquent être considéré que comme une variété constante dans cette espèce.

Il est donc presque prouvé que le chamois produiroit avec nos chèvres, puisque ce même chamois, transporté et devenu plus petit en Amérique, prodnit avec la petite chèvre d'Afrique. Le chamois n'est donc qu'une variété constante dans l'espèce de la chèvre, comme le dogue dans celle du chien: et d'autre còté nous ne pouvons guère douter que le bouquetin ne soit la vraie chèvre, la chèvre primitive 
dans son état sauvage, et qu'il ne soit à l'égard des chèvres domestiques ce que le mouflon est à l'égard des brebis. Le bouquetin ou bouc sauvage ressemble entièrement et exactement au bouc domestique par la conformation, l'organisation, le naturel, et les habitudes physiques; il n'en diffère que par deux légères diflérences, l'une à l'extérieur et l'autre à l'intérieur : les cornes du bouquetin sont plus grandes que celles du bouc; elles ont deux arêtes longiludinales, celles du bouc n'en ont qu'une; elles ont aussi de gros nouds aux tubercules transversaux, qui marquent les années de l'accroissement, au lieu que celles de's boucs ne sont, pour ainsi dire, marquées que par des stries transversales : la forme du corps est, pour tout le reste, absolument semblable dans le bouquetin et le bouc. A l'intérieur tont est aussi exactement pareil, à l'exception de la rate, dont la forme est ovale dans le bouquetin, et approche plus de eelle de la rate du chevreuil ou du cerf que de celle du bouc ou du belier. Cette dernière différence peut provenir du grand mouvement et du violent exercice de l'animal. Le bouquetin court aussi vite que le cerf, et saute plus légèrement que le chevreuil : il doil donc avoir la rate faite comme celle des meilleurs coureurs. Cette différence vient donc moins de la nature que de l'habitude, et il est à présumer que si nos boucs domestiques devenoient sauvages, et qu'ils fussent forcés à courir et à sauter comme les bouquetins, la rate reprendroit hientôt la forme la plus convenable à cet exercice; et à l'égard de ses cornes, les différences, quoique très apparentes, n'empêchent pas 'qu'clles ne ressemblent plus à celles du bouc qu'à celles 
d'aueun autre animal. Ainsi le bouquetin et le bouc étant plus voisins l'un de l'autre que d'aucun autre animal par cette partie mème, qui est la plus différente de toutes, l'on doit en conclure, tout le reste étant le même, que, malgré cette légère et unique disconvenance, ils sont tous deux d'une seule et même espèce.

Je considère donc le bouquetin, le chamois, et la chèvre domestique comme une même espèce, dans laquelle les mâles ont subi de plus grandes variétés que les femelles; et je trouve en même temps dans les chèvres domestiques des variétés secondaires, qui sont moins équivoques, et qu'il est plus aisé de reconnoître pour telles, parce qu'elles appartiennent également aux mâles et aux femelles. On a vu que la chèvre d'Angora, quoique très différente de la nôtre par le poil et par les cornes, est néanmoins de la même espèce. On peut assurer la même chose du bouc de Juda, duquel M. Linnæus a eu raison de ne faire qu'une variété de l'espèce domestique. Cette chèvre, qui est commune en Guinée, à Angole, et sur les autres côtes d'Afrique, ne diflère, pour ainsi dire, de la nôtre, qu'en ce qu'elle est plus petite, plus trapue, plus grasse: sa chair est aussi bien meilleure à manger; on la préfère dans son pays au mouton, comme nous préférons ici le mouton à la chèvre. Il en est encore de même de la chèvre mambrine ou chèvire du Levant, à longues oreilles pendantes. Cie n'est qu'une variété de la chèvre d'Angora, qui a aussi les oreilles pendantes, mais moins longues que la chèvre nambrine. Les anciens connoissoient ces deux chèvres, et ils n'en séparoient pas les espèces de l'espèce commune. Cette variété de la chèvre mambrine s'est 
plus étendue que celle de la chèvre d'Angora; car on trouve ces chèvres à très longues oreilles en Égypte et aux Indes orientales, aussi bien qu'en Syrie. Elles donnent beaucoup de lait, qui est d'assez bon goût, et que les Orientaux préfèrent à celui de la vache et du buffle.

A l'égard de la petite chèvre que M. Linnæus a vue vivante, et qui a produit avec le petit chamois d'Amérique, l'on doit penser, comme nous l'avons dit, qu'originairement elle a été transportée d'Afrique; car elie ressemble si fort à notre bouc d'Afrique, qu'on ne peut guère douter qu'elle ne soit de cetle espèce, ou qu'elle n'en ait au moins tiré sa première origine. Cette miême chèvre, déjà petite en Afrique, sera devenue encore plus petite en Amérique; et l'on sait, par le témoignage des voyageurs, qu'on a souvent et depuis long-temps transporté d'Afrique, comme d'Europe, en Amérique, des brebis, des cochons, et des chèvres dont les races se sont maintenues dans ce nouveau monde, et y subsistent encore aujourd'hui, sans autre altération que celle de la taille.

En reprenant donc la liste des chèvres, et après les avoir considérées une à une et relativement entre clles, il me paroît que de neuf ou dix espèces dont parlent les nomenclateurs, l'on doit n'en faire qu'une. D’abord, $1^{\circ}$ le bouquetin est la tige et la souche principale de l'espèce. $2^{\circ}$ Le capricorne n'est quiun bouquetin bâtard, ou plutôt dégénéré par l'influence du climat. $5^{\circ}$ Le bouc domestique tire son origine du bouquetin, qui n'est lui-même que le bouc sauvage. $4^{\circ}$ Le chamois n'est qu'une variété dans l'espèce de la chèvre, avec laquelle il doit, 
comme le bouquetin, se mêler et produire. $5^{\circ} \mathrm{La}$ petite chèvre à cornes droites et recourbées à la pointe, dont parle M. Linnæus, n'est que le chamois d'Europe devenu plus petit en Amérique. $6^{\circ}$ L'autre petite chèvre à cornes rabattues, et qui a produit avec ce petit chamois d'Amérique, est le mêmè que le bouc d'Afrique, et la production de ces deux animaux prouve que notre chamois et notre chèvre domestique doivent de même produire ensemble, et sont, par conséquent, de la même espèce. $7^{\circ} \mathrm{La}$ chèvre naine, qui probablement est la femelle du bouc d'Afrique, n'est, aussi bien que son mâle, qu'une variété de l'espèce commune. $8^{\circ} \mathrm{Il}$ en est de même du bouc et de la chèvre de Juda, et ce ne sont aussi que des variétés de notre chèvre domestique. $9^{\circ}$ La chèvre d'Angora est encore de la même espèce, puisqu'elle produit avec nos chèvres. $10^{\circ} \mathrm{La}$ chèvre mambrine, à très grandes oreilles pendantes, est une variété dans la race des chèvres d'Angora. Ainsi ces dix animaux n'en font qu'un pour l'espèce; ce sont seulement dix races différentes produites par l'influence du climat. Capres in multas similitudines transfigurantur, dit Pline. Et en effet, nous voyons par cette énumération que les chèvres, quoique dans le fond semblables entre elles, varient beaucoup pour la forme extérieure; et si nous comprenions, comme Pline, sous le nom générique de chèvres, non seulement celles dont nous venons de faire mention, mais encore le chevreuil, la gazelle, l'antilope, etc., cette espèce seroit la plus étendue de la nature, et contiendroit plus de races et de variétés que celle du chien. Mais Pline n'étoit pas assez hien 
informé de la différence réelle des espèces, lorsqu’il a joint celles du chevreuil, des gazelles, de l'antilope, etc., à l'espèce de la chèvre : ces animaux, quoique ressemblants, à beaucoup d'égards, à la chèvre, sont cependant tous d'espèces différentes; et l'on verra dans les articles suivants combien les gazelles varient, soit pour l'espèce, soit pour les races, et combien, après l'énumération de toutes les chèvres et de toutes les gazelles, il reste encore d'autres animaux qui participent et des unes et des autres. Dans l'histoire entière des quadrupèdes, je n'ai rien trouvé de plus difficile pour l'exposition, de plus confus pour la connoissance, et de plus incertain pour la tradition, que cette histoire des chèvres, des gazelles, et des autres espèces qui y ont rapport. J'ai fait mes efforts et employé toute mon attention pour y porter quelque lumière; et je n'aurai pas regret à mon temps, si ce que j'en écris aujourd'hui peut servir dans la suite à prévenir les erreurs, fixer les idées, et aller au devant de la vérité, en étendant les vues de ceux qui veulent étudier la nature. Mais revenons à notre sujet.

Toutes les chèvres sont sujettes à des vertiges, et cela leur est commun avec le bouquetin et le chamois, aussi bien que le penchant qu'elles ont à grimper sur les rochers ; et encore une autre habitude naturelle, qui est de lécher continuellement les pierres, surtout celles qui sont empreintes de salpêtre ou de sel. On voit, dans les Alpes, des rochers creusés par la langue des chamois : ce sont ordinairement des pierres assez tendres et calcinables, dans lesquelles, comme l'on sait, il y a toujours une certaine quantité 
LE BOUQUETIN, LE GHAMOIS, etc.

de nitre. Ces convenances de naturel, ces habitudes conformes, me paroissent encore être des indices assez sûrs de l'identité d'espèce dans ces animaux. Les Grecs, comme nous l'avons dit, ne les ont pas séparés en trois espèces différentes. Nos chasseurs, qui vraisemblablement n'avoient pas consulté les Grecs, les ont aussi regardés comme étant de même espèce. Gaston Phœbus, en parlant du bouquetin, ne l'indique que sous le nom du bouc sauvage : et le chamois, qu'il appelle ysarus et sarris, n'est aussi, selon lui, qu'un autre bous sauvage. J'avoue que toutes ces autorités ne font pas preuve complète; mais en les réunissant avec les raisons et les faits que nous venons d'exposer, elles forment au moins de si fortes présomptions sur l'unité d'espèce de ces trois animaux, qu'on ne peut guère en douter.

Le bouquetin et le chamois, que je regarde, l'un comme la tige mâle et l'autre comme la tige femelle de l'espèce des chèvres, ne se trouvent, ainsi que le mouflon, qui est la souche des brebis, que dans les déserts et surtout dans les lieux escarpés des plus hautes montagnes : les Alpes, les Pyrénées, les montagnes de la Grèce et celles des îles de l'Archipel, sont presque les seuls endroits où l'on trouve le bouquetin et le chamois. Quoique tous deux craignent la chaleur et n'habitent que la région des neiges et des glaces, ils craignent aussi la rigueur du froid excessif. L'été ils demeurent au nord de leurs montagnes; l'hiver ils cherchent la face du midi, et descendent des sornmets jusque dans les vallons. Ni l'un ni l'autre ne peuvent se soutenir sur les glaces unies: mais, pour peu que la neige y forme des aspérités, 
ils y marchent d'un pas ferme, et traversent en bolldissant toutes les inégalités de l'espace. La chasse de ces animaux, surtout celle du bouquetin, est très pénible; les chiens y sont presque inutiles: elle est aussi quelquefois dangereuse; car lorsque l'animal se trouve pressé, il frappe le chasseur d'un violent coup de tête, et le renverse souvent dans le précipice voisin. Les chamois sont aussi vifs, mais moins forts que les bourqetins; ils sont en plus grand nombre, ils vont ordinairement en troupeaux : cependant il y en a beaucoup moins aujourd'hui qu'il n'y en avoit autrefois, du moins dans nos Alpes et dans nos Pyrénées. Le nom de chamoiseurs, que l'on a donné à tous les passeurs de peau, semble indiquer que dans ce temps les peaux de chamois étoient la matière la plus commune de leur métier; au lieu qu'aujourd'hui ce sont les peaux de chèvre, de mouton, de cerf, de chevreuil, et de daim, qui font plus que celles du chanois l'objet du travail et du commerce des chamoiseurs.

Et à l'égard de la propriété spécifique que l'on attribue au sang du bouquetin pour de certaines maladies, et surtout pour la pleurésie, propriété qu'on croyoit particulière à cet animal, et qui par conséquent auroit indiqué qu'il étoit lui-même d'une nature particulière, on a reconnu que le sang du chamois, et même celui du bouc domestique, avoit les mêmes vertus lor'squ'on le nourrissoit avec les herbes aromatiques que le bouquetin et le chamois ont coutume de paître; en sorte que par ceite même propriété ces trois animaux paroissent encore se réunir à une seule et même espèce. 


\section{LE SAÏGA.}

Antilope Saiga. Pall.

$O_{N}$ trouve en Hongrie, en Pologne, en Tartarie et dans la Sibérie méridionale, une espèce de chèvre sauvage, que les Russes ont appelée seigak ou saïga, laquelle, par la figure du corps et par le poil, ressemble à la chèrre domestique; mais, par la forme des cornes et le défaut de barbe, se rapproche beaucoup des gazelles, et paroît faire la nuance entre ces deux genres d'animaux : car les cornes du saiga sont tout-à-fait semblables à celles de la gazelle; elles ont la même forme, les anrieaux transversaux, les stries longitudinales, etc., et n'en diffèrent que par la couleur : les cornes de toutes les gazelles sont noires et opaques; celles du saiga sont au contraire blanchâtres et transparentes. Cet animal a été indiqué par Gesner sous le nom de colus, et par M. Gmelin, sous celui de saiga. Les cornes que nous avons au Cabinet du Roi y ont été envoyées sous la dénomination decornes de bouc de Hongrie : elles sont d'une matière si transparente et si nette, qu'on s'en sert comme de l'écaille et aux mêmes usages. Par les habitudes naturelles, le saiga ressemble plus aux gazelles qu'au bouquetin et au chamois : car il n'affecte pas les pays de montagnes; il vit, comme les gazelles, sur les collines et dans les plaines; il est, comme elles, très bondissant, très léger à la course; et sa chair est aussi bien. 
meilleure à manger que celle du bouquetin ou des autres chèvres sauvages et domestiques.

* M. Pallas pense que le saiga, qui se trouve en Hongrie, en Transylvanie, en Valachie, et en Grèce, peut aussi se trouver dans l'île de Candie; et il croit qu'on doit lui rapporter le strepsiceros de Belon. Je ne suis pas du même avis, et j'ai rapporté le strepsiceros de Belon au genre des brebis, et non à celui des gazelles.

"Saigis, saïga, dit M. Gmelin, est un animal qui ressemble beaucoup au chevreuil, sinon que ses cornes, au lieu d'être branchues, sont droites et permanentes, au lieu que celles du chevreuil sont annuelles. On ne connoît cet animal que dans quelques cantons de la Sibérie; car celui qu'on appelle saïga dans la province d'Irkutzk est le musc. Cette espèce de chèvre sauvage (le saiga) est assez commune dans certaines contrées : on en mange la chair; cependant notre compagnie ne voulut point en goûter, vraisemblablement parce que nous n'y étions pas accoutumés, et que d'ailleurs il est dégoûtant de voir dans cet animal des vers, même de son vivant, nichés entre la peau charnue et l'épiderme; c'est une grande quantité de vers blancs et gros, d'environ trois quarts de pouce de long, et pointus des deux côtés. On trouve la miême chose aux élans, aux rennes et aux biches : les vers de ces chèvres paroissent être les mêmes que ceux de ces autres animaux, et n'en différer que par la grosseur. Quoi qu'il en soit, il nous sulfit d'avoir vu les vers pour ne point vouloir de cette viande, dont on nous dit d'ailleurs que le goût étoit exactement semblable ì celle du cerf." 
J'observerai que ce n'est que dans une saison, après le temps du rut, que les cerfs, les élans, et probablement les saiggas, ont des vers sous la peau. Voyez ce que j’ai dit de la production de ces vers à l'article du cerf.

M. Forster m’a écrit « que le saïga se trouve depuis la Moldavie et la Bessarabie jusqu'à la rivière d'Irtish en Sibérie. Il aime les déserts secs et remplis d'absinthes, aurones, et armoises, qui font sa principale nourriture. Il court très vite, et il a l'odorat fort fin; mais il n'a pas la vue bonne, parce qu'il a sur les yeux quatre petits corps spongieux qui servent à le défendre du trop grand reflet de la lumière dans ces terrains, dont le sol est aride et blanc en été, et couvert de neige en hiver. Il a le nez large, et l'odorat si fin, qu'il sent un homme de plus d'une lieue lorsqu'il est sous le vent, et on ne peut même l'approcher que de l'autre côté du vent. On a observé que le saïga semble réunir tout ce qui est nécessaire pour bien courir : il a la respiration plus facile qu'aucun autre animal, ses poumons étant très grands, la trachéeartère fort large, et les narines ainsi que les cornets du nez fort étendus, en sorte que la lèvre supérieure est plus longue que l'inférieure : elle paroît pendante, et c'est probablement à cette forme des lèvres qu'on doit attribuer la manière dont cet animal paît; car il ne broute qu'en rétrogradant. Ces animaux vont la plupart en troupeaux, qu'on assure être quelquefois jusqu'au nombre de dix mille; cependant les voyageurs modernes ne font pas mention de ces grands attroupements : ce qui est plus certain, c'est que les inâles se réunissent pour défendre leurs petits et leurs 
femelles contre les attaques des loups et des renards; car ils forment un cercle autour d'elles, et combattent courageusement ces animaux de proie. Avec quelques soins, on vient à bout d'élever leurs petits et de les rendre privés : leur voix ressemble au bêlement des brebis. Les femelles mettent bas au printemps, et ne font qu'un chevreau à la fois, et rarement deux. On en mange la chair en hiver comme un bon gibier; mais on la rejette en été, à cause des vers qui s'engendrent sous la peau. Ces animaux sont en chaleur en automne, et ils ont alors une forte odeur de musc. Les cornes du saiga sont transparentes, et estimées pour différents usages; les Chinois surtout les achètent assez cher. On trouve quelquefois des saigas à trois cornes, et même on en voit qui n'en ont qu'une seule, ce qui est confirmé par M. Pallas; et il semble que c'est le même animal dont Rzaczynski parle, en disant: "Aries campestris (baran poluy) " unius cornu instructus spectatur in desertis locis "ultra Braclaviam Oczokoviam usque protensis. "

"Le saiga est de la grandeur d'une chèvre commune. Les cornes sont longues d'un pied, transparentes, d'un jaune terne, ridées en bas d'anneaux, et lisses à la pointe; elles sont courbées en arrière, et les pointes se rapprochent. Les oreilles sont droites et lerminées en pointe mousse. La tête est arquée ou en chanfrein, depuis le front jusqu'au museau, et, en la regardant de profil, on lui trouve quelque rapport avec celle de la brebis. Les narines son graudes et en forme de tube. Il y a huit dents incisives d̀ la màchoire inférieure; elles ne tiennent pas fortement dans leuss alvéoles, et tombent au moindre 


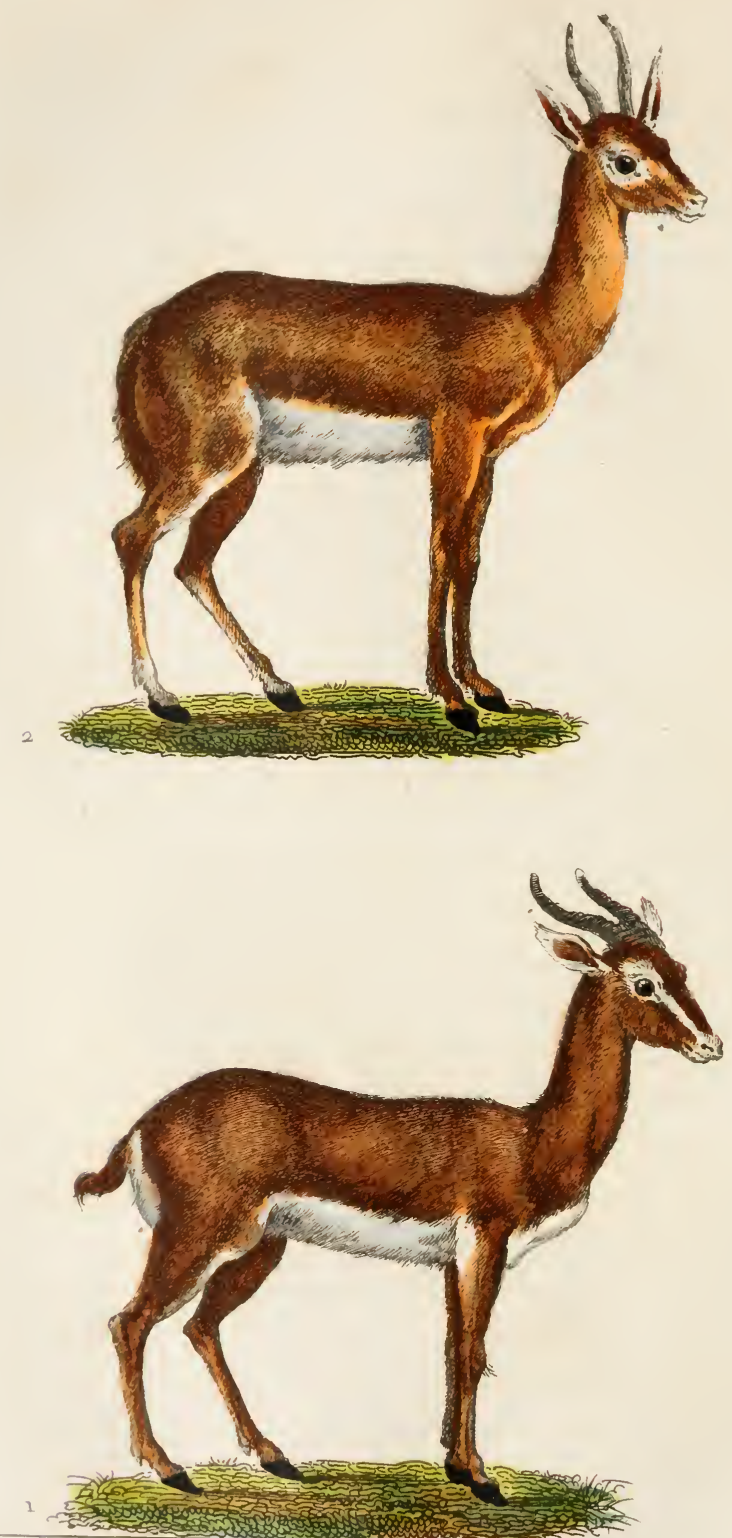

1 - 
choc. Il n'y a que les mâles qui aient des cornes, et les femelles en sont dépourvues. La queue est courte, n'ayant à peu près que trois pouces de longueur: le poil du dessus et des côtés du corps est de couleur isabelle, et celui du ventre est blanc; il y a une ligne brune le long de l'épine du dos.

"Saiga est un mot tartare qui signifie chèvre sauvage; mais communément ils appellent le mâle matgatch, et la femelle saiga."

\section{ES GAZELLES}

Nous avons reconnu treize espèces, ou du moins treize variétés bien distinctes dans les animaux qu'on appelle gazelles; et dans l'incertitude où nous sommes si ce ne sont que des variétés, ou si ce seroient en effet des espèces réellement différentes, nous avons cru devoir les présenter ensemble, en leur assignant néanmoins à chacune un nom particulier, qui, dans le premier cas, ne sera qu'une dénomination précaire, et pourra, dans le second, devenir le nom spécifique et propre à l'espèce. Le premier de ces animaux, et le seul auquel nous conserverons le nom générique de gazelie, est la gazelle commune (Antilope Dorcas. L.), qui se trouve en Syrie, en Mésopotamie, et dans les autres provinces du Levant, aussi bien qu'en Barbarie et dans toutes les parties septentrio-

1. En arabe, gazal; nom générique que l'on a donné à plusicurs animaux d'espèces différentes. 
nales de l'Afrique. Les cornes de cette gazelle ont environ un pied de longueur; elles portent des anneaux entiers à leur base, et ensuite des demi-anneaux jusqu'à une pelite distance de leur extrémité, qui est lisse et pointue; elles sont non seulement environnées d'anneaux, mais sillonnées longitudinalement par de petites stries : les anneaux marquent les années de l'accroissement; ils sont ordinairement au nombre de douze ou treize. Les gazelles en général, et celle-ci en particulier, ressemblent beaucoup au chevreuil par la forme du corps, par les fonctions naturelles, par la légèreté des mouvements, la grandeur, et la vivacité des yeux, ete. Et comme le chevreuil ne se trouve point dans le pays qu'habite la gazelle, on seroit d'abord tenté de croire qu'elle n'est qu'un chevreuil dégénéré, ou que celui-ci n'est qu'une gazelle dénaturée par l'influence du climat et par l'effet de la différente nourriture : mais les gazelles diffirent du chevreuil par la nature des cornes; celles du chevreuil sont une espèce de bois solide, qui tombe et se renouvelle tous les ans, comme celui du cerf; les cornes des gazelles, au contraire, sont creuses et permanentes, comme celles de la chèvre. D'ailleurs le chevreuil n'a point de vésicule du fiel, au lieu que les gazelles ont cette vésicule comme les chèvres. Les gazelles ont, comme le chevreuil, des larmiers ou enfoncements au devant de chaque ceil : elles lu i ressemblent encore par la qualité du poil, par la blancheur des fesses, et par la brosse qu'elles ont sur les jambes; mais ces brosses dans le chevreuil sont sur les jambes de derrière, au lieu que dans les gazelles clles sont sur les jambes de devant. Les gazelles pa- 
roissent donc être des animaux mi-partis, intermédiaires entre le chevreuil et la chèvre : mais lorsque l'on considère que le chevreuil est un animal qui se trouve également dans les deux continents; que les chèvres, au contraire, ainsi que les gazelles, n'existoient pas dans le Nouveau-Monde, on se persuade aisément que ces deux espèces, les chèvres et les gazelles, sont plus voisines l'une de l'autre qu'elles ne le sont de l'espèce du chevreuil. Au reste, les seuls caractères qui appartiennent en propre aux gazelles sont les anneaux transversaux avec les stries longitudinales sur les cornes, les brosses de poils aux jambes de devant, une bande épaisse et bien marquée de poils noirs, bruns, ou roux, au bas des flancs, et enfin trois raies de poils blanchâtres qui s'étendent longitudinalement sur la face interne de l'oreille.

La seconde gazelle (Ant. Kevella. GusL.) est un animal qui se trouve au Sénégal, où M. Adanson nous a dit qu'on l'appeloit kevel. Il est un peu plus petit que la gazelle commune, et à peu près de la grandeur de nos petits chevreuils. Il diffère aussi de la gazelle en ce que ses yeux sont beaucoup plus grands, et que ses cornes, au lieu d'être rondes, sont aplaties sur les côtés : cet aplatissement des cornes n'est pas une différence qui provienue de celle du sexe; les gazelles mâles et femelles les ont rondes; les kevels mâles et femelles les ont plates, ou, pour mieux dire, comprimées. Au reste, le kevel ressemble en entier à la gazelle, et a comme elle le poil court et fauve, les fesses et le ventre blanes, la queue noire, la bande brune au dessus des flancs, les trois raies blanches dans les oreilles, les cornes noires el envirounées d'an. 
neaux, les stries longitudinales entre les anneaux, etc.; mais il est vrai que le nombre de ces anneaux est plis grand dans le kevel que dans la gazelle : celle-ci n'en a ordinairement que douze ou treize; le kevel en a at: moins quatorze, et souvent jusqu'à dix-huit et vingt.

Le troisième animal est celui que nous appellerons corine (Ant. Corima. Gule.), du nom korin, qu'il porte au Sénégal. Il ressemble beaucoup à la gazelle et au kevel; mais il est encore plus petit que le kevel, et ses cornes sont beaucoup plus menues, plus courtes, et plus lisses que celles de la gazelle et du kevel, les anneaux qui environnent les cornes de la corine étant très peu proéminents et à peine sensibles. II. Adanson, qui a bien voulu me communiquer la description qu'il a faite de cet animal, dit qu'il paroît tenir un peu du chamois, mais qu'il est beaucoup plus petit, n'ayant que deux pieds et demi de longueur et moins de deux pieds de hauteur, qu'il a les oreilles longues de quatre ponces et demi, la queue de trois pouces, les cornes de six pouces de longueur et de six lignes seulement d'épaisseur; qu'elles sont distantes l'une de l'autre de deux pouces à leur naisance, et de cinq à six pouces à leur extrémité; qu'elles portent, au lieu d'anneaux, des rides Iransversales, annulaires, fort serrées les unes contre les autres dans la partie inférieure, et beaucoup plus distantes dans la partie supérieure de la corne; que ces rides, qui liennent lieu d'anneaux, sont au nombre de près de soixante; qu'au reste, la corine a le poil court, luisant, et fourni, fauve sur le dos et les flancs, blanc sous le ventre et sous les cuisses, avec la queuc noire, et qu'il y a dans cette nême espèce de la cam 
rine des individus dont le corps est tigré de taches blanchâtres semées sans ordre.

Ces différences que noưs venons d'indiquer entre la gazelle, le kevel, et la corine, quoique fort apparentes, surlout pour la corine, ne nous semblent pas essentielles, ni suffisantes pour faire de ces animaux des espèces réellement différentes; ils se ressemblent si fort à tous autres égrards, qu'ils nous paroissent au contraire être tous trois de la wême espèce, laquelle sculement a subi, par l'influence du climat et de la nourriture, plus ou moins de variétés : car le kevel et la gazelle diffèrent beaucoup moins entre eux que la corine, dont les cornes surtout ne sont pas semblables à celles des deux autres; mais tous trois ont les mêmes habitudes naturelles, se rassemblent en troupes, vivent en société, et se nourrissent de la même manière; tous trois sont d'un naturel doux, et s'accoutument à la domesticité; tous trois ont aussi la chair très bonne à manger. Nous nous croyons donc fondés à conclure que la gazelle et le kevel sont certainement de la même espèce, et qu'il est incertain si la corine n'est qu'une variété de celte même espèce, ou si c'est une espèce différente.

Nous avons au Cabinet du Roi les dépouilles, en tout ou en partie, de ces trois différentes gazelles, et nous avons de plus une corne qui a beaucoup de ressemblance avec celles de la gazelle et du kevel, mais qui est beaucoup plus grosse. Cette corne est aussi gravée dans Aldrovande ${ }^{1}$. Sa grosseur et sa longueur semblent indiquer un animal plus grand que la ga-

8. Lib. 1, de bisuleis, cap., $2 \mathrm{r}$. 
zelle commune, et elle nous paroît appartenir à une gazelle que les Turcs appellent tzeiran, et les Persans ahu. Cet animal, selon Oléarius, ressemble en quelque sorte à notre daim, sinon qu'il est plutôt roux que fauve, et que les cornes sont sans andouillers, couchées sur le dos, etc. ; et, selon M. Gmelin, qui le désignesous le nom de dsheren, il ressemble au chevreuil, à l'exception des cornes, qui, comme celles du bouquetin, sont creuses et ne tombent jamais. Cet auteur ajoute qu'à mesure que les cornes prennent de l'accroissement, le cartilage du larynx grossit au point de former sous la gorge une proéminence considérable lorsque l'animal est âgé. Selon hæmpfer, l'ahu ne diffère en rien du cerf par la figure; mais il se rapproche des chèvres par les cornes, qui sont simples, noires, annelées jusqu'au delà du milieu de leur longueur, etc. Quelques autres voyageurs ont aussi fait mention de celte espèce de gazelle sous les noms corrompus de geiran et de jairain, qu'il est aisé de rapporter, aussi bien que celui de dsheren, au nom primitif tzeiran. Cette gazelle est commune dans la Tartarie méridionale, en Perse, en Turquie, et paroît aussi se trouver aux Indes orientales.

Nous devons ajouter à ces quatre premières espèces ou races de gazelles deux autres animaux qui leur ressemblent en beaucoup de choses : le premier s'appelle koba au Sénégral, où les François l'ont nommé grande vache brune; le second, que nous appellerons $k o b$, est aussi un animal du Sénégal, que les François y ont appelé petite vache brune. Les cornes du kob ont beaucoup de ressemblance et de rapport à celles de la gazelle et du kevel; mais la forme 
de la tête est différente, le museau est plus long, et il n'y a point d'enfoncements ou de larmiers sous les yeux. Le koba (Ant. Senegalensis) est beaucoup plus grand que le kob : celui-ci est comme un daim, et celui-là comme un cerf. Par les notices que nous a données M. Adanson, et que nous publions avec bien de la reconnoissance, il paroît que le koba ou grande vache brune a cinq pieds de Jongueur depuis l'extrémité du museau jusqu'à l'origine de la queue; qu'il a la tête longue de quinze pouces, les oreilles de neuf, et les cornes de dix-neuf à vingt pouces; que ces cornes sont aplaties par les côtés, et environnées de onze ou douze anneaux, au lieu que celles du kob ou petite vache brune n'ont que huit ou neuf anneaux, et ne sont longues que d'environ un pied.

Le septième animal de celte espèce ou de ce genre est une gazelle qui se trouve dans le Levant, et plus communément encore en Égyple ${ }^{1}$ et en Arabie. Nous l'appellerons de son nom arabe, algazel (Ant. Gazella. L.). Cet animal est de la forme des autres gazelles, et à peu près de la grosseur d'un daim : mais ses cornes sont très longues, assez menues, peu courbées jusqu'à leur extrémité, où elles se courbent davantage; elles sont noires et presque lisses, les anneaux étant très légers, exceplé vers la base, où ils sont un peu mieux inarqués : elles ont près de trois pieds de longueur, tandis que celles de la gazelle n'ont communément qu'un pied, celles du kevel quatorze ou

1. Les naturalistes nous paroissent avoir donné mal à propos le nom de gazelle d'Inde à cette espèce. On verra par les témoignages des voyageurs qu'elle ne se trouve qu'en Égypte, en Arabie et dans le Levant. 
quinze pouces, et celles de la corine (lesquelles néanmoins ressemblent le plus à celles-ci) six ou sept pouces seulement.

Le huitième animal est celui qu'on appelle vulgairement la gazclle du bézoard, que les Orientanx appellent pasan (Antilope Oryx. PalL.), et à laquelle nous conserverons ce nom. Une corne de cette gazelle est très bien représentée dans les Éphémérides d'Allemagne, et la figure de l'animal même a été donnée par Kæmpfer; mais cette figure de Kæmpfer pèche en ce que les cornes ne sont pas assez longues ni assez droites : et d'ailleurs sa description ne nous paroît pas exacte: car il dit que cet animal du bézoard porte une barbe comme le bouc, et néanmoins la figure qu'il en donne est sans barbe : ce qui nous paroîi plus conforme à la vérité; car, en général, les. gazelles n'ont point de barbe, c'est même le principal caractère qui les distingue des chèvres. Cette gazelle est de la grandeur de notre bouc domestique, et elle a le poil, la figure, et l'agilité du cerf. Nous avons vu de cet animal un crâne surmonté de ses cornes, et deux autres cornes séparées. Les cornes qui sont gravées dans Aldrovande ressemblent beaucoup à celles-ci. Au reste, ces deux espèces, l'algazel et le pasan, nous paroissent très voisines l'une de l'autre; elles sont aussi du même climat, et se trouvent dans le Levant, en Égypte, en Perse, en Arabie, etc. : mais l'algazel n'habite guère que dans les plaines, et le pasan dans les montagnes. Leur chair est aussi très bonne à manger.

La neuvième gazelle est un animal qui, selon M. Adanson, s'appelle nangueur ou nanguer au Sé- 
négal (Antilope Dama. L.) : il a trois pieds et demi de longueur, deux pieds et demi de hauteur; il est de la forme et de la couleur du chevreuil, fauve sur les parties supérieures du corps, blanc sous le ventre et sur les fesses, avec une tache de cette même couleur sous le cou. Ses cornes sont permanentes comme celles des autres gazelles, et n'ont qu'environ six ou sept pouces de longueur; elles sont noires et rondes: mais ce qu'elles ont de très particulier, c'est qu'elles sont fort courbées à la pointe en avant, à peu près comme celles du chamois le sont en arrière. Ces nanguers sont de très jolis animaux, et fort faciles à apprivoiser. Tous ces caractères, et principalement celui des petites cornes recourbées en avant, m'ont fait penser que le nanguer pourroit bien être le dama ou daim des anciens. Cornua rupicapris in dorsum adunca, damis in adversum, dit Pline. Or, les seuls animaux qui aient les cornes aussi courbées sont les nanguers dont nous venons de parler : on doit donc présumer que le nanguer des Africains est le dama des anciens; d'autant qu'on voit, par un autre passage de Pline, que le dama ne se trouvoit qu'en Afrique; et qu'enfin, par les témoignages de plusieurs autres auteurs anciens, on voit aussi que c'étoit un animal timide, donx, et qui n'avoit de ressource que dans la légèreté de sa course. L'animal dont Caius a donné la description et la figure sous le nom de dama Plinii, se trouvant, selon le témoignage même de cet auteur, dans le uord de la GrandeBretagne et en Espagne, ne peut pas être le daim de Pline, puisque celui-ci dil qu'il ne se trouve qu'en Afrique. D’ailleurs, cet animal, désigné par Caïus, 
porte une barbe de chèvre, el aucun des anciens n'a dit que le dama eût une barbe. Je crois donc que ce prétendu dama décrit par Caius n'est qu'une chèvre, dont les cornes s'étant trouvées un peu courbées en avant à leur extrémité, comme celles de la gazelle commune, lui ont fait penser que ce pouvoit être le dama des anciens; et d'ailleurs ce caractère des cornes recourbées en avant, qui est, en effet, l'indice le plus sûr di dama des anciens, n'est bien marqué que dans le nanguer d'Afrique. Au reste, il paroît, par les notices de M. Adanson, qu'il y a trois espèces ou variétés de ces nanguers, qui ne diffèrent entre eux que par les couleurs du poil, mais qui tous ont les cornes plus ou moins courbées en avant.

La dixième gazelle est un animal très commun en Barbaric et en Mauritanie, que les Anglois ont appelé antilope ${ }^{1}$ (Ant. Cervicapra. Pals.), et auquel nous conserverons ce nom. 11 est de la taille de nos plus grands chevreuils; il ressemble beaucoup à la gazelle et au kevel, et néanmoins il en diffère par un assez grand nombre de caractères pour qu'on doive le regarder conme un animal d'une autre espèce. L'antilope a les larmiers plus grands que la gazelle : ses cornes ont environ quatorze pouces de longueur; elles se touchent, pour ainsi dire, à la base, et sont distantes à la pointe de quinze ou seize pouces; elles sont environnées d'anneaux et de demi-anneaux moins relevés que ceux de la gazelle et du kevel; et ce qui caractérise plus particulièrement l'antilope, c'est que les cornes ont une double flexion symétrique et très remar-

1. Nom que les $\Lambda$ nglois ont donné à cet animal, et que nous avons adopté. 
quable, en sorte que les deux cornes prises ensemble représentent assez bien la forme d'une lyre antique. L'antilope a, comme les autres gazelles, le poil fauve sur le dos et blanc sous le ventre; mais ces deux couleurs ne sont pas séparées au bas des flancs par une bande brune ou noire, comme dans la gazelle, le kevel, la corine, etc. Nous n'avons au Cabinet du Roi que le squelette de cet animal.

Il nous paroît qu'il y a dans les antilopes, comme dans les autres gazelles, des races ou des espèces différentes entre elles. $1^{\circ}$ Nous avons au Cabinet du Roi une corne qu'on ne peut attribuer qu'à une antilope beaucoup plus grande que celle dont nous venons de parler : nous l'appellerons lidmée, du nom que, selon le docteur Shaw, les Africains donnent aux antilopes. $2^{\circ}$ Nous avons vu au cabinet de M. le marquis de Marigny, dont le goût s'étend également aux objets des beaux-arts et à ceux de la belle nature, une espèce d'arme offensive, composée de deux cornes pointues et longues d'environ un pied et demi, qui, par leur double flexion, nous paroissent appartenir à une antilope plus petite que les autres: elle doit être très commune dans les grandes Indes, car les prêtres gentils ${ }^{1}$ portent cette espèce d'arme comme une marque de

1. "Les gazelles aux Indes ne sont pas tout-à-fait comme celles des ఐ autres pays ; elles ont même beaucoup plus de cœur, et à l'extérieur " on les distingue par les cornes : les gazelles ordiuaires les ont grises, " et moins longues de la moitié ciue celles des Indes, qui les on t noirâ„ tres et longues d'un grand pied et demi; ces cornes s'en vont en ser"pentant jusqu'à la pointe comme une vis, et les faquirs et santons " en portent ordinairement deux qui sont jointes..., et ils s'en servent " comme d'un petit bâton à deux bouts. "(Relation du voyage de T'hévenot, lome IIf, pag. 111 et 112.) 
dignité. Nous appellerons cet animal antilope des Indes, dans l'idée où nous sommes que ce n'est qu'une simple variété de l'antilope d'Afrique.

En reprenant tous les animaux que nous venons d'exposer, nous avons donc déjà douze espèces ou variétés distinctes dans les gazelles; savoir : $1^{\circ}$ la gazelle commune; $2^{\circ}$ le kevel $; 5^{\circ}$ la corine $; 4^{\circ}$ le tzeiran; $5^{\circ}$ le koba ou grande vache brune; $6^{\circ}$ le kob ou petite vache brune; $7^{\circ}$ l'algazel, ou gazelle d'Égyple; $8^{\circ}$ le pasan ou la prétendue gazelle du bézoard; $9^{\circ}$ le nanguer, ou dama des anciens; $10^{\circ} \mathrm{l}^{\prime}$ antilope; $11^{\circ} \mathrm{le}$ lidmée; $12^{\circ}$ et enfin l'antilope des Indes. Après les avoir soigneusement comparées entre elles, nous croyons, $i^{\circ}$ que la gazelle commune, le kevel, et la corine, ne sont que trois variétés de la même espèce; $2^{\circ}$ que le tzeiran, le koba, et le kob, sont tous trois des variétés d'une autre espèce; $5^{\circ}$ nous présumons que l'algazel et le pasan ne sont aussi que deux variétés de la même espèce, et nous pensons que le nom de gazelle du bézoard, qu'on a donné au pasan, n'est point un caraclère distinctif; car nous croyons être en état de prouver que le bézoard oriental ne vient pas seulement du pasan, mais de toutes les gazelles et chèrres qui habitent les montagnes de l'Asie; $4^{\circ}$ il nous paroît que les nanguers, dont les cornes sont courbées en avant, et qui font ensemble deux ou trois variétés particulières, ont été indiqués par les anciens sous le nom de dama; $5^{\circ}$ que les antilopes, qui sont au nombre de trois ou quatre, et qui diffèrent de toutes les autres par la double flexion de leurs cornes, ont aussi été connues des anciens et désignées par les noms de strepsiceros et d'addax. Tous ces ani- 
maux se trouvent en Asie et en Afrique, c'est-à-dire dans l'aucien continent; et nous n'ajouterons pas à ces cinc espèces principales, qui contiennent douze variétés très distinctes, deux ou trois autres espèces du Nouveau-Monde, auxquels on a aussi donné le nom vague de gazelles, quoiqu'elles soient différentes de toutes celles que nous venons d'indiquer : ce seroit augmenter la confusion, qui n'est déjà que trop grande ici. Nous donnerons, dans l'article suivant, l'histoire de ces animaux d'Amérique, sous leurs vrais noms mazame, temamaçame, etc., et nous nous contenterons de parler actucllement des animaux de ce genre qui se trouvent en Afrique et en Asie : nous renvoyons même à l'article suivant, pour plus grande clarté et pour simplifier les objets, plusieurs autres animaux de ce même climat d'Afrique et d'Asie, qu'on a encore regardéscomme des gazelles ou comme des chèvres, et qui cependant ne sont ni gazelles ni chèvres, mais paroissent être intermédiaires entre les deux: ces animaux sont le bubale ou vache de Barbarie, le condoma, le guib, la chèvre de Grimm, etc., sans compter les chevrotains, qui ressemblent beaucoup aux plus petites chèvres ou gazelles, et dent nous ferons aussi un article particulier.

Il est maintenant aisé de voir combien il étoit difficile d'arranger toutes ces bêtes, qui sont au nonbre de plus de trente, dix chèvres, douze ou treize gazelles, trois ou quatre bubales, autant de chevrotains et de mazames, tous différents entre eux; plusieurs absolument inconnus, les autres présentés pêle-mêle par les naturalistes, et tous pris les uns pour les autres par les voyageurs. Aussi c'est pour la 
troisième fois que j'écris aujourd'hui leur histoire, et javoue que le travail est ici bien plus grand que le produit; mais, au moins, j'aurai fait ce qu'il étoit possible de faire avec les matériaux donnés et les connoissances acquises, que j'ai encore eu plus de peine à rassembler qu'à employer.

En comparant les indications que nous ont laissées les anciens, et les notices que l'on trouve dans les auteurs modernes, avec les connoissances que nous avons acquises, nous reconnoîtrons au sujet des gazelles, $1^{\circ}$ que le dorcas d'Aristote n'est point la gazelle, mais le chevreuil, et que cependant ce même mol dorcas a été employé par Élien non seulement pour désigner les chèvres sauvages en général, mais particulièrement la gazelle de Libye ou gazelle commune; $2^{\circ}$ que le strepsiceros de Pline ou l'addax des Africains est l'antilope; $5^{\circ}$ que le dama de Pline est le nanguer de l'Afrique, et non pas notre daim, ni aucun autre animal d'Europe; $4^{\circ}$ que le prox d'Aristote est le même que le zorces d'Élien, et encore le même. que le platycerôs des Grecs plus récents, et que les Latins ont adopté ce mot platyceros pour désigner le daim; animalium quorumdam cornua in palmas finxit natura, digitosque emisit $a x$ iis, unde platycerotas vocant, dit Pline; $5^{\circ}$ que le pygargos des Grecs est probablement la gazelle d'Égypte ou celle de Perse, c'est-à-dire l'algazel ou le pasan. Le mot pygargus n'est employé par Áristote que pour désigner un oiseau, et cet oiseau est l'aigle á queue blanche; mais Elien et Pline se sont servis du même mot pour désigner un quadrupède. Or, l'étymologie de pygargus indique, $1^{\circ}$ un animal à fesses blanches, 
tel que les chevreuils ou les gazelles; $2^{\circ}$ un animal timide, les anciens s'imaginant que les fesses blanches étoient un indice de timidité, et attribuant l'intrépidité d'Hercule à ce qu'il avoit les fesses noires. Mais, comme presque tous les auteurs qui parlent du $p y-$ gargus quadrupède font aussi mention du chevreuil, il est clair que ce nom pygargus ne peut s'appliquer qu’à quelque espèce de gazelle différente du dorcas Libyca ou gazelle commune, et du strepsiceros ou antilope, desquelles les mêmes auteurs font aussi mention. Nous croyons donc que le pygurgus désigne l'algazel ou gazelle d'Égypte, qui devoit être connue des Grecs, comme elle l'étoit des Hébreux, car l'on trouve ce nom pygargus dans la version des Septante 1 , et l'on voit que l'animal qu'il désigne est mis au nombre des animaux dont la chair étoit pure. Les Juifs mangeoient donc souvent du pygargus, c'est-àdire de cette espèce de gazelle, qui est la plus commune en Égypte et dans les pays adjacents.

M. Russel, dans son Histoire naturelle du pays d' $A$ lep, dit qu'il y a auprès de cette ville deux sortes de gazelles: l'une qu'on appelle gazelle de montagne, qui est la plus belle, dont le poil sur le cou et le dos est d'un brun foncé ; l'autre qu'on appelle gazellede plaine, qui n'est ni aussi légère ni aussi bien faite que la première, et dont la couleur du poil est plus pâle. Il ajoute que ces animaux courent si vite et si long-temps, que les meilleurs chiens courants peuvent rarement les forcer sans le secours d'un faucon... qu'en hiver les gazelles sont maigres, et que néanmoins leur chair 
est de bon goût; qu'en été elle est chargée d'une graisse semblable à la venaison du daim; que les gazelles qu'on nourrit à la maison ne sont pas aussi excellentes à mangrer que les grazelles sauvages, etc. Par ce témoignange de M. Russel, et par celui de M. Hasselquist, on voit que ces gazelles d'Alep ne sont pas les gazelles communes, mais les gazelles d'Égypte, dont les cornes sont droites, longues et noires, et dont la chair est en effet excellente à manger. L'on voit aussi par ces témoignages que les gazelles sont des animaux à demi domestiques, que les hommes ont souvent et anciennement apprivoisés, et dans lesquels par conséquent il s'est formé plusieurs variétés ou races différentes, comme dans les autres animaux domestiques. Ces gazelles d'Alep sont les mêmes que celles que nous avons appelées algazels; elles sont encore plus communes dans la Thébaide et dans toute la haute Egypte qu'aux environs d'Alep; elles se nourrissent d'herhes aromatiques et de boutons d'arbrisseaux, surtout de ceux de l'arbre de sial, d'ambroisie, d'oseille sauvage, etc.; elles vont ordinairement par troupes ou plutôt par familles, c'est-à-dire cinc ou six ensemble : leur cri est semblable à celui des chèvres. On les chasse non seulement avec les chiens courants, aidés du faucon, mais aussi avec la petite panthère, que nous avons appelée once. Dans quelques endroits on prend les gazelles sauvages avec des gazelles apprivoisées, aux cornes desquelles on attache un piége de cordes.

Les antilopes, surtout les grandes, sont beaucoup plus communes en Afrique qu'aux Indes : elles sont plus fortes et plus farouches que les autres gazelles, 
desquelles il est aisé de les distinguer par la double flexion de leurs cornes, et parce qu'elles n'ont point de bande noire on brune au bas des flancs. Les antilopes moyennes sont de la grandeur et de la couleur du daim; elles ont les cornes fort noires, le ventre très blanc, les jambes de devant plus courtes que celles de derrière. On les trouve en grand nombre dans les contrées du Tremecen, du Duguela, du Tell, et du Zara. Elles sont propres, et ne se couchent que dans des endroits secs et nets. Elles sont aussi très légères à la course, très attentives au danger, très vigilantes, en sorte que dans les lieux découverts elles regardent long-temps de tous côtés; et dès qu'elles aperçoivent un homme, un chien, ou quelque autre ennemi, elles fuient de tontes leurs forces : cependant elles ont, avec cette timidité naturelle, une espèce de courage, car, lorsqu'elles sont surprises, elles s'arrêtent tout court et font face à ceux qui les attaquent.

En général les gazelles ont les yeux noirs, grands, très vifs, et en même temps si tendres, que les Orientaux en ont fait un proverbe, en comparant les beaux yeux d'une femme à ceux de la gazelle. Elles ont, pour la plupart, les jambes plus fines et plus déliées que le chevreuil; le poil aussi court, plus doux, et plus lustré : leurs jambes de devant sont moins longues que celles de derrière, ce qui leur donne, comme au lièvre, plus de facilité pour courir en montant qu'en descendant. Leur légèreté est au moins égale à celle du chevreuil; mais celui-ci bondit et saute plutôt qu'il ne court, au lieu que les gazelles courent uniformément plutôt qu'elles ne bondissent. 
La plupart sont fauves sur le dos, hlanches sous le ventre, avec une bande brune qui sépare ces deux coulenrs au bas des flancs. Leur queue est plus ou moins grande, mais toujours garnie de poils assez longs et noirâtres; leurs oreilles sont droites, longrues, assez ouvertes dans leur milieu, et se terminent en pointe. Toutes ont le pied fourchu et conformé à peu près comme celui des moutons : toutes ont, màles et femelles, des cornes permanentes, comme les chèvres; les cornes des femelles sont seulement plus minces et plus courtes que celles des mâles.

Voila toutes les connoissances que nous avons pu acquérir au sujet des différentes espèces de gazelles, et à peu près aussi tous les faits qui ont rapport à leur naturel et à leurs habitudes. Voyons maintenant si les naturalistes ont été fondés à n'attribuer qu'à un seul de ces animaux la production de la pierre fameuse qu'on appelle bंzoard oriental, et si cel animal est en effet le pasen on pasan qu'ils ont désigné spécifiquement par le nom de gazelle du bézourd. En examinant la description et les figures de Kæmpfer, qui a beaucoup écrit sur cette matière, on doutera si c'est la gazelle commune ou le pasan ou l'algazel qu'il a voulu désigner comme donnant exclusivement le vrai bézoard oriental. Si l'on consulte les autres naturalistes et les voyageurs, on seroit tenté de croire que ce sont indistinctement les gazelles, les chèvres sauvages, les chèvres domestiques, et même les moutons, qui portent cette pierre, dont probablement la formation dépend plus de la température du climat et de la qualité des herbes que de la nature et de l'espèce de l'animal. Si l'on vouloit en croire Rumphius, Seba, et quelques 
autres auteurs, le vrai bézoard oriental, celui qui a le plus d'excellence et de vertu, proviendroit des singes, et non pas des gazelles, des chèvres, ou des moutons; mais cette opinion de Rumphius et de Seba n'est pas fondée : nous avons vu plusieurs de ces concrétions auxquelles on donne le nom de bézoard des singes; et ces concrétions sont toutes différentes du bézoard oriental, qui vient certainement d'un animal ruminant, et qu'on peut aisément distinguer, par sa forme et par sa substance, de tous les autres bézoards : sa couleur est ordinairement d'un vert d'olive, brun en dehors et en dedans, et celle du bézoard qu'on appelle occidental est d'un petit jaune plus ou moins terne. La substance du premier est plus moelleuse et plus tendre; celle du dernier est plus dure, plus sèche, et, pour ainsi dire, plus pétrée. D'ailleurs, comme le bézoard oriental a eu une vogue prodigieuse, et qu'on en a fait une grande consommation dans les derniers siècles, puisqu'on s'en servoit en Europe et en Asie dans tous les cas où nos médecins emploient aujourd'hui les cordiaux et les contre-poisons, ne doit-on pas présumer, par cette grande quantité qu'on en a consominée, et que l'on consomme encore, que cette pierre vient d'un animal très commun, ou plutôt qu'elle ne vient pas d'une seule espèce d'animal, mais de plusieurs animaux, et qu'elle se tire également des gazelles, des chivres, et des moutons, mais que ces animaux ne peuvent la produire que dans de certains climats du Levant et des Indes?

Dans tout ce que l'on a écrit sur ce sujet, nous n'avons pas trouvé une observation bien faite ni une seule raison décisive : il paroît seulement par ce 
qu'ont dit Monard, Garcias, Clusius, Aldrovande, Hernandès, etc. , que le prétendu animal du bézoard oriental n'est pas la chèvre commune et domestique, mais une espèce de chèvre sauvage qu'ils n'ont point. caractérisée; de même tout ce que l'on peut conclure de ce qu'a écrit Kæmpfer, c'est que l'animal du bézoard est une espèce de chèvre sauvage, ou plutôt une espèce de gazelle, aussi très mal décrite : mais par les témoignages de Thévenot, Chardin, et Tavernier, il paroit que cette pierre se tire moins des gazelles que des moutons et des chèvres sauvages ou domestiques; et ce qui paroît donner plus de poids à ce que les voyageurs en disent, c'est qu'ils parlent comme témoins oculaires, et que, quoiqu'ils ne citent pas les gazelles au sujet du bézoard, il n'y a guère d'apparence qu'ils se soient trompés, et qu'ils les aient prises pour des chèvres, parce qu'ils les connoissoient bien, et qu'ils en font mention dans d'autres endroits de leurs relations. L'on ne doit donc pas assurer, comme l'ont fait nos naturalistes modernes, que le bézoard oriental vient particulièrement et exclusivement d'une certaine espèce de gazelle; et j'avoue qu'après avoir examiné non seulement les témoignages des auteurs, mais les faits mêmes qui pouvoient décider la question, je suis très porté à croire que celte pierre vient également de la plupart des animaux ruminants, mais plus communément des chèvres el des gazelles. Elle est, comme on sait, formée par couches concentriques, èt contient souvent au centre quelque matière étrangère. Nous avons recherché de quelle nature étoient ces matières qui servent de noyau au bézoard orien- 
tal, pour tâcher de juger en conséquence de l'espèce de l'animal qui les avoit avalées. On tronve au centre de ces pierres de petits cailloux, des noyaux de prunes, de mirobolans, de tamarins, des graines de cassie, et surtout des brins de paille et des boutons d'arbre : ainsi l'on ne peut gnère attribuer cette production qu'aux animaux qui broutent les herbes et les feuilles.

Nous croyons donc que le bézoard oriental ne vient pas d'un animal particulier, mais de plusieurs animaux différents, et il n'est pas difficile de concilier avec cetle opinion les témoignages de la plupart des voyageurs; car, en disant chacun des choses contraires, ils n'auront pas laissé de dire tous à peu près la vérité. Les anciens Grecs et Latins n’ont pas connu le bézoard 3 Galien est le premier qui fasse mention de ses vertus contre le venin; les Arabes ont beaucoup parlé de ces mêmes vertus du bézoard: mais ni les Grecs, ni les Latins, ni les Arabes, n'ont indiqué précisément les animaux qui le produisent. Rabi Moses, égyptien, dit seulement que quelques uns prétendent que cette pierre se forme dans l'angle des yeux, et d'autres dans la vésicule du fiel des moutons en Orient. Or il y a des bézoards ou concrétions qui se font en effet dans les angles des yeux et dans les larmiers des cerfs et de quelques autres animaux; mais ces concrétions sont très différentes du bézoard oriental, et les concrétions de la vésicule du fiel sont toutes d'une matière légère, huileuse, et inflammable, qui ne ressemble point à la substance du bézoard. André Lacuna, médecin espagnol, dans ses Commentaires sur Dioscoride, dit que le bézoard 
oriental se tire d'une espèce de chèvre sauvage dans les montagnes de Perse. Amatus Lusitanus répète ce que dit Lacuna, et ajoute que cette chèvre montagnarde est ressemblante au cerf. Monard, qui les cite lous trois, assure plus positivement que cette pierre se tire des parties intérieures d'une chèvre de montagne aux Indes, à laquelle, dit-il, j’ai cru devoir donner le nom de cervi-capra, parce qu'elle tient du cerf et de la chèvre, qu'elle est à peu près de la grandeur et de la forme du cerf, mais qu'elle a, comme les chèvres, des cornes simples et fort recourbées sur le dos. Garcias ab Horto (du Jardin) dit que dans le Corassan et en Perse il y a une espèce de boucs appelée pasan ${ }^{1}$, et que c'est dans l'estomac de ces boucs que s'engendre le bézoard oriental; que cette pierre se trouve non seulement en Perse, mais aussi à Malaca et dans lîle des Vaches, près le cap Comorin; que dans la grande quantité de boucs que l'on tuoit pour la subsistance des troupes, on cherchoit ces pierres dans l'estomac de ces animaux, et qu'on y en trouvoit assez communément. Christophe Acosta répète à ce sujet ce que disent Garcias et Monard, sans y rien ajouter de nouveau. Enfin, pour ne rien omettre de tout ce qui a rapport au détail historique de cette pierre, nous observerons que Kæmpfer, homme plus savant qu'observateur exact, s'étant trouvé dans la province de Laar en Perse, assure être allé avec des naturels du pays à la chasse du bouc pasan, qui produit le bézoard; qu'il dit en avoir,

1. Il nous paroît que Kæempfer a emprunté de Monard et de Garcias les noms de cervi-capra ou capri-cerva, et de pasan, qu'il domne à l'aniınal du bézoard oriental. 
pour ainsi dire, vu tirer celte pierre; et il assure encore que le vrai bézoard oriental vient de cet animal; qu’à la vérilé, le bouc ahu, dont il donne aussi la figure, produit dans ce même pays des bézoards, comme le bouc pasan, mais qu'ils sont fort inférieurs en qualité. Par les figures qu'il donne de ces deux animaux, le pasan et l'ahu, on seroit induit à croire que la première figure représente la gazelle commune plutôt que le vrai pasan; et par sa description on seroit porté à imaginer que son pasan est en effet un bouc et non pas une gazelle, parce qu'il lui donne une barbe semblable à celle des chèvres, et enfin par le nom ahu qu'il donne à son autre bouc, aussi bien que par la seconde figure, on seroit fondé à reconnoître le bouquetin plutôt que le véritable ahu, qui est notre tzeiran ou grosse gazelle. Ce qu'il y a dc plus singulier encore, c'est que Kæmpfer, qui semble vouloir décider l'espèce de cet animal du bézoard oriental, et qui assure que c'est le bouc sauvage appelé pasan, cite en même temps un homme qu'il dit très digne de foi, lequel cependant assure avoir palpé les pierres de ce même bézoard dans le ventre des gazelles à Golconde. Ainsi tout ce qu'on peut tirer de pusitif de ce qu'a écrit Kæmpfer à ce sujet se réduit à ce que ce sont deux espèces de chèvres sauvages et montagnardes, le pasan et l'ahu, qui portent le bézoard en Perse, et qu'aux Indes cette pierre se trouve aussi dans les gazelles. Chardin dit positivement que le bézoard oriental se trouve dans les boucs et chèvres sauvages et domestiques, le long du golfe Persique et dans plusieurs provinces de l'Inde; mais qu'en Perse on le trouve aussi dans les moutons. Les 
voyageurs hollandois disent de mêne qu'il se produit dans l'estomac des brebis ou des chèvres. Tavernier témoigne encore plus positivement que ce sont des chèvres domestiques; il dit qu'elles ont du poil fin comme de la soie, et qu'ayant acheté six de ces chèvres vivantes, il en avoit tiré dix-sept bézoards entiers et une portion grosse comme une moitié de noisette; et ensuite il dit qu'il y a d'autres bézoards que l'on croit venir des singes, dont les vertus sont encore plus grandes que celles du bézoard des chèvres; qu'on en lire aussi des vaches, mais dont les vertus sont inférieures, etc. Que doit-on inférer de cette variété d'opinions et de témoignages? qu'en peut-nn conclure, sinon que le bézoard oriental ne vient pás d'une seule espèce d'animal, mais qu'on le trouve au contraire dans plusieurs animaux d'espèces différentes, et surtout dans les gazelles et dans les chèvres?

A l'égard des bézoards occidentaux, nous pouvons assurer qu'ils ne viennent ni des chèvres ni des gazelles; car nous ferons voir dans les articles suivants qu'il n'y a ni chèvres, ni gazelles, ni même aucun animal qui approche de ce genre dans toute l'étendue du Nouveau-Monde : au lieu de gazelles l'on n'a trouvé que des chevreuils dans les bois de l'Amérique; au lieu de ehèvres et de moutons sauvages, on a trouvé sur les montagnes du Pérou et du Chili des animaux tout différents, les lamas et les pacos, dont nous avoris déjà parlé. Les anciens Péruviens n’avoient pas d'autre bétail; et en même temps que ces deux espèces étoient en parlie réduites à l'élat de domesticité, elles subsistoient en beaucoup plus grand nombre dans leur état de nature et de liberté sur les mon- 
tagnes : les lamas sauvages se nommoient huanacus, et les pacos, vicunnas, d'où l'on a dérivé le nom de vigogne, qui désigne en effet le mème animal que le pacos : tous deux, c'est-à-dire le lama et le pacos, produisent des bézoards, mais les domestiques plus rarement que les sauvages.

M. Daubenton, qui a examiné de plus près que personne la nature des bézoards, pense qu'ils sont composés d'une matière de même nature que celle qui s'altache en forme de tartre brillant et coloré surles dents des animaux ruminants. On verra dans la description qu'il a faite des bézoards, dont nous avons une collection très nombreuse au Cabinet du Roi, quelles sont les différences essentielles entre les bézoards orientaux et les bézoards occidentaux. Ainsiles chèvres des Indes orientales ou les gazelles de Perse ne sont pas les seuls animaux qui produisent des concrétions auxquelles on a donné le nom de bizoards : le chamois, et peut-être le bouquetin des Alpes, les boucs de Guinée, et plusieurs autres animaux d'Amérique, donnent aussi des bézoards; et si nous comprenons sous ce nom toutes les concrétions de cette nature que l'on trowve dans les animaux, nous pouvons assurer que la plupari des quadrupèdes, à l'exception des carnassiers, produisent des bézoards, et que même il s'en trouve dans les crocodiles et dans les grandes couleuvres.

Il faut donc, pour avoir une idée nette de ces concrétions, en faire plusieurs classes; il faut les rapporter aux animaux qui les produisent, et en même temps reconnoître les climats et les aliments qui favorisent le plus cette espèce de production. 
$1^{\circ}$ Les pierres qui se forment dans la vessie, dans les reins de l'homme et des autres animaux, doivent être séparées de la classe des bézoards, et désignées par le nom de calculs, leur substance élant tonte différente de celle desbézoards. On les reconnoît aisément à leur pesanteur, à leur odeur urineuse, et à leur composition, qui n'est pas régulière, ni par couches minces et concentriques, comme celle des bézoards.

$2^{\circ}$ Les concrétions que l'on trouve quelquelois dans la vésicule du fiel, et dans le foie de l'homme el des animaux, ne doivent pas ètre regardées comme des bézoards. On les distingue facilement à leur légèreté, leur couleur, et leur inflammabilité; cl d'ailleurs elles ne sont pas formées par couches autour d'un noyai, comme le sont les bézoards.

$3^{\circ}$ Les pelotes que l'on trouve assez souvent dans l'estomac des animaux, et surtout des ruminants, ne sont pas de vrais bézoards. Ces pelotes, que l'on appelle égagropiles, sont composées à lintérieur des poils que l'animal a avalés en se léchant, ou des racines dures qu'il a broutées et qu'il n'a pu digérer, et à l'extérieur elles sont, pour la plupart, enduites d'une substance visqueuse assez semblable à celle des bézoards : ainsi les égagropiles n’ont rien des bézoards que cette couche extérieure, et la seule inspection suffit pour distingruer les uns des autres.

$4^{\circ}$ On trouve souvent des égagropiles dans les animaux des climats tempérés, et jamais des bézoards. Nos bœuís et vaches, les chamois des Alpes, les porcsépics d'Italie ${ }^{1}$, ne produisent que des égagropiles.

1. Nous avons trouvé une égagropile dans nn pócéépic qqui nous a sté envoyé de Rone en 1765. 
Les animaux des pays les plus chauds ne donnent au contraire que des bézoards. L'éléphant, le rhinocéros, les boucs, les gazelles de l'Asie et de l'Afrique, le lama du Pérou, etc., produisent tous, au lieu d'égagropiles, des bézoards solides, dont la grosseur et la substance varient relativement à la différence des animaux et des climats.

5. Les bézoards auxquels on a trouvé ou suppsoé le plus de vertus et de propriétés sont les bézøards orientaux, lesquels, comme nous l'avous dit, proviennent des chèvres, des gazelles, et des moutons qui habitent sur les hautes montagnes de l'Asie; les bézoards d'une qualité inférieure, et qu'on appelle occidentaux, viennent des lamas et des pacos, qui ne se tronvent que clans les montagnes de l'Amérique méridionale; enfin les chèvres et les gazelles de l'A friquedonnent aussi des bézoards, mais qui ne sont pas si bons que ceux de l'Asie.

De tous ces laits, on peut conclure qu'en général les bézoards ne sont qu'un résidu de nourriture végétale, qui ne se trouve pas dans les animaux carnassiers, et qui ne se produit que dans ceux qui se nourrissent de plantes; que, dans les montagnes de l'Asie méridionale, les herbes étant plus fortes et plus exaltées qu'en aucun autre endroit du monde, les bézoards, qui en sont les résidus, ont aussi plus de qualité que tous les autres; qu'en Amérique, où la chaleur est moindre, les herbes des montagnes ayant aussi moins de force, les bézoards qui en proviennent sont inférieurs atix premiers, et qu'enfin en Europe, où les herbes sont foibles, et dans toutes tes plaines des deux continents oú elles sont grossièrès, il ne se produit point de bézoards, mais seulement 
des égagropiles qui ne contiennent que des poils ou des racines, et des filaments trop durs que l'animal n'a pu digérer.

Sur les Gazelles et les Antilopes.

* Depuis l'année 1 z64 que j’ai publié l'article des gazelles et des antilopes, quelques voyageurs naturalistes on reconnu, en Asie et en Afrique, de nouvelles espèces dans le genre de ces animaux, et ont donné des figures entières de quelques autres dont je n'avois pu donner que quelques parties détachées, comme les têtes, les cornes, etc. M. Pallas, docteur en médecine, de l'université de Leyde, a publié à Amsterdam en 1;6; un premier ouvrage sous le nom de Miscellanea zoologica; et peu de temps après il en a donné une seconde édition corrigée et imprimée à Berlin dans la mêne année, sous le titre de Spicilegia zoologica. Nous avons Iu ces deux ouvrages avec satisfaction; l'auteur y montre parlout autant de discernement que de connoissances, et nous donnerons l'extrait de ses observations.

D'autre part, MMI. Forster père et fils, qui ont accompagné M. Cook dans son second voyage, ont eu la bonté de me communiquer les remarques et observations qu'ils ont faites sur les chèvres du cap de Boune-Espérance, aussi bien que sur les lions marins, ours marins, etc., dont ils m'ont donné des figures très bien dessinées. J'ai reçu toutes ces instructions avec reconnoissance, et l'on verra que ces savants naturalistes m'ont été d'un grand secours pour perfectionner l'histoire de ces animaux. 
Enfin M. Allamand, que je regarde comme l'un des plus savants naturalistes de l'Europe, ayant pris soin de l'édition qui se fait en Hollande de mes ouvrages, $\mathrm{y}$ a joint d'excellentes remarques et de très bonnes descriptions de quelques animanx que je n'ai pas été à portée de voir. Je réunis ici toutes ces nouvelles connoissances qui m’ont été communiquées, et je les joins à celles que j’ai acquises par moi-même depuis l'année 1764 jusqu'en 1780 .

M. Pallas impose aux gazelies et aux chèvres sauvages le nom générique d'untilopes, et il dit que les zoologistes méthodistes ont eu tort de joindre le genre des gazelles à celui des chèvres, et qu'il en est plus éloigné que du genre des brebis. La nature, seIon lui, a placé le genre des gazelles entre celui des cerfs et celui des chèvres. Au reste; il convient avec moi, dans son second ouvrage, que les gazelles ne se trouvent ni en Europe, ni en Amérique, mais seulement en Asie, et surtout en Afrique, où les espèces en sont très variées et fort nombreuses. Le chamois est, dit-il, le seul animal qu'on pourroit regarder comme une gazelle européenne, et le bouquetin semble faire la nuance entre les chèvres et certaines espèces de gazelles. L'animal du musc, ajoute-t-il, et les chevrotains, ne doivent point être rangés avec les gazelles, mais peuvent aller ensemble, parce que les uns el les autres, dans les deux sexes, manquent de cornes, et ont de grandes dents ou défenses dans la mâchoire supérieure.

Cie que je rapporte ici d'après $M$. Pallas souffre quelques exceptions; car il y a une espèce de chevrolain dont le mâle a des cornes, et le chamois, 
qu'il prétend être du genre des gazelles et non de celui des chèvres, s'unit néanmoins avec les chèvres; on les a souvent vus s'accoupler, et l'on nous a même assuré qu'ils avoient produit ensemble. Le premier fait est certain, et suffit seul pour démontrer que le chamois est non seulement du même genre, mais d'espèce très voisine de celle de la chèvre commune.

Eı d'ailleurs le genre des chèvres et celui des brebis sont si voisins, qu'on peut les faire produire ensemble, comme j'en ai donné des exemples: ainsi l'on ne peut guère admeltre un genre intermédiaire entre eux; de même que l'on ne doit pas dire que les gazelles, dont les cornes sont permanentes dans toutes les espèces, soient voisines du genre des chevreuils ou des cerfs, dont les bois tombent et se renouvellent chaque année. Nous ne nous arrêterons donc pas plus long-temps sur cette discussion méthodique de M. Pallas, et nous passerons aux observations nouvelles que nous avons faites sur chacun de ces animaux en particulier.

\section{Sur le Nanguer et le Nagor.}

Nous mettons ces deux animaux ensemble, parce qu'ils ont un caractère commun, qui n'appartient qu'à eux ; c'est d'avoir les cornes recourbées en avant, au lieu que, dans toutes les autres espèces de gazelles et de chèvres, les cornes sont recourbées en arrière ou tout-d-fait droites. J'ai dit, d'après M. Adanson, qu'il y avoit trois variétés ou trois espèces de ces animaux, dont la première, c'est-à-dire le nanguer, paroît être le dama des anciens. M. Pallas est du mêtne avis: il 
dit que la femelle et le mâle nanguer ont également des cornes; et il a remąrqué, comme dans le kob, une disposition singulière dans les dents ${ }^{1}$.

La seconde espèce est le nagor. M. Pallas avoit écrit dans son premier ouvrage (Micellanea) que cet animal étoit le mazame de Seba : mais il avoue dans son second ouvrage (Spicilegia) qu’il s'étoit trompé; et il convient avec moi que ce n'est point le, mazame d'Anérique, mais une gazelle d'Afrique.

Au reste, l'espèce du nanguer paroît être isolée et sans variété; mais celle du nagor a des espèces voisines, dont je dois la connoissance à MM. Forster : ils ont bien voulu me donner le dessin de la tête d'une de ces variétés du nagor du cap de Bonne-Espérance, qui me paroît différer du nagor en ce que ce nagor du Cap a le museau un peu éffilé, et les cornes un peu moins courbées en avant que le nagor du Sénégal. Voici les notices qu'ils m’ont données à ce sujet.

"La chèvre que l'on appelle steenbok ou bouquetin au cap de Bonne-Lspérance nous paroît être une variété du nagor donné par M. de Buffon. On trouve ces animaux sur les rochers qui font la pointe des terres du cap de Bonne-Espérance, et sur les plateanx de ces montagnes pierreuses parmi les broussailles. Ils courent avec une très grande vitesse, et font des sauts de huit à neuf pieds de hauteur; comme

1. a Solum hujus arimalis caput cum cornibus vidi, e quo dentium " primorum in inferiore maxilla numerum plane singularem esse di- dici : habet enim tantum senos, quorum duo medii latissimi, subobli- qui, recta transversa acie terminantur; laterales vero parvi, lineares "sunt. "(Pallas. Spicilegic zoologica, pag. 8.) 
leur chair est très bonne à manger, on les chasse sans cesse, et l'on en a beaucoup détruit.

- Cet animal est de la grandeur d'une chèvre commune, d'environ deux pieds six pouces de hauteur. Son poil est rouge brun sur le dos et les côtés du corps, et d'un blanc sale sous le ventre; il y a au dessus des yeux, sous le cou et sur les fesses, une tache de cette dernière couleur blanc sale : le poil des oreilles est fauve; elles sont arrondies à leurs extrémités. On voit sous chaque œil un larmier avec un petit orifice. Les cornes n'ont que cinq ou six pouces de longueur; elles sont noires, ridées à la base, lisses à la pointe, extrêmement effilées et courbées en avant. La queue est courte, à peu près comme celle des chèvres ordinaires.

"Une autre espèce ou variété du nagor, est l'animal que l'on appelle au Cap grysbok on chèvre grise; elle diffère du steenbok par la couleur de son poil, qui est gris, ạ lieu que celui du steenbok est rouge brun. Ce grysbok est une seconde espèce de nagor; il est de la grandeur d'une chèvre commune, et il a les jambes plus longues que le steenbok à proportion du corps. Son poil ne paroît gris que parce qu'il est mêlé de longs poils blancs; car en voyant l'animal de près, on s'aperçoit que le fond est d'un brun roussâtre ou marron: la tête et les pieds sont d'un brun plus clair que le corps, et le ventre est d'une couleur encore moins foncée; le museau est noir ; les yeux sont environnés de poils de cette même couleur noire. Il y a, comme dans les autres chèvres, des larmiers sous les angles antérieurs des yeux. Les oreilles sont à peu. près de même longueur que la lête; clles sont de 
forme ovale, et couvertes en dehors de poils courts et noirs. Les cornes ont environ cinq pouces de longueur; elles sont ridées d'un ou deux anneaux à la base, lisses vers la pointe, qui est très aiguë, courbées en avant, et de couleur noire.

„Cette espèce de nagor se trouve toujours dans les plateaux au dessus des montagnes parmi les rochers, les broussailles et la bruyère. Il n'est pas si léger à la course que le steenbock, car les chiens l'atteignent quelquefois à la chasse. Sa chair est aussi bonne à manger que celle du steenbock, et on les trouve quelquefois ensemble sur les montagnes du cap de Bonne-Espérance.

-Une troisième espèce de nagor est le bleclibok ou chèvre pale, qui ressemble presque en tout au steenbok, à l'exception de la couleur du poil, qui est beaucoup plus pâle; ce qui lui a fait donner son nom."

En comparant ces trois animaux d'après les notices que nous venons de citer, il me paroît qu'il n'y a tout au plus que deux espèces distinctes, c'est-à-dire le nagor steenbok et-le nagor grysbok, et que le bleekbok n'est qu'une variété du premier.

\section{Sur le Kevel.}

M. Pallas ue paroît se tromper en avançant que le kevel et la corine ne sont pas deux espèces différentes, mais le mâle et la femelle dans la même espéce de gazelle : s'il eût fait attention que j'ai décrit les deux sexes, ce savant nailuraliste ne seroit pas tombó dans celte méprise. 


\section{Sur le Koba et le Kob.}

J'ai donné, d'après M. Adanson, le nom de koba à un animal d'Afrique que quelques voyageurs ont appelé grande vache brune, et dont l'espèce n'est pas éloignée de celle du bubale. J'ai donné de même le nom de kob à un animal un peu moins grand, et que les voyageurs ont appelé petite vache brune. Le koba est grand comme un cerf, et par conséquent approche de la grandeur du bubale, tandis que le kobn'est pas tout-à-fait si grand qu'un daim. M. Pallas dit'que, de toutes les antilopes, celle-ci lui paroît être liı plus voisine du genre des cerfs, le pelage étant semblable. Nous avons donné la figure des cornes du kob : elles ont à peu près un pied de longueur; ce qui ne s'accorde pas avec ce que dit M. Pallas, qui ne leurdomne qu'un demi-pied : et ce qui me paroît démontrer que M. Pallas n'avoit pris cette mesure des cornes que sur un jeune individu, c'est que M. Forster m'a écrit qu'il avoit rapporté du cap de Bonne-Espérance des cornes de cet animal kob, de même grandeur, et toutes semblables à celles que j’ai fait représenter. II dit que cet animal avoit une tache triangulaire blanche au bas des cornes, que son pelage est en général d'un rouge brun; el il pense, comme moi, que le kob n'est qu'une variété du koba, et que tous deux ne s'éloignent pas de l'espèce du bubale. 


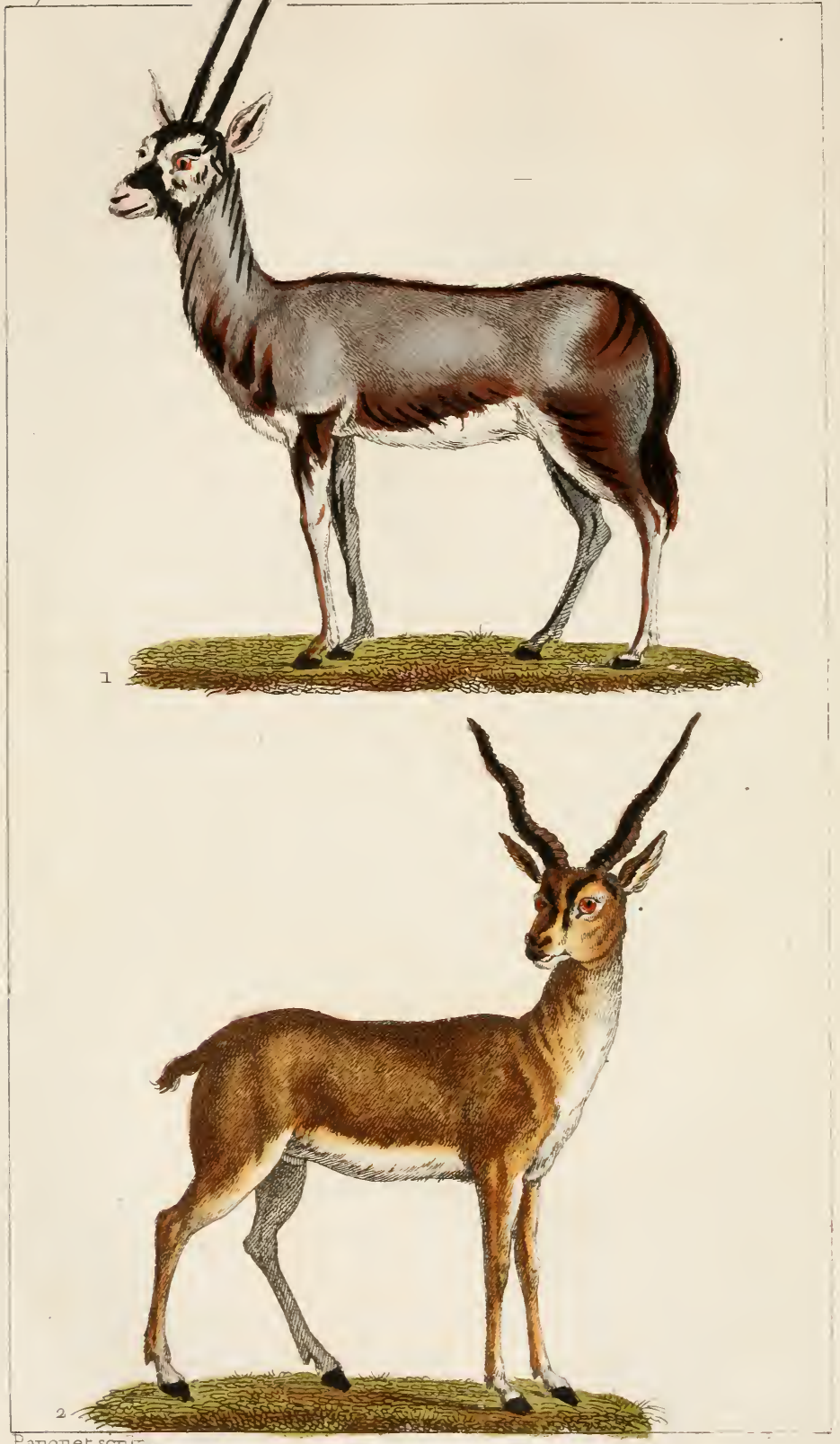

Parquet,sctip

1.IA GAZEILEPASAN - 2.IA GAZEIIE ANTIIOPE 


\section{LA GAZELLE PASAN.}

Antilope Oryz. Palc.

JE donne ici, d'après une peau bourrée, la figure de la gazelle pasan, dont j'ai parlé, et de laquelle nous n'avons au Cabinet du Roi qu'un crâne surmonté de ses cornes, dont $j$ 'a fait graver la figure. M. Pallas pense avec moi que le pasan et l'algazel ne sont que deux variétés de la même espèce. J'ai dit que ces deux espèces, l'algazel et le pasan, me paroissent très voisines l'une de l'autre, qu'elles sont des mêmes climats, mais que néanmoins l'algazel n'habite guère que dans les plaines, et le pasan dans les montagnes; c'est par cette seule différence des habitudes naturelles que j'ai cru qu'on pouvoit en faire deux espèces. J'ai même dit positivement que je présumois que l'algazel et le pasan n’étoient que deux variétés de la même espèce, et j'ai été fort satisfait de voir que M. Pallas est du même sentiment. Il dit, au sujet de ce dernier animal, que M. Houttuyn en a aussi donné une figure d'après les tableaux de M. Burman; mais je n'ai pas eu occasion de voir ces tableaux, et j’ignore si celui du pasan ressemble ou non à la figure que je donne ici.

- MM. Forster m'ont écrit que la gazelle pasan porte aussi le nom de chamois du Cap, et celui de chèvre du bézoard, quoiqu'il y ait une autre chèvre du bézoard 
en Orient, dont M. Gmelin le jeune a donné une description sous le nom de paseng, qui est différente du pasan. Il ajoute que dans la femelle les cornes ne sont pas aussi grandes que dans le mâle; que ces cornes sont marquées vers leur origine d'une large bande noire en demi-cercle, qui s'étend jusqu’à une autre grande tache de même conleur noire, laquelle couvre en partie le museau, dont l'extrémité est grise; que de plusil y a deux bandes noires qui partent du inuseau et s'étendent jusqu'aux cornes, et une ligne noire le long du dos, qui se termine au croupion et y forme une plaque triangulaire; qu'on voit aussi une bande noire entre la jambe et la cuisse de devant; et une tache ovale de même couleur sur le genou; que les pieds de derrière sont aussi marqués d'une tache noire sous la jointure, et qu'il y a une ligne noire de longs poils le long du cou, au dessous duquel se trouve une espèce de fanon qui tombe sur la poitrine; qu'enfin le reste du corps est gris, à l'exception du ventre, qui est blanchâtre, ainsi que les pieds.

Cet animal, dit M. Forster, a près de quatre pieds de hauteur, en le mesurant aux jambes de devant; les cornes ont jusqu’à trois pieds de longueur. Ces gazelles ne vont point en troupes, mais seulement par paires, et il me semble que c'est le même animal que le $p a-$ rasol du Congo, dont parle le P. Charles de Plaisance. 


\section{LA GAZELLE ANTILOPE.}

Antilope Cervi-cupra. Pall.

M. Pallas observe, avec grande raison, qu'il y a des animaux, surtout dans le genre des chèvres sauvages et des gazelles, dont les noms donnés par les anciens demeureront éternellement équivoques; celui de cervi-capra que j'ai dit être le même animal que le strepsiceros des Grecs ou l'adax des Africains, doit être appliqué, suivant M. Pallas, à la gazelle que j'ai nommée l'antilope. Il dit, c'est la vérité, qu'Aldrovande a donné le premier une bonne figure des cornes; et nous avons donné non seulement les cornes, mais le squelette entier de cet anima!. Je pensois alors qu'il étoit l'un des cinq que MM. de l'Académie des Sciences avoient disséqués sous le nom de gazelle; mais M. Pallas me fournit de bonnes raisons d'en douter. J'avois cru de même que la corne dessinée ${ }^{1}$ pouvoit appartenir à une espèce différente de notre antilope; mais M. Pallas s'est assuré qu'elle appartient à cette espèce, et que la seule différence qu’il y ait, c'est que la corne représenlée appartient à l'animal adulte, tandis que les autres plus petites sont du même animal jeune.

J'ai dit que l'espèce de l'antilope paroissoit avoir

1. Tome XII in $-4^{\circ}$ de l'edition avec la partic anatomique. 
des races différentes entre elles, et j’ai insinué qu'elle se trouvoit non sculement en Asie, mais en Afrique, et surtout ein Barbarie, où elle porte le nom de lidméc. NI. Pallas dit la même chose, et il ajoute à plusieurs faits historiques une bonne description de cet animal, dont nous croyons devoir donner ici l'extrait.

"J'ai eu occasion, dit-il, d'examiner et de bien décrire ces animaux qui vivent depuis dix ans dans la ménagerie de monseigneur le prince d'Orange, lesquels, quoique amenés de Bengale en 1755 on 1756 , non seulement ont vécu, mais ont multiplié dans le climat de la Hollande; on les garde avec les axis on daims mouchetés; ils vivent en paix et y élèvent égalementleurs petits.

Le premier mâle étoit déjà vieux lors de son arrivée, et la femelle étoit adulte. Ce màle est mort en 1766 : mais la femelle étoit encore vivante aiors; et, quoiqu'elle fût âgée de plus de dix ans, elle avoit mis bas l'année précédente 1765 . Le mâle, qui étoit très sauvage, ne s'est janais apprivoisé. La femelle, au contraire, est très familière : on la fait aisément. approcher et suivre en lui présentant du pain; elle se lève comme les axis sur les pieds de derrière, pour y atteindre lorsqu'on le lui présente trop haut : cependant elle se fâche aisément dès qu'on la tourmente, elle donne même des coups de tête comme un belier; on voit alors sa peau et son poil frémir. Les jeunes, à l'exemple du père, sont sauvages et fuient lorsqu'on veut les approcher; ils vont en troupes, marchant d'abord assez doucement, ensuite par petits sauts; et quand ils précipitent leur fuite, ils bondissent et font des sauts qu'on ne peut comparer 
qu'à ceux du cerf ou du chamois. Je n'ai jamais entendu leur voix ; cependant les gardes de la ménagerie déposent que, dans le temps du rut, les mâles ont une espèce de hennissement. On les nourrit comme les autres animaux ruminants, et ils supportent assez bien nos hivers : ils aiment la propreté, car la troupe entière choisit un terrain pour aller faire ses ordures. Le temps de la chaleur des femelles n'est pas fixe; elles sont quelquefois pleines deux mois après avoir mis bas : les mâles en usent en toutes saisons, ils ne s'en abstiennent que quand elles sont pleines. L'accouplement ne dure que très pet de temps. Ia femelle porte près de neuf mois, ne produit qu'un petit qu'elle allaite, sans se refuser à en allaiter d'autres. Les petits restent couchés pendant huit jours après leur naissance, après quoi ils accompagnent la troupe. Les jeunes femelles suivent les mères lorsqu'elles se séparent de la troupe.... Ces animaux croissent pendant trois ans, et ce n'est guère qu'à cet âge que les mâles sont en état d'engendrer : les femelles sont mûres de meilleure heure, et peuvent produire à deux ans d'âge. Dans les six premières années, il y a peu de différence entre les mâles et les femelles; mais ensuite les femelles se distinguent aisément par une bande blanche sur les flaucs près du dos, par un caractère encore moins équivoque, c'est qu'il ne leur vient jamais de cornes sur la tête, tandis que, dans le mâle, on peut apercevoir les rudiments des cornes dès l'âge de sept mois, et ces cornes forment deux tours de vis, avec dix ou douze rides à l'âge de trois ans : c'est alors aussi que les bandes blanches du dos et de la tête commencent ì 
s'évanouir; la couleur des épaules et du dos noircit, et le dessus du coa devient jaune : ces mêmes couleurs prennent une teinte plus foncée à mesure que l'animal avance en âge.... Les cornes croissent bien lentement.... Cies animaux, surtout après leur mort, ont une légère odeur, qui n'est pas désagréable, et qui est pareille à celle que les cerfs et les daims exhalent aussi après leur mort.... Au reste, cet animal approche de l'espèce que M. de Buffon a appelée la gazelle, par la couleur noire des côtés du cou et du corps, par les touffes de poil au dessous des genoux dans les jambes de devant; elle approche du tzeiran et de la grimme de M. de Buffon, parce que les femelles n'ont de cornes dans aucune de ces trois espèces : mais elle diffère en général de toutes les autres gazelles en ce qu'il n'y a aucune espèce où le mâle et la femelle, devenus adultes, soient de couleurs aussi différentes que dans celle-ci."

M. Pallas donne en même temps les figures du mâle et de la femelle en deux planches séparées qui mont paru très bonnes. Voici encore quelques remarques de M. Pallas sur les parlies extérieures de cet animal.

- Il est à peu près de la même figure de notre dain d'Europe; cependant il en diffère par la forme de la tête, et lui cède en grandeur. Les narines sont ouvertes : la cloisón qui les sépare est épaisse, nue, et noire... Les poils du menton sont blancs, et le tour de la bouche brun; la langue est plane et arrondie : les dents de devant sont au nombre de huit; celles du milieu sont fort larges et bien tranchantes, et celles des côtés plus aiguës... Les yeux sont environnés 
d'une aire blanche, et l'iris est d'un brun jaunâtre; il y a une raie blanche au devant des yeux, au commencement de laquelle se trouvent les narines. Les oreilles sont assez grandes, nues en dedans, bordées de poils blanes, et couvertes en dehors d'un poil de la même couleur que celui de la tête... Les jambes sont longues et menues, mais celles de derrière sont un peu plus hautes que celles de devant: les sabots sont noirs, pointus, et assez serrés l'un contre l'autre. La queue est plate et nue par dessous vers l'origine. La verge du mâle est appliquée longitudinalement sous le ventre : le scrotum est si serré entre les cuisses, que l'un des testicules est devant et l'autre derrière. Le poil est très fort et très roide au dessus du cou et au commencement du dos; il est blanc comme neige sur le ventre et au dedans descuisses el des jambes, ainsi qu'au bout de la queue. '"

\section{LA GAZELLE TZEIRAN.}

Antilope Leucophca. Gmes.

M. Pallas remarque, avec raison, que MM. Houltuyn et Linnæus ont eu tort de nommer cervi-capra cette gazelle, d'autant plus qu'ils citeni en même temps les figures du cervi-capra de Dodard et de Jonston, qui sont très différentes de celle de notre tzeiran : mais M. Pallas auroit ılû adopter le nom tzeiran que cette gazelle porte dans son pays natal, et l'on ne voit pas pourquoi il a préféré de lui donner celui BUFFUN, XVII. 
de pygargus. Il a jugé par la grandeur des peaux que cet animal est plus grand que le daim : la description qu'il en donne ajoute peu de chose à ce que nous en avons dit, et la signification du mot pygargus ne peut pas distinguer cette gazelle du chevreuil, ni même de quelques autres gazelles qui ont une grande tache blanche au dessus de la queue.

MM. Forster père et fils m'ont donné sur cet animal les notices suivantes.

"Jusqu'ici on ignore, disent-ils, s'il y a des tzeirans en Afrique, et il paroît qu'ils affectent le milieu de l'Asie. On les trouve en Turquie, en Perse, en Sibérie, dans le voisinage du lac Baikal, en Daourie, et ì la Chine. M. Pallas décrit une chasse à l'arc avec des flèches très lourdes, qu'un grand nombre de chasseurs décochent à la fois sur ces animaux qui vont en troupes. Quoiqu'ils passent l'eau à la nage de leur propre mouvement, et pour aller chercher leur pâture au delà d'une rivière, cependant ils ne s'y jettent pas lorsqu'ils sont poursuivis et pressés par les chiens et par les hommes; ils ne s'enfuient pas même dans les forèts voisines, et préfèrent d'attendre leurs ennemis. Les femelles entrent en chaleur à la fin de l'automne, et mettent bas au mois de juin. Les mâles ont sous le veutre, aux environs du prépuce, un sac ovale qui est assez grand, et dans lequel est un orifice particulier : ces sacs ressemblent à la poche du musc; mais ils sont vides, et ce ne peut être que dans la saison des amours qu'il s'y produit quelque matière par sécrétion. Ce sont aussi les mâles qui ont des proíminences au larynx, lesquelles grossissent à mesure que les cornes prennent de l'accroissement. On prend 
quelquefois des faons de tzeiran qui s'apprivoisent tellement qu'on les laisse aller se repaître aux champs, et qu'ils reviennent régulièrement le soir à l'étable. Lorsqu'ils sont apprivoisés, ils prennent en affection leur maitre. Ils vont en troupes dans leur état de liberté, el quelquefois ces troupes de tzeirans sauvages se mêlent avec des troupeaux de bœuls et de veaux ou d'autres animaux domestiques; mais ils prennent la fuite à la vue de l'homme. Ils sont de la couleur et de la grandeur du chevreuil, et plus roux que fauves. Les cornes sont noires, un peu comprimées en bas, ridées d'anneaux et courbées en arrière, de la longueur d'un pied. La femelle ne porte point de cornes."

Je vais ajouter à ces notices de MII. Forster la description et la figure du tzeiran que M. le professeur Allamand a publiées dans l'édition faite en Hollande de mes ouvrages sur l'histoire naturelle.

"On a vu, dit ce savant naturaliste, dans l'article où j’ai parlé du pasan, que je doutois fort que l'anjmal auquel j’ai donné ce nom fût celui qu'on appelle ainsi daus l'Orient; cependant je lui ai conservé ce nom, parce que c'est vraisemblablement le même que le pasan de M. de Buffon. Une semblable raison m'engage à nommer tzeiran l'animal qui est représenté (planche LxIII ${ }^{1}$ ). Par un heureux hasard, mais qui ne se présente qu'à ceux qui méritent d'en être favorisés, M. le docteur Klockner en a découvert la dépouille dans la boutique d'un marchand. Ses cornes sont les mêmes que celles que M. de Buffon a

2. Tome IV du supplément, édition de Hollande. 
trouvées dans le Cabinet du Roi, et qu’ii a jugé appartenir à une gazelle que les Tures appellent tzeiran, et les Persans ahu. Il en a porté ce jugement à cause de sa ressemblance avec les cornes que Kæmpfer : données à son tzeiran dans la figure qu'il en a fait graver; mais celte figure est si mauvaise, qu'on ne pent guère se former une idée de l'animal qu'elle doit représenter; et d'ailleurs, conme M. de Buffon l'a remarqué, elle ne s'accorde point avec la descriplion que Kæmpfer en a donnée, et même dans la planche on tronve le nom d'ahu sous la figure de l'animal qui dans le texte porte le nom de pasan, et celui de pasan sous la figure du tzeiran. Si le tzeiran de cet auteur est, comme M. de Buflon paroît le supposer, le même auimal que M. Gmelin a décrit dans ses Voyıges en Sibérie, et qu'il a appelé dsheren, et dont il a donné la figure dans les Nouveaux Actes de l'académic de Saint-Pétersbourg, sous le nom de caprea campestris gutturosa, il est encore plus douteux que la corne trouvée dans le Cabinet du Roi lui appartienne; car elle ne ressemble aucunoment à celle que porte le dsheren de M. Gmelin, si au moins on peut compter sur la figure qu'il en a publiéc, et qui le représente avec de courtes cornes de gazelle, tandis que, dans le texte, il est dit qu'elles sont semblables ì celles du bouquetin.

"M. Pallas nomme le Izeiran antilope pygargus, et il lui donne des cornes pareilles à celles que M. de Buffon lui suppose, puisqu'il renvoie à la figure qu'il en a publiće; et cependant dans la description quil en a faite, il dit que ces cornes sont recourbées en forme de lyre, et plus petites à proportion que celles 
de la gazelle : or il n'y a qu'à jeter les yeux sur la figure qu'ii cite, pour se convaincre qu'elle représente une corne très différente de celle qu'il décrit.

n Je ne déciderai point si l'animal dont je vais parler est le véritable tzeiran de Krmpfer ou non : pour lui en conserver le nom, il me suffit qu'il ait des cornes semblables à celles que M. de Buffon lui attribue; l'on n'en dontera pas si l'on compare la corne, quoique tronquée, qui est représentée, avec cclles que porte noire tzeiran; elles sont annelées de même, et quelques uns de leurs anneaux se partagent en forme de fourche; leur courbure est aussi semblable, et leur grosseur ne paroît pas différer, non plus que leur longueur, comme on le verra en comparant les dimensions que nous en donnerons, avec celles que M. Daubenton en a rapportées. Je n'oserai pas en dire autant de la corne qui est gravée dans Aldrovande, liv. I, de bisulcis, page 757 . Les anneaux de celle-ci me semblent ètre différents, aussi bien que sa longueur, sa grosseur, et sa courbure : cependant ce n'est pas sans raison que M. de Buffon croit que c'est la même que celle qu'il donne au tzeiran. Cet animal est rangé par Kæmpfer parmi ceux qui portent des bézoards, et Aldrovande a fait représenter cette corne dans le chapitre où il est question de ces animaux.

"J'ai déjà remarqué que c'est à M. le docteur Klockner que l'on doit la découverte de notre tzei-ran; et c'est à lui aussi que l'on est redevable de la description que j'en vais faire. II en a préparé la peau avec beaucoup de soin, et elle est actuellement un des principaux ornements du riche cabinet d'histoire 
naturelle que feu M. J. C. Sylvius van Lennep, conseiller et échevin de la ville de Harlem, a laissé par testament à la société hollandoise des sciences établie dans ladite ville. Celui de qui il acheta cette peau ne put lui dire de quel endroit ellẹ avoit été envoyée; mais la manière dont elle éloil empaquetée, et quelques autres circonstances, lui firent juger qu'elle venoit du Cap.

"Cet animal a la grandenr et la figure d'un cerf; mais son front avance plus en devant : sa couleur est d'un gris blanchâtre, où se trouvent quelques poils tirant sur le noir; sous le ventre, il esst tout-à-fait blanc; la tête est d'un gris plus sombre, et au devant des yeux il y a une large tache d'un blanc pâle qui descend, en devenant moins large, presque jusqu'au coin de la bouche. Ses cornes forment un arc de cercle, mais dont la courbure est plus forte que celle de la corne qui est représentée dans la figure 6 du tome XII ; elles sont noires et creuses; elles sont environnées d'anneaux circulaires jusqu'aux trois quarts de leur longueur, et ces anneaux sont plus éminents du côté intérieur que du côté opposé; le reste de ces cornes est fort lisse, et se termine en une pointe très aiguë.

"Les oreilles sont pointues, et d'une longueur remarquable à proportion de la tête.

"Le cou ressemble à celui d'un cerf, mais il est un peu plus mince. Les poils qui le couvrent, tant en dessus qu'en dessous. sont singulièrement arrangés : sur une moitié ils sont dirigés vers en bas, et sur l'autre moitié ils sont tournés vers en haut. Un pareil arrangement a lieu sur le dos : sur la partie anté- 
rieure les poils sont dirigés vers la tête; et sur la partie postérieure jusqu'à la queue, ils sont placés en sens contraire, et ils sont d'une couleur plus sombre : de còté et d'autre du cou on voit des places de la grandeur d'un écu, où les poils sont disposés en rond, et semblent partir d'un centre, comme autant de rayons dirigés un peu obliquement vers la circonférence d'un cercle.

"La quene est plus longue que dans la plupart des animaux de ce genre, et elle est terminée par une touffe de poils.

"Les jambes ressemblent à celles d'un cerf, mais elles n'ont point de brosses de poils sur le genon; celles de devant sont tant soit peu plus courtes que celles de derrière; au lieu d'ergots au dessus des talons, il y a une simple éminence ou bouton.

"En général, cet animal se rapproche plus de la race des boucs que de toute autre espèce : si c'est le tzeiran de Kæmpfer, sa femelle n'a point de cornes, ou n'en a que de très petites. On se formera des idées plus justes de sa grandeur par les dimensions que M. Klockner en a prises."

Longueur du corps mesurée le long du dos, depuis

le bout da museau jusqu'à la queue. . . . . . 5 5 10 8

Hauleur du train de devant. . . . . . . $3 \quad 6 \quad 6 \quad 9$

Hauteur du train de derrière. ...... $3: 7: 8$

Longueur de la tête, depuis le commencement du

nez jusqu'aux cornes. ..........

Longueur de la tête jusqu'aux oreilles. . . . . . I

Longueur des oreilles............ 8

Longueui des cornes prise en suivant leur cour-

bure...................... 2

Contour des cornes près de la tête. . . . . . 6467

Circonférence du corps derrière les jambes de de- 
vant..................... 4 " 5

Circonférence du milieu du corps. . . . . 4 4 2 6

Circonférence devant les jambes de derrière.. . . $\begin{array}{llll}4 & 3 & 4\end{array}$

Hauteur des jambes de devant, depuis la plante du

pied jusquà la poitrine. . . . . . . 1 1 1 \& 8

Hauteur des jambes de derrière. . . . . . . . 2 3 ,

Longueur de la queue. ........... 95

Longueur de la touffe de poils qui est au bout de

la queue.................... 33

\section{LA GHÈVRE SAUTANTE}

\section{DU CAP DE BON NE-ESPERANCE。}

Antilope Euchore. Forster.

Nous donnons ici la description de cet animal d'après un dessin qui m’a été communiqué par M. Forsterr, et qu'il a fait d'après nature vivante. Il me paroît qu'on doit le rapporter au genre des gazelles plutôt qu'à celui des chèvres, quoiqu'on l'ait appelée chèvre sautante. L'espèce de ces gazelles est si nombreuse dans les terres du Cap, où M. Forster les a vues, qu'elles arrivent quelquefois par milliers, surtout dans de certains temps de l'année, où elles passent d'une contrée à l'autre. II m'a assuré qu'ayant vu, pendant son séjour en Afrique, un grand nombre de gazelles de plusieurs espèces, il a reconnu que la forme el la direction des cornes n'est pas un caractère bien constant, et que, dans la même espèce, on trouve des 


$$
\frac{n}{2}
$$



indivldus dont les cornes sont de différente grandeur et contournées différemment.

Au reste, il paroît que, dans les terres du cap de Bonne-Espérance, il se trouve deux espèces de ces gazelles ou chèvres sautantes; car on m'a donné un dessin que j'ai fait graver, dont l'animal porte le nom de klippspringer (sauteur de rochers), et dont nous parlerons dans l'article suivant. En comparant sa figure avec celle de la chèvre sautante, on voit que ce sauteur de rochers a les cornes plus droites et moins longues; la queue beaucoup plus courte; le pelage plus gris, plus uniforme que la chèvre sautante : ces différences me paroissent plus que suffisantes pour en faire deux espèces distinctes.

Voici les observations que $\mathbf{M}$. Forster a faites sur la première espèce de ces chèvres sautantes, qui jusqu'ici n'étoit pas bien connue.

"Les Hollandois du cap de Bonne-Espérance appellent, dit-il, ces animaux springbok (chèvres sautantes). Elles habitent les terres intérieures de l'Afrique, et n'approchent les colonies du Cap que lorsque la grande sécheresse, ou le manque d'eau et d'herhage, les force de changer de lieu; mais c'est alors qu'on en voit des troupes depuis dix mille jusqu'à cinquante mille, quoiqu'elles soient toujours accompagnées ou suivies par les lions, les onces, les léopards, et les byènes qu'on appelle au Cap chiens sauvages, qui en dévorent une grande quantité. L'avantgarde de la troupe, en s'approchant des habitations, a de l'embonpoint; le corps d'armée est en moins bonne chair, et l'arrière-garde est fort maigre et mourant de faim, mangeant jusqu'aux racines des plantes 
dans ces terrains pierreux : mais en s'en retournant, l'arrière-garde devient à son tour plus grasse, parce qu'elle part la première; et l'avant-garde, qui alors se trouve la dernière, devient plus maigre. Au reste, ces chèvres ne sont point peureuses lorsqu'elles sont ainsi rassemblées, et ce n'est même qu'à coups de fouet ou de bâton qu'un homme peut passer à travers leur troupe. En les prenant jeunes, elles s'apprivoisent aisément; on peut les nourrir de lait, de pain, de blé, de feuilles de choux, etc. Les mâles sont assez pétulants et méchants même en domesticité, et ils donnent des coups de cornes aux personnes qu'ils ne connoissent pas; lorsqu'on leur jette des pierres, ils se mettent en posture de défense, et parent souvent le coup de pierre avec les cornes. Une de ces chèrres sautantes, âgée de trois ans, que nous avions prise au Cap, et qui étoit fort farouche, s'apprivoisa sur le vaisseau, au point de venir prendre du pain dans la main, et elle devint si friande de tabac, qu'elle en demandoil avec empressement à ceux qui en usoient; elle sembloit le savourer et l'avaler avec avidité; on lui donna une assez grande quantité de tabac en fenille, qu'elle mangea de même avec les côtes et les tiges de ces feuilles : mais nous remarquâmes en même temps que les chèvres d'Europe qu'on avoit embarquées sur le vaisseau pour avoir du lait, mangreoient aussi très volontiers du tabac.

"Les chèvres sautantes ont une longue tache blanche qui commence par une ligne au milieu du dos, et finit vers le croupion en s'élargissant; cette tache blanche n'est pas apparente sur le dos lorsque l'animal est tranquille, parce qu'elle est couverte par les 
longs poils fauves qui l'entourent : mais lorsqu'il saute ou bondit en baissant la tête, on voit alors cette grande tache blanche à découvert.

"Les chèvres sautantes sont de la grandeur des axis du Bengale : inais le corps ct les membres en sont plus délicats et plus déliés; les jambes sont plus hautes. Le pelagge en général est d'un fauve jaunâtre, ou d'une couleur vive de cannelle; la partie postérieure des pieds, une partie du cou, la poitrine, le ventre, et la queue sont d'un assez beau blanc, à l'exception de l'extrémité de la queue, qui est noire. Le blanc du ventre est bordé par une bande d'un brun rougeâtre, qui s'étend tout le long du flanc; il y a aussi une bande de brun noirâtre qui descend depuis les yeux jusqu'aux coins de la bouche, et sur le front une autre bande triangulaire de fauve jaunâtre, qui descend quelquefois jusque sur le museau, où elle finit en pointe, et qui, en remontant sur le sommet de la tête, où elle s'élaryit, se joint au fauve jaunâtre du dessus du corps : le reste de la tête est de couleur blanche; elle est de forme oblongue. Les narines sont étroites et en forme de croissant; leur cloison répond à la division de la lèvre supérieure qui est fendue, et c'est là qu'on remarque un amas de petites éminences hémisphériques, noires, dénuées de poils, et toujours humides. Les yeux sont grands, vifs, et pleins de feu ; l'iris est de couleur brune; sous l'angle antérieur de chaque wil il y a un larmier dont l'orifice est presque rond. Les oreilles sont à peu près aussi longues que la tête entière; elles forment d'abord un tube assez étroit, s'élargissent ensuite, et finissent en pointe mousse. Le cou est assez long, grềle, et un 
peu comprimé sur les côtés. Les jambes de devant paroissent moins hautes que celles de derrière, qui sont divergentes, de manière qu'en marchant l'animal semble se balancer de côté et d'autre. Les sabots des quatre pieds sont petits, de forme triangulaire, et de coule ur noire, de même que les cornes, qui ont euviron un pied de longueur, avec douze anneaux à compler depuis la base, et qui se terminent en une pointe lisse.

"Il semble que ces chèvres sautantes aient quelque pressentiment de l'approche du mauvais temps, surtout du vent du sud-est, qui, au cap de Bonne-Espérance, est très orageux et très violent; c'est alors qu'elles font des sauts et des bonds, et que la tache blanche qui est sur le dos et le croupion paroît à découvert : les plus vieilles commencent à sauter, et bientôt tout le reste de la troupe en fait de mêne. La femelle, dans cette espèce, a des cornes ainsi que le mâle, et la corne qui est figurée dans le tome XII de l'Histoire naturelle ${ }^{1}$ est celle d'un vieux mâle. Au reste, les cornes sont de figures si différentes dans ces animaux, que, si on vouloit ranger l'ordre des gazelles par ce caractère, il y auroit des chèvres saulantes dans toutes les divisions."

Après avoir comparé cette description de M. Forster, et la figure que nous donnons ici de cette chèvre sautante du Cap, il paroîtroit au premier coup d'oeil yue c'est le même animal que celui que M. Allamand appelle bontebok, et dont il domne la description et la ligure dans le nouveau supplément à inon ouvrage,

1. Édition in $-4^{\circ}$, avec la partic anatomique. 
imprimé à Amsterdam cetle année 1781, et que j’ai fait copier ici; cependant j'avoue qu'il me reste encore quelque doute sur l'identité de ces deux espèces, d'autant que la chèvre sautante est appelée springerbok, et non pas bontebok, par les Hollandois du Cap.

Il se pourroit donc que cette chèvre santante, décrite par M. Forster, fût de la même espèce ou d'une espèce très voisine de celle que M. Allamand a nommée la gazelle à bourse sur le dos, d'autant que tous deux s'accordent à lire qu'on n'apercoit la bande blanche qui est sur le dos que quand cette chèvre on gazelle court ou saute, et qu'on ne voit pas ce blanc lorsqu'elle est en repos. Voici ce que ce savant naturaliste en a publié dans le supplément à mes ouvrages, vol. IV, édition de Hollande, pag. 142.

\section{DE LA GAZELLE A BOURSE SUR LE DOS1,}

\section{Par M. Allamand.}

Avec sa sagacité ordinaire, M. de Buffon a éclairci tout ce qui a été dit jusqu'à présent d'embrouillé ar sujet des gazelles: il en a exactement décrit et déterminé toutes les différentes espèces qui sont parvenues à sa connoissance, et il en a connu plus que personne avant lui; mais dans la nombreuse liste qu'il nous en a donnée, il n'a pas cru qu'il les avoil toutes compri-

1. Cette espèce est la même que la précédente. 
ses. Ces animaux habitent pour la plupart l'Afrique, dont l'intérieur est presque encore entièrement inconnu : ainsi on ne peut pas donter qu'il n'y en ait nombre d'espèces qui n'ont point été décrites. La gazelle dont je vais parler en est une preuve; c'est à M. le capitaine Gordon que nous en sommes redevables. Cet officier, que j'ai eu plus d'une fois occasion de nommer, joint à toutes les connoissances de l'art militaire un vif désir d'enrichir l'histoire naturelle de nouvelles découvertes : c'est ce qui l'a déterminé, il y a quelques années, à entreprendre un voyage au cap de Bonne-Espérance, et à y retourner l'année passée, après avoir obtenu de la compagnie des Indes un emploi de confiance qui ne pouvoit être mieux exercé que par lui, mais qui ne l'empêchera point de pousser ses recherches comme naturaliste. Depuis qu'il y est arrivé, j'ai eu la satisfaction d'apprendre par ses lettres qu'il a déjà découvert trois animaux qu'il m'envoie, et qui jusqu'à présent n'ont point été vus en Europe. En les attendant avec impatience, je vais faire connoître la gazelle qui fera le sujet de cet article, et qu'il avoit placée dans la ménagerie du prince d'Orange : c'étoit la seule qui fût restée en vie d'une douzaine qu'il avoil amenćes avec lui.

Nous sommes redevables du dessin de cette gazelle à M. J. Temminck, receveur de la compagnie des Indes, amateur bien connu par sa ménagerie précieuse d'oiseaux vivants, et par son cabinet d'oiseaux préparés très rares. Cette gazelle ressemble presque en tout à la gazclle communc, décrite par MM. de 
LA GAZELLE A BOURSE SUR LE DOS.

Buffon et Daubenton. Elle a les cornes annelées et contournées de la même façon, et également noires; elle est de la même couleur, avec les mêmes taches: elle est un peu plus grande: mais ce qui la distingue, est une raie de poils blancs, longue de dix pouces, qui au premier coup d'œil n'offre rien de particulier, et qui est placée sur la partie postérieure du dos, en s'étendant vers l'origine de la queue. Quand elle court, on est frappé de voir tout d'un coup cette raie s'élargir et se convertir en une grande tache blanche qui s'étend presque de côté et d'autre sur toute la croupe; voici comment cela s'opère. L'animal a sur le dos une espèce de bourse faite par la peau, qui, se repliant des deux côtés, forme deux lèvres qui se touchent presque : le fond de cette bourse est couvert de poils blancs, et c'est l'extrémité de ces poils qui, passant entre les deux lèvres, paroît être une raie ou une ligrie blanche. Lorsque la gazelle court, cette bourse s'ouvre, le fond blanc paroît à découvert; et dès qu'elle s'arrête, la bourse se referme. Cette belle gazelle n’a pas vécu long-temps dans ce pays; elle est morte quelques mois après son arrivée. Elle étoit fort douce et craintive; la moindre chose lui faisoit peur et l'engageoit à courir. J'ai joui très souvent du plaisir de lui voir ouvrir sa bourse. 


\section{LE KLIPPSPRINGER,}

\section{OU SAUTEUR DES ROCHERS.}

\section{Antilope Oreotragus. L.}

Vorci la seconde espèce de gazelle on chèvre sautante dont MM. Forster ont bien voulu me donner ic dessin, et que j’ai fait graver.

"M. Kolbe est le seul, disent-ils, qui ait jamais parlé de ce bel animal, le plus leste de tous ceux de son genre. 11 se tient sur les rochers les plus inaccessibles; et, lorsqu'il aperçoit un homme, il se retire d'abord vers des places qui sont entourées de précipices : il franchit d'un saut de grands intervalles d'une roche à l'autre, et sur des profondeurs affreuses; et, lor'squ'il est pressé par les chiens ou les chasseurs, il se laisse tomber sur de petites saillies de rocher, où l'on croiroit qu'à peine il y eût assez d'espace pour le recevoir. Quelquefois les chasseurs, qui ne peuvent les tirer que de très loin et à balle seule. les blessent et les font tomber dans le fond des précipices. Leur chair est excellente à manger, et passe pour le meilleur gibier du pays. Leur poil est léger, peu adhérent, et tombe aisément en toute saison : on s'en sert au Cap pour faire des matelas, et même on pique avec ses poils des jupes de femme.

"Ce sauteur des rochers est de la grandeur de la 


$$
\text { th }
$$



chèvre commune, mais il a les jambes beaucoup plus longues. Sa tête est arrondie; elle est d'un gris jaunâtre marqueté par-ci par-là de petites raies noires; le museau, les lèvres et les environs des yeux sont noirs; devant chaque oil il y a un larmier avec un grand orifice de forme ovale; les oreilles sont assez grandes, el finissent en pointe. Les cornes ont environ cinq pouces de longueur; elles sont droites et lisses à la pointe, mais ridées de quelques anneaux à la base : la femelle n'a point de cornes. Le poil du corps est d'un fauve jaunâtre; chaque poil est blanc à sa racine, brun ou noir au milieu, et d'un jaune grisâtre à l'extrémité : les pieds et les oreilles sont couverts de poils blanchâtres. La queue est très courte."

\section{LE BOSBOK.}

Antilope Sylvatica. L.

Vorcr encore une très jolie gazelle, dont M. Allamand vient de publier la description dans le nouveau supplément à mon ouvrage sur les animaux quadrupèdes; nous en donnons ici la figure (voy. planche 59), et croyons ne devoir rien omettre de ce qu'en dit ce savant naturaliste.

"Les Hollandois du cap de Bonne-Espérance donnent le nom de bosbok à une très jolie gazelle. Ce mot, que j’ai conservé, signifie le bouc des bois, et c'est effectivement dans les forêts qu'on trouve cette gazelle. 
Ses cornes ont quelque rapport avec celles du ritbok; elles sont dirigées et courbées en avant, mais si légèrement, qu'on a peine à s'en apercevoir: cependant, s'il n'y avoit que cette différence dans la courbure des cornes, je n'hésiterois pas à regarder le bosbok comme une variété dans l'espèce du ritbok; mais ils diffèrent si fort à d'autres égards, qu'on ne peut guère douter qu'ils n'appartiennent à deux familles distinctes.

"Le bosbok est plus petit que le ritbok; la longueur de son corps est de trois pieds six pouces, c'estì-dire d'environ un pied plus courte que celle du ritbok. Il en diffère encore plus par les couleurs: le dessus de son corps est d'un brun fort obscur, mais qui tire un peu sur le roux à la tête et sous le cou; son ventre est blanc, de même que l'intérieur de ses cuisses et de ses jambes; il a aussi une tache blanche au bas du cou: les fesses ne sont pas blanches, comme dans la plupart des autres gazelles; mais la croupe est parsemće de petites taches rondes d'un blanc qui se fait d'abord remarquer, et qui lui sont particulières: ses cornes sont noires et torses en longues spirales, qui s'étendent au delà de la moitié de leur hauteur: on voit sur son front une tache noire. Il n'a point de larmiers; ses oreilles sont longues et pointues; sa queue a près de six pouces, et elle est garnie de longs poils blancs; il a quatre mamelles, et à leur côté les deux poches ou tubes qui se trouvent dans le ritbok.

"Les femelles diffèrent des mâles en ce qu'elles n'ont point de cornes, et qu'el!es sont un peu plus rousses. M. Gordon, en m'envoyant le dessin de cet animal, y a joint la peau d'une femelle, où j'ai trouvé 
les mêmes taches blanches qui sont sur la croupe du mâle.

"Les bosboks ne se trouvent guère qu'à soixante lienes du Cap; ils se tiennent, comme je l'ai déjà dit, dans les bois, où ils se font souvent entendre par une sorte d'aboiement assez semblable à celui du chien."

\section{Dimensions du bosbok.}

Longueur du corps depuis le bout du museau jus-

pieds. pouc. lign.

qu'à l'origine de la queue. . . . . . . . 560 „

Hauteur du train de devant. .........2 56

Hauteur du train de derrière. ........2 727

Longueur de la tête depuis le bout du nuseau jus. qu'à la base des cornes. .......... 7 "

Longueur des cornes. . . . . . . . . . 10 ".

Longueur des oreilles. ....................... 6

Longueur de la queue. ............... 6 "...

\section{LE RITBOK.}

Antilope Eleotragus. Sсивев.

Cet animal me paroît être une troisième variété dans l'espèce du nagor : voici la description qu'en a donnée M. Allamand, et que j’ai cru devoir rapporter ici sans y rien changer.

"L'animal dont le mâle est représenté dans la planche 59 est nommé, par les Hollandois habitants du cap de Bonne-Espérance, rictrheebok, que l’on prononce rîtrébok. C'est un mot composé qui signifie chevreuil des roseaux. Ce n'est pas un chevreuil : ainsi c'est 
mal à propos qu'on lui en donne le nom. J'ai cru devoir lui laisser celui de rictbok ou ritbok, qui signifie bouc des roseaux : quoiqu'il soit aussi composé, il ne paroîtra point tel aux François. Il ne m'a pas été possible de lui conserver celui que les Hottentots lui donnent: ils l'appellent $a, e i, a$, en prononçant chacune de ces trois syllabes avec un claquement de langue que nous ne saurions exprimer.

"Cet animal n'est pas un bouc, il n'en a pas la barbe; il n'a pas non plus toutes les marques auxquelles on peut reconnoître les gazelles : cependant il appartient à leur classe plus qu'à toute autre. M. Gordon, qui m'en a envoyé les dessins et la peau, me mande que, quoique la race de ces animaux soit assez nombreuse, ils marchent cependant en petites troupes, et quelquefois même le mâle est seul avec sa. femelle; ils se tiennent près des fontaines, parmi les roseaux, d'où ils ont tiré leur nom, et aussi dans les bois; il y en a d'une couleur différente, mais qui paroissent cependant être de la même espèce, qui se liennent le plus souvent sur les montagnes.

"Ceux dont nous parlons ici ont tout le dessus du corps d'un gris cendré; ils ont le dessous du ventre, la gorge, les fesses blanches : mais ils n'ont point cette bande roussâtre ou noire qui sépare la couleur du ventre d'avec celle du reste du corps, et qui se trouve dans la plupart des autres gazelles. Leur tête est chargée de deux cornes noires, environnées d'anneaux jusqu'au delà de la moitié de leur longueur; mais ils ne sont pas fort proéminents: j'en ai compté dix sur celles de ces gazelles dont j'ai la peau bourrée. Ces cornes sont tournées en avant, et se terminent. 
par une pointe lisse et fort aiguë : leur longueur est considérable pour la taille de l'animal; en droite ligne elles ont dix pouces de hauteur, et, en suivant leur courbure, elles sont longues d'un pied trois pouces. Les oreilles sont aussi très longues; elles sont blanches en dedans; près de chacune d'elles il y a une tache chauve ou sans poil.

"Ces animaux ont de beaux yeux noirs et des larmiers au dessous; ils ont quatre mamelles, à côté desquelles il y a ces deux ouvertures dans la peau, qui forment deux tubes, où l'on peut faire entrer le doigt, et dont il a été parlé dans l'article précédent sur les gazelles; leur queue est longue, plate, et garnie de longs poils blanchâtres.

"M. Gordon m'a envoyé la peau d'un autre individu de cette espèce, qui ressemble tout-à-fait par les cornes à celui que je viens de décrire, mais qui en diffère par sa couleur, qui est d'un fauve roussâtre très foncé : c'est apparemment un de ceux qui habitent les montagnes.

"Les femelles des ritboks ressemblent par leur couleur aux mâles; mais elles n'ont point de cornes, et elles sont plus petites, comme on pourra le voir par leurs dimensions, que je donnerai à la fin de cet. article.

"Pour trouver ces animaux, il faut aller assez avant dans l'intérieur du pays. M. Gordon n'en a vu qu'à cent lieues du Cap.

"Leurs cornes, tournées en devant, font d'abord penser au nanguer décrit par M. de Buffon : mais ce dernier animal a les cornes beaucoup plus courbées en crochet vers leur pointe, et moins longues que 
celles du ritbok; il est aussi plus petit, sa couleur est différente, et il y a sur son corps beaucoup plus de blanc. Il est vrai que M. Adanson a observé qu'il y a trois espèces ou variétés de ces nanguers, qui ne diffèrent que par la couleur : ainsi la couleur ne suffit pas pour prononcer que ces animaux ne sont pas de la même espèce; mais ce sont les cornes qui l'indiquent. Je crois, avec M. de Buffon, que le nanguer est le dama des anciens : on ne peut guère se refuser aux preuves qu'il en donne. Or Pline compare les cornes du dama à celles du chamois, avec cette seule différance, que ces derniers les ont tournées en arrière, au lieu que dans les autres elles sont tournées en avant. Cornua, dit-il, rupicapris in dorsum adunca, damis in adversum. Je doute que Pline se fût exprimé ainsi, s'il avoit voulu parler des cornes du ritbok; leur courbure n'a rien de commun avec celle des cornes du chamois. Les cornes de l'animal que M. de Buffon a nommé nagor leur ressemblent davantage; elles sont aussi diriggées en avant, mais légèrement : cependant elles sont beaucoup plus courtes que celles du ritbok, puisqu'elles ne s'élèvent pas à la hauteur de six pouces, et elles n'ont que deux ou trois anneaux près de la base, autant au moins qu'on en peut juger par la figure que $M$. de Buffon en a donnée. Ajoutez à cela que le nagor a une queue fort courte. Ces différences paroissent indiquer une diversité de race, et no: pas une simple variété dans la même espèce. M. de Buffon croit que ce nagor est le mêtne animal que Seba a représenté dans la planche 42 , figure 5 , de son ouvrage, et auquel il a donné très iusproprement le nom de mazame, ou cerf d'Amirique. Mais 
ce prétendu cerf américain a les cornes tournées en arrière, assez grandes, et environnées d'une arêle contournće en spirale, depuis la base presque jusqu'à l'extrémité, et, de plus, une fort grosse queue; caractères qui ne conviennent point au nagor.

"A cette occasion, je remarquerai encore que la quatrième figure de la même planche de Seba, que je viens de citer, ne me paroît pas représenter le kob ou la petite vache brune du Sénégal, comme le suppose M. de Buffon, mais le bubale, qu'on reconnoît à la conformation de ses cornes, et aux taches noires qu'il a sur les cuisses. M. Pallas l'a bien reconnu : cependant il n'en est pas moins vrai que Seba s'est grossièrement trompé en appelant cet animal temamacama, et en le disant originaire de la NouvelleEspagne."

\section{Dimensions du ritbok mâle.}

Longueur du corps depuis l'origine de la queue

pleds. pouc. lign.

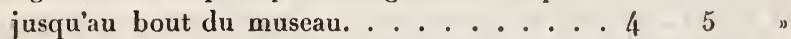

Hauteur du train de devant. ........ 299

Hauteur du train de derrière. . . . . . . 3 "

Longueur de la tête depuis le bout du museau jusqu' la base des cornes. .......... 10 .

Longueur des cornes en ligne droite. ..... $10 \quad 6$

Longueur des cornes en suivant la courbure. . • 15 ”

Circonférence de la base des cornes. . . . . . 5 "

Distance entre les pointes des cornes. . . . . " 10 "

Distance entre leurs bases. . . . . . . . . 2 " "

Longueur des oreilles. . . . . . . . . 7 .

Distance entre leurs bases. ......... 4 . . . . . .

Longueur de la queue. . . . . . . . . 11 n

Dimensions de la femelle du ritbok.

pieds. pciuc. lign.

Longueur du corps depuis l'origine de la queue jusqu'au bout du museau. ........ . 3 
Hauteur du train de devant. . . . . . . . . . 24078

Hauteur du train de derrière. . . . . . . . . . 9296

Longueur des oreilles. .......... " 7 "

Longueur de la queue........... 10 "

\section{LA GHÈVRE BLEUE.}

“CEtte antilope, dit M. Forster, est très commune au cap de Bonne-Espérance, où on l'appelle la chèvre bleue; cependant sa couleur n'est pas tout-à-fait bleue, et encore moins bleu céleste, comme Hall l'a supposé dans son Histoire des quadrupédes, mais seulement d'un gris tirant un peu sur le bleuâtre : cette couleur n'est même occasionée que par le reflet du poil, qui est hérissé lorsque l'animal est vivant; car, dès qu'il est mort, le poil se couche ou s'applique sur le corps, et alors tout le bleuâtre disparoît entièrement, et on ne voit à sa place qu'une couleur grise. Cet animal est plus grand que le daim l'Europe; son ventre est couvert de poils blancs, ainsi que les pieds; la touffe de poil qui termine la queue est aussi blanche, et il y a sous chaque ceil une tache de cette même couleur; la quece n'a que sept pouces de longueur; les cornes sont noires, ridées d'environ vingt anneaux, un peu courbées en arrière, et ont dix-huit ou vingt pouces de longueur; la femelle en porte aussi bien que le mâle. " 


\section{LE BUBALE ${ }^{1}$.}

Antilope Bubalis. L.

Nous avons dit, à l'article du buffle, que les Latins modernes lui avoient appliqué mal à propos le nom de bubalus : ce nom appartenoit anciennement à l'animal dont il est ici question, et cet animal est d'une nature très éloignée de celle du buffle; il ressemble au cerf, aux gazelies, et au bœuf par quelques rapports assez sensibles; au cerf par la grandeur et la figure du corps, et surtout par la forme des jambes : mais il a des cornes perınanentes et faites à peu près comme celles des plus grosses gazelles, desquelles il approche par ce caractère et par les habitudes naturelles; cependant il a la tête beaucoup plus longue que les gazelles, et même que le cerf: enlin il ressemble au bœuf par la longueur du museau et par la disposition des os de la tête, dans laquelle, comme dans le bœuf, le crâne ne déborde pas en arrière au delà de l'os frontal. Ce sont ces différents rapports de conformation, joints à l'oubli de son ancien nom, qui ont fait donner au bubale, dans ces derniers temps, les dénominations composées de busclaphus, taureau-cerf, bucula-cervina, vache-biche, vache de Barbarie, etc.; le nom même de bubalus vient de bu-

1. En latin, bubalus. 
bulus, et par conséquent a été tiré des rapports de similitude de cet animal au bouf.

Le bubale a la tête étroite et très allongée, les yeux placés très haut, le front court et étroit, les cornes permanentes, noires, grosses, chargées d'anneaux très gros aussi; elles prennent naissance fort près l'une de l'autre, el s'éloignent beaucoup à leur extrémité; elles sont recourbées en arrière, et torses comme une vis dont les pas seroient usés en devant et en dessous : il a les épaules élevées. de manière qu'elles forment une espèce de bosse sur le garrot; la queue est à peu près longue d'un pied, et garnie d'un bouquet de crins à son extrémité; les oreilles sont semblables à celles de l'antiloper Kolbe a donné à cet animal le nom d'élan, quoiqu'il ne lui ressemble que par un caractère très superficiel. Le poil du bubale est, comme celui de l'élan, "plus menu vers sa racine que dans son milieu et qu'à l'extrémité : cela est parliculier à ces deux animaux; car, dans presque tous les quadrupèdes, le poil est toujours plus gros à la racine qu'au milieu et à la pointe. Ce poil du bubale est à peu près de la même couleur que celui de l'élan, quoique beaucoup plus conrt, moins fourni, et plus doux. Ce sont là les seules ressemblances du bubale à l'élan; pour tout le reste, ces deux animaux sont absolument différents l'un de l'autre : l'élan porte un bois plus large et plus pesant que celui du cerf, et qui de même se renonvelle tous les ans; le bubale, au contraire, a des cornes qui ne tombent point, qui croissent pendant toute la vie, et qui, pour la forme et la texture, sont semblables à celles des gazelles : i) leur ressemble encore par la figure du corps, la lé- 
gèreté de la tête, l'allongement du cou, la position des yeux, des oreilles, et des cornes, la forme et la longueur de la queve. MM. de l'Académie des Sciences, auxquels cet animal fut présenté sous le nom de vache de Barharie, et qui ont adopté cette dénomination, n'ont pas laissé que de le reconnoître pour le bubalus des anciens. Nous avons cru devoir rejeter la dénomination de vache de Barbarie, comme équivoque et composée; mais nous ne pouvons mieux faire, au reste, que de citer ici la description exacte ${ }^{1}$ qu'ils ont donnée de cet animal, et par laquelle on voit qu'il

1. a L'habitude du corps, les jambes et l'eneolure de cet animal le - faisoient mieux ressembler à un eerf qu'à une vache, dont il n'avoit " que les eornes, lesquelles étoient encore différentes de celles de n vaches en beaucoup de choses; elles prenoient leur naissanee fort - proche l'une de l'autre, paree que la tête étoit extraordinairement n étroite en eet endroit là, tout au contraire des vaches, qui ont le - front fort large, suivart la remarque d'Homère; elles étoient lon. "gues d'un pied, fort grosses, recourbées en arrière, noires, torses - comme une vis, et usées en devant et en dessus, en sorte que les - eôtés élevés qui formoient la vis étoient là entièrement effacés; la "queue n'étoit longue que de treize pouces, en eomprenant un "bouquet de crins longs de trois pouces qu elle avoit à son extrémité; - les oreilles étoient semblables à celles de la gazelle, étant garnies - en dedans d'un poil blanc en quelques endroils, le reste étant pelé, " et découvrant un cuir parfaitement noir et lisse; les yeux étoient si " hauts et si proche des cornes, que la tête paroissoit n'avoir presque " point de front : les mamelons du pis étoient très menus, très courts, " et seulenseni an nombre de deux, ce qui les rendoit fort différents " de ceux de nos vaches; les épaules étoient fort élevées, faisant » entre l'extrémité du cou et le commencement du dos une bosse.... - Il y a apparence que cet animal doit être plutôt pris pour le bubale n des anciens, que le petit bouf d'Afrique, que Belon déerit; car Solin compare le bubale au eerf. Oppien lui attribue des eornes re" courbées en arrière, et Pline dit qu’il tient du veau et du cerf." (Mémoires pour servir à l'histoire des animaux, partie II, pages 25 et 26 .) 
n'est ni gazelle, ni chèvre, ni vache, ni élan, ni $\operatorname{cerf}^{\mathbf{}}$; mais qu'il est d'une espèce particulière et différente de toutes les autres. Au reste, cet animal est le même que Caïus a décrit sous le nom de buselaphus, et je suis étonné que MM. de l'Académie n'aient pas fait cette remarque avant nous, puisque tous les caractères que Caïus donne à son buselaphus conviennent à leur vache de Barbarie.

Nous avons au Cabinet du Roi, $1^{\circ}$ un squelette de bubale qui provient de l'animal que MM. de l'Académie des Sciences ont décrit et disséqué sous le nom de vache de Barbarie; $2^{\circ}$ une tête beaucoup plus grosse que celle de ce squelette, et dont les cornes sont aussi beaucoup plus grosses et plus longues; $3^{\circ}$ une antre portion de téte, avec les cornes, qui sont tout aussi grosses que les précédentes, mais dont la forme et la direction sont différentes. Il y a donc dans les bubales, comme dans les gazelles, dans les antilopes, etc., des variétés pour la grandeur du corps et pour la figure des cornes : mais ces différences ne nous paroissent pas assez considérables pour en faire des espèces distinctes et séparées.

Le bubale est assez commun en Barbarie et dans toutes les parties septentrionales de l'Afrique : il est à peu près du même naturel que les antilopes; il a, comme elles, le poil court, le cuir noir, et la chair bonne à manger. On peut voir la description des parties intérieures de cet animal dans les Mémoires pour

1. Deux caractìres essentiels séparent le bubale du genre des cerfs : le premier, ce sont les cornes, qui ne tombent pas; le second, c'est la vésicule du fiel, qui se trouve dans le bubale, et qui, comme l'on sait, manque dans les cerfs, les daims, les chevreuils, etc. 
servir à l'histoire des animaux, où MM. de l'Académie des Sciences en ont fait l'exposition anatomique avec leur exactitude ordinaire.

* Nous donnons ici (planche 59) la figure du bubale, qui nous manquoit. M. Pallas dit avoir vu cet animal vivant: il est doux, mais d'une figure moins élégante et d'une forme plus robuste que les autres grandes gazelles; il a même par la grosseur de la tête, par la longueur de la queue et par la figure du corps, une assez grande ressemblance avec nos génisses; il est plus haut qu'un âne, et plus élevé sur le train de devant que sur celui de derrière. Les dents sont toutes larges, tronquées, égales; celles dı milieu sont néanmoirs les plus grandes. La lèvre inférieure est noire, et porte une moustache, ou plutôt un petit faisceau de poils noirs de chaque côté. Il a, sur le museau et le long du chanfrein, une bande noire terminée sur le front par une louffe de poils placée en devant des cornes. Le reste de la courte description de M. Pallas s'accorde avec la mienne et avec celle de MM. de l'Académie des Siciences, qui ont donné cet animal sons le nom de vache de Barbarie. J'observerai seulement que cet animal est assez différent de toutes les gazelles, pour qu'on doive le regarder comme faisant une espèce particulière et moyenne entre celle des boufs el celle du cerf, tandis que les gazelles forment la nuance entre les chèves et les cerfs.

M. Forster soupconne que le bubale et le koba sont le même animal, ou que du moins ils sont de deux espèces très voisines. Il dit aussi que la grande vache brune ou cerf du Cap est le même animal. Il a 
rapporté la peau d'un de ces prétendus cerís du Cap, et il dit avoir trouvé que, par rous ses caractères, il ressembloit parfaitement au koba. Les chasseurs disent que ces animaux ne se trouvent quà une grande profondeur dans les terres du Cap, et qu'ils ne vont jamais en troupes. "Ils disent aussi, ajoute M. Forster, que le bubale a quatre pieds de hauteur, et qu'il est en tout de la grandeur du cerf d'Europe, mais qu'il est en même temps d'une forme moins élégante.

n Le pelage de cet animal est d'un rouge brun, et le poil est lisse et ondoyé; le ventre et les pieds sont d'une couleur plus pâle. Il y a depuis les cornes jusqu'au garrot une ligne noire, ainsi que sur le devant des pieds; mais, dans ceux de derrière, cette ligne noire est interrompue au genou. Deux autres bandes de même couleur descendent de chaque côté de la tête, depuis le dessous des cornes jusqu'au museau, qui est aussi rayé de noir. Ces deux dernières bandes sont surmontées d'une tache blanche, qui est placée tout auprès de l'origine de la corne. Il y a sur le front un épi de poils en étoile qui se dirige en haut. Les poils du menton sont de couleur noire, longs d'environ un pouce et demi, et forment une espèce de barbe, auprès de laquelle on voit une tache noire. La queue est terminée par une touffe de longs poils de cette dernière couleur, et est longue de plus d'un pied. La figure des cornes est absolument semblable à celle que M. de Buffon a fait graver dans son Histoire nalureile; elles sont ridées de dixneuf ou vingt anneaux, et ont environ vingt pouces de longueur." 
Après avoir écrit cet article sur le bubale, j’ai reçu, de la part de M. Allamand, les observations suivantes, qui confirment ce que je viens de dire; et comme il a joint à ces observations une figure dessinée d'après l'animal vivant, j'ai cru devoir la faire graver. (Voy. planche 39.) Je vais de même rapporter ici ce que MM. Gordon et. Allamand ont observé et publié dans le nouveau supplément à mon Histoire des animaux quadrupèdes, imprimé à Amsterdam cette année 1781 .

"Le bubale est un de ces animaux dont la race est répandue dans toute l'Afrique; au moins se trouvet-il dans les contrées méridionales et septentrionales de cette partie du monde. L'espèce est très nombreuse près du cap de Bonne-Espérance, et on la retrouve dans la Barbarie. MM. de l'Académie royale des Sciences en ont décrit la femelie sous le nom de vache de Barbarie, et M. de Buffon a prouvé, par des raisons qui me paroissent convaincantes, que notre bubale est le vrai bubalus des anciens Grecs et Romains, qui sûrement n'ont pas connu les animaux qui n'habitent qu'aux environs du Cap.

"MM. de l'Acariémie des Sciences ont ajouté à la description qu'ils ont faite de la femelle bubale, une figure qui est très exacte, mais qui ne suffit pas pour faire comprendre ce que je dirai sur ses différentes couleurs et sur la forme de ses cornes. Je donne ici la figure d'un mâle.

"Le dessin en est fait d'après l'animal vivant, et j'en suis redevable à $\mathbf{M}$. Gordon, qui m’a envoyé en même temps la peau d'une femelle, que j'ai fait remplir, et que j’ai placée dans le cabinet de notre aca- 
démie. Suivant sa coutume il a joint à cet envoi ses observations; elles me fourniront diverses particularités qui n'ont pu être connues par M. de Buffon, qui, n'ayant point vu le bubale, n'en a parlé que d'après MM. de l'Académie. Il est vrai qu'il ne pouvoit pas suivre de meilleurs guides; mais ce qu'ils ont dit de cet animal se borne presque à une description anatomique.

"Le bubale est nommé camaa par les Hottentots, et licama par les Caffres. Sa longueur, depuis le bout du muscau jusqu'à l'origine de la queue, est de six pieds quatre pouces six lignes; il a quatre pieds de haut: la circonférence de son corps derrière les jambes de devant est de quatre pieds deux pouces, et devant les jambes de derrière, de quatre pieds. On voit, par ces dimensions, qu'il est plus pelit que le canna que j'ai décrit dans l'article précédent. La couleur de son corps est d'un roux assez foncé sur le dos, mais qui s'éclaircit sur les côtés; le ventre est blanc, de même que la croupe, l'intérieur des cuisses et des jambes, tant antérieures que postérieures. Sur la partie extérieure des cuisses, il y a une grande tache noire qui s'étend sur les jambes : on roit une semblable tache sur les jambes de devant, laquelle commence près du corps, et parvient extérieurement jusqu'aux sabots, qui sont noirs aussi; une bande de cette même couleur, qui a son origine à la base des cornes et se termine an museau, partage tout le devant de sa tête en deux parties égales. Cette bande a été remarquée par J. Caius, qui a donné une bonne description du bubale, qu'il a nommé buselaphus. C'est la seule qu'on voie sur les femelles, dont tout 
le corps est couvert de poils d'une même couleur rousse. Sa tête est assez longue à proportion de son corps: mais elle est fort ét roite; elle n'a guère que six pouces dans l'endroit le plus large. Ses yeux, comme MM. de l'Académie l'ont observé, sont situés fort haut : ils sont grands el vifs; leur couleur est d'un noir qui lire un pen sur le bleu. Ses cornes, qui s'élèvent au dessus de sa tête, en s'écartant un pen de chaque côté, sont presque droites jusqu'à la hauteur de six pouces; là elles s'avancent obliquement en devant à peu près aussi jusqu’à la distance de six pouces, et ensuite formant un nouvel angle, elles se tournent en arrière, comme la figure l'indique : elles sont noires; leurs bases se touchent et ont une circonférence de dix pouces : elles ont des anneaux saillants, comme des pas de vis qui seroient usés aux côtés, et qui s'étendent, mais quelquefois peu sensiblement, jusqu'à la hauteur de huit ou dix ponces; la partie qui est retournée en arrière est lisse et se termine en pointe; leurs extrémités sont éloignées environ d'un pied l'une de l'autre. Les femelles sont un peu plus petites que les mâles : aussi leurs cornes sont moins grosses et moins longues.

"Les bubales ont des larmiers au dessous des yeux, comme les cerfs. Lenr queue, longue de plus d'un pied, est garnie en dessus d'une rangée de poils placés à peu près comme les dents d'un peigne.

"On a vu, dans l'article précédent, que le canna étoit nommé élan par les habitants du Cap. M. de Buffon, qui ignoroit cela, et qui ne connoissoit point cet animal, dont aucun voyageur n'a parlé, a eru que, sous le nom d'élan, Kolbe avoit désigné le bu-BUFFON. XVII. 
hale; mais ce que Kolbe en dit ne lui convient pas. II assure que ce prétendu élan a la tête courte à proportion de son corps, que sa hauteur est de cinq pieds, et que la couleur de son corps est cendrée. Ce sont là autant de caractères qui se trouvent dans le canna, mais dont aucun n'est applicable au bubale. Je croirois plutôt que Kolbe en a parlé sous le nom de cerf d'A frique; et c'est effectivement celui qu'on lui donne au Cap. Voici de quelle manière il en décrit les cornes : "Ses cornes sont d'un brun obscur, environnées comme d'une espèce de petite vis, pointues, et droites jusqu'au milieu, où elles se recourbent tant soit peu; depuis là elles continuent à suivre une ligne droite, de manière qu'en dessus elles sont à peu près trois fois plus éloignées l'une de l'autre qu'à la racine." On reconnoît à cette description, tout imparfaite qu'elle est, les cornes du bubale; mais, quoique Kolbe assure qu'il a vu plus de mille de ces animaux, je doute qu'il en ait examiné un seul attentivement, puisqu'il dit que ce cerf africain est si semblable à ceux d'Europe, qu'il seroit superflu de le décrire, et qu'il est persuadé que c'est le spies hirsch qu'on trouve communément en Allemagne.

"Les bubales, de même que les cannas, se sont éloignés des lieux habités du Cap, et se sont retirés dans l'intérieur du pays, où on les voit courir en grandes troupes, et avec une vitesse qui surpasse celle de tous les autres animaux; un cheval ne sauroit les atteindre. M. Gordon n'en a jamais rencontré sur les montagnes; ceux qu'il a vus étoient toujours dans les plaines. Leur cri est une espèce d'éternuement. Leur chair est d'un très bon goût : les paysans qui sont 
éloignés du Cap en coupent des tranches fort minces qu'ils font sécher au soleil, et qu'ils mangent souvent avec d'autres viandes au lieu de pain.

"Les femelles n'ont que deux mamelles, et, pour l'ordinaire, elles ne font qu'un petit à la fois: elles mettent bas en septembre, et quelquefois aussi en avril.

"M. Pallas a donné une bonne description du bubale ; et M. Zimmerman a soupçonné que M. de Buffon pourroit s'être mépris en prenant cet animal pour l'élan de Kolbe."

\section{LE COUDOUS ${ }^{1}$}

Antilope Oreas. Pali.

LA classe des animaux ruminants est la plus nombreuse et la plus variée; elle contient un très grand nombre d'espèces, et peut-être un nombre encore plus grand de races distinctes, c'est-à-dire de variétés constantes. Malgré toutes nos recherches et les détails immenses dans lesquels nous avons été contraint d'entrer, nous avouerons volontiers que nous ne l'avons pas épuisée, et qu'il reste encore des animaux, même très remarquables, que nous ne connoissons, pour ainsi dire, que par échantillons, souvent très difficiles à rapporter au tout auquel ils appartiennent. Par

1. Cette gazelle est le vrai canna des Hottentots. 
exemple, dans la grande et très grande quantité de cornes rassemblées au Cabinet du Roi, ou dispersées dans les collections des particuliers, et que nous avons, après bien des comparaisons, rapportées chacune à l'animal duquel elles proviennent, il nous en est resté une sans étiquelte, sans nom, absolument inconnue, et dont nousn'avions d'aulres indices que cenx qu'on pouvoit tirer de la chose même. Cette corne est très grosse, presque droite, et d'une substance épaisse et noire; ce n'est point un bois solide comme celui du cerf, mais une corne creuse et remplie, comme celles des bœufs, d'un os qui lui sert de noyau : elle porte, depuis la base et dans la plus grande partie de sa longueur, une grosse arête, épaisse et relevée d'environ un pouce; et quoique la corne soit droite, cette arète proéminente fait un tour et demi de spirale dans la partie inférieure, et s'efface en entier dans la partie supćrieure de la corne quise termine en pointe: en tout, celte corne, différente de toutes les autres, nous paroissoit seulement avoir plus de rapport avec celles du buffle qu'avec aucune autre; mais nous ignorions le nom de l'animal, et ce n'est qu'en dernier lien et en cherchant dans les différents cabinets, que nous avons trouvé dans celui de M. Dupleix un massacre surmonté de deux cornes semblables; et cette portion de têle étoit étiquetée : Cornes d'un animal ì peu près comme un cheval, de couleur grisâtre, avec une crinière comme un cheval au devant de la tête; on l'appelle ici (à Pondichéry) coeshoes, qui doit se prononcer coudous. Cette petite découverte nous a fait grand plaisir : mais cependant nous n'avons pu trouver ce nom coesdoes ou coudous dans aucun voyagcur; 
l'étiquette seulement nous a appris que cet animal est de très grande taillé, et qu'il se trouve dans les pays les plus chauds de l'Asie. Le buffle est de ce même climat, et il a d'ailleurs une crinière au dessus de la tête : il est vrai que ses cornes sont courbes et aplaties, au lieu que celles-ci sont rondes et droites, et c'est ce qui distingue ces deux animaux, aussi bien que la couleur : car le buffle a la peau et le poil noirs; et, selon l'étiquette, le coudous a le poil grisâtre. Cies rapports nous en ont indiqué d'autres; les voyageurs en Asie parlent de grands buffles de Bengale, de buffles roux, de bœuf's gris du Mogol, qu'on appelle nil-gauts : le coudous est peut-être l'un ou l'autre de ces animaux; et les voyageurs en Afrique, où les buflles sont aussi communs qu'en Asie, font une mention plus précise d'une espèce de buffle appelée $p a-$ kasse au Congo, qui, par leurs indices, nous paroît être le coudous. "Sur la route de Louanda, au "royaume de Congo, nous aperçumes, disent-ils, "deux pakasses, qui sont des animaux assez sembla"bles aux buffles, et qui rugissent comme des lions: "le mâle et la femelle vont toujours de compagnie; " ils sont blancs avec des iaches rousses et noires, et ") ont des oreilles de demi-aune de long, et les cornes "toutes droites. Quand ils voient quelqu'un ils ne "fuient point, ni ne font aucun mal, mais regardent "les passants. "Nous avons dit à l'article du buflle, que l'animal appelé à Congo empakassa ou pakassa nous paroissoit être le buffle : c'est en effet une espèce de buffle, mais qui en diffère par la forme des cornes et la couleur du poil; e'est, en un mot, un coudous, qui pent-être forme une espèce séparée do 
celle du buffle, mais qui peut-être aussi n'en est qu'une variété.

\section{LE GANNA.}

Antilope Oreas. PaLL.

$J_{E}$ n'ai d'abord connu cet animal que par ses cornes, dont j'ai donné la description dans l'article précédent, et jétois assez incertain non seulement sur son espèce et sur son climat, mais même sur le nom coudous, qui servoit d'étiquette à ses cornes; mais anjourd'hui mes doutes sont dissipés, et c'est à M. Gordon et à M. Allamand que je dois la connoissance de cet animal, l'un des plus grands de l'Afrique inéridionale. Il se nomme canna dans les terres des Hottentots, et voici les observations que ces savants naturalistes en ont publiées, cette année 1781 , dans un supplément à l'édition de Hollande de mes ouvrages.

“M. Buffon a été embarrassé à déterminer l'animal auquel avoit appartenu une corne qu'il a trouvée au Cabinet du Roi, sans étiquette, et dont il a donné la figure. Deux semblables cornes qu'il a vues dans le cabinet de M. Dupleix, et qui étoient étiquetées, l'ont tiré en partie de son embarras; l'étiquette portoit ceci : Cornes d'un animal à peu près comme un cheval, de couleur grisatre, avec une crinière comme un cheval au devant de la tête; on l'appelle ici (à Pondichéry) coesdoes, qui doit se prononcer coudous. 
"Cette description, toute courte qu'elle est, est cependant fort juste, mais elle ne suffisoit pas à $M$. de Buffon pour lui faire connoître l'animal qui y est désigné. Il a dû avoir recours aux conjectures, et il a soupçonné, avec beaucoup de vraisemblance, que le condous pouvoit bien être une sorte de buffle, ou plutôt le $n y l$-ghau : effectivement ce dernier animal est celui dont les cornes ont le plus de rapport à celles dont il s'agit; et ce qui est dit dans l'étiquette lui convient assez, comme on peut le remarquer par la description que j'en ai donnée. Cependant cette corne est celle d'un autre animal, auquel M. de Buffon n'a pas pu penser, parce qu'il n'a pas été encore décrit, ou que du moins il l'a été si imparfaitement, qu'il étoit impossible de s'en former une juste idée. Il étoit réservé à M. Gordon de nous le faire bien connoître; c'est à lui que je suis redevable de la figure que j'en ai donnée et des particularités qu'on va lire.

"Kolbe est le seul qui en ait parlé sous le nom d'élan qui ne lui convient point, puisqu'il en différe essentiellement par ses cornes, qui n'ont rien d'analogue à celles du véritable élan. Les Holtentots lui donment le nom de canna, que je lui ai conservé : les Caffres le nomment inpoof. C'est un des plus grands animaux à pieds fourchus qu'on voie dans l'Afrique méridionale. La longueur de celui qui est représenté ici, depuis le bout du museau jusqu'à l'origine de la queue, étoit de huit pieds deux pouces; sa hauteur étoit de cinq pieds, mesurée depuis la partie du dos qui est au dessus des épaules, et qui forme là une éminence assez remarquable; sa circonférence, derrière les jambes de devant, étoit de six pieds sept 
pouces, et devant les jambes postérieures, de cinq pieds neuf pouces : mais il fautobserver qu'il étoit assez maigre; s'il avoit eu son embonpoint ordinaire, il auroit pesé environ sept à huit cents livres. La couleur de son corps étoit d'un fauve tirant sur le roux, et il étoit blanchâtre sur le ventre; sa tête et son cou étoient d'un gris cendré, et quelques uns de ces animaux ont tout le corps de cette couleur; tous ont au devant de la tête des poils qui forment une espèce de crinière.

" Jusqu'ici cette description s'accorde fort avec celle du coudous, et les cornes du canna sont précisément semblables à celles que M. de Buffon a décrites; ainsi on ne peut pas douter que le coudous de Pondichéry ne soit notre canna: mais je suis surpris, avec M. de Buffon, qu'on lui ait donné le nom de coudous, qui n'a jamais été employé par aucun voyageur dans les Indes; je soupconne qu’il a été emprunté des Hollandois, qui l'écrivent effectivement coedoe ou coesdoes, et qui le prononcent coudous. Ils le donnent à l'animal que M. de Buffor a nommé condoma, et qui, par sa grandeur, approche un peu du canna. Ces cornes, qui se trouvent dans le cabinet de M. Dupleix, n'auroient-elles point été apportées du cap de BonneEspérance à Pondichéry? Celui qui en a écrit l'étiquette, en suivant l'orthographe hollandoise, ne se seroit mépris que sur le nom. Ce qui autorise ce soupcon, c'est le silence des voyageurs sur un animal aussi remarquable par sa grandeur que le canna. S'il habitoit un pays autant fréquenté par les Européens que le sont les Indes, il est très vraisemblable que quelques uns en auroient parlé." 
Je suis ici, comme dans tout le reste, parfaitement de l'avis de M. Allamand, et je reconnois que le nom hollandois de coesdoes ou coudous doit rester à l'animal que j'ai nommé condoma, et que ce nom coudous avoit été écrit mal à propos sur l'étiquette des cornes que nous reconnoissons être celles du canna dont il est ici question.

"Ses cornes, dit M. Allamand, étoient telles que M. de Buffon les a décrites; elles avoient une grosse arête qui formoit deux tours de spirale vers leur base; elles étoient lisses dans le reste de leur longueur, droites, et noires ; leurs bases étoient éloignées l'une de l'autre de deux pouces, et il y avoit l'intervalle d'un pied entre leurs pointes; leur longueur étoit d'un pied et demi, mais elle varie dans les différents individus. Celles des femelles sont, pour l'ordinaire, plus menues, plus droites et plus longues; elles sont creuses et soutenues par un os qui leur sert de noyau; ainsi elles ne tombent jamais. A cette occasion, M. Gordon m'écrit qu'on ne connoît dảns l'Afrique méridionale aucun animal qui perde ses cornes; par conséquent il n'y a ni élans, ni cerfs, ni chevreuils. Kolbe seul les y a vus.

"Le canna a un fanon très remarquable qui lui pend au devant de la poitrine, et qui est de la même couleur que la tête et le cou. Celui des femelles est moins grand; aussi sont-elles un peu plus petiles que les mâles; elles ont moins de poils sur le front, et c'est presque en cela seulement que leurs figures diffèrent.

" J'ai déjà dit que Kolbe donne au canna le nom d'élan; et c'est effectivement celui sous lequel il est connu au Cap, quoique très improprement : cepen- 
dant il a, comme notre élan du Nord, une loupe sous la gorge, de la hauteur d'un pouce, comme on peut le voir dans la figure. Si l'on en croit M. Linnæus, c'est là un caractère distinctif de l'élan qu'il définit : alces, cervus cornibus acaulibus palmatis, carunculı gutturali. Mais $M$. de $B u f f o n$ remarque, avec raison, que les élans femelles n'ont pas cetle loupe, et qu'elle n'est par conséquent point un caractère essentiel à l'espèce. J'ignore si elle se trouve dans la femelle du canna.

"Sa queue, qui est longue de deux pieds trois pouces, est terminée par une touffe de longs poils ou crins noirs; ses sabots sont aussi noirs, et le peuple (sur la foi du noin) leur attribue la même vertu qu’à ceux de nos élans, c'est d'être un souverain remède contre les convulsions.

„Il a quatre mamelles et une vésicule du fiel. Quoique sa tête, qui a un pied sept pouces de longueur, ressemble assez à celle du cerf, elle n'a cependant point de larmiers.

"Les cannas sont presque tous détruits dans le voisinage du Cap; mais il ne faut pas s'en éloigner beaucoup pour en rencontrer : on en trouve dans les montagnes des Hottentots hollandois. Ces animaux marchent en troupes de cinquante ou soixante; quelquefois même on en voit deux ou trois cents ensemble près des fontaines. Il est rare de voir deux mâles dans une troupe de femelles, parce qu'alors ils se battent, et le plus foible se retire : ainsi les deux sexes sont souvent à part. Le plus grand marche ordinairement le premier; c'est un très beau spectacle que de les voir trotter et galoper en troupes. Si l'on tire un coup de fusil chargé à balle parmi eux, tout 
pesants qu'ils sont, ils sautent fort haut et fort loin ; ils grimpent sur des lieux escarpés, où il semble qu'il est impossible de parvenir. Quand on les chasse, ils courent tous contre le vent, et, avec un bon cheval, il est aisé de les couper dans leur marche. Ils sont fort doux : ainsi on peut pénétrer au milieu d'une troupe, et choisir celui sur lequel on veut tirer, sans courir le moindre danger. Leur chair est une excellente venaison; on casse leurs os pour en tirer la moelle qu'on fait rôtir sous la cen dre ; elle a un bon goût, et on peut la manger même sans pain. Leur peau est très ferme; on s'en sert pour faire des ceintures et des courroies. Les poils qui sont sur la tête des mâles ont une forte odeur d'urine, qu'ils contractent, diton, en léchant les femelles. Celles-ci ne font jamais qu'un petit à la fois.

"Comme ces animaux ne sont point méchants, M. Gordon croit qu'on pourroit aisément les rendre domestiques, lesfaire tirer au chariot, et les employer comme des bêtes de somme; ce qui seroit une acquisition très importante pour la colonie du Cap.

"M. Pallas a vu, dans le cabinet de Mgr le prince d'Orange, le squelette d'un canna, et il l'a reconnu pour être l'élan de Kolbe. Il l'a rangé dans la classe des antilopes, sous la dénomination d'antilope ory'x. Je n'examinerai pas les raisons qu'il a eues pour lui donner cette dernière épithète; je me contenterai de remarquer qu'il me paroît douteux que le canna se trouve dans les parties septentrionales de l'Afrique; au moins aucun voyageur ne le dit. S'il est particulier aux contrées méridionales de cette partie du monde, il n'est pas apparent que ce soit l'oryx des anciens: 
d'ailleurs, suivant le ténoignage de Pline, l'ory $x$ étoit une chèvre sauvage, et il est peu vraisemblable que Pline, qui ne s'étoit pas formé un système de nomenclature, comme nous autres modernes, ait donné le nom de chèrre à un aussi gros animal que le canna."

Avant d'avoir reçu ces remarques très judicieuses de M. Allamand, j’avois fait à peu près les mêmes réflexions, et voici ce que j’en avois écrit et même livré à l'impression.

M. Pallas appelle cet animal oryx, et le met au nombre de ses antilopes; mais ce nom me paroît mal appliqué : je l'aurois néanmoins adopté si j’eusse pu penser que cet animal du cap de Bonne-Espérance fût l'ory $x$ des anciens; mais cela n'est ni vrai ni même vraisemblalle. M. Pallas croit que l'élan d'Afrique indiqué par Kolbe est le même animal que celui-ci, et je ne suis pas fort éloigné de ce sentiment, quoique j’aie rapporté l'élan d'Afrique de Kolbe au bubale: mais, soit qu'il appartienne en effet au bubale on an canna, il est certain que le nom d'élan lui a été très mal appliqué, puisque l'élan a des bois solides qui tombent tous les ans comme ceux du cerf, an lieu que l'animal dont il est ici question porte des cornes creuses et permanentes, comme celles des bœut's et des chèvres.

Et ce qui me fait dire que le nom d'ory $x$ a été mal appliqué à cel animal par M. Pallas, et qu'il n'est pas l'ory' $x$ des anciens, c'est qu'ils ne connoissoient qu'une assez petite partie de l'Asie, et la seule portion de l'Afrique qui s'étend le long de la Méditerranée. Or cet. animal auquel M. Pallas donne le nom d'ory $x$ ne se trouve ni dans l'Asie mineure, ni dans l'Arabie, ni 
dans l'Égypte, ni dans toutes les terres de la Barbarie et de la Mauritanie. Ainsi l'on est fondé à présumer qu'il ne pouvoit être ni connu ni nommé par les anciens.

M. Forster m'écrit qu'il a vu une femelle de cette espèce, en $177^{2}$, à la ménagerie du cap de BonneEspérance, laquelle avoit environ quatre pieds de hauteur, mesurée aux jambes de devant. "Elle portoit, dit-il, une sorte de crinière le long du cou, qui s'étendoit jusqu'aux épaules, où l'on voyoit aussi de très longs poils; il y avoit une ligne noire sur le dos, et les genoux étoient de celte même couleur noire, ainsi que le nez el le museau; le pelage du corps éloit fauve, et à peu près semblable à celui du cerf : mais le ventre et le dedans des jaınbes étoient blanchâtres.

"On voyoit sous la gorge de cette femclle une prośminence de la grosseur d'une pomme, qui étoit formée par l'os du larynx, plus apparent el plus grand dans cette espèce d'animal que dans toute autre.

"Ainsi la femelle cauna a, comme le mâle, cette proéminence sous la gorge, au lieu que, dans l'espèce de notre élan du Nord, le mâle seul porte cet attribut.

"Toutes les dents incisives étoient, selon M. Forster, d'une largeur considérable; mais celles du milieu étoient encore plus larges que les autres. Les yeux étoient vifs et pleins de feu. La longueur des cornes étoit d'environ un pied et demi; et pour avoir une idée de leur position, il faut se les représenter comme formant un grand V en regardant l'animal de face, et comme s'effaçant parfaitement l'une l'autre en le regardant dans le sens transversal. Ces cornes étoient noires, lisses dans leur plus grande longueur, avec 
quelques rides annulaires vers la base : on remarquoit une arête mousse qui suivoit les contours de la corne, laquelle étoit droite dans sa direction, et un peu inrse dans sa forme. Les oreilles étoient larges; les sabots des pieds fort petits à proportion du corps, leur forme étoit triangulaire, et leur couleur noire.

"Au reste, cette femelle étoit très apprivoisée, et mangeoit volontiers du pain, des feuilles de choux, et les prenoit même dans la main : elle étoit dans sa quatrième année; et, comme elle n'avoit point de mâle et qu'elle étoit en chaleur, elle sautoit sur des antilopes et même sur une autruche qui étoit dans le même parc. On assure que ces animaux se trouvent sur les hautes montagnes de l'intérieur des terres du Cap; ils font des sauts surprenants, et franchissent des murs de huit et jusqu'à dix pieds de haut."

\section{LE CONDOMA ${ }^{1}$.}

\section{Antilope Strepsiceros. PaLL.}

M. le marquis de Marigny, qui ne perd pas la plus petite occasion de favoriser les sciences et les arts, m'a fait voir dans son cabinet la tête d'un animal, que je pris au premier coup d'œil pour celle d'un grand bubale; elle est semblable à celle de nos plus grands cerfs : mais, au lieu de porter un bois solide et plein comme celui des cerfs, elle est surmontée de deux

3. C'est le vrai coudous. 


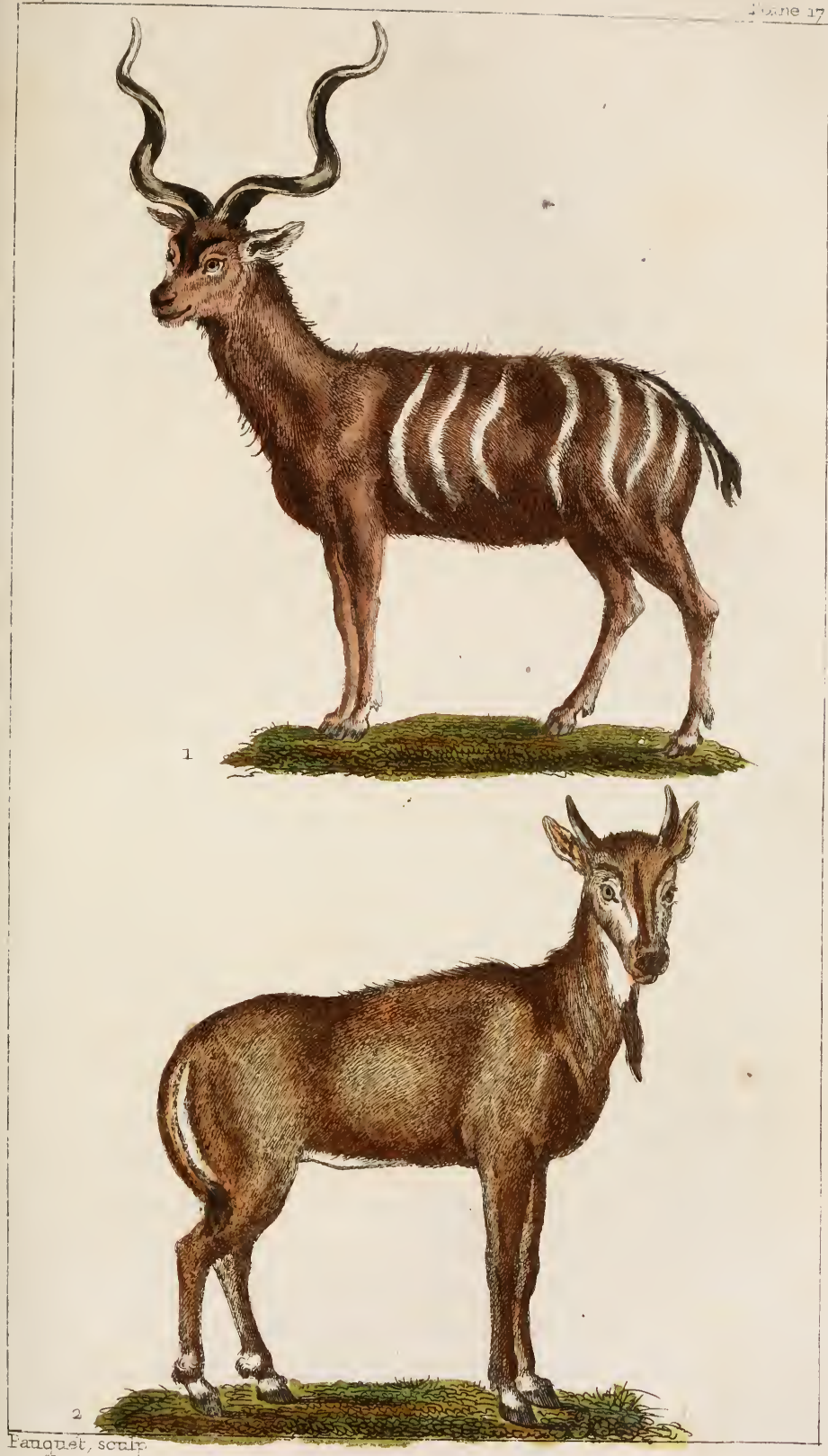

1. E CONJOMA - 2. IE NUG GAUT 

grandes cornes creuses, portant arête comme celles des boucs, et doublement réfléchies comme celles des antilopes. En cherchant au Cabinet du Roi les morceaux qui pouroient être relatifs à cet animal, nous avons trouvé deux cornes qui lui appartiennent : la première. sans aucun indice ni étiquette, venoit du garde-meuble de Sa Majesté; la seconde m'a été donnée, en 1760 , par M. Baurhis, commis de la marine, sous le nom de condoma du cap de Bonne-Espérance. Nous avons cru devoir adopter ce nom, l'animal qu'il désigne n'ayant jamais été dénommé ni décrit.

Par la longueur, la grosseur, et surtout par la double flexion des cornes, le condoma nous paroît approcher beaucoup de l'animal que Caïus a donné sous le nom de strepsiceros. Non seulement la figure et les contours des cornes sont absolument les mêmes, mais toutes les dimensions se rapportent presque exactement; et en comparant la description que M. Daubenton a faite de la tête du condoma avec celle du strepsiceros de. Caïus, il m'a paru qu'on pouvoit présumer que c'étoit le même animal, surtout en faisant précéder notre jugement des réflexions suivantes : $1^{\circ}$ Caïus s'est trompé en donnant cet animal pour le strepsiceros des anciens : cela meparoît évident; car le strepsiceros des anciens est certainement l'antilope, dont la tête est très différente de celle du cerf. Or, Caïus convient, et même assure, que son strepsiceros a la tête semblable à celle du cerf; donc ce strep. siceros n'est pas celui des anciens. $2^{\circ} \mathrm{L}$ 'animal de Caïus a, comme le condoma, les cornes grosses et longues de plus de trois pieds, et couverles de rugosités, et non pas d'annearix ou de tubercules; au lieu que le 
strepsiceros des anciens, ou l'antilope, a les cornes non seulement beaucoup moins grosses et plus courtes, unais aussi chargées d'anneaux et de tubercules très apparents. $5^{\circ}$ Quoique les cornes de la tête du condoma, qui est au cabinet de M. le marquis de Marigny, aient été usées et polies, et que la corne qui vient du garde-meuble du Roi ait même été travaillée à la surface, on voit cependant qu'elles n'étoient point chargées d'anneaux; et cela nous a été démontré par celle que nous a donnée M. Baurhis, qui n'a point été touchée, et qui ne porte, en effet, que des rugosités comme les cornes de bouc, et non pas des anneaux comme celles de l'antilope. Or, Caïus dit lui-même que les cornes de son strepsiceros ne portent que des rugosités; donc ce strepsiceros n'est pas celui des anciens, mais l'animal dont il cst ici question, qui porte, en eflet, tous les caractères que Caïus donne au sien.

En recherchant dans les voyageurs les notices qui pouvoient avoir rapport à cet animal remarquable par sa taille et surtout par la grandeur de ses cornes, nous n'avons rièn trouvé qui en approche de plus près que l'animal indiqué par Kolbe sous le nom de chievre sauvage du cap de Bonne-Espérance. "Cette chèvre, dit" il , qui chez les Hottentots n'a point recu de nom, " et que jappelle chievre sauvage, est fort remarqua"ble à plusieurs égards : elle esı de la taille d'un grand " cerf; sa tête est fort belle et ornée de deux cornes "unies, recourbées et pointues, de trois pieds de "long, dont les extrémités sont distantes de deux "pieds. "Ces caractères nous paroissent convenir parfaitement à l'animal dont il est ici question : mais 
il est vrai que, n’en ayant vu que la tête, nous nc pouvons pas assurer que le reste de la description de Kolbe lui convienne également; nous le présumons seulement comme une chose vraisemblable, qui demande à être vérifiée par des observations ultérieures.

* Nous donnons ici la figure du condoma, qu'on appelle au cap de Bonne-Espérance coesdoes : cette figure manquoit à mon ouvrage. N'ayant pas eu la dépouille entière de l'animal, je n'avois pu donner alors que la figure de la tête et des cornes, et c'est de là qu'étoit venue, sur le mot coesdoes ou coudous, la méprise que nous venons de rectifier dans l'article du canna : mais il nous est arrivé depuis une peau bien conservée de ce bel animal. M. le chevalier d'Auvillars, lieutenant-colonel du régiment de Cambresis. en a aussi apporté une, de laquelle M. de Brosse, premier président du parlement de Dijon, m'a envoyi une très bonne description qui se rapporie parfaitement avec tout ce que j’ai dit au sujet du condoma.

"L’animal entier, dit M. de Brosse, fut donné au chevalier d'Auvillars, au cap de Bonne-Espérance. par M. Berg, secrétaire du conseil hollandois, comme venant de l'intérieur de l'Afrique, et d'un lieu situé à environ cent lieues du Cap; on lui dit qu'il s'appeloit coesdoes. Il y avoit trois de ces animaux morts, l'un plus grand, l'autre plus petit que celui-ci : il le fit très exactement dépouiller de sa peau qu'il a apportée en France; cette peau étoit assez épaisse pour faire des semelles de souliers. J'ai vu la peau entière : l'animal sembloit être de la forme d'un petit bœuf, mais plus haut sur ses jambes. Cette peáu étoit couverte d'un poil gris de souris assez ras; il y avoit me raio BUFFON. XVIr. 
blanche le long de l'épine du dos, d'où descendoient de chaque côté six ou huit raies transversales de même couleur blanche : il y avoit aussi an bas des yeux deux raies blanches posées en chevron renversé, et, de chaque côté de ces raies, deux taches de même couleur : le haut dı cou étoit garni de longs poils en forme de crinière, qui se prolongeoit jusque sur le garrot. Les cornes, mesurées en ligne droite, avoient deux pieds cinq pouces sept lignes de longueur, et trois pieds deux pouces trois lignes en suivant exactement leurs triples sinuosités sur l'arête continue; l'intervalle entre les cornes, à leur naissance, n'étoit que d'un pouce six lignes, et de deux pieds sept pouces à leurs extrémités : leur circonférence à la base étoit de huit pouces trois lignes : elles étoient bien faites, diminuoient régulièrement de grosseur en s'éloignant de leur naissance, et finissoient en pointe aiguë; elles étoient de couleur grise, lisses, et assez semblables, pour la substance, à celles du bouc, avec quelques rugosités dans le bas, mais sans aucune strie véritable. On pouvoit enlever en entier cette corne jusqu'au bout; après avoir ôté cette enveloppe cornée, mince, et parfaitement évidée, il reste un os de moindre diamètre, presque aussi long, pareillement contourné, de couleur blanc jannâtre, mais mal lisse, d'une substance lâche, peu compacte, friable, et cellulaire. La corne du pied ressembloit à celle d'une génisse de deux ans. La queue étoit courte et garnie de poils assez longs à l'extrémité."

Cette description faite par M. le président de Brosse est très bonne; je l'ai confrontée avec les dépouilles 
de ce même animal que j'avois reçues presque en même temps pour le Cabinet du Roi, et je n'ai rien trouvé à y ajouter ni retrancher.

MM. Forster, qui ont vu cet animal vivant, m'ont communiqué les notices suivantes. "Le condoma ou coesdoes a quatre pieds de hauteur, mesuré aux jambes de devant, et les cornes ont trois pieds neuf pouces de longueur; leurs extrémités sont éloignées l'une de l'autre de deux pieds sept ou huit pouces; elles sont grises, mais blanchâtres à la pointe; leur arête suit toutes leurs inflexions ou courbures, et elles sont un peu comprimées et torses en hélice. La femelle porte des cornes comme le mâle. Les oreilles sont larges; et la queue, qui n'a qu'un demi-pied de longueur, est brune à son origine, blanche sur le milieu, et noire à l'extrémité, qui est terminée par une touffe de poils assez longs.

"Le pelage est ordinairement gris et quelquefois roussâtre. Il y a sur le dos une ligne blanche qui s'étend jusquà la queue; il descend de cette ligne sept barres de même couleur blanche, dont quatre sur les cuisses et trois sur les flancs. Dans quelques individus, ces barres descendantes sont au nombre de huit èt même de neuf; dans d'autres, il n'y en a que six : mais ceux qui en ont sept sont les plus communs. Il y a sur l'arête du cou une espèce de crinière formée de longs poils. Le devant de la tête est noirâtre, et du coin antérieur de chaque oil il part une ligne blanche qui s'étend sur le inuseau; le ventre et les pieds sont d'un gris blanchâtrẹ. Il y a des larmiers sous les yeux.

"Ces animaux se trouvent dans l'intérieur des ter- 
res du cap de Bonne-Espérance; ils ne vont point en troupes comme certaines espèces de gazelles. Ils font des bonds et des sauts surprenants; on en a vu franchir une porte grillée qui avoit dix pieds de hauteur, quoiqu'il n'y eût que très peu d'espace pour pouvoir s'élancer. On peut les apprivoiser et les nourrir de pain; on en a eu plusieurs à la ménagerie du cap de Bonne-Espérance."

Nous ajouterons encore à ces observations l'excellente description de cet animal que M. Allamand vient de publier à la suite du quatrième volume de mes suppléments à l'Histoire naturelle, édition de Hollande; il y a joint une très belle figure d'un individa beaucoup plus grand que celui que $j$ 'ai fait dessiner et graver.

\section{SUR LE CONDOMA,}

Par M. le professeur ALraanasd.

* Quoique les cornes de l'animal à qui M. de Buffon a donné le nom de condoma soit assez connues et se trouvent très souvent dans les cabinets de curiosités naturelles, l'animal n'a jamais été décrit; il est pourtant assez remarquable pour mériter l'attention des voyageurs et des naturalistes.

M. de Buffon a eu raison de dire qu'il approchoit beancoup de l'animal que Caïus a donné sous le nom de strepsiceros, puisqu'on ne sauroit douter que ce ne soit le même, vu la parfaite conformité des cornes ${ }^{1}$.

1. M. de Buffon remarque que Gaïus s'est trompé en donnant à cet aniınal le nom de strepsiceros, qui ne désigne que l'antilope, dont le 
II soupçonne aussi que ce pourroit bien être l'animal auquel Kolbe a donné le nom de chèvre sauvage : et effectivement la description que celui-ci en a faite a quelque rapport à celle que je vais donner du condoma; mais aussi il y a des différences nutables, comme on s'en apercevra bientôt.

M. Pallas, qui dans ses Spicilegia zoologica, fasc. I, page 17 , a donné une bonne description des cornes et de la tête du condoma, croit que M. de Buffon. s'est trompé en prenant cet animal pour cetre chèvre sauvage, parce qu'il n'en a point la barbe. S'il n'a pas d'autre raison que celle-là pour appuyer son avis, c'est lui qui s'est trompé; car le condoma a une barbe très remarquable.

Mais, sans nous arrêter aux conjectures qu'on a pu former sur la figure de cet animal, faisons-le connoître véritablement tel qu'il est, en lui conservant le nom de condoma que M. de Buffon lui a donné, quoique ce ne soit pas celui qu'on lui donne au Cap, où on l'appelle coesdoes ou coudous. Nous avons eu la

condoma diffère beaucoup. Le nouveau traducteur de Pline prétend que M. de Buffon s'est entièrement mépris au caractère distinctif des cornes du strepsiceros, auxquelles il n'accorde point la double flexion que $M$. de Buffon leur attribue : il veut qu'elles soient droites, mais cannelées en spirale; et cela fondé sur ce passage de Pline : "Erecta n autem (cornua) rugarumque ambitu contorta et in leve fastigium n exacuta, ut lyras diceres, strepsiceroti, quam addacem Africa ap"pellat; " ce quil traduit ainsi :

"Le chevreuil strepsiceros des Grecs, nommé addax en Afrique, a „ les cornes droites et terminées en pointes, mais contournées en spi- rale, et cannelées tout autcur. »

S'il avoit fait attention qu'il a omis dans sa traduction celle de ces mots, ut lyras diceres, qui ne convient qu’à la figure des cornes de l'antilope, il n'auroit sans doute pas fait cette critique. 
satisfaction d'en voir un ici vivant, qui a été envoyé du cap de Bonne-Espérance, en 1776 , à la ménagerie du prince d'Orange.

Je lui ai rendu de fréquentes visites; frappé de sa beauté, je ne pouvois me lasser de l'admirer, et je renvoyois de jour à autre d'en faire une description exacte : comme je me proposois d'y retourner pour le mieux examiner, j'eus le chagrin d'apprendre qu'il étoit mort ; et ainsi tout ce que j'en pourrois dire se' réduiroit à ce que ma mémoire me fourniroit. Heureusement avant que d'être conduit à la ménagerie du prince, il avoit passé par Amsterdam; là M. Schneider en fit faire le dessin, et M. le docteur Klockner, qui ne perd aucune occasion d'augmenter nos connoissances en fait d'histoire naturelle, l'examina avec les yeux d'un véritable observateur, et en fit une description qu'il a eu la bonté de me communiquer : ainsi c'est à lui qu'on doit les principaux détails où je vais entrer.

On est surpris au premier coup d'œil qu'on jette sur cet animal : la légèreté de sa marche, la finesse de ses jambes, le poil court dont la plus grande partie de son corps est couverte, la manière haute dont i! porte sa tête, la grandeur de sa taille, tout cela annonce un très beau cerf; mais les grandes et singulières cornes dont il est orné, les taches blanches qu'il a au dessous des yeux, et les raies de même couleur que l'on voit sur son corps, et qui ont quelque rapport à celles du zèbre, font qu'on l'en distingue bientôt, de façon cependant qu'on seroit tenté de lui donner la préférence. La tête du condoma ressemble assez à celle du cerf; elle est couverte de poils bruns, 
avec un petit cercle de couleur roussâtre autour des yeux, du bord inférieur de chacun desquels part une ligne blanche, qui s'avance obliquement et en s'élargissant du côté du museau, et enfin se termine en pointe; de côté et d'autre de ces lignes on voit trois taches rondes d'un blanc pâle, dont les deux supérieures sont de la grandeur d'une pièce de vingt sous, et celle qui est au dessous, près du museau, est un peu plus grande. Les yeux sont noirs, bien fendus, et ont beaucoup de vivacité; le bout du museau est noir et sans poils ; les deux lèvres sont couvertes de poils blancs, et le dessous de la mâchoire inférieure est garni d'une barbe grisâtre de la longueur de cinq à six pouces, qui se termine en pointe. La tête est surmontée de deux cornes, de couleur brune tirant sur le noir, et couvertes de rugosités; elles ont une arête qui s'étend sur toute leur longueur, excepté vers leur extrémité, qui est arrondie et qui se termine en une pointe noirâtre; elles ont une double flexion, comme celles des antilopes, et sont précisément telies que celles qui ont été décrites par MM. de Buffon et Daubenton. Leur longueur perpendiculaire n'étoit que de deux pieds un pouce huit lignes dans l'animal que je décris; ce qui me porte à croire qu'il n'avoit pas encore acquis toute sa grandeur, car on trouve de ces cornes qui sont plus longues: j'en ai placé deux paires au cabinet de notre académie, dont les plus courtes ont deux pieds cinq pouces en ligne droite, et trois pieds et demi en suivant les contours; la circonférence de leur base est de neuf pouces, et il y a entre leurs pointes une distance de deux pieds et demi.

Les oreilles sont longues, larges, et de la même 
couleur que le corps, qui est couvert d'un poil fort court, d'une couleur fauve tirant sur le gris. Le dessus du cou est garni d'une espèce de crinière, coutposée de longs poils bruns, qui s'étendent depuis l'origine de la tête jusqu'au dessus des épaules; là ils deviennent plus courts; changeant de couleur, ils forment tout le long du dos jusqu'à la queue une raie blanche: le reste du cou est couvert de semblables poils bruns et assez longs, particulièrement dans la partie inférieure jusqu'au dessous de la poitrine. De chaque côté de cette ligne blanche qui est sur le dos, partent d'autres raies aussi blanches, de la largeur d'environ un pouce, qui descendent le long des côtés; ces raies sont au nombre de neuf, et la première est derrière les pieds de devant; il y en a quatre qui descendent jusqu'au ventre; la troisième est plus courte; les quatre dernières sont sur la croupe, cemme on le voit dans la figure.

La queue est longue de plus d'un pied; elle est un peu aplatie et fournie de poils d'un gris blanchâtre sur les bords, et qui forment à l'extrémité une touffe d'un brun noirâtre. Les jambes sont déliées, mais nerveuses, sans cette touffe de poils ou brosse qui se trouve sur le haut des canons des jambes postérieures des cerfs. La corne du pied est noire et fendue, comme celle de tous les animaux qui appartiennent d cette classe.

Cetle description est celle du condoma de la ménagerie du prince d'Orange : cependant il ne faut pas eroire que tous les condomas soient précisément ınarqués de la.même façon. M. Klockner a vu diverses peaux où les raies blanches différoient par leur lon- 
gueur et par leur position : mais on comprend qu'une telle différence n'est pas une variété qui mérite quelque attention. Il y a une chose plus importante à remarquer ici, c'est que la plupart de ces peaux n'ont point de barbe, et l'on en voit une dans le cabinet de la société de Harlem, qui est très bien préparée pour représenter au vrai la figure de l'animal, mais aussi sans barbe. Y auroit-il donc des condomas barbus et d'autres sans barbe? c'est ce que j'ai peine à croire; et je pense avec M. Klockner que la barbe est tombée de ces peaux quand on les a préparées, et cela d'autant plus que si on les regarde avec attention, on voit la place où parroissent ayoir été les poils dont la barbe éloit composée.

Notre condoma étoit fort doux; il vivoit en bonne union avec les animaux qui paissoient avec lui dans le même parc; et dès qu'il voyoit quelqu'un s'approcher de la cloison qui étoit autour, il accouroit pour prendre le pain qu'on lui offroit. On le nourrissoit de riz, d'avoine, d'herbes, de foin, de carottes, etc. Dans son pays natal, il broutoit l'herbe et mangeoit les boutons et les feuilles des jeunes arbres, comme les cerfs et les boucs. Quoique je l'aie vu très fréquemment, je ne l'ai jamais entendu donner aucun son, mais M. Klockner nous apprend que sa voix étoit à peu près celle de l'âne.

Voici ses dimensions telles qu'elles ont été prises sur l'animal vivant, par le même M. Klockner, sur la mesure pied de roi.

Longueur du corps depuis le bout du museau jusqu’à la queue. .............

Longueur de la tếte depuis le bont du museau jus-

pieds. pouc. ligu. 
qu'aux oreilles.

pieds. pour. lign.

Longueur de la lête jusqu'aux cornes. . . . . . . . 848

Longueur des cornes mesurées en ligne droite . . 2 1 8

Longueur des oreilles. .................... 84

Ilauteur du train de devant, ......... $4 \quad 3 \quad 6$

Hauteur du train de derrière. . . . . . . 4 1 "

Circonférence du corps derrière les jambes de devant...................... 4 4

Circonférence du milieu du corps. ..... $4 \quad 5 \quad 8$

Girconférence du corps devant les jambes posté-

rieures. . . . . . . . . . . . . . . . . . . . . . . . . . ${ }^{2}{ }_{2}{ }_{2}$

En comparant cette description du condoma avec celle que Kolbe a donnée de la chèvre sauvage du cap de Bonne-Espérance, on a la confirmation de ce que j'ai dit ci-devant; c'est que le condoma ressemble, à quelques égards, à cette chèvre : il est de la même taille; son poil est à peu près de la même couleur grise, et il a, comme elle, une barbe et des raies qui descendent depuis le dos sur les côtés. En voilà assez pour autoriser M. de Buffon à dire qu'il n'avoit trouvé aucune notice d'animal qui approchât de plus près du condoma que la chèvre sauvage de Kolbe; mais aussi j’ai observé qu'il y avoit des différences remarquables entre ces deux animaux. Le nombre des raies blanches qui descendent sur leurs côtés n'est pas le même, et elles sont différemment posées; la chèvre ne paroît point avoir ces taches blanches qui sont au dessous des yeux du condoma, et qui sont trop frappantes pour qu'on puisse supposer que Kolbe ait oublié d'en parler: mais ce qui distingue principalement ces animaux sont les cornes; celles de la chèvre sont dites simplement recourbées, ce 
qui n'exprime point cette double flexion qui est si remarquable dans celles du condoma : aussi, dans la figure que Kolbe a ajoutée à sa description, la chèvre y est représentée avec des cornes qui seroient toutà-fait droites sans une légère courbure au haut, à peine perceptible.

L'auteur d'une histoire naturelle qui se publie en hollandois a donné la figure d'un animal tué sur les côtes orientales d'Afrique, et dont le dessin lui a été communiqué par un médecin de ses amis. A en juger par les cornes, cet animal est un véritable condoma; mais s'il est bien représenté, il a le corps plus lourd, et il n'a aucune des raies ni des taches blanches qui se trouvent sur celui que nous avons décrit.

M. Muller, qui travaille en Allemagne à éclaircir le Système de la Nuture de Linnæus, a donné une planche coloriée qui représente passablement le condoma.

\section{LE NIL-GAUT.}

Antilope picta. L.

CET animal est celui que plusieurs voyageurs ont: appelé bæuf gris du Mogol, quoiqu'il soit connu sous le nom de nil-gaut dans plusieurs endroits de l'Inde. Nous avons vu vivants le mâle et la femelle dans le parc du château royal de la Muette, où on les nourrit encore aujourd'hui (juin 1774), et où on les laisse en pleine liberté : nous les avons fait dessiner tous deux d'après nature. 
Quoique le nil-gaut tienne du cerf par le con et la tête, et du bœuf par les cornes et la queue, il est néanmoins plus éloigné de l'un et de l'autre de ces genres que de celui des gazelles ou des grandes chèvres. Les climats chauds de l'Asie et de l'Afrique sont ceux où les grandes espèces des gazelles et des chèvres sont plus multipliées : on trouve dans les mêmes lieux, ou à peu de distance les uns des autres, le condoma, le bubale, le koba, et le nil-gaut dont il est ici question. L'espèce de barbe qu'il a sous le cou et le poitrail, la disposition de son pied et de ses sabots, plusieurs autres rapports de conformation avec les grandes chèvres, le rapprochent de cette famille plus que de celle des cerfs ou de celle des boeufs; pt dans les animaux d'Europe, c'est au chamois qu'on pourroit le comparer plutôt qu'à tout autre animal : mais dans la réalité, le nil-gaut est le seul de son genre, et d'une espèce particulière qui ne tient au genre dubouf, du cerf, de la chèvre, de la gazelle et du chamois, que par quelques caractères ou rapports particuliers. Il a, comme tous ces animaux, la faculté de ruminer; il court de manvaise grâce et plus mal que le cerf, quoiqu'il ait la tête et l'encolure aussi legères : mais ses jambes sont plus mauvaises et plus inégales en hauteur; celles de derrière étant considérablement plus courtes que celles de devant, il porte la queue horizontalement en courant, et la tient basse et entre les jambes lorsqu'il est en repos. Le mâle a des cornes et la femelle n'en a point; ce qui la rapproche encore du genre des chèvres, dans lequel d'ordinaire la femelle n'a point de cornes; celles du nil-gaut sont creuses, et ne tombent pas comme le bois des cerfs, 
des daims et des chevreuils; caractère qui le sépare absolument de ce genre d'animaux. Comme il vient d'un pays où la chaleur est plus grande que dans notre climat, il sera peut-être difficile de le multiplier ici : ce seroit néanmoins une bonne acquisition à faire, parce que cet animal, quoique vif et vagabond comme les chèvres, est assez doux pour se laisser régir, et qu'il donneroit, comme elles, de la chair mangeable, du bon suif, et des peaux plus épaisses et plus fermes. La femelle est actuellement plus brune que le mâle, et paroît plus jeune ; mais elle deviendra peut-être d. la même couleur grise avec l'âge.

Voici le détail de la description que j'ai faite de ces deux animaux avec M. Sève, qui les a dessinés. Le mâle étoit de la gyrandeur d'un cerf de taille moyenne; les cornes n'avoient que six pouces de longueur, sur deux pouces neuf lignes de grosseur à la base. Il n'y avoit point de dents incisives à la mâchoire supérieure; celles de la mâchoire inférieure étoient larges et peu longues : il y a un espace vide entre elles et les mâchelières. Le train de derrière, dans le mâle, est plus bas que celui de devant, et l'on voit une espèce de bosse ou d'élévation sur les épaules, et cet endroit est garni d'une petite crinière qui prend du sommet de la tête et finit au milieu du dos: sur la poitrine se trouve une touffe de longs poils noir's. Le pelage de tout le corps est d'un gris d'ardoise : mais la tête est garnie d'un poil plus fauve, mêlé de grisâtre, et le tour des yeux d'un poil fauve clair, avec une petite tache blanche à l'angle de chaque œil; le dessus du nez brun; les naseaux sont noirs avec une bande blanche à côté. Les oreilles sont fort grandes 
et larges, rayées de trois bandes noires vers leurs extrémités; la face extérieure de l'oreille est d'un gris roussâtre, avec une tache blanche à l'extrémité. Le sommet de la tête est garni d'un poil noir, mêlé de brun, qui forme, sur le haut du front, une espèce de fer à cheval; il y a sous le cou, près de la gorge, une grande tache blanche; le ventre est gris d'ardoise comme le corps. Les jambes de devant et les cuisses sont noires sur la face extérieure, et d'un gris plus foncé que celui du corps sur la face intérieure. Le pied est court et ressemble à celui du cerf; les sabots en sont noirs : il y a, sur la face externe des pieds de devant, une tache blanche, et sur l'interne deux autre taches de même couleur. Les jambes de derrière sont beaucoup plus fortes que celles de devant : elles sont couvertes de poils noirâtres, avec deux grandes taches blanches sur les pieds, tant en dehors qu'en dedans; et plus bas il y a de grands poils châtains qui forment une touffe frisée. La queue est d'un gris d'ardoise vers le milieu, et blanche sur les côtés; elle est terminée par une touffe de grands poils noirs; le dessous est en peau nue. Les poils blancs des côtés de la queue sont fort longs, et ne sont point couchés sur la peau comme ceux des autres parties du corps; ils s'étendent au contraire en ligne droite de chaque côté. Le fourreau de la verge est peu apparent, et l'on a observé que le jet de l'urine est fort petit dans le mâle.

Il y a à l'École vétérinaire une peau bourrée d'un de ces animaux qui diffère de celui qu'on vient de décrire par la couleur du poil, qui est beaucoup plus brune, et par les cornes qui sont plus grosses à leur 
base, et cependant moins grandes, n'ayant que quatre pouces et demi de longueur.

La femelle du nil-gaut, qui étoit au parc de la Muette, vient de mourir an mois d'octobre 1774 ; elle étoit bien plus petite que le mâle, et en même temps plus svelte et plus haute sur ses jambes; sa couleur étoit roussâtre, mélangée d'un poil fauve pâle et de poils d'un brun roux, au lieu que le pelage du mâle étoit en général de couleur ardoisée. La plus grande différence qu'il y eût entre cette femelle et son mâle étoit dans le train de derrière, qu'elle avoit plus élevé que celui de devant, tandis que c'est le contraire dans le mâle ; et cette différence pourroit bien n'être qu'individuelle, et ne se pas trouver dans l'espèce entière. Au reste, ce mâle et cette femelle se ressễnbloient par tous les autres caractères extérieurs et même par les taches; ils paroissoient avoir un grand attachement l'un pour l'autre; ils se léchoient souvent, et, quoiqu'ils fussent en pleine liberté dans le parc, ils ne se séparoient que rarement, et ne se quittoient jamais pour long-temps.

M. William Hunter, docteur en médecine, membre de la Société de Londres, a donné, dans les Transactions philosophiques, un Mémoire sur le nilgaut, avec une assez bonne figure. M. Leroy, de l'Académie des Sciences de Paris, en ayant fait la traduction avec soin, j'ai cru faire plaisir aux amateurs de l'histoire naturelle de la joindre ici, d'autant que M. Hunter a observé cet animal de beaucoup plus près que je n'ai pu le faire.

"On doit compter, dit M. Hunter, au nombre des richesses qui nous ont été apportées des Indes dans 
ces derniers temps, un bel animal appelé nil-ghau; il est fort à souhaiter qu'il se propage en Angleterre, de manière à devenir un de nos animaux les plus utiles, ou, au moins, un de ceux qui parent le plus nos campagnes; il est plus grand qu'aucun des ruminants de ce pays-ci, excepté le bœuf; il y a tout lieu de croire qu'on en trouvera la chair excellente; et, s'il peut être assez apprivoisé pour s'accoutumer au travail, il y a toute apparence que sa force et sa grande vitesse pourront être employées avantageusement.

"Les représentations exactes des animaux par la peinture en donnent des idées beaucoup plus justes que de simples descriptions. Quiconque jettera les yeux surqe portrait qui a été fait sous mes yeux par M. Stublo, cet excellent peintre d'animaux, ne sera jamais embarrassé de reconnoître le nil-ghau partout où il pourra le rencontrer. Quoi qu'il en soit, je vais tenter la description de cet animal, en y joignant ensuite tout ce que j'ai pu apprendre de son histoire. Ce détail ne sera pas très exact : mais les naturalistes auront une sorte de plaisir en apprenant au moins quelque chose de ce qui regarde ce bel et grand animal, dont jusqu'ici nous n'avions ni descriptions ni peintures.

„Le nil-ghau mâle me frappa à la première vue, comme étant d'une nature moyenne entre le taureau et le cerf, à peu près comme nous supposerions que seroit un animal qui seroit le produit de ces deux espèces d'animaux; car il est d'autant plus petit que l'un, qu'il est plus grand que l'autre, et on trouve dans ses formes un grand mélange de ressemblance a 
tous les deux; son corps, ses cornes, et sa queue ressemblent assez à ceux du taureau; et sa tête, son cou, et ses jambes approchent beaucoup de celles du cerf.

\ Sa couleur. La couleur est, en général, cendrée ou grise, d'après le mélange des poils noirs et blancs: la plupart de ces poils sont à moitié noirs et à moitié blancs; la partie blanche se trouve du côté de la racine. La couleur de ses jambes est plus foncée que celle du corps : on en peut dire de même de la tête, avec cette singularité que cette couleur plus foncée n'y est pas générale, mais seulement dans quelques parties qui sont presque toutes noires; dans quelques autres endroits, dont nous parlerons plus bas, le poil est d'une belle couleur blanche.

"Son tronc. La hauteur de son dos, où il y a une légère éminenee au dessus de l'omoplate, est de quatre pieds un pouce (anglois); et à la partie la plus élevée immédiatement derrière les reins, cette hauteur n'est que de quatre pieds; la longueur du tronc en général, vu de profil depuis la racine du cou jusqu'à l'origine de la queue, est d'environ quatre pieds, ce qui est à peu près la hauteur de l'animal; de façon que, vu de profil, et lorsque ses jambes sont parallèles, son dos et ses membres forment les trois côtés d'un carré, dont le terrain sur lequel il est placé fait le quatrième. Il a quatre pieds dix pouces de circonférence immédiatement derrière les épaules, et quelque chose de plus au devant des jambes de derrière; mais cette dernière dimension doit varier beaucoup, comme on l'imagine bien, selon que l'animal a le corps plus ou moins plein de nourriture.

"Son poil. Le poil sur le corps est, en général, HUF()N. XVH. 
plus rare, plus fort, el plus roide que celui du bouf; sous le ventre et aux parties supérieures de ses membres, il est plus long et plus doux que sur les côtés et sur le dos; tout le long du cou et de l'épine du dos, jusqu'à la partie postérieure de l'élévation qui est au dessus des omoplates, le poil est plus noir, plus long, et plus redressé, formant une espèce de courte crinière rare et élevée; les régions ombilicales et hypogastriques du ventre, lintérieur des cuisses, et toutes les parties qui sont recouvertes par la queue, sont blanches; le prépuce n'est point marqué par une touffe de poils, et ce prépuce ne saille que très peu.

"Ses testicules. Les testicules sont oblongs et pendants comme dans le taureau; la queue descend jusqu'à deux pouces au dessus de l'os du talon; l'extrémité en est ornée de longs poils noirs, ainsi que de quelques poils blancs, particulièrement du côté de l'intérieur : la queue, sur cette face intérieure, n'est point garnie de poils, excepté, comme on vient de le dire. vers son extrémité; mais, à droile el à güuche, il y a une bordure de longs poils blancs.

"Scs jambes. Les jambes sont minces en proporlion de leur longueur, non pas autant que celles de notre cerf, mais plus que celles de nos taureaux; les jambes de devant ont un peu plus de deux pieds sept pouces de long. 11 y a une tache blanche sur la partie de devant de chaque pied, presque immédiatement au dessus de chaque sabot, et une autre tache blanche plus petite au devant du canon, et au dessus de chacune il y a une touffe remarquable de hongs poils blancs, qui tourne autour en forme de boucles pendantes. Les sabots des jambes de devant paroissent 
être d'une longueur trop grande : cette singularité étoit fort remarquable dans chacun des cinq nil-ghaux que j'ai vus; cependant on conjecture que cela venoit d'avoir été renfermés, et en l'examinant dans l'animal mort, la conjecture s'est trouvée fondée.

.) Son cou. Le cou est long et mince comme dans le cerf; il y a à la gorge une belle tache de poils blancs de la forme d'un bouclier; et plus bas, au commencement de l'arrondissement du cou, il y a une touffe de longs poils noirs en forme de barbe.

"Sa tête. La tête est longue et mince; sa longueur depuis les cornes jusqu'à l'extrémité du nez est d'environ un pied deux ponces trois quarts; la cloison qui sépare les narines avoit été percée pour y passer une corde ou une bride, selon la manière des Orientaux d'attacher et de mener le bétail.

" $S a$ bouche. La fente de la bouche est longue, et la mâchoire inférieure est blanche dans toute l'étendne de cette fente; la mâchoire supérieure n'est blanche qu'aux narines.

"Ses dents. Ii y a six dents molaires de chaque côté des mâchoires, et huit incisives à la mâchoire inférieure; la première des incisives est fort large, et les autres plus petites en proportion de ce qu'elles sont placées plus en avant ou en arrière.

"Ses yeux. Les yeux, en général, sont d'une couleur foncée; car toute la partie de la conjonctive qu'on peut voir est de cette couleur : de profil, la cornée et tout ce qu'on peut voir au travers paroît bleu comme. l'acier bruni; la pupille est ovale et transversalement oblongue, et l'iris est presque noire.

"Ses oreilles. Les oreilles sont grandes et belles; 
elles ont plus de sept pouces de long, et s'élargissent considérablement vers leurs extrémités; elles sont blanches à leurs bords et dans l'intérieur, excepté dans l'endroit où deux bandes noires marquent le creux de l'oreille.

"Ses cornes. Les cornes ont sept pouces de long; elles ont six pouces de tour à leur origine, et diminuent par degrés; elles se terminent en une pointe mousse. Elles ont à leur origine trois faces plates, séparées par autant d'angles: l'un de ces angles est en devant de la corne, et par conséquent l'une des faces en forme le derrière; mais cette forme triangulaire diminue peu à peu, et se perd vers l'extrémité. Il y a sur la base, à l'origine des cornes, de légers plis ou rides circulaires, dont le nombre coirrespond à l'âge de l'animal. La corne, depuis la base jusqu'en haut, en est unie, et le hout est d'une couleur fort foncée. Ces cornes s'élèvent en haut et en avant, formant un anyle fort obtus avec le front ou la face; elles sont légèrement courbées; la concavité en est tournée vers l'intérieur et un peu en devant; leur intervalle, à leur origine, est de trois pouces un quart, à leur sommet de six pouces un quart, et dans l'intervalle du milieu un peu moins de six pouces.

"Sa nourriture. Il mange de l'avoine, mais pas avidement; il aime mieux l'herbe et le foin : cependant ce qu'il aime encore davantage, c'est le pain de froment, qu'il mange toujours avec délices. Quand il est altéré, il boit jusqu’à huit pintes d'eau.

n Sa fiente. Sa fiente est en forme de petites boules rondes de la grosseur d'une noix muscade.

* Ses mœurs. Quoiqu'on m'eût rapporté qu'il étoit 
extrêmement farouche, j'ai trouvé, tant que je l'ai eu en ma garde, que c'étoit, dans le fond, un animal très doux, et qui paroissoit aimer qu'on se familiarisât avec lui, léchant toujours la main de celui qui le flattoit ou qui lui présentoit du pain, et n'ayant jamais tenté de se servir de ses armes pour blesser qui que ce soit. Le sens de l'odorat dans cet animal paroît très fin, et semble le guider dans tous ses mouvements; quand quelque personne l'approche, il la flaire en faisant un certain bruit : il en faisoit autant quand on lui apportoit à boire ou à manger; et il étoit si facilement offensé par une odeur extraordinaire, ou si circonspect, qu'il ne vouloit pas goûter le pain que je lui présentois, lorsque ma main avoit touché de l'huile de térébenthine, ou quelques liqueurs spiritueuses.

"Sa manière de se battre est fort singulière; milord Clive l'a observée sur deux mâles qui avoient été enfermés dans une petite enceinte, et il me l'a raconté comme il suit : "Étant encore à une distance " considérable l'un de l'autre, ils se préparèrent au " combat en tombant sur leurs genoux de devant, et " s'avancèrent l'un vers l'autre d'un pas assez rapide, " en tortillant toujours et agenouillés de cette ma"nière; et quand ils furent arrivés à quelques pas "de distance, ils firent un saut et s'élancèrent l'un " contre l'autre."

"Pendant tout le temps que j'en eus deux dans mon écurie, je remarquai que, toutes les fois qu'on vouloit les toucher, ils tomboient sur leurs genoux de devant; ce qui leur arrivoit même quelquefois Jorsque je m'avancois devant eux : mais, comme ils 
ne s'élançoient jamais contre moi, j'étois si loin de penser que cette posture annonçoit leur colère ou une disposition au combat, que je la regardois au contraire comme une expression de tirnidité, ou d'une grande douceur, ou même d'humilité.

- La femelle. La femelle diffère tellement du mâle, qu'à peine pourroit-on les croire de la même espèce; elle est beaucoup plus petile: elle ressemble, par sa for'me et par sa couleur jaunâtre, à une jeune biche, et n'a point de cornes; elle a quatre tettes, et l'on croit qu'elle porte neuf mois; quelquefois elle produit deux petits, mais le plus souvent elle n'en fait qu'un. Le nil-ghau mâle, étant jeune, ressemble beaucoup par sa couleur à la femelle, et par conséquent à un jeune cerf.

"Son espèce. Lorsqu'on nous présente un nouvel animal, il est souvent fort difficile, et quelquefois même impossible, de déterminer son espèce uniquement par ses caractères extérieurs; mais, lorsque cet animal est disséqué par un anatomiste habile dans l'anatomie comparée, alors la question se décide communément avec certitude.

n D'après les caractères extérieurs uniquement, je soupçonnai ou plutôt je crus que le nil-ghau étoit un animal particulier et d'une espèce distincte. Quelques uns de mes anis le prirent pour un cerf; mais je fus convaincu qu'il n'étoit pas de ce genre, par la permanence de ses cornes qui ne tombent pas. D'autres pensèrent que c'étoit une antilope: mais les cornes et la grandeur de l'animal me firent croire encore que cen'en étoil pas une; et il avoit tant de rapport par sa forme, particulièrement la femelle, avec le 
cerf, que je ne pouvois pas le regarder comme du même genre que le taureau. Dans le temps du rut, on mit un de ces mâles nil-ghau avec une biche; mais on ne remarqua ni amour, ni même aucune attention particulière, entre ces deux animaux. Enfin, l'un de ces animaux étant mort, je fus assuré par mon frère, qui l'a disséqué, et qui a disséqué presque tous les quadrupèdes connus, que le nil-ghau est un animal d'une espèce nouvelle.

"Son histoire. Plusieurs de ces animaux mâles et femelles ont été apportés en Angleterre depuis quelques années : les premiers furent envoyés de Bombay en présent à milord Clive; ils arrivèrent au mois d'août $1_{76} 7$; il y en avoit un mâle et l'autre femelle, et ils continuèrent de produire dans ce pays-ci chaque année. Quelque temps après, on en amena deux autres qui furent présentés à la reine par M. Sukivan : et celte princesse, étant toujours disposée à encourager toute espèce de recherches curieuses et utiles dans l'histoire naturelle, me fit donner la permission de les garder pendant quelque temps; ce qui me mit à portée, non seulement de pouvoir les décrire et d'en avoir une peinture bien exacte, mais encore de disséquer, avec le secours de mon frère, l'animal mort, et d'en conserver la peau et le squelette. Milord Clive a eu la bonté de me donner tous les éclaircissements qu'il a pu me fournir pour en faire l'histoire, ainsi que le général Carnat, et quelques autres personnes.

" Ces animaux sont regardés comme des raretés dans tous les établissements que nous avons dans I'Inde; ils y sont amenés de l'intérieur du pays en 
présent aux nababs et autres personnes considérables. Le lord Clive, le général Carnat, M. Walsh, M. Watts, et beaucoup d'autres personnes qui ont vu une grande partie de l'Inde, m'ont tous dit qu'ils ne l'avoient jamais vu sauvage. Bernier, autant que je l'ai pu décou. vrir, est le seul auteur qui en fasse mention. Dans le quatrième volume de ses Mémoires, il fait le récit d'un voyage qu'il entreprit en 1664, depuis Delhi jusqu'à la province de Cachemire, avec l'empereur mogol Aureng-zeb, qui alla dans ce paradis terrestre, comme le regardent les Indiens, pour éviter les chaleurs de l'été. En parlant de la chasse, qui faisoit l'amusement de l'empereur dans ce voyage, il décrit, parmi plusieurs autres animaux, le nil-ghau, mais sans rien dire de plus de cet animal, sinon que quelquefois l'empereur en tuoit un si grand nombre, qu'il en distribuoit des quartiers tout entiers à tous ces omrhas; ce qui montre qu'ils étoient en grand nombre, sauvages dans cette contrée, et qu'on en regardoit la chair ou la viande comme fort bonne ou délicieuse.

" Ceci paroît s'accorder avec la rareté de ces animaux au Bengale, à Madras et à Bombay. Cachemire est une des provinces les plus septentrionales de l'empire du Mogol : et ce fut en allant de Delhi vers cette province que Bernier vit l'empereur les chasser.

"Son nom. Le mot nil-ghau (car telles sont les lettres composantes de ce nom qui correspondent au persan), quoique prononcé comme s'il étoit écrit neel-gau (en françois nil-ga), signifie une vache bleue, ou plutòt un taureau bleu, gau étant masculin. Le mâle de ces animaux a en eflet de justes titres à 
ce nom, non seulement par rapport à sa ressemblance avec le taureau, mais encore par la teinte bleuâtre qui se fait remarquer sensiblement dans la couleur de son corps; mais il n'en est nullement de même de la femelle, qui a beaucoup de ressemblance, et quant ¿े la couleur et quant à la forme, avec notre cerf. Les nil-ghaux qui sont venus en Angleterre ont été presque tous apportés de Surate ou de Bombay, et ils paroissent moins rares dans cette partie de l'Inde que dans le Bengale; ce qui donne lieu de conjecturer qu'ils pourroient être indigènes dans la province de Guzarate, l'une des provinces les plus occidentales de l'empire du Mogol, étant située au nord de Surate, et s'étendant jusqu'à l'océan indien.

"Un officier ${ }^{4}$ qui a deıneuré long-temps dans l'Inde a écrit pour obtenir toutes les connoissances et tous les éclaircissements qu'on pourroit se procurer sur cet animal. Nous espérons recevoir en conséquence, dans le cours de l'année prochaine, quelques détails satisfaisants à ce sujet, quoique les habitants de ces contrées, selun ce qu'en dit cet officier, aient peu d'inclination pour l'histoire naturelle, et même en général pour toute espèce de connoissances."

En comparant la gravure de cet animal donnée dans les Transactions philosophiques, avec les dessins que nous avons faits d'après nature dans le parc de La Muette, près de Paris, nous avons reconnu que, dans la gravure angloise, les oreilles sont plus courtes, les cornes un peu plus émoussées, le poil, sous la partie du cou, plus court, plus roide, et ne faisant pas un 
flocon. Dans cette même gravure, on ne voit pas la touffe de poil qui est sur les éperons des pieds de derrière du mâle; enfin la crinière sur le garrot paroît aussi plus courte que dans nos dessins : mais toutes ces petites différences n'empêchent pas que ce ne soit le même animal.

M. Forster m'écrit, au sujet du nil-gaut, que, quoique M. Hunter, qui en a donné la description, ait dit qu'il est d'un nouveau genre, il paroît cependant qu'il appartient à la classe des antilopes, et que ses mœurs et sa forme, comparées avec quelques unes des grandes espèces d'antilopes, semblent prouver qu'on ne devroit pas l'en séparer. Il ajoute que l'animal décrit par le docteur Parsons est certainement le même que le nil-gaut; mais il croit que M. Parsons n'a pas bien remarqué les pieds : car ils sont ordinairement marqués de blanc dans tous ceux que l'on a vus depuis; et il dit, comme M. Hunter, que ces animaux avoient produit en Angleterre, et que même on l'a assuré qu'il y avoit exemple d'une femelle qui avoit fait deux petits à la fois.

\section{LE GUIB.}

Antilope Scripta. L.

LE guib est un animal qui n'a été indiqué par ancun naturaliste, ni même par aucun voyageur; cependant il est assez commun au Sénégal, d’où M. Adan- 
son en a rapporté les dépouilles, et a bien voulu nous les donner pour le Cabinet du Roi. Il ressemble aux gazelles, surtout au nanguer, par la grandeur et la figure du corps, par la légèreté des jambes, par la forme de.la tête et du museau, par les yeux, par les oreilles, et par la longueur de la queue et le défaut de barbe ; mais toutes les gazelles, et surtout les nanguers ont le ventre d'un beau blanc, au lieu que le guib a la poitrine et le ventre d'un brun marron assez foncé : il diffère encore des gazelles par ses cornes, qui sont lisses, sans anneaux transversaux, et qui portent deux arêtes longitudinales, l'une en dessus et l'autre en dessous, lesquelles forment un tour de spirale depuis la base jusqu'à la pointe; elles sont aussi un peu comprimées, et par ces parties le guib approche plus de la chèvre que de la gazelle : néanmoins il n'est ni l'un ni l'autre; il est d'une espèce particulière, qui nous paroît intermédiaire entre les deux. Cet animal est remarquable par des bandes blanches sur un fond de poil brun marron; ces bandes sont disposées sur le corps en long et en travers, comme si c'étoit un harnois. Il vit en société, et se trouve par grandes troupes dans les plaines et les bois du pays de Podor. Comme M. Adanson est le premier qui ait observé le guib, nous publions ici bien volontiers la description qu'il en a faite, et qu'il nous a communiquée ${ }^{1}$.

1. Guib chez les Nègres Oualofes ou Jalufes. "Gazella cornibus " rectis spiralibus; caput, rostrum, nasus, oculi, uti nanguer. Cornua b recta spiralia, spira prima nigra, nitida, subcompressa, angulis - duobus lateralibus, antice convexa, pone plana, apice conico terew tia... Aures uti nanguer intus subnuda, quinrque pollices longæ... 


\section{LA GRIMME.}

\section{Antilope Grimmia. I.}

CET animal n'est connu des naturalistes que sous le nom de chèvre de Grimm; et comme nous ignorons celui qu'il porte dans son pays natal, nous ne pouvons mieux faire que d'adopter cette dénomination précaire. On trouve une figure de cet animal dans les Éphémérides d'Allemagne, qui a été copiée dans la Collestion académique. Le docteur Herman Grimm est le seul avant nous qui en ait parlé; et ce qu'il en dit a été copié par Ray, et ensuite par tous ceux qui ont écrit sur la nomenclature des animaux. Quoique sa description soit incomplète, elle désigne deux caractères si marqués, que nous ne croyons pas nous méprendre en présentant ici pour la chèvre de Grimm la tête d'un animal du Sénégal, qui nous a été don-

" Cauda decem pollices longa, pilis longis hirta. Dentes duo et tri- ginta. Pedes uti nanguer. Corpus totum fere fulvum. Albæ fasciæ sex n utrinque in dorso transversæ, et fasciæ albæ duæ longitudinales ven^ tri laterales. Maculæ albæ utrinque octo ad decem supra femora, n orbiculatæ. Collum subtus album et genæ albæ; latera pedum inte" riora alba; macula alba paulo infra oculos. Frons media nigra, - linea supra dorsum longiturlinalis nigra, venter subtus niger; pars " antica peclum anteriorum, ungulæ et cornua nigra; longitudo ab „ apice rostri ad unum quatuor pedes cum dimidio; altitudo a pedi- bus posticis ad dorsum duos pedes octo pollices; pili omnes bre" vissimi, lucidi, vix unum pollicem longi, corpori adpressi. Pul" chrum animal a $D$. Andriot missum. " (Notice manuscrite, communiquéc par M. Adanson, de l'Académie royale des Sciences. 

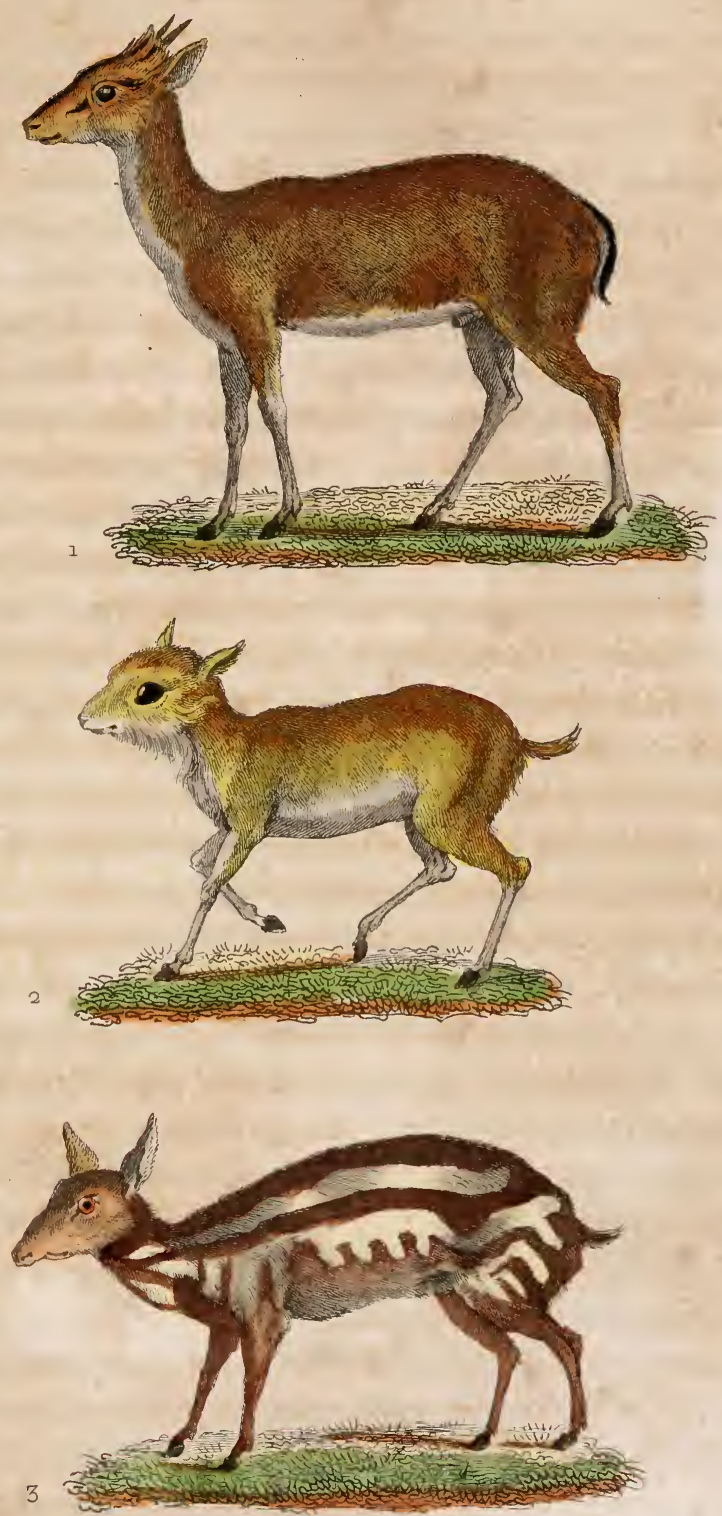

1. LA GRTMME - 2. LE CHEVROTATN_- 3. LE MEMINA 

née par M. Adanson. Le premier de ces caractères est une énorme cavité an dessous de chaque œil, laquelle forme de chaque côté du nez un enfoncement si grand dans la mâchoire supérieure, qu'il ne laisse qu'une lame d'os très mince contre la cloison du nez; le second caractère est un bouquet de poils bien fourni, et dirigé en haut sur le sommet de la tête. Ils suffisent pour distinguer la grimme de toutes les autres chèvres ou gazelles : elle ressemble cependant aux unes et aux autres, non seulement par la forme du corps, mais même par les cornes, qui sont annelées vers la base et striées longitudinalement, comme celles des autres gazelles, et en même temps dirigées horizontalement en arrière et très courtes, comme celles de la petite chèvre d'Afrique dont nous avons parlé. Au reste, cet animal étant plus petit que les chèvres, les gazelles, etc., et ne portant que des cornes très courtes, nous paroît faire la nuance entre les chèvres et les chevrotains.

Il y a apparence que dans l'espèce de la grimme le mâle seul porte des cornes; car l'individu dont le docteur Grimm a donné la description et la figure n'avoit point de cornes; et la tête que nous a donnée M. Adanson porte au contraire deux cornes, à la vérité très courtes et cachées dans le poil, mais cependant assez apparentes pour ne pouvoir échapper au dessinateur, et encore moins à l'observateụr. D'ailleurs on verra dans l'histoire des chevrotains que dans celui de Guinée le mâle seul a des cornes; et c'est ce qui nous fait présumer qu'il en est de même dans l'espèce de la grimme, qui, à tous égards, approche plus du chevrotain que d'aucun autre animal. 
* Aux faits historiques que nous avons pu recueillir sur cet animal, nous n'avons joint que la figure de deux têtes, l'une décharnée, et l'autre couverte d'une partie de la peau. MM. Vosmaër et Pallas ont donné depuis des descriptions de ce joli animal, avec une bonne figure que nous avons fait copier. Nous remarquerons que les têtes de la grimme qui sont au Cabinet du Roi ont les cornes un peu courbes en avant à leurs extrémités, au lieu que les cornes de la grimme de MM. Vosmaër et Pallas sont au contraire un peu courbes en arrière dans leur longueur. Les oreilles de la grimme qui est au Cabinet du Roi sont rondes à leurs extrémités, au lieu que, dans la figure donnée par MM. Pallas et Vosmaër, ces mêmes oreilles finissent en pointe. Seroit-ce variété de nature, ou incorrection de dessin? La grimme de MM. Vosmaër et Pallas a le bout du nez noir, et une bande noire qui s'étend depuis le nez le long du chanfrein, et finit au bouquet ou à l'épi de poils qui est placé sưr le haut du front. La tête qui est au Cabinet du Roi n'a point cette bande noire sur le chanfrein. Ces légères différences n'empêchent pas que ce ne soit le inême animal; et nous allons donner ici un extrait de la description qu'en fait $M$. Vosmaër.

Il appelle cet animal petit bouc damoiseau de Guinée; apparemment à cause de sa gentillesse et de l'élégance de sa figure; mais le nom ne fait rien à la chose, et nous lui conserverons celui de chèvre de Grimm, parce qu'il est connu sous ce nom de tous les naturalistes.

"L'animal étoit mâle, dit M. Vosmaër; il est des plus jolis et des plus mignons qu'on puisse voir : il fut 
envoyé de Guinée en Hollande avec treize autres de même espèce et des deux sexes, dont donze moururent pendant le voyage, et de ce nombre furent toutes les femelles; en sorte qu'il ne resta que deux mâles vivants, que l'on mit dans la ménagerie de M. le prince d'Orange, où l'un des deux mourut bientôt, pendant l'hiver de 1764 . Suivant nos informations, les femelles de cette espèce ne portent point de cornes. Ces animaux sont d'un naturel fort timide; le bruit, et surtout le tonnerre, les effraie beaucoup. Lorsqu'ils sont surpris, ils marquent leur épouvante en soufflant du nez subitement et avec force.

Celui qui est encore vivant dans la ménagerie de M. le prince d'Orange (en 1 -66), étoit d'abord sauvage : mais il est devenu, avec le temps, assez privé; il écoute quand on l'appelle par son nom tetje, et en l'approchant doucement avec un morceau de pain, il se laisse volontiers gratter la tête et le cou. Il aime la propreté, au point de ne jamais souffrir aucune petite ordure sur tout son corps, se grattant souvent à cet effet de l'un de ses pieds de derrière; et c'est ce qui lui a fait donner ici le nom de tetje, dérivé de tettig, c'est-à-dire, net ou propre : cependant, si on le frotte un peu long-temps sur le corps, il s'attache aux doigts une poussière blanche, comme celle des chevaux qu'on étrille.

Cet animal est d'une extrême agilité; et lorsqu'il est en repos, il tient souvent un de ses pieds de devant élevé et recourbé, ce qui lui donne un air très agréable. On le nourrit avec du pain de seigle et des carottes; il mange volontiers aussi des pormmes de terre; il est ruminant, et il rend ses excréments en 
petites pelotes, dont le volume est considérable, relativement à sa taille..."

Le docteur IIerman Grimm a dit que l'humeur jaunâtre, grasse, et visqueuse, qui suinte sur les cavités ou enfoncements que porte cet animal au dessous des yeux, a une odeur qui participe du castoréum et du musc. M. Vosmaër observe que, dans le sujet vivant qu'il décrit, il n'a pu découvrir la moindre odeur dans cette matière visqueuse; et il remarque avec raison que la fgure donnée par Grimm est défectueuse à tous égards, représentant sur le devant de la tête une touffe de poils qui n'y est pas, et son sujet, qui étoit femelle, n'ayant point de cornes : "au lieu que le nôtre, dit M. Vosmaër, qui est mâle, en a d'assez grandes à proportion de sa taille; et, au lieu de cette haute et droite touffe de poils, il a seulement entre les cornes un petit bouquet de poils qui s'élève un peu en pointe. Il est à très peu près de la grandeur d'un chevreau de deux mois ^ (quoique âgé probablement de trois ou quatre ans: je crois devoir faire cette observation, parce qu'il avoit été envoyé avant l'hiver $1-64$, et que M. Vosmaër a publié sa description en 176 ). "Il a les jambes fines et très bien assorties à son corps; la tête belle et ressemblant à celle d'un chevreuil; l'œil vif et plein de feu; le nez noir et sans poil, mais toujours humide; les narines en forme de croissant allongé; les bords du museau noirs. La lèvre supérieure, sans être fendue, paroît divisée en deux lobes. Le menton a peu de poils; mais plus haut il y a, de chaque côté, une espèce de petite moustache, et, sous le gosier, un poireau garni de poil " (ce qui rapproche encore cet 
animal du genre des chèvres, dont la plupart ont de même sous le cou des espèces de poireaux garnis de poils).

"La langue est plutôt ronde qu'oblongue ou pointue... Les cornes sont noires, finement sillonnées du haut en bas, et longues d'environ trois pouces, droites sans la moindre courbure, et se terminant par le haut en une pointe assez aiguë. A leur base, elles ont à peu près l'épaisseur de trois quarts de pouce; elles sont ornées de trois anneaux qui s'élèvent un peu en arrière vers le corps.

"Les poils du front sont un peu plus droits que les autres, rudes, gris, et hérissés à l'origine des cornes, entre lesquelles le poil de la tête se redresse encore davantage, et y forme une espèce de toupet pointu et noir, dont descend an milieu du front une raie de même couleur qui vient se perdre dans le nez.

"Les oreilles sont grandes, et ont en dehors trois cavités ou fossettes, qui se dirigent du haut en bas. Au sommiet, du côté intérieur, elles sont garnies d'un poil ras et blanchâtre, du reste, nues et noirâtres. Les yeux sont assez grandis et d'un brun foncé. Le poil des paupières est noir, serré et long aux paupières supérieures. Au dessus des yeux se voient encore quelqques poils longuets, mais clairsemés ou plus dis. perses.

"Des deux côtés, entre les yeux et le nez, se mon tre cette particularité remarquable et singulière, qui fait reconnôitre cet animal, et dont nous avons déjà parlé. Cette partie est moins élèvée, nue, et noire. Dans son milieu paroît une cavité ou fossette, qui est comme calleuse et toujours humide; il en découle, BUFFON. XVII. 
mais en petite quantité, une humeur visqueuse, gluante et gommeuse, qui, avec le temps, se durcit et devient noire. L'animal semble se débarrasser de temps à autie de cette matière excrémentitielle; car on la trouve durcie et noire aux bâtons de sa loge, comme si elle y avoit été essuyée. Quant à l'odeur dont parle Grimm et ses copistes, je n'ai pu la découvrir.

"Le cou, qui est médiocrement long, est couvert au bas d'un poil assez roide et gris jaunâtre, tel que celui de la tête, mais blanc au gosier et à la partie supérieure du cou en dessous.

"Le poil du corps est noir et roide, quoique doux au toucher. Celui des parties antérieures est d'un beau gris clair; plus en arrière, d'un brun très clair; vers le ventre, gris, et plus bas tout-à-fait blanc.

"Les jambes sont très minces, noiràtres au bas près des sabots. Les pieds de devant sont, par devant jusqu'auprès des genoux, ornés d'une raie noire : ils n'ont point d'ergots ou d'éperons ongulés; mais à leur place on voit une légère excroissance. Ces pierds sont fourchus et pourvus de beaux sabots noirs, pointus et lisses.

"La queue est fort courte, blanche, et en dessus marquée d'une bande noire. A l'égard des parties naturelles, elles sont fortes, et consistent en un gros scrotum noir, pendant entre les jambes, accompagné d'un ample prépuce."

M. Allamarid a donné la wîme figure de la grimme dans ses additions à mon ouvrage; mais il n'ajoute rien à ce qu'en ont dit MM. Pallas et Vosmaër.

* Je dois ajouter à ce que j’ai dit de cet animal quelques remarques de MII. Forster. 
"Le docteur Grimin est le premier, disent-ils, qui ait décrit cet animal au cap de Bonue-Espérance; mais comme il n'en a vu que la femelle, Linnaus a cru qu'elle appartenoit au chevrotain à musc. M. de Buffon a été le premier qui ait rangé la grimme avec les gazelles; et après lui M. Pallas, ayant examiné un mâle de cette espèce à la ménagerie du prince d'Orange, en a donné une belle et très exacte description. M. Vosmaër, directeur de cette ménagerie, se plaignit amèrement que M. Pallas eût donné le premier une connoissance exacte de cet animal ai public; cependant il n'étoit pas capable de corriger la description du savant Pallas, qui est un excellent zoologue. Étant au cap de Bonne-Espérance je fis l'acquisition d'une corne qu'on me donnoil pour celle d'une chèvre plongeunte (duykerbok); ctj'appris qu'on l'appeloit chèvre plongeante, parce qu'elle se tenoit toujours parmi les broussailles, et que, dès qu'elle apercevoit un homme, elle s'élevoit par un saut pour découvrir sa position et ses mouvements, après quoi elle replongeoit dans les broussailles, s'enfuyoit, et de temps en temps reparoissoit pour reconnoître si elle étoit poursuivie. M. Pallas avoit connoissance de cette chèvre plongeante, parce qu'il l'avoit trouvée dans Kolbe; mais il ne savoit pas que c'étoit le même animal que la grimme : il l'appelle en latin capra nictitans. Je fus encore informé que, dans cette espèce, la femelle n'a point de cornes, mais qu'elle porte, comme le mâle, un petit toupet de poil sur le front. Les cornes n'ont que quatre pouces de longueur; eiles sont droites, noires, ridées d'environ quatre ou cinc anneaux peu distincts : elles mont paru un peu 
comprimées, avec une strie sans rides sur la face postérieure; le reste jusqu'à la pointe en est lisse. On m'a aussi assuré que cettc grimme n'excédoit jamais la grandeur d'un faon de daim."

\section{LES GHEVROTA INS ${ }^{1}$.}

\section{Moschus Pygmcus. L.}

L'ox a donné en dernier lieu le nom de chcvrotair (rragulus) à de petits animaux des pays les plus chauds de l'Afrique et de l'Asie, que les voyageurs ont presque tous indiqués par la dénomination de petit cerf ou petite biche. En effet, les chevrotains ressemblent en petit au cerf par la figure du museau, par la légéreté du corps, la conrte queue, et la forme des jambes : mais ils en diflèrent prodigieusement par la taille, les plus grands chevrotains n'étant tout au plus que de la grandeur du lièvre; d'ailleurs ils n'ont point de bois sur la tête: les uns sont absolument sans cornes, et ceux qui en portent les ont creuses, annelíes, et assez semblables à celles des gazelles. Leur petil pied fourchu ressemble aussi beaucoup plus à celui de la gazelle qu'à celui du cerf, et ils s'éloignent également des cerfis et des gazelles, en ce qu'ils n'ont point de

1. Tragulus en latin moderne; guevei au Sénégal. Selon les notices nanuscrites qui nous ont été communiquées par M. Adanson, le plas petit chevrotain s'appelle guevei-laior, parce qu'il vient de la province de Kaior, dans l'étendue de laquelle se trouvent le cap' Vert et les terres adjacentes à ce cap. 
larmier ou d'enfoncement au dessous des yeux; par là ils se rapprochent des chèvres : mais, dans le réel, ils ne sont ni cerfs, ni gazelles, ni chèvres, et font une ou plusieurs espèces à part. Seba donne la description et les figures de cinq chevrotains : le premier sous la dénomination de petite biche africaine de Guinée, rougeatre, sans cornes; le second sous celle de fuon ou jeune cerf d'Afrique très délié; le troisième sous le nom de jeune cerf très petit de Guinée; le quatrième sous la dénomination de petite biche de Surinam, rougeâtre et marquetée de taches blanches; et le cinquième sous celle de cerf d'A frique à poil rouge. De ces cinq chevrotains donnés par Seba, le premier, le second, et le troisième sont évidemment le même animal; le cinquième, qui est plus grand que les trois premiers, et qui a le poil beaucoup plus long et d'un fauve plus foncé, ne nous paroît être qu'une variété de cette première espèce ; le quatrì̀me, que l'auteur indique comme un animal de Surinam, n'est encore, à notre avis, qu'une seconde variété de cette espèce, qui ne se trouve qu'en Afrique et dans les parties méridionales de l'Asie; et nous sommes très portés à croire que Seba a été mal informé lorsqu'il a dit que cet animal venoit de Surinam. Tous les voyageurs font mention de ces petits cerfs ou chevrotains au Sénégal, en Guinée et aux grandes Indes; aucun ne dit les avoir vus en Amérique; et si le chevrotain à peau tachée dont parle Seba venoit en effet de Surinam, on doit présuner qu'il y avoit été transporté de Guinée, ou de quelque autre province méridionale de l'ancien continent. Mais il paroît qu'il y a une seconde espèce de chevrotain réellement différente de tous 
ceux que nous venons d'indiquer, qui ne nous semblent être que de simples variétés de la première. Ce second chevrotain porte de petites cornes qui n'ont qu'un pouce de longueur et autant de circonférence; ces petites cornes sont creuses, noirâtres, un peu courbées, fort pointues, et environnées à la base de trois ou quatre anneaux transversaux. Nous avons au Cahinet du Roi les pieds de cet animal, avec une de ses cornes, et ces parties suffisent pour démontrer que c'est ou un chevrotain ou une gazelle beaucoup plus petite que les autres gazelles. Kolbe, en faisant mention de celte espèce de chevrotain, a dit an hasard que ses cornes étoient semblables à celles du cerf, et qu'elles ont des branches à proportion de leur âge : c'est une erreur évidente, et que la seule inspection de ces cornes suffit pour démontrer.

Ces animaux sont d'une figure élégante, et très bien proportionnés dans leur taille : ils font des sauts et des bonds prodigieux; mais apparemment ils ne peuvent courir long-temps, car les Indiens les prennent à la course; les Nègres les chassent de même, et les tuent à coups de bâtori ou de petites zagaies : on les recherche beaucoup, parce que la chair en est excellente à manger.

En comparant les témoignages des voyageurs, il paroît, $1^{\circ}$ que le chevrotain duquel nous donnons la figure, et qui n'a point de cornes, est le chevrotain des Indes orientales; $2^{\circ}$ que celui qui a des cornes est le chevrotain du Sénégal, appelé guevei par les naturels du pays; $5^{\circ}$ qu'il n'y a que le mâle du guevei qui porte des cornes, et que la femelle, comme celle de la grimme, n'en porte poin: ; $4{ }^{\circ}$ que le cheyrotain à 
peau marquetée de taches blanches, et que Seba dit se trouver à Surinam, se trouve au contraire aux Grandes-Indes, et notamment à Ceylan, où il s'appelle memina. Donc l'on doit conclure qu'il n'y a (du moins jusqu'à ce jour) que deux espèces de chevrotains, le memima, ou chevrotain des Indes sans cornes, et le guevei, ou chevrotain de Guinée à cornes, que les cinq cherrotains de Seba ne sont que des variétés du memina, et que le plus petit chevrotain, qu'on appelle au Sénégal gutevei-kaior, n'est qu'une variété du guevei. Au reste, tous ces petits animaux ne peuvent vivre que dans les climats excessivement chauds; ils sont d'une si grande délicatesse, qu'on a beaucoup de peine à les transporter vivants en Europe, où ils ne peuvent subsister, et périssent en peu de temps; ils sont doux, familiers, et de la plus jolie figure : ce sont les plus petits, sans aucune comparaison, des animaux à pied fourchu : à ce titre de pied fourchu, ils ne doivent produire qu'en petit nombre; et, à cause de leur petitesse, ils doivent au contraire produire en grand nombre à chaque portée. Nous demandons à ceux qui sont à portée de les observer de vouloir bien nous instruire sur ce fait; nous croyons qu'ils ne font qu'un ou deux petits à la fois, comme les gazelles, les chevreuils, etc. : mais peut-être produisent-ils plus sonvent : car ils sont en très grand nombre aux Indes, à Java, à Ceylan, au Sénégal, à Congo, et dans tous les autres pays excessivement chauds, et il ne s'en trouve point en Amérique, ni en aucune des contrées tempérées de l'ancien continent. 


\section{LE MEMINA.}

\section{Moschus Memina. L. .}

Nous donnons ici la description d'un chevrotain différent de celui décrit sous le nom de Guib. Nous avons dit que le chevrotain à peau marquetée de taches blanches, et que Seba dit se trouver à Surinam, ne se trouve point en Amérique, mais au contraire aux Grandes-Indes, où il s'appelle memina. Nous avons reçu la dépouille d'un chevrotain sous ce nom memina, qui a une parfaite ressemblance avec la description que j'en ai publiée, et c'est celui duquel je donne ici la figure. En la comparant à celle qui précède, on verra que ces deux petits animaux sont également sans cornes, et qu'ils ne font tous deux qu'une simple variété dans la même espèce.

\section{LE GHEV.ROTAIN,}

APPELÉ A JAVA PETITE GAZELLE.

Nous donnons ici la description d'un chevrotain venu de Java sous le nom de petile gazelle, et qui nous paroît être de lat même espèce, à très peu près, 



$$
\frac{\pi}{M}
$$


que celle du chevrotain memina de Ceylan : les seules différences que nous puissions y remarquer sont, qu'il n'a point comme le memina, de bandes ou de livrée sur le corps; le poil est seulement ondé ou jaspé de noir, sur un fond couleur de musc foncé, avec trois bandes blanches distinctement marquées sur la poitrine; le bout du nez est noir, et la tête est moins arrondie et plus fine que celle du memina, et les sabots des pieds sont plus allongés. Ces différences, assez légères, pourroient n'être qu'individuelles, et ne doivent pas nous empêcher de regarder ce chevrotain de Java comme une simple variété dans l'espèce du memina de Ceylan. Au reste, nous n'avons pas eu d'autre indication sur ce petit animal, qui n'est certainement pas du genre des gazelles, mais de celui des chevrotains.

\section{LE CHEVREUIL DES INDES.}

Nous donnons ici la description d'un animal des Indes, qui nous paroît être d'une espèce très voisine de celle de nos chevreuils d'Europe, mais qui néanmoins en diffère par un caractère assez essentiel, pour qu'on ne puisse pas le considérer comme ne formant qu'une simple variété dans l'espèce du chevreuil; ce caractère consiste dans la structure des os supérieurs de la tête, sur-lesquels sont appuyées les meules qui portent le bois de ce chevreuil. C'est encore au savaut professeur M. Allamand que je dois la connoissance 
de cet animal; et je ne puis mieux faire que de rapporter ici la description qu'il en a publiée dans le nouveau supplément à mon ouvràge sur les animaux quadrupèdes.

"Nous avons vu, dans les articles précédents, que l'Afrique renferme grand nombre d'animaux qui n'ont jamais été décrits; cela n'est pas étonnant, l'intérieur de cette vaste partie du monde nous est presque entièrement inconnu. On a plus de raison d'être surpris que l'Asie, habitée en général par des peuples policés, et très fréquentée par les Européens, en fournisse souvent dont aucun voyageur n'a parlé : nous en avons un exemple dans le joli animal qui est représenté dans cette planche.

`Il a été envoyé de Bengale, en 1778 , à feu M. Van der Stel, commissaire de la ville d'Amsterdam; il est arrivé chez lui en très bon état, et il y a vécu pendant quelque temps. Ignorant le nom sous lequel il est connu dans le pays dont il est originaire, je lui ai donné celui de chevreuil, parce qu'il lui ressemble par son bois et par toute sa figure, quoiqu'il soit beaucoup plus petit. Celui de chevrotain auroit mieux répondu à sa taille; mais ceux d'entre les chevrotains qui portent des cornes, les ont creuses, et non pas solides comme le sont celles de l'animal dont nous parlons, qui par conséquent en diffère par un caractère essentiel. Il a plus de traits de ressemblance avec le cerf : mais il en est trop différent par la grandeur, pour qu'on puisse lui en donner le nom; à peine at-il deux pieds sept pouces de longueur, et sa plus grande hauteur n'est que d'un pied et demi.

"Le poil court doñt son corps est couvert est blanc 
depuis sa racine jusqu'à la moitié de sa longueur, l'extrémité en est brune; ce qui fait un pelage gris, où cependant le brun domine, principalement sur le dos et moins sous le ventre; l'intérieur des cuisses et le dessous du cou sont blanchâtres; les sabots sont noirs et surmontés d'une petite tache blanche; les ergots sont à peine visibles.

„Sa tête, comme celle de la plupart des animaux mâles à pieds fourchus, est chargée de deux cornes qui offrent des singularités bien remarquables. Elles ont une origine commune à la distance de deux pouces du bout du museau; là elles commencent à s'écarter l'une de l'autre, en faisant un angle d'environ quarante degrés sous la peau, qu'elles soulèvent d'une manière très sensible; ensuite elles montent en ligne droite le long des bords de la tête, toujours recouvertes de la peau, mais de facon que l'œil peut les suivre avec autant de facilité que l'attouchement les fait découvrir; car elle forment sur les os auxquels elles sont appliquées une arête d'un travers de doigt d'élévation. Parvenues au haut de la tête, elles prennent une autre direction; elles s'élèvent perpendiculairement au dessus de l'os frontal, jusqu'à la hauteur de trois pouces, sans que la peau qui les environne là de tous côtés les ait quittées : à ce degré d'élévation, elles sont surmontées par ce qu'on nonme les meules et leurs pierrures dans les cerfs; elles couronnent la peau qui reste en dessous. Du milieu de ces meules, les cornes continuent à monter, mais inégalement. La corne gauche s'élève jusqu'à la hauteur de trois pouces, et elle est recourbée à son extrémité, qui se termine en pointe; elle pousse, presque im- 
médiatement au dessus de la meule, un andouiller dirigé en avant, de la longueur d'un demi-pouce : la corne droite n'a que deux pouces et demi de longueur, et il en sort un andouiller plus petit encore que celui de la gauche, et dirigé en arrière. La figure qui a été faite d'après l'animal vivant représente bien tout ce que je viens de dire. Ces cornes sont sans écorces, lisses, et d'un blanc tirant un peu sur le jaune; elles sont sans perlures, et par conséquent sans goultières.

"Cet aniusal n'a pas vécu fort long-temps dans ce pays, et rien n'a indigiré son âge : ainsi j'ignore s’il auroit mis bas sa tête, comme les chevreuils, ou si celle qu'il avoit étoit naissante, et seroit devenue plus grande et plus chargée d'andouillers.

"Si l'on regarde comme une portion du bois celte partie qui a son origine près du museau, qui s'étend sous la peau de la face, et qui en reste couverte jusqu'à la meule, on ne peut pas douter que ce bois ne soit permanent; et, dans ce cas, cet animal offrira, de même que la girafe, une anomalie très remarquable dans la classe des animaux qui ont du bois ou des cornes solides.

"Mais on sait que le bois des cerfs, des daims, et des chevreuils, pose sur deux éminences de l'os frontal. Dans notre chevreuil indien, ces éminences sont des tubérosités beaucoup plus élevées, dont les prolongements s'étendent entre les yeux jusqu'au museau, en s'appliquant fortement aux os du nez, si même ils ne font pas corps avec eux; car, quelque effort que jaie fait pour insinuer à travess la peau une pointe entre deux, il m'a été impossible d'y réussir. Comme la déponille de cet animal ne m’appar- 
tient pas, je regrelte de n'avoir pas la permission d'enlever la peau qui convre ces os, pour savoir au juste ce qui en est. Quoi qu’il en soit, il peut metire bas sa tête avec autant de facilité que le cerf, puisque, posées sur le haut de ces éminences, les meules ne sont pas plus fortement adhérentes à ce point d'appui que dans les autres animaux qui perdent leur bois chaque année; ainsi je suis très porté à croire qu'il le perd aussi : mais ce qu'il y a ici de certain, c'est que cette singulière conformation en forme une espèce particulière dans la classe des ruminants, et non pas une simple variété, telle qu'est le cuguacu-apara dı Brésil, qui est à peu près de la même grandeur.

"Au milieu du front, entre les denx prolongements des tubérosités dont je viens de parler, il y a une peau molle, plissée et élastique, dans les plis de laquelle on remarque une substance glanduleuse, d'où il suinte une matière qui a de l'odeur.

"Il a huit dents incisives dans la mâchoire inférieure, et six dents molaires à chaque côté des deux mâchoires. Il y a de plus deux crochets dans la mâchoire supérieure, comme le cerf, qui ne se trouvent point dans le chevreuil d'Europe; ces crochets se projellent tant soit peu en dehors, et is font une légère impression sur la lèvre inférieure.

"Il a de beaux yeux bien fendus: au dessous sont deux larmiers tres remarquables par lear grandeur et leur profondeur, comme cenx du cerf; ces larmiers, qui manquent au chevreuil, avec ses deux dents en crochets, mont fait dire ci-flessus qu'il avoit plus de traits de ressemblance avec le cerf qu'ivec ce dernier animal. 
„Il a la langue fort longue : il s'en servoit non seulement à nettoyer ses larmiers, mais encore ses yeux, et quelquefois même il la poussoit au delà.

"Ses oreilles ont trois pouces en longueur; elles sont placées à un demi-pouce de distance de la partie inférieure des éminences qui soutiennent le bois. Sa queue est fort courte, mais assez large; elle est blanche en dessous.

" La figure de cet animal avoit la même grâce et la même élégance que celle de notre chevreuil ordinaire; il paroissoit même être plus leste et plus éveillé. Il n'aimoit pas à être touché de ceux qu'il ne connoissoit point; il preuoit cependant ce qu'ils lui présentoient: il mangeoit du pain, des carottes et toutes sortes d'herbes. Il étoit dans un parc, où il entra en chaleur dans les mois de mars et d'avril : il y avoit avec lui une femelle d'axis qu'il tourmentoit beaucoup pour la couvrir; mais il étoit trop petit pour y réussir. Il mourut pendant l'hiver de 1779.

„Voici ses dimensions:

Longueur du corps depuis le bout du museau jus-

qu’à l'origine de la queue. . . . . . . . 2

Hauteur du train de derant. . . . . . . . .

Hlauteur du train de derrière. . . . . . . . . I

Longueur de la tête depuis le bout du museau jusqu'aux oreilles. . . . . . . . . . .

Distance entre le bout du museau el l'extrémité des prolongements des éminences de l'os frontal, qui soutiennent le bois. . . . . . . . .

Longueur de ces prolongements jusqu'à l'endroit où ils s'élèrent áu dessus de la tête. . . . . . .

Longueur des éminences de l'os frontal, qui sont recouvertes de la peau, et terminées par les meules.

7
4
6


Longueur de la corne gauche depuis la meule jusqu’à son extrémité en ligne droite. . . . . . .

Longueur de son andoüiller. ........ " 6

Longueur de la corne droite depuis la meule jus. qu'à son extrémité. ............ 2 . 24

Longueur de son andoviller. .........

Distance entre les cornes, mesurée sur l'os frontal. » $2 \quad 1$

Circonférence des cornes au dessous de la meule. " 2 "

Longueur des oreilles.. . . . . . . . . 3 "

Longueur des yeux d'un angle à l'autre. ..... 1 .

Longuear des oreilles. ........... 2 . . . .

Ouverture des yeux. ............... 9

Longueur de la queue. . . . . . . . . 3 "

Circonférence du museau derrière les naseaux. . 4 „

Girconférence de la tête entre les cornes et les oreilles........................... 11

Grosseur du milieu du cou. . . . . . . . I ,

Grosseur du corps derrière les jambes de devant. $\begin{array}{lll} & 9 & 9\end{array}$

Grosseur du milieu du corps. . . . . . . I 10 "

Grosseur du corps devant les jambes de derrière. $1 \quad 9$ „

\section{LES MAZAMES.}

Mazame, dans la langue mexicaine, étoit le nom du cerf, ou plutôt le nom du genre entier des cerfs, des daims, et des chevreuils. Hernandès, Recchi, et Fernandès, qui nous ont transmis ce nom, distinguoient deux espèces de mazames, tous deux comununs au Mexique et dans la Nouvelle-Espagne : le premier et le plus grand, auquel ils donnent le nom simple de mazame, porte un bois semblable à celui du chevreuil d'Europe, c'est-à-dire un bois de six à sept pouces de longueur, dont l'extrémité est diviséc 
en deux pointes, et qui n’a qu'un seul andouiller à la partie moyenne du merrain; le second, qu'ils appellent temamacame, est plus petit que le mazame, et ne porte qu'un bois simple et sans andouillers, comme celui d'un daguet. Il nous paroîl que ces deux animaux sont vraiment des chevretils, dont le premier est absolument de la même espèce que le chevreuil d'Europe, et le second n'est qu'une variété ; il nous paroît aussi que ces chevreuils ou mazames et temamaçames du Mexique sont les mêmes que le cuguacu-apara ${ }^{1}$ et le cuguacu-été du Brésil, et qu’à Cayenne le premier se nomme cariacou ou biche des bois, el le second petit cariacou ou biche des palétuviers. Quoique personne avant nous n'ait rapproché ces ropports, nous ne présumons pas qu’il y eût eu sur cela ni difficultés ni doutes, si Seba ne s'étoit avisé de donner sous les noms de mazame et de temamacame deux animaux tout différents : ce ne sont plus des chevreuils à bois solide et branchu; ce sont des gazelles à cornes creuses et torses : ce ne sont pas des animaux de la Nouvelie-Espagne, quoique l'anteur les donne pour tels; ce sont au contraire des ani-

1. La figure que l'on tronve dans Pison, page $9^{8}$, sous le nom de cuguacu-été, ressemble parlaitewent à notre chevreuil, et il ne faut que la comparer arec celle du mazame de Recchi pour reconnoître que c’ost le même auimal. Ce cuguacu-élé de Pison a un bois; cependant Maregrave, qui ne donne pas la figure, dit qu'il n'a point de hois, et que c'est le cuguacu-apara qui a un bois à trois andouillers. Il est viaisemblable que, comme dans l'espèce du chevreuil, la femelle n'a point de bois. L'un de ces animaux désignés par Marcgrave étoit la femelle de l'autre. La description que ces auteurs donnent de ces animaux ne permet pas de douter que ce ne soient des chevreuils absolument semblables aux cherreuils gle l'Europe. 
maux d'Afrique. Ces erreurs de Seba ont été adoptées par la plupart des auteurs qui ont écrit depuis; ils n'ont par douté que ces animaux, indiqués par Seba sous le nom de mazame et de temamacame, ne fussent des animaux d'Amérique. et les mêmes que ceux dont Hernandès, Recchi, et Fernandès avoient fait mention: la confusion du nom a été suivie de la méprise sur la chose; et en conséquence les uns ont indiqué ces animaux sous le nom de chevrotains, et les autres sous celui de gazelle ou de chèvres. Cependant il paroît que M. Linnæus s'est douté de l'erreur, car il ne l'a point adoptée; il a mis le mazame dans la liste des cerfs, er a pensé comme nous que ce mazame du Mexique est le même animal que le cuguacu du Brésil.

Pour démontrer ce que nous venons d'avancer, nous poserons en fait qu'il n'y a ni gazelles ni chevrotains dans la Nouvelle-Espagne, non plus que dans aucune autre partie de l'Amérique; qu'avant la découverte de Nouveau-Monde, il n'y avoit pas plus de chèvres que de gazelles, ét que toutes celles qui y sont à présent y ont étú aptortées de l'ancien continent; que le vrai mazame du Mexique est le même animal que le cuguacu-apara du Brésil; que le nom cuguacu se prononce couguacon', et que, par corruption, cet animal s'appelle, à Cayenne, cariacou, d'où il nous a été envoyé vivant sous ce même nom cariacou, et nous en donnerons ici la description; ensuite nous rechercherons quelles peuvent être les espèces des deux animaux donnés par Seba sous les faux noms de mazame et de temamacame; car, pour détruire une erreur, il ne suffit pas de ne la pas adopter, 
il faut eneore en constater la cause et en démontrer les effets.

Les gazelles et les chevrotains sont des animaux qui n'habitent que les pays les plus chauds de l'ancien continent; ils ne peuvent vivre dans les contrées tempérées, et encore moins dans les pays froids; ils n'out donc pu ni fréquenter les terres du Nord, ni passer d'un continent à l'autre par ces mêmes terres : aussi aucun voyageur, aucun historien du NouveauMonde, n'a dit qu'il s'y trouvât nulle part des gazelles ou des chevrotains. Les cerfs et les chevrenils sont au contraire des animaux des climats froids et tempérés; ils ont donc pu passer par les terres du Nord, et on les trouve en effet dans les deux contineuts. L'on a vu dans notre histoire du cerf ${ }^{1}$ que le cerf du Canada est le même que celui d'Europe, qu'il est seulement plus petit, et qu'il n'y a que quelques légères variétés dans la forme du bois el la couleur du poil : nous pouvons même ajouter à ce que nous avons dit, qu'il y a en Amérique autant de variétés qu'en Europe parmi les cerfs, et que néanmoins ils sont tous de la même espèce; l'une de ces variétés, dont nous avons donné la figure, est le cerf de Corse, plus petit et plus brun que le cerf commun. Nous avons aussi parté des cerfs et des biches blanches, et nous avons dit que celte couleur provenoî de leur état de domesticité. On les trouve en Ainérique, aussi bien que nos cerfs comrruns et nos petits cerfs bruns : les Mexicains, qui élevoient ces cerfs blancs dans leurs parcs, les appelvient les rois des cerfs. Mais une troisième va- 
riété dont nous n'avons pas fait mention, c'est celle du cerf d'Allemagne, communément appelé cerf des Ardennes, brandhirsch par les Allemands : il est toul au moins aussi grand que nos plus grands cerfs de France, et il en diffère par des caractères assez marqués; il est d'un pelage plus foncé et moins noirâtre sur le ventre, et il a sur le cou et la gorge de longs poils comme le bouc, ce qui lui a fait donner par les anciens ${ }^{2}$ et les modernes le nom de tragelaphe ou bouc-cerf. Les chevreuils se sont aussi trouvés en Amérique, et même en très grand nombre; nous n'en connoissons en Europe que deux variétés, les roux et les bruns ${ }^{2}$ : ceux-ci sont plus petits que les premiers; mais ils se ressemblent à tous autres égards, et ils ont tous deux le bois branchu. Le mazame du Mexique, le cuguacu-apara du Brésil, et le cariacou ou biches des bois de Cayenne ressemblent en entier à nos chevreuils roux : il suffit d'en comparer les descriptions pour être convaincu que tous ces noms ne désignent que le même animal; mais le temamaçame, que nous croyons être le cuguacu-été du Brésil, le petil cariacou ou biche des palétuviers de Cayenne, pourroit être une variété différente de celles de l'Europe. Le temamaçame est plus petit et a aussi le ventre plus blanc que le mazame, comme notre chevreuil brun a le ventre plus blanc et la taille plus petite que notre chevreuil roux; néanmoins il paroît en différer par le bois, qui est simple et sans andouil-

1. Cette race de cerfs se trouve aujourd'hui dans les forêts d'Allemagne et de Bohême, comme elle se trouvoit du temps de Pline dans les terres qu'arrose le Phase.

2. Voyez l'article du chevreuil. 
lers dans la figure qu'en a donriée Recchi : mais si l'on fait attention que, dans nos chevreuils et nos cerfs, le bois est sans andouillers dans la première et qquelquefois même dans la seconde année de leur âge, on sera porté à croire que le mamaçame de Recchi étoit de cet âge, et que c'est par cette raison qu'il n'avoit qu'un bois simple et sans andouillers. Ces deux animaux ne nous paroissent donc être que de simples variétés dans l'espèce du chevreuil; on pourra s'en convaincre aisément en comparant les figures et les passages des auteurs que nous venons de citer, avec la figure que nous donnons ici du cariacou qui nous est venu de Cayenne, et que nous avons nourri en Bourgogne pendant quelques années; l'on verra, en insistant nême sur les différences, qu'elles ne sont pas assez grandes pour séparer le cariacou de l'espèce du chevreuil.

II nous reste maintenant à rechercher ce que sont réellement les deux animaux donnés par Seba sous les faux noms de mazame et de temamacame. La seule inspection des figures, indépendamment même de sa description, démontre que ce sont des animaux du genre des chèvres ou des gazelles, et non pas de celui des cerls ni des chevreuils. Le défaut de barbe et la figure des cornes prouvent que ce ne sont pas des chèvres, mais des gazelles; et en comparant ces figures de Seba avec les gazelles que nous avons décrites, ¡’ai reconnu,que son prétendu temamacame de la Nouvelle-Espagne est le kob ou petite vache brune du Sénégal: la forme, la couleur, et la grandeur des cornes est la même, la couleur du poil est aussi la même, et differe de celle des autres gazelles, en ce qu'elle n'est 
pas blanche, mais fauve sous le ventre comme sur les flancs; ct à l'égard da prétendu mazame, quoiqu'il ressemble, en général, aux gazelles, il diffère cependant en particulier de toutes celles dont nous avons ci-devant fait l'énumération : mais nous avons trouvé dans le cabinet de $M$. Adanson, où il a rassemblé les productions les plus rares du Sénégal, un animal empaillé que nous avons appelé nagor, à cause de la ressemblance de ses cornes avec celles du nanguer. Cet animal se trouve dans les terres voisines de l'île de Gorée, d'où il fut envoyé à M. Adanson par M. Andriot: il a tous les caractères que Seba donne à son prétendu mazame; il est d'un roux pâle sur tout le corps, et n'a pas le ventre blanc comme les autres gazelles; il est grand comme un chevreuil : ses cornes n'ont pas six pouces de longueur; elles sont presque lisses, légèrement courbées et dirigées en avant, mais moins que celles du nanguer. Cet animal, donné par Seba sous le nom de mazame ou cerf d'Amérique, est donc au contraire une chèvre ou gazelle de l'A frique, que nous ajoutons ici, sous le nom de nagor, aux douze autres gazelles dont nous avons ci-devant donné l'histoire.

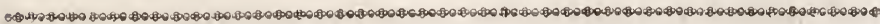

\section{LE MUSC.}

Moschus moschiferus. L.

Pour achever en entier l'histoire des chèvres, des gazelles, des chevrotains, et des autres animaux de 
ce genre, qui tous se trouvent dans l'ancien continent, il ne nous manque que celle de l'animal aussi célèbre que peu connu duquel on tire le vrai musc. Tous les naturalistes modernes et la plupart des voyageurs de l'Asie en ont fait mention, les uns sous le nom de cerf, de chevreuil, ou de chèvre du musc; les antres l'ont considéré comme un grand chevrotain : et en effet, il paroît être d'une nature ambiguë et participant de celle de tous ces animaux, quoique en même temps on puisse assurer que son espèce est une et différente de tous les autres. Il est de la grandeur d'un petit chevreuil ou d'une gazelle : mais sa tête est sans cornes et sans bois ; et par ce caractère il ressemble au memina ou chevrotain des Indes. Il a deux grandes dents canines ou crochets à la mâchoire supérieure, et par là il s'approche encore du chevrotain, qui a aussi deux grandes dents canines à cette même mâchoire : mais ce qui le distingue de tous les animaux, c'est une espèce de bourse d'environ deux ou trois pouces de diamètre, qu'il porte près du nombril, et dans laquelle se filtre la liqueur, ou plutôt l'humeur grasse du musc, différente par son odeur et par sa consistance do celle de la civette. Les Grecs ni les Romains n'ont fait aucune mention de cet animal du musc; les premiers qui l'aient indiqué sont les Arabes ${ }^{1}$; Gesner, Aldrovande, Kircher et

1. Abusseid Serasi dit que l'anirnal du musc ressemble assez au chevreuil, qu'il a la peau et la couleur semblables, les jambes menues, la corne fendue, le bois droit et un peu courbé, et qu'il est armé de deux dents blanches du côté de chaque joue. Cet auteur est le seul qui ait avancé que l'animal du musc portoit un bois; et ce n'est vraisemblablement que par analogie qu'il a pensé que cet animal, ressem. b)ant d'ailleur: aulcherreail, devoil avoir un bois sur la téte. Comme 


\section{Boym en ont donné des notions plus étendues; mais Grew $^{1}$ est le seul qui en ait fait une description exacte}

Aldrovande a copié cette erreur, nous avons cru devoir la remarquer. Avicenne, en parlant du rnusc, dit que c'est la bourse ou la follicule d'un animal assez semblable au chevreuil, mais qui porte deux grandes dents canines recourbées. On trouve aussi une figure de l'aninal dans le fragment de Cosmas, imprimé dansle premier volume des Voyages de Tavernier.

1. Le cerf du musc se trouve à la Chine et aux Indes orientales. Il n'est pas mal représenté dans le Museum de Calceolarius. La figure qu'en a donnée Kircher (China illustrata) pèche par le museau et par les pieds. Celle de Jonston est absurde. Presque partout cet animal est mal décrit. "Tous les auteurs connoissent, dit Aldrovande, qu'il a "deux cornes, excepté Siméon Sethi, qui dit qu'il n'en a qu'une. „ Ni l'un ni l'autre n'est vrai. Il en est de même de la description donnée par Scaliger, et ensuite par Chiocco dans le Calceolarii Museum; elle est très défectueuse. La meilleure est celle qui se trouve dans les Éphémérides d'Allemagne; cependant, en la comparant avec celle que j'ai faite moi-même, et que je vais donner ici, i'y ai trouvé quelques différences.

Cet animal a du bout du nez jusqu’à la queue environ trois pieds, la tête cinqà six pouces, le cou sept à huit pouces de longueur, le front trois poinces de largeur : le bout du nez n'a pas un ponce de largeur; il est pointu et semblable a celui d'un lévrier : les oreilles ressemblent à celles d'un lapin; elles sont droites, et ont environ trois pouces de hanteur : la queue est droite aussi, et n'a pas plus de deux pouces de longueur; les jambes de devant ont environ treize à quatorze pouces de hauteur. Cet animal est du nombre des pieds fourchus; le pied est fendu profondément, armé en avant de deux cornes ou sabots de plus d'un pouce de long, et en arrière, de deux autres presque aussi grands. Les pieds de derrière manquoient au sujet que je décris ici. Les poils de la tête et des jambes n'étoient longs que d'un demi-pouce, et étoient assez fins; sous le ventre ils étoient un peu plus gros, et longs d'un pouce et demi; sur le dos et les fesses, ils avoient trois pouces de longueur, et ils étoient trois ou quatre fois plus gros que les soies de cochon, c'est-à-dire plus gros que dans aucun autre animal. Ces poils étoient marqués alternativement de brun et de blanc, depuis la racine jusqu'à l'extrémité; ils étoient bruns sur la tête et sur Ins jamhes. blanchatres sur le ventre et sous la queuc, ondés, c'est- 
d'après la déponille de l'animal, qui de son temps étoit conservée dans le cabinet de la Société royale de Iondres. Cette description est en anglois, et jai cru devoir en donner ici la traduction. Un an après la publication de cet ouvrage de Grew, en 1681, Luc Schrokius fit imprimer à Vienne en Autriche l'histoire de cet animal, dans laquelle on ne trouve rien de fort exact, ni d'absolument nouveau : nous combinerons seulement les faits que nous en pourrons tirer, avec ceux qui sont épars dans les autres auteurs, et surtout dans les voyageurs les plus récents; et au

à-dire un peu frisés sur la croupe et le ventre, plas doux au toucher que dans la plupart des autres animaux. Ils sont aussi extrêmement légers, et d'une texture très peu compacte; car en les fendant et les regardant avec la loupe, ils paroissent comme composés de petites vessies semblables à celles que l'on voit dans le tuyau des pluznes, en sorte qu'ils sont, pour ainsi dire, d'une substance moyenne entre celle des poils et cles tuyaux de plume. De chaque côté de la mâchoire inférieure, et un peu au dessus des coins de la bouche, il y a un petit toupet de poils d'environ trois quarts de pouce de long, durs, roides, d'égale grandeur, et assez semblables à des soies de cochon.

"La vessic ou la bourse qui renferme le musc a environ trois pouces - de longueur sur deux de largeur ; elle est proéminente au dessus de - la peau du ventre d'enviroi un pouce et demi.... L'animal a vingtn six dents, seize dans la mâchoire inférieure, dont huit incisives de" vant, et quatre molaires derrière, et de chaque côté autant de mo. " Laires darıs la mâchoire supérieure, et à un pouce et demi de dis^ tance de l'extrémité du nez. Il y a de chaque côté, dans cette même * mâchoire supérieure, une défense ou dent canine d'environ deux " pouces et demi de long, courbée en arrière et en bas, el se termi"nant en pointe : ces défenses ne sont pas rondes, mais aplaties; elles " sont larges d'un demi-pouce, peu épaisses, et tranchantes en ar? rière, en sorte qu'elles ressemblent assez à une petite faucille. Il n'y " a point de cornes sur la tête, etc. "Passage que j'ai traduit de l'anglois dans le livre qui a pour titre : Muscum regiae societatis, by Neliemiah Grew, M. D. , Lomd. 1681; pag. 22 et 23. 
moins, ne pouvant faire mieux, nous aurons rassemblé, non pas tout ce que l'on a dit, mais le peu que l'on sait au sujet de cet animal, que nous n'avons pas vu et que nous n'avons pu nous procurer. Par la description de Grew, qui est la seule pièce authentique et sur laquelle nous puissions compter, il paroît que cet animal a le poil rude et long, le unuseau pointu, et les défenses à peu près comme le cochon, et que, par ces premiers rapports, il s'approche du sanglier, et peut-être plus encore de l'animal appelé babiroussa, que les naturalistes ont nommé sanglier des Indes, lequel, avec plusieurs caractères du cochon, a néanmoins, comme l'animal du musc, la taille moins grosse, et les jambes hautes etl égères, comme celles d'un cerf ou d'un chevreuil. D'autre côté, le cochon de l'Amérique, que nous avons appelé pecari, a sur le dos une cavité ou bourse qui contient une humeur abondante et très odorante, et l'animal du musc a cette même bourse, non pas sur le dos, mais sur le ventre. En général, aucun des animaux qui rendent des liqueurs odorantes, tels que le blaireau, le castor, le pecari, l'ondatra, le desman, la civette, le zibet, n'est du genre des cerfs ou des chèvres. Ainsi nous serions portés à croire que l'animal du musc approche plus de celui des cochons, dont il a les défenses, s'il avoit en même temps des dents incisives à la mâchoire supérieure; mais il manque de ces dents incisives, et par ce rapport il se rapproche des animaux ruminanls, et surtout du chevrotain, qui rumine aussi, quoiqu'il n'ait point de cornes. Mais tous ces indices extérieurs ne suffisent pas, ils ne peuvent que nous fournir des conjectures; l'inspection seule des 
parties intérieures pent décider de la nature de cet animal, qui jusqu'à ce jour n'est pas connue. J'avoue mêrne que ce n'est que pour ne pas choquer les préjugés du plus grand nombre que nous l'avons mis à la suite des chèvres, gazelles, et chevrotains, quoiquil nous ait paru aussi éloigné de ce genre que d'aucun autre.

Marc Paul, Barbosa, Thévenot, le P. Philippe de Marini, se sont tous plus on moins trompés dans les notices ${ }^{1}$ qu'ils ont données de cet animal : la seule chose vraie et sur laquelle ils s'accorlent, c'est que

1. Paolo le décrit de eette façon : " Il a le poil gros comme eelui du - cerf, les pieds et la queue eomme une gazelle, et n'a point de cornes n non plus qu'elle. Il a quatre dents en haut, longues de trois doigts, " délieates et blanches comme l'ivoire, dcux qui s'élèrent en haut et "deux tournées en bas, et cet animal est beau à voir. Dans la pleine "lune, il lui vient un apostume au ventre, près du nombril, et alor's " les ehasseurs le prennent et ouvrent cet apostume. "Barbosa dit qu'il est plus semblable à la gazelle; mais il ne s'aecorde pas avec les autres auteurs, en ee qu'il dit qu'il a le poil blane. Voici ses paroles : "Le musc se troive dans de petits animaux blanes qui ressemblent " aux gazelles, et qui ont des dents comme les éléphants, mais plus " petites. Il se forme à ces animaux une manière d'apostume sous le " ventre et sous la poitrine; et quand la matière est mûrie, il leur "vient une telle démangenison, qu'ils se frottent eontre les arbres, et " ce qui tombe en petits grains est le musc le plus exeellent et le plus " parfait. " La deseription que donne M. Thévenot eonvient encure moins avec les autres; il en parle en ces termes : "Il y a dans ees " pays un animal semblable à un renard par le museau, qui n'a pas "le eorps plus gros qu'un lièvre; il a le poil de la eouleur de cclui du " cerf, et les dents comme eelles d'un ehien; il produit de très excel"lent muse; il a au ventre une vessie qui est pleine de sang eorrompu, n et c'est ce sang qui eompose le muse ou qui est le muse même; on " la lui ôte, et on couvre aussitôt avec le euir l'endroit de la vessie "qui est coupé, afin d'empéeher que l'odeur ne se dissipe : mais, " après que l'opération est faite, la bête ne demeure plus long-temps „en vie. " La deseription d'Atoine Pigafetta, qui dit que le musc est 
le musc se forme dans une poche ou tumeur qui est près du nombril de l'animal ; et il paroît, par leurs témoignages et par ceux de quelques autres voyageurs, qu'il n'y a que le mâle qui produise le bon musc; que la lemelle a bien la même poche près dı nombril, mais que l'humeur qui s'y filtre n'a pas la même odeur : il paroît de plus que cetle tuneur du mâle ne se remplit de musc que dans le temps du rut, et que, dans les autres temps, la quantité de cette humeur est moindre et l'odeur plus foible.

A l'égard de la matière même du musc, son essence, c'est-à-dire sa substance pure, est peut-être aussi peu connue que la nature de l’anima! qui le produit: tous les voyageurs oonviennent que cette dro-

de la taille d'un chat, ne peut convenir avec celle des autres auteurs. La description que donue le P. Philippe de Marini ne convient pas tout-à-fait avec celle des autres auteurs; car il dit que cet, animal a la tête semblable à celle d'un loup : et le P. Kircher, dans la figure qu'il en donne, le représente avec un groin de cochon; ce qui est peutêtre la faute du graveur, qui lui donne aussi des ongles, au lieu qu'il a la corne fendue. Siméon Sethi s'éloigne encore plus de la vérité, en nous représentant cet animal grand comme la licorne, et même comme étant de celle espèce. Voici ses paroles : a Le musc de moindre valeur " est celni qu'on apporte des Indes, qui tire sur le noir; et le moindre "de tous est celui qui vient de la Chine. Tout ce musc se forme sous "le nombril d'un animal fort grand, qui n'a qu'une corne, et qui res" semble à un chevreuil : lorsqu'il est en chaleur, il se fait autour de " son nombril un amas de sang épais, qui lui cause une enflure, el la ^ douleur l'empêche alors de boire et de manger; il se roule à terre, n et net bas cette tumeur remplie de sang bourbeux, qui s'étant " caillé après un temps considérable, acquiert la bonne odeur. "Tout ces auteurs conviennent de la manière dont le musc se forme dans la vessie, ou dans la tumeur qui paroît au nombril de l'animal quand il est en rut. (Anciennes relations des Indes et de la Chine, pages 216 et suivantes. ) 
gue est toujours altérée et mêlée avec du sang, ou d'autres drogues par ceux qui la vendent; les Chinois en augmentent non seulement le volume par ce mélange, mais ils cherchent encore à en augmenter le poids en y incorporant du plomb bien trituré. Le nusc le plus pur et le plus recherché par les Chinois mêmes est celui que l'animal laisse couler sur des pierres ou des troncs d'arbres, contre lesquels il se frotte lorsque cette matière devient irritante ou trop abondante dans la bourse où elle se forme. Le musc qui se trouve dans la poche même est rarement aussi bon, parce qu'il n'est pas encore mûr, on bien parce que ce n'est que dans la saison du rut qu'il acquiert toute sa force et toute son odeur, et que dans cette même saison l'animal cherche à se débarrasser de cette matière trop exaltée qui lui cause alors des picotements et des démangeaisons. Chardin et Tavernier ont tous deux bien décrit les moyens dont les Orientaux se servent pour falsifier le musc : il faut nécessairement que les marchands en augmentent la quantité bien au delà de ce qu'on pourroit imaginer, puisque, dans une seule année, Tavernier en acheta seize cent soixante treize vessies; ce qui suppose un nombre égal l'animaux auxquels cette vessie anroit. été enlevée : mais comme cet animal n'est domestique nulle part, et que son espèce est confiée à quelques provinces de l'Orient, il est impossible de supposer qu'elle est assez nombreuse pour produire une aussi grande quantité de celte matière; et l'on ne peut pas douter que la plupart de ces prétendues poches ou vessies ne soient de petits sacs artificiels faits de la peau même des autres parties du corps de l'ani- 
mal, et remplis de son sang mêlé avec une très petite quantité de vrai musc. En effet, cette odeur est peutêtre la plus forte de toutes les odeurs connues; il n'en faut qu'une très petite dose pour parfuner une grande quantité de matière : l'odeur se porte à une grande distance; la plus petite particnle suffit pour se faire sentir dans un espace considérable ; et le parfum même est si durable et si fixe, qu'au bout de plisieurs années il semble n'avoir pas perdu beaucoup de son activité.

* Nous donnons ici (voy. planche 44) la figure de l'animal du musc, que jai fait dessiner d'après la nature vivante. Cette figure manquoit à mon ouvrage, et n'a jamais été donnée que d'une manière très incorrecte par les autres naturalistes. Il p roît que cet animal, qui n'est commun que dans lesparties orientales de l'Asie, pourroit s'habituer et peut-être même se propager dans nos climats; car il n'exige pas des soins trop recherchés : il a vécu pendant trois ans dans un pare de M. le duc de La Vrillère, à l'Ernitage, près de Versailles, où il n'est arrivé qu'au mois de juin $177^{2}$, après avoir été trois autres années en chemiu. Ainsi voilà six années de captivité et de malaise, pendant lesquelles il s'est très bien soutenu, et il n'est pas mort de dépérissement, mais d'une maladie accidentelle. On avoit recommandé de le nourrir avec du riz crevé dans l'eau, de la mie de pain, mêlés avec de la mousse prise sur le tronc et les branches de chêne: on a suivi exactement cette recette; il s'est toujours bien porté, et sa mort, en avril 1775 , n'a été causée que par une égagropile, c'est-à-dire par une pelote ou globe de son propre poil qu'il avoit détaché 
en se léchant et qu'il avoit avalé. M. Daubenton, de l'Académie des Sciences, qui a disséqué cet animal, a trouvé cette pelote dans la caillette à l'orifice du pylore. Il ne craignoit pas beaucot $p$ le froid : néanmoins, pour l'en garantir, on le tenoit en hiver dans une orangerie, et, pendant toute cette saison, il n'avoit point d'odeur de musc; mais il en répandoit une assez forte en été, surtout dans les jours les plus chauds. Lorsqu'il étoil en liberté, il ne marchoit point à pas comptés. mais couroit en sautant à peu près comme un lièvre.

Voici la description de cet animal que M. de Sève a faite àvec exactitude.

"Le musc est un animal d'une jolie figure; il a deux pieds trois pouces de longuear, vingt pouces de hauteur au train de derrière, et dix-neuf pouces six lignes à celui de devant. Il est vif et léger à la course et dans tous ses mouvements; ses jambes de derrière sont considérablement plus longues et plus fortes que celles de devant. La nature l'a armé de deux défenses de chaque côté de la mâchoire supérieure , qui sont larges, dirigées en bas et recourbées en arrière; elles sont tranchantes sur leur bord postérieur en finissant en pointe; leur longueur, au dessous de la lèvre, est de dix-huit lignes, et leur largeur d'une ligne et demie; elles sont de couleur blanche, et leur substance est une sorte d'ivoire. Les yeux sont grands à proportion du corps, et l'iris est d'un brun roux ; le bord des paupières est de couleur noire, ainsi que les naseaux. Les oreilles sont grandes et larges, elles ont quatre pouces de hauteur sur deux pouces quatre ou cinq lignes de largeur; elles sont garnies en dedans de 
grands poils d'un blanc mêlé de grrisâtre, et en dessus, de poil noir roussâtre mêlé de gris, comme celui du front et du nez. Le noir du front et relevé par une tache blanche qui se trouve au milieu; il y a du fauve jaunâtre au dessus et au dessnus des yeux : mais le reste de la tête paroît d'un gris d'ardoise, parce que le poil y est mélangé de noir et de blanc, comme celui du cou, où il y a de plıs quelques légères teintes de fauve. Les épaules et les jambes de devant sont d'un brun noir, ainsi que les pieds; mais cette couleur noire est moins forcée sur les cuisses et les janbes de derrière, où il y a quelques teintes de fauve. Les pieds sont petits; ceux de devant ont deux ergots qui touchent la terre, et qui sont situr's ai talon; les sabots des pieds de derrière sont inégaux en longueur, l'intérieur étant considérablement plus long que l'extérieur; il en est de même des ergots, dont l'interne est aussi bien plus long que l'externe. Tous les sabots des pieds, qui sont fendus comme ceux des chèvres, sont de couleur noire, ainsi que les ergots. Le poil du dessus, du dessous et des côtés du corps, est noirâtre, mélangé de teintes fauves, et même de roussâtres en quelques endroits, parce qu'en général les poils, et surtout les plus longs, sont blanes sur la plus grande partie de leur longueur, tandis que leur extrémité est brune, noire, ou de couleur fauve. Les crotles de cet animal sont très petites, d'un brun luisant, et de forme allongée; et̀ n’ont aucune odeur; et le parfum que l'animal répand dans sa cabane n'est guère plus fort que l'odeur d'une civette. Au reste, le musc paroît ĉtre un animal fort doux, mais en même temps timide et craintif; il est remuant et très agile 
dans ses mouvements, et il paroissoit se plaire à sauter el à s'élancer contre un mur, qui lui servoit de point d'appui pour le renvoyer à l'opposite. "

Comme M. Daubenton a donné à l'Académie des Sciences un bon Mémoire au sujet de cet animal, nous croyons devoir en rapporter ici l'extrait.

"L'odeur forte et pénétrante du musc, dit-il, est trop sensible pour que ce parfum n'ait pas été remarqué en même temps que l'animal qui le porte; aussi leur a-t-on donné à tous les deux le même nom de musc. Cet animal se trouve dans les royaumes du Boutan et de Tuncuin, à la Chine et dans la Tartarie chinoise, et même dans quelques parties de la Tartarie moscovite. Je crois que, de temps immémorial, il a été recherché par les habitants de ces contrées, parce que sa chair est très bonne à manger, et que son parfum a toujours dû faire un commerce; mais on ne sait pas en quel temps le musc a commencé à être connu en Europe, et même dans la partie occidentale de l'Asie. Il ne paroît pas que les Grees ni les Romains aient eu connoissance de ce parfum, puisque Aristote niPline n'en ont fait aucune mention dans leurs écrits. Les auteurs arabes sont les premiers qui en aient parlé; Sérapion donna une description de cet animal dans le huitième siècle.....

"Je l'ai vu, au mois de juillet 1772, dans un parc de M. de La. Vrillière, à Versailles; l'odeur du musc, qui se répandoit de temps en temps, suivant la direction du vent, autour de l'enceinte où étnit le portemusc, auroit pu me servir de guide pour trouver cet animal. Dès que je l'apercus, je reconnus dans sa figure et dans ses attitudes beaucoup de ressemblance 
avec le chevreuil, la gazelle et le chevrotain; aucun animal de ce genre n'a plus de légèreté, de souplesse et de vivacité dans les mouvements, que le portemusc. Il ressemble encore aux animaux ruminants, en ce qu'il a les pieds fourchus, et qu'il manque de dents incisives à la mâchoire supérieure; mais on ne peut le comparer qu'au chevrotain pour les deux défenses ou longues dents canines qui tiennent à la mâchoire de dessus, et sortent d'un pouce et demi au dehors des lèvres.

"La substance de ces dents est une sorte d'ivoire, comme celle des défenses du babiroussa et de plusieurs autres espèces d'animaux : mais les défenses du porte-musc ont une forme très particulière; elles ressemblent à de petits couteaux courbes, placés au dessous de la gueule, et dirigés obliquement de haut en bas et de devant en arrière; leur bord postérieur est tranchant.... Je crois qu'il s'en sert à différents usages, suivant les circonstances, soit pour couper les racines, soit pour se soutenir dans des endroits où il ne peut pas trouver d'autre point d'appui, soit enfin pour se défendre ou pour attaquer.....

"Le porte-musc n'a point de cornes; les oreilles sont longues, droites, et très mobiles; les deux dents blanches qui sortent de la gueule, et les renflements qu'elles forment à la lèvre supérieure, donnent à la physionomie du porte-musc, vu de face, un air singulier, qui pourroit le faire distinguer de tout autre animal, à l'exception du chevrotain.

"Les couleurs du poil sont peu apparentes; au lieu de couleur décidée, il n'y a que des teintes de brun, de fauve et de blanchâtre, qui semblent changer lors- 
qu'on regarde l'animal sous différents points de vue, parce que les poils ne sont colorés en brun ou en fauve qu'à leur extrémité; le reste est blanc et paroît plus ou moins à différents aspects... II y a du blanc et du noir sur les oreilles du porte-musc, et une étoile blanche au milieu du front.

"Cette étoile me paroît être une sorte de livrée, qui disparoîtra lorsque l'animal sera plus âgé; car je ne l'ai pas vue sur deux peaux de porte-musc qui m'ont été adressées pour le Cabinet du Roi par M. Le Monnier, médecin du roi, de la part de madame la comtesse de Marsan... Les deux peaux dont il s'agit m'ont paru venir d'animaux adultes, l'un mâle et l'autre femelle; les teintes des couleurs du poil y sont plus foncées que sur le porte-musc vivani que je viens de décrire; il y a de plus, sur la face inférieure du cou, deux bandes blanchâtres, larges d'environ un pouce, qui s'étendent irrégulièrement le long du con, et qui forment une sorte d'ovale allongé, en se rejoignant en avant sur la gorge, et en arrière entre les jambes de devant.

"Le musc est renferné dans une poche placée sous le ventre à l'endroit du nombril : je n'ai vu, sur le porte-musc vivant, que de petites éminences sur le milieu de son ventre; je n'ai pu les observer de près, parce que l'animal ne se laisse pas approcher.... La poche du musc tient à l'une des peaux envoyées au Cabinet du Roi : mais cette poche est desséchée; il m'a paru que si elle étoit dans son état naturel, elle auroit au moins un pouce et demi de diamèrre; il y a dans le milieu un orifice très sensible, dont j'ai tiré de la substance du musc, très odorante et de couleur 
rousse.... M. Gmelin, ayant observé la situation de cette poche sụ deux mâles, rapporte, dans le quatrième volume des Mémoires de l'Académie impériale de Pétersbourg, qu'elle étoit placée au devant et un peu à droite du prépuce.....

"Le porte-musc differe de tout autre animal par la poche qu'il a sous le ventre, et qui enferme le musc; cependant, quoique ce caractère soit unique par sa situation, il ne contribue nullement à déterminer la place du porte-musc parmi les quadrupèdes, parce qu'il y a des substances odoriférantes qui viennent d'animaux très différents du porte-musc.

"Les caractères extérieurs du porte-musc, qui indiquent ses rapports avec les autres quadrupèdes, sont les pieds fourchus, les deux longues dents canines et les huit dents incisives de la mâchoire du dessus, sans qu'il y en ait dans celle du dessous. Par ces caractères, le porte-musc ressemble plus au chevrotain qu'à aucun autre animal : il en diffère en ce qu'il est beaucoup plus grand; car il a plus d'un pied et demi de hauteur, prise depuis le bas des pieds de devant jusqu'au dessus des épaules, tandis que le chevrotain n'a guère plus d'un demi-pied.

n Les dents molaires du porte-musc sont au nombre de six de chaque côté de chacune des mâchoires; le chevrotain n'en a que quatre. Il y a aussi de grandes différences entre ces deux animaux pour la forme des dents molaires et des couleurs du poil. La poche du musc fait un caractère qui n'appartient qu'au porte-musc mâle : la femelle n'a ni poche, ni musc, ni dents canines, suivant les observations de M. Gmelin, que j’ai cité. 
"Le porte-musc que j'ai vu vivant paroît n'avoir point de queue. M. Gmelin a trouvé, sur trois individus de cette espèce, au lieu de quêue, un petit prolongement charnu, long d'environ un pouce... Il y a des auteurs qui ont fait représenter le porte-musc avec une queue bien apparente, quoique fort courte. Grew dit qu'elle a deux pouces de longueur; mais il n'a pas observé si cette partie renfermoit des vertèbres.

"Dans la description que M. Gnelin a faite du portemusc, les viscères m'ont paru ressemblants à ceux des animaux ruminants, surtout les quatre estomacs, dont le premier a trois convexités, comme dans les animaux sauvages qui ruminent. Si l'on joint ce caractère à celui des deux dentśćcanines dans la mâchoire du dessus, le porte-musc ressemble plus, par ces deux caractères, au cerf qu'à aucun autre animal ruminant; excepté le chevrotain, au cas qu'il rumine, comme il y a lieu de le croire.

" Ray dit qu'il est douteux que le porte-musc rumine. Les gens qui soignent celui que j’ai décrit vivant ne savent pas s'il rumine : je ne l'ai pas vu assez longtemps pour en juger par moi-même; mais je sais, par les observations de M. Gmelin, qu'il a les organes de la rumination, et je crois qu'on le verra ruminer, etc., etc." 


\title{
LE BABIROUSSA
}

\author{
Sus babirussa. I.
}

Quorque nous n'ayons au Cabinet du Roi que la tête de cet animal, il est trop remarquable pour que nous puissions le passer sous silence (voy. pl. 40 ). Tous les naturalistes l'ont regardé comme une espèce de cochon, et cependant il n'en a ni la tête, ni la taille, ni les soies, ni la queue : il a les jambes plus hautes et le museau moins long; il est couvert d'un poil court et doux comme de la laine, et sa queue est terminée par une touffe de cette laine; il a aussi le corps moins lourd et moins épais que le cochon; son poil est gris, mêlé de roux et d'un peu de noir; ses oreilles sont courtes et pointues : mais le caractère le plus remarquable et qui distingue le babiroussa de tous les autres animaux, ce sont quatre énormes défenses ou dents canines, dont les deux moins longues sortent, comme celles des sangliers, de la mâchoire inférieure; et les deux autres, qui sont beaucoup plus grandes, partent de la mâchoire supérieure en perçant les joues, ou plutôt les lèvres du dessus, et s'étendent en courbe jusqu'au dessus des yeux. Ces défenses sont d'un très bel ivoire, plus net, plus fin, mais moins dur que celui de l'éléphant.

1. Babiroussa ou Babiroesa, nom de cet animal aux Indes orientales, et que nous avons adopić. 
La position et la direction de ces deux défenses supérieures qui percent le museau du babiroussa, et qui d'abord se dirigent droit en haut et ensuite se recourbent en cercle, ont fait penser à quelques physiciens, même habiles, tels que Grew, que ces défenses ne devoient point être regardées comme des dents, mais comme des cornes : ils fondoient leur sentiment sur ce que tous les alvéoles des dents de la mâchoire supérieure ont, dans tous les animaux, l'ouverture tournée en bas: que dans le babiroussa, comme dans les autres, la mâchoire supérieure a tous ses alvéoles tournés en bas, tant pour les mâchelières que pour les incisives, tandis que les seuls alvéoles de ces deux grandes défenses sont au contraire tournés en haut; et ils concluoient de là que le caractère essentiel de toutes les dents de la mâchoire supérieure étant de se diriger en bas, on ne pouvoit pas mettre ces défenses, qui se dirigent en haut, au nombre des dents, et qu'il falloit les regarder comme des cornes : mais ces physiciens se sont trompés. La position ou la direction ne sont que des circonstances de la chose, et n'en font pas l'essence : ces défenses, quoique situées d'une manière opposée à celle des autr'es dents, n'en sont pas moins des dents; ce n'est qu'une singularité dans la direction, qui ne peut changer la nature de la chose, ni d'une vraie dent canine en faire une fausse corne d'ivoire.

Ces énormes et quadruples défenses donnent à ces animaux un air formidable; cependant ils sont peutêtre moins dangereux que nos sangliers : ils vont de même en troupe, et ont une odeur forte qui les décèle et fait que les chiens les chassent avec succès : 
ils grognent terriblement, se défendent, et blessent des défenses de dessous; car celles du dessus leur nuisent plutôt qu'elles ne servent. Quoique grossiers et féroces comme les sangliers, ils s'apprivoisent aisément; et leur chair, qui est très bonne à manger, se corrompt en assez peu de temps. Comme ils ont aussi le poil fin et la peau mince, ils ne résistent pas à la dent des chiens, qui les chassent de préférence aux sangliers et en viennent facilement à bout. Ils s'accrochent à des branches avec les défenses d'en hant, pour reposer leur tête ou pour dormir debout : celte habitude leur est commune avec l'éléphant, qui, pour dormir sans se concher, soutient sa tête en mettant le bout de ses défenses dans des irous qu’il creuse à cet effet dans le mur de sa loge.

Le babiroussa diffère encore du sanglier par ses appétits naturels : il se nourrit d'herbe et de feuilles d'arbres, et ne cherche point à entrer dans les jardins pour manger des légumes; au lieu que, dans le même pays, le sanglier vit de fruits sauvages, de racines, et dévaste souvent les jardins. D'ailleurs ces animaux, qui vont également en troupe, ne se mêlent jamais; les sangliers vont d'un côté et les babiroussas de l'autre. Ceux-ci marchent plus légèrement; ils ont l'odorat très fin, et se dressent souvent contre des arbres pour éventer de loin les chiens et les chasseurs : lorsqu'ils sont poursuivis long-temps et sans relache, ils courent se jeter à la iner, où nageant avec autant de facilité que des canards, et se plongeant de même, ils échappent très souvent aux chasseurs; car ils nagrent très long-temps, et vont quelquefois à d'assez grandes distances et d'une île à une autre. 
Au reste, le babiroussa se trouve non seulement à l'île de Bouro ou Bœro, près d'Amboine, mais encore dans plusieurs autres endroits de l'Asie méridionale et de l'Afrique, comme aux Célèbes, à Estrila , au Sénégal, à Madagascar : car il paroît que les sangliers de cette île, dont parle Flaccourt, et dont il dit que les males principalement ont deux cornes $\dot{a}$ coté du nez, sont des babiroussas. Nous n'avons pas élé à portée de nous assurer que la femelle manque en effet de ces deux défenses si remarquables dans le mâle; la plupart des auteurs qui ont parlé de ces animaux semblent s'accorder sur ce fait, que nous ne pouvons ni confirmer ni détruire.

* Nous n'avons donné que les faits historiques relatifs au babiroussa, et la description de sa tête dépouillée des chairs; nous donnons ici (voy. pl. 40) la figure de cet animal d'après deux esquisses, dont l'une nous a été donnée par M. Sonnerat, correspondant du Cabinet du Roi, où l'animal étoit représenté debout, et dont l'autre m'a été envoyée d'Angleterre par M. Pennant, où l'animal étoit couché sur le ventre. Celte dernière esquisse envoyée par M. Pennant étoit surmontée de l'inscription suivante : Un babiroussa de l'île de Banda, dessiné d'après nature; sa couleur est noirâtre; il croît en grandeur comme le plus grand cochon, et sa chair est très bonne à manger. Notre dessinateur, ayant combiné ces esquisses, en a fait un dessin d'après lequel on a gravé la planche, qui ne peut pas être exacte, mais qui du moins donne une idée assez juste de la forme du corps et de la tête de cet animal. 

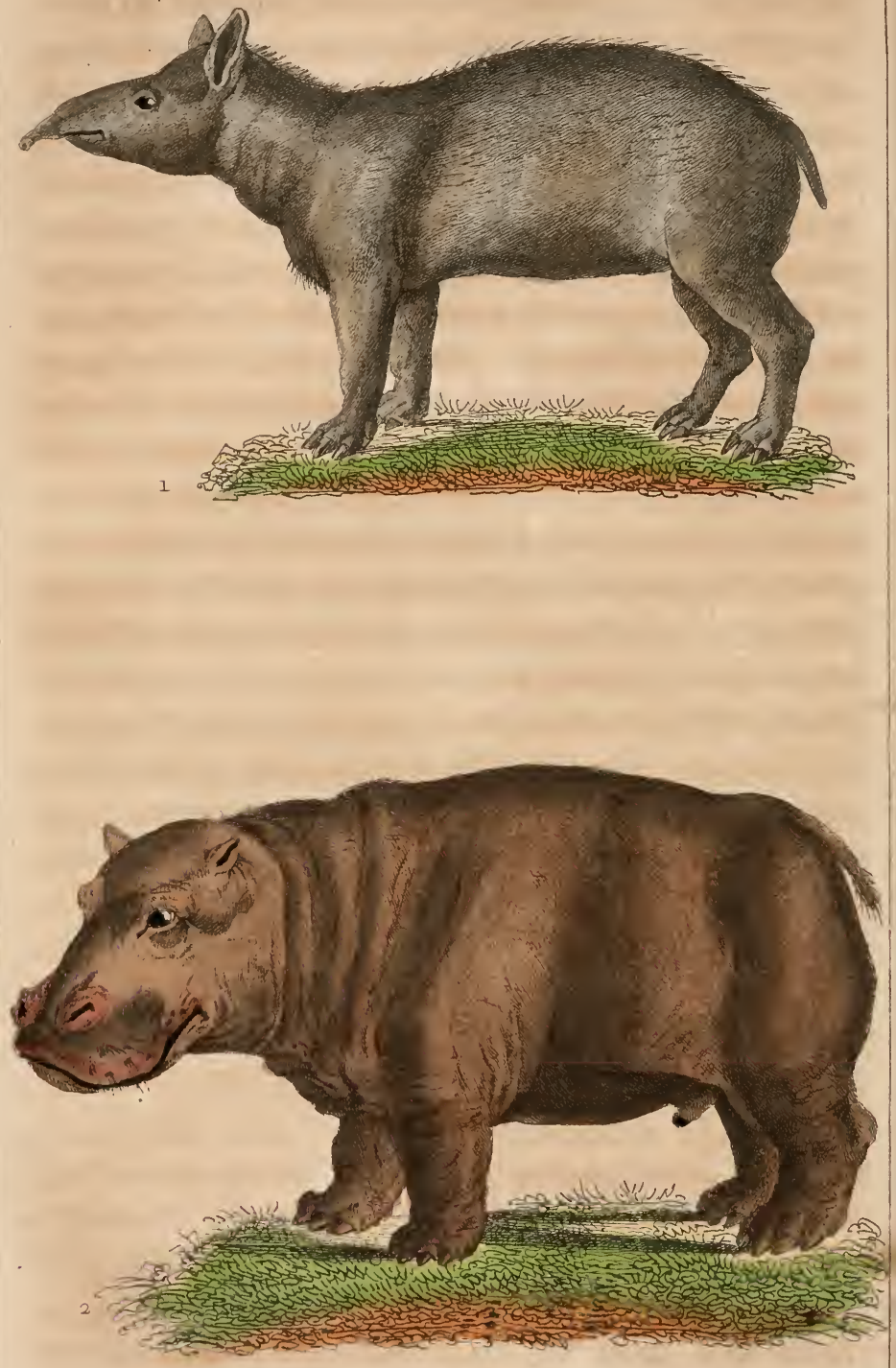


\section{LE TAPIR OU L'ANTA.}

Tapir americanus. L.

C'Est ici l'animal le plus grand de l'Amérique, de ce nouveau monde où, comme nous l'avons dit, la nature vivante semble s'être rapetissée, ou plutôt n'avoir pas eu le temps de parvenir à ses plus hautes dimensions. Au lieu des masses colossales que produit la terre antique de l'Asie, au lieu de l'éléphant, du rhinocéros, de l'hippopotame, de la girafe, et du chameau, nous ne trouvons dans ces terres nouvelles que des sujets modelés en petit, des tapirs, des lamas, des vigognes, des cabiais, tous vingt fois plus petits que ceux qu'on doit leur comparer dans l'ancien continent : et non seulement la matière est ici prodigieusement épargnée, mais les formes mêmes sont imparfaites, et paroissent avoir été négligées ou manquées. Les animaux de l'Amérique méridionale, qui seuls appartiennent en propre à ce continent, sont presque tous sans défenses, sans cornes, et sans quene; leur figure est bizarre, leur corps et leurs meinbres mal proportionnés, mal unis ensemble; et quelques uns, tels que les fourmilliers, les paresseux, etc., sont d'une nature si misérable, qu'ils ont à peine les facultés de se mouvoir et de manger. Ils trainent avec douleur une vie languissante dans la solitude du désert, et ne pourroient subsister dans 
une terre habitée, où l'homme et les animaux puissants les auroient bientôt détruits.

Le tapir est de la grandeur d'une petite vache ou d'un zébu, mais sans cornes et sans queue; les jambes courtes ; le corps arqué, comme celui du cochon, portant une livrée dans sa jeunesse, comme le cerf, et ensuite un pelage uniforme d'un brun foncé ; la tête grosse et longue, avec une espèce de trompe, comme le rhinocéros; dix dents incisives et dix molaires à chaque mâchoire, caractère qui le sépare entièrement du genre des bœufs et des autres animaux ruminants, etc. Au reste, comme nous n'avons de cet animal que quelques dépouilles, et un dessin que M. de La Condamine a eu la bonté de nous donner, nous ne pouvons mieux faire que de citer ici les de. scriplions qu'en ont faites, d'après nature, Marcgrave ${ }^{1}$

1. Tapiierete Brasiliensibus, Lusitanis anta. Animal quadrupes, " magnitudine jurenci semestris; figura corporis qrodam modo ad " porcum accedens, capite etiam tali, verum crassiori, oblongo, supe"rius in acumen desinente; promuscide super os prominente, quam " validissimo nervo contrahere et extendere potest $:$ in promuscide " autem sunt fissuræe oblongæ; inferior oris pars est brevior superiore. "Maxillæ ambæ anterius fastigiatæ, et in qualibet decem dentes incin sores superne et inferne; hine per certum spatium utraque maxilla " caret dentibus : sequuntur dein molares grandes omnes in quolibet " latere quinque, ita ut haberet viginli molares et vigenti incisores. n Oculos habet parvos porcinos, aures obrotundas, majusculas, quas n versus anteriora surrigit, crura vix longiora porcinis, et crassius- cula; in anterioribus pedibus quatuor ungulas, in posterioribus tres : - media inter eas major est in umnibus pedibus, in prioribus pedibus " tribus quarta parvula exterius est adjuncla. Sunt autem uingula ni" gricantes, non solidæ sed cavæ, et quæ detrahi possunt. Caret " cauda, et ejus loco processum habet nudum pilis, conicum, par" vum, more cutian (agouti). Mas membrum genitale longe exserere "potest, instar cercopilheci. Incedit dorso incurvato ut capybara 
et Barrère, et présenter en même temps ce qu'en ont dit les voyageurs et les historiens.

Il paroît que le tapir est un animal triste et ténébreux, qui ne sort que la nuit, qui ne se plait que dans les eaux, où il habite plus souvent que sur la terre; il vit dans les marais, el ne s'éloigne guère du bord des fleuves ou des lacs : dès qu'il est menacé, poursuivi, ou blessé, il se jette à l'eau, s'y plonge, et y demeure assez de temps pour faire un grand trajet avant de reparoître. Ces habitudes, qu'il a communes avec l'hippopotame, ont fait croire à quelques naturalistes qu'il étoit du même genre : mais il en diffère autant par la nature qu'il en est éloigné par le climat; il ne faut, pour en être assuré, que comparer les descriptions que nous venons de citer avec celle que nous avons donnée de l'hippopotame. Quoique habitant des eaux, le tapir ne se nourrit pas de poisson; et quoiqu'il ait la gueule armée de vingt

" (cabiai). Gutem solidam habet instar alcis, pilos breves. Color pi* lorum in junioribus est umbræ lucidæ; maculis variegatus albican- tibus ut capreolus; in adultis fuscus sive nigricans sine maculis. - Animal interdiu dormit in opacis sylvis latitans : noctu aut mane - cgreditur pabuli causa. Optime potest natare. Vescitur gramine, n arundine saccharifera, brassica, etc. Caro ejus comeditur, sed in" grati saporis est. n (Macgrave, Hist. Brasil. pag. 229.)

"Tapyr ou maypouri, animal amphibie, qui reste plus souvent " dans l'eau que sur la terre, où il va de temps en temps brouter " l'herbe la plus tendre. Il a le poil fort court, mêlé de blanc et de - noir en manière de bandes qui sétendent en long depuis la tête "jusqu'à la queue. Il siflle comme un yzard; il sembie tenir un peu " du mulet et du cochon. On voit des manipouris, comme prononn cent quelques uns, dans la rivière d'Ouyapok. Cette viande est gros" sière, et d'un goût désagréable. " (Barrère, Essai sur l'histoire naturelle de la France équinoxiale, pag. 160. ) 
dents incisives et tranchantes, il n'est pas carnassier : il vit de plantes et de racines, et ne se sert point de ses armes contre les autres animaux; il est d'un naturel doux, timide, et fuit tout combat, tout danger. Avec des jambes courtes et le corps massif, il ne laisse pas de courir assez vite, et il nage encore mieux qu'il ne court. Il marche ordinairement de compagnie, et quelquefois en grande troupe. Son cuir est d'un tissu très ferme et si serré, que souvent il résiste à la balle. Sa chair est fade et grossière; cependant les Indiens la mangent. On le trouve communément au Brésil, au Paraguay, à la Guiane, aux Amazones, et dans toute l'étendue de l'Amérique méridionale, depuis l'extrémité du Chili jusqu'à la Nouvelle-Espagne.

* Cet animal, qu'on peut regarder comme l'éléphant du Nouveau-Monde, ne le représente néanmoins que très imparfaitement par la forme, et en approche encore moins par la grandeur : il sera facile d'en faire au juste la comparaison; car j'ai cru devoir donner ici (planche 4o) une figure du tapir qui est plus exacte que celle que j’avois précédemment donnée, laquelle n'avoit été faite que sur une esquisse dessinée par feu M. de La Condamine : celle-ci a été prise sous nos yeux et sur l'animal vivant, auquel notre climat ne convient guère; car, après son arrivée, il n'a vécu que très peu de temps à Paris entre les mains du sieur Rugiéri, qui cependant en avoit beaucoup de soin.

On voit que l'espèce de trompe qu'il porte au bout du nez n'est qu'un vestige ou rudiment de celle de l'éléphant; c'est le seul caractère de conformation par 
lequel on puisse dire que le tapir ressemble à l'éléphant. M. de La Borde, médecin du roi à Cayenne, qui cultive avec succès différentes parties de l'histoire naturelle, m'écrit que le tapir est en effet le plus gros de tous les quadrupèdes de l'Amérique méridionale, et qu'il y en a qui pèsent jusqu’à cinq cents livres: or ce poids est dix fois moindre que celui d'un éléphant de taille ordinaire, et l'on n'auroit jamais pensé à comparer deix animaux aussi disproportionnés, si le tapir, indépendamment de cette espèce de trompe, n'avoit pas quelques habitudes semblables à celles de l'éléphant. Il va très souvent à l'eau pour se baigner, et non pour y prendre du poisson, dont il ne mange jamais; car il se nourrit d'herbes comme l'éléphant, et de feuilles d'arbrisseaux : il ne produit aussi qu'un petit.

Ces animaux fuient de même le voisinage des lieux habités, et demeurent aux environs des marécages et des rivières, qu'ils traversent souvent pendant le jour et même pendant la nuit. La femelle se fait suivre par son petit, et l'accoutume de bonne heure à entrer dans l'eau, où il plonge et joue devant sa mère, qui semble lui donner des leçons pour cet exercice: le père n'a point de part à l'éducation; car l'on trouve les mâles toujours seuls, à l'exception du temps où les femelles sont en chaleur.

L'espèce en est assez nombreuse dans l'intérieur des terres de la Guiane, et il en vient de temps en temps dans les bois qui sont à quelque distance de Cayenne. Quand on les chasse, ils se réfugient dans l'eau, où il est aisé de les tirer : mais, quoiqu'ils soient d'un naturel tranquille et doux, ils deviennent 
dangereux lorsqu'on les blesse; on en a vu se jeter sur le canct d'où le coup étoit parti, pour tâcher de se venger en le renversant. Il faut aussi s'en garantir dans les forêts : ils y font des sentiers ou plutot d'assez larges chemins battus par leurs fréquentes allées et venues; car ils ont l'habitude de passer et repasser toujours par les mêmes lieux; et il est à craindre de se trouver sur ces chemins, dont ils ne se détournent jamais ${ }^{1}$, parce que leur allure est brusque, et que, sans chercher à offenser, ils heurtent rudement tout ce qui se rencontre devant eux. Les terres voisines du haut des rivières de la Guiane sont habitées par un assez grand nombre de tapirs, et les bords des eaux sont coupés par les sentiers qu'ils y pratiquent; ces chemins sont si frayés, que les lieux les plus déserts semblent, au premier coup d'œil, être peuplés et fréquentés par les hommes. Au reste, on dresse des chiens pour chasser ces animaux sur terre, et pour les suivre dans l'eau : mais, comme ils ont la peau très ferme et très épaisse, il est rare qu'on les tue du premier coup de fusil.

Les tapirs n'ont pas d'autre cri qu'une espèce de

1. Un voyageur m'a raconté quill avoit failli d'être la victime de son peu d'expérience à ce sujet; que, dans un voyage par terre, il avoit attaché son hamac à deux arbres pour y passer la nuit, et que le hamac traversoit un chemin battu par les tapirs. Vers les neuf à dix heures du soir, il entendit un grand bruit dans la forêt; c'étoit un tapir qui venoit de son côté : il n'eut que le temps de se jeter hors de son hamac, et de se serrer contre un arbre. L'animal ne s'arrêta point; il fit sauter le hamac aux branches, et froissa cet homme contre l'arbre; ensuite, sans se détourner de son sentier battu, il passa au milieu de quelques nègres qui dormoient à terre auprès d'un grand feu, et il ne leur fit aucun mal. 
silllet vif et aigu, que les chasseurs et les sauvages imitent assez parfaitement pour les faire approcher et les tirer de près. On ne les voit guère s'écarter des cantons qu'ils ont adoptés. Ils courent lourdement et lentement. Ils n'attaquent ni les hommes ni les animaux, à moins que les chiens ne les approchent de trop près; car, dans ce cas, ils se défendent avec les dents et les tuent.

La mère tapir paroît avoir grand soin de son petit : non seulement elle lui apprend à nager, jouer, et plonger dans l'eau, mais encore, lorsqu'elle est à terre, elle s'en fait constamrnent accompagner ou suivre; et si le petit reste en arrière, elle retourne de temps en temps sa trompe, dans laquelle est placé l'organe de l'odorat, pour sentir s'il suit ou s'il est trop éloigné, et, dans ce cas, elle l'appelle et l'attend pour se remettre en marche.

On en élève quelques uns à Cayenne en domesticité; ils vont partout sans faire de mal : ils mangent du pain, de la cassave, des fruits; ils aiment qu'on les caresse, et sont grossièrement'familiers, car ils ont un air pesant et lourd, à peu près comme le cochon. Quelquefois ils vont pendant le jour dans les bois, et reviennent le soir à la maison; néanmoins il arrive souvent lorsqu'on leur laisse cette liberté, qu'ils en abusent et ne reviennent plus. Leur chair se mange, mais n'est pas d'un bon goût; elle est pesante, semblable, pour la couleur et par l'odeur, à celle du cerf. Les seuls morceaux assez bons sont les pieds et le dessus du cou.

M. Bajon, chirurgien du roi à Cayenne, a envoyé 
à l'Académie des Sciences, en 1774, un Mémoire au sujet de cet animal. Nous croyons devoir donner par extrait les bonnes observations de M. Bajon, et faire remarquer en même temps deux méprises qui nous parcissent s'être glissées dans son écrit, qui d'ailleurs mérite des éloges.

"La figure de cet animal, dit M. Bajon, approche en général de celle du cochon; il est cependant de la hauteur d'un petit mulet, ayant le corps extrêmement épais, porté sur des jambes très courtes. Il est couvert de poils plus gros, plus longs, que ceux de l'âne ou du cheval, mais plus fins et plus courts que les soies du cochon, et beaucoup moins épais. Il a une crinière dont les crins, toujours droits, ne sont qu'un peu plus longs que les poils du reste du corps; elle s'étend depuis le sommet de la tête jusqu'au commencement des épaules. La tête est groșse et un peu allongée, les yeux sont petits et très noirs; les oreilles courtes, ayant, pour la forme, quelque rapport avec celles du cochon. Il porte au bout de sa mâchoire supérieure une trompe d'environ un pied de long, dont les mouvements sont très souples, et dans laquelle réside l'organe de l'odorat; il s'en sert, comme l'éléphant, pour ramasser des fruits, qui font une partie de sa nourriture : les deux ouvertures des narines partent de l'extrémité de la trompe. Sa queue est très petite, n'ayant que deux pouces de long; elle est presque sans poils.

"Le poil du corps est d'un brun légèrement foncé. Les jambes sont courtes et grosses; les pieds sont aussi fort larges et un peu ronds. Les pieds de devant 
ont quatre doigts, et ceux de derrière n'en ont que trois : tous ces doigts sont enveloppés d'une corre dure et épaisse. La tête, quoique fort grosse, contient un très petit cerveau. Les mâchoires sont fort allongées et garnies de dents, dont le nombre ordinaire est de quarante; cependant il y en a quelquefois plus et quelquefois moins. Les dents incisives sont tranchantes, et c'est dans celles-ci qu'on observe de la variété dans le nombre. Après les incisives, on trouve une dent canine de chaque côté, tant supérieurement qu'inférieurement, qui a beancoup de rapport aux défenses du sanglier. On trouve ensuite un petit espace dégarni de dents, et les molaires suivent aprés, qui sont très grosses et ont des surfaces fort étendues.

"En disséquant le tapir ou maïpouri, la première chose qui m’avoit frappé, continue M. Bajon, c'est de voir qu'il est animal ruminant... Les pieds et les dents du maipouri n'ont pourtant aucun rapport avec ceux de nos animaux ruminants... Cependant le maïpouri a trois poches ou estomacs considérables qui communément sont fort pleins, surtout le premier, que jai tonjours trouvé comme un ballon... Cet estomac répond à la panse du bcuf : mais ici le réseau ou bonnet n'est presque point distinct, de sorie que ces deux parties n'en font qu'une. Le deuxième estomac, nommé le feuillet, est aussi fort cousidérable, el ressemble beaucoup à celui du bœuf, avec cette différence que les feuillets en sont beaucoup plus petits, et que les tuniques en paroissent plus minces. Enfin le troisième estomac est le moins grand et le plus mince; on n'y observe dans l'intérieur que de simples rides, et je l'ai presque toujours trouvé plein de ma* 
tière tout-à-fait digérée. Les intestins ne sont pas bien gros, mais très longs; l'animal rend les matières en boules, à peu près comme celles du cheval. "

Je suis obligé de contredire ici ce qu'avance M. Bajon, et d'assurer en même temps que cet animal n'est point ruminant, et n'a pas trois estomacs comme it le dil. Voici mes preuves. On nous avoit amené d'Amérique un tapir ou maipouri vivant; il avoit bien supporté la mer, et étoit arrivé à vingt lieues de Paris, lorsque tont à coup il tomba malade et monrut : on ne perdit pas de temps à nous l'envoyer, et je priai M. Mertrud, habile chirurgien démonstrateur en anatomie aux écoles du Jardin du Roi, d'en faire l'ouverture, et d'examiner les parties intérieures : chose très familière à M. Mertrud, puisque c'est lui qui a bien voulu disséquer, sous les yeux de M. Daubenton, de l'Académie des Sciences, la plupart des animanx dont nous avons donné les descriptions. M. Mertrud joint d'ailleurs à toutes les connoissances de l'art de l'anatomie une grande exactitude dans ses opérations. De plus, cette dissection a, płour ainsi dire, été faite en ma présence, et M. Daubenton le jeune en a suivi loutes les opérations et en a rédigé les résultats. Enfin M. de Sève, notre dessinilleur, qui voit très bien, y étoit aussi. Je ne rapporte ces circonstances que pour faire voir à M. Bajon que nous ne pouvons nous dispenser de le contredire sur cu prem ier point très essentiel : c'est qu'au lieu de trois estomacs, nous n'en avons trouvé qu'un seul dansi cet animal. La capacité en étoit, à la vérité, fort ample et er forme d'une poche étranglée en deux endroits; mais cê n'étoit qu'un seul viscère, un estomac sis nple et unique, 
qui n'avoit qu'une simple issue dans le duodenum, et non pas trois estomacs distincts et séparés, comme le dit M. Bajon : cependant il n'est pas étonnant qu'il soit tombé dans cette méprise, puisque l'un des plus célèbres anatomistes de l'Europe, le docteur Tyson, de la Société royale de Londres, s'est trompé en disséquant le pecari ou tajaca. d'Amérique, duquel au reste il a donné une très bonne description dans les Transactions philosophiques, $\mathrm{n}^{\circ} 153$. Tyson assure, comme M. Bajon le dit ru tapir, que le pecari a trois estomacs, tandis qu'il n'en a réellement qu'un seul, mais partagé à peu près, comme celui du tapir, par deux étranglements qui semblent, au premier coup d'œil, en indiquer trois.

Il nous paroît donc certain que le tapir ou maïpouri n'a pas trois estomacs, et qu'il n'est point animal ruminant; car nous pouvons encore ajouter à la preuve que nous venons d'en donner, que jamais cet animal, qui est arrivé vivant jusqu'auprès de Paris, n'a ruminé. Ses conducteurs ne le nourrissoient que de pain, de grain, etc. Mais cette méprise de M. Bajon n'empêche pas que son mémoire ne contienne de très bonues observations; l'on en va juger par la suite de cet extrait, dans lequel j'ai cru devoir interposer quelques faits qui m’ont été communiqués par des témoins oculaires.

"Le tapir ou maïpouri mâle, dit M. Bajon, est constamment plus grand et plus fort que la femelle; les poils de la crinière sont plus longs et plus épais. Le cri de l'un et de l'autre est précisément celui d'un gros sifflet; le cri du mâle est plus aigu, plus fort et plus perçant que celui de la femelle. Les parties de 
la géénération du mâle semblent avoir un rapport très grand avec celles du cheval ou de l'âne; elles sont situées de la même façon; et on observe sur le fourreau, comme dans le cheval, à peu de distance des testicules, deux petits mamelons très peu apparents, qui indiquent l'endroit des mamelles. Les testicules sont très gros, et pèsent jusqu'à douze ou quatorze onces chacun... La verge est grosse et n'a ru'un corps caverneux. Dans son état ordinaire, elle est renfermée dans une poche considérable, formée par le fourreau; mais lorsqu'elle est en érection, elle sort tout entière comme celle du cheval. "

Une des femelles que M. Bajon a disséquées avoit six pieds de longueur, et paroissoit n'avoir pas encore porté. Ses mamelles, au nombre de deux, n'étoient pas bien grosses; elles ressemblent en tout à celles de l'ânesse ou de la jument. La vulve étoit à un bon pouce de l'anus.

Les femelies entrent ordinairement en chaleur aux mois de novembre et de décembre; chaque mâle suit une femelle, et c'est là le seul temps où l'on trouve deux de ces animaux ensemble. Lorsque deux mâles se rencontrent auprès de la même femelle, ils se battent et se blessent cruellement. Quand la femelle est pleine, le mâle la quitte et la laisse aller seule. Le temps de la gestation est de dix à onze mois; car on en voit de jeunes dès le mois de septembre. Pour mettre bas, la femelle choisit toujours un endroit élevé et un terrain sec.

Cet animal, bien loin d'être amphibie, comme quelques naturalistes l'on dit, vit continuellement sur la terre, et fait constamment son gîte sur les collines 
et dans les endroits les plus secs. Il est vrai qu'il fréquente les lieux marécageux; mais c'est pour y chercher sa subsistance, et parce qu'il y trouve plus de f'uilles et d'herbes que sur les terrains élevés. Comme il se salit beaucoup dans les endroits marécageux, et qu'il aime la propreté, il va tous les matins et tous les soirs traverser quelque rivière, ou se laver dans quelque lac. Malgré sa grosse masse, il nage parfaitement bien, et plonge aussi fort adroitement : mais il n'a pas la faculté de rester sous l'eau plus de temps que tout autre animal terrestre; aussi le voit-on à loui instant tirer sa trompe hors de l'eau pour respirer. Quand il est poursuivi par les chiens, il court aussitôt vers quelque rivière, qu'il traverse promptement pour tâcher de se soustraire à leur poursuite.

Il ne mange point de poisson; sa nourriture ordinaire sont des rejetons et des pousses tendres, et surtout des fruits tombés des arbres. C'est plutôt la nuit que le jour qu'il cherche sa nourriture; cependant il se promène le jour, surtout pendant la pluie. II a la vue et l'ouie très fines; au moindre mouvement qu'il entend, il s'enfuit, et fait un bruit considérable dans le bois. Cet animal, très solitaire, esi fort doux et même assez timide; il n'y a pas d'exemple qu'il ait cherché à se défendre des hommes. Il n'en est pas de même avec les chiens : il s'en défend très bien, surtout quand il est blessé; il les tue même assez souvent, soit en les mordant, soit en les foulant aux pieds. Lorsqu'il est élevé en domesticité, il senıble être susceptible d'attachement. M. Bajon en a nourri un qu'on lui apporta jeune, et qui n'étoit encore pas plus gros qu'un mouton; il parvint à l'élever fort 
grand, et cet animal prit pour lui une espèce d'anitié; il le distinguoit à merveille au milieu de plusieurs personnes; il le suivoit comme un chien suit son maître, et paroissoit se plaire beaucoup aux caresses qu'il lui faisoit; il lui léchoit les mains; enfin il alloit seul se promener dans les bois, et quelquefois fort loin, e! il ne manquoit jamais de revenir tous les soirs d'assez bonne heure. On en a vu un autre, également apprivoisé, se promener dans les rues de Cayenne, aller à la campagne en toute liberté, et revenir chaque soir : néanınoins, lorsqu'on voulut l'embarquer pour l'amener en Europe, dès qu'il fut à bord du navire, on ne put le tenir; il cassa des cordes très fortes avec lesquelles on l'avoit attaché, il se précipita dans l'eau, gagna le rivage à la nage, et entra dans un fort de palétuviers, à une distance assez considérable de la ville; on le crut perdu, mais le soir méme il se rendit à son gîte ordinaire. Comme on avoit résolu de l'embarquer, on prit de plus grandes précautions, qui ne réussirent que pendant un temps; car, à environ inoitié chemin de l'Amérique en France, la mer étant devenue fort orageuse, l'animal se mit de mauvaise humeur, brisa de nouveau ses liens, enfonça sa cabane, et se précipita dans la mer, d'où on ne put le retirer.

L'hiver, pendant lequel il pleut presque tous les jours à Cayenne, est la saison la plus favorable pour chasser ces animaux avec succès.

"Un chasseur indien, qui étoit à mon service, dit 11. Bajon, alloit se poster au milieu des bois; il donnoit cinq à six coups d'un sifllet fait exprès, et qui imitoil très bicn leur cri: s'il s'en trouvoit quelqu'un aux 
environs, il répondoit tout de suite ; et alors le chasseur s'acheminoit doucement vers l'endroit de la réponse, ayant soin de le faire répéter de temps en temps, et jusqu'à ce qu'il se trouvât à portée de tirer. L'animal, pendant la sécheresse de l'été, reste au contraire tout le jour couché; cet Indien alloit alors sur les petites hauteurs, et tâchoit d'en découvrir quelqu'un, et de le tuer au gîte : mais cette manière étoit bien plus stérile que la première. On se sert de lingots ou de très grosses balles pourles tirer, parce que leur peau est si dure, que le gros plomb ne fait que l'égratigner; et avec les balles et même les lingots, il est rare qu'on les tue du premier coup: on ne sauroit croire combien ils ont la vie dure. Leuv chair n'est pas absolunient mauvaise à manger : celle des vieux est coriace, et a un goût que bien des gens trouvent désagréable: mais celle des jeunes est meil. leure, et a quelque rapport avec celle du veau. ”

Je n'ai pas cru devoir tirer par extrait, du mémoire de M. Bajon, les faits anatomiques; je n'ai cité que celui des prétendus trois estomacs, qui néanmoins n'en font qu'un : j'espère que M. Bajon le reconnoîträ lui-même, s'il se donne la peine d'examiner de nouveau cette partie intérieure de l'animal.

Une autre remarque qui me pàroît nécessaire, et que nous croyons devoirfäre, quoique nous ne soyons pas aussi certains du fait quie de celui du seul ęstomac, c'est au sujet des cornes de la matrice. M. Bajon assure que, dans toutes les femelles qu’il a disséqquées, l'extrémité des trompę, qui répond aux ovaires, est exactement fermée, et que leur cavité n'a absolument aucune communication avec ces narties. 
"J'ai, dit-il, soufflé de l'air dans ces trompes, el je l'ai pressé avec force; il ne s'en est point échappé, il n'en est point entré du côté des ovaires. Cette extrémité des trompes, qu'on appelle le pavillon ou le morceau frangé, paroît être terminée en rond, et on observe à l'extérieur de son extrémité plusieurs culsde-sac, que l'on diroit d'abord être autant de communications avec son intérieur : mais ils sont formés par des replis membraneux, produits par la membrane qui leur est fournie par les ligaments larges; au moyen de laquelle membrane les trompes se trouvent attachées aux ovaires. L'entière oblitération de l'extrémité des trompes qui répond aux ovaires est un phénomène qui portera sans doute quelque atteinte au système ordinaire de la génération. La nouveauté, l'imporlance, et la singularité de ce phénomène, ajoute M. Bajon, ont fait que je me suis mis en garde contre mes propres observations. J'ai donc cherché à m'assurer du fait par de nouvelles recherches, pour qu'il ne me restât point de doute; de sorte que la dissection de dix à douze fenelles, que j’ai faite dans l'espace de trois à quatre mois, m'a mis à même de pouvoir attester la réalité du fait, tant dans les jeunes femelles que dans celles qui avoient porté; car j’en ai disséqué qui avoient du lait dans les mamelles, et d'autres qui étoient pleines. „

Quelque positive que soit cette assertion, et quelque nombreuses que puissent être à cet égard les observations de M. Bajon, elles ont besoin d'être répétées, et nous paroissent si opposées à tout ce que l'on sait d'ailleurs, que nous ne pouvons y ajouter foi. 
Voici maintenant les notes que j'ai recueillies pendant la dissection que M. Mertrud a faite de cet animal à Paris.

L'estomac étoit situé de manière qu'il paroissoit également éte ndu à droite comme à gauche; la poche s'en terminoit en pointe, moins allongée que dans le cochon, et il y avoit un angle bien marqué entre l'œsophage et le pylore, qui faisoit une espèce d'étranglement, et la partie gauche étoit beaucoup plus ample que la droite : le colon avoit beaucoup d'ampleur; il étoit plus étroit à son origine et à son extrémité que dans son milieu : la grande circonférence de l'estomac étoit de trois pieds un pouce; la pelite circonférence, de deux pieds six lignes.

Longueur du foie. ........... " . . . 11 ".

Epaisseur du foie. . . . . . . . . . . . ${ }^{\infty} \quad 3 \quad 6$

Largeur du foie. . . . . . . . . . . 1 1 1

Il n'y avoit point de vésicule du fiel, mais seule-

ment un conduit biliaire qui s'ouvroit dans le

duodenum, à côté du cunal pancréatique.

Longueur de la rate............... 146 . . . . . .

Largeur de la rate............ „ ${ }_{2}{ }_{2}$

Épaisseur de la rate........... „ $1 . \ldots$ n

Hauleur du coeur. ............... 5 "

Girconférence du cour. ........., , 2 ,

Le trou ovale étoit fermé.

Diamètre de l'aorte. . . . . . . . . „ 1 ,

Longueur des intestins grêles, depuis le pylore jusqu'au cœcum.............. $38{ }_{2}$ "

Circonférence des intestins grêles dans les endroits

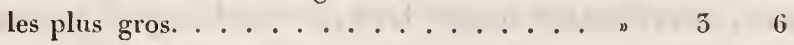

Circonférence dans les endroits les plus petits. . " $\begin{array}{llll} & 5 & 2\end{array}$

Longueur du cœecum. .............. 1 10 "

Circonférence du coecum à l'endroit le plus gros. $\begin{array}{llll}2 & 4 & 10\end{array}$

Circonférence du colon à l'endroit le plus gros. . 1 9 "

Circonférence du colon à l'endroit le plus petit. " 7 " 
picds. pour. lign.

Circonférence du rectum à l'endroit le plus gros. I Circonférence du rectum à l'endroit le plus petit. "

Centre nerveux. . . . . . . . . .

Longueur des reins. . . . . . . . . .

Largeur des reins. . . . . . . . . . .

Épaisseur des reins.

Diamètre de la vulve.

Longueur du vagin.

n $n$

Longueur du corps de la matrice. . . . . .

Longueur des cornes de la matrice. . . . . .

Grande circonférence de la vessie. . . . . . .

Petite circonférence de la vessie. . . . . . .

Longueur de l'aretère. . . . . . . . . .

Circonférence de l'uretère.. . . . . . . . .

Longueur des testicules ou ovaires. ...... ”

Largeur des testicules. . . . . . . . . "

Épaisseur des testicules. .......... ”

Longueur de la langue. . . . . . . . . 1

Longueur de l'animal, depuis le bout du nez à

l'anus................ . . .

Hanteur du train de derrière. . . . . . . .

Hauteur du train de derant. , . . . . . . .

Longueur de l'œil d'un angle à l'autre. . . . . .

$7 \quad 6$

Dans le temps que l'on a fait cette dissection et pris les mesures précédentes, nous n'avions pas encore reçu le mémoire de M. Bajon. Nous eussions sans doute examiné de beaucoup plus près l'estomac, et surtout les cornes de la matrice de cet animal; mais , quoique cet examen ultérieur n'ait pas été fait, nous sommes néanmoins convaincus qu'il n'a qu'un estomac, et en même temps très persuadés qu'il y a communication entre les ovaires et l'extrémité des trompes de la matrice.

Au reste, le tapir, qui est le plus gros quadrupède de l'Amérique méridionale, ne se trouve que dans 
cette partie du monde. I'espèce ne s'est pas étendue au delà de l'isthme de Panama, et c'est probablement parce qu'il n'a pu franchir les montagnes de cet isthme; car la température du Mexique et des autres provinces adjacentes auroit convenu à la nature de cet animal, puisque Samuel Wallis et quelques autres voyageurs disent en avoir trouvé, ainsi que des lamas, jusque dans les terres du détroit de Magellan.

\section{L'H IPP OPO'TA ME'.}

Hippopotamus amphibius. L.

Quoroque l'hippopotame ait été célébré de toute antiquité, que les livres saints en fassent mention sous le nom de behemoth, que la figure en soit gravée sur les obélisques d'Égypte et sur les médailles romaines, il n'étoit cependant qu'imparfaitement connu des anciens. Aristote ne fait, pour ainsi dire, que l'indiquer; et darıs le peu qu'il en dit, il se trouve plus d'erreurs que de faits vrais. Pline, en copiant Aristote, loin de corriger ses erreurs, semble les confirmer et en ajouter de nouvelles. Ce n'est que vers le milieu du seizième siècle que l'on a eu quel-

1. En hébreu, behemoth. Hoc animal esse quod nomine behemoth in lióro Job describitur, a Sam. Dochart in Hierozoïco solide demonstratur. (Ray, Synop. quadr. pag. 12.) Hippopotamus en latin; ippopotano en italien; forcis l'bar en Egyple, selon Zerenghi, ce qui signifie chcval de mer. 
ques indications précises au sujet de cet anitia!. BeIon, étant alors à Constantinople, en vit un vivant, duquel néanmoins il n’a donné qu'une connoissance imparfaite; car les deux figures qu'il a jointes à sa description ne représentent pas l'hippopotame qu'il a vu, mais ne sont que des copies prises du revers de la médaille de l'empereur Adrien et du colosse du Nil à Rome. Ainsi l'on doit encore reculer l'époque de nos connoissances exactes sur cet animal jusqu'en 1605, que Federico Zerenghi, chirurgien de Narni en Italie, fit impriner à Naples l'histoire de deux hippopotames qu'il avoit pris vivants et tués lui-même en Égypte, dans une grande fosse qu'il avoit fait creuser aux environs du Nil, près de Damiette. Ce petit ouvrage, écrit en italien, paroît avoir été ignoré des naturalistes contemporains, et a élé depuis absolument négligé; cependant c'est le seul qu'on puisse regarder comme original sur ce sujet. La description qque l'autcur donne de l'hippopotame est aussi la seule qui soit bonne; et elle nous a paru si vraie, que nous croyons devoir en donner ici la traduction et l'extrait.

"Dans le dessein d'avoir un hippopotame, dit Zerenghi, j'apostai des gens sur le $\mathrm{Nil}$, qui, en ayant vu sortir deux du fleuve, firent une grande fosse dans l'endroit où ils avoient passé, et recouvrirent cette fosse de bois léger, de terre, et d'herbes. Le soir, en revenant au fleuve, ces hippopolames y tombèrent tous deux : mes gens vinrent m'avertir de cette prise; j’accourus avec mon janissaire; nous tuâmes ces deux animaux en leur tirant à chacun daus la tête trois coups d'arquebuse d'un calibre plus gros 
que les mousquets ordinaires. Ils expirèrent presque sur-le-champ, et firent un cri de douleur qui ressembloit un peu plus au mugissement d'un buffle qu'au hennissement d'un cheval. Cette expédition fut faite le 20 juillet 1600 : le jour suivant, je les fis tirer de la fosse et écorcher avec soin; l'un étoit mâle, et l'autre femelle; $j$ 'en fis saler les pcaux : on les remplit de feuilles de cannes de sucre pour les transporter au Caire, on on les sala une seconde fois avec plus d'attention et de commodité; il me fallut quatre cents livres de sel pour chaque peau. A mon retour d'Égypte, en 1601 , ¡'apportai ces peaux à Venise, et de là à Rome; je les fis voir à plusieurs médecins intelligents. Le docteur Jérôme Aquapendente et le célèbre Aldrovande furent les seuls qui reconuurent l'hippopotame par ces dépouilles; et comme l'ouvrage d'Aldrovande s'imprimoil alors, il fit, de mon consentement, dessiner la figure qu'il a donnée dans son livre, d’après la peau de la femelle.

"L'hippopotame a la peau très épaisse, très dure, et elle est impénétrable, à moins qu'on ne la laisse long-temps tremper dans l'eau. Il n'a pas, comme le disent les anciens, la gueule d'une grandeur médiocre; elle est, au contraire, énormément grande; il n'a pas, comme ils le disent, les pieds divisés en deux ongles, mais en quatre : il n'est pas grand comme un âne, mais beaucoup plus grand que le plus grand cheval oa le plus gros buffle; il n'a pas la queue comme celle du cochon, mais plutôt comme celle de la tortue, sinon qu'elle est incomparablement plus grosse : il n'a pas le museau ou le nez relevé en haut, il l'a semblable au buffle, mais beaucoup plus grand: 
il n'a pas de crinière comme le cheval; mais seulement quelques poils courts et très rares; il ne hennit pas comme le cheval, mais sa voix est moyenne entre le mugissement du buffle et le henuissement du cheral : il n'a pas les dents saillantes hors de la gueule; car, quand la bouche est fermée, les dents, quoique extrêmement grandes, sont toutes cachées sous les ièvres.... Les habitants de cette partie de l'Égypte l'appellent foras l'bar, ce qui signifie le cheval de mer... Belon s'est beaucoup trompé dans la description de cet animal; il lui donne des dents de cheval : ce qui feroit croire qu'il ne l'auroit pas vu, comme il le dit; car les dents de l'hippopotame sont très grandes et très singulières.... Pour lever tous les doutes et fixer toutes les incertitudes, continue Zerenghi, je donne ici la figure de l'bippopotame femelle: toutes les proportions ont été prises exactement d'après nature, aussi bien que les mesures du corps et des membres.

"La longueur du corps de cet hippopotame, prise depuis l'extrémité de la lèvre supérieure jusqu’à l'origine de la queue, est à peu près de onze pieds deux pouces de Paris.

"La grosseur du corps en circonférence est environ de dix pieds, mesure de Paris.

"Isa hauteur, depuis la plante du pied jusqu'an sommet du dos, est de quatre pieds cinq pouces de Paris.

" La circonférence des jambes auprès des épaules est de deux pieds neuf pouces, mesure de Paris.

"La circonférence des jambes, prise plus bas, est d'un pied neuf pouces et demi, mesure de Paris. 
"La hauteur des jambes, depuis la plante des pieds jusque sous la poitrine, est d'un pied dix pouces el demi de Paris.

"La longueur des pieds, depuis l'extrémité des ongles, est de quatre pouces et demi, mesure de Paris.

" Les ongles sont aussi longs que larges, et ont à peu près deux pouces deux lignes.

"Il y a un ongle pour chaque doigt, et quatre roigts pour chaque pied.

"La peau sur le dos est épaisse à peu près d'un pouce.

"La peau sur le ventre est épaisse environ de sept lignes.

"Ceite peau est si dure lorsqu'elle est desséchée, qu'on ne peat la percer en entier d'un coup d'arquebuse. Les gens du pays en font de grands boucliers; ils en coupent aussi des lanières, dont ils se servent comme nous nous servons du nerf de bœuf. Il y a sur la surface de la peau quelques poils très rares, de couleur blonde, que l'on n'aperçoit pas au premier coup d'œil; il y en a sur le cou qui sont un peu plus gros que les autres; ils sont tous placés un à un, à plus ou moins de distance les uns des autres; mais sur les lèvres ils forment une espèce de moustache, car il en sort dix ou douze du même point en plusieurs endroits. Ces poils sont de la même conleur que les autres, seulement ils sont plus durs, plus gros, et un peu plus longs, quoique les plus grands ne le soient que de cinq lignes et demie.

"La longueur de la quene est de onze pouces quatre lignes. 
n. La circonférence de la queue, prise à l'origine, est un peu plus d'un pied.

"I Ia circonférence de la queue, prise à son extrémité, est de deux pouces dix lignes.

"Cette queue n'est pas ronde; mais, depuis le milieu jusqu'au bout, elle est aplatie, à peu près comme celle d'une anguille. Il y a sur la peau de la queue et sur celle des cuisses quelques petites écailles rondes, de couleur blanchâtre, larges comme de grosses lentilles. On voit aussi de ces petites écailles sur la poitrine, sur le cou, et sur quelques endroits de la tête.

"La tête, depuis l'extrémité des lèvres jusqu'au commencement du cou, est longue de deux pieds quatre pouces.

"La circonférence de la tête est de cinq pieds huit pouces.

"Les oreilles sont longues de deux pouces neuf lignes.

"Les oreilles sont larges de deux pouces trois lignes.

"Les oreilles sont un peu pointues, et garnies en dedans de poils épais, courts, et fins, de la même couleur que les autres.

"Les yeux ont d'un angle à l'autre deux pouces trois lignes.

"Les yeux ont d'une paupière à l'autre treize lignes.

"Les narines sont longues de deux pouces quatre lignes.

"Les narines sont larges de quinze lignes.

"La gueule ouverte a de largeur un pied six pouces quatre lignes.

"Cette guenle est de forme carrée, et elle est garnie de quarante-quatre dents de figures liféren- 
res ${ }^{1}$.... Toutes ces dents sont d'une substance si dure, qu'elles font feu avec le fer : ce sont surtout les dents canines (zanne) dont l'émail a cette dureté; la substance intérieure de toutes ces dents n'est pas si dure... Lorsque l'hippopotame tient la bouche fermée, il ne paroît aucune dent au dehors: elles sont. toutes couvertes et cachées par les lèvres, qui sont extrêmement grandes.

"A l'égard de la figure de l'animal, on pourroit dire qu'elle est moyenne entre celle du buffle et celle du cochon, parce qu'elle participe de l'une et de l'aulre, à l'exception des dents incisives, qui ne ressemblent à celles d'aucun animal : les dents molaires ressembleit un peu en gros à celles du buffle ou du cheval, quoiqu'elles soient beaucoup plus grandes. La couleur du corps est obscure et noirâtre... On assure que l'hippopotane ne produit qu'un petit, qu'il ne vit que de poisson, de crocodiles, et même de cadavres et de chair; cependant il mange du riz, des grains, etc., quoiqu'à considérer ses dents, il paroisse que la nature ne l'a pas fait pour paître, mais pour dévorer les autres animaux."

Zerenghi finit sa description en assurant que toutes

1. $1^{\circ}$ Dans trois têtes d'hippopolames que nous avons au Cabinet du Roi, il n'y a que trente-six dents : comme ces têtes sont beaucoup plus petites que celle de l'hippopotame de Zerenghi, on peut présumer que dans ces jeunes hippopotames toutes les dents molaires n'étoient pas encore développees, ot que les adultes en ont huit de plus. $2^{\circ}$ Nous passons ici les dimensions détaillées de toutes ces dents, que Zerenghi donne de même, par des mesures actuelles, parce que l'on trouvera les figures et les proportions des dents et des autres os de la tête de l'hippopotame dans la description et les figures qu'en donne M. Daubenton, au toune XXIV de l'édition avec la partie anatomique. 
ses mesures ont été prises sur l'hippopolame femelle, à laquelle le mâle ressemble parfaitement, à l'excep)tion qu'il est d'un tiers plus grand dans toutes ses dimensions. Il seroit à souhaiter que la figure donnée par Zerenghi fût aussi bonne que sa description : mais cet animal ne fut pas dessiné vivant. Il dit luimême qu'il fit écorcher ses deux hippopotames sur le lieu ou il venoit de les prendre, qu'il ne rapporta que les peaux, et que c'est d'après celle de la femelle qu'Aldrovande a donné sa figure. Il paroît aussi que c'est d'après la même peau de la femelle, conservée dans du sel, que Fabius Columna a fait dessiner la figure de cet animal; mais la description de Fabius Columna, quoique faite avec érudition, ne vaut pas celle de Zerenghi, et l'on doit même lui reprocher de n'avoir cité que le nom et point du tout l'onvrage de cet auteur, inprimé trois ans avant le sien, et de s'être écarté de sa description en plusieurs points essentiels, saus en donner aucune raison. Par exemple, Columna dit que de son temps, en 1603 , Federico Zerenghi a apporté d'Égypte en Italie un hippopotame entier, conservé dans du sel, tandis que Zerenghi lui-même dit qu'il n'en a apporté que les peaux; ensuite Columna donne au corps de son hippopotame treize pieds de longueur, quatorze pieds de circonférence, et aux jambes trois pieds et demi de longueur, tandis que par les mesures de Zerenghi, le corps n'avoit que onze pieds deux pouces de longueur, dix pieds de circonférence, et les jambes un pied dix pouces et demi, etc. Nous ne devons donc pas tabiex sur la description de Fabius Columna, mais sur celle de Zerenghi, et l'on no peut excuser ce premier 
auteur, ni supposer que sa description ait été faite sur un autre sujet; car il est évident, par son propre texte, qu'il l'a faite sur le plus petit des deux hippopotames de Zerenghi, puisqu'il avoue lui-mêne que, quelques mois après, Zerenghi fit voir un second hippopotame beaucoup plus grand que le premier. Ce qui me fait insister sur ce point, c'est que personne n'a rendu justice à Zerenghi, qui cependant est le seul qui mérite ici des éloges; qu'au contraire tous les naturalistes, depuis cent soixante ans, ont attribué à Fabius Columna ce qu'ils auroient dû donner à Zerenghi, et qu'au lieu de rechercher l'ouvrage de celui-ci, ils se sont contentés de copier et de louer celui de Columna, quoique cet auteur, très estimable d'ailleurs, ne soir, sur cet article, ni original, ni exact, ni même sincère.

La description et les figures de l'hippopotame que Prosper Alpin a publiées plus de cent ans après sont encore moins bonnes que celles de Columna, n'ayant été faites que d'après des peaux mal conservées; et M. de Jussieu, qui a écrit surl'hippopotame en 1724 , n'a donné la description que du squelette de la tête et des pieds.

En comparant ces descriptions, et surtout celle de Zerenghi, avec les indications que nous avons tirées des voyageurs, il paroît que l'hippopotame est un animal dont le corps est plus long et anssi gros que celui du rhinocéros, que ses jambes sont beaucoup plus courtes, qu'il a la tête moins longue ct plus grosse à proportion du corps; qu'il n'a de cornes, ni sur le nez comme le rhinocéros, ni sur la tête comme les animaux ruminants; que son cri de douleur tenant au- 
fant du henuissement du cheval que du mugissement du buffle, il se pourroit, comme disent les auteurs anciens et les voyageurs modernes, que sa voix orditraire fût semblable au hennissement du cheval, du-fuel néanmoins il diffère à tous autres égards : et, si cela est, l'on peut présumer que ce seul rapport de If ressemblance de la voix a suffi pour lai faire donde: le nom d'hippopotame, qui veut dire, cheval de rivere; comme le hurlement du lynx, qui ressemble en yuelque sorle à celui du loup, l'a fait appeler loupcrpvier. Les dents incisives de l'hippopotame, et surtout les deux canines dans la mâchoire inférieure, sont très longues, très fortes, et d'une substance si dure, ru'elle fait feu contre le fer : c'est vraisemblablement ce qui a donné lieu à la fable des anciens, qui ont déhité que l'hippopolame vomissoit le feu par la gueule. Cette matière des dents canines de l'hippopotame est si blanche, si nette, et si dure, qu'elle est de beancoup préférable à l'ivoire pour faire des dents artificielles et postiches. Les dents incisives de 'hippopotame, surtout celles de la mâchoire inférieure, sont très longues, cylindriques et annelées : les dents canines, qui sont aussi très longues, sont courbées, prismatiques, et coupantes, comme les défrnses du sanglier. Les dents molaires sont carrées ou bs rlongues, assez semblables aux dents mâchelières de Thomme, et si grosses, qu'une seule pèse plus de zrois livres; les plus grandes incives et canines ont insqu'à douze et même seize pouces de longueur, et risent quelcuefois douze ou treize livres chacune.

Enfin, pour donner une juste idée de la grandeur de l'hippopotane, nous emploierons les mesures de 
Zerenghi, en les augmentant d'un tiers, parce que ces mesures, comme il le dit lui-même, nont éte prises que d'après la femelle, qui étoit d'un tiers plus petite que le mâle dans toutes ses dimensions. Cet hippopotane mâle avoit par conséquent seize pieds neufs pouces de longueur depuis l'extrémité du museau jusqu'à l'origine de la queue, quinze pieds dt circonférence, six pieds et demi de hautear, environ deux pieds dix pouces de longueur de jambes, la tête longue de trois pieds et demi, et grosse de huit pieds et demi de circonférence; la gaeule de deux pieds quatre pouces d'ouverture, et les grandes dents longues de plus d'un pied.

Avec d'anssi puissantes armes et une force prodigieuse de corps, l'hippopotame pourroit se rendre redontabie à tous les animaux; mais il est naturellement doux; il est d'ailleurs si pesant et si lent à la course, qu'il ne pourroit attraper aucun des quadrupèdes. Il nage plus vite qu'il ne court; il chasse le poisson et en fait sa proie. II se plaît dans l'eau, et y séjourne aussi volontiers que sur la terre : cependant il n'a pas, comme le castor et la loutre, des membranes entre les doigls des pieds, et il paroît qu'il ne nage aisément que par la grande capacité de son ventre, qui fait que, volume pour volume, il est à peu près d'un poids égal à l'eau. D'ailleurs il se tient longrtemps au fond de l'eau, et y narche comme en plein air; et lorsqu'il en sort pour paitre, il mange des cannes de sucre, des joncs, du millet, du riz, des racines, etc.; il en consomme et détruit une grande quantité, et il fait beaucoup de dommage dans le terres cultivées; mais, comme il est plus timide sur 
terre que dans l'eau, on vient aisément à bout de l'écarter; il a les jambes si courtes, qu'il ne pourroit échapper par la fuite, s'il s'éloignoil du bord des eaux : sa ressource, lorsqu'il est en danger, est de se jeter à l'eau, de s'y plonger et de faire un grand trajet avant de reparoître. Il fuit ordinairement lorsqu'on le chasse : mais si l'on vient à le blesser, il s'irrite, et, se relournant avec fureur, se lance contre les barques, les saisit avec les dents, en enlève souvent des pièces, et quelquefois les submerge. "J'ai vu, dit un voyageur, l'hippopotame ouvrir la gueule, planter une dent sur le bord d'un bateau, et une autre au second bordage depuis la quille, c'est-à-dire à quatre pieds de distance l'une de l'autre, percei' la planche de part en part, faire couler ainsi le bateau à fond.... J'en ai vu un autre le long du rivage de la mer, sur lequel les vagues poussèrent une chaloupe chargée de quatorze muids d'eau, qui demeura sur son dos à sec; un autre coup de mer vint qui l'en retira, sans qu'il parût du tout avoir senti le moindre mal... Lorsque les nègres vont à la pêche dans leurs canots et qu'ils rencontrent un hippopotame, ils lui jettent du poisson, et alors il passe son chemin sans troubler davantage leur pêche. Il fait le plus de mal lorsqu'il peut s'appuyer contre terre; mais quand il flotte sur l'eau il ne peut que mordre. Une fois que notre chaloupe étoit auprès du rivage, je le vis se mettre dessous, la lever avec son dos au dessus de l'eau, et la renverser avec six hommes qui éloient dedans; mais par bonheur il ne leur fit aucun mal. Nous n'osions pas, dit un antre voyageur, irriter les hippopotames dans l'eau, depuis une aventure qui 
pensa être funeste à trois hommes : ils étoient allés avec un petit canot pour en tuer un dans une rivière où il y avoit huit ou dix pieds d'eau; après l'avoir découvert au fond, où il marchoit selon sa coutume, ils le blessèrent avec une longue lance; ce qui le mit en une telle furie, qu'il remonta d'abord sur l'eau, les regarda d'un air terrible, ouvrit la gueule, emporta d'un coup de dent une grosse pièce du rebord du canot, et peu s'en fallut même qu'il ne le renversât : mais il replongea aussitôt au fond de l'eau. "Ces deux exemples suffisent pour donner une idée de la force de ces animaux. On trouvera quantité de pareils faits dans l'Histoirt générale des voyages, où M. l'abbé Prévôt a présenté, avec avantage et avec cette netleté de style qui lui est ordinaire, un précis de tout ce que les voyageurs ont rapporté de l'hippopotaine.

Au reste, cet animal n'est en grand nombre que dans quelques endroits, et il paroît même que l'espèce en est confinée à des climats particuliers, et qu'elle ne se trouve guère que dans les fleuves de l'Afrique. La plupart des naturalistes unt écrit que l'hippopotane se trouvoit aussi aux Indes: mais ils n’ont pour garants de ce lait que des témoignages qui me paroissent un pen'équivoques; le plus positif de tous seroit celui d'Alexandre dans sa lettre à Aristote, si l'on pouvoit s'assurer, par cette même lettre, que les animaux dont parle Alexandre fussent réellement des hippopotames: ce qui me donne quelques doutes, c'est qu'Aristote, en décrivant l'hippopotame dans son Histoire des animaux, auroit dit qu'il se trouvoit aux Indes aussi bien qu'en Egyte, sil hit 
pensé que ces animaux dont lui parle Alexandre dans sa lettre eussent été de vrais hippopotames. Onésicrite ef quelques autres auteurs anciens ont écrit que l'hippopotame se trouvoit sur le fleuve Indus : mais les voyageurs modernes, du moins cenx cqui méritent le plus de confiance, n'ont pas confirmé ce fait; tous s'accordent à dire que cet animal se trouve dans le Nil, le Sénégal ou Niger, la Cambra, le Zair, et les autres grands fleuves, et même dans les lacs de l'Afrique, surtout dans la partie méridionale et orientale; aucun d'eux n'assure positivement qu'il se trouve en Asie : le P. Boym est le seul qui semble l'indiquer; mais son récit me paroît suspect, et, selon moi, prouve seulement que cet aninal est commun au Mosambique et dans toute celte partie orientale de l'Afrique. Aujourd'hui l'hippopotame, que les anciens appeloient le cheval du Nil, est si rare dans le bas Nil, que les habitants de l'Egypte n'en ont aucune idée et en ignorent le nom; il est également inconnu dans toutes les parties septentrionales de l'Afrique, depuis la Méditerranée jusqu'au fleuve Bambot, qui coule au pied des montagnes de l'Atlas. Le climat que l'hippopotame habite actuellement ne s'étend donc guère que du Sénégal à l'Éthiopie, et de là jusqu'an cap de Bonne-Espérance.

Comme la plupart des auteurs ont appelé l'hippopotame cheval marin ou bxuf marin, on l'a quelquefois confondu avec la vache marine, qui est un animal très différent de l'hippopotame, et qui n'habite que les mers du Nord. Il paroît donc certain que les hippopotanes que l'aateur de la Description de la Moscovie dit se trouver sur le bord de la mer, près de 
Petzora, ne sont autre chose que des vaches marines; et l'on doit reprocher à Aldrovande d'avoir adopté cette opinion sans examen, et d'avoir dit en conséquence que l'hippopotame se trouvoit dans les mers du Nord; car non seulement il n'habite pas les mers du Nord, mais il paroît même qu'il ne se trouve que rarement dans les mers du Midi. Les témoignages d'Odoard Barhosa et d'Edwart Vuot, rapportés par Aldrovande, et qui semblent prouver que les hippopotames habitent les mers des Indes, me paroissent presque aussi équivoques que celui de l'auteur de la Description de la Moscovie; et je serois fort porté à croire, avec M. Adanson, que l'hippopotame ne se trouve, au moins aujourd'hui, que dans les grands fleuves de l'Afrique. Kolbe, qui dit en avoir vu plusieurs au cap de Bonne-Espérance, assure qu'ils se plongent également dans les eaux de la mer et dans celles des fleuves; quelques autres auteurs rapportent la même chose. Quoique Kolbe me paroisse plus exact qu'il ne l'est ordinairement, dans la description qu'il donne de cet animal, l'on peut douter qu'il l'ait. vu aussi souvent qu'il le dit, puisque la figure qu'il a jointe à sa description est plus mauvaise que celles de Columna, d'Aldrovande, et de Prosper Alpin, qui cependant n'ont été faites que sur des peaux bourrées. Il est aisé de reconnoître qu'en général les descriptions et les figures de l'ouvrage de Kolbe n'ont été faites ni sur le lieu ni d'après nature : les descriptions sont écrites de mémoire, et les figures ont pour la plupart été copiées ou prises d'après celles des autres naturalistes; et en particulier la figure qu'il donnc 
de l'hippopotame ressemble beaucoup au chéropotame de Prosper Alpin ${ }^{1}$.

Kolbe, en assurant donc que l'hippopotame séjourne dans les eaux de la mer, pourroit bien ne l'avoir dit que d'après Pline, et non pas d'après ses propres observations: la plupart des autres auteurs rapportent que cet animal se trouve seulement dans les lacs d'eau douce et dans les fleuves, quelquefois à leur embouchure, et plus souvent à de très grandes distances de la mer; il y a même des voyageurs qui s'étonnent, comme Merolla, qu'on ait appelé l'hippopotame cheval marin, parce que, dit-il, cet animal ne peut souffrir l'eau salée. II se tient ordinairement dans l'eau pendant le jour, et en sort la nuit pour paître; le mâle et la femelle se quittent rarement. Zerenghi prit le mâle et la femelle le même jour et dans la même fosse. Les voyageurs hollandois disent qu'elle porte trois ou quatre petits; mais ce fait me paroît très suspect et démenti par les lémoignages que cite Zerenghi : d'ailleurs, comme l'hippopotame est d'une grosseur énorme, il est dans le cas de l'éléphant, du rhinocéros, de la baleine, et de tous les autres grands animaux qui ine produisent qu'un petit; et celte analogie me paroît plus sûre que tous les lémoignages.

* Comme nous n'avions donné la figure que d'un foetus d'hippopotame, nous avons cru devoir ajouter

1. Les figures de ces chéropotames de Prosper Alpin (livre IV, chapitre 12, tab. 22) paroissent aroir été faites d'après des peaux bourrées d'hippopotames, auxquels peut-être on avoit arraché les dents. 
ici celle d'un jeune hippopotame mâle, dont la dépouille bien entière a été envoyée à S. A. S. Mgr le prince de Condé, et se voit dans son magnifique cabinet d'histoire naturelle à Chantilly. Ce très jeune hippopotame venoit de naitre: car il n'a que deux pieds onze pouces trois lignes de l'extrémité du nez jusqu'au bout du corps; la tête, dix pouces de longueur sur cinq pouces dix lignes dans sa plus grande largeur : cette tête, vue de face, ressemble à celle d'un bœuf sans cornes : les oreilles, petites et arrondies par le bout, n'ont que deux pouces deux lignes; les jambes sont grosses et courtes; le pied tient beaucoup de celui de l'éléphant: la queue-n'est longue que de trois pouces onze lignes, et elle est couverte, comme tout le reste du corps, d'un cuir dur et ridé; sa forme est ronde, mais large à son origine, et plus aplatie vers son extrémité, qui est arrondie au bout en forme de petite palette, en sorte que l'animal peut s'en aider à nager.

Par une note que m'a communiquée M. le chevalier Bruce, il assure que, dans son voyage en Abyssinie, il a vu un grand nombre d'hippopotames dans le lac de Tzana, situé dans la haute Abyssinie, à peu de distance des vraies sources du Nil, et que ce lac Tzana, qui a au moins seize lieues de longueur, sur dix ou douze de largeur, est peui-être l'endroit du monde où il y a le plus d'hippopotames. Il ajoute qu'il en a vu qui azoient au moins vingt pieds de longueur, avec les jambes fort courtes et fort massives.

Nous avons reçu de la part de M. L. Boyer de Calais, ollicier de marine, une petite relation qui ne peut appartenir qu'il l'hippopotame. 
"Je crois, dit-il, devoir vous faire part de l'histoire d'une fameuse bête que nous venons de détruire à Jouangue. Cet animal. qu'aucun marin ne connoît, étoit plus grand et plus gros qu'un cheval de carrosse. Il habiloit la rade de Louangue depuis deux ans. Sa tête est monstrueuse et sans cornes; ses oreilles sont petites, et il a le mouflon du lion. Sa peau n'a point re poil, mais elle est épaisse de quatre pouces. Il a les jambes et les pieds semblables à ceux du bœuf, mais plus courtes. C'est un amphibie qui nage très bien, et toujours entre deux eaux. II ne mange que de l'herbe. Son plaisir étoit d'enfoncer toutes les petiles chaloupes ou canots; et, après qu'il avoit mis à la nagre le monde qu'elles contenoient, il s'en retournoit sans faire de mal aux hommes. Mais comme il ne laissoit pas que d'être incommode et même nuisible, on prit le parti de le détruire : mais on ne put en venir à bout avec les armes à feu; il a le coup d'œil si fin, qu'à la seule lumière de l'amorce il étoit bientôt plongé. On le blessa sur le nez d'un coup de hache, parce qu'il approchoit le monde de fort près, et qu'il étoit assez familier; alors il devint si furieux, qu'il renversa toutes les chaloupes et canots sans exception. On ne réussit pas mieux avec un piége de grosses cordes, parce qu'il s'en apercut, et que dès lors il se tenoit au loin. On crut pouvoir le joindre à terre; mais il n'y vient Tue la nuit, s'en relourne avaut le jour et passe tantôt dans un endroit, tantôt dans un autre. Cependant. comme on avoit remarqué qu'il ne s'étoit pas éloigné d'un passage pendant plusieurs jours de suite, nous fûmes cinq nous y embusquer la nuit, armés de fusils chargés de lingots, et munis de sabres. L'animal ayant 
paru, nous tirâmes lous ensemble sur lui ; il fut blessé dangereusement : mais il ne resta pas sur le coup; car il fut encore se jeter dans un étang voisin, où nous le perdimes de vue, et ce ne fut que le surlendemain que les Nègres vinrent dire qu'ils l'avoient trouvé mort sur le bord de l'étang. Je pris deux dents de cet animal, longues d'un pied et grosses comme le poing; il en avoit six de cette taille, et trois au milieu du palais beaucoup plus petites. Ces dents sont d'un très bel ivoire."

\section{SUR I'HIPPOPOTAME.}

Par M. Aleamand.

* Il ne manque à la description que M. de Buffon a donnée de l'hippopotame adulte, d'après Zerenghi, qu'une figure qui représente au vrai cet animal. M. de Buffon, toujours original, n'a pas voulu copier celles que différents auteurs en ont publiées; elles sont toutes trop imparfaites pour qu'il ait daigné en faire usage: et, quant à l'animal même, il ne lui étoit guère possible de se le procurer; il est fort rare dans les lieux mêmes dont il est originaire, et trop gros pour être transporté sans de grandes difficultés. On en voit à Leyde, dans le cabinet de curiosités naturelles de l'université, une peau bourrée qui y a été envoyée du cap de Bonne-Espérance. Quoiqu'elle y soit depuis près d'un siècle, elle a été si bien préparée, qu'elle offre encore la figure exacte de cet animal : elle est soutenue par des cercles de fer et par des pièces de 
bois assez solides pour que le desséchement n'y ait produit que des altérations peu considérables. Comme c'est vraisemblablement la seule curiosité de ce genre qui soit en Europe, je crois que tous cenx qui aiment l'histoire naturelle me sauront bon gré de la leur avoir fait connoître par la gravure, et d'en avoir enrichi le magnifique ourrage de M. de Buffon. Ainsi la planche que nous ajoutons ici représente l'hippopotame mieux qu'il n'a été représenté jusqu'à présent, ou plutôt c'est la seule figure que l'on en ait; car, dans toutes les autres qui ont été publiées, cet animal n'est pas reconnoissable, si l'on en excepte celle qui se trouve daus un livre hollandois, où il est question du léviathan dont il est parlé dans l'Écrilure sainte, et qui a été faite sur le même modèle que l'on a copié ici: mais les proportions y ont été mal observées.

"Il seroit inutile de joindre ici une description de ce monstrueux animal : il n'y a rien à ajouter à celle que MM. de Buffon et Daubenton en ont donnée. Je me contenterai d'en indiquer les dimensions prises avec exactitude. La mesure que j’ai employée est celle du pied de Paris."

Longneur du corps, depuis l'extrémité de la lèvre supérieure jusqu’à l'origine de la queue. . . . . 9 448

Hauteur depuis la plante des pieds jusqu'au sommet du dos.............................. 34

Longuenr de la tête, depuis le bout du museau jus-

qu'̀ l'occiput. ........................ 1 1 "

Circonférence du bout du museau. . . . . . 2 2 1 1 9

Circonférence du museau, prise au dessous des

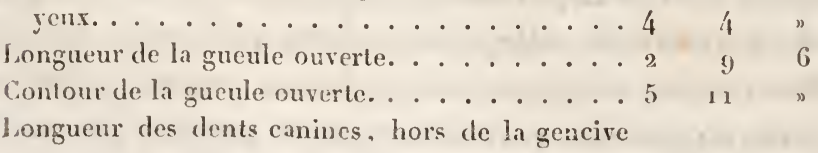


inféricure, en suivant leur courbure.

piects. pouc. ligr.

Longueur des dents incisives de la mâchoire infé-

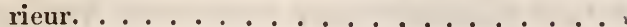

Distance entre les deux naseaux. ....... 4

Distance entre le bout du museau et l'angle antérieure de l'xil. . . . . . . . . . . 1 \&

Dislance entre l'angle postérieur et l'oreille. . . . n 5

Longueur de l'œeil, d'un angle à l'autre. . . . . .

Distance entre les angles antérieurs des yeux, en

suivant la courbure du chanfrein. ...... 1010

La même distance en ligue droite. . . . . . . 9011

Circonférence de la tête entreles yeux et les oreilles. 4 11 6

La longueur des orcilles n'a pat être mesurée, parce qu'elles se sont affaissées par le desséchcment.

Largeur de la base des oreilles, mesurée sur la courbure extérieure............ n 23

Distance entre les deux oreilles, prise dans le bas. $» \begin{array}{lll}9 & 9\end{array}$ Longueur du cou. . . . . . . . . . . . . . . .

Circonférence du milieu du corps. . . . . 9 8 8 n

Longueur du tronçon de la queue. ...... 10 ".

Circonférence de la quene à son origine. ...." 104

Hauteur des jambes, depuis la plante des pieds

jusque sous la poitrine ou le ventre..... 18 \&

Largeur du haut de la jambe. . . . . . . . . . 8 "

Épaisseur.............................. 68

Largeur à l'endroit du talon. . . . . . . . 410

Circonférence du métatarse. . . . . . . $12^{2}{ }^{2}$ ”

Largeur du pied de devant. . . . . . . . . 78

Largeur du pied de derrière. . . . . . . . . . . 7 "

Largeur des plus grands sabots. ....... 3 "

Comme la figure du jeune hippopotame, que j'ai fait dessiner dans le cabinet de S. A. S. Mgr le prince de Condé, diffère de celle que M. Allamand a fait graver d'après la peau bourrée du cabinet de Leyde, et. qu'elle ressemble plus à une nouvelle figure donnée par M. le docteur Klockner d'après une autre peau d'hippopotame du cabinet de Mor le prince 
d'Orange, j'ai préféré de donner ici la figure de ce dernier hippopotame d'après celle de M. Klockner; et je crois devoir y joindre une note avec quelques observations du même auteur, que jai fait traduire du hollandois.

\section{SUR L'HIPPOPOTAME.}

Par M. le docteur KLocksen, d'Amsterdam.

* Je métonne que M. de Buffon ne cite pas un passage remarquable de Diodore de Sicile, touchant l'hippopotame ou cheval de rivière, d'autant plus que cet auleur ancien y olsserve que la voix de cet animal ressemble au hennissement du cheval; ce qui peut-être lui a fait donner le nom d'hippopotame ou cheval de fieuve. M. de Buffon appuie son sentiment sur cette singularité des témoignages des auteurs anciens et des voyageurs modernes, et Diodore de Sicile doit certainement tenir le premier rang parmi les anciens, puisque non seulement il a voyagé lui-même en Égypte, mais qu'il passe encore, avec justice, pour un des meilleurs historiens de l'antiquité. Quoi qu'il en soit, je placerai ici ce passage, où il est dit :

"Le Nil nourrit plusieurs espèces d'animaux, dont deux entre autres méritent de fixer notre attention, qui sont le crocodile et l'hippopolame... Celui-ci est long de cinq coudées; il a les pieds fourchus comme les bêtes à cornes, et de chaque côté trois dents saillantes, plus grandes que les défenses d'un sanglier. La masse entière du corps ressemble beaucoup à celle de l'éléphant. Sa peau est très dure et très ferme, 
et peut-être plus que celle d'aucun autre animal. II est amphibie, se tenant pendant le jonr au fond de l'eau, où il se meut et agit comme sur la terre même où il vient la nuit pour paître l'herbe des campagnes. Si cet animal étoit plus fécond, il causeroit de grands dommages à la culture des Égyptiens. La chasse de l'hippopotame exige un nombre de personnes qui cherchent à le percer avec des dagues de fer. On l'assaillit avec plusieurs barques jointes ensemble, et on le frappe avec des harpons de fer, dont quelques uns ont des angles ou des acraux; on attache à quelques uns de ces dards une corde, et on laisse ensuite l'animal se débattre jusqu'à ce qu'il ait perdu ses forces avec son sang. La chair en est fort dure, et de difficile digestion."

Voilà peut-être la meilleare description que l'on trouve de cet animal chez les anciens; car Diodore ne s'est Irompé que sur le nombre des doigts.

* Comme les feuilles précédentes étoient déjà imprimées, j’ai reçu de la part de M. Schneider des observations récentes sur cet animal, qui ont été rédigées par M. le professeur Allamand, et publiées à Anisterdam au commencement de cette année 1781 . Voici l'extrait de ces observations :

"Ce que M. de Buffon a dit de l'hippopotame dans son histoire naturelle étoit tout ce qu'on en pouvoit dire de plus exact dans le temps qu'il écrivoit cet article. Il me parut alors qu'il n'y manquoit qu'une planche qui représentât mieux cet animal qu'il n'est représenté dans les figures que divers auteurs en ont données. Je pris la liberté d'en ajouter une à la description de M. de Buffon, faite d'après une peau 
bourrée qui est dans le cabinet de l'université de Leyde depuis plus d'un siècle.

"Deux années après, j'en donnai une meilleure; une peau récemment envoyée au Cabinet de S. A. S. Mgr le prince d'Orange me servit de modèle. Elle avoit été très bien préparée par M. le docteur Klockner; je l'accompagnai de quelques remarques intéressantes qui m’avoient été communiquées par M. le capitaine Gordon.

"Je crnyois que cela suffisoit pour faire bien connoître cet animal, lorsque le même M. Gordon m'envoya, au commencement de cette année $1-80$, deux dessins qui représentoient un hippopotame mấle et une femelle, faits d'après les animaux mêmes, au moment qu'on venoit de les tuer. Je fus frappé, en les comparant avec les figures que j'en avois données, et je vis clairement que la peau d'un si gros animal, quoique préparée et dressée avec tout le soin possible, éloit bien éloignée de représenter au juste son original : aussi n'hésitai-je pas à faire graver ces deux dessins.

"M. Gordon a encore eu la bonté d'y joindre des descriptions el de nouvelles observations très curieuses, qu’il a eu fréquemment occasion de faire. Son zèle infatigable pour les nouvelles découvertes, et pour l'avancement de l'histoire naturelle, l'a engagé à pénétrer beaucoup plus avant dans l'intérieur de l'Afrique qu'il ne l'avoit fait encore; et si les hippopotames sont devenus rares aux environs du cap de Bonne-Espérance, il les a trouvés très nombreux dansles lieux où il a élé. On n'en doutera pas quand on saura qne, pour sa part, il en a tué neuf, et que, 
dans une chasse à laquelle il a assisté avec M. Plettenberg, gouverneur du Cap, on en a lué vingt-un en quelques heures de temps, et que même ce ne fut qu'à son intercession qu'on n'en fit pas un plus grand carnage. Cette chasse se fit sur la rivière qu'il a nommée Plettenberg, à peu près à sept degrés de longitude à l'est du Cap, et à trente degrés de latitude méri dionale. Le nombre de ces animaux doit donc être fort grand dans tout l'intérieur de l'Afrique, où ils sont. peu inquiétés par les habitants. C'est là où il les faut voir pour les bien connoître, et jamais personne n'en a eu une plus belle occasion que $\mathbb{M}$. Gordon; aussi en a-t-il profité en les observant avec les yeux d'un véritable naturaliste. En donnant l'extrait de ce qu'il m'en a écrit, je suppose que le lecteur se souvient du contenu des articles de cet ouvrage où il est parlé de ces animaux.

"Lorsque les hippopotames sortent de l'eau, ils ont le dessus du corps d'un brun bleuâtre, qui s'éclaircit en descendant sur les côtés, el se termine par une légère teinte de couleur de chair; le dessous du ventre est blanchâtre : mais ces dilférentes couleurs deviennent plus foncées partout lorsque leur peau se sèche. Dans l'intérieur et sur les bords de leurs oreilles, il y a des poils assez doux et d'un brun roussâtre; il y en a aussi de la même couleur aux paupières, et par-ci par-là quelques uns sur le corps, particulièrement sur le cou et les côtés, mais qui sont plus courts et fort rudes.

"Les mâles surpassent toujours les femelles en grandeur, mais non pas d'un tiers, comme l'a dit Zerenghi, si l'on en excepte les dents incisives et ca- 
nines, qui, dans la femelle, peurent en effet être d'un tiers plus petites que dans le mále. M. Gordon a tué une femelle dont la longueur du corps étoit de onze pieds, et le plus grand hippopotame mâle qu'il ait tué étoit long de onze pieds huit pouces neuf lignes. Ces dimensions diffèrent beaucoup de celles qu'a données Zerenghi: car, à en juger par les dimensions de la femelle qu'il a décrite, le mâle, d'un tiers plus grand, devoit être long de seize pieds neuf pouces; elles diffèrent plus encore de celles des hippopotames du lac de Tzana, dont quelques uns, suivant M. Bruce, ont plus de vingt pieds en longueur. Des animaux de celle dernière grandeur seroient énormes; mais on se trompe facilement sur la taille d'un animal, quand on en juge uniquement en le voyant de loin et sans pouvoir le mesurer.

"Le nombre des dents varie dans les hippopolames, suivant leur âge, comme M. de Buffon l'a soupçonné : tous ont quatre dents incisives et deux canines dans chaque mâchoire; mais ils diffèrent dans le nombre des molaires: celui dont j'ai donné la figure avoit trente-six dents en tout; M. Gordon en a vu un qui avoit vingt-deux dents dans la mâchoire supérieure, et vingt dans l'inférieure. Il m'a envoyé une têie qui en a dix-huit dans la mâchoire d'en bas, et dix-neuf dans celle d'en haut; mais ces dents surnuméraires ne sont ordinairement que de petites pointes qui précèưent les véritables molaires, et qui sont peu fermes.

"La largeur de la partie de la mâchoire supérieure qui forme le museau est de seize pouces et un quart, et son contour, mesuré d'un angle de la gueule jus- 
qu’à l'autre, est de trois pieds trois pouces; la lèvre supérieure avance d'un pouce par dessus l'inférieure, et cache toutes les dents : à côté des incisives antérieures d'en haut, il y a deux éminences charnues, qui sont reçues dans deux cavités de la mâchoire inférieure quand la gueule se ferme.

"L'hippopotame a les yeux petits; leur plus long dianètre est de onze lignes, et leur largeur de nenf et demie; la prunelle est d'un bleu obscur, et le blanc de l'œil paroît peu.

"La queue varie en longueur dans ces animaux: celui qui est représenté ici en avoit une de la longueur d'un pied trois pouces six lignes; son contour à son origine étoit d'un pied sept pouces; là, elle a une forme un peu triangulaire, et un des côtés esí plat en dessons : ainsi, ayant un mouvement perpendiculaire, elle bouche exactement l'ouverture de l'anus; vers son milieu, sés côtés s'aplatissent; et son articulation lui permettant un mouvement horizontal, elle peut servir à diriger l'animal quand il nage. Au premier coup d'œil, elle paroît couverte d'écailles, mais qui ne sont que des rides de la peau; les bords extérieurs de cette queue semblent être des coutures arrondies.

"Le pénis tiré hors de son fourreau est long de deux pieds un pouce six lignes, et ressemble assez à celui du taureau; sa circonférence près du corps est de neuf pouces; et, à un pouce de son extrémité, elle est de trois pouces neuf lignes : quand il est toutà-fait retiré, sa pointe est recouverte par des anneaux charnus et ridés qui terminent le fourreau; c'est sur la base de ce fourreau, du côté de l'anus, que sont placés los mamelons. Dans plisieurs des hippopota- 
mes que 11. Gordon a exaninés, il a trouvé que le fourreau mème étoit entièrement retiré en sledans du corps, aussi bien que le pénis, et que le ventre étoit tout-à-fait uni ; s’il paroissoit dans les autres, c'étoit par l'effet des mouvements qu'ils avoient éprouvés quand on les avoit tirés à terre. Les testicules ne sont pas renfermés dans un scrotum extérieur; ils sont en dedans du corps, et ne paroissent point en dehors; on peut les sentir à travers l'épaisseur de la peau : ainsi tout ce qui appartient à ses parlies est caché en dedans, excepté dans les temps du rut.

„Dans la femelle, au dessous de l'entrée du vagin, est un follicule qui a environ deux pouces de profondeur, mais où l'on ne peut voir aucune ouverture en dedans; il ressemble assez à celui de l'hyène, excepté qu'il est au dessous de la vulve, au lieu que, dans l'hyène, il est situé entre l'anus et la queue. L'hippopotame femelle n'a point de mamelles pendantes, mais seulement deux petits mamelons; quand on les presse, il en jaillit un lait doux et aussi bon que cclui de la vache.

- Les os de ces animaux sont extrêmement durs; dans un os de la cuisse, scié en travers, on trouva un canal long de cinq pouces, et de dix lignes en diamètre, assez ressembiant à la cavité où est la moelle : cependant il n'y en avoit point immédiatement après la wort; mais on y vit un corps fort dur, où l'on croyoit remarquer du sang.

- "La largeur du pied de devant est égale à sa longueur; l'une et l'autre est de dix pouces : la plante du pied de derrière est tant soit peu plus petite; elle a 
neuf pouces neuf lignes dans ses deux dimensions. Ses pieds sont propres pour nager; car les doigts peuvent se mouvoir, s'approcher les uns des autres, et se plier en dessous. Les ongles sont un peu creux, comine les sabots des autres animaux. Le dessous du pied est une semelle fort dure, séparéc des doigts par une fente profonde; elle n'est pas horizontale, mais un peu en biais, comme si l'animal, en marchant, avoit plus pressé son pied d'un côté que de l'autre : aussi les a-t-il tous un peu tournés en dehors. Comme il a les jambes courtes et les jointures pliables, il peut appliquer et presser ses jambes contre le corps; ce qui lui facilite encore les mouvements nécessaires pour nager. Aidé de quelques hommes, M. Gordon a roulé, comme un tonneau, un grand hippopotame hors de l'eau, sur un terrain uni, sans que les pieds fissent un obstacle sensible.

"Quoique les hippopolames passent une partie de leur vie dans l'eau, ils ont cependant le trou ovale fermé. Quand ils sont parvenus à toute leur grandeur, le plus grand diamètre de leur cœur est d'un pied....

D. M. Gordon s'est assuré, par l'ouverture de plusieurs hippopotames jeunes et adultes, que ces animaux n'ont qu'un seul estomac, et ne ruminent point, quoiqu'ils ne mangent que de l'herhe qu'ils rendent en pelote et mal broyée dans leurs excréments.

" J'ai dit ci-devant, continue M. Allamand, qu’il me paroissoit très douteux que les hippopotames mangeassent des poissons; à présent je peux dire qu'il est presque certain qu'ils n'en mangent pas. Dans une trentaine de ces animaux dont M. Gordon 
a fait ourrir les estomacs en sa présence, il n'y a trouvé que de l'herbe, et jamais aucun reste de poisson. J'ai dit aussi qu'il n'y avoit pas d'apparence qu'ils entrassent dans la mer; on peut voir, dans l'endroit cité, les raisons que j'avois pour penser ainsi, et M. de Buffon semble avoir été dans la même idée. Les nouvelles observations de M. Gordon m'ont désabusé : il a tué un hippopotame à l'embouchure de la rivière Ga mbous, où l'ean étoit salée; il en a vu dans la baie de Sainte-Hélène, et il en a vu sortir d'autres de la mer à deux lieues de toute rivière. A la vérité, ils ne s'éloignent pas beaucoup de terre; la nécessité d'y venir prendre leur nourriture ne le leur permet pas : ils vont le long des côtes d'une rivière à l'autre; cependant cela suffit pour prouver qu'ils peùvent vivre dans l'eau salée, et justifier en quelque facon ceux qui leur ont donné le nom de chevaux marins, aussi bien que Kolbe qui suppose qu'ils vivent indifféremment dans les rivières et dans la mer. Ceux qui habitent dans l'intérieur du pays n'y vont vraisemblablement jamais : si ceux qui en sont près y entrent, ce n'est pas pour aller fort loin. à cause de la raison que je viens de dire, et cette même raison doit les engager à préférer les rivières.

"Lorsqu'ils se rencontrent au fond de l'eau, ils cherchent à s'éviter; mais, sur terre, il leur arrive souvent de se battre entre eux d'une manière terrible : aussi en voit-on fort peu qui n'aient pas quelques dents cassées, ou quelques cicatrices sur le corps; en se battant, ils se dressent sur leurs pieds de derrière, et c'est danseette attitude qu'ils se mordent.

" Dans les lienx où ils sont peu inquiétés, ils ne 
sont pas fort craintifs; quand on tire sur enx ils viennent voir ce que c'est : mais, quand une fois ils ont appris à connoître l'effet des armes à feu, ils fuient devant les hommes en trottant pesamment comme les cochons; quelquefois même ils galopent, mais toujours pesamment : cependant un homme doit marcher bien vite pour être en état de les suivre. M. Gordon en a accompagné un pendant quelque temps; mais, quoiqu'il courût très vite, si la course eût été plus longue, l'hippopotame l'auroit devancé.

"M. de Buffon a eu raison de révoquer en doute ce que disent quelques voyageurs des femelles hippopotames, c'est qu'elles portent trois ou quatre petits : l'analogie l'a conduit à regarder ce fait comme très suspect; l'observation en démontre la fausseté. M. Gordon a vu ouvrir plusieurs femelles pleines, et jamais il n'y a trouvé qu'un seul petit; il en a tiré un du corps de la mère, qu'il a eu la bonté de m'envoyer: ce fœetus, qui étoit presque entièrement formé, étoit long de trois pieds deux pouces; le cordon ombilical étoit parsemé de petits boutons de couleur rouge; ses ongles étoient mous et élastiques; on pouvoit déjà lui sentir les dents, et ses yeux avoient à peu près leur forme et toute leur grandeur. Dès qu'un jeune hippopotame est né, son instinct le porte à courir à l'eau, et quelquefois il s'y met sur le dos de sa mère.

"La chair de l'hippopotame, comme il a été dit ci-devant, est fort bonne au goût et très saine; le pied rôti est surtout un morceau délicat, de même que la queue. Quand on fait cuire son lard, il surnage une graisse que les paysans aiment fort; c'es? 
un remède qu'on estime beaucoup au Cap, en exagérant cependant ses qualités.

"Pour bien fixer nos idées sur la grandeur de ces animaux, et sur la proportion qu'il y a entre celle du mâle et de la temelle, je donnerai ici leurs dimensions telles qu'elles ont été prises par M. Gordon sur deux des plus grrands sujets qu'il ait eu nccasion de voir, quoiqu'elles diffèrent de celles qu'on peut prendre sur des peaux bourrées; on sera surpris qu'elles s'accordent si bien avec celles que Zerenghi a données : je les ai aussi vérifiées sur la peau d'un grand hippopolame mâle que S. A. S. Mgr le prince d'Orangye a eu la bonté de me donner, pour être placée au cabinet des curiosités naturelles que jai formé dans l'université de Leyde. Cette peau, récemment envoyée du cap de Bonne-Espérance, est arrivée sntière el bien conservée; j’ai heureusement réussi à la faire dresser suivant le dessin que j'ai reçu de M. Gordon, de manière qu'elle oflìe, aussi exactement qu’il est possible, la figure de l'animal vivant. ”

\section{Dimensions d'un hippopotame mâle.}

Longueur du corps, depuis l'estrémité de la lèrre

supérieure jusqu'à l'origine de la queue. . . J

Hauteur du train de devant en ligne droite. . . . 5

Hauleur du train de devant en suivant la rondeur.

Hauteur du train de derrière en suivant la ligne droite.

pieds. pouc. lign.

Hauteur du train de derrière en suivant la cour-

bure.

Longueur de la lête.

Largeur de la poitrine depuis le milieu des jam-

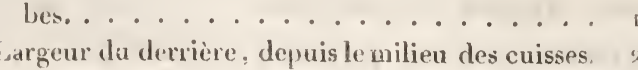


Distance de la partie la plus basse du ventre au terrain.

piedss punc. lign.

Circonférence du corps mesurée derrière les épaules. . . . . . . . . . . 10 $10 \quad 6$

Circonférerce devant les jambes de derrière. - 980 "

Circonférence du milieu du ccu. . . . . . . . $6 \begin{array}{llll}6 & 8 & 6\end{array}$

Circonférence des jambes de devant près la poitrine.......................... 344

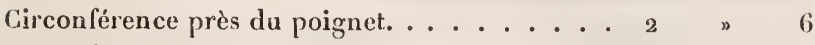

Circonférence près du talon. . . . . . . . 1 . 10 o

Circonférence des jambes de derrière près du corps................... 4 \& 9

Circonférence au dessus du genou. ..... 533 "

Longueur de la queue. . . . . . . . . . I 3 . 6

Sa circonférence près de l'anus. . . . . . . 117 „

Longueur du fourreau du pénis, comme il pend lorsque le pénis est retiré en dedans. . . . " 4 "

Isongueur du pénis quandil est hors de son four-

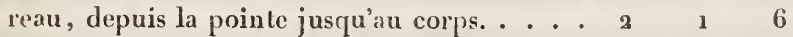

Longueur des dents canines de la unâchoire supéricure. ............... " 2 . 6

Contour de ces dents près de leur base. . . . „ 5 "

Longueur des dents incisives de la même mâchoire................. " 2 .

Contour de ces dents près de leur basc. . . . " $\quad 3 \quad 6$

Longueur des dents canines de la mâchoire inférieure, mesurées suivant leur courbure. . . " " 899 Longueur des dents incisives. . . . . . . " 7 76

Contour des dents canines près de leur base. . . " $7 \begin{array}{ll}7 & 3\end{array}$

Dimensions d'une femelle hippopotame, tuée le 22 janvier 1778 , par M. Le capitaine Gordon, dans l'eau salée, près de l'embouchure de la rivière Gambous. Pour parvenir du Cap à l'embouchure de celte rivière dans la mer a l'est du Cap, on emploie deux cents heures en voyageant sur un chariot tiré par des beufs.

Longueur du corps, depuis l'extrénité de la lèvre supéricure jusqqu'i l'origine de la queue. . . 11 " n

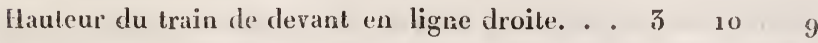
Hatuleur en suivant la courbure. . . . . . 4 4 11 6 
pirats. ponc. Magris. Circonférence en suivarit la courbure.. . . . 5 1 6 Longueur de la tête................. 4 Dislance de la plus basse partie du ventre au terrain. . . . . . . . . . . .

Circonférence dti corps derrière les épaules. . g Circonférence devant les jambes de derrière. . 9 Circonférence du milien du corps. . . . . . 1 1 4 , 
fendue, les dents et les pieds tout différents, des nembranes entre les doigts, point de queue ni de défenses; les yeux plus grands, les oreilles plus courtes; et il en diffère encore autant par le naturel et les mœurs que par la conformation. Il habite souvent dans l'eau, où il nage comme une loutre, y cherche de même sa proie, et vient manger au bord le poisson qu'il prend et qu'il saisit avec la gueule et les ongles; il mange aussi des grains, des fruits, et des cannes de sucre. Comme ses pieds sont longs et plats, il se tient souvent assis sur ceux de derrière. Son cri est plutôt un braiement comme celui de l'âne, qu'un grognement comme celui du cochon. Il ne marche ordinairement que la nuit, et presque toujours de compagnie, sans s'éloigguer du bord des eaux : car, comme il court mal à cause de ses longs pieds et de ses jambes courtes, il ne pourroit trouver son salut dans la fuite; et, pour échapper à ceux qui le chassent, il se jelte à l'eau, y plonge, et va sortir au loin, ou bien il y demeure si long-temps, qu'on perd l'espérance de le revoir. Sa chair est grasse et tendre; mais elle a plutôt, comme celle de la loutre, le goût d'un mauvais poisson que celui d'une bonne viande: cependant on a remarqué que la hure n'en éloit pas mauvaise; et cela s'accorde avec ce que l'on sait du castor, dont les parties antérieures ont le goût de la chair, tandis que les parties postérieures ont le goût du poisson. Le cabiaitest d'un naturel tranquille et doux; it ne fait ni mal ni querelle aux autres animaux : on l'apprivoise sans peine; il vient à la voix, et suil assez volontiers ceux qu'il connoît et qui l'ont bien traité. On ne le nourrissoit à Paris qu'avec de 
l'orge, de la salade, et des fruits; il s'est bien porté lant qu'il a fait chaud. Il paroît, par le grand nombre de ses manelles, que la femelle produit des petits en quantité. Nous ignorons le temps de la gestation, celui de l'accroissement, et par consérquent la durée de la vie de cet animal. Nos habitants de Cayenne pourront nous en instruire; car il se trouve assez communément à la Guiane aussi bien qu’au Brésil, aux Amazones, et dans toutes les terres basses de l'Amérique méridionale.

* Nous n'avons que peu de chose à ajouter aux faits historiques, et rien à la description très exacte que nous avons donnée de cet animal d'Amérique. M. de La Borde nous a seulement écrit qu'il est fort commun à la Gruiane, et encore plus dans les terres qui avoisinent le fleuve des Amazones, où le poisson est très abondant : il dit que ces animaux vont toujours par couple, le mâle et la femelle, et que les plus grands pèsent environ cent livres. Ils fuient les endroits habités, ne quiltent pas le bord des rivières; et s'ils apercoivent quelqu'un ils se jettent à l'eau, sans plonger comme les loutres, mais toujours nageant comme les cochons; quelquefois néanmoins ils se laissent aller au fond de l'eau, et y restent même assez long-temps. On en prend souvent de jeunes qu'on élève dans les maisons, où ils s'accoutument aisérnent à manģer du pain, du mil, et des légumes, quoique, dans leur état de nature, ils vivent principalement de poisson. Ils ne font qu'un petit. Ils ne sont nullement dangereux, ne se jetant jamais ni sur les hommes ni sur les chiens. Leur chair est blanche, tendre, et de fort bon goût. Ce dernier fait semble 


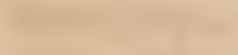



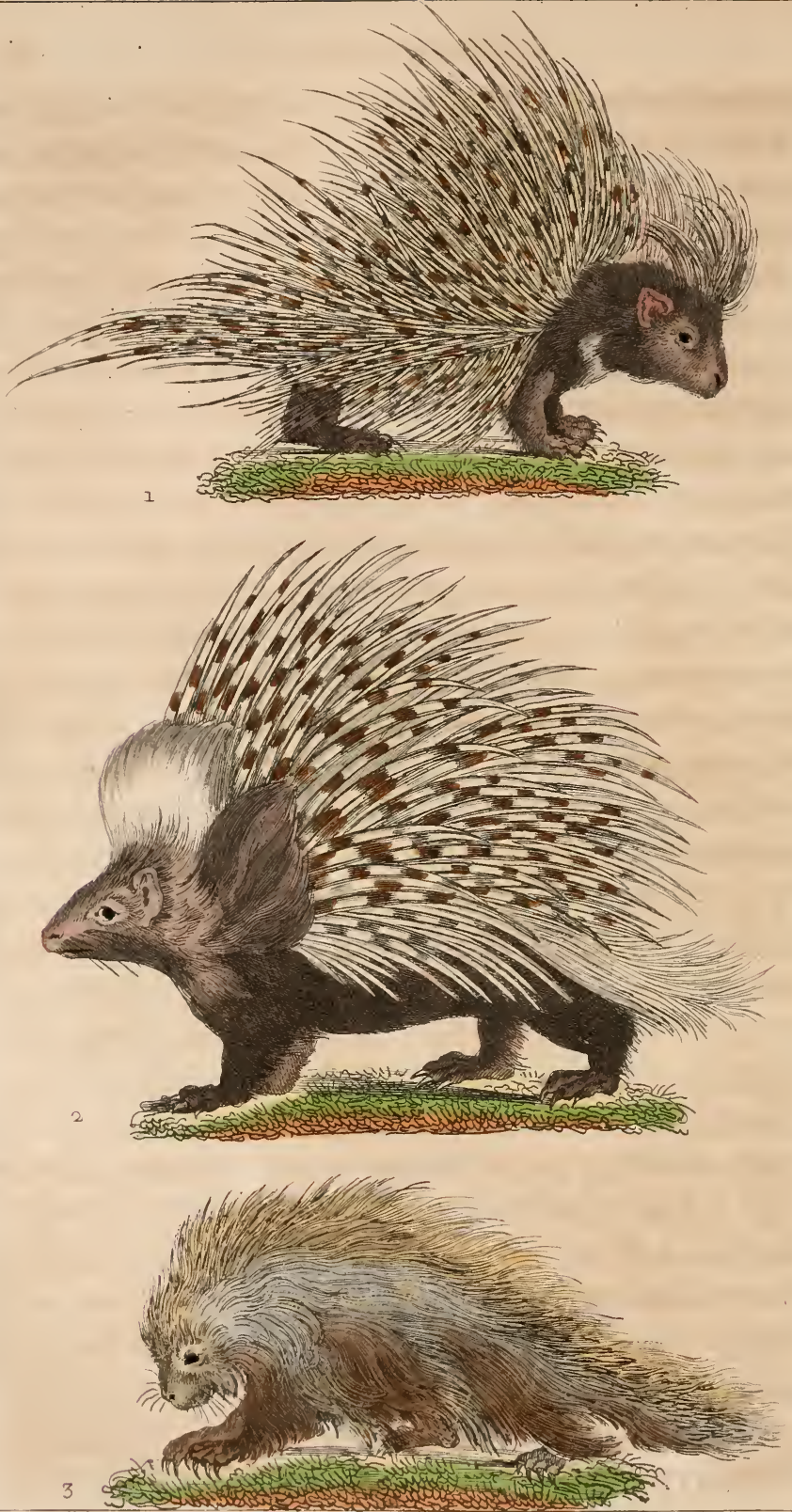
contredire ce que disent les autres relateurs, que la chair du cabiai a plutôt le goût d'un mauvais poisson que celui d'une bonne viande. Cependant il se pourroit que la chair du cabiai vivant de poisson eùt ce mauvais goût, et que celle du cabiai vivant de pain et de grain fût en effet très boune.

Au reste, comme nous avons eu à Paris cet animal vivant, et que nous l'avons gardé longु-temps, je suis persuadé qu'il pourroit virre dans notre climal; c'est par erreur que j'ai dit qu'il étoit mort de froid. J'ai été informé depuis qu'il supportoit fort bien le froid de l'hiver, mais que, comme on l'avoit enfermé dans un grenier, il se jeta par la fenêtre et tomba dans un bassin où il se noya; ce qui ne lui seroit pas arrivé s'il n'eût pas été blessé dans sa chute sur les bords du bassin.

\section{LE PORG-ÉPIC.}

Histryx cristata. I.

IL ne faut pas que le nom de porc-épineux, qu'on a donné à cet animal dans la plupart des langues de l'Europe, nous induise en erreur, et fasse imaginer que le porc-épic soit en effet un cochon chargé d'épines : car il ne ressemble au cochon que par le gro-

1. En grec et en latin, hystrix; en arabe, tzurban, selon le docteur Shaw; en anglois, porcupine; en allemand, stachelschwein: en italien, porco-spinoso; en espagnol, puerco-espino. 
gnement; par tout le reste il en diffère autant qu'aucun autre animal, laut pour la figure que pour la conformation intérieure: au lieu d'une tête allongée, surinontée de longues oreilles, armée de défenses et terminée par un boutoir, au lieu d'un pied fourchu et garni de sabots comme le cochon, le porc-épic a, comme le castor, la tête courte, deux grandes dents incisives en avant de chaque mâchoire, nulles défenses ou dents canines, le museau fendu comme les lièvres, les oreilles rondes et aplaties, et les pieds armés d'ongles; au lieu d'un grand estomac avec un appendice en forme de capuchon, qui, dans le cochon, semble faire nuance entre les ruminants et les autres animaux, le porc-épic n'a qu'un simple estomac et un grand cœcum : les parties de la génération ne sont point apparentes au dehors, comme dans le cochon mâle; les testicules du porc-épic sont recélés au dedans et renfermés sous les aines; la verge n'est point apparente; et l'on peut dire que, par tous ces rapports, aussi bien que par la queue courte, la longue moustache, la lèvre divisée, il approche beaucoup plus du lièvre ou du castor que du cochon. Le hérisson, qui, comme le porc-épic, est arıné de piquants, ressembleroit plus au cochon; car il a le museau long et terminé par une espèce de groin en boutoir : mais toutes ces ressemblances étant fort éloignées, et toutes les différences étant présentes et réelles, il n'est pas douteux que le porc-épic ne soit d'une espèce particulière et différente de celle du hérisson, du castor, du lièvre, ou de tout autre animal auquel on voudroit le comparer.

II ne faut pas non plus ajouter foi à ce que disent 
presque unanimement les voyageurs et les naturalistes, qui donnent à cet animal la faculté de lancer ses piquants à une assez grande distance et avec assez de force pour percer et blesser profondément; ni s'imaginer avec eux que ces piquants, fout séparés qu'ils sont du corps de l'animal, ont la propriété très extraordinaire et toute particulière de pénétrer d'euxmêmes et par leurs propres forces plus avant dans les chairs, dès que la pointe y est une fois entrée : ce dernier fait est purement imaginaire et destitué de tout fondement, de toute raison. Le premier est aussi faux que le second: mais au moins l'erreur paroît fondée sur ce que l'animal, lorsqu'il est irrité ou seulement agité, redresse ses piquants, les remue, et que comme il y a de ces piquants qui ne tiennent à la peau que par une espèce de filet ou de pédicule délié, ils tombent aisément. Nous avons vu des porcsépics vivants, et jamais nous ne les avons'vus, quoique violemment excités, darder leurs piquants. On ne peut donc trop s'étonner que les auteurs les plus graves, tant anciens que modernes ${ }^{1}$, que les voyageurs les plus sensés, soient tous d'accord sur an fait

1. MM. les anatomistes de l'Académic des Sciences. "Ceux d's pi" quants, disent-ils, qui étoient les plus forts et les plus courts, étoient " aisés à arracher de la peau, n’y étant pas attachés fermenent comme "les autres; aussi sont-ce ceux que ces animaux (les porcs-épics) " ont accoutumé de lancer contre les chasseurs, en seconant leur peau " comme font les chiens lorsqu'ils sortent de l'eau. Claudien dit égale" ment que le porcépic est lui-même l'arc, le carquois, et la fliche "dont il se sert contre les chasseurs. "( Mémoires pour sorvir á l'histoirc des animaux, tome III, page 114.)

La fable est le domaine des poëles, et il n'y a pas de ruproches à faire à Claudien : mais les anatomisies de l'Académie ont eu fort d'aBUFFON. XVII. 
aussi faux. Ouciques uns d'entre eux disent avoir été eux-mêmes blessés de cotte espèce de jaculation; d'autres assurent qu'elle se fait avec tant de roideur, que le dard ou piquant peut percer une planche à quelques pas de aistance. Le merveilleux, qui n'est que le faux qui fait plaisir à croire, angmente et croît à mesure qu'il passe par un plus grand nombre de têtes; la vérité perd, au contraire, en faisant la même roule; et, malgré la négation positive que je viens de graver au bas de ces deux faits, je suis persuadé qu'on écrira encore mille fois après moi, comme on l'a fait mille fois auparavant, que le porcépic darde ses piquants, et que ces piquants, séparés de l'animal, entrent d'eıx-mêmes dans les corps où leur pointe est engragée ${ }^{1}$.

Le porc-épic, quoique originaire des climats les plus chands de l'Afrique el des Indes, peut vivre et

dopter cette fable apparemment pour citer Claudien; car on voit, par leur propre exposé, que le porc-épic ne lance point ses piquants, et que seulement ils tombent lorsque l'animal se secoue.

1. $1^{\circ}$ Il faut cependant excepter du nombre de ces voyageurs crédules le docteur Shaw. $2^{\circ}$ Le P. Vincent-llarie ne dit point du tout que le porc-épic lance des piquants; il assure seulement que quand il rencontre des serpents, avec lesquels il est toujours en guerre, il se net en boule, cachant ses pieds èt sa tête, et se roule sur eux arec ses piđquants jusqu’à leur ôter la vie, sans courir risque d'être blessé. 11 ajoute un fait que nous croyons très vrai, c'est qu'il se forme dans l'estomac du porc-épic des bézoards de différentes sortes : les uns ne sont que des amas de racines enveloppées c'une croûte; les autres, plus petis, paroissent être pétris de petites pailles et de puudre de pierre; et les plus petits de tous, qui ne sont pas plus gros qu'une ncix, paroissent pétrifiés en enlier : ces derniers sont les plus estimés. Nous ne doutons pas de ces faits, ayant trouvé nous-même un bézo ord de la première sorle, c'est-d-dire une égagropile, dans l'estomac du porc-épic qui nons a été envoyé d'Italie. 
se multiplier clans des pays moins chauds, tels que la Perse, l'Espagne, et l'Italie. Agricola dit que l'espèce n'a été transportée en Furope que dans ces derniers siècles : elle se trouve en Espagne, et plus communément en Italie, surtont dans les montagnes de l'Apennin, aux environs de Rome; c'est de là que M. Mauduit, qui, par son goût pour l'histoire naturelle, a bien voulu se charger de quelques unes de nos commissions, nous a envoyé celui qui a servi à M. Daubenton pour sa description. Nous avons cru devoir donner la figure de ce porc-épic d'Italie, aussi bien que celle du porc-épic des Indes: les petites différences qu'on peut remarquer entre les deux sont de légères variétés indépendantes du climat, ou peutêtre ne sont que des différences purement individuelles.

Pline et tous les naturalistes ont dit, d'après Arisrote, que le porc-épic, comme l'ours, se cachoit pendant l'hiver, et mettoit bas au bout de trente jours. Nous ríavons pu vérifier ces faits; et il est singulier qu'en Italie, où cet animal est commun, et où de tout temps il y a eu de bons physiciens et d'excellents observateurs, il ne se soit trouvé personne qui en ait écrit l'histoire. Aldrovande n'a fait sur cet article, comme sur beaucoup d'autres, que copier Gesner; et MM. de l'Académie des Sciences, qui ont décrit et disséqué huit de ces animaux, ne disent presque rien de ce qui a rapport à leurs habitudes naturelles : nous savons seulement, par le témoignage des voyageurs et des gens qui en ont élevé dans des ménagreries, que, cians l'état de domesticité, le porcépic n'est ni féroce ni farouche, qu'il n'est que jaloux 
de sa liberté; qu'à l'aide de ses dents de devant, qui sont fortes et tranchantes comme celles du castor, il coupe le bois et perce aisément la porte de sa loge. On sait aussi qu’on le nourrit aisément avec de la mie de pain, du fromage, et des fruits; que, dans l'état de liberté, il vit de racines et de grains sauvages; que quand il peut entrer dans un jardin, il y fait un grand dégât et mange les légumes avec avidité; qu’il devient gras, comme la plupart des autres animaux, vers la fin de l'été; et que sa chair, quoiqu'un peu fade, n'est pas mauvaise à manger.

En considérant la forme, la substance, et l'organisation des piquants du porc-épic, on reconnoît aisément que ce sont de vrais tuyaux de plumes, auxquels ils ne manque que les barbes pour être de vraies plumes: par ce rapport il fait la nuance entre les quadrupèdes et les oiseaux. Ces piquants, surtout ceux qui sont voisins de la queue, sonnent les uns contre les autres lorsque l'animal marche; il peut les redresser par la contraction du muscle peaussier, et les relever à peu près comme le paon ou le coq d'Inde relèvent les plumes de leur queue. Ce muscle de la peau a donc la même force et est à peu près conformé de la même façon dans le porc-épic et dans certains oiseaux. Nous saisissons ces rapports, quoique assez fugitifs : c'est toujours fixer un point dans la nature, qui nous fuit el qui semble se jouer, par la bizarrerie de ses productions, de ceux qui veulent la. connoître. 


\section{LE PORG-ÉPIC DE MALACA.}

\section{Hystrix fasciculata. L.}

Nous avons parlé et donné la figure d'un porc-épic des Indes orientales ${ }^{1}$, et nous avons dit que ce porcépic ne nous paroît être qu'une variété de l'espèce du porc-épic d'Italie : mais il existe dans les contrées méridionales de notre continent, et particulièrement à Malaca, une autre espèce de porc-épic que nous avons fait dessiner vivant chez M. Aubry, curé de Saint-I_ouis, et dont nous donnons ici la description. Nous en avons vu un tout semblable, aussi vivant, entre les mains d'un marchand d'animaux, qui le faisoit voir à Paris au mois d'octobre 1777. Cette espèce diffère de l'espèce commune par plusieurs caractères très sensibles, et surtout par la forme et la longueur de la queue : elle est terminée par un bouquet de poils longs et plats, ou plutôt de petites lanières blanches semblables à des rognures de parchemin; et la queue, qui porte cette houppe à son extrémité, est nue, écailleuse, et peut avoir le tiers de la longueur du corps, qui est de quinze à seize pouces. Ce porc-épic de Malaca est plus petit que celui d'Europe; sa tête est néanmoins plus allongée, et son museau, revêtu d'une peau noire, porte des moustaches de cinq à six

2. Voyez l'article de l'urson. 
pouces de longueur. L'ceil est petit et noir; les oreil. les sont lisses, nues et arrondies. Il y a quatre doigts réunis par une membrane aux pieds de devant, et il n'y a qu'un tubercule en place du cinquième; les pieds de derrière en ont cinc, réunis par une membrane plus petite que celle des pieds de derant. Les jambes sont couvertes de poils noirâtres; tout le dessous du corps est blanc. Les flancs et le dessus du corps sont hérissés de piquants moins longs que ceux du porcépic d'Italie, mais d'une forme toute particulière, étant un peu aplatis et sillonnés sur leur longueur d'une raie en goultière. Ces piquants sont blancs à la pointe, noirs dans leur milieu, et plusicurs sont noirs en dessus et blancs en dessous : de ce mélange résulte un reflet ou un jeu de traits blancs et noirâtres sur tout le corps de ce pórc-épic.

Cet animal, comme ceux de son grenre, que la nature semble n'avoir armé que pour la défensive n'a de même qu'un instinct repoussant et farouche. Lorsqu'on l'approche, i! trépigne des pieds, et vient en s'enflant présenter ses piquants, qu'il hérisse et secone. Il dort bcaucoup le jour, et n'est bien éveillé que sur !e soir. II mange assis et tenant entre sespattes les pommes et autres fruits à pepin, qu'il pèle avec les dents; mais les fruits à noyau, et surtout l'abricot, lui plaisent davantage : il mange aussi du melon, et il ne boit jamais. 


\section{LE GOENDOU}

\section{IIsstrix Cuendu. Cuv.}

Dass chaque arlicle que nous avons à traiter, il se présente toujours plas d'erreurs à détruire que de vérités à exposer : cela vient de ce que l'histoire des animaux n’a, dans ces derniers temps, été traitée que par des gens à préjugés, à méthodes, et qui prenoient la liste de leurs petits systèmes pour les registres de la nature. Il n'existe en Amérique aucun des animaux du climal chaud de l'ancien continent, et réciproquement il ne se trouve sous la zone brûlanle de l'Afrique et de l'Asie aucun de ceux de l'A mérique méridionale. Le porc-épic est, comme nous l'avons dit, originaire des pays chauds de l'ancien monde; et, ne l'ayant pas trouvé dans le nouveau, on n'a pas laissé de donner son nom aux animaux qui ont paru lui ressembler, et particulièrement à celui dont il est ici question. D'autre côté, l'on a transporté le coendou d'Amérique aux Indes orientales; et Pison, qui vraisemblablement ne connoissoit point le porc-épic, a fait graver dans Bontius, qui ne parle que des ani-

1. Nom de cel animal à la Guiane, et que nous arons adopté; cuandu (qui se doit prononcer couandou), au Brésil et daus quelques autres parties de l'Amérique méridionale; hoitztlacuatzin ou hoitzla. quatzin par les Indiens du Mexique et de la Nouvelle-Espagne ;ouricoeasheiro par los Portugais qui habitent on Amérique. 
maux du midi de l'Asie, le coendon d'Amérique sous le nom et la description du vrai porc-épic, en sorte qu'à la première vue on seroit tenté de croire que cet animal existe également en Amérique et en Asie : cependant il est aisé de reconnoître, avec un peu d'attention, que Pison, qui n'est ici, comme presque partout ailleurs, que le plagiaire de Marcgrave, a non seulement copié sa figure da coendou pour l'insérer dans son Histoire du Brésil, mais qu'il a cru devoir la copier encore pour la transporter dans l'ouvrage de Bontius, dont il a été le rédacteur et l'éditeur. Ainsi, quoíqu'on trouve dans Bontius la figure du coendou, l'on ne doit pas en conclure qu'il existe à Java ou dans les autres parties de l'Asie méridionale, ni prendre cette figure pour celle du porc-épic, auquel en effet le coendou ne ressemble que parce qu'il a comme lui des piquarits.

C'est à Ximenès, et ensuite à Hernandès, que l'on doit la première connoissance de cet animal; ils l'ont indiqué sous le nom de hoitztlacuatzin que lui donnoient les Mexicains. Le tlacuatzin est le sarigue, et hoitztlacualzin doit se traduire par sarigue épineux. Ce nom avoit été mal appliqué, car ces animaux se ressemblent assez peu : atissi Marcgrave n'a point adopté cette dénomination mexicaine, et il a donné cet animal sous son nom brasilien cuandu, qui doit se prononcer couandou. La seule chose qu'on puisse reprocher à Marcgrave, c'est de n'avoir passeconnu que son cuandu du Brésil éloit le même animal que l'hoitzlacuatzin du Mexique, d'autant que sa description et sa figure s'accordent assez arec celles de Hernandès, et que de Laët, qui a été l'éditeur et le commentá- 
teur de l'ouvrage de Marcgrave, dit expressément que le tlacuatzin épineux de Ximenès et le cuandu ne sont vraisemblablement que le même animal. II paroît, en rassemblant le peu de notices éparses que nous ont données les voyageurs sur ces animaux, qu’il y en a deux variétés, que les naturalistes ont, d'après Pison, insérées dans leurs listes comme deux espèces différentes, le grand et le petit cuandu : mais ce qui prouve d'abord l'erreur ou la négligence de Pison, c'est que, quoiqu'il donne ces coendous dans deux articles séparés et éloignés l'un de l'autre, et qu'il paroisse les regarder comme étant deux espèces différentes, il les représente cependant tous deux par la même figure; ainsi nous nous croyons bien fondés à prononcer que ces deux n'en font qu'un. Il y a aussi des naturalistes qui non seulement ont fait deux espèces du grand et du pelit coendou, mais en ont encore séparé l'hoitztlacuatzin, en les donnant tous trois pour des animaux différents; et j'avoue que, quoiqu'il soit très vraisemblable que le coendou et l'hoitzllacuatzin sont le même animal, cette identité n'est pas aussi certaine que celle du grand et du petit coendou.

Quoi qu’il en soit, le coendou n'est point le porcépic; il est de beaucoup plus petit; il a la tête à proportion moins longue et le musean plus court; il n'a point de panache sur la tète, ni de fente à la lèvre supérieure; ses piquants sont lrois ou quatre fois plus courts et beancoup plus menus; il a une longue queue, et celle du porc-épic est très courte; il est carnassier plutôt que frugivore, et cherche à surpren- 
dre les oiseaux, les petits animaux, les volailles ${ }^{4}$, au lieu que le porc-épic ne se nourrit que de légumes, de racines ei de fruits. Il dort pendant le jour comme le hérisson, et court pendant la nuit: il monte sur les arbres, et se retient aux branches avec sa queue; ce que le porc-épic ne fait ni ne pourroit faire. Sa chair, disent tous les voyageurs, est très bonne à manger : on peut l'apprivoiser. Il demeure ordinairement dans les lieux élevés, et on le tronve dans toute l'élendue de l'Amérique, depuis le Brésil et la Guiane jusqu'à la Louisiane et aux parlies méridionales du Canada, au lieu que le porc-épic ne se trouve que dans les pays chauds de l'ancien continent.

En transportant le nom du porc-épic au coendou, on lui a supposé et transmis les mêmes facultés, celle surtout de lancer ses piquants. Il est étonnant que les naturalistes et les voyageurs s'accordent sur ce fait, et que Pison, qui devoit être moins superstitieux qu'aucun autre, puisqu'il étoit médecin, dise gravement que les piquants du coendou entrent d'euxmêmes et par leur propre force dans la chair, et percent le corps jusqu'aux viscères les plus intimes. Ray est le seul qui ait nié ces faits, quoiqu'ils paroissent évidemment absurdes. Mais que de choses absurdes ont été niées par des grens sensés, et qui cependant sont tous les jours affirmées par d'autres gens qui se croient encore plus sensés!

* La Guiane fournit deux espèces de coendous: Les

1. Ce fait, assuré par Maregrave nt Pison, nest pas certain; car Hernandes dit, au contraire, que lhoilzllacuatzin se nourrit de fruils. 


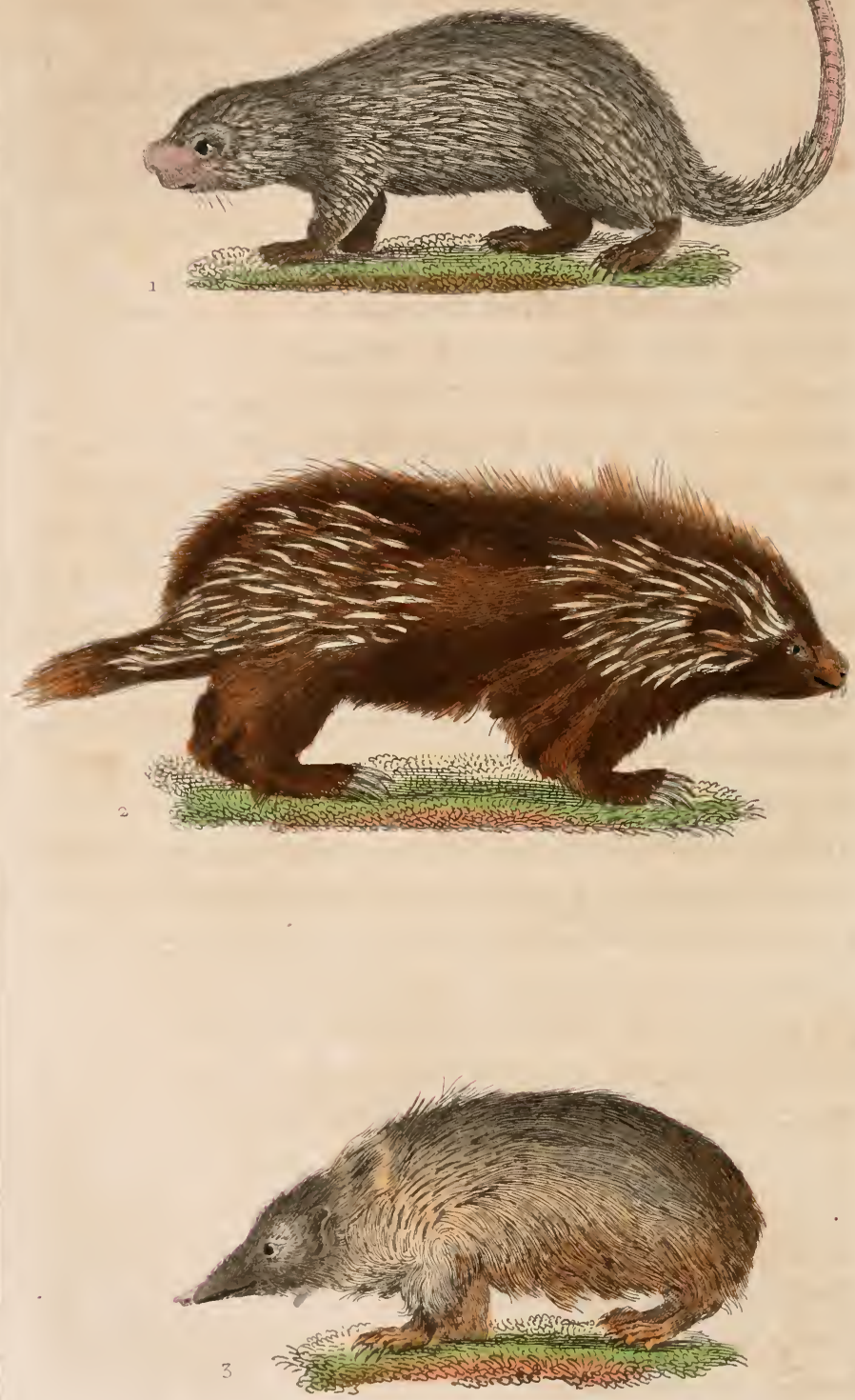
plus grands pèsent douze à quinze livres. Ils se tiennent sur le haut des arbres et sur les lianes qui s'élèvent jusqu'aux plus hautes branches. Ils ne mangent pas le jour. Leur odeur est très forte, et on les sent de fort loin. Ils font leurs petits dans des trous d'arbres, au nombre de deux. Ils se nourrissent des feuilles de ces arbres, et ne sont pas absolument bien communs. Leur viande est fort bonne; les nègres l'aiment autant que celle du paca. Suivant M. de La Borde, les deux espèces ne se mêlent pas : on ne les trouve deux à deux que quand ils sont en chaleur; dans les autres temps ils sont seuls, et les femelles ne quittent jamais l'arbre où elles font leurs petits. Ces animaux mordent quand on s'y expose, sans cependant serrer beaucoup.

Ceux de la petite espèce peuvent peser six livres. Ils ne sont pas plus nombreux que les autres. Les tigres leur font la guerre, et on ne les trouve jamais à terre pendant le jour.

Nous avons parlé de ces deux espèces de coendous, lesquelles existent en effet dans les climats chauds de l'Amérique méridionale.

\section{LE COENDOU.}

\section{A LONGUE QUEUE.}

Hystrix prchensilis. I.

Un autre animal à piquants qui ne nous éloit pas connu, a élé apporté de Cayenne is Paris avec la 
collection de M. Malouet, intendant de cette colonie.

Il est plus grand que le coendou.

Sa longueur, du bout du museau à l'origine de la

queue, est de. ................ 2 ". 6

Longueur de la queue. ........... 1 . 56

Il est couvert de piquants noirs et blancs à la tête, sur le corps, les jambes, et une partie de la queue; et sa longue queue le distingue de toutes les autres espèces de ce genre. Elle n'a pas de houppe ou bouquet de piquants à son extrémité, comme celle des autres porcs-épics.

Le diamètre de la queue, mesurée à son origine, est de vingt-une lignes; elle va en diminuant et finit en pointe. Il n'y a sur celte queue d'autres piquants que ceux de l'extrémité du tronc, qui s'étendent jusqu'au milieu de la queue; elle est noirâtre et couverte d'écailles depuis ce milieu jusqu'à son extrémité; et le dessous de cette queue jusqu'au milieu, c'est-àdire jusqu'à l'endroit où s'étendent les piquants, est couvert de petits poils d'un brun clair. Le reste est garni d'écailles en dessus comme en dessous.

La tête de ce coendou ressemble plus à celle du porc-épic de Malaca qu’à toute autre; cependant elle est un peu moins allongée : les plus grands poils des moustaches, qui sont noirs, ont quatre pouces cinq lignes de longueur.

Les oreilles nues et sans poil ont quelques piquants sur le bord. Au reste, il n'a pas les piquants aussi grands que les porcs-épics d'Italie, et par ce caractère il se rapproche du coendou. La pointe de ces piquants 
est blanche, le milieu noir, et ils sont blancs à l'origine : ainsi le blanc domine sur le noir.

Les plus longs piquants sur le corps ont. ...

Sur les jambes de devant. .......... $1 . \ldots 10$

Sur celles de derrière............

Il y a quelques poils longs de deux pouces et demi, interposés entre les piquants sur le haut des jambes de devant et de derrièrc.

Il n'y a point de membrane entre les doigts des pieds de devant, qui sont au nombre de quatre. Ceux de derrière ont cinq doigts, mais le pouce est peu excédant; ces doigts sont couverts de poils bruns et courts : les ongles sont bruns, courbes, et en goultière.

C'est à ce coendou à longue queue que nous croyons devoir rapporter ce que M. Roume de SaintLaurent a écrit dans les notices gu'il a bien voulu nous adresser des objets qui composent sa riche collection d'histoire naturelle.

"Ce coendou, dit-il, qui est un individu jeune, m'est venu de l'île de la Trinité; sa longueur est d'environ un pied. La queue a dix pouces de long; elle est couverte de piquants sur la moitié de sa longueur, où ils finissent en se raccourcissant par gradation: le reste de la queue est recouvert par une pean grise, remplie de rides transversales très près les unes des autres, et très profondes. Les piquants les plus longs ont environ deux pouces un quart; ils sont blancs à leur origine et à leur extrémité, et noirs au milieu. Le poil ne se laisse apercevoir que sur le ventre, où les piquants sont très courts : les moustachęs son: 
délices, noires, et ont environ trois pouces de longueur. Le plus grand des ongles des quatre doigts de devant a cing lignes de longueur, ceux des pattes de derrière sont de la même longueur; il n'a que quatre doigts onglés aux pattes de derrière, avec un tubercule un peu plus allongé que celui des pattes de devánt. Cet individu diffère de celui décrit dans l'Histoire naturelle de M. de Buffon, en ce qu'il a la queue plus longue à proportion et en partie nue, qu'il n'a que quatre doigts onglés derrière, que les ongles paroissent moins grands que ceux de l'animal représenté dans ce même ouvrage, et qu'il n'a pas le corps garni de poils plus longs que les piquants : les bouts des piquants de celui-ci sont blancs, et ceux du premier sont noirs. "

\section{L'URSON.}

Hystrix dorsata. L.

CEт animal n’a jamis été nommé : placé par la nature dans les terres désertes du uord de l'Amérique, il existoit indépendant, éloigné de l'homme, et ne lui âpartenoit pas même par le nom, qui est le premier signe de son empire. Hudson ayant découvert la terre où il se trouve, nous lui donnerons un nom qui rappelie celui de son premier maître, et qui indique en uême temps sa nature poignante et hérissée; d'ailleurs il éloit nécssaire de le nommer, pour 
ne pas le confontre avec le porc-épic ou le coendou, auxquels il ressemble par quelyues caractires, mais rlont cependant il diffère asse z à tous autres égards pour qu'on doive le regarder comme une espéce parliculière et appartenant au climat du Nord, comme les autres appartiennent à celui du Midi.

MM. Edwards, Ellis, et Catesby ont tous trois parlé de cet animal. Les figures données par ces deux premiers auteurs s'accordent avec la nôtre, et nous ne doutọns pas que ce ne soit le même animal; nous sommes même très porté à croire que celui dont Seba donne la figure et la description sous le nom de porc-épic sinsulier des Indes orientales, et qu'ensuite MM. Klein, Brisson, et Linnaus ont chacun indiqué dans leurs listes par des caractères tirés de Seba, pourroit être le même animal que celui dont il est ici question. Ce ne seroit pas, comme on l'a vu, l'unique et première fois que Seba auroit donné pour orientaux des animaux d'Amérique; cependant nous ne pouvons pas l'assurer pour celui-ci comme nous l'avons fait pour plusieurs autres animaux : tout ce que nous pouvons dire, c'est que les ressemblances nous paroissent grandes; et les différences assez légères, et que comme l'on a peu vu de ces animaux, il se pourroit que ces mêmes différences ne fussent que des variétés d'individu à individu; ou même du mâle à la femelle.

L'urson anroit pu s'appeler le castcr épineux : il est du même pays, de la même grandeur, et à peu près de la même forme de corps; il a, comme lui, à l'extrémité de chaque inâchoire, deux dents incisives, iongues, fortes, et tranchantes. Indépendamment de 
ses piquants, qui sont assez courts et presque cachés dans le poil, l'urson a, comme le castor, une double fourrure, la première de poils longs et doux, et la seconde d'un duvet ou feutre encore plus doux et plus mollet. Dans les jeunes, les piquants sont à proportion plus grands, plus apparents, et les poils plus courts et plus rares, que dans les adultes ou les vieux.

Cet animal fuit l'eau et craint de se mouiller; il se retire et fait sa bauge sous les racines des arbres creux. II dort beaucoup, et se nourrit principalement l'écorce de genièvre : en hiver, la neige lui sert de boisson: en été, il boit de l'eau et lape comme un chien. Les sauvages mangent sa chair, et se servent de sa fourrure, après en avoir arraché les piquants, qu'ils emploient au lieu d'épingles et d'aiguilles.

\section{LE TANREG ${ }^{1}$ ET LE TENDRAG.}

Erinaceus ecaudatus. Gu. - Erinaceus setosus. Gi.

LEs tanrecs ou tendracs sont de petits animaux des Indes orientales, qui ressemblent un peu à notre hérisson. mais qui cependant en different assez pour constituer des espèces différentes : ce qui le prouve, indépendamment de l'inspection et de la comparaison, c'est qu'ils ne se mettent point en boule comme

1. Tanrec et tendrac, noms de ces animaux, et que nous arons adoptés. 
le hérisson, et que dans les mêmes endroits où se trouvent les tanrecs, comme à Madagascar, on y trouve aussi des hérissons de la même espèce que les nôtres, qui ne portent pas le nom de tanrec, mais qui s'appellent sora.

Il paroît qu'il y a des tanrecs de deux espèces, on peut-être de deux races différentes : le premier, qui esı à peu près grand comme notre hérisson, a le museau à proportion plus long que le second; il a aussi les oreilles plus apparentes et beaucoup moins de piquants que le second, auquel nous avons donné le nom de tendrac pour le distinguer du premier. Ce tendrac n'est que de la grandeur d'un gros rat; il a le museau et les oreilles plus courtes que le tanrec. Celui-ci est couvert de piquants plus petits, mais aussi nombreux que ceux du hérisson: le tendrac, au contraire, n'en a que sur la tête, le cou, et le garrot; le reste de son corps est couvert d'un poil rude, assez semblable aux soies du cochon.

Ces petits animaux, qui ont les jambes très courtes, ne peuvent marcher que fort lentement; ils grognent comme les pourceaux, ils se vautrent comme eux dans la fange; ils aiment l'eau et y séjournent plus long-temps que sur la terre : on les prend dans les petits canaux d'eau salée èt dans les lagunes de la mer. Ils sont très ardents en amour et multiplient beaucoup. Ils se creusent des terriers, s'y retirent et s'engourdissent pendant plusieurs mois : dans cet état de torpeur, leur poil tombe, et il renaît après leur réveil. Ils sont ordinairement fort gras; et quoique leur chair soit fade, longue et mollasse, les Indiens la trouvent de leur goût, et en sont même fort friands. 
Sur le Tanrec.

* M. de Bruguières, médecin du roi, très habile botanisle, qui a été envoyé pour faire des recherches d'histoire naturelle aux terres anstrales en 1772 , nous a donné un petit animal que nous avons reconnu pour être un jeune tanrec, et que nous avons fait graver. On a vu la figure du tanrec adulte. La figure du jeune tanrec dont nous parlons ici est de grandeur naturelle, et ne diffère de l'autre que par sa petitesse et par trois bandes blanchâtres qui nous paroissent être la livrée de ce jeune animal. La première de ces bandes s'étend depuis le museau tout le long de la tête, et continue sur le con et sur l'épine du dos; les deux autres bandes sont chacune sur les flancs; et comme tous les autres caractères, notamment la forme du museau, les longs poils parsemés sur le corps, la couleur noire des piquants, etc., se trouvent, dans ce petit tanrec, semblables à ceux du grand, nous avons cru être fondés à n'en faire qu'une seule et même espèce.

\section{Sur le Tendrac.}

*Nous donnons ici la figure (voyez planche 41 ) d'un très petit tendrac qui a été envoyé de lî̀le de France, par M. Poivre, à M. Aubry, curé de SaintLouis : il ne nous paroît différer de notre tendrac que par sa petitesse et par quelques bandes blanches qui semblent être la livrée de cet animal fort jeune. On a écrit à M. le curé de Saint-Iouis qu'il se trouve à 
Madagascar, et que les François de cette contrée le connoissent sous le nom de rat-épic. Voici les dimensions et la courte description de ce très petit animal.

Longueur du corps entier, depuis le bout du nez

jusqu'à l'extrémilé du corps près l'anus. . . . . $3 \quad 3$

Distance du bout du nez à l'œil. . . . . . . . . 6

Distance entre l'œil et l'oreille......... . .

Longueur de la tête depuis le bout du nez jusqu'à

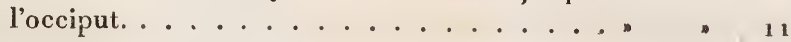

Longueur des piquants.. . . . . . . . . . 4

Longueur des grands ongles des pieds de devant. " n 2

Longueur des grands ongles des pieds de derrière. " " 1

Cet animal a le museau très allongé et presque pointu; sa tête est couverte d'un poil d'un roux noirâtre, et le corps, qui est couvert du même poil, porte une grande quantité de piquants d'un blanc jaunâtre, qui semblent se réunir par bandes irrégulières. On remarque au dessus du nez une bande d'un blanc jaunâtre, qui s'étend jusqu'au commencement du dos, et se termine en pointe à ses deux extrémités : cette bande blanche est du même poil que le brun du corps et des côtés de la tête; ce poil est assez rude, mais cependant fort délié en comparaison des piquants. Le dessous du cou et du corps est d'un blanc jaune, ainsi que les jambes et les pieds, qui sont néanmoins un peu mêlés de brun. Les plus grands poils des moustaches ont huit lignes de longueur. Les pieds ont chacun cinq doigts, et l'on ne voit dans ce très petit animai aucune apparence de queue. 


\section{LA GIRAFE .}

\section{Camelopardalis Girafe. L.}

La girafe est un des premiers, des plus beaux, des plus grands animaux, et qui, sans être nuisible, est en même teups l'un des plus inutiles. La disproportion énorme de ses jambes, dont celles de devant sont une fois plus longues que celles de derrière, fait obstacle à l'exercice de ses forces : son corps n'a point d'assiette, sa démarche est vacillante, ses mouvements sont lents et contraints; elle ne peut ni fuir ses ennemis dans l'état de liberté, ni servir ses maîtres dans l'état de domesticité : aussi l'espèce en est peu nombreuse, et a toujours été confinée dans les déserts de l'Éthiopie et de quelques autres provinces de l'Afrique méridionale et des Indes. Comme ces contrées étoient inconnues des Grecs, Aristote ne fait aucune mention de cet animal; mais Pline en parle, et Oppien le décrit d'une manière qui n'est

1. Mot dérivé de girnaffa, siraphah, zurnaba, noms de cet animal en langue arahe, et que les Européens ont adopté depuis plus de deux siècles; camelopardalis en grec et en latin. Pline donne l'étymoJogie de ce nom composé. Camelorum, dit-il, aliqua similitudo in alivid transfertur animal; nabin Ethiopes vocant, collo similem equo, pédibus et cruribus bovi, camelo capite, albis maculis rutilum colorem distinguentibus, unde appellata camelopardalis : dictatoris Casaris circensibus ludis primum visa Roma. Ex eo subinde cernitur, aspectu magis quam feritate conspicua: quare etiam ovis ferce romen invenit. 

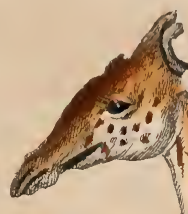

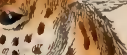

$-\infty)$

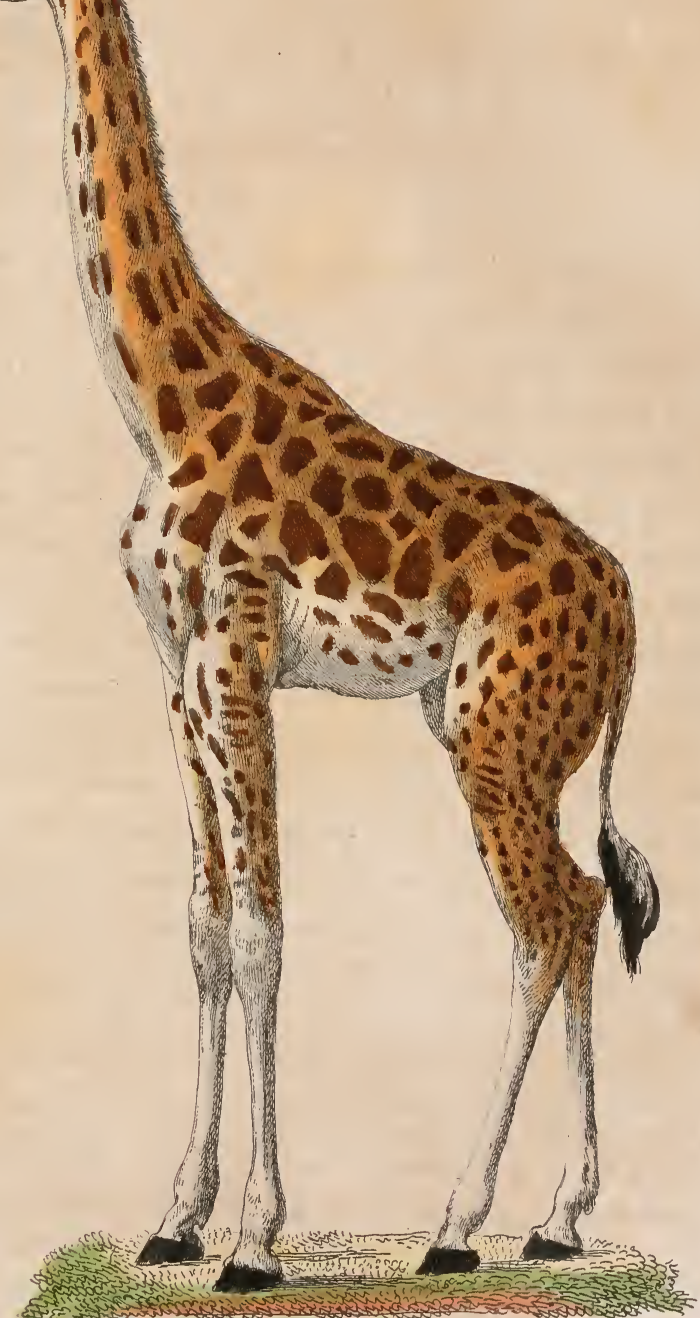



point équivoque. Le camelopardalis, dit cet auteur, a quelque ressemblance an chameau; sa peau est tigrée comme celle de la panthère, et son cou est long comme celui du chameau; il a la tête et les oreilles petites, les pieds larges, les jambes longues, mais de hauteur fort inégale; celles de devant sont beaucoup plus élevées que celles de derrière, qui sont fort courtes et semblent ramcner à terre la croupe de l'animal : sur la tête, près des oreilles, il y a deux éminences semblables à deux petites cornes droites : au reste, il a la bouche conme un cerf, les dents petites et blanches, le yeux brillants, la quete courte et garnie de poils noirs à son extrémité. En ajoutant à cette description d'Oppien celle d'Héliodore et de Strabon, l'on aura déjà une idée assez juste de la girafe. Les ambassadeurs d'Éthiopie, dit Héliodore, amenèrent un animal de la grandeur d'un chameau, dont la peau étoit marquée de taches vives et de couleurs brillantes, et dont les parties postérieures du corps étoient beaucoup trop basses, ou les parties antérieures beaucoup trop élevées; le cou étoit menu, quoique partant d'un corps assez épais; la tête étoit semblable pour la forme à celle du chameau, et pour la grandeur n'étoit guère que du donble de celle de l'autruche; les yeux paroissoient teints de différentes couleurs. La démarche de cet animal étoit différente de celle de tous les autres quadrupèdes, qui portent en marchant leurs pieds diagonalement, c'est-à-dire le pied droit de devant arec le pied gauche de derrière; au lieu que la girafe marche l'amble naturellement en portant les deux pieds gauches et les droits ensemble. C'est un animal si doux, qu'on peut le con- 
duire partout ou l'on veut avec une petite corde passée autour de la tête. Il y a, dit Strabon, une grande bête en Ethiopie, qu'on appelle camelopardalis, quoiqu'elle ne ressemble en rien à la panthère; car sa peau n'est pas marquée de même: les taches de la panthère sont orbiculaires, et celles de cet animal sont longues et à peu près semblables à celles d'un jeune faon ou jeune cerf qui a encore la livrée. Il a les parties postérieures du corps beaucoup plus basses que les antérieures, en sorte que vers la croupe il n'est pas plus haut qu'un bœuf, et vers les épaules il a plus de hauteur que le chameau. A juger de sa légèreté par cette disproportion, il ne doit pas courir avec bien de la vitesse. Au reste, c'est un animal doux qui ne fait ancun mal, et qui ne se nourrit que d'herbes et de feuilles.

Le premier des modernes qui ait ensuite donné une bonne description de la girafe est Belon. "J'ai vu, dit-il, au château du Caire l'animal qu'ils nomment vulgairement zurnapa : les Latins l'ont anciennement appelé camelopardalis, d'un nom composé de léopard et chumeau; car il est bigarré des taches d'un léopard, et a le cou long comme un chameau : c'est une bête moult belle, de la plus donce nature qui soit, quasi comme une brebis, et autant amiable que nulle autre bête sauvage. Elle a la tête presque semblable à celle d'un cerf, hormis la grandeur, mais portant de petites cornes mousses de six doigts de long, couvertes de poil; mais en tant où il y a distinction de mâle à la femelle, celles des mâles sont plus longues : mais au demeurant. en tant le mâle que la femelle ont les oreilles grandes comme d'une 
vache, la langue d'un bouf et noire, n'ayant point de dents dessus la mâchelière; le cou long, droit et grêle; les crins déliés et ronds; les jambes grêles, hautes, et si basses par derrière, qu'elle semble être debout; ses pieds sont semblables à ceux d'un bouf; sa queue lui va pendante jusque dessus les jarrets, ronde, ayant les poils plus gros trois fois que n'est celui d'un cheval; elle est fort grêle au travers du corps; son poil est blanc et roux. Sa manière de fuir est semblable à celle d'un chamean; quand elle court, les deux pieds de devant vont ensemble. Elle se couche le ventre contre terre, et a une dureté à la poitrine el aux cuisses comme un chamean. Elle ne sauroit paître en terre, étant debout, sans élargir grandement les jambes de devant, encore est-ce avec graude difficulté; par quoi il est aisé à croire qu'elle ne vit aux champs, sinon des branches des arbres, ayant le cou ainsi long, tellement qu'elle pourroit arriver de la tête à la hauteur d'une demi-pique."

La description de Gillius me paroît encore mieux faite que celle de Belon. "J'ai vu, dit Gillius (chapitre IX), trois girafes au Caire; elles portent au dessus du front deux cornes de six pouces de longueur, et au milieu du front un tubercule élevé d'environ deux pouces, et qui ressemble à une troisième corne. Cet animal a seize pieds de hauteur lorsqu'il lève la tête; le cou seul a sept pieds, et il a vingt-deux pieds depuis l'extrémité de la queue jusqu'au bout du nez. Les jambes de devant et de derrière sont ì peu près d'égale hauteur: mais les cuisses du devant sont si longues en comparaison de celles de derrière. que le dos de l'animal paroît être incliné comme cin toit. 
Tout le corps est marqué de grandes taches fauves, de figures à peu près carrées... Il a le pied fourchu comme le bœuf, la lèvre supérieure plus avancée que l'inférieure, la queue menue avec du poil à l'extrémité; il rumine comme le bœuf, et mange comme lui de l'herbe; il a une crinière comme le cheval, depuis le sommet de la tête jusque sur le dos. Lorsqu'il marche, il semble qu'il boite non seulement des jambes, mais des flancs, à droite et à gauche alternativement; et lorsqu'il veut paître ou boire à terre, il faut qu'il écarte prodigieusement les jambes de devant."

Gesner cite Belon, pour avoir dit que les cornes tombent à la girafe comme au daim. J'avoue que je n'ai pu trouver ce fait dans Belon; on voit qu'il dit seulement ici que les cornes de la girafe sont couvertes de poil; et il ne parle de cet animal que dans un autre endroit, à l'occasion du daim axis, où il dit que "la girafe a le champ blanc, et les taches phéni"cées, semées par dessus, assez larges, mais non pas "rousses comme l'axis. "Cependant ce fail, que je n'ai trouvé nulle part, seroit un des plus importants pour décider de la nature de la girafe; car si ses cornes tombent tous les ans, elle est du genre des cerfs, et au contraire, si ses cornes sont permanentes, elle est de celui des bœuls ou des chèvres : sans cette connoissance précise, on ne peut pas assurer, comme l'ont fait nos nomenclateurs, que la grirafe soit du genre des cerfs; et on ne sauroit assez s'étonner qu'Hasselquist, qui a donné nouvellement une très longue mais très sèche descriplion de cet animal, n'en ait pas mềne indiqué la nature. et qu'après 
avoir entassé méthodiquement, c'est-à-dire en écolier, cent petits caractères inutiles, il ne dise pas un not de la substance des cornes, et nous laisse ignorer si elles sont solides ou creuses, si elles tombent ou non; si ce sont, en un mot, des bois ou des cornes. Je rapporte ici cette description d'Hasselquist ${ }^{1}$, non pas pour l'utilité, mais pour la singularité, et en

1. "Cervus camelopardalis. Caput prominens; labium superius crasn sum, inferius tenue; nares oblongæe, amplæ; pili rigidi, sparsi in * utroque labio anterius et ad latera. Supercilia rigida, distinctissima, " serie una composita. Oculi ad latera capitis; vertici quam rostro, "ut et fronti quam collo propiores. Dentes, lingua, cornua simpli„ cissima, cylindrica, brevissima, basi crassa, in vertice capitis sita, "pilosa, basi pilis longissimis rigidis tecta, apice pilis Jongioribus " erectis rigidissimis, apicem longitudine superantibus, cincla. Apex " cornuum in medio horum pilorum obtusus nudus. Eminentia in " fronte, infra cornua, inferius oblonga humilior, superius elevatior " subrotunda, postice parurn depressa, inæqualis. Auricula ad latera „ capitis infra cornua pone illa posita. Collum erectum, compressum, " longissimum, versus caput angustissimum, inferius latiusculum. "Crura cylindrica, anterioribus plus quam dimidio longioribus. Tu" berculum crassum, durum in genuflexum. Ungues bisulci, ungu"lati. Pili brevissimi universum corpus, caput et pedes tegunt. Linea "pilis rigidis longiorihus per dorsum à capite ad caudam extensa. "Cauda teres, lumborum dimidia longitudine, non jubata. Color to"tius corporis, capitis ac pedum, ex maculis fuscis et ferrugineis va„ riegatus. Maculæ palnari latitudine, figura irregulari, in vivo animali " ex lucidiori et obscuriore variantes. Magnitudo caneli minoris; lon" gitudo totius a labio superiore ad finem dorsi, spitl. 24. Longitudo " capitis spith. 4; colli spith. 9 ad 10 ; pedum anter. spith. 11 ad 13 , "poster. spith. 7 ad S. Longit. cornuum vix spithamalis. Spatium inter " cornua spith. $1 / 2$; longit. pilorum in dorso poll. 3 ; latitud. capitis "juxta tuberculum vel eminentiam spith. $1 \frac{1}{2}$, prope maxillam "spith. 1 , colli utrinque prope caput spith. 1, in medio spith. 1/2 "ad basin spith. 2 ad 3, latitud. Lat. abd. anterius spith. 4, poster. "spith. 6 ad 7 . Crassities pellis ut corii cervi vulgaris... Deseriptio " antecedens juxta pellem animalis facta; animal vero nondum vidi. , (Voyage d'Ilasselquist: Rosiock, 1762. 
même temps pour engager les voyageurs à se servir de leurs lumières et à ne pas renoncer à leurs yeux pour prendre la lunette des autres; il est nécessaire de les prémunir contre l'usage de pareilles méthodes, avec lesquelles on se dispense de raisonner, et on se croit d'autant plus savant que l'on a moins d'esprit. En sornmes-nous en effet plus avancés, après nous être ennuyés à lire celte énumération de peti is caractères équivoques, inutiles? et les descriptions des aneiens et des modernes que nous avons cités ci-dessus ne donnent-elles pas de l'animal en question une image plus sensible et des idées plus nettes? C'est aux figures à suppléer à tous ces petits caractères, et le discours doit être réservé pour les grands: un seul coup d'œil sur une figure en apprendroit plus qu'une pareille description, qui devient d'autant moins claire qu'elle est plus minutieuse, surtout n'étant point accompagnée de la figure, qui seule peut soutenir l'idée principale de l'objet au milieu de tous ces traits variables et de toutes ces petites images qui servent plutôt à l'obscurcir qu'à le représenter.

On nous a envoyé cette année (1-64) à l'Académic des Sciences, un dessin et une notice de la girafe, parlaquelle on assure que cet animal, que l'on croyoit particulier à l'Éthiopie, se trouve aussi dans les terres voisines du cap de Bonne-Espérance. Nous eussions bien rlésiré que le dessin eât été un peu mieux tracé ; mais ce n'est qu'un croquis informe et dont on ne peut faire aucun usage. A l'égard de la notice, comme elle contient une espèce de description, nous avons cru devoir la copier ici. "Dans un voyage que l'on fit en 1762, à deux cents lieues dans les terres au nord 
du cap de Bonne-Espérance, on trouva le camelopardalis, dont le dessin est ci-joint; il a le corps ressemblant à un bouf, et la tête et le cou ressemblent au cheval. Tous ceux qu'on a rencontrés sont hlancs avec des taches brunes. Il a deux cornes d'un pied de long sur la tête, et a les pattes fendues. Les deux qu'on a tués, et dont la peau a été envoyée en Europe, ont été mesurés comme il suit : la longueur de la tête, un pied huit pouces; la hauteur depuis l'extrémité du pied de devant jusqu'au garrot, dix pieds, et depuis le garrot jusqu'au dessous de la tête, sept pieds; en tout, dix-sept pieds de hauteur : la longueur depuis le garrot jusqu'aux reins est de cinq pieds six pouces; celle depuis les reins jusqu'à la queue, d'un pied six pouces : ainsi la longueur du corps entier est de sept pieds; la hauteur depuis les pieds de derrière jusqu'aux reins est de huit pieds cinq pouces. Il ne paroît pas que cet animal puisse être de quelque service, vu la disproportion de sa hauteur et de sa longueur. II se nourrit des feuilles des plus hauts arbres; et quand il veut boire ou prendre quelque chose à terre, il faut qu'il se mette à genoux."

En recherchant dans les voyageurs ce qu'ils ont dit de la girafe, je les ai trouvés assez d'accord entre eux : ils conviennent tous qu'elle peut atteindre avec sa tête à seize ou dix-sept pieds ${ }^{1}$ de hauteur, étant dans sa

1. Prusper Albin est le seul qui semble donner une autre idée de la grandeur de cet animal, en le comparant à un petit cheval. Anno 1581, Alexandria vidimus cameloparáalem quem Arabes zurnap et nostri giraffam appellant; hac equum parvum elegantissimumque reprosentare videtur. (Page 236.) Il y a toute apparence que cette girafe vue par Prosper Albin étoit fort jeune, et navoic pas encore acquis, a beaucoup près, tout son accroissement. Il en est de même de celle 
situation naturelle, c'est-à-dire posée sur ses quatre pieds, et que les jambes du devant sont une fois plus hautes que celles de derrière; en sorte que, quand elle est assise sur sa crompe, il semble qu'elle soit entièrement debout. Ils conviennent aussi qu'à cause de cette disproportion, elle ne peut pas courir vite; qu'elle est d'un naturel très doux, et que par cette cqualité, aussi bien que par loutes les autres habitudes physiques, et même par la forme du corps, elle approche plus de la figure et de la nature du chameau yne de celle d'aucun autre animal; qu'elle est du nombre des ruminants, et qu'elle manque, comme cux, de dents incisives à la mâchoire supérieure; et l’on voit, par le témoignage de quelques uns, qu'elle se trouve dans les parties méridionales de l'Afrique, aussi bien que dans celles de l'Asie.

Il est bien clair, par tout ce que nous venons d'exposer, que la girafe est d'une espèce unique est très différente de loute autre : mais si on vouloit la rapprocher de quelque autre animal, ce seroit plutôt du chamean que du cerf ou du bœuf. Il est vrai qu'elle a deux petites cornes, et que le chameau n'en a point; mais elle a tant d'autres ressemblances avec cet animal, que je ne suis pas surpris que quelques voyageurs lui aient donné le nom de chameau des Indes. D'ailleurs l'on ignore de quelle subsiance sont les cornes de la girate. el par conséquent si par celte partie elle approche plus des cerfs que des bœufs; et peut-être ne sont-elles ni du bois comme celles des cerfs, ni des cornes creuses conme celles des bònfs ou des chèdont Hasselquist a décrit la peau, et qu'il compare, pour la grandeur, a un pelit chameau. 
vres. Qui sait si elles ne sont pas composées de poils réunis, comme celles des rhinocéros, ou si elles ne sont pas d'une substance et d'une texture particulière? Il m'a paru que ce qui avoit induit les nomenclateurs à mettre la girafe dans le genre des cerfs, c'est $\iota^{\circ}$ le prétendu॰passage de Belon, cité par Gesner, qui seroit en effet décisif, s'il étoit réel. $2^{\circ}$ Il me semble que l'on a mal interprété les auteurs ou mal entendu les voyageurs lorsqu'ils ont parlé du poil de ces cornes; l'on a cru qu'ils avoient votilu dire que les cornes de la girafe étoient velues comme le refait des cerfs, et de là on a conclu qu'elles étoient de même nature: mais l'on voit au contraire, par les notes citées ci-dessus, que ces cornes de la girafe sont seulement environnées et surmontées de grands poils rudes, et non pas revêtues d'un duvet ou d'un velours, comme le refait du cerf; et c'est ce qui pourroit porter à croire qu'elles sont composées de poils réunis, à peu près comme celles du rhinocéros; leur extrémité, qui est mousse, favorise encore cette idée : et si l'on fait attention que dans tous les animaux qui portent des bois au lieu de cornes, tels que les élans, les rennes, les cerfs, les daims, et les chevreuils, ces bois sont toujours divisés en branches ou andouillers, et qu'au contraire les cornes de la girafe sont simples et n'ont qu'une seule tige, on se persuadera aisément qu'elles ne sont pas de même nature, sans quoi l'analogie seroit ici entièrement violée. Le tubercule au milieu de la tête, qui, selon les voyageurs, paroît faire une troisième corne, vient encore à l'appui de cette opinion; les deux autres. qui ne sont pas pointues, mais mousses à leur extrémité, ne sont peut-être que des tuber- 
cules semblables au premier, et seulement plus élevés. Les femelles, disent tous les voyageurs, ont des cornes comme les mâles, mais un peu plus petites. Si la girafe étoit en effet du ge nre des cerfs, l'analogie se démentiroit encore ici : car de tous les animaux de ce genre, il n'y a que la femelle du renne qui ait un bois; toutes les autres femelles en sont dénuées, et ncus en avons donné la raison. D'autre côté, comme la girafe, à cause de l'excessive hauteur de ses jambes, ne peut paître l'herbe qu'avec peine et difficulté, qu'elle se nourrit principalement et presque uniquement de feuilles et de boutons d'arbres, l'on doit présumer que les cornes, qui sont le résidu le plus apparent du superflu de la nourriture organique, tiennent de la nature de cette nourriture, et sont par conséquent d'une substance analogue au bois, et semblable à celle di bois de cerf. Le temps confirmera l'une ou l'autre de ces conjectures. Un mot de plus dans la description d'Hasselquist, si minutieuse d'ailleurs, auroit fixé ces doutes et déterminé nettement le genre de cet animal. Mais des écoliers, qui n'ont que la gamme de leur maître dans la tête, ou plutôt dans leur poche, ne peuvent inanquer de faire des fautes, des bévues, des omissions essentielles, parce qu'ils renoncent à l'esprit qui doit guider tout observateur, et qu'ils ne voient que par une méthode arbitraire et fautive, qui ne sert qu'à les empêcher de réfléchir sur la nature et les rapports des objets qu'ils rencontrent, et desquels ils ne font que calquer la descriplion sur un mauvais modèle. Comme dans le réel tout est différent l'un de l'autre, tout doit aussi être traité différemment; un seul grand caractèrebien saisi décide. 
quelquefois, et souvent fait plus pour la connoissance de la chose que mille autres petits indices : dès qu'ils sont en grand nombre, ils deviennent nécessairement équivoques et communs, et dès lors ils sont au moins superflus, s'ils ne sont pas nuisibles à la connoissance réelle de la nature, qui se joue des formules, échappe à toute méthode, et ne peut être aperçue que par la vue immédiate de l'esprit, ni jamais saisie que par le coup d'œil du génie.

*Nous donnons ici (voy. planche 42) la figure de la girafe d'après un dessin qui nous a été envoyé dı cap de Bonne-Espérance, et que nous avons rectifié dans quelques points d'après les notices de M. le chevalier Bruce. Nous ne sommes pas encore assurés que ses cornes soient permanentes comme celles des bœufs, des gazelles, des chèvres, etc., ou, si l'on veut, comme celles du rhinocéros, ni qu'elles se renouvellent tous les ans comme celles des cerfs, quoiqu'elles paroissent être de la même substance que le bois des cerfs; il semble qu'elles croissent pendant les premières années de la vie de l'animal, sans cependant s'élever jamais à une grande hauteur, puisque les plus longues que l'on ait vues n'avoient que douze à treize pouces de longueur, et que communément elles n'ont que six ou huit pouces, comme celles de la figure 14. C'est à M. Allamand, célèbre professeur à Leyde, que je dois la connoissance exacte de ces cornes. Voici l'extrait de la lettre qu'il a écrit à ce sujet, le 31 octobre 1766 , à M. Daubenton, de l'Académie des Sciences.

"J'ai eu l'honneur de vous dire que j'avois ici une jeune girafe empaillée, el vous m'avez paru souhaiter, 
ainsi que M. de Buffon, de connoître la nature de ses cornes; cela m'a déterminé à en faire couper une, que je vous envoie pour vous en donner une juste idée. Vous observerez que cette girafe étoit fort jenne. Le gouverneur du Cap, de qui je l'ai reçue, m'a écrit qu'elle avoit été tuée couchée auprès de sa mère. Sa hauteur n'est, en effet, que d'environ six pieds, et, par conséquent, ses cornes sont courtes et n'excèdent guère la hauteur de deux pouces et demi; elles sont couvertes partout de la peau garnie de poils, et ceux qui terminent la pointe sont beaucoup plus grands que les autres. et forment un pinceau dont la hauteur excède celle de la corne. La base de ces cornes est large de plus d'un pouce: ainsi elle forme un cône obtus. Pour savoir si elle est creuse ou solide, si c'est un bois ou une corne, je l'ai fait scier dans sa longueur avec le morceau du crâne auquel elle étoit adhérente; je l'ai trouvée solide et un peu spongieuse, sans doute parce qu'elle n'avoit pas encore acquis toute sa consistance. Sa contexture est telle, qu'il ne paroît point qu'elle soit formée de poils réunis comme celle du rhinocéros, et elle ressemble plus à celle du bois d'un cerf qu'à toute autre chose; jo dirois même que sa substance n'en diffère point, si j'étois sûr qu'une corne qu'on m'a donnée depuis quelques jours pour une corne de girafe, et qui m'a été envoyée sous ce nom, en fût véritablement une. Elle est droite, longue d'un demipied, et assez pointue : on y voit encore quelques vestiges de la peau dont elle a été recouverte, et elle ne diffère da bois d'un cer que par la forme. Si ces observations ne vous suffisent pas, je vous en- 
verrai avec plaisir ces deux cornes, pour que vous puissiez les examiner avec M. de Buffon. Je dois encore remarquer, par rapport à cet animal, que je crois qu'on a exagéré en parlant de la différence qu'il y a entre la longueur de ses jambes de devant et celles de derrière; cette différence est assez peu sensibie dans la jeune girafe que j'ai."

C'est d'après ces cornes envoyées par M. Allamand que nous en donnons ici la figure.

Mais, indépendamment de ces deux cornes ou bois qui se trouvent sur la tête de la femelle girafe, aussi bien que sur celle du mâle, il y a au milieu de la tête, presque à distance égale, entre les narines et les yeux, une excroissance remarquable, qui paroît être un os couvert d'une peau molle, garnie d'un poil doux. Ce tubercule osseux a plus de trois pouces de longueur, et est fort incliné vers le front, c'està-dire quill fait un angle très aigu avec l'os du nez. Les couleurs de la robe de cet animal sont d'un fauve clair et brillant, et les tcches, en général, sont de figure rhomboidale.

Il est maintenant assez probable, par l'inspection de ces cornes solides et d'une substance semblable au bois des cerfs, que la girafe pourroit être mise dans le genre des cerfs, et cela ne seroit pas douteux si l'on étoit assuré que son bois tombe tous les ans; mais il est bien décidé qu'on doit la séparer du genre des bœufs et des autres animaux dont les cornes sont creuses. En attendant, nous considererons ce grand et bel animal comme faisant un genre particulier et unique : ce qui s'accorde très bien avec les autres faits de la nature, qui, dans les grandes espèBUPFON. XVII. 
ces, ne double pas ses productions; car l'éléphant, le rhinocéros, l'hippopotame, et peut-être la girafe, sont des animaux qui forment des genres particuliers ou des especes uniques qui n'ont point d'espèces collatérales; c'ést un privilége qui ne paroît accordé qu'à la grandeur"de ces aniniaúx, qui surpasse de beaucoup celle de tous les autres

Dans une lettre que j'ai reçu'e de Hollande, et dont je n'ai pu lire la signature, on m'a envoyé la déscription et lés dimensions d'une girafe, que je vais rapporter ici.

"La'girafe est l'animal le plus beau et le plus curieux" que l'Afrique produise. Il a vingt-cinq pieds de longueur du boút de la tête à la queue. On lui a donnéle nom de chameau-lépard, parce qu'il a quelque ressemblance an chameau par la forme de sa tête, par la longueur de són cou, etc., el que sa robe ressêmble à celle des léopards par les taches dispérsées aussi régulièrement. On en trouvé à quatre-vingts lieues du cap de Bonne-Espérance, et encore plus communément à une profondeur plus grande. Cet animal a les dents comíne les cerfs : ses deux cornes soht longués d'in pied; elles sont droites et grosses coume le bras, garnies de poil, et comme conpées à leurs extrémités. Le cou fait au moins la moitié de la longueur dú corps, fuii, pour la forme, ressémble assez à celui du cheval. La queue seroit aussi assez semilable; mais elle est moins garnic de poil que celle du cheval. Les jambés ressemblent assez à celles du cerf; les pieis' sont garnis de sabots très noirs, obtüs et ćcarlés. Quand l'animal sauté, il lève ensemble les deux pieds de devant, et ensuite les deux de derrière, 
comme un cheval qui auroit les deux jambes de devant attachées : il court mal et de mauvaise grâce; on peut très aisément l'attra per à la course. Il porte toujours la tête très haute, et ne se nourrit que des feuilles des arbres, ne pou vant paître l'herbè à terre, à cause de sa trop grande hauteur. Il est même forcé de se mettre à genoux pour boire. Les femelles sont en général d'un fauve plus clair, et les mâles d'un fauve brun. Il y en a aussi de presque blancs ; les taches sont brunes ou noires. Voici les dimensions d'un de ces animaux, dont les peaux ont été envoyées en Europe."

pieds. pouc. lign.
Hauteur du pied de devant jusqu'au garrot. ... r 10
Hauteur du garrot au dessus de la tête. . . . . 7
Longueur depuis le garrot jusqu'aux reins. . . . 5
Longucur depuis les reins jusqu'à la queue. . . . 116 , 6 ,
Hauteur depuis les pieds de derrière jusqu'aux reins. ............. 8 . 5 "

J'avois livré cet article sur la girafe à l'impression, lorsque j'ai reçu, le 23 juillet 1775 , la belle édition que M. Schneider a faite de mon ouvrage, et dans láquelle jai vu, pour la première fois, les excellentes additions que M. Allamand y a jointes: je ne puis donc mieux faire aujourd'hui que de copier en entier ce que MM. Schneider et Allamand disent au sujet de cet animal, tome XIII, page 17 , de l'Histoire naturelle, édition de Hollande.

"M. de Buffon blâme avec raison nos nomenclateurs modernes de ce qu'en parlant de la girafe ils ne nous disent rien de la nature de ses cornes, qui seules peuvent fournir le caractère propre à déter- 
miner le genre auquel elle appartient, et de ce qu'ils se sont amusés à nous en faire une description sèche et minutieuse, sans y joindre aucune figure. Nous allons remédier à ce double aéfaut.

"M. Allamand, professeur d'histoire naturelle à l'université de Leyde, a placé, dans le cabinet des curiosités d'histoire naturelle de l'université, la peau bourrée d'une jeune girafe : il a bien voulu nous en communiquer le dessin, que nous avons fait graver dans la planche première ${ }^{1}$, et il y a joint la description suivante.

"M. Tulbagh, gouverneur du cap de Bonne-Espérance, qui a enrichi le cabinet de notre académie de plusieurs curiosités naturelles très rares, in’a écrit, en m'envoyant la jeune girafe que nous avons ici, qu'elle avoit été tuée par ses chasseurs, fort avant dans les terres, couchée auprès de sa mère qu'elle tétoit encore. Par là il est constaté que la girafe n'est pas particulière à l'Éthiopie, comme l'a cru Thévenot.

"Dis quée je l'eus reçue, mon premier soin fut d'en examiner les cornes, pour éclaircir le doate dans lequel est M. de Buffon sur leur substance. Elles ne sont point creuses comme celles des bœufs et des chèvres, mais solides comme le bois des cerfs, et d'une consistance presque semblable; elles n'en diffèrent qu'en ce qu'elles sont minces, droites, et simples, c'est-à-dire sans être divisées en branches ou andouillers : elles sont recouvertes dans toute leur longueur de la peau de l'animal, et jusqu'aux trois quarts de leur hauteur; cette peau est chargée de poils courts,

1. Tome XIII de cel ouvrage, edition de Hollande, in-4 $4^{\circ}$. 
semblables à ceux qui couvrent tout le corps; vers leur extrémité, ces poils deviennent plus longs; ils s'élèvent environ trois pouces au dessus du bout mousse de la corne, et ils sont noirs; ainsi ils sont très différents du duvet qu'on voit sur le refait des cerfs.

" Ces cornes ne paroissent point être composées de ces poils réunis, comme celles du rhinocéros : aussi leur substance et leur texture est tout autre. Quand on les scie suivant leur longueur, on voit que, comme les os, elles sont formées d'une lame dure qui en fait la surface extérieure, et qui renferme au dedans un tissu spongienx; au moins cela est-il ainsi dans les cornes de ma jeune girafe : peut-être que les cornes d'une girafe adulte sont plus solides; c'est ce que M. de Buffon est actuellement en état de déterminer : je lui ai envoyé une des cornes de ma girafe, avec celle d'une autre plus âgée, qu'un de mes amis a reçue des Indes orientales.

"Quoique ces cornes soient solides comme celles des cerfs, je doute qu'elles tombent de même que ces dernières : elles semblent être une excroissance de l'os frontal, comme l'os qui sert de noyau aux cornes creuses des bœufs et des chèvres, et il n'est guère possible qu'elles s'en détachent. Si mon doute est fondé, la girafe fera un genre particulier, différent de ceux sous lesquels on comprend les animaux dont les cornes tombent, et ceux qui ont les cornes creuses, mais permanentes.

"I Ies girafes adultes ont au milieu du front un tubercule qui semble être le commencement d'une troisième corne : ce tubercule ne paroît point sur la tête 
de la nôtre, qui vraisemblablement étoit encore trop jeune.

- Tous les auteurs, tant anciens que modernes, qui ont décrit cet animal, disent qu'il y a une si grande différence entre la longueur de ses jambes, que celles de devant sont une fois plus hautes que celles de derrière. Il n'est pas possible qu'ils se soient trompés sur un caractère si marqué; mais j'ose assurer qu'à cet égard la girafe doit changer beaucoup en grandissant; car, dans la jeune que nous avons ici, la hauteur des jambes postérieures égale celle des jambes antérieures; ce qui n'empêche pas que le train de devant ne soit plus haut que celui de derrière, et cela à cause de la différence qu'il y a dans la grosseur du corps, comme on le voit dans la figure : mais cette différence n'approche pas de ce qu'on en dit, comme on pourra le conclure par les dimensions que je vais donner.

" Le cou de la girafe est ce qui frappe le plus ceux qui la voient pour la première fois : il n'y a aucun quadrupède qui l'ait aussi long, sans en excepter le charneau, qui d'ailleurs fait replier son cou en diverses façons; ce qu'il ne paroît pas que la girafe puisse faire.

"Sa coulcur est d'un blanc sale, parsemé de taches fauves ou d'un jaune pâle, fort près les unes des autres au cor, plus éloignées dans le reste du corps, et d'une figure qui approche du parallélogramme ou du rhombe.

"La queue est mince par rapport à la longueur et à la taille de l'animal; son extrémité est garnie de poils ou plutôt de crins noirs, qui ont sept à huit pouces de longueur. 
"Une crinière composée de poils roussâtres, de trois pouces de longueur, et inclinée vers la partie postérieure du corps, s'étend depuis la tête tout le long du cou jusqu’à la moitié du dos; là elle continue à la distance de quelques pouces: mais les poils qui la forment sont penchés vers la tête, et près de l'origine de la queue elle semble recommencer, et. s'étendre jusqu'à son extrémité ; mais les poils en sont fort courts, et à peine les distingue-t-on de ceux qui couvrent le reste du corps.

"Ses paupières, tant les supérieures que les inférieures, sont garnies de cils formés par une rangée de poils fort roides; on en voit de semblables, mais clairsemés et plus longs, autour de la bouche.

"Sa physionomie indique un animal doux et docile, et c'est là ce qu'en disent ceux qui l'ont vue vivante."

Cette description de la girafe, ajoutée à ce qu'en dit M. de Buflon d'après divers auteurs, et accompagnée de la figure que j’ai jointe ici, suffit pour en donner des ílées plus justes que celles qu'on en a eues jusqu'à présent; il n'y manque que les dimensions de ses principales parties. Les voici :

Eongueur du corps entier, mesuré en ligue droite,

depuis le bout du museau jusqu'à l'anus. $\ldots \begin{array}{cccc}5 & 7 & 6\end{array}$

Hanteur du train de devant ........ 54 "...

Hauteur du train de derrière. ....... 4 " 5

Longueur de la tête, depuis le bout du museau

jusqu'à l'origine des cornes. ......... n 9 . 7

Circonférence du bout du museau, prise derrière

les naseaux. . . . . . . . . . . 95

Circonférence de la tête, prise au dessus des yeux. $1 \quad 5 \quad 5 \quad 9$

Contour de l'ouverture de la bouche...... 11 " 
Distance entre les angles de la mâchoire inféríeure. " pieds. pouc. ligu.

Distance entre les naseaux. . . . . . . . .

Distance entre les yeux, mesurée en ligne droite. , $6 \begin{array}{lll}6 & 3\end{array}$

Longueur de l'œil d'un angle à l'autre. . . . . . . . 119

Distance entre les deux paupière: ouvertes..... 11

Distance entre l'angle antérieur et le bout des lè-

vres. ..................... 66

Distance entre l'angle postérieur et les cornes. . . 54

Longueur des cornes. ........... \& 9

Distance d'une corne à l'autre, prise au bas. . . , I 9

Distance des cornes aux oreilles. ....... a 9

Longueur des oreilles. . . . . . . . . 6 . 6

Largeur de la base, mesurée sur la courbure. . . a 5

Distance entre les deux oreilles, prise au bas. . . n $4 \quad 6$

Longueur du cou. .......................... 48

Circonférence près de la tête......... I n "

Circonférence près des épaules. ........ 2 ע

Circonférence du corps, prise derrière les jambes

de devant. ..................... 114

Circonférence devant les jambes de derrière. . . $\begin{array}{lll}3 & 7 & 7\end{array}$

Longueur du tronçon de la queue. . . . . . . 1333

Circonférence à son origine ........ 7 "

Hauteur des jambes de devant, depuis la plante

des pieds jusque sous la poitrine. . . . . 3 1 5

Hauteur des jambes de derrière, depuis la plante

des pieds jusque sous le ventre. ...... 3 1

Longueur des sabots. ........................ 4 r

Hauteur des sabots. ........... $33_{7} 7$

Largeur des deux sabots dans les pieds de devant. „ $3 \quad 3$

Largeur des deux sabots dans les pieds de derrière. ^ $\begin{array}{lll}3 & 3\end{array}$

Circonférence des deux sabots réunis, prise sur les

pieds de devant............... 1 1 6

Circonférence prise sur les pieds de derrière. . . 1 „

- Je ne donne point ici les circonférences du genou, du boulet, ni du paturon, non plus que les longueurs des différentes parties qui composent les jambes, parce qu'il ne m'a pas été possible de les prendre 
LA GIR A F E.

sur une peau bourrée, où ces différentes parties ne sont pas exactement déterminées."

On voit par cette description, non seulement la grande intelligence, mais la circonspection et la prudence que M. Allamand met dans les sujets qu'il traite. J'aurois fait copier sa planche pour accompagner sa description; mais comme j'en donne ure autre, et que d'ailleurs sa girafe étoit fort jeune, j’ai cru que je devois m'en dispenser. Je ferai seulement une observation au sujet des cornes que le même M. Allamand a eu la bonté de m'envoyer : je doute beaucoup que la plus longue ait appartenu à une girafe; elle n'a nul rapport de proportion avec les autres, qui sont très grosses, relativement à leur longueur, tandis que celle-ci est menue, c'est-à-dire fort longue pour sa grosseur. Il est dit, dans la description anonyme rapportée ci-dessus, que les girates adultes ont les cornes longues d'un pied et grosses comme le bras; si celle-ci, qui est longue d'un demi-pied, étoit en effet une corne de girafe, elle seroit deux fois plus grosse qu'elle ne l'est : d'ailleurs cetle prétendue corne de girafe m'a paru si semblable à la dague d'un daguet, c'est-à-dire au premier bois d'un jeune cerf, que je crois qu'on peut, sans se tromper, la regarder comme telle.

Mais je sercis assez de l'avis de M. Allamand au sujet de la nature des cornes de girafe : le tubercule qui, dans cet animal, fait, pour ainsi dire, une troisième corne au milieu du chanfrein, ce tubercule, dis-je, est certainement osseux ; les deux petites cornes sciées étoient adhérentes au crâne sans être appuyées sur des meules, elles doivent donc être regrardées comme des prolongements osseux de cette 
partie. D'ailleurs le poil ou plutôt le crin dont elles sont environnées et surmontées ne ressemble en rien au velours du refail des cerfs ou des daims : ces crins paroissent être permanents, ainsì que la peau dont ils sortent; et dès lors la corne de la girafe ne sera qu'un os qui ne diffère de celui de la vache que par son enveloppe, celui-ci étant recouvert d'une substance cornée ou corne creuse, et celui de la girafe couvert seulement de poil et de peau.

* Lorsque nous avons donné la première addition à l'article de cet animal, dont la hauteur surpasse celle de tous les autres animaux quadrupèdes, nous n'avions pu recueillir encore que des, notions imparfaites, tan t par rapport à sa conformation qu'à ses habitudes. A vec quelque soin que nous eussions comparé tout ce qui a été écrit au sujet de la girafe par les anciens naturalistes et les modernes, nous ignorions encore si elle portoit sur la tête des bois ou des cornes; et, quoique la figure que nous avons donnée de cet animal soit moins défectueuse qu'aucune de celles que l'on avoit publiées avant nous, cependant nous avons reconnu qu'elle n'est point exacte à plusieurs égards. M. Gordon, observateur très éclairé, que nous avons cité plusieurs fois, avec éloge, a fait un second voyage dars l'intérieur de l'Afrique méridionale : il a vu et pris plusieurs girafes, et, les ayant examinées avec attention, il en a envoyé à M. Allamand un dessin que j'ai fait copier et graver; nous y joindrons plusieurs détails intéressants sur les habitudes et la conformation de cet animal si remarquable par sa grandeur.

4 Les girafes se trouvent, dit-il, vers le vingt-hui- 
tième degré de latitude méridionale, dans les pays habités par les nègres, que les Hottentots appellent Brinas ou Briquas; l'espèce ne paroît pas être répandue vers le sud au delà du vingt-neuvième degré, et ne s'étend à l'est qu'à cinç ou six degrés du méridien du Cap. Les Caffres, qui habitent les côt es orientales de l'Afrique, ne connoissent point les girafes; il paroît aussi qu'aucun voyageur n'en a vu sur les côtes occidentales de ce continent, dont elles habitent seulement l'intérieur. Elles sont confinées dans les limites que nous venons d'indiquer vers le sud, l'est, et l'ouest, et du côté du nord on les retrouve jusqu'en Abyssinie, et même dans la haute Égypte.

n Lorsque ces animaux sont debout et en repos, leur cou est dans une position vertiçale. Leur hauteur, depuis la terre jusqu'au dessus de.la tête, est, dans les adultes, de quinze à seize pieds. La girafe que j'ai fait représenter et dont la dépouille est dans le cabinet de M. Allamand, étoit haute de quinze pieds deux pouces. Sa longueur étoit peu proportionnée à sa hauteur : elle n'avoit que cinq pieds cinq pouces de longueur de corps, mesurée en droite ligne depuis le devant de la poitrine jusqu'à l'anus. Le train de devant, mesuré depuis terre jusqu'au dessus des épaules, avoit neuf pieds onze pouces de hauteur; mais celui de derrière n'étoit haut que de huit pieds deux pouces."

On a cru qu'en général la grande différence de hauteur qui se trouve entre le derrière. et le devant de la girafe provenoit de l'inégalité de hauteur dans les jambes : mais M. Gordon a envoyé à M. Allamand tous les os d'une dos jambes de devant et d'une des 
jambes de derrière; elles sont à peu près de la même longueur, comme on pourra le voir par les dimensions rapportées à la fin de cet article, en sorte que l'inégalité des deux trains ne peut être attribuéé à cette cause, mais provient de la grandeur des omoplates et des apophyses épineuses des vertèbres du dos. L'os de l'omoplate a deux pieds de longueur, et les premières apophyses épineuses sont longues de plus d'un pied; ce qui suffit pour que le train de devant soit plus élevé que celui de derrière d'environ un pied huit à neuf pouces, comme on peut le vơir dans le squelette de cet animal que nous donnons ici.

La peau de la girafe est parsemée de taches rousses ou d'un fauve foncé sur un fond blanc. Ces taches sont très près l'une de l'autre, et de figure rhomboïdale ou ovale, et même ronde. La couleur de ces taches est moins foncée dans les femelles et dans les jeunes mâles que dans les adultes, et toutes en général deviennent plus brunes et même noires à mesure que l'animal vieillit. Pline a écrit que le caméléopard, qui est le même animal que la girafe, avoit des taches blanches sur un fond roussâtre ; et en effet, Jorsqu'on voit de loin une girafe, elle paroît presque entièrement rousse, parce que les taches sont beaucoup plus grandes que les espaces qu'elles laissent entre elles, de façon que ces intervalles semblent être des taches blanches semées sur un fond roussâtre. La forme de la tête de la girafe a quelque ressemblance avec celle de la tête d'une brebis : sa longueur est de plus de deux pieds; le cerveau est très petit; elle est couverte de poils parsemés de taches semblables à celles du corps, zmais plus petites. La lèvre supérieure dépasse l'infé. 
rieure de plus de deux pouces; il y a huit denis incisives assez petites dans la mâchoire inférieure; et, comme dans tout autre animal ruminant, il ne s'en trouve point dans la mâchoire supérieure.

Joseph Barbaro, cité par Aldrovande, a écrit que la girafe a une langue ronde, déliée, violette, longue de deux pieds, et qu'elle s'en sert comme d'une main pour cueillir les feuilles dont elle se nourrit : mais c'est une erreur, et M. Gordon a reconnu, dans toutes les girafes qu'il a prises et disséquées, que la langue de ces animaux ressemble par la forme et la substance à la langue des gazelles; et il a reconnu aussi que leur structure intérieure est à peu près la même, et que la vésicule du fiel est fort petite.

Les yeux sont grands, bien fendus, brillants, et le regard en est doux. Leur plus long diamètre eşt de deux pouces neuf lignes, et les paupières sont garnies de poils longs et roides en forme de cils; et il n'y a point de larmier au bas des yeux.

La girafe porte au dessus du front deux cornes un peu inclinées en arrière. Nous avions déjà pensé, d'après celle que M. Allamand nous avoit envoyée, qu'elles ne tomboient pas chaque année comme les bois des cerfs, mais qu'elles étoient permanentes comme celles des bœuls, des béliers, etc. Notre opinion a été entièrement confirmée par les observations de M. Allamand sur une tête décharnée qu'il a dans sa collection. Les cornes de la girafe sont une excroissance de l'os du front, dont elles font partie, et sur lequel elles s'élèvent à la hauteur de sept pouces; leur circonférence à la base est de plus de neuf pouces ; leur extrémité est terminée par une espèce dẹ 
gros bouton. Elles sont recouvertes d'une peau garnie de poils noirs, et plus longs vers l'extrémité, où ils forment une sorte de pinceau qui manque cependant à plusieurs individus, vraisemblablement parce qu'ils les usent en se frottant contre les arbres. Ainsi les cornes de la girafe ne sont pas des bois, mais des cornes comme celles des bœufs, et elles n'en diffèrent que par leur enveloppe, les cornes des bœufs étant renfermées dans une substance cornée, et celles de la girafe étant seulement recouvertes d'une peau garnie de poils.

Indépendamment de ces deux cornes, il y a au milieu du front un tubercule qu'on prendroit, au premier coup d'œil, pour une troisième corve, mais qui n'est qu'une excroissance spongieuse de l'os frontal, d'environ quatre pouces de diamètre sur deux pouces de hauteur. La peau qui le couvre est quelquefois calleuse et dégarnie de poils, à cause de l'habitude qu'ont ces animaux de frotter leur tête contre Jes arbres.

Les oreilles ont huit à neuf pouces de longueur; et l'on remarque entre les oreilles et les cornes deux protubérances composées de glandes qui forment un assez gros volume.

Le cou a six pieds de longueur; ce qui donne à chaque vertèbre une si grande épaisseur, que le cou ne peut guère se fléchir. Il est à l'extérieur garni en dessus d'une crinière qui commence à la tête, et qui se termine au dessus des épaules dans les adultes, mais qui s'élend jusqu'au milieu du dos dans les jeunes girafes. Les poils qui la composent sont longs de trois pouces, et forment des touffes alternativement plus ou moins foncées. 
La partie du dos qui est près des épaules est fort élevée; il s'abaisse ensuite; il se relève et se rabaisse encore vers la queue, qui est très mince et a deux pieds de longueur. Elle est couverte de poils très courts, ef son extrémité est garnie d'une touffe de poils noirs aplatis, très forts et longs de deux pieds. Les nègres se servent de ces crins de girafe pour lier les anneaux de fer et de cuivre quils portent en forme de bracelet.

- Le ventre, élevé áu dessus de terre de cinq pieds sept pouces vers la poitrine, et seulement de cinq pieds vers les jambes de derrière, est couvert de poils blanchâtres. Les jambês sont tachetées comme le reste du corps, jusqu'au canon, qui est sans tache et d'un blanc sale.

Les sabots sont beaucoup plus hauts par devant que par dérrière, 'et ne sont point surmontés d'ergots comme dans les autres animaux à pieds fourchus.

- D'après toutes les comparaisons que l'on a pu faire entre les mâles et les femelles, soit pour la forme, soit pour les couleurs, on 'n'y à pas trouvé de-différence sensible; et il n'y en a qu'une qui est réelle; ç'est cèlle dé la grandeur, les femelles étant toujours plus petites que les mâlés. Elles ont quatre mamelles, et cependant ne portent ordinairement qu'un petit; ce qui s'accorde avec ce que nous savons de tous les grands animaux, qui communément ne produisent qu'un seul petit à chaque portée.

Quoique le corps de ces animaux paroisse disproportionné dans plusieurs de leurs parties, ils frappent cependant les regards, et attirent l'attention par leur beauté, lorsqu'ils sont debout et qu'ils relèvent leur 
tête. La douceur de leurs yeux annonce celle de leur naturel. Ils n'attaquent jamais les autres animaux, ne donnent point de coups de tête, comme les beliers; et ce n'est que quand ils sont aux abois qu'ils se défendent avec les pieds, dont ils frappent alors la terre avec violence,

Le pas de la girafe est un amble; elle porte ensemble le pied de derrière et celui de devant du même côté; et, dans sa démarche, le corps paroît toujours se balancer. Lorsqu'elle veut précipiter son mouvement, elle ne trotle pas, mais galope en s'appuyant sur les pieds de derrière; et alors, pour maintenir l'équilibre, le cou se porte en arrière lorsqu'elle élève ses pieds de devant, et en avant lorsqu'elle les pose à terre : mais en général les mouvements de cet animal ne sont pas très vifs; cependant, comme ses jambes sont très longues, qu'elle fait de très grands pas, et qu'elle peut marcher de suite pendant très long-temps, i) est difficile de la suivre et de l'atteindre même avec un bon cheval.

Ces animaux sont fort doux, et l'on peut croire qu'il est possible de les apprivoiser et de les rendre domestiques; néanmoins ils ne le soat nulle part, et dans leur état de liberté ils se nourrissent des feuilles et des fruits des arbres, que, par la conformation de leur corps et la longueur de leur cou, ils saisissent avec plus de facilité que l'herbe qui est sous leurs pieds, et à laquelle ils ne peuvent aticindre qu'en pliant les genoux.

Leurchair, surtout celle des jeunes, est assez bonne a manger, et leurs os sont remplis d'une moelle que les Hottentots tronvent exquise : aussi vont-ils sou- 

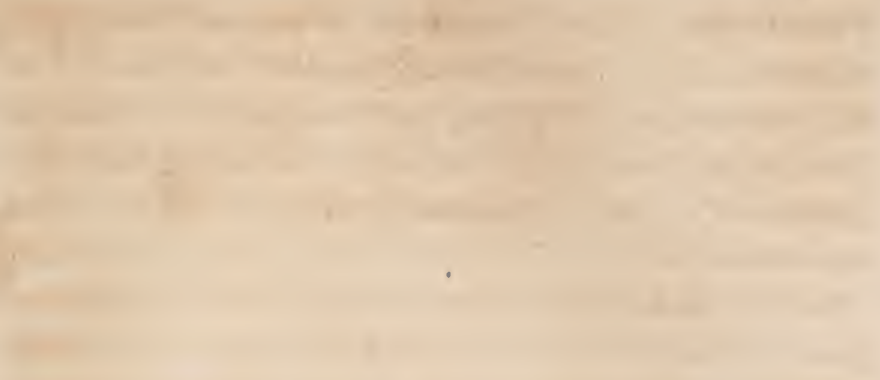

.

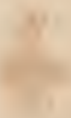

14. 


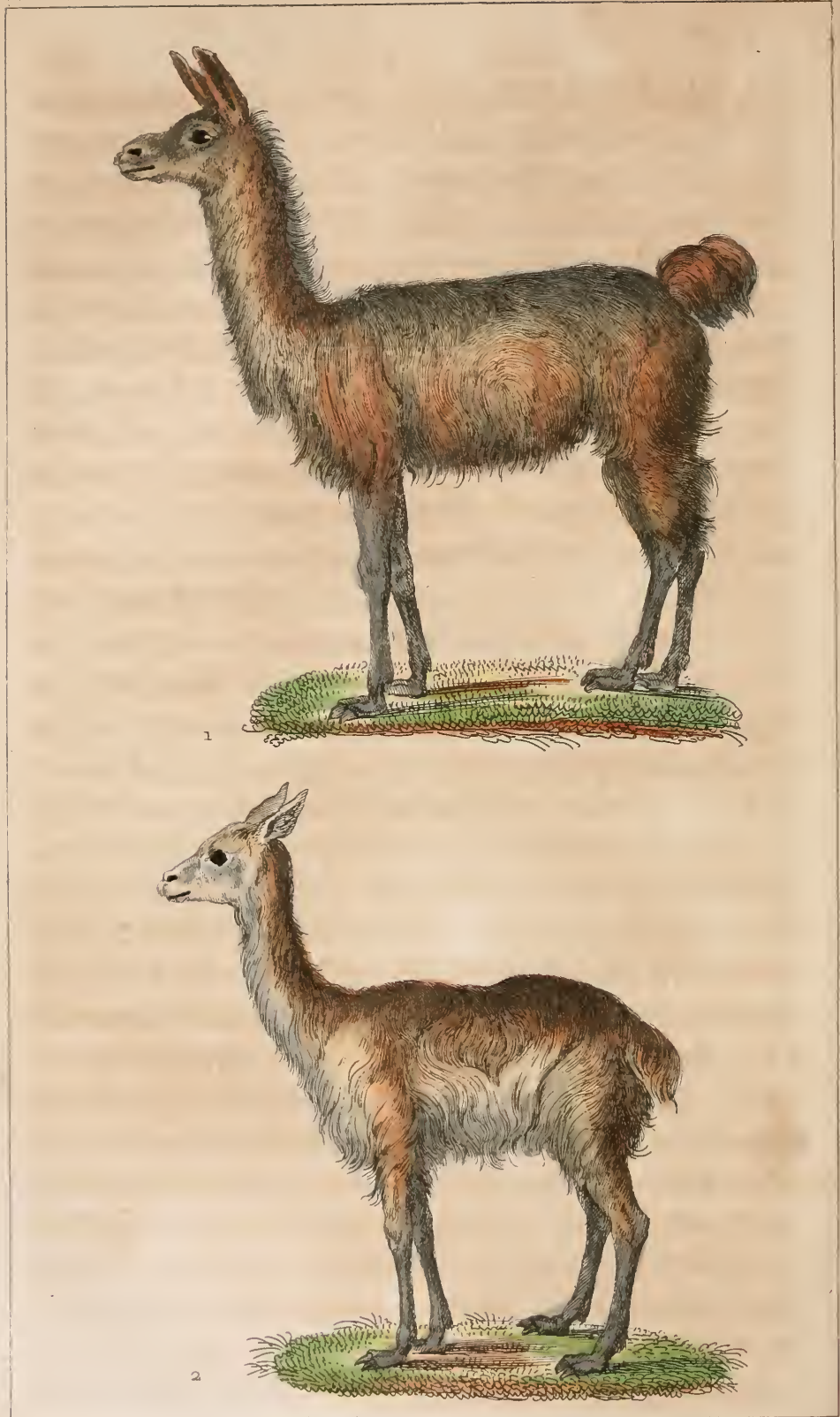


vent à la chasse des girafes, qu'ils tuent avec leurs flèches empoisonnées. Le cuir de ces animaux est épais d'un demi-pouce. Les Africains s'en servent à différents usages; ils en font des vases où ils conservent de l'eau.

Les girafes habitent uniquement dans Jes plaines : elles vont en petite troupes de cinq ou six, et quelquefois de dix ou douze; cependant l'espèce n'est pas très nombreuse. Quand eiles se reposent, elles se couchent sur le ventre, ce qui leur donne des callosités au bas de la poitrine et aux jointures des jambes.

\section{LE LAMA ET LE PACO ${ }^{2}$.}

Camelus Llacma. L. - Camelus Vicunna. L.

IL y a exemple, dans toutes les langues, quion donne quelquefois au tnême animal deux noms différents, dont l'un se rapporte à son état de liberté, et

1. Lama, Lhama, glama, nom que les Espagnols ont donné à cet animal du Nouveau-Monde, et que nous avons adopté. Ils l'appellent aussi au Péron huanacus, guanaco, cornera de tierra (mouton de lerre ); guanapo, selon Le Gentil (tome I, page 94); wianaque, seIon Wood (Voyage de Dampier, tome V, page 181). Autrefois il s'appeloit au Mexique, pelon ichiatl oquitli; et au Chili, hueque Chillehueque, e'est-à-dire hueque du Chili; car les premiers voyageurs de l'Amérique écrivoient Chillé pour Chili. Les Anglois ont désigné le l ama par la dénomination de Pernicl cattle, c'est-à-dire bétail du Pérou. Matthiole lui a donné le nom composé d'elaphocamelus, chameau-cerf.

2. Paco, pacos, nom de cet animal dans son pays natal au Pérou, UITIFON. XVII. 
l'autre à son état de domesticiú. Le canglier et le cochon ne font qu'un animal; et ces deax noms ne sont pas relatifs à la différence de la nature, mais à celle de la condition de cette espèce, dont une partie est sous l'empire de l'homme, et l'autre indépendante. Il en est de même des lamas et des pacos, qui étoient les seuls animaux domestiques des anciens Américains. Ces noms sont ceux de leur élat de domesticité : le lama sauvage s'appelle huanacus ou guanaco, et le paco sauvage vicunna ou vigogne. J'ai cru cette remarque nécessaire pour éviter la confusion des noms. Ces animaux ne se trouvent pas dans l'ancien contineut, mais appartiennent uniquement au nouveau; ils affectent même de certaines terres, hors de l'étendue desquelles on ne les trouve plus : ils paroissent altachés à la chaîne des montagnes qui s'étendent depuis la Nouvelle-Espagne jusqu'aux terres Magrellaniques; ils habitent les régions les plus élevées du globe lerrestre, et semblent avoir besoin pour vivre de respirer un air plus vif el plus léger que celui de nos plus hautes montagnes.

Il est assez singulier que, quoique le lama et le paco soient domestiques au Pérou, au Mexique, au Chili, comme les chevaux le sont en Europe ou les chameaux en Arabie, nous les connoissions à peine, et que depuis plus de deux siècles que les Espagnols règnent dans ces vastes contrées, aucun de leurs auteurs ne nous ait donné l'histoire détaillée et la description exacte de ces animaux dont on se sert tous les jours : ils prétendent, à la vérité, qu'on ne peut

et que nous avons adopté. On l'appelle aussi vigogne, mot dérivé de vicunar, autre nom de cel animal dans le même pays. 
les transporter en Europe, ni même l's descendre de leurs hanteurs sans les perdre, ou du moins sans risquer de les voir périr au bout d'un petit temps; mais à Quito, à Lima, et dans beaucoup d'autres villes où il y a des gens lettrés, on auroit pu les dessiner, décrire et disséquer. Herrera dit peu de chose de ces animaux; Garcilasso n'en parle que d'après les autres; Agosta et. Grégoire de Bolivar sont ceux qui ont rassemblé le plus de faits sur l'utilité et les services qu'on tire des lamas et sur leur naturel : mais on ignore encore comment ils sont conformés intérieurement, combien de temps ils portent leurs petits; l'on ignore si ces deux espèces sont absolument séparées l'une de l'autre, si elles ne peuvent se mêler, s'il n'y a point entre elles de races intermédiaires, et beaucoup d'autres faits qui seroient nécessaires pour rendre leur histoire complète.

Quoiqu'on prétende qu'ils périssent lorsqu'on les éloigne de leur pays natal, il est pourtant certain que dans les premiers temps après la conquête du Pérou, et même encore long-temps après, l'on a transporté quelques lamas en Europe. L'animal dont Gesner parle sous le nom d'allocamelus, et dont il donne la figure, est un lama qui fut amené vivant du Pérou en Hollande en 1558 : c'est le même dont Matthiole fait mention sous le nom d'elaphocamelus, et la description qu'il en donne est faite avec soin. On a transporté plus d'nne fois des vigougnes, et pent-être aussi des lamas, en Espagne, pour tâcher de les y naturaliser : on devroit donc être mieux instruit qu'on ne l'est sur la nature de ces animaux, qui pourroient nous devenir utiles; car il est probable qu'ils réussiroient 
aussi bien sur nos Pyrénécs et sur nos Alpes que sur les Cordilières.

Le Pérou, selon Grégoire de Bolivar, est le pays natal, la vraie patrie des lamas. On les conduit, à la vérité, dans d'autres provinces, comme à la NouvelleEspagne, mais c'est plutôt pour la curiosité que pour l'utilité; au lieu que dans toute l'étendue du Pérou depuis Polosi jusqu'à Caraccas, ces animaux sont en très grand nombre. Ils sont aussi de la plus grande nécessité; ils font seuls toute la richesse des Indiens, et contribuent heaucoup à celle des Espagnols. Leur chair est bonne à manger, leur poil est une laine fine d'un excellent usage, et pendant toute leur vie ils servent constamment à transporter toutes les denrées du pays; leur charge ordinaire est de cent cinquante livres, et les plus forts en portent jusqu’à deux cent cinquante; ils font des voyages assez longs dans des pays impraticables pour tous les autres animaux; ils marchent assez lentement et ne font que quatre ou cinq lienes par jour; leur démarche est grave et ferme, leur pas assuré; ils descendent des ravines précipitées, et surmontent des rochers escarpés, où les hommes mêrnes ne peuvent les accompagner : ordinairement ils marchent quatre ou cinq jours de suite, après quoi ils veulent du repos, et prennent d'eux-mêmes un séjour de vingt-quatre ou trente heures avant de se remettre en marche. On les occupe beaucoup au transport des riches matières que l'on tire des mines de Potosi : Bolivar dit que de son temps on employoit à ce travail trois cent mille de ces animaux.

Leur accroissement est assez prompt, et leur vie n'est pas bien longue; ils sont en état de produire à 
trois ans, en pleine vigueur jusquà douze, et ils commencent ensuile à dépérir, en sorte qu'à quinze ils sont entièrement usés. Letar naturel paroît être modelé sur celui des Américains; is sont doux et flegmaliques, el font tout avec poids et mesure. I.orsqu'ils voyagent et qu'ils veulent s'arrêter pour quel ques instants, ils plient les genoux avec la plus grande précaution, et baissent le corps en proportion, afin d'empêcher leur charge de tomber ou de se déranger : et dis qu'ils entendent le coup de sifflet de leur conducdeur, ils se relèvent avec les mêmes précautions et se remettent en marche. Ils broutent chemin faisant et partout où ils trouvent de l'herbe : mais jamais ils ne mangent la nuit, quand même ils auroient jeûné pendant le jour; ils emploient ce temps à ruminer. IIs dorneni appuyés sur la poitrine, les pieds repliés sous le ventre, et ruminent aussi dans cette situation. Lorsqu'on les excède de travail et qu'ils succombent une fois sous le faix, il n'y a nul moyen de les faire relever, on les frappe inutilement : la dernière ressource pour les aiguillonner est de leur serrer les testicules, et souvent cela est inutile; ils s'obstinent à demeurer au lieu même où ils sont tombés; èt si l'on continue de les maltraiter, ils se désespèrent et se tuent, en battant la terre à droite et à gauche avec leur tête. Ils ne se défendent ni des pieds ni des dents, et n'ont, pour ainsi dire, d'autres armes que celles de l'indignation; ils crachent à la face de ceux qui les insultent, et l'on prétend que cette salive qu'ils lancent dans la colère est âcre t mordicante au point de faire lever des ampoules sur la peau.

Je lama est haut d'environ quatre pieds, et son 
corps, y compris le cou et la tête, en a cinq ou six de longueur : le cou seul a près de trois pieds ale long. Cet animal a la tête bien faite, les yeux grands, le museau un peu allongé, les lévres épaisses, la supérieure fendue et l'inférieure un peu pendante; il manrque de dents incisives et canines à la mâchoìre supérieure. Les oreilles sont longues de quatre pouces; il les porte en avant, les dresse, et les remue avec facilité. La queue n'a gुnère que huit pouces de long; elle est droite, menue, et un peu relevée. Les pieds sont fourchus comme ceux du bœuf; mais ils sont surmontés d'un éperon en arrière qui aide à l'animal à se retenir et à s'accrocher dans les pas difficiles. II est couvert d'une laine courte sur le dos, la croupe, et la queue, mais fort longue sur les flancs et sous le ventre. Du reste les lamas varient par les couleurs; il y en a de blancs, de noirs, et de mêlés. Leur fiente ressemble à celle des chèvres. Le mâle a le membre génital menu et recourbé, en sorte qu'il pisse en arrière. C'est un animal très lascif, et qui cependant a beancoup de peine à s'accoupler. La fomelle a l'orifice des parties de la génération très petit; elle se prosterne pour attendre le mâle, et l'invite par ses soupirs : mais il se passe toujours plusieurs heures et quelquefois un jour entier avant qu'ils puissent jouir l'un de l'autre, et tout ce temps se passe à gémir, à gronder, et surtout à se conspuer; et comme ces longs préludes les fatiguent plus que la chose même, on leur prête la main pour abréger, et on les aide à s'arranger. Ils ne produisent ordinairement qu'un petit et très rarement deux. La mère n'a aussi que dewx mamelles, et le petit la suit au moment qu'il 
est né. La chair des jeunes est très bonne à inanger, celle des vieux est sc̀che et trop dure; en général, celle des lamas domestiques est hien meilleure que celle des sauvagres, et leur laine est aussi beaucoup plus douce. Leur peau esi assez ferme; les Indiuns en faisoient leur chaussure, et les Espagnols l'emploient pour faire des harnois. Ces animaux si utiles, et même si nécessaires dans lc pays qu’ils habitent, ne coûtent ni entretien ni nourriture : comme ils ont ie pied fourchu, il n'est pas nécessaire de les ferrer; la laine épaisse dont ils sont couverts dispense de tes bâter : ils n'ont besoin ni de grain, ni davoine, nite foin; l'herbe verte qüils broutent cux-mêmes leur suffit, et ils n'en prennent qu'en pelite quantité : ils sont encore plus sobres sur la boisson; ils s'abreuvent de leur salive, qui, dans cet animal, est plus abondante que dans aucun autre.

Le huanacus ou lama dans l'état de nature est plus fort, plus vif, et plus léger que le lana domestique; il court comme un cerf, et grimpe comme le chamois sur les rochers les plus escarpés : sa laine est moins lorigue et toute de couleur fauve. Quoique en pleine liberté, ces animaux se rassemblent en troupes, et sont quelquefois deux ou trois cents ensemble : lorsqu'ils aperçoivent quelqu'un, ils regardent avec étonnement, sans marquer d'abord ni crainte ni plaisir; ensuite ils soufllent des narines, et hennissent à peu près comme les chevaux, et enfin ils prennent la fuite tous ensemble vers le sommet des montagnes. Ils cherchent de préférence le côté du nord et la région froide; ils grimpent et séjournent souvent an dessus de la ligne de neige : voyageant dans les glaces, et 
couverts de frimas, ils se portent mieux que dans la région tempérée; autant ils sont nombreux et vigoureux dans les Sierras, qui sont les parties élevées des Cordilières, autant ils sont rares et chétifs dans les Lanos qui sont au dessous. On chasse ces lamas sauvages pour en avoir la toison: les chiens ont beaucoup de peine à les suivre; et si on leur donne le temps de gagner leurs rochers, le chasseur et les chiens sont contraints de les abandonner. Ils paroissent craindre la pesanteur de l'air, autant que la chaleur; on ne les trouve jamais dans les terres basses; et comme la chaîne des Cordilières, qui est élevée de plus de trois mille toises au dessus du niveau de la mer au Pérou, se soutient à peu près à cette même élévation au Chili et jusqu'aux terres Magellaniques, on y trouve des huanacus ou lamas sauvages en grand nombre, au lieu que du côté de la Nouvelle-Espagne, où cette chaîne de montagnes se rabaisse considérablement, on n'en trouve plus, et l'on n'y voit que les lamas domestiques que l'on prend la peine d'y conduire.

Les pacos ou vigognes sont aux lamas une espèce succursale, ̀̀ peu près comme l'âne l'est au cheval: ils sont plus petits et moins propres au service, mais plus utiles par leur dépouille; la longue et fine laine dont ils sont couverts est une marchandise de luxe aussi chère, aussi précieuse que la soie. Les pacos, que l'on appelle aussi alpaques, et qui sont les vigognes domestiques, sont souvent toutes noires, et quelquefois d'un brun mêlé de fauve. Les vigognes ou pacos sauvages sont de couleur de rose sèche; et celte couleur naturelle est si fixe qu'elle ne s'altère 
point sous la main de l'ouvrier : on fait de lrès beanx gants, de tris bons bas, avec cette laine de vigogne; l'on en fait d'excellentes couvertures et des lapis d'un très grand prix. Cette denrée seule forme une branche daris le commerce des Indes espagnoles; le castor du Canada, la brebis de Calmouquie, la chèvre de Syrie, ne fournissent pas un plus beau poil : celui de la vigogne est aussi cher que la soie. Cel anima! a beaucoup de choses communes avec le lama : il est du même pays, et comme lui il en est exclusivement, car on ne le trouve nulle part ailleurs que sur les Cordilières; il a aussi le même naturel et à peu près les mêmes mœurs, le même tempérament. Cependant comme sa laine est beaucoup plus longue et plus touffue que celle du lama, il paroît craindre encore moins le froid; il se tient plus volontiers dans la neige, sur les glaces, et dans les contrées les plus froides: on le trouve en grande quantité dans les terres Magellaniques.

Les vigognes ressemblent aussi par la figure aux lamas; nais elles sont plus petites, leurs jambes sont plus courtes, et leur mufle plus ramassé : elles ont la laine de couleur de rose sèche un peu clair: elles n'ont point de cornes. Elles habitent et paissent dans les endroits les plus élevés des montagnes; la neige et. la glace semblent plutôt les récréer que les incommoder. Elles vont en troupes et courent très légèrement : elles sont timides; et dès qu'elles aperçoivent quelqu'un, elles s'enfuient en chassant leurs petits devant elles. Les anciens rois du Pérou en avoieut rigoureusement défendu la chasse, parce qu'elles ne multiplient pas beaucoup; et aujourd'hui il y cn a in- 
funiment moins que dans le temps de l'arrivée des Espagnols. La chair de ces animaux n'est pas si bonne que celle des huanacus; on ne les recherche que pour leur toison et pour les bézoards qu'ils produisent. La manière dont on les prend prouve leur extrême limidité, ou, si l'on vent, leur imbécillité. Plusieurs hommes s'assemblent pour les faire fuir et les engager dans quelques passages étroits où l’on a tendu des cordes à mois on quatre pieds de haut, le long desquelles on laisse pendre des morceaux de linge ou de drap; les vigognes qui arrivent à ces passages sont tellement intimidées par le mouvement de ces lanbeaux agités pär le vent, qu'elles n'osent passer au delà, et qu'elles s'attroupent et demeurent en foule, en sorte qu'il est facile de les tuer en grand nombre : mais sil se trouve dans la troupe quelques huanacus, comme ils sont plus haut de corps et moins timides que les vigognes, its sautent par dessus les cordes; et dès qu'ils ont donné l'exemple, les vigognes sautent de même et échappent aux chasseurs.

A l'égard des vigognes domestiques ou pacos, on s'en sert comme des lamas pour porter des fardeaux : mais, indépendamment de ce qu'étant plus petits on plus foibles ils portent beaucoup moins, ils sont encore plus sujets à des caprices d'obstination; lorsqu'une fois ils se couchent avec leur charge, ils se laisseroient plulòt hacher que de se relever. Les Indiens n'ont jamais fait usage du lait de ces animaux, parce qu'ils n'en ont qu'autant qu'il en faut pour nourrir leurs petits. Le grand profit que l'on tire de leur haine avoit engagé les Expagnols à tâcher de les naturaliser en Europe pour les faire peupler; mais le 
climat se trouva si peu convenable, qu’ils y périrent tous. Cependant, comme je l'ai déjà dit, je suis persuadé que ces animaux, plus précieux encore que les lanas, pourroient réussir dans nos montagnes, et surtout dans les Pyrénées : ceux rui les ont transportés en Espagne n'ont pas fait attention qu'au Pérou même ils ne subsistent que dans la région froide, c'est-i-dire dans la partie la plus élevée des montagnes; ils n'ont pas fait attention qu'on ne les trouve jamais dans les terres basses, et qu'ils meurent dans les pays chands; qu'au contraire ils sont encore aujourd'hui très nombreux dans les terres voisines du détroit de Magellan, où le froid est beancoup plus grand que dans notre Europe méridionale, et que par consérquent il falloit, pour les conserver, les débarquer, non pas en Lispagne, mais en Écosse, ou mème en Norwége, et plus sûrement encore au pied des Pyrénées, des Alpes, etc., où ils eussent pu grimper et atteindre la région qui leur convient. Je n'insiste sur cela que parce que j'imagine que ces animaux seroient une excellente acquisition pour l'Europe, et produiroient plus de biens réels que tout le métal' du Nouveau-Monde, qui n'a servi quà̀ nous charger d'un poids inutile, puisqu'on avoit auparavant pour un gros d'or ou d'argent ce qui nous coûte une once de ces mêmes métaux.

Les animaux qui se nourrissent d'herbes et qui habitent les hautes montagnes de l'Asie. et même de l'Afrique. donnent les bézoards que l'on appelle orien-

1. Quel bien ont produit en effet ces riches mines du Pérou? il a péri des millions d'hommes dans les entrailies de la terre pour les exploiter; et leur sang et leurs travaux n'ont servi qu ì nous charger d'un poids incommode. 
laux, dont les vertus sont les plus exaltées; ceux des montagnes de l'Europe, où la qualité des plantes el des herbes est plus tempérée, ne produisent que des pelotes sans vertu, qu'on appelle égragropiles; et dans l'Amérique méridiona!e, tous les animaux qui fréquentent les montagnes sous la zone torride donnent d'autres bézoards que l'on appelle occidentaux, qui sont encore plus solides et peut-être aussi qualifiés que les orientaux. La vigogne surlout en fournit un grand nombre; le huanacus en donne aussi, et l'on en tire des cerfs et des chevreuils dans les moniagnes de la Nouvelle-Espagne. Les lamas et les pacos ne donnent de beaux bézoards qu'autant qu'ils sont huanacus et vigognes, c'est-à-dire dans leur état de liberté; ceux qu'ils produi nt dans leur condition de servitude sont petits, noirs, et sans vertu : les meilleurs sont ceux qui ont une couleur de vert obscur, et ils viennent ordinairement des vigognes, surlout de celles qui habitent les parties les plus élevées de la montagne, et qui paissent habituellement dans les neiges; de ces vigognes montagnardes, les fenelles comme les mâles produisent des bézoards, et ces bézoards du Pérou tiennent le premier rang après les bézoards orientaux, et sont beaucoup plus estimés que les bézoards de la Nouvelle-Espagne, qui vieuuent des cerf́s, et sont les moins efficaces de tous.

* Nous donnons ici la figure d'un lama dessiné d'après nature, et qui est encore actuellement vivant (aoùt 1777 ) à l'École vétérinaire au château d'Alfort. Cet animal, amené des Indes Espagnoles en Angleterre, nous fut envoyé au mois de novembre 1773 : il étoit jeune alos's, el sa mère, qui étoit avec lui, 
est morte presque en arrivant; on en peut voir lit peau bourrée et le corps injecté sous la peau, dans le beau cabinet anatomique de M. Bourgelat.

Quoique ce lama fût encore jeune, et que le transport et la domesticité eussent sans doute influé sur son accroissement, et l'eussent en partie retardé, il avoit néanmoins près de cinq pieds de hauteur, en le mesurant en ligne droite depuis le sommet de la tête aux pieds de devant, et dans son état de liberté il devient considérablement plus grand et plus épais de corps. Cet animal est, dans le nouveau continent, le représentant du chameau dans l'ancien : il semble en être un beau diminutif, car sa figure est élégante; et, sans avoir aucune des difformités du chameau, il lui rient néanmoins par plusieurs rapports et lui ressemble à plusieurs égards. Comme le chameau il est propre à porter des fardeaux; il a le poil laineux, les jambes assez minces, les pieds courts et conformés à peu près comme les jambes et les pieds du chamean : mais il en differe en ce qu'il n'a point de hosse, qu'il a la queue courte, les oreilles longues, el qu'en général il est beaucoup mieux fait et d'une forme plus agréable par les proportions du corps. Son cou long, bien couvert de laine, et sa tête qu'il tient toujours haute, lui donnent un air de noblesse et de légèreté que la nature a refusé au chameau. Ses oreilles longues de sept pouces sur deux pouces dans leur plus grande largeur se terminent en pointe, et se tiennent toujours droites en avant; elles sont garnies d'un poil ras et noirâtre. La tête est longue, légère, ct d'une forme élégante. Les yeux sont grands, noirs, et ornés, dans les angles internes, de grands poils noirs. 
Le nez est plat, ei les narines sont écartées. La lèvre supérieure est fendue et tellement séparée au devant des mâchoires, qu'elle laisse paroître les deux dents incisives du milieu, qui sont longues et plates, et au nomb:e de quatre à la mâchoire inférieure : ces dents incisives manquent à la mâchoire supérieure, comme dans les autres animaux ruminants; il y a seulement cing mâchelières en haut comme en bas de chaque côté, ce qui fait en tout vingt dents mâchelières et quatre incisives. La tête, le dessus du corps, de la crompe, de la queue, et des jambes, sont couverts d'un poil laineux couleur du musc un peu vineux, plus clair sur les joues, sous le con et sur la poitrine, et plus foncé sur les cuisses et les jambes, où cette couleur devient brune et presque noire. Le sommet de la tête est aussi noirâtre, et c'est de là que part le noir qui se roit sur le front, le tour des yeux, le nez, les narines, la lèvre supérieure, et la moitié des joues. La laine qui est sur le cou est d'un brun foncé, et forme comme une crinière qui pend du sommet de la tête et va se perdre sur le garrot: celte même couleur brune s'étend, mais en diminuant de teinte, sur le dos, et y forme une bande d'un brun foible. Les cuisses sont couvertes d'une grande laine sur les parties postérieures, el cette longue laine est en assez gros flocons; les jambes ne sont garnies que d'un poil ras d'un brun noirâtre. Les genoux de devant sont remarquables par leur grosseur, au lieu que, dans !es jambes de derriere, il se trouve vers le milieu un espace sous la peau, qui est enfoncé d'environ deux pouces. Les pieds sont séparés en deux doigts; la corne du sabot de chaque doigt est longue de plus 
d'un pouce el demi, el celte corne est noire, lisse, plate sur sa face interne, et arrondie sur sa face externe; les cornes du sabol des pieds de derière sont singulières en ce qu'elles forment un crochet à leurs extrémités. Le ironçon de la queue a plus d'un pied de longueur; il est couverl d'une laine assez courte: celte queue ressemble à une houppe; l'animal la porte droile, soit en marchant, soit en courant, et mềne lorsquiil est en repos el couché.

pieds. ponc, lign.

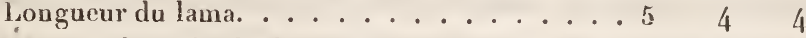

Hauteur du train de devant. ....... 33 . 3 "

llauteur du train de derrière. . . . . . . . . 36 . 6 "

llanteur da ventre au dessus de terre. . . . . . 1 1 g 2

Longueur de la tête du bout des lèvres à l'occiput. " 11 "

Cel animal est fort doux, il n’a ni colère ni méchanceté, il est même caressant; il se laisse mouter par celui qui le nourrit, et ne refuseroit pas le même service à d'autres; il marche au pas, irotie, et prend même une espèce de galop. Lorsqu'il esı en liberté, il bondit et se roule sur l'herbe. Ce lama que je décris étoit un mâle: on a observé qu'il paroît souvent être excité par le besoin d'amour. Il urine en arrière, et la verge est petile pour la grosseur de son corps. Il avoit passé plus de dix-huit mois sans boire au mois de mai dernier; et il me paroît que la boisson ne lui est pas nécessaire, attendu la grande abondance de salive dont l'intérieur de sa bouche est continuellement humecté.

On lit dans le voyage du commodore Byron, qu'on urouve des guanaques, c est-à-dire des lamas, à l'île des Pinguins. el dams l’intérieur des terres, jusqu'au cap des Vierges. qui forme au nord l'entrée du dé- 
troit de Magellan. Ainsi ces animaux ne craignent nullement le froid. Dans leur état de nature et de liberté, ils marchent ordinairement par troupe de soixante ou quatre-vingts, et ne se laissent point approcher : cependant ils sont très aisés à apprivoiser; car les gens de l'équipage du vaisseau de Byron s'étant saisis d'un jeune lama dont on admiroit la jolie figure, ils l'apprivoisèrent au point qu'il venoit leur lécher les mains. Le commodore Byron et le capitaine Wallis comparent cet animal au daim pour la grandeur. la forme, et la couleur : mais Wallis est tombé dans l'erreur en disant qu'il a une bosse sur le dos.

\section{LA VIGOG NE.}

* Nous donnons ici la figure d'une vigogne mâle qui a été dessinée vivante à l'École vétérinaire en $17-4$, et dont la dépouille empaillée se voit dans le cabinet de M. Bourgelat : cet animal est plus petit que le lama, et voici ses dimensions.

Longueur du corps mesurí en ligne droite, depuis

pieds. pouc. lign.

le bout du nez jusqu’à l'origine de la queue. . $4 \quad 4 \quad 4 \quad 6$

Hauteur du train de devant. . . . . . . . $24 \quad 4 \quad 9$

ilauteur du train de derrière. . . . . . . . . 2462

Hauteur du ventre au dessus de terre. . . . . . . 18 " 8 "

Longueur de la tête. . . . . . . . . . 6 6

Longueur des oreilles........... /... / 3

Largeur des oreilles. .......... 1 . 5

frandeur de l'œil. . . . . . . . . . . . 14

Distance entre l'œil et le bout du museau. . . . " 59

Longueur de la queue avec sa laine. . . . . . . $8 \begin{array}{lll} & 8 & 9\end{array}$ 
La vigogne a beaucoup de rapport et même de ressemblance avec le lama; mais elle est d'une forme plus légère, ses jambes sont plus longues à proportion du corps, plus menues et mieux faites que celles du lama. Sa tête, qu'elle porle droite et haute sur un cou long et délié, lui donne un air de légèreté, même dans l'état de repos; elle est aussi plus courte à proportion que la tête du lama; elle est large au front et étroite à l'ouverture de la bouche, ce qui rend la physionomie de cet animal fine et vive $;$ et cette vivacité de physionomie est encore fort augmentée par ses beaux yeux noirs, dont l'orbite est fort grande, ayant seize lignes de longueur ; l'os supérieur de l'orbite est fort relevé, et la paupière inférieure est blanche. Le nez est aplati, et les naseaux, qui sont écartés l'un de l'autre, sont, comme les lèvres, d'une couleur brune mêlée de grris; la lèvre supérieure est fendue comme celle du lama, et cette séparation est assez grande pour laisser voir dans la mâchoire inférieure deux dents incisives longues et plates.

La vigogne porte aussi les oreilles droites, longues, et se terminant en pointe; elles sont nues en dedans, et couvertes en dehor's d'un poil court. La plus grande partie du corps de l'animal est d'un brun rougeâtre tirant sur le vineux, et le reste est de couleur isabelle; le dessous de la mâchoire est d'un blanc jaune; la poitrine, le dessous du ventre, le dedans des cuisses, et le dessous de la queue sont blancs. La laine qui pend sous la poitrine a trois pouces de longueur, et celle qui couvre le corps n'a guère qu'un pouce; l'extrémité de la queue est garnie de longue laine. Cet animal a le pied fourchu, séparé en deux doigts 
qui s'écartent lorsqu'ils marchent; les sabots sont noirs, minces, plats par dessous el convexes par dessus; ils ont un pouce de longueur sur newf lignes de hauteur, et cinq lignes de largeur ou d'empatement.

Cette vigogne a vécu quatorze mois à l'École vétérinaire, et avoit passé peut-être autant de temps en Angleterre; cependant elle n'étoit pas à beaucoup près aussi privée que le lama : elle nous a aussi parud'un naturel moins sensible; car elle ne donnoit nulle marque d'attachement à la personne qui la soignoit; elle cherchoit même à mordre lorsqu'on vouloit la contraindre, et elle souffloit ou crachoit continuellement au visage de ceux qui l'approchoient. On lüi donnoit du son sec et quelquefois détrempé dans l'eau; elle n'a jamais bu d'eau pure ni d'autre liqueur, et il paroît que la vigogne a, conme le lama, une si grande abondance de salive, qu'ils n'ont nul besoin de boire. Enfin elle jette, comme le lama, son urine en arrière; et par toutes ces ressemblances de nature, on peut regarder ces deux animaux comme des espèces du même genre, mais non pas assez voisines pour se mêler ensemble.

Lorsque j'ai écrit, en 1766 , l'histoire du lama et du paco, je croyois qu'il n'y avoit dans ce genre que ces deux espèces, et je pensois que l'alpaco ou aljuaca étoit le même animal que la vigogne sous un nom différent; l'examen que j’ai fait de ces deux animaux, et dont je viens de rendre compte, m'avoit encore confirmé dans cette idée : mais j’ai été réceminent informé que l'alpaca ou paco forme une troisiène espèce qu'on peut regarder comme intermédiaire entre le lama et la vigogne. C'est à $M$. le marquis 
de Nesle que je dois ces connoissances nouvelles. Ce seigneur, aussi zélé pour l'avancement des sciences que pour le bien public, a même formé le projet de faire venir des Indes espagnoles un certain nombre de ces animaux, lamas, alpacas, et vigognes, pour tâcher de les naturaliser et multiplier en France, et il seroit très à désirer que le gouvernement voulût seconderses vues, la laine de ces animaux étant, comme l'on sait, d'un prix inestinıable. Les avantages et les difficultés de ce projet sont présentés dans le mémoire suivant, qui a été donné à M. le marquis de Nesle par M. l'abbé Béliardy, dont le mérite est bien connu, et qui s'est trouvé à portée, par son long séjour en Espagne, d'être bien informé.

"Le nom de lama, dit-il, est un mot générique que les Indiens du Pérou donnent indifféremment à toutes sortes de bêtes à laire. Avant la conquête des Espagnols, il n'y avoit point de brebis en Amérique; ces conquérants les y ont introduites, et les Indiens du Pérou le sont appelées lamas, parce que apparemment, daus leur lanģue, c'est le mot pour désigner tout animal laineux : cependant, dans les provinces de Cusco, Potosi, et Tucuman, on distingue trois espèces de lamas, dont les variétés leur ont fait assigner des noms différents.

"Le lama, dans son état de nature et de liberté, est un animal qui a la forme d'un petit chameau. II est de la hauteur d'un gros âne, mais beaucoup plus long; il a le pied fourchu comme les bœufs; son cou a trente à quarante pouces de long; sa tête, qu'il porte toujours haute, ressemble assez à celle d'un 
poulain: une longue laine lui couvre tout le corps; celle du cou et du ventre est beaucoup plus courte.

"Cet animal est originairement sauvage; on en trouve encore en petites troupes sur des montagnes élevées et froides. Les naturels du pays l'ont réduit à l'étąt de domesticité, et on a remarqué qu'il vit également dans les climats chauds comme dans les plus froids; il produit aussi dans cet état. La femelle ne fait qu'un petit à chaque portée, et on n'a pu me dire de combien de temps est la gestation.

"Depuis que les Espaguols ont introduit dans le royaume du Pérou les chevaux et les mulets, l'usage des lamas est fort diminué; cependant on ne laisse pas de s'en servir encore, surtout pour les ouvrages de la campagne. On le charge comme nous chargeons nos ânes; il porte de soixante-quinze à cent livres sur le dos. Il ne trotte ni ne galope; mais son pas ordinaire est si doux, que les femmes s'en servent de préférence à toute antre monture. On les envoie paître dans la campagne en toute liberté, sans qu'ils cherchent à s'enfuir. Outre le service domestique qu'on en tire, on a l'avantage de profiter de leur laine. On les tond une fois l'an, ordinairement à la fin de juin; on emploie dans ces contrées leur laine aux mêmes usages que nous employons le crin, quoique cette laine soit aussi douce que notre soie, et plus belle que celle de nos brebis.

"Le lama de la seconde espèce est l'alpaca. Cet animal ressemble en général au lama; mais il en diffère en ce qu'il est plus bas de jambe et beaucoup plus large de corps. L'alpaca est absolument sauvage, et 
se trouve en compagnie des vigognes. La laine est plus fournie et beaucoup plus fine que celle du lama; aussi est-elle plus estimée.

"La troisième espèce est la vigogne, qui est encore semblable au lama, à la réserve qu'elle est bien plus petite; elle est, comme l'alpaca, tout-à-fait sauvage. Quelques personnes de Lima en nourrissent par rareté et par pure curiosité (mais on ignore si, dans cet état, ces animaux se multiplient et même s'ils s'accouplent). Les vigognes, dans cet état de captivité, mangent à peu près de tout ce qu'on leur présente, du maïs ou blé de Turquie, du pain el toutes sortes d'herbes.

"La laine de la vigogne est encor: plus fine que celle de l'alpaca, et ce n'est que pour avoir sa dépouille quon lui fait la guerre. It y a dans sa toison trois sortes de laine : celle du dos, plus foncée et plus line, est la plus estimée; ensuite celle des flancs, qui est d'une couleur plus claire; et la moins appréciéc est celle du ventre, qui est argentée. On distingue dans le commerce ces trois sortes de laine par la différence de leur prix.

"Les vigognes vont toujours par troupes assez nombreuses; elles se tiennent sur la croupe des montagnes de Cusco, de Potosi, et du Tucuman, dans des rochers âpres et des lieux sauvages; elles descendent dans les vallons pour paître. Lorsqu'on veut les chasser, on recherche leurs pas ou leurs crottes, qui indiquent les endroits où on peut les trouver; car ces animaux ont la propreté et l'instinct d'aller déposer leur crottin dans le inême tas... Ou commence par teudre des cordes dans les endroits par où elles pour- 
roient s'échapper; on attache de distance en distance à ces cordes des chiffons d'étoffes de différentes couleurs : cet animal est si timide, qu'il n'ose franchir cette foible barrière. Les chasseurs font grand bruit, et tâchent de pousser les vigognes contre 'quelques rochers qu'elles ne puissent surmonter: l'extrême timidité de cet animal l'empêche de tourner la tête vers ceux qui le poursuivent; dans cet état, il se laisse prendre par les jambes de derrière, et l'on est sûr de n'en pas manquer un : on a la cruauté de massacrer la troupe entière sur le lieu. Il y a des ordonnances qui défendent ces tueries; mais elles ne sont pas observées. Il seroit cependant aisé de les tondre lorsqu'ils sont pris, et de se ménager une nouvelle laine pour l'année suivante. Ces chasses produisent ordinairement de cinq cents à mille peaux de vigognes. Quand les chasseurs ont le malheur de trouver quelque alpaca dans leur battue, leur chasse est perdue : cet animal, plus hardi, sauve immanquablement les vigognes; il franchit la corde sans s'effrayer ni s'embarrasser des chiffons qui flottent, rompt l'enceinte, et les vigognes le suivent.

- Dans toutes les Cordilières du nord de Lima, en se rapprochant de Quito, on ne trouve plus ni lamas, ni alpacas, ni vigognes, dans l'état sauvage; cependant le lama domestique est fort commun à Quito, où on le charge et on l'emploie pour tous les ouvrages de la campagne.

"Si on vouloit se procurer des vigogues en vie de la côte du sud du Pérou, il faudroit les faire descendre des provinces de Cusco ou Polosi au port d'Arica; là on les embarqueroit pour l'Europe; mais la naviga- 
tion depuis la mer du Sud par le cap de Horn est si longue et sujette à tant d'événements, qu'il seroit peut-être très difficile de les conserver pendant la traversée. Le meilleur expédient et le plus sûr seroit d'envoyer un bâtiment exprès dans la rivière de la Plata; les vigognes qu'on auroit fait prendre, sans les maltraiter, dans la province de Tucuman, se trouveroient très à portée de desceudre à Buenos-Ayres, et d'y être embarquées. Mais il seroit difficile de tronver à Buenos-Ayres un bâtiment de retour préparé et arrangé pour le transport de trois ou quatre douzaines de vigognes : il n'en coûteroit pas davantage pour l'armement en Europe d'un bâliment destiné lout exprès pour cette commission, que pour le fret d'un navire trouvé par hasard à Bucnos-Ayres.

"Il faudroit, en conséquence, charger une maison de commerce à Cadix de faire armer un bâliment espagnol pour la rivière de la Plata; ce bâtiment, qui seroit chargé de marchandises permises pour le compte du commerce, ne feroit aucun tort aux finances d'Espagne : on demanderoit seulement la permission d'y mettre à bord un ou deux hommes chargés de la commission des vigognes pour le retour; ces hommes seront munis de passe-ports et de recommandations efficaces du ministère d'Espagne pour les gouverneurs du pays, afin qu'ils soient aidés dans l'objet et pour le succès de leur commission. II faut nécessairement que de Buenos-Ayres on donne ordre à Santa-Cruz de la Sierra, pour que des montagnes de Tucuman on y amène en vie frois ou quatre donzaines de vigognes femelles, avec une demi-douzaine de mâles, quelques alpacas et quelques lamas, 
moitié mâles et moitié femelles. Le bâtiment sera arrangé de manière à les y recevoir et à les y placer commodément; c'est pour cela qu'il faudroit lui défendre de prendre aucune autre marchandise en retour, et lui ordonner de se rendre d'abord à Cadix, où les vigognes se reposeroient, et d'où l'on pourroit ensuite les transporter en France... Une pareille expédition, dans les termes qu'on vient de la projeter, ne sauroit être fort coûteuse.... On pourroit même donner ordre aux officiers de la marine du roi, ainsi qu'à tous les bâtiments qui reviennent de l'Ile-deFrance et de l'Inde, que si, par hasard, ils sont jetés sur les côtes de l'Amérique et obligés d'y chercher un abri, de préférer la relâche dans la rivière de la Plata. Pendant qu'on seroit occupé aux réparations du vaisseau, il faudroit ne rien épargner avec les gens du pays pour obtenir quelques vigognes en vie, mâles et femelles, ainsi que quelques lamas et quelques alpacas. On trouvera à Montevideo des Indiens qui font trente à quarante lieues par jour, qui iront à Santa-Cruz de la Sierra, et qui s'acquitteront fort bien de la commission.... Cela seroit d'autant plus facile, que les vaisseaux françois qui reviennent de l'Ile-de-France ou de l'Inde peuvent relâcher à Montevideo, au lieu d'aller à Sainte-Catherine sur la côte du Brésil, comme il leur arrive très souvent. Le ministre qui auroit contribué à enrichir le royaume d'un' animal aussi utile pourroit s'en applaudir comme de la conquête la plus importante. Il est surprenant que les jésuitesn'aient jamais songé à essayer de naturaliser les vigognes en Europe, eux qui, inaîtres du Tucuman et du Paraguay, possédoient ce trésor au milieu de 
leurs missions et de leurs plus beaux établissements."

Ce mémoire intéressant de M. l'abbé Béliardy m'ayant été communiqué, j’en fis part à mon digne et respectable ami, M. de Tolosan, intendant du commerce, qui, dans toutes les occasions, agit avec zèle pour le bien public. Il a donc cru devoir consulter, sur ce mémoire et sur le projet qu'il contient, un homme intelligent (M. de Ia Folie, inspecteur général des manufactures), et voici les observations qu'il a faites à ce sujet :

"L'auteur du mémoire, animé d'un zèle très louable, dit M. de La Folie, propose, cornme une grande conquête à faire par un ministre, la population des lamas, alpacas, et vigognes en France; mais il me perınettra les réflexions suivantes.

"Ies lamas, ainsi nommés par les Péruviens, et corneros de la terra par les Espagnols, sont de. bons animaux domestiques, tels que l'auteur l'annonce; on observe seulement qu'ils ne peuvent point marcher pendant la nuit avec leurs charges: c'est la raison qui détermina les Espagnols à se servir de mulets et de chevaux. Au reste, ne considérons point ces animanx comme bêtes de charge ( nos ânes de France sont bien préférables); le point essentiel est leur toison : non senlement leur laine est très inférieure à celle des vigognes, comme l'observe l'auteur, mais elle a une odeur forte et désagréable qu'il est difficile d'enlever.

"La laine de l'alpaca est, en effet, cornme il le dit, bien supérieure à celle du lama; on la confond tous les jours avec celle de la vigogne, et il est rare que cette dernière n'en soit pas mêlée. 
\Le lama s'apprivoise très bien, comme l'observe l'auteur; mais on lui objecte que les Espagnols ont fait beaucoup d'essais chez eux pour y naturaliser les alpacas et les vigognes. L'auteur, qui prétend le contraire, n'a pas eu, à cet égard, des éclaircissements fidèles. Plusieurs fois on a fait venir en Espagne une quantité de ces animaux, et on a tenté de les faire peupler; les épreuves qu'on a multipliées à cet égard ont été absolument infructueuses : ces animaux sont tous morts, et c'est ce qui est cause qu'on a depuis long-temps abandonné ces expériences.

"Il y auroit donc bien à craindre que ces animaux n'éprouvassent le même sort en France. Ils sont accoutumés dans leur pays à une nourriture particulière : cette nourriture est une espèce de jonc très fin, appelé ycho, et peut-être nos herbes de pâturages n'ont-elles pas les mêmes qualités, les mêmes principes nutritifs en plus ou en moins.

" La laine de la vigogne fait de belles étoffes, mais qui ne durent pas autant que celles qui sont faites avec la laine des brebis."

Ayant reçu cette réponse satisfaisante à plusieurs égards, et qui confirme l'existence réelle d'une troisième espèce, c'est-à-dire de l'alpaca, dans le genre du lama, mais qui semble fonder quelques doutes sur la possibilité d'élever ces animaux, ainsi que la vigogne, en Europe, je l'ai communiquée, avec le mémoire précédent, de M. Béliardy, à plusieur's personnes instruites, et particulièrement à M. l'abbé Bexon, qui a fait sur cela les observations suivantes. "Je remarque, dit-il, que le lama vit dans les vallées basses et chaudes du Pérou, aussi bien que dans 
la partie la plus froide de la Sierra, et que par conséquent ce n'est pas la température de notre climat qui pourroit faire obstacle et l'empêcher de s'y habituer.

"A le considérer comme animal de monture, son pas est si doux, que l'on s'en sert de préférence au cheval et à l'âne; il paroît de plus qu'il vit aussi durement que l'âne, d'une manière aussi agreste et sans exiger plus de soins. (Page 215.)

"Il semble que les Esparynols eux-mêmes ne savent pas faire le meilleur ou le plus bel emploi de la laine du lama, puisqu'il est dit "que, qunique cette laine " soit plus belle que celle de nos brebis, et aussi douce " que la soie, on l'emploie aux mêmes usages aux"quels nous employons le crin." (Ibidem.)

"L'alpaca, espèce intermédiaire entre le lama et la vigogne, et jusqu'ici peu connu, même des naturalistes, est encore entièrement sauvage; néanmoins c'est peut-être des trois animaux péruviens celui dont la conquête seroit la plus intéressante, puisque avec une laine plus fournie et beaucoup plus fine que celle du lama, l'alpaca paroît avoir une constitution plus forte et plus robuste que celle de la rigogne. (Ibidem.)

"La facilité avec laquelle se sont nourries les vigognes privées que l'on a eues par curiosité à lima, mangeant du maïs, du pain, et de toutes sortes d'herbes, garantit celle qu'on trouveroit à faire en grand l'éducation de ces animaux. Une négligence inconcevable nous laisse ignorer si les vigognes privées que l'on a eues jusqu'ici ont produit en domesticité; mais je ne fais aucun doute que cet animal, sociable par instinct, foible par nature, et doué, comme le mouton, d'une timidité douce, ne se plût en troupeaux 
rassemblés, et ne se propageât volontier's dans l'asile d'un parc ou dans la paix d'une étable, etbien mieux que dans les vallons sauvages, où leurs troupes fugitives tremblent sous la serre de l'oiseau de proie ou à l'aspect du chasseur.

"La cruauté avec laquelle on nous dit que se font au Pérou les grandes chasses, ou plutôt les grandes lueries de vigognes, est une raison de plus de se hâter de sauver dans l'asile domestique une espèce précieuse que ces massacres auront bientôt détruite ou du moins affoiblie au dernier point.

- Les dangers et les longueurs de la navigation par le cap Horn me semblent, comme à M. Béliardy, être un grand obstacle à tirer les vigognes de la côte du sud par Aricá, Cusco ou Potosi ; et la véritable route pour amener ces animaux précieux seroit en effet de les faire descendre du Tu cuman par Rio de la Plata jusqu’à Buenos-Ayres, où un bâliment frété exprès et monté de gens entendus aux soins délicats qu'exigreroient ces animanx dans la traversée, les amèneroit à Cadix, ou mieux encore dans quelques uns de nos ports les plus voisins des Pyrénées ou des Ciévennes, où il seroit le plus convenable de commencer l'éducation de ces animaux dans une région d'air analogue à celle des Sicrras, d'où on les a fait descendre.

" Il mé reste quelques remarques à faire sur la lettre de M. de La Folie, qui ne me paroît offrir que des doutes assez peu fondés et des difficultés assez légères.

" $1^{\circ} \mathrm{On}$ a vu que si cheval et l'âne l'emportent par la constance du service sur le lama, celui-ci à son tour leur est préférable à d'autres égards; et d'ailleurs l'ob. 
jet est bien moins ici de considérer le lama comme bête de somme, que de le regarder, conjointement avec la vigogne et l'alpaca, comme bétail à toison.

" $2^{\circ}$ Qui peut nous assurer qu'on ait fait en Espagne beaucoup d'essais pour naturaliser ces animaux? et les essais supposés faits l'ont-ils été avec intelligence? Ce n'est point dans une plaine chaude, mais, comme nous venons de l'insinuer, sur des croupes de montagnes voisines de la région des neiges, qu'il faut faire retrouver aux vigognes un climat analogue à leur climat natal.

" $5^{\circ}$ C'est moins des vigognes venues du Pérou que l'on pourroit espérer de former des troupeaux, que de leur race née en Europe; et c'est à obtenir cette race et à la multiplier qu'il faudroit diriger les premiers soins, qui sans doute devroient être grands et continuels pour des animaux délicats et ainsi dépaysés.

" $4^{\circ}$ Quant à l'herbe $y c h o$, il est difficile de croire qu'elle ne puisse pas être remplacée par quelques uns de nos gramens ou de nos joncs : mais, sil le falloit absolument, je proposerois de transporter l'herbe $y c h o$ elle-même; il ne seroit probablement pas plus difficile d'en faire le semis que tout autre semis d'herbage, et il seroit heureux d'acquérir une nouvelle espèce de prairie artificielle avec une nouvelle espèce de troupeaux.

" $5^{\circ}$ Et pour la crainte de voir dégénérer la toison de la vigogne transplantée, elle paroît peu fondée: il n'en est pas de la vigogne comme d'une race domestique et factice perfectionnée, ou, si l'on vent, dégénérée tant qu'elle peut l'être, telle que la chèvre d'Angora, qui en effet, quand on la transporte hors de la Syrie, perd en peu de temps sa beauté; la vi- 
gogne est dans l'état sauvage; elle ne possède que ce que Jui a donné la nalure, et que la domesticité pourroit sans doute, comme dans toute autre espèce, perfëctionner pour notre usage."

J'adopte entièrement ces réflexions très justes de M. l'abbé Bexon, et je persiste à croire qu'il est aussi possible qu'il seroit important de naturaliser chez nous ces trois espèces d'animaux si utiles au Pérou, et qui paroissent si disposés à la domesticité.

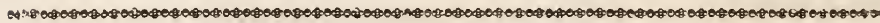

\section{L'UNAU ${ }^{1}$ E'T L'A İ}

Bradypus didactylus. I. - Bradypus tridactylus. L.

L'on a donné à ces deux animaux l'épithète de $p a-$ resseux, à cause de leurs mouvements et de la difficulté

1. Nou de cet animal au Maragnon, et que nous avons adopté Le P. d'Abbeville distingue deux espèces d'unaux : le plus grand, qui est celui dont il est ici question, qu'il appelle unau ouasou; et le plus petit, qu'il nomme simplement unau, qui est le même animal̀ que l'ai. "Il y en a de deux sortes, dit-il : aucuns sont grands environ comme "les lières, les autres sont deux fois presque plus grands." (Mission au Maragnon, page 252.) On a donné quelquefois à l'unau le nom de lèche-patte: mais ce nom, qui sembleroit avoir été pris de l'habitude de cet animal, n'est pas fondé; car il ne lèche pas ses pieds, ni même aucune aatre partie de son corps.

2. Nom de cet animal au Brésil, et que nous avons adopté. Ce nom vient du son plaintif $a, i$, qu’il répète souvent. Ouaikaré à la Guiane, selon Barrère; hay, selon de Léry; hau ou hauthi, selon Thevet; perrillio ligero, selon Oviedo; unau, selon le P. d'Abbeville; haut, sclon Nieremberg. 
3

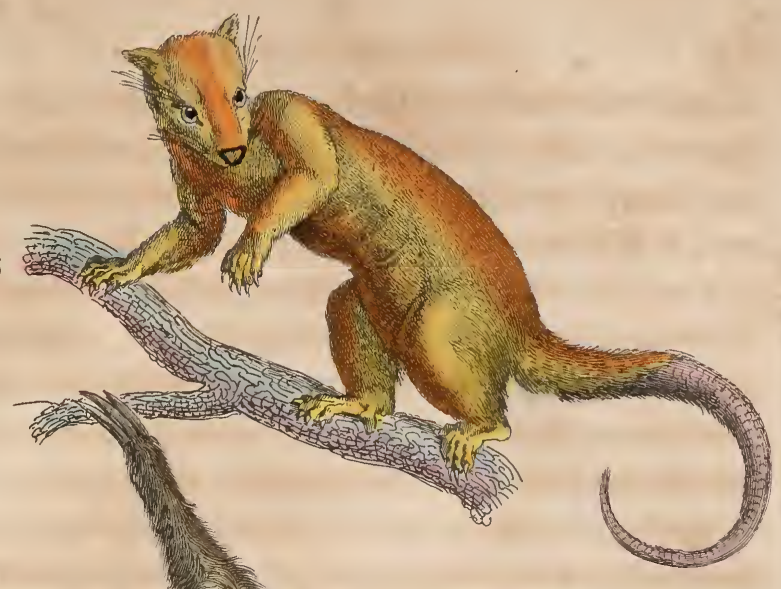

2
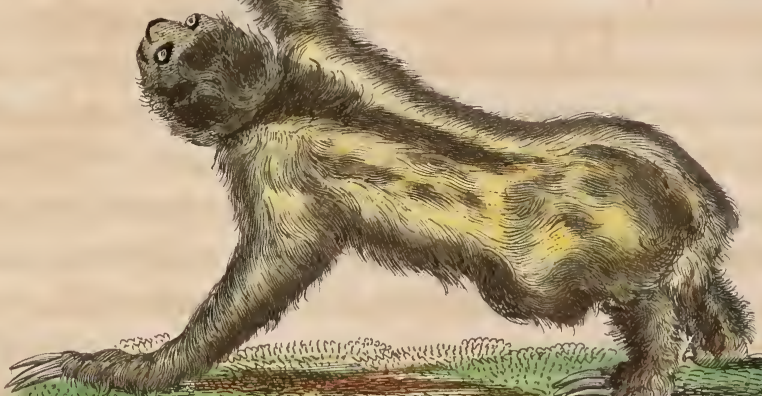

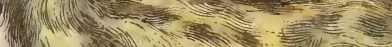
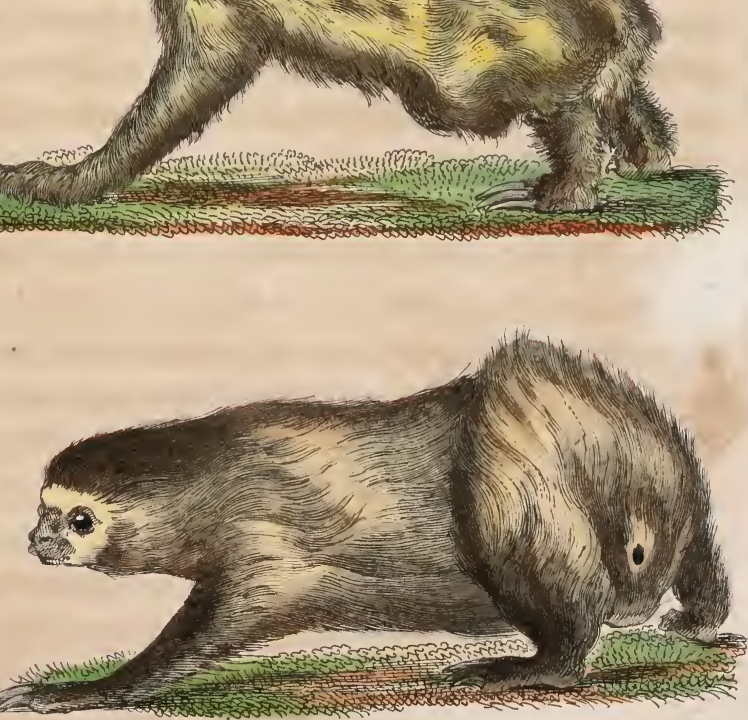


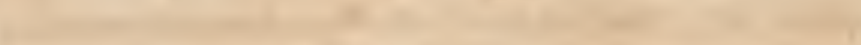

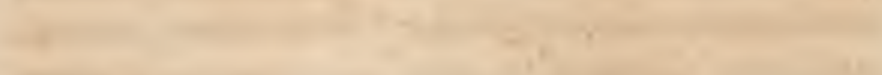

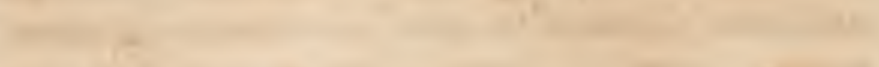
$\sqrt{2}$

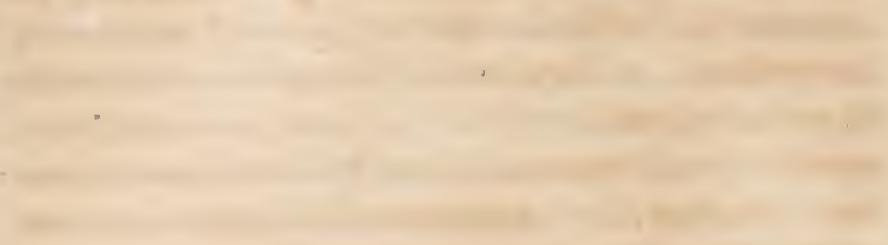

\section{(1)}
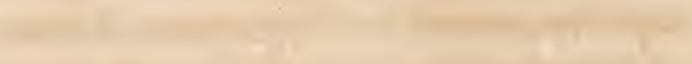

(n)

10

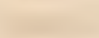

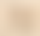

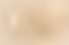

$\sqrt{2}$

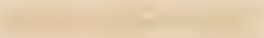

• $\sqrt{2}+x^{2}$ $\sqrt{2}+x^{2}$

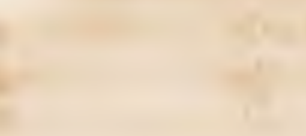

$$
\cdot
$$

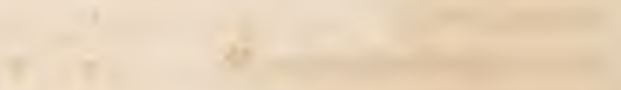


qu'ils ont à marcher : mais nous avons cru devoir leur conserver les noms qu'ils portent dans lear pays natal, d'abord pour ne les pas confondre avec d’autres animaux presque aussi paresseux qu'eux, et encore pour les distinguer nettement l'un de l'autre; car, quoiqu'ils se ressemblent à plusieurs égards, ils diffèrent néanmoins, tant à l'extérieur qu'à l'intérieur, par des caractères si marqués, qu'il n'est plus possible, lorsqu'on les a examinés, de les prendre l'un pour l'autre, ni même de douter qu'ils ne soient de deux espèces très éloignées. L'unau n'a point de queue, et n'a que deux ongles aux pieds de devant; l'aï porte une queue courte, et trois ongles à tous les pieds. L'unau a le museau plus long, le front plus élevé, les oreilles plus apparentes que l'ai ; il a aussi le poil tout différent : à l'intérieur, ses viscères sont autrement situés et conformés différemment dans quelques unes de leurs parties. Mais le caractère le plus distinctif et en même temps le plus singulier c'est que l'unau a quarante-six côtes, tandis que l'ai n'en a que vingt-huit. : cela suppose deux espèces très éloignées l'une de l'autre; et ce nombre de quarante-six côtes dans un animal dont le corps est si court est une espèce d'excès ou d'erreur de la nature; car de tous les animaux, même des plus grands, et de ceux dont le corps est le plus long relativement à leur grosseur, aucun n'a autant de chevrons à sa charpente. L'éléphant n'a que quarante côtes, le cheval trente-six, le blaireau trente, le chien vingt-six, l'homme vingt-rfuatre, etc. Cette différence dans la construction de l'unau et de l'ai suppose plus de distance entre ces deux espèces, qu'il 
n'y en a entre celle du chien et du chat, qui ont le même nombre de côtes : car les différences extérieures ne sont rien en comparaison des différences intérieures; celles-ci sont, pour ainsi dire, les causes des autres, qui n'en sont que les effets. L'intérieur, dans les êtres vivants, est le fond du dessein de la nature; c'est la forme constituante, c'est la vraie figure : l'extérieur n'en est que la surface ou même la draperie; car combien n'avons-nous pas vu, dans l'examen comparé que nous avons fait des animaux, que cet extérieur, souvent très diflérent, recouvre un intérieur parfaitement semblable; et qu'au contraire la moindre différence intérieure en produit de très grandes à l'extérieur, et change même les habitudes naturelles, les facultés, les attributs de l'animal! combien n'y en a-t-il pas qui sont armés, couverts, ornés de parties excédantes, et qui cependant, pour l'organisation intérieure, ressemblent en entier à d'autres qui en sont dénués! Mais ce n'est point ici le lieu de nous étendre sur ce sujet, qui, pour être bien traité, suppose non seulement une comparaison réfléchie, mais un développement suivi de toutes les parties des êtres organisés. Nous dirons seulement, pour revenir à nos deux animaux, qu'autant la nature nous a paru vive, agissante, exaltée dans les singes, autant elle est lente, contrainte et resserrée dans les paresseux; et c'est moins paresse que misère; c'est défaut, c'est dénuement, c'est vice dans la conformation : point de dents incisives ni canines; les yeux obscurs et couverts; la mâchoire aussi lourde qu'épaisse; le poil plat et semblable à de l'herbe séchée; les cuisses nal emboîtées et presque hors des 
hanches; les jambes trop courtes, mal tournées, et encore plus mal terminées; point d'assiette de pied, point de pouces, point de doigts séparément mobiles; mais deux ou trois ongles excessivement longs, recourbés en dessous, qui ne peuvent se mouvoir qu'ensemble, et nuisent plus à marcher qu'ils ne servent à grimper : la lenteur, la stupidité, l'abandon de son être, et même la douleur habituelle, résultant de cette conformation bizarre et négligée; point d'armes pour attaquer ou se défendre; nul moyen de sécurité, pas même en grattant la terre; nulie ressource de salut dans la fuite : confinés, je ne dis pas au pays, mais à la motte de terre, à l'arbre sous lequel ils sont: nés; prisonniers au milieu de l'espace; ne pouvant parcourir qu'une toise en une heure ${ }^{1}$; grimpant avec peine, se trainant avec douleur; une voix plaintive et par accents entrecoupés, qu'ils n'osent élever que la nuit; tout annonce leur misère, tout nous rappelie ces monstres par défaut, ces ébauches imparfaites mille fois projetées, exécutées par la nature, qui, ayant à peine la faculté d'exister, n'ont dû subsister qu'un temps, et ont été depuis effacées de la liste des

1. Tum lentus est illius gressus et membrorum motus, ut quindecim ipsis diebus ad lapidis ictum continuo tractu vix prodeat. (Pison, Hist. Bras., page 322.) Cette assertion de Pison, empruntée de Maffée et de Herrera, est très exagérée.

"Il n'y a point d'animal plus paresseux que celui-ci; il ne faut "point de lévriers pour le prendre à la course, une torlue suffiroit. " (Desmarchais, tome III, page 3o1.) Ceci est encore exagéré.

"On lui donne ironiquement l'épithète de coureur, parce qu'il lui " faut une grande journée pour faire un quart de lieue. " (Hist. de l'Orènoq., par Gumilla, tome II, page 13.) Cet auteur est le seul qui , sur le fait de la lenteur de ces animanx, me paroisse avoir approché de la vérité. 
êtres : et en offot. si les terres gu'habitent et l'unau et l'ai n'étoient pas désertes, si les hommes ê les animaux puissants s'y fussent anciennement multipliés, ces espèces ne seroient pas parvenues jusqu'à nous; elies eussent été détruites par les autres, comme elles le seront un jour. Norrs avons dit qu'il semble que tout ce qui peut être est; ceci paroît en être un indice frappant : ces paresseux sont le dernier terme de l'existence dans l'erdre des animaux qui ont de la chair et du sang; une défectuosité de plus les auroit empêchés de subsister. Regarder ces ébauches comme des êtres aussi absolus que les autres, admettre des causes finales pour de telles disparates, et trouver que la nature y brille autant que dans ses beaux ouvrages, c'est ne la voir que par un tube étroit, et prendre pour son but les fins de notre esprit.

Pourquoi n'y auroit-il pas des espèces d'animaux créés pour la misère, puisque, dans l'espèce humaine, le plus grand nombre y est voué dès la naissance? Le mal, à la vérité, vient plus de nous que de la nature: pour un malheureux, qui ne l'est que parce qu'il est né foible, impotent, ou difforme, que de millions d'hommes le sont par la seule dureté de leurs semblables! Les animaux sont en général plus heureux; l'espèce n'a rien à redouter de ses individus: le mal n'a pour eux qu'une source; il en a deux pour l'homme : celle du mal moral, qu'il a lui-même ouverte, est un torrent qui s'est accru comme une mer dont le débordement couvre et afflige la face entière de la terre : dans le physique, au contraire, le mal est resserré dans des bornes étroites, il va rarement seul; 
le bien est sunvent au dessus, ou du moins de nivieau. Peut-on douter du bonheur des animaux, s’ils sont libres, s’ils ont la faculté de se procurer aisément la subsistance, et s'ils manquent moins que nous de la santé, des sens, et des organes nécessaires ou relatifs au plaisir? or le commun des animaux est, à lous ces égards, très richement doué; et les espèces disgraciées de l'unau et de l'ai sont peut-être les seules que la nature ait maltraitées, les seules qui nous offrent l'image de la misère innée.

Voyons-la de plus près. Faute de dents, ces pauvres animaux ne peuvent ni saisir une proie, ni se nourrir de chair, ni même brouter l'herbe; réduits à vivre de feuilles et de fruits sauvages, ils consument du temps à se traîner au pied d'un arbre; il leur en faut encore beaucoup pour grimper jusqu'aux branches; et pendant ce lent et triste exercice, qui dure quelquefois plusieurs jours, ils sont obligés de supporter la faim, et peut-être de souffrir le plus pressant besoin : arrivés sur leur arbre, ils n'en descendent plus, ils s'accrochent aux branches, ils le dépouillent par parties, mangent successivement les feuilles de chaque rameau, passent ainsi plusieurs semaines sans pouvoir délayer par aucune boisson cette nourriture aride; et lorsqu'ils ont ruiné leur fonds, et que l'arbre est entièrement nu, ils y restent encore retenus par l'impossibilité d'en descendre : enfin, quand le besoin se fait de nouveau sentir, qu'il presse et qu'il devient plus vif que la crainte du danger de la mort, ne pouvant descendre ils se laissent tomber, et tombent très lourdement comme un bloc, une masse sans 
ressort; car leurs jambes roides et paresseuses n'on! pas le temps de s'étendre pour rompre le coup.

A terre ils sont livrés à tous leurs ennemis : comme leur chair n'est pas absolument mauvaise, les hommes et les animaux de proie les cherchent et les tuent. II paroît qu’ils multiplient peu, ou du moins que s’ils produisent fréquemment, ce n'est qu'en petit nomhre; car ils n'ont que deux mamelles. Tout concourt lonc à les détruire, et il est bien difficile que l'espèce se maintienne. Il est vrai que, quoiqu'ils soient lents, gauches, el presque inhabiles au mouvement, ils sont durs, forts de corps, et vivaces; qu'ils peuvent supporter long-temps la privation de toute nourriture: que couverts d'un poil épais et sec, et ne pouvant faire d'exercice, ils dissipent peu, et engraissent par le repos, quelque maigres que soient leurs aliments; et que, quoiqu'ils n'aient ni bois ni corres sur la tête, ni sabots aux pieds, ni dents incisives à la mâchoire inférieure, ils sont cependant du nombre des animaux ruminants, et ont, comme eux, plusieurs estomacs; que par conséquent ils peuvent compenser ce qui manque à la qualité de la nourriture par la quantité qu'ils en prennent à la fois; et ce qui est encore extrêmement singulier, c'est qu'au lieu d'avoir, comme les ruminants, des intestins très longs, ils les ont très petits et plus courts que les animaux carnivores. L'ambiguité de la nature paroît à découvert par ce contraste : l'unau et l'aï sont certainement des animaux ruminants; ils ont qualre estomacs, et en même temps ils manquent de tous les caractères, tant extérieurs qu'intérieurs, qui appartiennent généralement à tous 
les animaux ruminants. Encore une autre ambiguité; c'est qu'au lieu de deux ouvertures au dehors, l'une pour l'urine et les autres pour les excréments, au lieu d'un orifice extérieur et distinct pour les parties de la génération, ces animaux n'en ont qu'un seul, au fond duquel est un égout commun, un cloaque comme dans les oiseaux. Mais je ne finirois pas, si je voulois m'étendre sur toutes les singularités que présente la conformation de ces animaux : on pourra les voir en détail dans l'excellente description qu'en a faite M. Daubenton.

Au reste, si la misère qui résulte du défaut de senliment n'est pas la plus grande de toutes, celle de ces animaux, quoique très apparente, pourroit ne pas être réelle; car ils paroissent très mal ou très peu sentir : leur air morne, leur regard pesant, leur résistance indolente aux coups qu'ils reçoivent sans s'émouvoir, annoncent leur insensibilité; et ce qui la démontre, c'est qu'en les soumettant au scalpel, en leur arrachant le cœur et les viscères, ils ne meurent pas à l'instant. Pison, qui a fait cette dure expérience, dit que le coeur séparé du corps battoit encore vivement pendant une demi-heure, et que l'animal remuoit toujours les jambes comme s'il n'eût été qu'assoupi. Par ces rapports, ce quadrupède se rapproche non seulement de la tortue, dont il a déjà la lenteur, mais encore des autres reptiles et de tous ceux qui n'ont pas un centre de sentiment unique et bien distinct: or tous ces êtres sont misérables sans être malheureux; et dans ses productions les plus négligées, la nature paroît toujours plus en mère qu'en marâtre. Cies deux aniwax appartiennent également l'un et 
l'autre aux terres méridionales du nouveau continent. et ne se trouvent nulle part dans l'ancien. Nous avons déjà dit que l'éditeur du Cabinet de Seba s'étoit trompé en donnant à l'unau le nom de paresseux de Ceylan; cette erreur, adoptée par MM. Klein, Linnæus et Brisson, est encore plus évidente aujourd'hui qu'elle ne l'étoit alors. M. le marquis de Montmirail a un unau vivant qui lui est venu de Surinam; ceux que nous avons au Cabinet du Roi viennent du même endroit et de la Guiane; et je suis persuadé qu'on trouve l'unau, aussi bien que l'aï, dans toute l'étendue des déserts de l'Amérique, depuis le Brésil ${ }^{1}$ au Mexique, mais que, comme il n'a jamais fréquenté les terres du nord, il n'a pu passer d'un continent à l'autre; et si l'on a vu quelques uns de ces animaux, soit aux Indes orientales, soit aux côtes de l'Afrique, il est sû: qu'ils y avoient été transportés. Ils ne peuvent supporter le froid; ils craignent aussi la pluie : les alternatives de l'humidité et de la sécheresse altèrent leur fourrure, qui ressemble plus à du chanvre mal serancé qu’à de la laine ou du poil.

Te ne puis mieux terminer cet article que par des observations qui m’ont été communiquées par M. le marquis de Montmirail, sur un unau qu'on nourrit depuis trois ans dans sa ménagerie. "Le poil de l'unau est beaucoup plus doux que celui de l'aï.... II est à présumer que tout ce que les voyageurs ont dit sur la lenteur excessive des paresseux ne se rapporte qu'à l'aï. L'unau, quoique très pesant et d'une allure très

1. L'aĩ décrit et gravé par M. Edwards venoit du pays de Honduras. Don Antonio de Ulloa dit qu'on en trouve aux environs de PortoBello. 
maladroite, monteroit et descendroit plusieurs fois en un jour de l'arbre le plus élevé. C'est sur le déclin dı jour et dans la nuit qu'il parô̂t s'animer davantage; ce qui pourroit faire soupçonner qu’il voit très mal le jour, et que sa vue ne peut lui servir que dans l'obscurité. Quand j'achetai cet animal à Amsterdam, on le nourrissoit avec du biscuit de mer, et l'on me dit que, dans le temps de la verdure, il ne falloit le nourrir qu'avec des fenilles. On a essayé en efiet de lui en donner : il en mangeoit volontiers quand elles étoient encore tendres; mais du moment où elles commençoient̊ à se sécher et à être piquées des vers, il les rejetoit. Depuis trois ans que je le conserve vivant dans ma ménagerie, sa nourriture ordinaire a été du pain, quelquefois des pommes et des racines, et sa boisson du lait. Il saisit toujours, quoique avec peine, dans une de ses pattes de devant, ce qu'il veut manger, et la grosseur du morceau augmente la difficulté qu'il a de le saisir avec ses deux ongles. II crie rarement; son cri est bref, et ne se répète janais deux fois dans le même temps. Ce cri, quoique plaintif, ne ressemble point à celui de l'ai, s'il est vrai que ce son ai soil celui de sa voix. La situation ja plus naturelle de l'uuau, et qu’il paroît préférer à toutes les autres, est de sé suspendre à̀ une branche, le corps renversé en bas; quelquefois il dort dans celte position, les quatre pattes accrochées sur un même point, son corps décrivant un arc. La force de ses muscles est incroyable : mais elle lui devient inutile lorsqu'il marche; car son allure n'est ni moins contrainte ni moins vacillante. Cette conformation scule me paroît être une 
cause de la paresse de cet animal, qui n'a d'ailleurs aucun appétit violent, et ne reconnoît point ceux qui le soignent."

* "On connoît à Cayenne, dit M. de La Borde, deux espèces de ces animaux, l'une appelée paresseux honteux, l'autre mouton paresseux : celui-ci est une fois plus long que l'autre, et de la même grosseur; il a le poil long, épais et blanchâtre, pèse environ vingtcing livres. Il se jette sur les hommes depuis le haut des arbres, mais d'une manière si lourde et sipesante, qu'il est aisé de l'éviter. Il mange le jour comme la nuit.

"Le paresseux honteux a des taches noires, peut peser douze livres, se tient toujours sur les arbres, inange des feuilles de bois canon, qui sont réputées poison. Leurs boyaux empoisonnent les chiens quand iis les mangent, et néanmoins leur chair est bonne à manger; mais ce n'est que le peuple qui en fait usage.

"Les deux espèces ne font qu'un petit, qu'ils portent tout de suite sur le dos. Il y a grande apparence que les femelles mettent bas sur les arbres; mais on n'en est pas sûr. Ils se nourrissent de feuilles de monbin et de bois canon. Les deux espèces sont également communes, mais un peu rares aux environs de Cayenne. Ils se pendent quelquefois par leurs griffes à des branches d'arbres qui se trouvent sur les rivières, et alors il est aisé de couper la branche et de les faire tomber dans l'eau; mais ils ne lâchent point prise, et y restent fortement attachés avec leurs pattes de devant. 
"Pour monter sur un arbre, cet animal étend nonchalamment une de ses pattes de devant, qu'il pose le plus haut qu'il peut sur le pied de l'arbre; il s'accroche ainsi avec sa longue griffe, lève ensuite son corps lourdement, et pelit à petit pose l'autre patte, et continue de grimper ainsi. Tous ces mouvements sont exécutés avec une lenteur et une nonchalance inexprimable. Si on en élève dans les maisons, ils grimpent toujours sur quelques poteaux ou même sur les portes, et ils n'airnent pas à se tenir à terre. Si on leur présente un bâton lorsqu'ils sont à terre, ils s'en saisissent tout de suite, et montent à l'extrémité, où ils se tiennent fortement accrochés avec les pattes de devant, et serrent avec tout le corps l'endroit où ils se sont ainsi perchés. Il ont un petit cri fort plaintif et langoureux qui ne se fait pas entendre de loin ${ }^{1}$. "

On voit que le paresseux mouton de M. de La Borde est celui que nous avons appelé unau, et que son pitresseux honteux est l'aï, dont nous avons donné les descriptions et les figures ( planche 44).

M. Vosmaër, habile naturaliste et directeur des cabinets de S. A. S. Mgr le prince d'Orange, m'a reproché deux choses que j'ai dites au sujet de ces animaux: la première, sur la manière dont ils se laissent quelquefois tomber d'un arbre. Voici les expressions de M. Vosmaër.

" On doit absolument rejeter le rapport de M. de Buffon, qui prétend que ces animaux (l'unau et l'aï), trop lents pour descendre de l'arbre, sont obligés de

1. Extrait des observations de M. de La Borde, médecin du roi à Cayene. 
se laisser tomber comme un bloc lorsqu'ils veulent être à terre ${ }^{1}$. n

Cependant je n'ai avancé ce fait que sur le rapport de témoins oculaires, qui mont assuré avoir vu tomber cet animal quelquefois à leurs pieds; et l'on voit que le témoignage de M. de La Borde, médecin du roi à Cayenne, s'accorde avec ceux qui m'ont raconté le fait, el que par conséquent l'on ne doit pas, comme le dit M. Vosmaër, absolument rejeter mon rapport à cet égard.

Le second reproche est mieux fondé. J'avoue très volontiers que j'ai fait une méprise lorsque j'ai dit que l'unau et l'aï n'avoient pas de dents, et je ne sais point du tout mauvais gré à M. Vosmaër d'avoir remarqué cette erreur, qui n'est venue que d'une inattention. J'aime autant une personne qui me relève d'une erreur qu'une autre qui m'apprend une vérité, parce qu'en effet une erreur corrigée est une vérité.

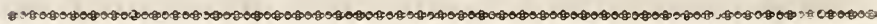

\section{LE KOURI,}

\section{OU LE PETIT UNAU.}

Nous donnons ici la description d'un animal dont l'espèce est voisine de celle de l'unau : il est, à la vérité, de moitié plus petit; mais il lui ressemble beaucoup par la forme du corps. Cet animal a été trouvé

1. Description dU un paresseux pentadactyle de Bengale; Amsterdam, 1767 , page 5. 
dans une habitation de la Guiane françoise; il étoit dans la basse-cour, au milieu des poules, et il mangreoit avec elles : c'est, dit-on, le seul individu de cette espèce que l'on ait vu à Cayenne, d'où il nous a été envoyé pour le Cabinet du Roi, sous le nom de kouri; mais nous n'avons eu aucune information sur ses habitudes naturelles, et nous sommes obligé de nous restreindre à une simple description.

Ce petit unau ressemble au grand par un caractère essentiel : il n'a, comme lui, que deux doigts aux pieds de devant, au lieu que l'aï en a trois, et par conséquent il est d'une espèce différente de celle de l'aï : il n'a que douze pouces de longueur, depuis l'extrémité du nez jusqu'à l'origine de la queue; tandis que l'unau, dont nous avons donné l'histoire et la description, avoit dix-sept pouces six lignes: cependant ce petit unau paroissoit être adulte. Il a, comme le grand, deux doigts aux pieds de devant et cinq à ceux de derrière: mais il en diffère non seulement par la taille, mais encore par son poil, qui est d'un brun muse nuancé de grisâtre et de fauve; et ce poil est bien plus court et plus terne en couleur que dans le grand unau; sous le ventre, il est d'une couleur de inusc clair, nuancé de cendré, et cette couleur s'éclaircit davantage sous le cou jusqu'aux épaules, où il forme comme une bande foible de fauve pâle. Les plus grands ougles de ce petit unau n'ont que neuf lignes, tandis que ceux du grand ont un pouce sept lignes et demie.

Nous avons eu le grand unau vivant; mais, comme nous n'avons pu faire la description du petit que d'après une peau bourrée, nous ne sommes pas en élat de prononcer sur toutes les différences qui peuvent 
se trouver entie ces deux animaux: nous présumous néanmoins qu'ils ne forment qu'une seule et même espèce, dans laquelle il se trouve deux races, l'une plus grande et l'autre plus petite.

J'ai dit, d'après M. de La Borde, que le paresseux, qu'il nomme mouton, se jette sur les hommes depuis le haut des arbres; cela a été mal exprimé par M. de La Borde. Il est certain qu'il n'attaque pas les hommes; mais, comme tous les paresseux en général ne peuvent descendre des arbres, ils sont forcés de se laisser tomber, et tombent quelquefois sur les hommes. M. de La Borde, dans ses nouveaux mémoires, indique quatre espèces de paresseux; savoir le paresseux cabri, le paresseux mouton, le paresseux dos brûlé, et le nouveau paresseux que nous venons d'appeler kouri. Comme il ne donne point la description exacte de ces quatre espèces, nous ne pouvons les comparer avec celles qne nous connoissons; nous présumons seulement que son paresseux cabri et son paresse ux mouton sont notre aï et notre unau. Il nous a envoyé une peau qui nous paroît être celle de son paresseux dos brûlé, mais qui n'est pas assez bien conservée pour que nous puissions juger si elle vient d'un animal dont l'espèce soit différente de celle de l'aï, à laquelle cette peau nous paroît ressembler plus qu'à celle de l'unau. 


\section{LE SURIKATE.}

Viverra tetradactyla. GMes.

Cet animal a été acheté en Hollande sous le non de surikate; il se trouve à Surinam et dans les autres provinces de l'Amérique méridionale : nous l'avons nourri pendant quelque temps, et ensuite M. de Sève, qui a dessiné avec autant de soin que d'intelligence les animaux de notre ouvrage, ayant gardé celui-ci vivant pendant plusieurs mois, m'a communiqué les remarques qu'il a faites sur ses habitudes naturelles. C'est un joli animal, très vif et très adroit, marchant quelquefois debout, se tenant souvent assis avec le corps très droit, les bras pendants, la tête haute et mouvante sur le cou comme sur un pivot; il prenoit cette attitude toutes les fois qu'il vouloit se mettre auprès du feu pour se chauffer. Il n'est pas si grand qu'un lapin, et ressemble assez, par la taille et par le poil, à la mangouste; il est seulement un peu plus étoffé, et a la queue moins longue : mais par le museau, dont la partie supérieure est proéminente et relevée, il approche plus du coati que d'aucun autre animal. Il a aussi un caractère presque unique, puisqu'il u'appartient qu'à lui et à l'hyène : ces deux animaux sont les seuls qui aient également quatre doigts à tous les pieds.

Nous avions nourri ce surikate d'abord avec du lait, 
parce qu'il étoit fort jenne : mais son goùt pour la chair se déclara bientôt; il mangeoit avec avidité la viande crue, et surtout la chair de poulet: il cherchoit aussi à surprendre les jeunes animaux; un petit lapin qu'on élevoit dans la même maison seroit devenu sa proie, si on l'eût laissé faire. Il aimoit aussi beaucoup le poisson, et encore plus les œufs; on l'a vu tirer avec ses deux palles réunies des oufs qu’on venoit de mettre dans l'eau pour cuire: il refusoit les fruits, et même le pain, à moins qu'on ne l'eût mâché. Ses pattes de devant lui servent, comme à l'écureuil, pour porter à sa gueule. Il lapoit en buvant comme un chien, et ne buvoit point d'eau, à moins qu'elle ne fît tiède; sa boisson ordinaire étoit son urine, quoiqu'elle eût une odeur très forte. Il jouoit avec les chats, et toujours innocemment; il ne faisoit aucun mal aux enfants, et ne mordoit qui que ce soit que le mấtre de la maison, qu'il avoit pris en aversion. Il ne se servoit pas deses dents pour ronger; mais il exerçoit souvent ses ongles, et grattoit le plâtre et les carreaux jusqu'à ce qu'il les eût dégradés. Il étoit si bien apprivoisé, qu'il entendoit son nom; il alloit seu! par toute la maison, et revenoit dès qu'on l'appeloit. Il avoit deux sortes de voix, l'aboiement d'un jeune chien lorsqu'il s'ennuyoit d'être seul ou qu'il entendoit des bruits extraordinaires; et au contraire, lorsqu'il étoit excité par des caresses, ou qu'il ressentoit. quelque mouvement de plaisir, il faisoit un bruit aussi vif et aussi frappé que celui d'une petite crécelle tournée rapidement. Cet animal étoit femelle, et paroissoit souvent être en chaleur, quoique dans un climat trop froid, et qu'il n'a pu supporter que pendant un 
hiver, quelqque soin que l'on ait pris pour le nourrir et le chauller.

* Nous avons dit que le surikate ne faisoit ancun mal aux enfants, qu'il ne mordoit que quelques personnes adultes, et, entre autres, le maître de la maison, qu'il avoit pris en aversion. J'ai appris depuis qu'en effet il ne mordoit ni la femme ni les enfants de celte maison, mais qu'il a mordu nombre d'autres personnes des deux sexes. M. de Sève a observé que c'étoit par l'odorat qu'il étoit induit à mordre. Lorsque quelqu'un le prenoit, le cartilage du bout du nez se plioit pendant qu'il flairoit, et, suivant l'odeur qu'il recevoit de la personne, il mordoit ou ne mordoit pas. Cela s'est trouvé constamment sur un assez grand nombre de gens qui ont risqué l'épreuve; et ce qu'il y a de singulier c'est que, quand il avoit mordu une fois quelqu'un, il le mordoit toujours, en sorte qu'on ne pouvoit pas dire que ce fût par humeur ou par caprice. Il y avoit des gens qui lui déplaisoient si fort, qu'il cherchoit à s'échapper pour les mordre; et quand il ne pouvoit pas attraper les jambes, il se jetoit sur les souliers et sur les jupons, qu’il déchiroit; il employoit même quelquefois la ruse pour approcher les personnes qu'il vouloit mordre.

M. Vosmaër, dans une note, page 7 , de sa description d'un écureuil volant, fait une remarque qui m'a paru juste, et dont je dois témoigner ici ma reconnoissance.

"M. de Buffon, dit M. Vosmaër, a vraisemblablement été trompé sur le nom de surikate et sur le lieu de l'origine de cet animal, qui a été envoyé l'été der- 
nier par M. Tulbagh à S. A. S. Mgr le prince d'Orange. Il n'appartient point à l'Amérique, mais hien à l'Afrique. Ce petit animal, dont on in'avoit adressé denx de sexe différent, mais dont la femelle est morte pendant le voyage, n'a pas été connu de Kolbe, qui du moins n'en a fait aucune mention, et il paroît qu'il ne se trouve que fort avant dans les terres, ce qu'on peut inférer de la lettre de M. le gouverneur, que je reçus en mème temps, et où il est dit :

" J'ai encore remis audit capitaine deux petits ani" maux vivants, mâle et femelle, auxquels nous ne " pouvons cependant donner de nom, ni les rapporter " à aucune autre espèce, attendu qu'on me les a en" voyés pour la première fois, et de bien loin, des " déserts et montagnes de pierres de cette vaste con" Irée. Ils sont fort doux, gentils, et mangent de la " viande fraiche, cuite ou crue, des œufs crus et des " fourmis, quand ils peuvent en attraper. Je souhaite "que ces petits animaux arrivent en vie, puisque je " ne crois pas qu'on en ait encore vu en Europe de "pareils. "

Ce témoignage de M. Tulbagh est positif, et ce que dit auparavant M. Vosmaër est juste : j'y souscris avec plaisir; car, quoique j'aie eu cet animal vivant pendant long-temps, et que je l'aie décrit et fait représenter, je n'étois assuré ni de son nom, ni de son climat originaire, que par le rapport d'un marchand d'animaux, qui me dit l'avoir acheté en Hollande sous le nom de surikate, el qu'il venoit de Surinam. Ainsi nous dirons maintenant qu'il ne se trouve point à Surinam, ni dans les autres provinces de l'Amérique méridionale, mais en Afrique, dans les terres mon- 
lagneuses, au dessus du cap de Bonne-Espérance. Et à l'égard du nom, il ne fait rien à la chose, et nous changerons volontiers celui de surikate lorsque nous serons mieux informés.

\section{LE PHAL, ANGER.}

Didelphis Orientalis. L.

Cies animaux, qui nous ont été envoyés mâle et femelle sous le nom de rats de Surinam, ont beaucoup moins de rapports avec les rats qu'avec les animaux du même climat dont nous avons donné l'histoire sous les nouns de marmose et de cayopollin. On peut voir par la description très exacte qu'en a faite M. Daubenton combien ils sont éloignés des rats, surtout à l'intérieur. Nous avons done cru devoir rejeter cette dénomination de rats de Surinam, comme composée, et de plus comme mal appliquée : aucun naturaliste, aucun voyageur, n'ayant nommé ni indiqué cet animal, nous avons fait son nom, et nous l'avons tiré d'un caractère qui ne se trouve dans aucun autre animal : nous l'appelons phalanger, parce qu'il a les phalanges singulièrement conformées, et que de quatre doigts qui correspondent aux cinq ongles dont ses pieds de derrière sont armés, le premier est soudé avec son voisin, en sorte que ce double doigt fait la fourche, et ne se sépare qu'à la dernière phalange pour arriver aux deux ongles. Le ponce est séparé des 
autres doigts, et n'a point d'ongle à son extrémité. Ce dernier caractère, quoique remarquable, n'est point unique; le sarigue et la marmose ont le pouce de même : mais aucun n'a, comme celui-ci, les plalanges soudées.

II paroît quie ces animaux varient entre eux pour les coulenrs rlu poil, comme on le peut voir par les figures du mâle et de la femelle. Ils sont de la taille d'un pelit lapin ou d'un très gros rat, et sont rènarquables par l'excessive longueur de leur quene, l'allongement de leur museau, et la forme de leurs dents, gui seule suffiroit pour faire distinguer le phalanger de la marmose, du sarigue, des rats et de toutes les autres espèces d'animaux auxquelles on voudroit le rapporter.

* Nous étions mal informés lorsque nous avons dit que les animaux auxquels nous avons donné le nom de phalangers apparienoient au nouveau continent. Un marchand dont je les ai achetés me les avoit don. nés sous le nom de rats de Surinam; mais probablement il avoit été trompé lui-même. M. Pallas est le premier qui ait remarqué cette méprise, et nous sommes maintenant assurés que le phalanger se trouve dans les Indes méridionales et même dans les terres australes, comme à la Nouvelle-Hollande. Nous savons aussi qu'on n'en a jamais vu dans les terres de l'Amérique. M. Banks ${ }^{1}$ dit avec raison que je me suis

1. a Manks, parcourant la campagne, prit un animal de la classe"des opossum; c'étoil. une femelle, et il en prit en oulre deux petits : "il tronva quils, ressembloient beancoup au quadrupède décrit par „ M. de Buffon sous le nom de phalanger; mais ce n'est pas le même. n Cet auteur suppose que cette espèce est particulière à l'Amérique, 
trompé, et qu'il a trouvé dans la Nouvelle-Hollande un animal qui a tant de rapports avec le phalanger. qu'on doit les regarder comme deux espèces très voisines.

\section{LE GOQUALLIN.}

Sciurus variegatus. L.

J'A r reconnu que cet animal, qui nous a été envoyé d'Amérique sous le nom d'écureuil orangé, étoit le même que Fernandès a indiqué sous celui de quauhtcallotquapachli ou coztiocotequallin; mais comme ces mots de la langue mexicaine sont trop difficiles à prononcer pour nous, j'ai abrégé lé dernier, et j’en ai

" mais il s'est sûrement trompé en ce point; il est probable que le "phalanger est indigène des Indes orientales, puisque l'animal que "prit I. Banks avoit quelque analogie avec lui par la conformation " extraordinaire de ses pieds, en quoi il diffère de tous les autres qua"drupèdes. " (Voyage autour du monde, tomẹ IV, page 56. )

Je crois que cette critique est juste, et que le phalanger appartient en effet aux climats des Indes orientales et méridionalcs; mais, quoiqu'il ait quelque ressemblance avec les opossum ou sarigues, je n'ai pas dit qu'il fût du même genre ; j’ai au contraire assuré qu'il différoit de tous les sarigues, marmoses, et cayopollins par la conformation des pieds, qui une paroissoit unique dans cette espèce.

Ainsi je ne me suis pas trompé en avançant que le genre des opossum ou sarigues appartient au nouveau continent, et ne se trouve nulle part dans l'aneien. Au reste, l'éditeur du Voyage de M. Cook s'est certainement trompé lui-même en disant que l'animal trouvé par M. Banks éloit de la classe des opossum ou sarigaes; car le phalanger m'a point de poche sous le ventre. 
fait coquallin, qui sera dorénavant le nom de cet animal. Ce n'est point un écureuil, quoiqu'il lui ressemble assez par la figure et par le panache de la queue; car il en diffère non seulement par plusieurs caractères extérieurs, mais aussi par le naturel et les mœurs.

Le coquallin est beaucoup plus grand que l'écureuil : in duplam fere crescit magnitudinem, dit Fernandès. C'est un joli animal et très remarquable par ses couleurs : il a le ventre d'un beau jaune, et la tête aussi bien que le curps variés de blanc, de noir, de brun, et d'orangé. Il se couvre de sa queue comme l'écureuil; mais il n'a pas comme lui des pinceaux de poil à l'extrémité des oreilles. 11 ne monte pas sur les arbres; il habite, comme l'écureuil de terre que nous avons appelé le suisse, dans des trous et sous les racines des arbres; il y fait sa bauge et y élève ses pelits : il remplit aussi son domicile de grains et de fruits pour s'en nourrir pendant l'hiver; il est défiant et rusé, et même assez farouche pour ne jamais s'apprivoiser.

Il paroît que le coquallin ne se trouve que dans les parties méridionales de l'Amérique. Les écureuils blonds ou orangés des Indes orientales sont bien plus petits, et leurs couleurs sont uniformes; ce sont de vrais écureuils qui grimpent sur les arbres et y font leurs petits, au lieu que le coquallin et le suisse d'Amérique se tiennent sous terre comme les lapins, et n'ont d'autre rapport avec l'écureuil que de lui ressembler par la figure. 



$$
\frac{1}{2}
$$




\section{LES GERBOISES.}

Gerboise est un nom générique, que nous employons ici pour désigner des animaux remarquables par la très grande disproportion qui se trouve entre les jambes de derrière et celles de devant, celles-ci n'étant pas si grandes que les mains d'une taupe, et les autres ressemblant aux pieds d'un oiseau. Nous connoissons dans ce genre quatre espèces ou variétés bien distinctes : $1^{\circ}$ le tarsier, dont nous avons fait mention ci-devant, qui est certainement d'une espèce particulière, parce qu'il a les doigts faits comme ceux des singes, et qu'il en a cinq à chaque pied; $2^{\circ}$ le gerbo ${ }^{1}$ ou gerboise proprement dite, qui a les pieds faits comme les autres fissipèdes, quatre doigts aux pieds de devant, et trois à ceux de derrière; $3^{\circ}$ l'alagtaga ${ }^{2}$, dont les jambes sont comme celles du gerbo.

1. Mot dérivé de jerbuah ou jerboa, nom de cet animal en Arabie et que nous avons adopté.

2. Nom de cet animal chez les Tartares-Mongous, et que nous avons adopté. M. Messerschmid, qui a transmis ce nom, dit qu'il signifie animal qui ne peut marcher; cependant le mot alagtaga me paroît très voisin de letaga, qui, dans le même pays, désigne le polatouche ou écureuil-volant : ainsi je serois porté à croire qu'alagtaga, comme letaga, sont plutôt des noms génériques que spécifiques, et qu'ils désignent un anirnal qui vole, d'autant plus que Strahlenberg, cité par M. Gmelin au sujet de cet animal, l'appelle liève-volant.

Cuniculus seu lepus Indicus utias dictus. (Aldrov. de quad. digit. fig. pag. $39^{5}$.)

1 MM. Linnasus et Edwards ont rapporté au gerbo cette figure doì- 
mais qui a cinq doigts aux pieds de devant et trois a ceux de derrière, avec un éperon qui peuit passer pour un pouce ou quatrième doigt beaucoup plus court que les autres; $4^{\circ}$ le daman Israël ou agneau d'Israël, qui a quatre doigts aux pieds de devant et cinq à ceux de derrière, qui pourroit bien être le même animal que M. Linnæus a désigné par la dénomination de mus longipes ${ }^{1}$.

Le gerbo (Mus sagitta. L.) a la tête faite à peu près comme celle du lapin, mais il a les yeux plus grands et les oreilles plus courtes, quoique hautes et aumples relativement à sa taille. Il a le nez couleur de chair et sans poil, le museau court et épais, l'ou-

née par Aldrovande; mais elle me paroît convenir un peu mieux ì l'alagtaga : l'éperon ou quatrième doigt des pieds de derrière y est bien marqué, et c'est par ce caractère que l'alagtaga diffère du gerbo, qui n'a que trois doigts sans apparence d'un quatrième.

$2^{\circ}$ Mldrovande a fait une faute en appliquant à cet animal le nom d'utias : ce mot est américain, et n'a jamais été employé que pour désigner un petit animal que les Espagnols trouvèrent à Saint-Domingue lorsqu'ils y arrivèreut; et, depuis. quelques auteurs l'ont appliqué au cochon d'Inde : mais janais il n'a pu désigner ni l'alagtaga ni le gerbo. Je crois que ce mot utias, qu'on doit prononcer outias, vient de coutias, nom que quelques auteurs donnent à l'acouti ou agouti, et que par conséquent l'utias ne désigne pas un autre animal que l'agouli, qui étoit et qui est encore naturel à l'ile de Saint-Domingue, et qu'on y a trouvé lorsqu'on en fit la découverte. "Il y a eu de lout - temps dans les Antilles, dit l'auteur de l'Histoire des Antilles, quel- ques bêtes à quatre pieds, telles que l'opossum (sarigue), le javaris n (pecari), le tatou, l'acouti, et le rat musqué (pilori). "

1. Longipes. Mus cauda elongata vestita, palmis tetradactylis, plantis pentadactylis, femoribus longissimis. (Linnæus, Syst. nat. édit. X, page 62.)

Le mot femoribus est ici mal appliqué : ce ne sont pas les cuisses ni mêtne les jambes, mais les premiers os du pied, les métatarses, que ces animaux ont très longs. 
verlure de la gueule très petite, la mâchoire supérieure fort ample, l'inférieure étroite et courte; les dents comme celles du lapin; les moustaches autour de la gueule, composées de longs poils noirs et blancs. Les pieds de devant sont très courts et ne touchent jamais la terre : cet animal ne s'en sert que comme de mains pour porter à sa gueule. Cies mains portent quatre doigts munis d'ongles, et le rudiment d'un cinquième doigt sans ongle. Les pieds de derrière n'ont que trois doigts, dont celui du milieu est un peu plus long que les deux autres, et tous trois garnis d'ongles. La queue est trois fois plus longue que le corps; elle est couverte de petits poils roides, de la même couleur que ceux du dos, et au bout elle est garnie de poils plus longs , plus doux, plus touflus, qui forment une espèce de houppe noire au commencement et blanche à l'extrémité. Les jambes sont nues et de couleur de chair, aussi bien que le nez et les oreilles. Le dessus de la tête et le dos sont couverts d'un poil roussâtre; les flancs, le dessous de la tête, la gorge, le ventre, et le dedans des cuisses sont blancs; il y a au bas des reins et près de la queue une grande bande noire transversale en forme de croissant.

L'alaglaga (Mus jaculus. L.) est plus petit qu'un lapin; il a le corps plus court : ses oreilles sont longues, larges, nues, minces, transparentes, et parsemées de vaisseaux sanguins très apparents; la mâchoire supérieure est beaucoup plus ample que linférieure, mais obtuse et assez large à l'extrémité : il y a de grandes moustaches autour de la gueule; les dents sont comme clles des rats; les yeux grands, 
l'iris et la paupière bruns : le corps est étroit en avant, fort large et presque rond en arrière; la quene très longue, et moins grosse qu'un petit doigt : elle est couverte, sur plus des deux tiers de sa longueur, de poils courts et rudes; sur le dernier tiers ils sont plus longs, et encore beaucoup plus longs, plus touffus, et plus doux vers le bout, où ils forment une espèce de touffe noire au commencement, et blanche à l'extrémité. Les pieds de devant sont très courts; ils ont cinq doigts : ceux de derrière, qui sont trìs longs, n'en ont que quatre, dont trois sont situés en avant, et le quatrième est à un pouce de distance des autres : tous ces doigts sont garnis d'ongles plus courts lans ceux de devant, et un peu plus longs dans ceux de derrière. Le poil de cet animal est doux et assez long, fauve sur le dos, blanc sous le ventre.

lion voit, en comparant ces deux descriptions, dont la première est tirée d'Edwards et d'Hasselquist, ef la seconde de Gmelin, que ces animaux se ressemblent presque autant qu'il est possible; le gerbo est seulement plus petit que l'alagtaga, et n'a que quatre doigts aux pieds de devant, et trois à ceux de derrière, sans éperon, au lieu que celui-ci en a cinq aux pieds de devant, et quatre, c'est-à-dire trois grands et un éperon, à ceux de derrière : mais je suis très porté à croire que cette différence n'est pas constante ; car le docteur Shaw, qui a donné la description et la figure d'un gerbo de Barbarie, le représente avec cet éperon ou quatrième doigt aux pieds de derrière; et $\mathrm{M}$. Edwards remarque qu'il a soigneusement observé les deux gerbos qu'il a vus en Angleterre, et qu'il ue leur a pas trouvé cet éperon : ainsi ce carac- 
tère qui paroîtroil distinguer spécifiquement le gerbo et l'alagtaga, n'étant pas constant, devient nul, eł marque plutôt l'illentité que la diversité d'espèce. La diffírence de grandeur ne prouve pas non plus que ce soient deux espèces différentes; il se peut que MM. Edwards et Hasselquist n'aient décrit que de jeunes gerbos, et M. Gmelin un vieux alagtaga. Il n'y a que deux choses qui me laissent quelque doute : la proporlion de la queue, qui est beaucoup plus grande dans le gerbo que dans l'alagtaga, et la différence du climat où ils se trouvent. Le gerbo est commun en Circassie, en Égypte, en Barbarie, en Arabie, et l'alaglaga en Tartarie, sur le Wolga, et jusqu'en Sibérie. Il est rare que le même animal habite des climats aussi différents; et lorsque cela arrive, l'espèce subit de grandes variétés : c'est aussi ce que nous présumons être arrivé à celle du gerbo, dont l'alaytaga, malgré ses différences, ne nous paroît être qu'une variété.

Ces pelits animaux cachent ordinairement leurs mains ou pieds de devant dans leur poil; en sorte qu'on diroil qu'ils n'ont d'autres pieds que ceux de derrière. Pour se transporter d'un lieu à un autre, ils ne marchent pas, c'est-à-dire qu'ils n'avancent pas les pieds l'un après l'autre; mais ils sautent très lígèrement et très vite, à trois ou quatre pieds de distance, et toujours debout, comme des oiseaux. En repos, ils sont assis sur leurs genoux; ils ne dorment que le jour, et jamais la nuit. Ils mangent du grain et des herbes comme les lièvres. Ils sont d'un naturel assez doux, et néanmoins ils ne s'apprivoisent que jusquài un certain point. Ils se creusent des terriers 
comme les lapins, et en beaucoup moins de temps; ils y font un magasin d'herbes sur la fin de l'úté, et dans les pays froids ils y passent l'hiver.

Comme nous n'arons pas été à portée de faire la dissection de cet animal, et que M. Gmelin est le seul qui ait parlé de la conformation de ses parties intérieures, nous donnons ici ses observations en attendant quion en ait de plus précises et de plus étendues ${ }^{1}$.

A l'égard du daman ou agneau d'Israël (Hyrax syriacus. L.), qui nous paroît être du genre des gerboises, parce qu'il a comme elles les jambes de devant très courtes en comparaison de celles de derrière, nous ne pouvons mieux faire, ne l'ayant jamais vu, que de citer ce qu'en dil le docteur Shaw, qui étoit à portée de le comparer avec le gerbo, et qui en parle comme de deux espèces différentes. "Le daman israël, dit cet auteur, est aussi un animal du mont Liban, mais également commun dans la Syrie et dans la Phé-

1. "OEsophagus, uti in lepore et cuniculo, medio ventriculo inse" vilur : intestinum coecum breve admodum, sed amplum est, in pro" ecssum vermiformem, duos pollices lougum, abieus. Choledochus " mox infra pylorum intestinum subit. Vesica urinaria citrina aqua "plena. Uteri nulla plane distinctio ; vagina cnim, canalis instar, sine " ullis artificiis in pubem usque protensa, in duo mox cornua dividi") lur, quae, ubi ovariis appropinquant, multas inflexiones faciunt $\mathrm{ct}$ " in ovariis terminantur. Penem masculus habet satis magnum, cui " circa vesicæ urinaria collum vesicula seminales, unciam cum dimi" dio longæ, graciles et extremitatibus intortæ adjacent. Foramen aut " sinus quosdan inter anum et penem, aut inter anum et rulvam, nulio modo potui disccrnere, licet quasvis in indagatione ista caute"las adhibuerim... Cunicali Americani, porcelli pilis ei voce. Marc- grav. Fabrica internarum partium ab hocanimali non nultum ablu"dunt. n 
nicie. C'est une bête innocente qui ne fait point de mal, et qui ressemble pour la taille et pour la figure au lapin ordinaire, ses dents de devant étant aussi disposées de la même manière; seulement il est plus brun, et il ales yeux plus petits et la tête plus pointue; ses pieds de devant sont courts et ceux de derrière longs, dans la même proportion que ceux du jerboa (gerbo). Quoiqu'il se cache quelquefois dans la terre, sa retraite ordinaire est dans les trous et fentes de rochers; ce qui me fait croire, continue M. Shaw, que c'est cet animal plutôt que le jerboa (gerbo) qu'on doit prendre pour le saphan de l'ḱcriture : personne n'a pu me dire d'où vient le nom inoderne de daman Israël, qui signifie agneau d'Isrä̈l. "Prosper Alpin, qui avoit indiqué cet animal avant le docteur Shaw, dit que sa chair est excellente à manger, et qu'il est plus gros que notre lapin d'Europe : mais ce dernier fait paroît douteux; car le docteur Shaw l'a retranché du passage de Prosper Alpin, cqu'il cite au reste en entier.

* Nous donnons ici (planche 48) la figure de la gerboise (gerbo), qui manquoit dans l'article précédent, où nous avons donné une courte histoire des différentes espèces de gerboises, et une description particulière de celle-ci, tirée d'Edwards et d'Hasselquist. Les petites différences qu'on pourroit y remarquer ne feroient tout au plus qu'une légère variété dans celte espèce, dont les couleurs et la longueur des pattes de devant et des ongles ne paroissent pas constantes.

Il existe dans le désert de Barca une gerboise différente de celle-ci en ce qu'elle a le corps encore plus 
mince, les oreilles plus longues, arrondies, et à peu près également larges du haut en bas; les ongles des quatre pieds beaucoup plus courts, et les couleurs en général moins foncées; la bande sur les cuisses moins marquée; les talons noirs; la pointe du museau beaucoup plus aplatie. On voit que ces disconvenances sont encore assez légères, et qu'on peut les regarder comme de simples variétés.

Les gerboises se trouvent dans tous les climats de l'Afrique, depuis la Barbarie jusqu'au cap de BonneEspérance; on en voit aussi en Arabie et dans plusicurs autres contrées de l'Asie : mais il paroît qu'il y en a de grandeur très différente, et il est assez étonnant que, dans ces animaux à longues jambes, il s'en trouve de vingt et même de cent fois plus gros que les petites gerboises dont nous avons parlé.

"J'ai vu, dit M. le vicomte de Querhoent, à la ménagerie du Cap, un animal pris dans le pays, qu'on nomme lière sauteur. Il est de la grandeur du lapin d'Europe ; il a la tête à peu près comme lui, les oreilles au moins de la même longueur, les pattes de devant très courtes et très petites : il s'en sert pour porter à sa gueule, et je ne crois pas qu'elles lui servent beaucoup à marcher; il les tient ordinairement ramassées dans son long poil, qui les recouvre entièrement : les pattes de derrière sont grandes et grosses : les doigts du pied, au nombre de quatre, sont longs et séparés; la queue est de la longueur du corps au moins, et couverte de longs poils couchés; le poil du corps est jaunâtre; le bout des oreilles et celui de la queue sont de la même couleur; les yeux sont noirs, grands, et saillants. On le nourrissoit de feuilles de 
laitue. 'Il aime beaucoup à ronger; on lui metloit exprès dans sa cage de pelits morceaux de bois pour l'amuser."

M. Forster nous a communiqué un dessin de cette grande gerboise ou lièvre sauteur du Cap, que nous donnons ici. Ce dessin étoit accompagné de la notice suivante :

"Cette gerboise, dit-il, a cinq doigts aux pieds de devant, et quatre à ceux de derrière: les ongles du devant sont noirs, longs, minces, et courbés; ceux des jambes de derrière sont bruns, gros, courts, de figure conique, un peu courbés vers l'extrémité : l'œil est noir et fort gros; le nez et les naseaux sont d'un brun roux; les oreilles sont grandes, lisses, nues en dedans, et couvertes en dehors d'un petit poil court qui est couleur d'ardoise. La tête ressemble assez à celle des petites gerboises; il y a des moustaches autour de la gueule et aux angles des yeux. Les jambes, ou plutôt les bras de devant, sont très courts, et les mains fort petites; les jambes de derrière, au contraire, sont très grosses, et les pieds excessivement longs. La quene, qui est aussi fort longue et fort chargée de poil, paroît mince à sa naissance, et fort grosse à son extrémité ; clle est d'un fauve foncé sur la plus grande partie de sa longueur, et d'un brun minime vers le bout. Les jambes et les pieds sont d'un fauve pâle mêlé de gris; la couleur du corps et de la tête d'un jaune pâle presque blanc; les cuisses et le dessous du corps sont plus jaunes; tout le dessus du corps, ainsi que l'extrémité de la mâchoire, le dessus du nez, les mains, ont une teinte de fauve; le der- 
rière de la tête est couvert de grands poils mêlés de noir, de gris, et de fauve.

Au reste, nous pensons que cette gerboise du Cap, décrite par M. de Querhoent et par M. Forster, est la même que celle dont M. Allamand a donné l'histoire et la figure (planche 15 de l'Histoire naturelle, édition de Hollande ).

II nous paroît aussi que cet animal dont nous avons donné la description, sous le nom de tarsier, est du même genre que les gerboises, et qu'il appartient à l'ancien continent. Aucune espèce de gerhoises, grandes et petites, ne se trouvant qu'en Afrique et en Asie, nous ne pr avons guère douter que le tarsier ne soit de l'une or de l'autre de ces parties du monde.

J'ai vu plusieurs figures de gerboises dessinées d'après des pièces antiques, et surtout d'après une ancienne médaille de Cyrène, qui portoit en revers une gerboise, dont la figure ne ressemble point à celle de la gerboise dont le docteur Shaw a donné la description sous le nom de daman-israël; car elle en diffère beaucoup par la grandeur, par la forme de la tête, par les yeux, et par plusieurs autres caractères. II est aisé de démontrer que le docteur Shaw s'est trompé en rapportant le daman-israël à cette espèce de gerboise. Celle qui est dessinée sur la médaille de Cyrène est une vraie gerboise, et n'a nul rapport avec le daman. Dans d'autres gravures tirées des marbres anliques d'Oxford, j'ai vu la figure de quelques gerboises, dont les unes avoient les pattes de devant, et surtout les oreilles, beaucoup plus longues que celles dont nous donnons ici les figures. Mais, an 
resle, ces grerboises gravées sur des marbres antiques n' sont pas assez bien représentées pour pouvoir les rapporter aux espèces que nous venons d'indiquer.

\section{SUR LA GERBOISE OU GERBO,}

Par M. le professeur Altamand.

* Dans l'histoire des gerboises, M. de Buffon distingue qualre espèces différentes de ces animaux : mais il n'en a vu qu'une, qui est celle du tarsier; aussi est-ce la seule dont il a donné la figure. Ce qüil a dit des trois autres est liré des auteurs qui en ont parlé avant lui : il a emprunté entre autres la descriplion du gerbo qui appartient à la seconde espèce, de MM. Edwards et Hasšelquist. Cet animal est actuellement vivant à Amsterdam, chez le docteur Klockner, qui nous a permis de le faire dessiner, et qui a bien voulu nous communiquer ce qu'il a offert de plus remarquable. C'est en faisant usage de ses observations que nous allons ajouter quelques particularités à celles que M. de Buffon en a rapportées.

La description que celui-ci en a faite est très exacte. On retrouve dans le gerbo de $M$. Klockner tout ce qu'il en a dit, à l'exception de cette grande bande noire transversale en forme de croissant qui est au bas des reins, près de la queue : c'cst une femelle, et peut-être cette bande ne se voit-elle que sur le mâle; ce qui me porte à le croire, c'est que j'ai mis dans le cabinel de l'académie de Leyde la peau d'un autre gerbo femelle, où cette bande ne paroît pas non plus. 
M. Klockner a reçu cette gerboise de Tunis: la caisse dans laquelle elle lui a été apportée étoit garnie en dedans de fer-blanc; elle en avoit enlevé avec ses dents quelques pièces, et en avoit rongé le bois en différents endroits. Elle fạit la même chose dans la cage où elle est actuellement gardée; elle n'aime pas à être renfermée : cependant elle n'est point farouche; car elle souffre qu'on la tire de son nid et qu'on l'y remette avec la main nue, sans qu'elle morde jamais. Au reste, elle ne s'apprivoise que jusqu'à un certain point, comme l'a remarqué $\mathbf{M}$. de Buffon; car elle ne paroît mettre aucune différence entre celui qui lui donne à manger et des étrangers. Lorsqu'elle est en repos, elle est assise sur ses genoux, et ses jambes de derrière étendúes sous le ventre atteignent presque ses jambes de devant, en formant une espèce d'arc de cercle : sa queue alors est posée le long de son corps; dans cette attitude, elle recueille les grains de blé ou les pois dont elle se nourrit : c'est avec ses pattes de devant qu'elle les porte à sa bouche, et cela si promptement, qu'on a peine à èn suivre de l'oeil les mouvements; elle porte chaque grain à sa bouche, et en rejette l'écorce pour ne manger que l'intérieur.

Quand elle se meut, elle ne marche pas en avancant un pied devant l'autre, mais en sautant comme une sauterelle, et en s'appuyant uniquement sur l'extrémité des doigts de ses pieds de derrière : alors elle tient ses pieds de devant si bien appliqués contre sa poitrine, qu'il semble qu'elle n'en a point. La figure qu'en offre la planche la représente dans l'attitude où elle est quand elle se prépare à sauter, et il est diffi- 
cile de concevoir comment elle peut se soutenir; quelquefois même son corps forme, avec ses jambes, un angle plus aigu encore : mais, pour l'ordinaire, elle se tient dans une situation qui approche plus de la perpendiculaire. Si on l'épouvante, elle saute à sept ou huit pieds de distance.

Lorsqu'elle veut grimper sur une hauteur, elle fait usage de ses quatre pieds; mais lorsqu'il faut descendre dans un creux, elle traîne après soi ses jambes de derrière sans s'en servir, et elle avance en s'aidant uniquement des pieds de devant.

Il semble que la lumière incommode cet animal : aussi dort-il pendant tout le jour, et il faut qu'il soit bien pressé par la faim pour qu'il lui arrive de manger quand le soleil luit encore : mais, dès qu'il commence à faire obscur, il se réveille, et durant toute la nuit il est continuellement en mouvement, et c'est alors seulement qu'il mange. Quand le jour paroît, il rassemble en tas le sable qui est dispersé dans sa cage; il met par dessus le coton qui lui sert de lit, et qui est fort dérangé par le mouvement qu'il vient de se donner; et, après avoir raccommodé son nid, il s'y fourre jusqu'à la nuit suivante.

Pendant le voyage qu'il a fait de Tunis à Amsterdam, et qui a été de quelques mois, on l'a nourri de gruau ou de biscuit sec sans lui donner à boire. Dès qu'il fut arrivé, le premier soin de M. Klockner fut de lui présenter un morceau de pain trempé dans l'eau, ne doutant pas qu'il ne fût fort altéré; mais il ne voulut point $\mathrm{y}$ toucher, et il préféra un biscuit dur : cependant M. Klockner, ne soupçonnant pas qu'il pût se passer d'eau, lui donna des pois verts et BUFFON, XVI. 
des grains de blé qui en étoient imbibés; mais ce fut inutilcment, il n'en goûta point : il fallut en revenir à ne lui donner que du manger sec sans ean; et jusqu’à présent, depuis une année et demie, il s'en est bien trouvé.

Quelques auteurs ont rangé cet animal parmi les lapins, auxquels il ressemble par la couleur et la finesse de son poil, et par la longueur de ses oreilles; d'antres l'ont pris pour un rat, parce qu'il est à peu près de la même grandeur: mais il n'est ni lapin ni rat: l'extrême disproportion qu'il y a entre ses jambes de devant et celles de derrière, et l'excessive longueur de sa queve, le distinguent des uns et des autres. II forme un genre à part et même très singulier avec l'alagtaga, dont M. Gmelin nous a donné la description et la figure, mais qui approche si fort de notre gerbo, qu'on ne peut le regarder, avec M. de Buffon, que comme une variété de la même espèce.

Il ne faut pas oublier que le gerbo a autour de la bouche une moustache composée de poils assez roides parmi lesquels il y en a un de côté d'une longuem extraordinaire, puisqu'il est long de trois pouces.

Je me suis servi de la peau bourrée qui est dans le cabinet de l'académie de Leyde, pour prendre les dimensions que voici :

Longueur du corps entier, mesurée en ligne droite,

depuis le bout du museau jusqu’à l'anus: . . . . $6 \begin{array}{cc}6 & 7\end{array}$

Longueur des oreilles. ........... " . . . 10

Distance entre l'oreille et l'œil. . . . . . . " " 6

Longueur de l'oeil d'un angle à l'autre. . . . . " " $6 \frac{1}{2}$

Ouverture de l'oil. . . . . . . . . . . ". " " 5

Distance entre l'oil et le bout du museau... . " : 1 "

Circonférence du bout du inusear. . . . . . . 2 24 
Circonférence de la tête cutre les oreilles et les

yeux.

Circonférence du corps prise derrière les jambes de devant.. . . . . . . . . . 5 . 5

Circonférence prise devant les jambes de derrière. " $6 \quad 6 \quad$,

Longueur des jambas de devant, depuis l'extrémilé des duigts jusquà la poitrine. ...... " 10

Longueur des jambes de derrière, depuis l'extrémité des pieds jusqüä l'abdomen. ...... 50 Longueur de la queue.. . . . . . . . . 8 " 8

Ces dimensions sout celles du gerbo dont jai la dépouille, et elles sont à peu près celles du gerbo de M. le docteur Klockner, et de presque lous ceux qui ont été décrits par les naturalistes; il y en a cependant qui sont heaucoup plus grands. Prosper Alpin, en parlant du daman ou agneau d'Jsraël, que M. de Buffon range, avec raison, an nombre des gerboises, avoit déjà dit que cet animal est plus gros que notre lapin d'Europe; ce qui a paru doutenx au docteur. Shaw et même à M. de Buffon. A présent nous sommes certains que cet auteur n'a point exagóré. Toute l'Europe sait que MM. Banks et Solander, animés d'un zèle, je dirois presque héroïque, pour avancer nos connois sances dans l'astronomie et dans l'histoire naturelle, ont entrepris le lour du monde: à leur retom en An gleterre, ils ont fait voir deux gerbos qui surpassent en grosseur nos plus grands lièvres; en courant sur leurs deux pieds de derrière, ils meitent en défaut les meilleurs chiens. Ce n'est la qu une des moindres curiosités qu’ils ont apportées avec eux; ils en ont fait une ample collection, qui leur fournira de quoi remplir un millier de planches. Oa prépare, par ordre de l'amiraulé d'Angleterre, une relation de leurvoyage: 
on y verra des particularités très intéressantes sur un pays des terres australes, que nous ne connoissions jusqu'à présent que de nom; je veux parler de la Nouvelle-Zélande, etc.

\section{Par le même.}

* Dans l'histoire que j'ai donnée du gerbo, j’ai remarqué que Prosper Alpin a eu raison de dire que le daman, qui appartient au genre des gerboises ${ }^{1}$, étoit plus gros que notre lapin d'Europe. J'ai avancé cela, fondé sur ce qu'on m'avoit écrit d'Angleterre, que M. Banks, revenu de son voyage autour du monde, avoit apporté un de ces animaux qui surpassoit en grosseur nos plus grands lièvres. A présent je suis en état de dire quelque chose de plus positif sur cet animal, dont M. Banks a eu la bonté de me faire voir la dépnuille, et dont nous avons la description et la figure dans la relation du voyage de M. le capitaine Cook. Il diffère de toutes les espèces de gerboises décrites jusqu'à présent, non seulement par sa grandeur, qui approche de celle d'une brebis, mais encore par le nombre ou l'arrangement de ses doigts. Parkinson, qui étoit parti avec M. Banks en qualité de son dessinateur, et dont on a publié les Mémoires, nous apprend qu'il avoit cinq doigts aux pieds de devant, armés d'ongles crochus, et quatre à ceux de derrière;

1. Le daman du docteur Shaw appartient en effet augenre des gerhoises; mais nous verrons, comme nous venons d'en avertir, les raisons qui nous persuadent que le docteur Shaw a mal appliqué à cet animal le nom de daman. 
comme c'étoit un jeune qui n'étoit pas encore parvenu à toute sa grandeur, il ne pesoit que trente-huit livres; sa tête, son cou et ses épaules étoient fort petits en comparaison des autres parties de son corps; ses jambes de devant avoient huit pouces de longueur, et celles de derrière en avoient vingt-deux; il avançoit en faisant de très grands sauts et en se tenant debout ; il tenoit ses jambes de devant appliquées à sa poitrine; et elles paroissoient ne lui servir qu'à creuser la terre; sa queue étoit épaisse à son origine, et son diamètre alloit en diminuant jusqu’à son extrémité; tout son corps étoit couvert d'un poil gris de souris foncé, excepté à la tête et aux oreilles, qui avoient quelque ressemblance à celles d'un lièvre.

Par cette description, on voit que cet animal n'est pas le gerbo qui a quatre doigts aux pieds de devant et trois à ceux de derrière, ni le daman ou agneau d'Israël, qui a quatre doigts aux pieds de devant et cinq à ceux de derrière ${ }^{1}$, avec lequel par conséquent je n'aurois pas dû le confondre: l'alagtaga est l'espèce de gerboises qui en approche le plus par le nombre des doigts; il en a cinq aux pieds de devant et trois à ceux de derrière, avec un éperon qui peut passer pour un pouce ou quatrième doigt, comme le remarque M. de Buffon: mais la différence de grandeur, la distance des lieux et la diversité du climat où ces deux animaux se trouvent, ne permettent guère do les regarder comme une senle et même espèce. Celui que M. Banks nous a fait connoître est habitant de la

1. Cela est vrai du prétendu daman du docleur Shaw, qui est une gerboise, mais faux à l'égard du véritable daman, qui n'a que trois loigts aux pieds de derrière. 
Nouvelle-Hollande, et l'alagtaga est commun en Tartarie et sur le Wolgra.

Notis avons actuellement en Hollande un animal vivant, qui pourroit être le même que celui de la Nouvelle-Hollande : on en jugrera par la description suivante, dont je suis redevable à M. le docteur Klockner, à qui j’ai dû aussi celle que j'ai donnée ci-devant du petit gerbo.

Cet animal a été apporté du cap de Bonne-Espérance par le sieur Holst, à qui il appartient; il a été pris sur une montagne nommée Snenwberg, située à une très grande distance du Cap et fort avant dans les terres; les paysans hollandois lui donnent le nom de aerdmannetje, de springendehaas ou lièvre sautant; il est de la grandeur d'un lièvre ou d'un lapin; son pelage est de couleur fauve par le haut, mais de couleur de cendré sur la peau, et entreınêlé de quelques poils plus longs, dont la pointe est noire; sa tête est fort courte, mais large et plate entre les oreilles, et elle se termine par un museau obtus qui a un fort petit nez; sa mâchoire supérieure est fort ample et cache l'inférieure. qui est très courte et petite; il n'est point de quadrupède connu qui ait l'ouverture de la guenle si en arrière au dessous de la tête.

Les oreilles sont d'un tiers plus courles que celles du lapin; elles sont fort minces et transparentes au grand jour; leur partie supérieure est noirâtre, l'inférieure est de conleur de chair et plus transparente que la partie supérieure. Il a de grands yeux à fleur de tête, d'un brun tirant sur le noir; ses paupières sont garnies de cils et surmontées de cinq ou six poils très longs. Chaque mâchoire est garnie de deux dents 
incisives très fortes; celles de la mâchoire supérieure ne sont pas si longues que celles de la mâchoire inférieure : la lè vre d'en haut est garnie d'une mousitache composée de longs poils.

Les pieds de devant sont petits, courts, et situés tout près du cou : ils ont chacun cinq doigts aus.si très courls, placés sur la même ligne; ils sont armés d'ongles crochus, de deux tiers plus grands que les dloigts mêmes; il y a au dessous une éminence charnue sur laquelle ces ongles reposent. Les deux jambes de derrière sont plus grandes que celles de devant : les pieds ont quatre doigts, dont les denx intérieurs sont plus courts que le troisième, qui est un tiers plus grand que l'extérieur; ils sont tous garnis d'ongles, clont le dos est élevé, et qui sont concaves en dessous.

Le corps est étroit en avant et un peu plus yros en arrière; la queue est aussi longue que le corps; les deux tiers en sont couverts de longs poils fauves, et l'autre tiers de poils noirs.

Comme les autres sortes de gerboises, il ne se sert que de ses pieds de derrière pour marcher, ou, pour parler juste, pour sauter : aussi ces pieds sont-ils très forts; et si on le prend par la queue, il en frappe avec beaucoup de violence. On n’a pu déterininer la longueur de ses plus grands sants, parce qu'il ne peut pas exercer sa force dans le petit appartement où il est renfermé : dans l'état de lil'zerté, on dit que ces arimaux font des sauts de vingit à trente pieds.

Son cri est une espèce de grognement. Quand il mange, il s'assied en étendant horizontalement ses grandes jambes et en courbant son dos. Il se sert de ses pieds de devant comme de naaius pour porter sa 
nourriture à sa gueule : il s'en sert ausși pour creuser l'a terre; ce qu'il fait avec tant de promptitude, qu'er peu de minutes il peut s'y enfoncer tout-àfait.

Sa nourriture ordinaire est du pain, des racines, du blé, etc.

Quland il dort, il prend une attitude singulière; il est asisis avec les genoux étendus; il met sa tête à peu près entre ses jambes de derrière, et avec ses deux pied:; de devant il tient ses oreilles appliquées sur ses yeux : il semble ainsi protéger sa tête par ses mains. C'est pendant le jour qu'il dort, et pendant la nuit il est ordinairement éveillé.

Par cette description on voit que cet animal doit être rangé dans la classe des gerboises décrites par M. de Buffon, mais qu'il en diffère cependant beaucoup, tant par sa grandeur que par le nombre de ses doigts. Nous en donnons ici la figure, qui, quoiqu'elle ait beaucoup de rapport avec celle que nous avons donnée du gerbo, en diffère cependant assez pour qu'on ne puisse pas les confondre : nous avons fait graver, au bas de la planche, les pieds de cet animal, pour qu'on comprenne mieux ce que nous en avons dit.

S’il est le même animal que celui qui a été décrit dans la relation du voyage du capitaine Cook, comme il y a grande apparence, la figure qui s'en trouve dans l'ouvrage anglois et dans la traduction françoise n'est pas exacte; la tête en est trop longue; ses jambes de devant ne sont jamais dans la situation où elles sont représentées comme pendantes vers le bas : le nôtre les tient loujours appliquées à sa poitrine, de façora 
que ses ongles sont placés immédiatement sous sa mâchoire inférieure; situation qui s'accorde avec celle que leur donne l'auteur anglois, mais qui a été mal exprimée par le dessinateur et par le graveur.

Voici les dimensions de notre grand gerbo, qui feront mieux connoître combien il diffère de toutes les autres espèces décrites.

Longueur du corps, mesurée en ligne droite, de-

pieds. pouc. lign.

puis le bout du museau jusqu'à l'origine de la

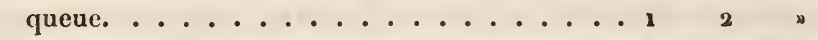

Longueur des oreilles. ............ 29

Distance entre les yeux.................. 2

Longueur de l'oeil d'un angle à l'autre. ...... $1{ }_{1} 1$

Ouverture de l'œil. ............ „ 9

Girconférence du corps prise derrière les jambes de devant. .................. 11"

Circonférence prise devant les jambes de derrière. 1 " 2

Hauteur des jambes de devant, depuis l'extrémité des ongles jusqu’à la poitrine......... 3 . 3

Longueur des jambes de derrière, depuis l'extrémité des pieds jusqu'à l'abdomen. ...... 899

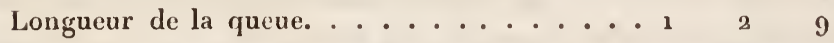

En comparant ces descriptions de M. Allamand, et en résumarit les observations que l'on vient de lire, nous trouverons dans ce genre des gerboises quatre espèces bien distinctement connues : $1^{\circ}$ la gerboise ou gerbo d'Edwards, d'Hasselquist, et de M. Allamand, dont nous avons donné la description, et à laquelle nous laissons simplement le nom de gerboisa, en persistant à lui rapporter l'alaggtaga, et en lui rapportant encore, comme simple variété, la gerboise de Barca de M. le chevalier Bruce; $2^{\circ}$ notre tarsier, qui est bien du genre de la gerboise, et même de sa tailte, mais qui néanmoins forme une espèce différente, 
puisqu'il a cinq doigts à tous les pieds; $3^{\circ}$ la grande gerboise ou liève sauteur du Cap, que nous venons de reconnoître dans les descriptions de MMI. de Querhoent, Forster, et Allamand; $4^{\circ}$ la très grande gerboise de la Nouvelle-Hollande, appelée kanguroo par les naturels du pays : elle approche de la grosseur d'une brebis, et par conséquent est d'une espèce beaucoup plus forte que celle de notre grande gerboise ou lièvre sauteur du Cap, quoique M. Allamand semble les rapporter l'une à l'autre. Nous n'avons pas cru devoir copier la figure de cette gerboise, donnée dans le premier Voyage du capitaine Cook, parce qu'elle nous paroît trop défectueuse : mais nous devons rapporter ici ce que ce célèbre navigateur a dit de ce singulier animal, qui, jusqu'à ce jour, ne s'est trouvé nulle part que dans le continent de la Nouvelle-Hollande.

"Comme je me promenois le matin à peu de distance du vaisseau, dit-il (à la baie d'Endeavour, côte de la Nouvelle-Hollande), je vis un des animaux que les gens de l'équipage m'aroient lécrits si souvent; il étoit d'une légère couleur de souris, et ressembloit beaucoup, par la grosseur et la figure, à un lévrier; et je l'aurois en effet pris pour un chien sauvage, si, au lieu de courir, il n'avoit pas sauté comme un lièvre ou un daim.... M. Banks, qui vit imparfaitement cet animal, pensa que son espèce éloit encore inconnue.... Un des jours suivants, comme nos gens partoient au premier crépuscule du matin pour aller chercher du gibier, ils virent quatre de ces animaux, dơnt deux furent très bien chassés par le lévrier de II. Banks; mais ils le laissèrent bientòt derrière, en 
sautant par dessus l'herbe longue et épaisse qui empêchoit le chien de courir. On observa que ces animaux ne marchoient pas sur leurs quatre jambes. mais qu'ils sautoient sur les deux de derrière ${ }^{1}$, comme le gerbua ou mus jaculus... Enfin M. Gore, mon lieutenant, faisant, peu de jours après, une promenade dans l'intérieur du pays avec son fusil, eut le bonheur de tuer un de ces quadrupèdes qui avoient été si souvent l'objet de nos spéculations. Cet animal n'a pas assez de rapport avec aucun autre déjà connu, pour qu'on puisse en, faire la comparaison : sa figure est très analogue à celle du gerbo, à qui il ressemble aussi par ses mouvements; mais sa grosseur est fort differente, le gerbo étant de la taille d'un rat ordinaire, et cet animal, parvenu à son entière croissance, de celle d'un mouton. Celui que tua mon lieutenant étoit jeune; et, comme il n'avoit pas encore pris tout son accroissement, il ne pesoit que trente-huit livres. La lête, le con, et les épaules sont très petits en proportion des autres parties du corps. La queve est presque aussi longue que le corps; elle est épaisse à sa naissance, et elle se termine en pointe à l'extrémité. Les jambes de devant n'ont que huil pouces de long, et celles de derrière en ont vingt-deux; it matche par sauts et par bonds; il tient alor's la tête droite, et ses pas sont fort longs; il replie ses jambes de devant tout près de la poitrine, et il ne parôit s'en servir que pour creuser la terre. La peau est converte d'un poil court, gris ou couleur de souris foncé; il faut en

1. Le traducteur dit les deux de devant; inais e'est évidemment unt faute, comme le prouve ce qui suit. 
excepter la tête et les oreilles, qui ont une légère ressemblance avec celles du lièvre. Cet animal est appelé kanguroo par les naturels du pays... Le même M. Gore, dans une autre chasse, tua un second kanguroo, qui, avec la peau, les entrailles et la tête, pesoit quatre-vingt-quatre livres; et néanmoins, en l'examinant, nous reconnûmes qu'il n'avoit pas encore pris toute sa croissance, parce que les dents mâchelières intérieures n'étoient pas encore formées... Ces animaux paroissent être l'espèce de quadrupèdes la plus commune à la Nouvelle-Hollande; et nous en rencontrions presque toutes les fois que nous allions dans les bois. "

On voit clairement par cette description historique que le kanguroo ou très grande gerboise de la Nouvelle-Hollande n'est pas le même animal que la grande gerboise ou lièvre-sauteur du cap de Bonne-Espérance; et MM. Forster, qui ont été à portée d'en faire la comparaison avec le kanguroo de la Nouvelle-Hollande, ont pensé, comme nous, que c'étoient deux espèces différentes dans le genre des gerboises. D’un autre côté, si l'on compare ce que dit le docteur Shaw de l'animal qu'il appelle daman, avec la description du lièvre sauteur, on reconnoîtra aisément que ces deux animaux ne font qu'une seule et même espèce, et que ce savant voyageur s'est trompé sur l'applicalion du nom daman, qui appartient à un animal tout différent.

On peut aussi inférer de ce qui vient d'être dit que l'espèce du lièvre sauteur appartient non seulement à l'Afrique, mais encore à la Phénicie, la Syrie, et 
autres régions de l'Asie mineure, dont la communication avec l'Afrique est bien établie par l'Arabie, pour des animaux suriout qui vivent dans les sables brûlants du désert. En séparant donc le vrai daman des gerboises, nous devons indiquer les caractères qui les distinguent.

\section{A MANGOUSTE .}

Viverra Ichncumon. L.

LA mangouste est domestique en Égypte comme le shat l'est en Europe, et elle sert de même à prendre les souris et les rats : mais son goût pour la proie est encore plus vif, et son instinct plus étendu que celıi du chat ; car elle chasse également aux oiseaux, aux quadrupèdes, aux serpents, aux lézards, aux insectes, attaque en général tout ce qui lui paroît vivant, et se nourrit de toute substance animale. Son courage est égal à la véhémence de son appétit : elle ne s'effraie ni de la colère des chiens, ni de la malice des chats, et ne redoute pas même la morsure des ser-

1. Mangouste, mot dérivé de mangutia, nom de cet animal aux Indes.

Ichneumon en grec et en latin; tezer-dea en arabe, selon le docteur Shaw.

Mungo par les Portugais, et muncus par les Hollandois de rinde, selon Kæmpfer; quil ou quilspele à Geylan, selon Garcias du Jardin. 
pents : elle les poursuit avec acharnement, les saisit, et les tue, quelque venimeux qu'ils soient; ot lorsqu'elle commence à ressentir les impressions de leur venin, elle va chercher des antidotes, et particulièrement une racine que les Indiens ont noinmée de son nom, et qu'ils disent être un des plus sûrs et des plus puissants remèdes contre la morsure de la vipère ou de l'aspic. Elle mange les œufs du crocodile, comme ceux des poules et des oiseaux; elle tue et mange aussi les petits crocodiles, quoiqu'ils soient déjà très forts peu de temps après qu'ils sont sortis de l'œuf; et comme la fable est toujours mise par les hommes à la suite de la vérité, on a prétendu qu'en vertu de celte antipathie pour le crocodile, la mangouste entroit dans son corps lorsqu'il étoit endormi, et n'en sorloit qu'après lui avoir déchiré les viscères.

Les naturalistes ont cru qu'il y avoit plusieurs espèces de mangoustes, parce qu'il y en a de plus grandes et de plus petites, et de poils différents : mais si l'on fait attention qu'étant souvent élevées daus les maisons, elles ont dû, comme les autres animaux domestiques, suhir des variétés, on se persuadera facilement que cette diversité de couleur et celte différence de grandeur n’indiquent que de simples variétés, et ne sufísent pas pour constituer des espèces, d'autant que dans deux mangoustes que j’ai vues vivantes, et dans plusieurs actres dont les peaux étoient bourrées, j’ai reconnu les nuances intermédiaires, tant pour la grandeur que pour la couleur, et remarqué que pas une ne différoit de toutes les autres par ancun caractère évident et coustant; il parô̂t seulement qu'en Égypte, 


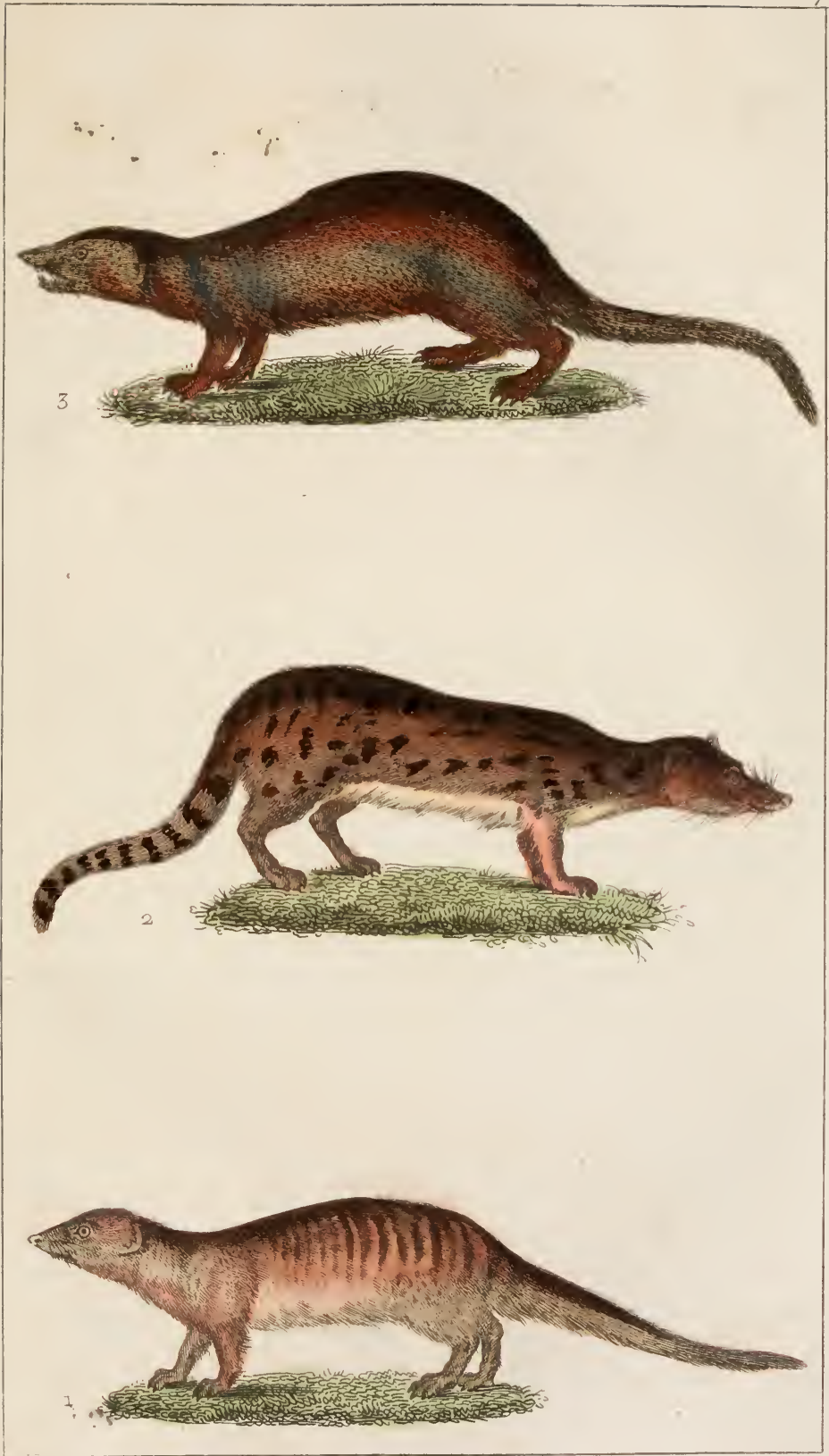



où les mangoustes sont pour ainsi dire domestiques, rlles sont plus grandes qu'aux Indes, où elles sont sauvages 1.

Les nomenclateurs, qui ue veulent jamais qu'un Ĉtre ne soit que ce qu'il est, c'est-à-dire qu'il soit seul de son genre, ont beaucoup varié au sujet de la mangrouste. M. Linnæus en avoit d'abord fait un blaireau, ensuite il en fait un furet; M. Hasselquist, àaprès les premières lecons de son maître, en fait aussi un blairean; MM. Klein et Brisson l'ont mise dans le genre des beletles; d'autres en ont fait une loutre, et d'auires un rat. Je ne cite ces idées que pour faire voir le

1. "Get Ichneumon, dit Edwards, venoit des Indes orientales, et "étoit lort petit : j'en ai vu un autre, venu d'Egypte, qui étoit plus " lu double... La seule différence qu'ily avoit, outre la grandeur, " entre les deux ichneunons, c'est que eelui d'Égypte avoit une pe" lite touffe de poil à l'extrémité de la queue, au liea que larquenc " de celui des Indes se terminoit en pointe; et je crois que cela fait " deux espèees distinctes et séparées, parce yue celui des Indes, qui n étoit si petit en comparaison de eelui d'Égypte, avoit eependant "pris son entier accroissement. " (Edwards, page 199.) Ces difiérences ne mont pas paru suffisantes pour établir deux espèces, allendu qu'entre les petites et les plus grandes, c'est-à-dire entre treize et vingt-teux ponees de longuenr, il s'en trouve d'intermédiaires, comme de quinze et dix-sept pouces de grandeur. Scha, qui a donné la figure et la deseription (volume 1, page 66, table XLI) d'une de' ces petiles mangoustes, qu'il avoit eue vivanie, et qui lui venoil de Geylan, dit qu'elle étoit très malpropre, et qu'on n'avoit pu l'apprivoiser. Cette différence du naturel pourroit faire penser que cette petite mangouste est d'une espèce différente des autres : cependant elle ressemble si fort à celle dout nous avons parlé, qu'on ne peut douter que ce ne soit le mêrne animal; et d'ailleurs je puis assurer moi-nême avoir vu une de ces petites mangoustes qui étoit si privée, que son maitre (M. le président de Robien), qui l'aimoit beaueoup, la portoit toujours dans son ehapeau, et faisoit à tout le monde l'éloge de sea gentillesse et de sa propreté. 
peu de consistance qu'elles ont dans la tête mêne de ceux qui les imaginent, et aussi pour mettre en garde contre ces dénominations qu'ils appellent génériques, et qui, presque toutes, sont fausses, ou du moins arbitraires, vagues, et équivoques ${ }^{1}$.

1. Hasselquist termine sa longue et sèche description de la mangouste par ces mols : Galli in Egypto conversantes, qui omnibus rebus quas non cognoscunt, sua imponunt nomina ficta, appellarunt hoc animal rat de Pharaon; quod secuti qui latine relationes de Egypto dedesunt. Alpin, Belon, murem Pharaonis effinxerunt.

Si cet homme eût seulement lu Belon et Alpin, quili cite, il auroit vu que ce ne sont pas les François qui ont donné le nom de rat de Pharaon à la mangouste, mais les Égyptiens mêmes, et il se seroit abstenu de prendre de là occasion de mal parler de notre nation; mais l'on ne doit pas être surpris de trouver lïmputation d'un pédant dans l'ourrage d'un écolier. En effet, cette description de la mangouste, ainsi que celle de la girafe et de quelques autres animaux, données par ce nomenclateur, ne pourront jamais servir qu’à excéder ceux qui voudroient s'ennuyer à les lire $: 1^{\circ}$ parce qu'elles sont sans figures, et que le nombre des mots ne peut suppléer à la représentation; un coup d'œil vaut mieux dans ce genre qu'un détail de paroles : $2^{\circ}$ parce que ces mots ou paroles sont la plupart d'un latin barbare, ou plutôt ne sont d'aucune langue $: 3^{\circ}$ parce que la méthode de ces descriptions n'est qu une routine que tout homme peut suivre, et qui ne suppose ni génie, ni même d'intelligence : $4^{\circ}$ parce que la description étant trop minutieuse, les caractères remarquables, singuliers, et distinctifs de l'être qu'on décrit, $y$ sont confondus avec les signes les plus obscurs, les plus indifférents, et les plus équivoques : $5^{\circ}$ enfin parce que le trop grand nombre de petits rapports et de combinaisons précaires dont on est obligé de charger sa mémoire, rendent le travail du lecteur plus grand que celui de l'auteur, et les laisse tous les deux aussi ignorants qüils l'étoient. Une preuve qu'avec cette méthode on se dispense de lire et de sïnstruire, c'est, $1^{\circ}$ la fausse imputation que l'auteur fait aux François au sujet du rat de Pharaon : $2^{\circ}$ l'erreur quïl commet en donnant à cet animal le nom arabe nems, tandis que ce mot arabe est le nom du furet, et non pas celui de la mangouste; il ne falloit pas même savoir l'arabe pour éviter cette faute, il auroit suff d'avoir lu les voyages de ceux qui l'avoient précédé dans le même 
La mangouste habite volontiers aux bords des eaux: dans les inondations, elle gagne les terres élevées, et s'approche souvent des lieux habités pour y chercher sa proie. Elle marche sans faire aucun bruit, et selon le besoin elle varie sa démarche : quelquefois elle porte la tête haute, raccourcit son corps, et s'élève sur ses jambes; d'autres fois elle a l'air de ramper et de s'allonger comme un serpent; souvent elle s'assied sur ses pieds de derrière, et plus souvent encore elle s'élance comme un trait sur la proie qu'elle veut saisir. Elle a les yeux vifs et pleins de feu, la physionomie fine, le corps très agile, les jambes conrles, la queue grosse et trìs longue, le poil rude et souvent hérissé. Le mâle et la femelle ont tous deux une ouverture remarquable et indépendanle des conduits naturels, une espèce de poche dans laquelle se filtre une humeur odorante : on prétend que la mangouste ouvre cette poche pour se rafraîchir lorsqu'elle a trop chaud. Son museau trop pointu et sa gueule étroite l'empêchent de saisir et de mordre les choses un peu grosses: mais elle sait suppléer, par agilité, par courage, aux armes et à la force qui lui manquent; elle étrangle aisément un chat, quoique plus gros et plus fort

pays : $5^{\circ}$ l'omission qu'il fait des choses essenticlles, en même temps qu'il s'étend sans mesure sur les indifférentes; par exemple, il dẹcrit la girafe aussi minuticusement que la mangouste, et ne laisse pas que de unanquer le caractère essentiel, qui est de savoir si les cornes sont permanentes, ou si elles tombent tous les ans. Dans vingt fois plus de paroles qu'il n'en faut, l'on ne trouve pas le mot nécessaire, et l'on ne peut juger par sa description si la girafe est du genre des cerfs ou de celui des boufs. Mais c'est assez s'arrêter sur une critique que tout homme sensé ne manquera pas de faire, lorsque de pareils ouvrages hi tomberont entre les mains. 
qu'elle; souvent elle combat les chiens, et, quelque grands qu'ils soient, elle s'en fait respecter.

Cet animal croît promptement et ne vit pas longtemps. Il se trouve en grand nombre dans toute l'Asie méridionale, depuis l'Égypte jusqu'à Java, et il paroît qu'il se trouve aussi en Afrique jusqu'au cap de BonneEspérance : mais on ne peut l'élever aisément, ni le garder long-temps dans nos climats tempérés, quelque soin qu'on en prenne; le vent l'incommode, le froid le fait mourir: pour éviter l'un et l'autre, et conserver sa chaleur, il se met en rond, et cache sa tête entre ses cuisses. Il a une petite voix douce, une espèce de murmure, et son cri ne devient aigre que lorsqu'on le frappe et qu'on l'irrite. Au reste, la mangouste étoil en vénération chez les anciens Égypliens. et mériteroit encore bien aujourd'hui d'être multipliée, ou du moins épargnée, puisqu'elle détruit un grand nombre d'animaux nuisibles, et surtout les crocodiles, dont elle sait trouver les œuís, quoique cachés dans le sable: la ponte de ces animaux est si nombreuse, qu'il y auroit rout à craindre de leur multiplication si la mangouste. n'en détruisoit les germes.

* Nous donnons ici la figure d'une grande mangouste qui nous paroît former une variété dans l'espèce des mangoustes; elle a le museau plus gros et un peu moins longr, le poil plus hérissé et plus long, les ongles aussi plus longs, la queue plus hérissée, et aussi plus longue à proportion du corps. 


\section{LA FOSSANE".}

Viverra Fossa. L.

Quelques voyageurs ont appelé la fossane genetle de Madagascar, parce qu'elle ressemble à la genette par les couleurs du poil et par quelques autres rapports : cependant elle est constamment plus petite; et ce 'fui nous fait penser que ce n'est point une genette, c'est qu'elle n'a pas la poche odoriférante qui, dans cet animal, est un attribut essentiel. Comme nous étions incertains de ce fait, n'ayant pu nous procurer l'animal pour le disséquer, nous avons consulté par lettres M. Poivre, qui nous en a envoyé la peau bourrée, et il a eu la bonté de nous répondre dans les termes suivants :

Lyon, 19 juillet 1761 .

"La fossane que j'ai apportée de Madagascar est un animal qui a les mœurs de notre fouine. Les habitants de l'île m'ont assuré que la fossane mâle étant en chaleur, ses parties avoient une forte odeur de musc. Lorsque j’ai fait empailler celle qui est au Jardin du Roi, je l'examinai attentivement, je n'y découvris aucune poche, et je ne lui trouvai aucune odeur de parfum. J'ai élevé un animal semblable à

1. Fossa ou fossane, nom de cet animal à Madagascar, et que nous avons adopté. 
la Cochinchine, et un autre aux îles Philippines; l'un et l'autre étoient des mâles; ils étoient devenus un peu familiers; je les avois eus très petits, et je ne les ai guère gardés que deux ou trois mois : je n'y ai jamais trouvé de poche entre les parties que vous m'indiquez: je me suis seulement aperçu que leurs excréments avoient l'odeur de ceux de notre fouine. Ils mangeoient de la viande et des fruits; mais ils préféroient ces derniers, et montroient surtout un goût plus décidé pour les bananes, sur lesquelles ils se jetoient avec voracité. Cet animal est très sauvage, fort difficile à apprivoiser; et, quoique élevé bien jeune, il conserve toajours un air et un caractère de férocité; ce qui m’a paru extraordinaire dans un animal qui vit volontiers de fruits. L'œil de la fossane ne présente qu'un globe noir fort grand, comparé à la grosseur de sa lête; ce qui donne à cet animal un air méchant."

Nous sommes très aises d'avoir cette occasion de marquer notre reconnoissance à M. Poivre, qui, par goût pour l'histoire naturelle, et par amitié pour ceux qui la cultivent, a donné au Cabinet un assez grand nombre de morceaux rares et précieux dans tous les genres.

Il noús paroît que l'animal appelé berbé en Guinée est le même que la fossane, et que, par conséquent, cette espèce se trouve en Afrique comme en Asie. "Le berbé, disent les voyageurs, a le museau plus pointu et le corps plus petit que le chat : il est marqueté comme la civette. "Nous ne connoissons pas d'animal auquel ces indications, qui sont assez précises, conviennent mieux qu'à la fossane. 


\section{LE VANSIRE?}

\section{Mustela Galera.. L.}

Cevx qui ont parlé de cet animal l'ont pris pour un furet, auquel, en effet, il ressemble à beaucoup d'égards : cependant il en diffère par des caractères qui nous paroissent suffisants pour en faire une espèce distincte et séparée. Le vansire a douze dents mâchelières dans la mâchoire supérieure, au lieu que le furet n'en a que huit; et les mâchelières d'en-bas, quoiqu'en égal nombre de dix dans ces deux animaux, ne se ressemblent ni par la forme ni par la situation respective : d'ailleurs, le vansire diffère, par la couleur du poil, de tous nos furets, quoique ceuxci, comme tous les animaux que l'homme prend soin d'élever et de multiplier, varient beaucoup entre eux, mêrne du mâle à la femelle.

Il nous paroît que l'animal indiqué par Seba sous la dénomination de belette de Java, qu'il dit que les habitants de cette île nomment koger-angan, et qu'ensuite M. Brisson a nommé furet de Java, pourroit bien

1. Mot dérivé de vohang-shira, nom de cel animal à Madagascar. "La province de Balta, dans le royaume de Congo, offre une infinité "de beaux sables (martres), qui portent le nom d'insires. "(Histoire générale des voyages, tome $\mathrm{V}$, page 87. )

Il n'y a point de sables ou de martres à Congo, et la ressemblance du non nous fait croire que l'insire de Congo pourroit bien être le. vansire de Madagascar. 
ètre le même animal que le vansire : c'est au moins de tous les animaux connus celui duquel il approche le plus. Mais ce qui nous empêche de prononcer décisivement, c'est que la description de Seba n'est pas assez complète pour qu'on puisse établir la juste comparaison qui seroit nécessaire pour juger sans scrupule. Nous la mettons sous les yeux du lecteur ${ }^{1}$, pour qu'il puisse lui-même la comparer avec la nôtre.

* Le vansire est, comme nous l'avons dit, un animal de Madagascar et de l'intérieur de l'Afrique, qui ressemble beaucoup au furet, à l'exception du nombre et de la forme des dents, et de la longueur de la queue, qui est beaucoup plus grande dans le vansire que dans notre furet. Nous donnons ici la figure d'un animal qui nous a été envoyé de la partie orientale de l'Afrique, sous le nom de neipse. Par sa forme, aussi bien que par cette dénomination, j'ai reconnu que c'étoit une espèce de furet; car nems ou nims est le nom du furet en langue arabe, et ces furets d'Arabie ou ces nems ressemblent beaucoup plus au vansire qu'à nos furets d'Europe. Voici la description qu'en a faite M. de Sève.

"Le nems est un vrai furet, à le considérer dans le détail de sa forme et de sa souplesse. Quand il marche, il s'allonge et paroît bas de jambe. Il a beaucoup de conformité avec nos furets. Celui-ci étoit mâle, et avoit treize pouces dix lignes de longueur du museau

1. Javanica hæc mustela, hic repræsentata, collo et corpore est "brevioribus quam nostra; caput tegentes pili obscure spadicei sunt, - rufi qui dorsum, dilute vero flavi qui ventrem vestiunt, cauda inte- rim in apicem acuturn et nigricantem desinente. " (Seba, volum. I, piog. 78.$)$ 


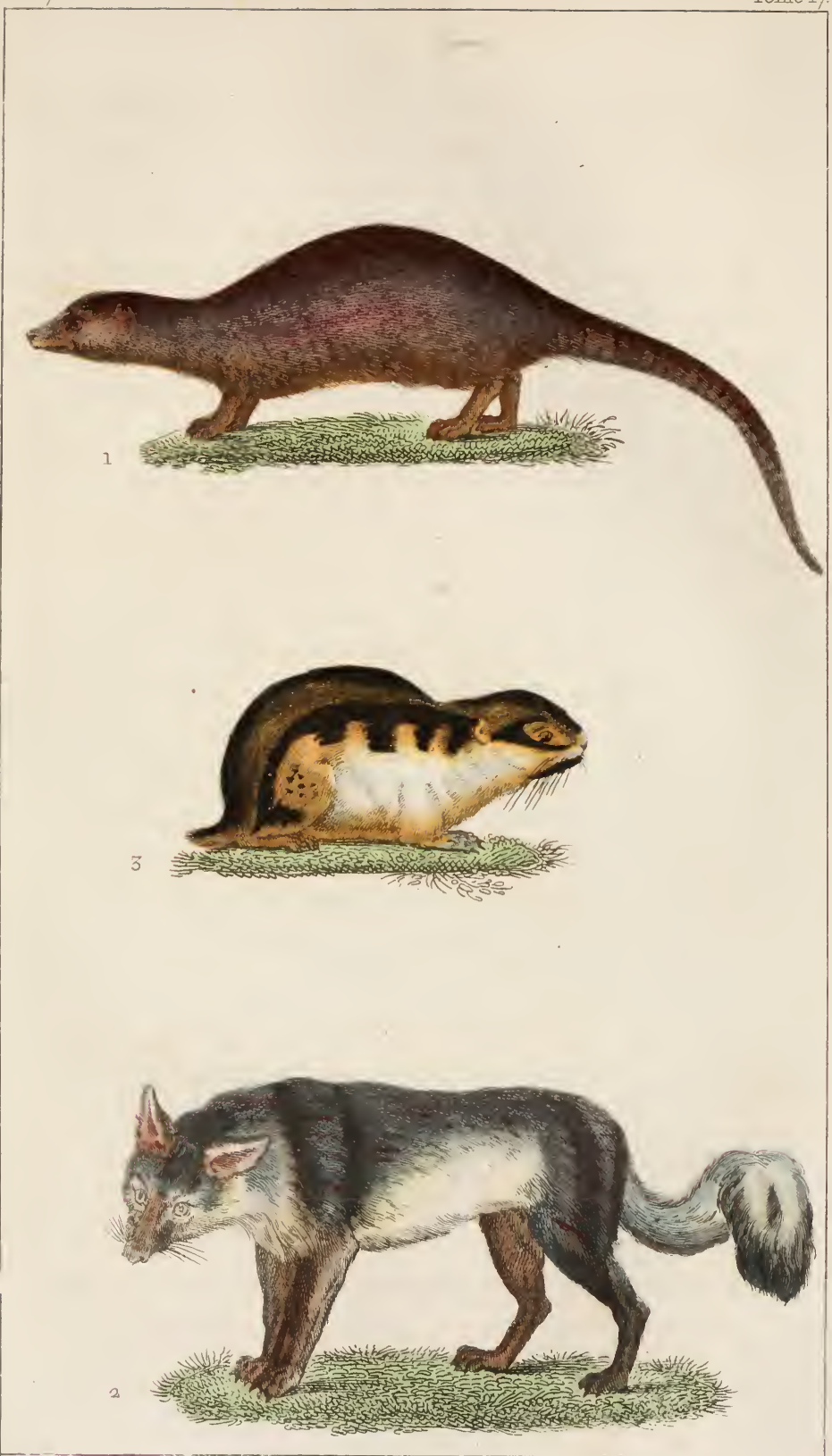

Pazquat colp 

à l'anus, le tronçon de la quene un pied; la hauteur du train de devant est de cinc pouces six lignes, celle du train de derrière six pouces six lignes; l'oreille est sans poil et de la même forme que celle du furet commun. Son ceil est vif, et. l'iris d'un fauve foncé; son museau, qui est très fin, ne m'a pas paru avoir de monstaches. Tout le corps est couvert d'un poil long, jaspé d'un brun foncé, nıêlé d'un blanc sale qui a dix lignes de longueur; ce qui fait que, par ses rayures, il ressemble au lapin riche. Le ventre est couvert d'un poil fauve clair sans mélange; le fond du poil de la tête, autour de l'œil, est d'une couleur jaunâtre claire, et sur le nez, les joues, les autres parties de la face où le poil est court, un ton fauve plus ou moins brun par endroit, règne partout sans mélange, se continue et se perd en diminuant dans les parties de la tête au dessus des yeux; ses jambes sont couvertes d'un poil ras fauve foncé; les pattes ont quatre doigts, et un petit doigt par derrière; les ongles sont petits et noirs; la queue, qui est au moins du double plus longue que celle de nos furets, est très grosse au commencement du tronçon, et très menue au bout qui finit en pointe; de grands poils jaspés comme sur le corps couvrent cette queue. Cet animal ne boit point, à ce qu'a dit avoir observé le garçon qui en a soin."

* M. Forster a bien voulu m'envoyer les remarques suivantes au sujet de cet animal.

" J'ai vu, dit-il, à la ménagerie du cap de BonneEspérance un animal du geare des mangonstes, qui venoit de l'ìle de Madagascar, et qui répondoit exactement à la description du vansire donnée par M. de Baflon. Il se plaisoit beaucoup à être daus un baquet 
rempli d'ean, d'où il sortoit de temps en temps. Le garde qui prenoit soin de la ménagerie nous assura que, lorsqu'on tenoit cet animal pendant quelque temps à sec et hors de l'eau, il s'y replongeoit avec empressement dès qu'on lui en laissoit la liberté. La figure qu'en a donnée M. de Buffon est assez exacte; mais elle paroît un peu trop allongée, parce qu'elle a été donnée sur une peau bourrée de cet animal, et d'ailleurs le poil est plus court que celui du vansire de là ménagerie du Cap. Ce dernier étoit à pen près de la taille de la martre ordinaire; sa queue égaloit en longueur celle du corps jusqu'à la tête; son poil étoit de couleur brune noirâtre; il avoit cinq doigts à chaque pied, bien divisés et sans membranes. Les dents incisives étoient au nombre de six, tant en haut qu'en has; il y avoit huit mâchelières à chaque mâchoire, c'est-à-dire quatre de chaque côté, et les canines étoient isolées; ce qui fait en tout trente-deux dents. L'animal marchoit comme les mangoustes, en appuyant sur le talon."

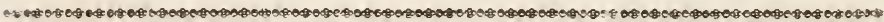

\section{LISATIS ${ }^{1}$.}

Canis Lagopus. L.

Si le nombre des ressemblances en général, si la parfaite conformité des parties intérieures suffisoient

1. Nom que M. Gmelin a donné à cet animal, et qุue nous avons adopté. Jonston indique aussi ce nom.

Peszi en langue russe, selon Gmelin. 
pour assurer l'unité des espèces, le loup, le renard, et le chien n'en formeroient qu'une seule ; car le nombre des ressemblances est beaucoup plus grand que celui des différences, et la similitude des parties internes est entière : cependant ces trois animaux forment trois espèces non seulement distinctes, mais encore assez éloignées pour admettre entre elles d'autres espèces; et comme celle du chacal est intermédiaire entre le chien et le loup, l'espèce de l'isatis se trouve placée de même entre le renard et le chien. Jusqu'à ce jour l'on n'avoit regardé cet animal que comme une variété dans l'espèce du renard : mais la description qu'en a donnée M. Grmelin, et de laquelle nous ferons ici l'extrait, ne permet plus de douter que ce ne soient deux espèces différentes.

L'isalis est. très commun dans toutes les terres du Nord voisines de la mer Glaciale, et ne se trouve guère en deçà du $69^{\mathrm{e}}$ degré de latiude. Il est toutà-fait ressemblant au renard par la forme de son corps et par la longueur de la queue; mais par la tête il ressemble plus au chien: il a le poil plus doux que le renard commun, et son pelage est blanc dans un temps, et bleu cendré dans d'autres temps. La tête est courte à proportion du corps; elle est large auprès du cou, et se termine par un museau assez pointu : les oreilles sont presque rondes. Il y a cinq doigts et cinc ongles aux pieds de devant, et seulement quatre doigts et quatre ongles aux pieds de derrière. Dans le mâle, la verge est à peine grosse comıne une plume à écrire; les testicules sont gros comme des amandes, et sifort cachés dans le poil, qu'on a peine à les trouver. Les poils dont tout le corps est couvert sont longs 
d'environ deux pouces; ils sont lisses, touffus, et doux comme de la laine : les narines et la mâchoire inférieure ne sont pas revêtues de poils; la peau est apparente, noire, et nue dans ces parties.

L'estomac, les intestins, les viscères, les váisseaux spermatiques, tant du mâle que de la femelle, sont semblables à ceux du chien; il y a de même un os dans la verge, et le squelette entier ressemble à celui d'un renard.

La voix de l'isatis lient de l'aboiement du chien et du glapissement du renard. Les marchands qui font commerce de pelleteries distinguent deux sortes d'isatis, les uns blancs, et les autres d'un bleu cendré : ceux-ci sont les plus estimés; et plus ils sont bleus ou bruns, plus ils sont chers. Cette dilférence dans la couleur du poil ne fait pas qu'ils soient d'espèces différentes : des chasseurs expérimentés ont assuré à M. Gmelin que, dans la même portée, il se trouvoit de petits isalis blancs et d'autre cendrés; ainsi l'un n'est qu'une variété de l'autre.

Le climat des isatis est le Nord, et les terres qu'ils habitent de préférence sont celles des bords de la mer Glaciale et des fleuves qui y tombent. Ils aiment les lieux découverts, et ne demeurent pas dans les bois : on les trouve dans les endroits les plus froids, les plus montueux, et les plus nus de la Norrége, de la Laponie, de la Sibérie, et rême en Islande. Ces animaux s'accouplent au mois de mars; et, ayant les parties de la génération conformées comme les chiens, ils ne peuvent se séparer dans le temps de l'accouplement. Leur chaleur dure quinze jours ou trois semaines : pendant ce temps ils sont toujours à l'air; mais 
ensuite ils se retirent dans des terriers qu'ils ont creusés d'avance : ces terriers, qui sont étroits et fort protonds, ont plusieurs issues; ils les tiennent propies, et y portent de la mousse pour être plus à l'aise. La durée de la gestation est, comme dans les chiennes, d'environ neuf semaines : les femelles mettent bas à la fin de mai ou au commericement de juin, et produisent ordinairement six, sept, ou huit petits ${ }^{1}$. Les isatis qui doivent être blancs sont jaunâtres en naissant, et ceux qui doivent être d'un bleu cendré sont noirâtres, et leur poil à tous est alors très court : la mère les allaite et les garde dans le terrier pendant cinq ou six semaines, après quoi elle les fait sortir, et leur apporte à manger. Au mois de septembre leur poil a déjà plus d'un demi-pouce de longueur. Les isatis qui doivent devenir blancs le sont déjà sur tout le corps, à l'exception d'une bande longitudinale sur le dos, et d'une autre transversale sur les épaules, qui sont brunes; et c'est alors que l'isatis s'appelle renard croise $^{2}$ : mais cette croix brune disparoît avant l'hiver; et alors ils sont entièrement blancs, et leur poil a plus de deux pouces de longueur : vers le mois de mai il commence à tomber, et la mue s'achève en entier dans le mois de juillet. Ainsi la fourrure n'en est bonne qu'en hiver,

L'isatis vit de rats, de lièvres et d'oiseaux; il a au-

1.M. Gmelin dit, d'après le térnoignage des chasseurs, que ces animaux produisent quelquefois vingt ou vingt-cinq petits d'une seule portée. Je crois ce fait très suspect et le nombre très exagéré.

2. Cette indication paroit assez précise puur qu'on puisse croire que le valpes crucigera de Gesner (Icon. quad. fig. pag. 190) et de Rzaczynski (Hist. nat. Pol., page $23_{1}$ ) est le méme animal que lisatis. 
tant de finesse que le renard pour les attraper : il se jette à l'eau, et traverse les lacs pour chercher les nids des canards et des oies; il en mange les oufs et les petits, et n'a pour ennemis, dans ces climats déserts et froids, que le glouton, qui lui dresse des embûches et l'attend au passage.

Comme le loup, le renard, le glouton, et les autres animaux qui habitent les parties du nord de l'Europe et de l'Asie, ont passé d'un continent à l'autre, et se retrouvent tous en Amérique, l'isatis doit s'y trouver aussi; et je présume que le renard gris argenté de l'Amérique septentrionale, dont Catesby a donné la figure, pourroit bien être l'isatis plutôt qu'une simple variété de l'espèce du renard.

* Par une lettre datée de Londres, le 19 février 1 768 , M. Collinson m’écrit dans les termes suivants :

"Un de mes amis, M. Paul Demidoff, Russien, qui admire vos ouvrages, vous envoie le dessin d'un animal qui n'est point encore décrit, appelé cossac. Il vient des grands déserts de Tartarie, situés entre les rivières Jaik, Emba, et les sources de l'Irtish. Ces cossacs y sont en si grand nombre, que les Tartares en apportent tous les ans cinquante mille peaux à Oremburgh, d'où on les porte en Sibérie et en Turquie. .

ll a pieds. pour. lign.

Il a du bout du museau à l'origine de la queue. $\begin{array}{llll}1 & 7 & 11\end{array}$

De la plante du pied au sommet de la tête. . . . . $1 \quad 1 \quad 2 \quad 5$

De la plante du pied au dessus des épaules. . . „ 11 "

Longueur de la tête........... . . . . $5 \quad 2$

Longueur des oreilles. . . . . . . . . . . . . $2{ }_{2} 2$

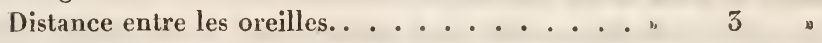

Longuear de la queue........... . . 10 „

"La forme de la tête, le doux regard et l'aboiement 
de cet animal, semblent le rapprocher du chien ; néanmoins il a de commun avec le renard sa queue et sa fourrure très belle et très douce. Son sang est d'une nature ardente, et il répand une assez mauvaise odeur par la respiration, comme le chacal et le loup."

Il m'a paru, par ce dessin, et encore plus par cette courte description de M. Demidoff et par celle de M. Gmelin, que cet animal est l'isatis dont nous avons parlé, et c'est pour cela que je l'ai fait graver (voyez planche 46).

\section{LE GLOUTON ${ }^{1}$.}

\section{Ursus Gulo. L.}

LE glouton, gros de corps et bas des jambes, est à peu près de la forme d'un blaireau; mais il est une fois plus épais et plus grand : il a la tête courte, les yeux petits, les dents très fortes, le corps trapu, la queue plutôt courte que longue, et bien fournie de poil à son extrémité. Il est noir sur le dos, et d'un brun roux sur les flancs : sa fourrure est une des plus belles et des plus recherchées. On le trouve assez communément en Laponie et dans toutes les terres voisines de la mer du Nord, tant en Europe qu'en Asie : on le retrouve sous le nom de carcajou au Canada et dans les autres parties de l'Amérique la plus septentrionale; il y a même toute apparence que l'a-

i. Nom que l'on a donné à cet animal à cause de son insatiable voracilé. 
nimal de la baie de Hudson que M. Edwards a donné sous le nom de quickhatch ou wolverenne, petit ours ou louveteau, selon son traducteur, est le même que le carcajou de Canada, le même que le glouton du nord de l'Europe; il me paroît aussi que l'animal indiqué par Fernandès sous le nom de tepeytzcuitli ou chien de montagne, pourroit bien être le glouton, dont l'espèce s'est peut-être répandue jusque dans les montagnes désertes de la Nouvelle-Espagne.

Olaüs Magnus me paroît être le premier qui ait fait mention de cet animal : il dit qu'il est de la grosseur d'un grand chien; qu'il a les oreilles et la face d'un chat, les pieds et les ongles très forts; le poil brun, long et touffu; la queue fournie comme celle du renard, mais plus courte. Selon Scheffer, le glouton a la tête ronde, les dents fortes et aiguës, semblables à celles du loup, le poil noir, le corps large, et les pieds courts comme ceux de la loutre. La Hontan, qui a parlé le premier du carcajou de l'Amérique septentrionale, dit : "Figurez-vous un double blaireau, c'est l'image la plus ressemblante que je puisse donner de cet animal." Selon Sarrazin, qui probablement n'en avoit vu que de petits, les carcajous n'ont guère que deux pieds de longueur de corps, et huit pouces de queue. "Ils ont, dit-il, la tête fort courte et fort grosse, les yeux petits, les mâchoirestrès fortes, garnies de trente-deux dents bien tranchantes. "Le petit ours ou le louveteau d'Edwards, qui me paroît être le même animal, étoit, dit cet auteur, une fois aussi gros qu'un renard; il avoit le dos arqué, la tête basse, les jambes courtes, le ventre presque traînant à terre, la quene d'une longueur médiocre et touffue vers l'ex- 
trémité. Tous s'accordent à dire qu'on ne trouve cet animal que dans les parties les plus septentrionales de l'Europe, de l'Asie et de l'Amérique : M. Gmelin est le seul qui semble assurer qu'il voyage jusque dans les pays chauds. Mais ce fait me paroît très suspect, pour ne pas dire faux : M. Gmelin, comme quelques autres naturalistes, a peut-être confondu l'hyène du Midi avec le glouton du Nord, qui se ressemblent en effet par les habitudes naturelles, et surtout par la voracité, mais qui sont, à tous autres égards, des animaux très différents.

Le glouton n'a pas les jambes faites pour courir; il ne peut même marcher que d'un pas lent; mais la ruse supplée à la légèreté qui lui manque; il attend les animaux au passage; il grimpe sur les arbres pour se lancer dessus, et les saisir avec avanlage; il se jette sur les élans et sur les rennes, leur entame le corps, et s'y at lache si fort avec les griffes et les dents, que rien ne peut l'en séparer : ces pauvres animaux précipitent en vain leur course; en vain ils se frottent contre les arhres, et font les plus grands efforts pour se délivrer; l'ennemi. assis sur leur croupe on sur leur cou, continue à leur sucer le sang, à creuser teur plaie, à les dévo rer en délail avec le mêrne acharnement, la même avidité, jusqu'à ce qu'il les ait mis à mort. Il est, dit-on, inconcevable combien de temps le glouton peut manger de suite, et combien il peut dévorer de chair en une seule fois.

Ce que les voyageurs en rapportent est peut-être exagéré : mais en rabattant beaucoup de leurs récits, il en reste encore assez pour être convaincu que le glouton est beaucoup plus vorace qu'aucun de nos 
animaux de proie; aussi l'a-t-on appelé le vautour des quadrupèdes: Plus insatiable, plus déprédateur que le loup, il détruiroit tous les autres animaux, s'il avoit autant d'agilité : mais il est réduit à se traîner pesamment, et le seul animal qu'il puisse prendre à la course est le castor, duquel il vient très aisément à bout, et dont il attaque quelque fois les cabanes pour le dévorer avec ses petits, lorsqu'ils ne peuvent assez tôt gagner l'eau; car le castor le devance à la nage, et le glouton, qui voit échapper sa proie, se jette sur le poisson; et lorsque toute chair vivante vient à lui manquer, il cherche les cadavres, les déterre, les dépèce, et les dévore jusqu'aux os.

Quoique cet animal ait de la finesse, et mette en œưve des ruses réfléchies pour se saisir des autres animaux, il semble qu'il n'ait pas de sentiment distinct pour sa conservation, pas même l'instinct commun pour son salut : il vient à l'homme ou s'en laisse approcher, sans apparence de crainte. Cette indifférence, qui paroît annoncer l'imbécillité, vient peutêtre d'une cause très différente. Il est certain que le glouton n'est pas stupide, qu'il trouve les moyens de satisfaire à son appétit toujours pressant, et plus qu'immodéré; il ne manque pas de courage, puisqu'il attaque indifféremment tous les animaux qu'il rencontre, et qu'à la vue de l'homme il ne fuit, ni ne marque, par aucun mouvement, le sentiment de la peur spontanée: s'il manque donc d'attention sur lui-même, ce n'est point indifférence pour sa conservation, ce n'est qu'habitude de sécurité. Comme il habite un pays presque désert, qu'il y rencontre très rarement des hommes, qu'il n'y connoît point d'au- 
tres ennemis, que toutes les fois qu'il a mesuré ses forces avec les animaux il s'est trouvé supérieur, il marche avec confiance, et n'a pas le germe de la crainte, qui suppose quelque épreuve malheureuse, quelque expérience de sa foiblesse : on le voit par l'exemple du lion, qui ne se détourne pas de l'homme, à moins qu’il n'ait éprouvé la force de ses armes; et le glouton, se traînant sur la neige dans son climat désert, ne laisse pas d'y marcher en toute sécurité, et d'y régner en lion, moins par sa force que par la foiblesse de ceux qui l'environnent.

L'isatis, moins fort, mais beaucoup plus léger que le glouton, lui sert de pourvoyeur : celui-ci le suit à la chasse, et souvent lui enlève sa proie avant qu'il l'ait entaméc : au moins il la partage; car, au moment que le glouton arrive, l'isatis, pour n'être pas mangé Jui-nême, abandonne ce qui lui reste à manger. Ces deux animaux se creusent également des terriers; mais leurs autres habitudes sont différentes: l'isatis va souvent par troupe; le glouton marche seul, ou quelquefois avec sa femelle. On les trouve ordinairement ensemble dans leurs terriers. Les chiens, même les plus courageux, craignent d'approcher et de combattre le glouton; il se défend des pieds et des dents, et leur fait des blessures mortelles: mais, comme il ne peut échapper par la fuite, les hommes en viennent aisément à bout.

La chair du glouton, comme celle de tous les animaux voraces, est très mauvaise à manger; on ne le recherche que pour en avoir la peau, qui fait une très bonne et magnifique fourrure : on ne met au dessus que celle de la zibeline et du renard noir; et Burpon. xvir, 
l'on prétend que, quand elle est bien choisie, bien préparée, elle a plus de lustre qu'aucune antre, et que, sur un fond d'un beau noir, la lumière se réfiéchit et brille par parties comme sur une étofle damassée.

* Nous donnons ici (voyez planche 46) la figure du glouton, qui manquoit dans l'article précédent. Cet animal m'a'été envoyé vivant des parties les plus septentrionales de la Russie; il a néanmoins vécu pendant plus de dix-huit mois à Paris : il étoit si fort privé, qu'il n'étoit ancunement féroce et ne faisoit de mal à personne. Sa voracité a élé aussi exagérée que sa cruauté : il est vrai qu'il mangeoit beaucoup; mais il n'importunoit pas vivement ni fréquemment quand on le privoil de nouriture. Le dessin représente très bien cet anima!, dont néanmoins j'ai cru devoir donner ici la description. Il avoit deux pieds deux pouces de longueur depuis le bout du nez jusqu'à l'origine de la quene; le museau noir jusqu'aux sourcils; les yeux petits et noirs; depuis les sourcils jusqu'aux oreilles le poil éloit blanc mêlé de brun ; les oreilles fort courtes, c'est-à-dire d'un pouce de longueur; le poil ras sur les oreilles; sous la mâchoire inférieure, il est tacheté de blanc, ainsi qu'entre les deux pieds de devant; les jambes de devant ont onze pouces de iongueur depuis l'extrémité des ongles jusqu'au corps; celles de derrière un pied; la queue hnit pouces, y compris quatre pouces de poil à son extrémité; les quatre jambes, la queue, et le dessus du dos noirs, ainsi que le dessous du ventre; an nombril une tache blanche; les parties de la génération rousses; le poil roux, depuis les épaules jusqu'à l'o- 
rigine de la queue; le poil intérieur ou duret blanc, il n'est pas aussi épais dans ces endroits que sur le dos; les pieds de devant, depuis le talon jusqn'au bout des ongles, longs de trois pouces neuf lignes; cinq ongles fort crochus et séparés, celui du milieu d'un pouce et demi de long; cinq durillons sous les ongles; quatre se tenant ensemble et formant sous le pied un demi-cercle et un autre an talon; cinq ongles de même aux pieds de derrière, neuf durillons et point de talon. Largeur du pied de devant, deux pouces et demi; longueur des pieds de derrière, quatre pouces neuf lignes; largeur des pieds de derrière, deux pouces neuf lignes. Six dents incisives à la mâchoire supérieure, dont une, de chaque côté, un peu plus grosse que les quatre autres; deux grosses dents de sept lignes de longueur un peu crochues, comme on le voit dans la tête au bas de la planche; cinq dents mâchelières, dont une du côté de la gorge entre en dedans de la gueule, et dont deux sont beaucoup plus grosses que les trois autres. Cinq dents mâchelières à la mâchoire inférieure, dont une fort grosse; deux grandes dents un peu crochues, et six peities presque ras. Un peu de poil de deux pouces de longueur autour de la gueule et au dessis des yeux.

Cet animal étoit assez doux; il craint l'eau, il a peur des chevaux et des hommes habillés de noir; il marche en sautant, mange considérablement. Quand il avoit bien mangé, et qu'il restoit de la viande, i! avoit soin de la cacher dans sa cage et de la couvrir de paille. En buvant, il lape comme un chien; il n'a aucun cri. Quand il a bu, il jette avec ses pattes ce 
qui reste d'eau par dessous son ventre. Il est rare de le voir tranquille, parce qu'il se remue toujours. I! mangeroit plus de quatre livres de viande par jour si on les lui donnoit; il ne mange point de pain, et mange si goulument presque sans mâcher, qu'il s'en étrangle.

Cet animal, qui n'est pas rare dans la plupart des contrées septentrionales de l'Europe, et même de l'Asie, ne se trouve fréquemment en Norwége, selon Pontoppidan, que dans le diocèse de Drontheim. Il dit que la peau en est très précieuse, et qu'on ne les tire point à coups de fusil pour ne la pas endommager; que le poil en est doux et d'un noir nuancé de brun et de ;aune.

* J'ai dit que le glouton n'est pas rare dans les contrées septentrionales de l'Europe et même de l'Asie. M. Krachenninikow rapporte à ce sujet qu'il y a au Kamtschatka un animal appelé glouton, dont la fourrure est si estimée, que, pour dire qu'un homme est richement habilié, on dit qu'il est vêtu de fourrure de glouton. "Les femmes de Kamtschatka, dit-il, ornent leurs cheveux avec les pattes blanches de cet animal, et elles en font très grand cas; cependant les Kantschatkadales en tuent si peu, qu'ils sont obligés d'en tirer de Jakustki, qui leur reviennent fort cher. Ils préfèrent les blanches et les jaunes, quoique les noires et les brunes soient plus estimées.... Ils ne peuvent faire un plus grand présent à leurs femmes ou à leurs maîtresses, que de leur donner une de ces peaux; et c'est pourquoi elles se vendoient autrefois depuis trente jusqu'à soixante roubles; ils donnent pour deux de leurs paltes jusqu'à deux castors ma- 
rius (saricoviennes). On trouve aussi beaucoup de ces gloutons dans les environs de Karaga, d'Anadirska, et de Kolima. lls sont très adroits à la chasse des cerfs, et voici la manière dont ils s'y prennent pour les tuer. Ils montent sur un arbre avec quelques brins de cette mousse qu'ils ont coutume de manger : lorsqu'ils en voient venir quelques uns, ils la laissent tomber à terre; et, prenant le moment que le cerf s'approche pour la manger, ils s'élancent sur son dos, le saisissent par le bois, lui crèvent les yeux, et le tourmentent si fort, que ce malheureux animal, pour mettre fin à ses peines et se débarrasser de son ennemi, se heurte la tête contre un arhre, et tombe mort sur la place. Il n'est pas plus tôt à has, que le glouton le dépèce par morceaux, cache sa chair dans la terre, pour empêcher que les autres animaux ne la mangent, et il n'y touche point qu'il ne l'ait mise en sûreté. Les gloutons qui se trouvent aux environs du fleuve Léna s'y prennent de la même manière pour tuer les chevaux. Cependant, quelque cruels que paroissent ces animaux, on les prive aisément, et ils paroissent alors bien moins voraces."

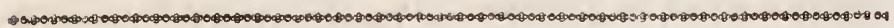

\section{LE GARGAJOU.}

Nous donnons ici la description d'un animal d'Amérique, dont on a envoyé la peau bourrée à M. Aubry, curé de Saint-Louis, sous le nom de carcajou, mais qui n'a pas autant de rapport yue je l'aurois 
pensé avec cet animal que j'ai dit être le même que le glouton de notre Nord; car il semble même approcher de très près de l'espèce de notre blaireau d'Europe : ses ongles ne sont point faits pour déchirer une proie, mais pour creuser la terre; en sorte que nous le regardons comme une espèce voisine, ou même comme une variété de l'espèce du blaireau; il ne faut que le comparer avec la figure de notre blaireau pour en reconnoître la ressemblance. Cependant il en diffère en ce qu'il n'a que quatre doigts aux pieds de devant, tandis que notre blaireau en a cinq; mais le cinquième petit doigt, qui paroît lui manquer, peut avoir été oblitéré dans la peau desséchée. Il différoit également du carcajou ou glouton par ce même caractère; car le glouton a aussi, coinme le blaireau, cinq doigts aux pieds de devant : ainsi nous doutons beaucoup que cet animal, envoyé sous le nom de carcajou, soit, en effet, le vrai carcajon. Nous joignnons ici la description de sa peau bourrée, qui est bien conservée dans le cabinet de M. le curé de Saint-Louis. On lui a assuré qu'il venoit du pays des Esquimaux. Il a deux pieds deux pouces du bout du museau à l'origine de la queue. Quoiqu'il ressemble beaucoup au blaireau, il en diffère par la couleur et la qualité du poil, qui est bien plus doux, plus soyeux, et plus long; et ce n'est que par ce seul caractère qu'il pourroit se rapprocher du carcajou et du glouton du nord de l'Europe. Il est à peu près de la couleur du loup-cervier, d'un hlanc grísâtre; sa têle est rayée de bandes blanches, mais dilféremment de celle du blairean. Les oreilles sont courtes of blanches; it a trente-deux dents, six incisives, 

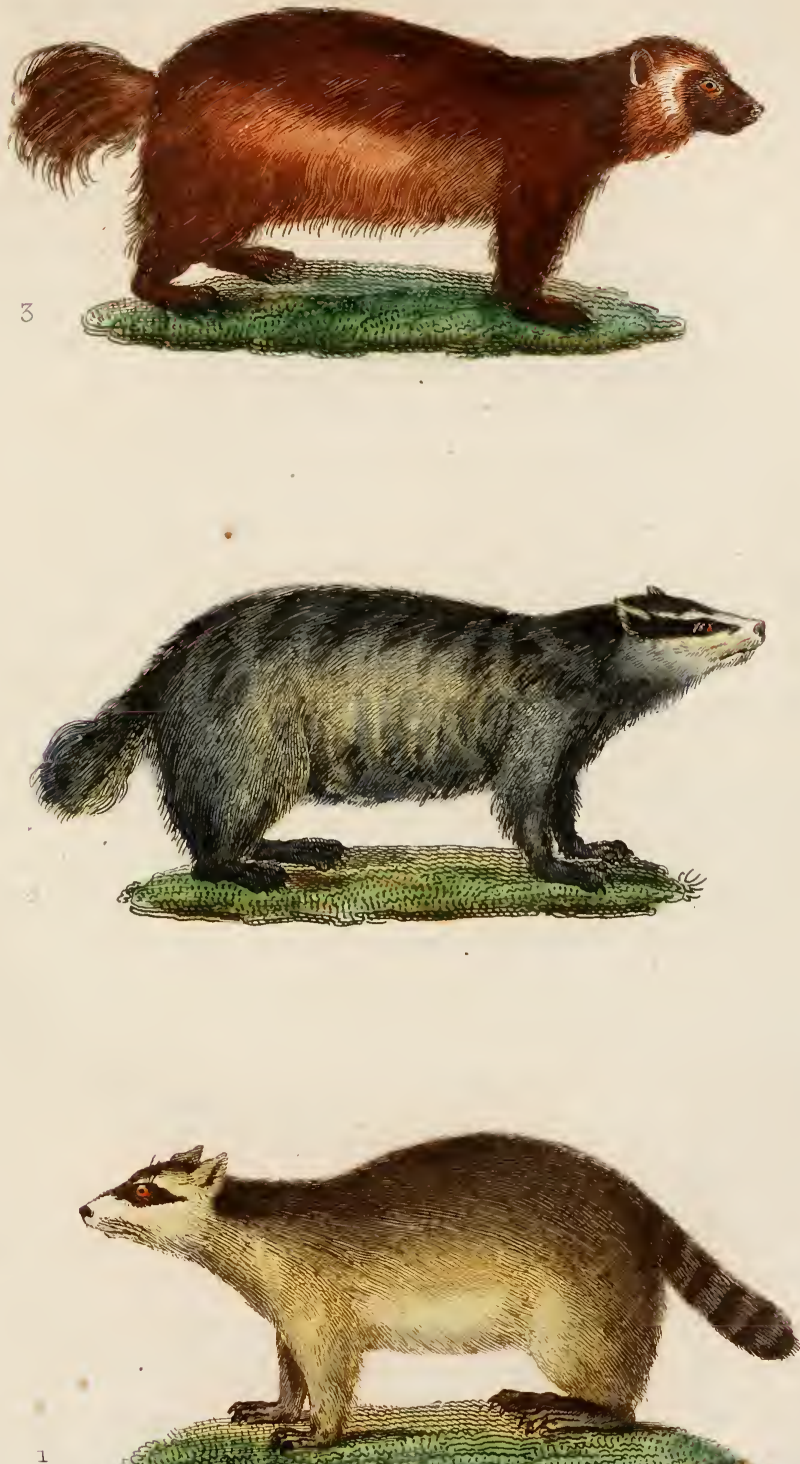

1

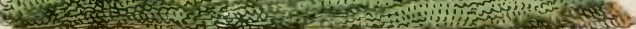

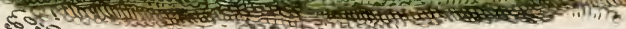



deux canines fort grosses, quatre mâchelières de chaque côté, et le blaireau en a cinq. Le bout du nez est noirâtre. Les poils du corps, qui ont communément quatre pouces et demi ou cinq pouces, sont de quatre couleurs dans leur longueur, d'un brun clair depuis l'origine jusqu'à près de la moitié, ensuite fauve clair', puis noirs près de l'extrémité qui est blanche; le dessous du corps est couvert de poils blancs; les jambes sont aussi couvertes de longs poils d'un brun musc foncé. Les pieds de devant n'oni que quatre doigts, et ceux de derrière cinq. Les ongles des pieds de devant sont fort grands; le plus long a jusqu’à seize lignes, et le plus long des pieds de derrière n'en a que sept. La queue n'a que trois pouces huit lignes de tronçon; elle est terminée par de longs poils qui l'environnent, et qui sont de couleur fauve.

Je suis persuadé que le carcajou d'Amérique est le mème animal que le glouton d'Europe, ou du moins qu'il est d'une espèce très voisine; mais je dois observer que, faute d'être assez informé, je crois être tombé dans une méprise occasionée par la ressemblance du nom et de quelques habitudes naturelles, communes à deux animaux différents. J'ai cru que le kinkajou étoit le mêne animal que le carcajou, et je n'ai reconnu cette errear qu'à la vue de deux animaux dont l'un étoit à la foire Saint-Germain en $177^{5}$, annoncé sur l'affiche, animal inconnu à tous les naturalistes; et il l'étoit en effet. Un autre tout pareil est encore actuellement vivant à Paris, chez M. Chauveau, qui l'a anené de la Nouvelle-Espagne, et M. Messier, astronome de l'Académie des Sciences, 
l'a nourri pendant deux ou trois ans. C'est celni dont nous donnons ici la figure, et que nous croyons être le vrai kinkajou. M. Chauveau pensoit que ce pouvoit être un acouchi ou un coati; il dit qu'à la vérité il n'a ni le nez allongé ni la queue annelée du coati, mais qu'il a d'ailleurs le même poil, les mêmes membres, le mêmo nombre de doigts, et surtout des dents canines pareilles, et telles que M. Perrault les a fait dessiner pour le coati, c'est-à-dire anguleuses et cannelées sur les trois faces. M. Chauveau avoue qu'il diffère encore du coati par sa queue prenante, avec laquelle il se suspend et s'accroche à tout ce qu'il rencontre lorsqu'il veut descendre.

"Il ne la redresse même, dit-il, que quand ses pieds sont assurés; il s'en sert heureusement pour sásir et approcher de lui les choses auxquelles il ne peut atteindre. II se couche et dort dès qu'il voit le jour, et s'éveille à l'approche de la nuit. Alors il est d'une vivacité extraordinaire. Il grimpe avec une grande facilité, et furette partout. Il arrache tout ce qu'il trouve, soit en jouant, soit en cherchant des insectes : sans cela on pourroit le laisser en liberté; et même, avant d'être en France, on ne l'attachoit pas du tout; il sortoit et alloit où il vouloit pendant la nuit, et le lendemain matin on le retrouvoit toujours couché à la même place. On vient à bout de l'éveiller en l'excitant pendant le jour; mais il semble que le soleil ou sa réverbération l'effraie ou le suffoque. Il est assez caressant, sans cependant être docile; il sait seulement distinguer son maître et le suivre. Il boit de tout, de l'ean, du café, du lait, du vin, et mêtne de l'eau-de-vie, surtout s'il y a du 
sucre; et il en boit jusqu'à s'enivrer, ce qui le rend malade pendant plusieurs jours. Il mange aussi de tout indistinctement, du pain, de la viande, des légumes, des racines, principalement des fruits; on lui a donné long-temps pour nourriture ordinaire du pain trempé de lait, des légumes, et des fruits. II aime passionnément les odeurs, et est très friand de sucre et de confitures.

„Il se jette sur.les volailles, et c'est toujours sous l'aile qu'il les saisit; il paroît en boire le sang, et il les laisse sans les déchirer : quand il a le choix, il préfère un canard à une poule, et cependant il craint l'eau. Il a différents cris; quand il est seul pendant la nuit, on l'entend très souvent jeter des sons qui ressemblent assez en petit à l'aboiement d'un chien, et il commence toujours par éternuer. Quand il joue et qu'on lui fait du mal, il se plaint par un petit cri pareil à celui d'un jeune pigeon. Quand il menace, il siffle à peu près comme une oie; quand il est en colère, ce sont des cris confus et éclatants. Il ne se met guère en colère que quand il a faim; il tire une langue d'une longueur démesurée lorsqu'il bâille. C'étoit une femelle, et l'on a cru remarquer que, depuis trois ans qu'elle est en France, elle n'a été qu'une fois en chaleur; elle étoit alors presque toujours furieuse ${ }^{1}$."

Voici la description que M. de Sève a faite d'un auimal tout semblable, qui étoit à la foire Saint-Germain en 1773 .

"Par le poil, dit-il, il a plus d'analogie à la loutre

ঐ. Note communiquée par M. Simon Chauveau à M. de Buffon. 
qu'aux autres animaux; mais il n'a point de membranes entre les doigts des pieds : il a la queue aussi longue que le corps, au lieu que celle de la loutre n'est que moitié de la longueur du corps. Il a bien en marchant l'allure de la fouine par son corps allongé; mais il n'y ressemble pas par la queue, ni par les formes de la tête, qui ont plus de rapport, dans cette partie, à celles de la loutre. L'œil est plus gros que celui de la fouine, qui a le museau plụs allongé; la tête, de face, tient un peu du petit chien danois. Il a une langue extrêmement longue et menue, qu'il allonge quelquefois dans la journée : cette langue est douce lorsqu'il lèche; car cet animal paroît être d'un assez bon naturel. Il étoit fort doux ce carême dernier, quand jai commencé à le dessiner : mais le public, qui l'agace, l'a rendı méchant; à présent il mord quelquefois après avoir léché. Il est jeune, et ses dents ne me paroissent pas formées, comme je le dirai ciaprès. Il est d'un tempérament remuant, aimant à grimper; souvent il se tient sur son derrière, se gratte avec ses pieds de devant comme les singes, joue, retourne ses pattes l'une dans l'autre, et fait d'autres singeries. Il mange comme l'écureuil, tenant entre ses pattes les fruits ou herbes qu'on lui donne. On ne lui a jamais donné de viande ni de poisson. Lorsqu’il s'irrite, il cherche à s'élancer, et son cri, dans sa colère, tient beaucoup de celui d'un gros rat. Son poil n'a aucune odeur. Il a la dextérité de se servir de sa quene pour accrocher les différentes choses qu'il veut attirer à lui. Il se pend avec cette queue, et aime à s'attacher de cette facon à tout ce qu'il rencontre. J'ai observé que ses pieds, dont les doigts ont une cer- 
taine longueur, se réunissent volontiers quand il marche ou grimpe; ils ne s'écartent point en s'appuyant, comme font les doigts des autres animaux, et les pieds ont par conséquent une forme alìongée; il a aussi en marchant un peu les pieds en dedans. Enfin cet animal (au dire de Saint-Louis, oiseleur rue de Richelieu, à Paris, qui l'a acheté d'un particulier) vient de la côte d'Afrique; on l'appeloit kinkajou, et l'espèce en est rare. Il se figure que c'est le nom de l'île ou du pays d'où il vient, ne pouvant avoir, par les personnes qui le lui ont vendu, les éclaircissements nécessaires. Je dirai seulement que ce kinkajou, qui est femelle, tient en général plus de la loutre que des autres animaux par rapport atx poils, qui sont courts et épais, mêlés de quelques poils plus longs. Les poils de la tête, comme ceux du corps et de la queue, sont d'une teinte jaune et olivâtre, mêlée de gris et de brun; par le luisant du poil qui est changeant à l'aspect du jour, il forme des tons différents, plus gris, plus verdâtres (qui sont les dominants), ou plus bruns. Ce poil est de couleur grise, blanchâtre dansla plus grande partie, et d'un fauve verdâtre sale à l'extrémité; il est mélangé d'autres poils dont l'extrémité est de couleur brune, indépendamment de plus grands poils noirs, mêlés plus ou moins dans les autres poils, et qui forment à côté des yeux des bandes qui s'étendent vers le front, et une autre au milieu qui s'affoiblit vers le cou. L'œil tient beaucoup de celui de la loutre; la pupille est fort petite, et l'iris d'un brun muse ou roussâtre. Le museau est d'un brun noir, comme le tour des yeux. Le bout du nez est méplat, comme aux petits chiens, el les narines très arquées. J'ou- 
verture de la bouche est de quinze lignes. Les dents, qui paroissent jaunes, sont au nombre de trente-deux. Dans la mâchoire supérieure il y a six incisives, comme dans la mâchoire inférieure, deux canines au devant de chacune, et quatre mâchelières de chaque côté aux deux mâchoires. Ces dents canines sont très grosses; la supérieure croise l'inférieure : aussi dans la mâchoire y a-t-il un vide entre les incisives et la canine inférieure pour y recevoir la supérieure. Les mâchelières paroissent peu fournies, surtout les dernières, qui annoncent la jeunesse de ce petit animal. Ainsi il a douze dents incisives, quatre canines, seize mâchelières, qui lui font trente-deux dents. Ses oreilles, plus longues que larges, sont arrondies à leurs extrémités, et couvertes d'un poil court de la couleur de celui du corps. Les côtés et le dessous du cou, le dedans des jambes, sont d'un jaune doré extrêmeunent vif par endroits. Cette même teinte dorée et plus foncée domine dans plusieurs endroits de la tête et des jambes de derrière. Le ventre est d'un blanc grisâtre, teint de jaune par endroits. La queue est partout garnie de poils; elle est grosse à l'origine du tronçon, va en diminuant imperceptiblement, et finit en pointe à l'extrémité. 11 la porte horizontalement en marchant. Le dessous de ses pattes, qui est sans poil, est couleur de chair vermeille. Les ongles sont blancs, crochus, et faisant la gouttière en dessous."

Longueur du corps entier, prise en ligne superficielle. . . . . . . . . . . . .

Longueur du corps entier, mesuré en ligne droite. pieds. pouc. lign.

Longueur de la tête, du bout du museau à l'occiput. 
Circonférence du bout du museau. . . . . . . 59

Circonférence du museau au dessus des yeux. . . " 51

Distance entre le bout du museau et l'angle antéricur de l'oil. ............. 15

Même distance entre l'angle postérieur de l'œil. , " 17

Largeur de l'œil d'un angle à l'autre. ..... . " " 7

Ouverture de l'oil. . . . . . . . . . " " 6

Distance entre les angles postérieurs des yeux en ligne superficiclle............ "

La même distance en ligne droite. ...... " " 7

Circonférence de la tête entre les yeux et les oreilles. " $\quad 7 \quad 70$

Longueur des oreilles............ 1 1

Largeur de la base mesurềe en ligne droile. . . " " 7

Longueur dn cor. . . . . . . . . . . . 19

Girconférence du cou. ........... 6 11

Hauteur du train de devant. . . . . . . . 69

Longueur de l'arant-bras depuis le coude jusqu'au

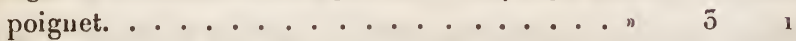

Longueur de l'avant-bras près du coude. . . . " 119

Eaisseur de l'avant-bras près du coude. . . . n 12

Circonférence du poignet. ......... n 247

Circonférence du métacarpe. ......... 248

Longueur du poignet jusqu'aux bout des ongles. . " 19

Circonférence du corps, prise derrière les jambes de devant. ...................... 104

Circonférence du corps, prise à l'endroit le plus gros. . . . . . . . . . . . n 11 (i

Girconférence du corps, devant les jambes de derrière......................... 9

Hauteur du train de derriere. ......... n 7

Longueur de la jambe depuis le genou jusqu'au talon................................ 4

Largeur du haut de la jambe. ......., " 2 ,

Épaisseur........................... 4

Largeur à l'endroit du talon. .......... 1 . 1 3

Circonférence du mélatarse. ....... " 2 " 24

Longueur depuis le talon jusqu'au bout des ongles. " 5 "

Largeur du pied de derant. . . . . . . . . . . 11

Largeur du pied de derrière. . . . . . . . . . . $1{ }_{2}$

Longueur des grands ongies. ........ w $4 \frac{1}{2}$ 
Largeur à la base. ........................

Longueur de la queue. . . . . . . . . . . 1 3 z

Circonférence de la queue à son origine. .... $4 \quad 4 \quad 6$

Diamètre de la queue à son origine. . . . . . . . $2_{2}$,

\section{LE KINKAJOU.}

Corcoleptes caudivolvulus. Intig.

LA conformité des noms de kinkajou et de carcajou m'avoit porté à croire, avec tous les autres naluralistes, qu'ils appartenoient au même animal. Cependant, ayant recherché dans les anciens voyageurs, ¡ai retrouvé ce même passage de Denis, que je n'avois cité qu'en partie, parce que j'avois imaginé que ce voyageur s'étoit trompé en disant que le kinkajou, que je prenois alors pour le carcajou, ressembloit à un chat, d'autant que tous les autres voyageurs s'accordoient à donner au carcajou une figure différente et semblable à celle du glouton. Voici donc ce passage en entier :

"Le kinkajou ressemble un peu à un chat d'un poil roux brun; il a la queue longue et la relève sur son ćos, pliće en deux ou trois plis; il a des griffes et grimpe sur les arbres, où il se couche tout de son long sur les branches pour attendre sa proie et se jeter dessus pour la dévorer. Il se jette sur le dos d'un orignal, l'entoure de sa queue, lui ronge le cou au dessus des oreilles, jusqu’à ce qu'il tombe. Quelque 
vite que puisse courir l'orignal, et quelque fort qu'il puisse se frotter contre les arbres ou les buissons, le kinkajou ne lâche jamais prise; mais s'il peut gagner l'eau, il est sauvé, parce qu'alors le kinkajou lâche prise et saute à terre. Il y a quatre ans qu'un kinkajou m'attrapa une génisse et lui coupa le cou. Les renards sont ses chasseurs; ils vont à la découverte tandis que le kinkajon est en embuscade, où il attend l'orignal, que les renards ne manquent pas de lui amener."

Cette notice s'accorde assez avec la figure et la description que nous venons de donner de cet animal. pour présumer que c'est le même, et que le carcajou et le kinkajou sont deux animaux d'espèces dislinctes et séparées, qui n'ont de commun entre eux que de se jeter sur les orignaux et sur les autres bêtes fauves pour en boire le sang.

Nous venons de dire que le kinkajou se trouve dans les montagnes de la Nouvelle-Espagne; mais il se trouve aussi dans celles de la Jamaĩque, où les naturels du pays le nomment potn, et non pas kinkajou. M. Coilinson m'a envoyé le dessin de ce poto ou kinkajou.

"Le corps de cet animal est de couleur uniforme, et d'un roux mêlé de gris cendré ; le poil court, mais très épais, la tête arrondie, le nuseau court, nu et noirâtre; les yeux bruns, les oreilles courtes et arrondies; des poils longs tout autour de la gueule, qui sont appliqués sur le musean et ne forment point de moustaches; la langue étroite, longue, et que l'animal fait souvent sortir de sa gueule, de trois ou quatre pouces; la queue de couleur uniforme, diminuant toujours de grosseur jusquà l'extrémité, qui se recourbe lorsque l'animal le veut, et avec laquelle it 
s'attache et peut saisir et serrer fortement. Cette queue est plus longue que le corps, qui a quinze pouces depuis le bout du nez jusqu'à l'extrémité du corps, et. la queue en a dix-sept.

"Cet animal avoit été pris dans les montagnes de la Jamaïque. Il est doux, el on peut le manier sans crainte; il est comme endormi la journée, et très vif pendant la nuit. Il diffère beaucoup de tous ceux dont le genre est déterminé. Sa langue n'est pas si rude que celle des chats ou des autres animaux du genre des viverra, auquel il a rapport par la forme de la tête et par celle des griffes. II a autour de la bouche beaucoup de poils longs de deux à trois pouces, qui sont bouclés et très doux. Les oreilles sont placées bas et presque vis-à-vis de l'œil. Quand il dort, il se met en boule, à peu près comme le hérisson, ses pieds ramassés en avant et étendus sous les joues. Il se sert de sa queue pour tirer un corps aussi pesant que son corps ${ }^{1}$. n

Il est évident, en comparant les deux dessins et la description de M. Collinson avec celle de M. Simon Chauveau, qu'elles ont toutes deux rapport au même animal, à quelques variétés près qui n'en changent pas l'espèce.

* Nous avons reconnu que le kinkajou, que nous n'avons pas d'abord distingué du carcajou ou glouton d'Amérique, est néanmoins d'une espèce toute différente; l'on peut voir ce que nous en avons dit dans ce volume. II ne nous reste qu'à y ajouter une nole que M. Simon Chauveau nous a donnée depuis, sur

1. Note envoyée par M. Collinson à M. de Buffon, 12 décembre $176 \mathrm{C}$. 
les habitudes du kinkajou qu’il a gardé vivant durant plusieurs années.

"Son altitude favorite est d'être assis d'aplomb sur son cul et ses pattes de derrière, le corps droit avec un fruit dans les pattes de devant, et la queue roulće en volute horizontale.

"J'ai plusieurs fơis pris la résolution, continue M. Simon Chauveau, de vous offrir cet animal vivant, pour le soumettre à vos observations : mais il venoit dans ces instants me caresser si doucement et jouer autour de moi avec tant de gaieté, que, séduit par ses gentillesses, je n'ai jamais eu le courage de m'en séparer. Il est mort le 3 janvier de cette année (1780), et c'étoit le neuvième hiver qu'il passoit à Paris, sans que le froid ni aucune autre chose eût paru l'avoir incomenodé."

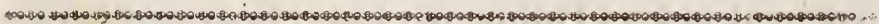

\section{LE LEMING ${ }^{1}$.}

Mus Lemmus. L.

- Olaus Magnus est le premier qui ait fait mention du leming; et tout ce qu'en ont dit Gesner, Scaliger, Zeigler, Jonston, etc., est tiré de cet auteur : mais Wormius, après des recherches plus exactes, a fait l'histoire de cet animal, et voici la description qu'il en

1. Nom de cet animal dans son pays natal en Norwége et que nous avons adopté. Mus Norvagicus a Norvagis leming, leminger, lemender, lemmer, appellatur. 
domne. "Il a, dit-il, la figure d'une somris, mais lit queue plus courle, le corps long d'environ cinq pouces, le poil lin el taché de diverses couleurs, la parlie antéricure de la tête noire, la partie supérieure jaunâtre, le cou et les épaules noirs, le reste du corps roussâtre, marqué de quelques petites taches noires de différentes figures jusqu'à la queve, qui n'à qu'un demi-pouce de longueur, el qui est couverte de poil jaune noirâtre. L'ordre des taches, non plus que leur figure et leur grandeur, ne sont pas les mêmes dans tous les individus. Il y a autour de la gueule plusieurs poils roides en forme de moustaches, dont il y en a six de chaque còté beaucoup plus longs et plus roides que les autres. L'ouverture de la gueule est pelite; la lèvre supérieure est fendue comme dans les écureuils. II sort de la mâchoire supérieure deux dents incisives longues, aiguës, un peu courbes, dont les racines pénètrent jusquà l'orbite des yeux; deux dents semblables dans la màchoire inféricure, qui correspondent à celles du dessus; trois mâchelières de chaqué côté, éloignées des dents incisives; la première des mâchelières fort large el composée de quatre lobes, la seconde de trois, la troisiène plus pelite, chacune de ces trois dents ayant son alvéole séparé, et toutes situées dans l'intérieur du palais, à un intervalle assez grand; la langue assez ample et s'étendant jusqu'à l'extrémité des dents incisives. Des débris d'herbe et de paille qui étoient dảns la grorge. de cet animal doivent faire penser qu'il rumine. Les yeux sont petits et noirs, les oreilles couchées sur le dos, les janbes de devant très courtes, les pieds couverts de poils et armés de cinq ongles aigus et courbés, dont 
celui du milieu est très long, et dont le cinquième est comme un pelit pouce ou comme un ergot de coq, silué quelquefois assez haut dans la jambe. Tout le ventre est blanchâtre, tirant tin peu sur le jaune, etc. » Get animal, dont le corps est épais et les jambes fort courtes, ne laisse pas de courir assez vite. Il habite ordinairement les montagnes de Norwége et de Laponie : mais il en descend quelquefois en si grand nombre dans de certaines années et dans de certaines saisons, qu'on regarde l'arrivée des lemings comme un fléau terrible, et dont il est impossible de se délivrer; ils font un dégât affreux dans les campagnes, dévastent les jardins, ruinent les moissons, et ne laissent rien que ce qui est serré dans les maisons, où heureusement ils n'entrent pas. Ils aboient à peu près comme de petits chiens; lorsqu'on veut les frapper avec un bâton, ils se jettent dessus et le tiennent si fort avec les dents, qu'ils se laissent enlever et transporter à quelque distance sans le vouloir quilter; ils se creusent des trous sous terre. et vont, comme les taupes, manger les racines; ils s'assemblent dans certains temps, et meurent, pour ainsi dire, tous ensemble; ils sont très courageux, et se défendent contre les autres animaux. On ne sait pas trop d'où ils viennent; le peuple croit qu'ils tombent avec la pluie. Le mâle est ordinairement plus grand que la femelle, et a aussi les taches noires plus grandes. Ils meurent infailliblement au renouvellement des herbes. Ils vont aussi en grandes troupes sur l'eau dans le beau temps; mais s'il vient un coup de vent, ils sont tous submergés. Le nombre de ces animaux est si prodigieux, que, quand ils meurent, l'air en est infecté, et cela occa- 
sione lieaucoup de maladies; il semble mêne qu'ils infectent les plantes qu'ils ont rongées, car le pâturage fait alors mourir le bétail. La chair des lemings n'est pas bonne à manger, et leur peau, quoique d'un beau poil, ne peut pas servir à faire des fourrures, parce qu'elle a trop peu de consistance.

\section{LES MOUFETTES.}

Nous donnons le nom générique de moufeltes à trois ou quatre espèces d'animaux qui renferment et répandent, lorsqu'ils sont inquiétés, une odeur si forte et si mauvaise, qu'elle suffoque comme la vapeur souterraine qu'on appelle moufette. Ces animaux se trouvent dans toute l'étendue de l'Amérique méridionale et tempérée: ils ont été désignés indistinctement par les voyageurs sous les noms de puants, bêtes puantes, enfants du diable, etc.; et non seulement on les a confondus entre eux, mais avec d'autres qui sont d'espèces très éloignées. Hernandès a indiqué assez clairement trois de ces animaux. Il appelle le premier ysquiepatl, nom mexicain que nous lui conserverions, s'il étoit plus aisé de le prononcer; il en donne la description et la figure, et c'est le même animal dont on trouve aussi la figure dans l'ouvrage de Seba: nous l'appellerons coase, du nom squash qu'il porte dans la Nouvelle-Espagne. Le second de ces animaux, que Hernandès nomme aussi ysquiepatl, est celui qui est ici représenté, et que nous appellerons chinche, du 

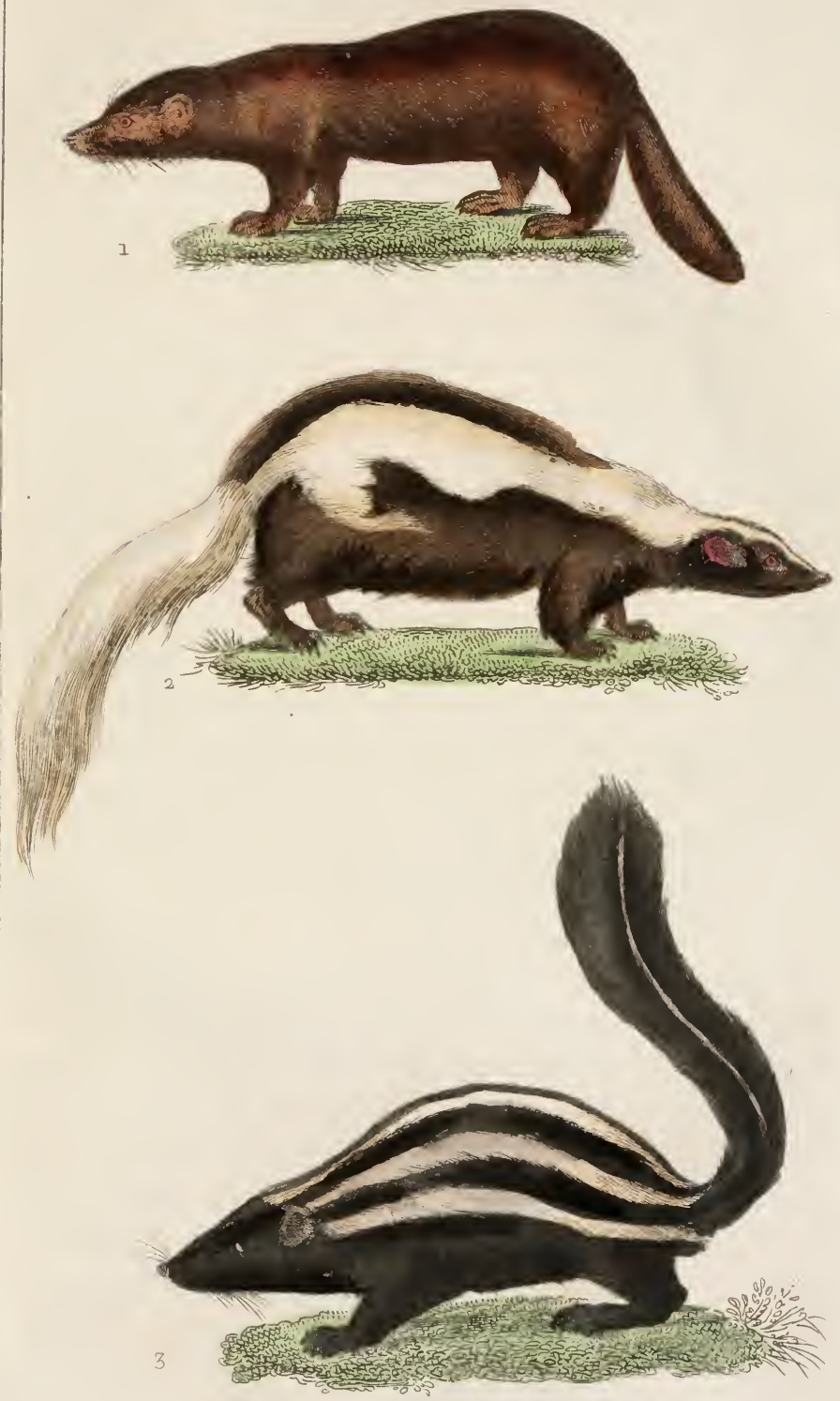

nom quil porte dans l'Amérique méridionale. Le troisieme, que Hernandès nomme conepatl, et auquel nous conserverons ce nom, est le même que celui qui a été donné par Catesby sous la dénomination de putois d'Amérique, et par M. Brisson sous celle de putois rayé. Enfiu nous connoissons encore une quatrième espèce de moufette, à laquelle nous donnerons le nom de zorille, qu'elle porte au Pérou et dans quelques autres endroits des Indes espagnoles.

C'est à M. Aubry, curé de Saint-Louis, que nous sommes redevables de la connoissance de deux de ces animaux; son goût et ses lumières en histoire naturelle brillent dans son cabinet, qui est un des plus cu. rieux de la ville de Paris : il a bien voulu nous communiquer ses richesses toutes les fois que nous en avons eu besoin, et ce ne sera pas ici la seule occasion que nous aurons d'en marquer notre reconnoissance. Ces animaux, que M. Aubry a bien voulu nous prêter pour les faire dessiner et graver, sont le coase, le chinche, et le zorille. On peut regarder ces deux derniers comme nouveaux, car on n'en trouve la figure dans aucun auteur.

Le premier de ces animaux est arrivé à M. Aubry sous le nom de pekan, enfant du diable, ou chat sauvage de Virginie. J'ai vu que ce n'étoit pas le pekan; j'ai rejeté les dénominations d'cnfant du diable et de chat sauvage, comme factices et composées, et j'ai reconnu que c'étoit le inême animal que Hernandès a décrit sous le nom d'ysquiepatl, et que les voyageurs ont indiqué sous celui de squash; et c'est de cette dernière dénomination que j’ai dérivé le nom de coase que je lui ai donné. Il a cuviron seize pouces de long. 
y compris la tête et le corps; il a les jambes courtes, le museau mince, les oreilles petites, le poil d'un brun foncé, les ongles noirs et pointus; il habite dans des trous, dans des fentes de rochers, où il élève ses petits; il vit de scarabées, de vermisseaux, de petits oiseaux; et lorsqu'il peut entrer lans une basse-cour, il étrangle les volailles, desquelles il ne mange que la cervelle. Lorsqu'il est irrité ou efrayé, il rend une odeur abominable : c'est pour cet animal un moyen sûr de défense; ni les hommes ni les chiens n'osent en approcher. Son urine, qui se mêle apparemment avec cette vapeur empestée, tache et infecte d'une manière indélébile. Au reste, il paroît que cette mauvaise odeur n'est point une chose habituelle. "On m'a envoyé de Surinam cet animal vivant, dit Seba; je l'ai conservé en vie pendant tout un été dans mon jardin, où je le tenois attaché avec une petite chaîne: il ne mordoit personne; et lorsqu'on lui donnoit à manger, on pouvoit le manier comme un petit chien. Il creusoit la terre avec son museau, en s'aidant des deux palles de devant, dont les doigts sont armés d'ongles longs et recourbés. Il se cachoit pendant le jour dans une espèce de tanière qu'il avoit faite luimême : il en sortoit le soir; et, après s'être nettoyé, il commençoit à courir, et couroil ainsi toute la uuit, à droite el à gauche, aussi loin que sa chaîne lui permettoit d'aller; il furetoit partont, portant le nez en terre. On lui donnoit chaque soir à manger, et it ne-prenoit de nourriture que ce qu'il lui en falloit, sans toucher au reste: il n'aimoit ni la chair, ni le pain, ni quantité d’autres nourritures; ses délices éloient les panais jaunes, les chevrelles crues, les 


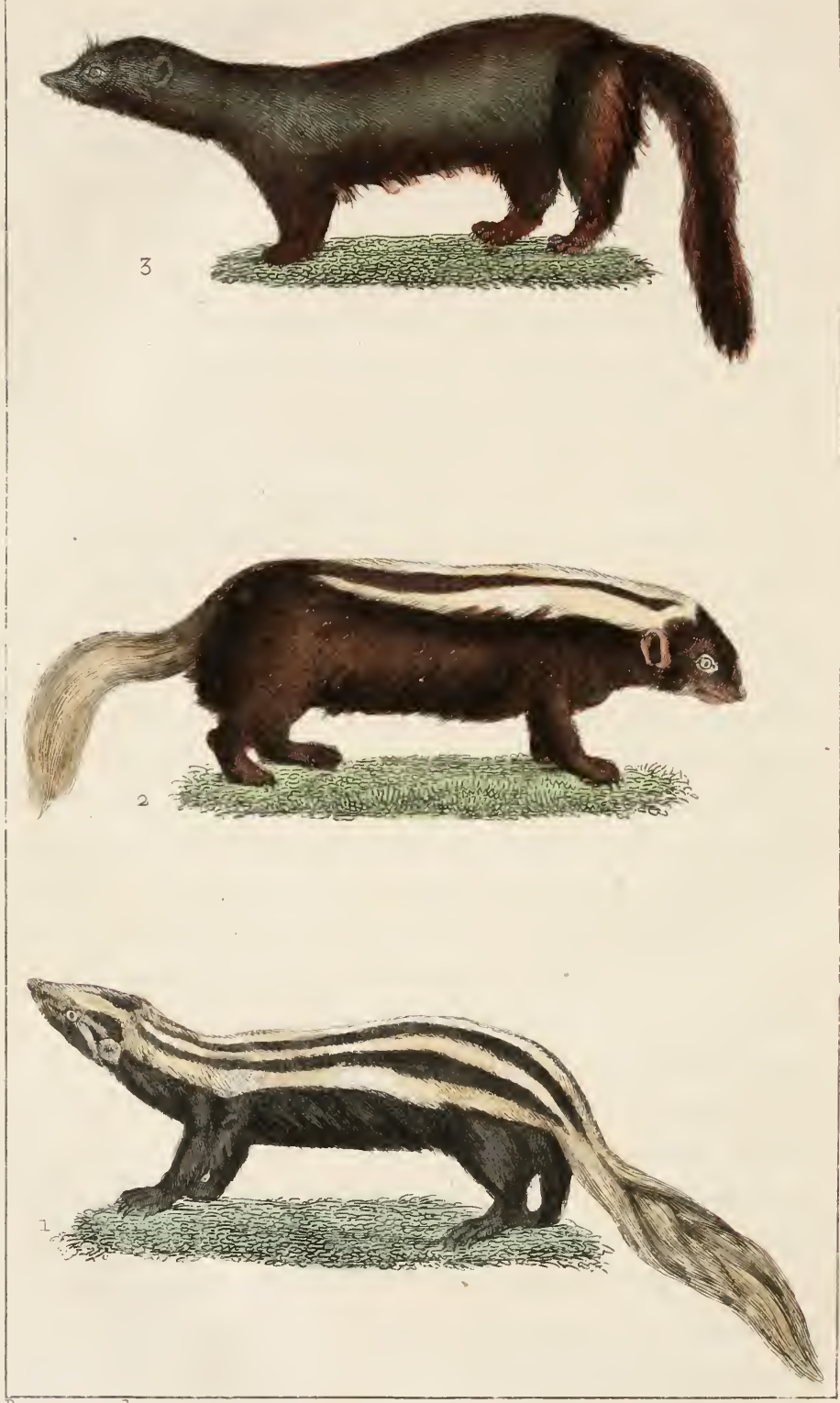

Paquaet, scult?

I.IE ZORITIF - 2.IA MOUFFETTEDU CHITI_3.IE PEKAÑ. 
chenilles et les araignées.... Sur la fin de l'automne, on le trouva mort dans sa tanière; il ne put sans doute supporter le froid. II a le poil du dos d'un châtain foncé, de courtes oreilles, le devant de la tête zond, d'une couleur un peu plus claire que le dos, et le ventre jaune. Sa queue est d'une longueur médiocre, couverte d'un poil brun et court : on y renarque tout autour comme des anneaux jaunâtres. " Nous observerons que, quoique la description et la figure données par Seba s'accordent très bien avec la description et la figure de Hernandès, on pourroit néanmoins douter encore que ce fût le même animal, parce que Seba ne fait aucune mention de son odeur délestable, et qu'il est difficile d'imaginer comment il a pu garder dans son jardin, pendant tout un été, une bête aussi puante, et ne pas parler, en la décrivant, de l'incommodité qu'elle a dû causer à ceux qui l'approchoient. On pourroit donc croire que cet animal, donné par Seba sous le nom d'ysquiepatl, n'est pas le véritable, ou bien que la figure donnće par Hernandès a été appliquée à l'ysquiepatl, tandis qu'elle appartenoit peut-être à un autre animal : mais ce loute, qui d'abord paroît fondé, ne subsistera plus quand on saura que cet animal ne rend cette odeur empestée que quand il est irrité ou pressé, et que plusieurs personnes en Amérique en ont élevé et apprivoisé.

De ces quatre espèces de moufettes que nous venons d'indiquer sous les noms de coase, conepate, chinche, et zorille, les deux dernières appartiennent aux clinats les plus chauds de l'Amérique méridionate, of pommoient bien n'ère que deux variétés. et 
non pas deux espèces différentes. Les deux premières sont du climat tempéré de la Nouvelle-Espagne, de la Louisiane, des Illinois, de la Caroline, etc., et me paroissent être deux espèces distinctes et différentes des deux autres, surtout le coase, qui a le caractère particulier de ne porter que quatre ongles aux pieds de devant, tandis que tous les autres en ont cinq. Mais, au reste, ces animaux ont tous à peu près la même figure, le même instinct, la même mauvaise odeur, et ne diffèrent, pour ainsi dire, que par les couleurs et la longueur du poil. Le coase est, comme on vient de le voir, d'une couleur brune assez uniforme, et n'a pas la queue touffue comme les autres. Le conepate a sur un fond de poil noir cinq bandes blanches qui s'étendent longitudinalement de la tête à la queue. Le chinche est blanc sur le dos et noir sur !es flancs, avec la tête toute noire, à l'exception d'une bande blanche qui s'étend depuis le chignon jusqu'au chanfrein du nez; sa queue est très touffue et fournie de très longs poils blancs, mêlés d'un peu de noir. Le zorille, qui s'appelle aussi mapurita, paroît être d'une espèce plus petite : il a néanmoins la queue tout aussi belle et aussi fournie que le chinche, dont il diffère par la disposition des taches de sa robe; elle est d'un fond noir, sur lequel s'étendent longitudinalement des bandes blanches depuis la tête jusqu'au milieu du dos, et d'autres espèces de bandes blanches transversalement sur les reins, la croupe, et l'origine de la queue, qui est noire jusqu'au milien de sa longueur, et blanche depuis le milieu jusqu'à l'extrémité, au lieu que celle du chinche est partout de la même couleur. Tous ces animaux sont à peu 
près de la même figure et de la même grandeur que le putois d'Europe : ils lui ressemblent encore par les habitudes naturelles, et les résultats physiques de leur organisation sont aussi les mêmes. Le putois est de tous les animaux de ce continent celui qui répand la plus mauvaise odeur; elle est seulement plus exaltée dans les moufettes, dont les espèces ou variétés sont nombreuses en Amérique, au lieu que le putois est seul de la sienne dans l'ancien continent: car je ne crois pas que l'animal dont Kolbe parle sous le nom de blaireau puant, et qui me paroît être une véritable moufette, existe au cap de Bonne-Espérance comme naturel au pays; il se peut qu'il y ait été transporté d'Amérique, et il se peut aussi que Kolbe, qui n'est point exact sur les faits, ait emprunté sa description du P. Zuchel, qu'il cite comme ayant vu cet animal au Brésil. Celui de la Nouvelle-Espagne, que Fernandès indique sous le nom de ortohua, me paroît être le même animal que le zorilla du Pérou; et le tepemaxtla du même auteur pourroit bien être le conepate, qui doit se trouver à la Nouvelle-Espagne comme à la Louisiane et à la Caroline.

\section{LA MOUFETTE DU GHILI.}

Mephitis chilensis. Georf.

M. Doniby, correspondant du Cabinet du Roi, ei que nous avons eu occasion de citer plusieurs lois, 
nous a rapporté la dépouille d'un individu de cette espèce. Cette moufette se trouve au Chili, et appirrtient à la famille du zorille, du conepate et d'autres animaux appelés bêtes puantes, et qui se trouvent également dans l'Amérique méridionale. Ses habitudes, sur lesquelles nous n'avons reçu aucune observation particulière, doivent être assez semblables à celles de ces animaux puants, dont elle se rapproche par sa conformation, ainsi que par la distribution de ses couleurs. L individu dont nous avons vu la peau bourrée étoit mâle. Il avoit la tête large et courte, les oreilles rondes et un peu aplaties, le corps épais et large à l'endroit des reins, les cuisses larges et char nues, les jambes courtes, les pieds petits, cinq doigts à chaque pied, et les ongles longs, crochus, et recourbés en gouttière ${ }^{1}$. Sa queue, relevée au dessus du dos comme celle des écureuils, étoit large et garnie de poils touffus, longs de près de trois pouces. Le poil qui couvroit sa tête, son corps, ses jambes, et le dessus de sa queue vers l'origine de cette partie, avoit en quelques endroits un pouce de longueur, el étoik d'un brun noirâtre et luisant; le reste du poil qui garnissoit sa queue étoit blanc, et l'on voyoit sur le dos deux larges bandes blanches qui se réunissoient en une seule ${ }^{2}$.

1. Liongle le plus long des pieds de derant avoit onze lignes de longueur; et celui des pieds de derrière, cinq lignes.

2. Cet individu avoit un pied sept pouces trois lignes, depuis le bout du museau jusqu’à l'anus; et la queue étoit longue de sept pouces quatre lignes, en y comprenant la longueur do poil. Les alents manquoient à la dépouille. 


\section{LE PEKAN ET LE VISON.}

Mustela Canadensis. Giet. - Mustela Vison. Gyez.

IL y a long-temps que le nom de pekan étoit en usage dans le commerce de la pelleterie du Canada, sans que l'on en connût mieux l'animal auquel il appartient en propre : on ne trouve ce nom dans aucun naturaliste, et les voyageurs l'ont employé indistinctement pour désigner différents animaux, et surtout les monfettes; d'autres ont appelí renard ou chat sauvage l'animal qui doit porter le nom de pekan, et it n'étoit pas possible de tirer aucune connoissance précise des notices courtes et fautives que tous en ont données. Il en est du vison comme du pekan, nous ignorons l'origine de ces deux noms, et personne n'en savoit autre chose, sinon qu'ils appartiennent à deux animaux de l'Amérique septentrionale. Nous les avons trouvés, ces deux animaux, dans le cabinet de M. Aubry, curé de Saint-Louis, el il a bien voulu nous les prêter pour les décrire et les faire dessiner.

Le pekan ressemble si fort à la marte, et le vison à la fouine, que nous croyons qu'on peut les regarder comme des variétés dans chacune de ces espèces ${ }^{4}$; ils ont non seulement la mème forme de corps, les mêmes proportions, les mémes longueurs de queue,

1. Je serois assez porté à croire que l'animal indiqué par Sagard Théodal sous le nom de otlay pourroil ètre le neème que le vison. 
la même qualité de poil, mais encore le même nombre de dents et d'ongles, le même instinct, les mêmes habitudes naturelles : ainsi nous nous croyons fondés à regarder le pekan comme une variété dans l'espèce do la marte, et le vison comme une variété dans celle de la fouine, ou du moins comme des espèces si voisines, qu'elles ne présentent aucune différence réelle: Le pekan et le vison ont seulement le poil plus brun, plus lustré, et plus soyeux que la marte et la fouine; mais cette différence, comme l'on sait, leur est commune avec le castor, la loutre, et les autres animaux du nord de. l'Amérique, dont la fourrure est plus belle que celle de ces mêmes animaux dans le nord de.l'Europe.

\section{LA ZIBELINE ${ }^{1}$.}

\section{Musiela Zibellina. L.}

P'resque tous les naturalistes ont parlé de la zibeline sans la connoître autrement que par sa fourrure. M. Gmelin est le premier qui en ait donné la figure et la description : il en vit deux vivantes chez le gouverneur de Tobolsk. "La zibeline ressemble, dit-il, à la marte par la forme et l'habitude du corps, et à la belette par les dents : elle a six dents incisives, assez longues, et un peu courbées, avec deux longues dents

1. Marte zibeline; zobel en allemand; sobol en polonvis; sabbel en suédois; sable en anglois. 
canines à la mâchoire inférieure, de petites dents très aiguës à la mâchoire supérieure, de grandes moustaches antour de la gueule, les pieds larges et tous arnés de cinq ongles. Ces caractères étoient communs à ces deux zibelines : mais l'une étoit d'un brun noirâtre sur tout le corps, à l'exception des oreilles et du dessous du menton, où le poil étoit un peu fauve; et l'autre, plus petite que la première, étoit, sur tout le corps, d'un brun jaunâtre, avec les oreilles et le dessous du menton d'une nuance plus pâle. Cics couleurs sont celies de l'hiver; car au printemps elles changent par la mue du poil : la première zibeline, qui étoit d'un brun noir, devint en été d'un jaune brun; et la seconde, qui étoit d'un brun jaune, devint d'un jaune pâle. J'ai admiré, continue M. Gmelin, l'agilité de ces animaux; dès qu'ils voyoient un chat, ils se dressoient sur les pieds de derrière comme pour se préparer au combat. Its sont très inquiets et fort remuants pendant la nuit ${ }^{1}$; pendant le jour, au contraire, et surtout après avoir mangé, ils dorment ordinairement une demi-heure ou une heure : on peut dans ce temps les prendre, les secouer, les piquer sans qu'ils se réveillent. "Par cette description de M. Gmelin, on voit que les zibelines ne sont pas toutes de la même couleur, et que par conséquent les namenclateurs qui les ont désignées par les taches et les couleurs du poil ont employé un mauvais caractère, puisque non seulement il change dans les différentes

1. Cette inquiétude et ce monvement pendant la nuit n'est pas pariiculier à la ribeline : $\mathrm{j}$ 'ai vu la même chose aux hermines que nous avors cues vivantes, et que nous avous nourries pendant plusieurs inois. 
saisons, mais qu'il varie d'individu à individu et de climat à climat ${ }^{1}$.

Les zibelines habitent le bord des fleuves, les lieux ombragés, et les bois les plus épais; elles sautent très agilement d'arbre en arbre, et craignent fort le soleil, qui change, dit-on, en très peu de temps la couleur de leur poil. On prétend qu'elles se cachent et qu'elles sont engourdies pendant l'hiver; cependant c'est dans ce temps qu'on les chasse et qu'on les cherche de préférence, parce que leur fourrure est alors bien plus belle et bien meilleure qu'en été. Elles vivent de rats, de poisson, de graines de pin, et de fruits sauvages. Elles sont très ardentes en amour: elles ont pendant ce temps de leur chaleur une odeur très forte, et en tout temps leurs excréments sentent mauvais. On les trouve principalement en Sibérie, et il n'y en a que pen dans les forêts de la grande Russie, et encore moins en Taponie. Les zibelines les plus noires sont celles qui sont les plus estimées. La différence qu'il y a de cette fourrure à toutes les autres, c'est qu'en quelque sens qu'on pousse le poil il obéit également, au lieu que les autres poils, pris à rebours, font sentir quelque roideur par leur résistance.

La chasse des zibelines se fait par des criminels confinés en Sibérie, ou par des soldats qu'on y envoie

1. Des deux zibelines doni parle M. Gmelin, la première venoit de la province de Tomskien, et la seconde de celle de Beresowien. On trouve aussi, dans sa relation de la Sibérie, que sur la montagne de sopka-Sinaia il y a des zibelines noires à poil court, auxquelles il est défendu de donner la chasse; qu'une semblable espèce de zibeline se trouve aussi plus avant dans les montagnes, de même que chez les Calmouks-Vrangais. 
exprès, et qui y demenrent ordinairement plusieurs années : les uns et les autres sont obligés de fournir une certaine quantité de fourrures à laquelle ils sont taxés. Ils re tirent qu'à balle seule, pour gâter, le moins qu'il est possible, la peau de ces animaux, et quelquefois, au licu d'armes à feu, ils se servent d'arbalètes et de très petites flèches. Comme le succès de cette chasse suppose de l'adresse, et encore plus d'assiduité, on permet aux officiers d'y intéresser leurs soldats, et de partager avec eux le surplus de ce qu'ils sont obligés de fournir par semaine; ce qui ne laisse pas de leur faire un bénéfice tiès considérable.

Quelques naturalistes ont soupçonné que la zibeline étoit le satherius d'Aristote, et je crois leur conjecture bien fondée. La finesse de la fourrure de la zibeline indique qu'elle se tient souvent daus l'eau; el quelques voyageurs disent qu'elles ne se trouvent en grand nombre que dans de petites îles, où les chasseurs vont les chercher. D'autre côté, Aristote parle du sutherius comme d'un animal d'eau, et il le joint à la loutre et au castor. On doit encore présumer que, du temps de la magnilicence d'Athènes, ces belles fourrures n'étoient pas inconunes dans la Grèce et que l'animal qui les fournit avoit un nom : or, il n'y en a aucun qu'on puisse appliquer ì la zibeline avec plus de raison que celui de satherius, si, en effet, il est vrai que la zibeline mange du poisson et se tienne assez souvent dans l'eau pour être mise au nombre des amphibies.

* Nous n'avons rien à ajouter à ce que nous avons dit de la zibeline, que quelques faits rapportés par les voyageurs russes, et qui ont été insérés dans les 
derniers volumes de l'Histoire générate des voyages.

"Les zibelines vivent dans des trous; leurs nids sont ou dans des creux d'arbres, ou dans leurs trones couverts de mousse, ou sous leurs racines, ou sur des hauteurs parsemées de rochers. Elles construisent ces nids de mousse, de branches, et de gazon. Elles restent dans leurs trous ou dans leurs nids pendant douze heures, en hiver comme en été, et le reste du temps elles vont chercher leur nourriture. En attendant la plus belle saison, elles se nourrissent de belettes, d'hermines, d'écureuils, et surtout de lièvres; mais, dans le temps des fruits, elles mangent des baies et plus volontiers le fruit du sorbier. En hiver, elles attrapent des oiseaux et des cors de bois. Quand il fait de la neige, elles se retirent dans leurs trous, où elles restent quelquefois trois semaines. Elles s'accouplent au mois de janvier. Leurs amours durent un mois, et souvent excitent des combats sanglants entre les inâles. Apr ès l'accouplement, elles gardent leui's nids environ quinze jours. Elles mettent bas vers la fin de mars, et font depuis trois jusqu'à cinq petits, qu'elles allaitent pendant quatre ou six semaines.

"On ne les chasse qu'en hiver, et les chasseurs vont ensemble jusqu'au nombre de quarante à cetie chasse; ils $\mathrm{y}$ vont en canot, et prenuent des provisions pour trois on quatre mois. Ils ont un chef qui, arrivé au lieu du rendez-vous, ainsi que tous les chasseurs, assigne à chaque bande son quartier, et tous les chasseurs doivent lui obéir. On écarte la neige où l'on veut dresser des piéges; chaque chasseur en dresse vingt par jour. On choisit un petit espace au- 
près des arbres; on l'entoure, à une certaine hauteur, de pieux pointus; on le couvre de petites planches, afin que la neige ne tombe pas dedans; on y laisse une entrée fort étroite, au dessus de laquelle est placée une poutre qui n'est suspendue que par un léger morceau de bois; et sitôt que la zibeline y touche pour prendre le morceau de viande ou de poisson qu'on a mis pour amorce, la bascule tombe et la tue. On porte toutes les zibelines au conducteurgénéral, ou bien on les cache dans des trous d'arbres, de crainte que les 'Tunguses ou d'autres peuples sauvages ne viennent les enlever de force. Si les zibelines ne se prennent pas dans les piéges, on a recours aux filets. Quand le chasseur a trouvé la trace d'un de ces animaux, il la suit jusqu'à son terrier, et l'oblige d'en sortir au moyen de la fumée du feu qu'il allume; il tend son filet autour de l'endroit où la trace finit, et se tient deux ou trois jours de suite aux aguets avec son chien; ce filet a treize toises de long sur quatre ou cinq pieds de haut. Lorsque la zibeline sort de son terrier, elle manque rarement de se prendre ; t quand elle est bien embarrassée dans le filet, les chiens l'étranglent. Si on les voit sur les arbres, on les tue à coups de flèches, dont la pointe est obtuse, pour ne point endommager la peau. La chasse étant finie, on regagne le rendez-vous général, et on se rembarque aussitòt que les rivières sont devenues navigables par le dégel. " 


\section{LE TARSIER.}

Lemur Spectrum. Parcas.

Nous arons eu cet animal par hasard, et d'une personne qui n'a pu nous dire ni d'où il venoit, ni comnent on l'appeloit : cependant il est très remarquable par la longueur excessive de ses jambes de derrière; les os des pieds, et surtout ceux qui composent la partie supérieure du tarse. sont d'une grandeur démesurée, et c'est de ce caractère très apparent que nous avons tiré son nom. Le tarsier n'est cependant pas le seul animal dont les jambes de derrière soient ainsi conformées; la gerboise a le tarse encore plus long : ainsi ce nom tarsier, que nous donnons aujourd'hui à cet animal, ne doit être pris que pour un nom précaire, qu'il faudra changer lorsqu'on connoîtra son vrai nom. c'est-à-dire le nom qu'il porke dans le pays qu'il habite. La gerboise se trouve en Egyte. en Barbarie, et aux Indes orientales. J'ai d'abord imaginé que le tarsier pouvoit être du mème continent ef du inême climat, parce qu'au premier coup d'œil il paroît lui ressembler beaucoup. Ces deux animaux sont de la même grandeur; tous deux ne sont pas plus gros qu'un rat de moyemne grosseur; tous deux on les jambes de derrière excessivement longues, et celles de devant extrêmement courles; tous deux ont la queue prodigieusement aliongée et garnie de grands poils à 
son extrémité ; tous deux ont de très grands yeux, des oreilles droites, larges et ouvertes; tous deux ont également la partie inférieure de leurs longues jambes dénuée de poil, tandis que tout le reste de leur corps en est couvert. Ces animaux ayant de commun ces caractères très singuliers, et qui n'appartiennent qu'ì eux, il semble qu'on devroit présumer qu'ils sont d'es. pèces voisines, ou du moins d'espèces produites par le même ciel et la même terre : cependant, en les comparant par d'autres parties, l'on doit non senlement en douter, mais même présumer le contraire. Le tarsier a cinq doigts à tous les pieds; il a, pour ainsi dire, quatre mains, car ces cinq doigts sont très longs et bien séparés : le pouce des pieds de derrière est terminé par un ongle plat; et quoique les nugles des autres doigts soient pointus, ils sont en même temps si courts et si petits, qu'ils n'empêchent pas que l'animal ne puisse se servir de ses quatre pieds comme de mains. La gerboise au contraire n'a que quatre doigts et quatre ongles longs et courbés aux pieds de devant, el au tieu du pouce il n'y a qu'un tubercule sans ongles : mais ce qui l'éloigne encore plus de notre tarsier, c'est qu'elle n'a que trois doigts ou trois grands ongles aux pieds de derrière. Cielte différence est trop grande pour qu'on puisse regarder ces animaux comme d'espèces voisines, et il ne seroit pas impossible qu'ils fussent aussi très éloignés par le climat; car le tarsier avec sa petite taille, ses quatre mains, ses longs doigts, ses petits ongles, sa grande queue, seslongs pieds, semble se rapprocher beaucoup de la marmose, du cayopollin, et d'un autre petit animal de l'Amérique méridionale, dont nous parlerons 
556

A I I A UX SAUVAGES.

dans Je volume suivant. L'on voit que nous ne faisons ici qu'exposer nos doules, et l'on doit sentir que nous aurions obligation à ceux qui pourroient les fixer en nous indiquant le climat et le nom de ce petit animal.

FIN DU DIX-SFPTIEME VOLUME. 


\section{TABLE}

\section{DES ARTIGI ES}

CONTENUS

DANS LE DIXSEP-TIEME VOLUME.

\section{MAMMIF́̀RES.}

Le Mouflon et les autres Brebis étrangères. . . . . Page 7

Le Belier et la Brebis de Valachie. . . . . . . . 25

Le Belier de Tunis. . . . . . . . . . . 24

Le Morvant de la Chine. . . . . . . . . . . ${ }_{2} 5$

Le Bouc à longs sabots. . . . . . . . . . . 30

L'Axis. . . . . . . . . . . . . . . 39

Le Zèbre. . . . . . . . . . . . . . . 45

Le Couagga. . . . . . . . . . . . . . . 59

L'Élan et le Renne. . . . . . . . . . . . . 63

Le Bouquetin, le Chamois, el les autres Chèrres. . . . 120

Le Saĩga. . . . . . . . . . . . . . 137

Les Grazelles. ................... 141

La Gazelle pasan. ....................... 175

La Gazelle antilope. . . . . . . . . . . 177

La Gazelle tzeiran. ............... 18 I

La Ghèrre sautante du cap de Bonne-Espérance. . . 188

La Gazelle à bourse sur le dos. . . . . . . . . . $19^{\mathbf{5}}$

Le Klippspringer, ou Sauteur des rochers. . . . . . ${ }_{196}^{6}$

Le Bosbok. . . . . . . . . . . . . . . 197

Le Ritbok. . . . . . . . . . . . . . . 199

La Chèvre bleue. . . . . . . . . . . . 204

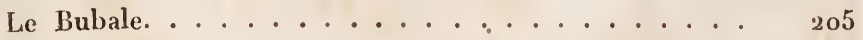

Le Coudous. . . . . . . . . . . . 215

Le Canna. . . . . . . . . . . . . 218

Le Condoma ................. . . . 226

Le Nil-Gaut. . . . . . . . . . . . ${ }_{2} 20$

Le Guib. . . . . . . . . . . . . . . 254

La Grimme. . . . . . . . . . . . 256 
Les Chevrotains.

Le Memina.

Le Cherrotain, appelé à Java petite Gazelle. ibid.

Le Chevreuil des Indes.

Les Mazammes.

Le Musc.

Le Babiroussa.

Le Tapir, ou l'Anta. . . . . . . . . . . 301

L'Hippopotame. ................... 319

Le Cabiai. . . . . . . . . . . . . 352

Le Pore-Epic. . . . . . . . . . . . 355

Le Porc-Épic de Malaca. . . . . . . . . . . 361

Le Coendou. . . . . . . . . . . . . . 363

Le Coendou à longue queue. . . . . . . . . . 367

L'Urson. . . . . . . . . . . . . . . $3_{70}$

Le Tanrec et le Teridrac. ............ $33_{72}$

La Girafe. . . . . . . . . . . . . . 5 5 56

Le Lama et le Paco. . . . . . . . . . . . 405

La Vigogne. . . . . . . . . . . . . . . 420

L'Unau et l'Ai. . . . . . . . . . . . . 434

Le Kouri, ou le petit Unau. .......... 446

Le Surikate. . . . . . . . . . . . . 449

Le Phalanger. ................ 453

Le Coquallin. . . . . . . . . . . . . . . 455

Les Gerboises. . . . . . . . . . . . 457

La Mangouste. . . . . . . . . . . . . 481

La fossane. . . . . . . . . . . . . . . 187

Le Vansire. . . . . . . . . . . . . . 489

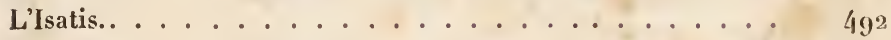

Le Glouton. . . . . . . . . . . . . . 497

Le Carcajou. . . . . . . . . . . . . . 505

Le Kinkajou. . . . . . . . . . . . 514

Le Leming. . . . . . . . . . . . . . 517

Les Houfeltes. . . . . . . . . . . . . 520

La Moufetle du Chili. . . . . . . . . . 525

Le Pekan et le Visou. . . . . . . . . . . 527

La Zibeline. . . . . . . . . . . . . 528

t.e 'Tarsier. . . . . . . . . . . . . 554 


ancyougr athor.

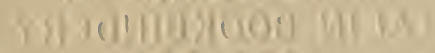

(1) () 19780 


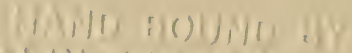

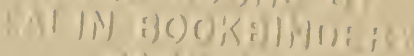
$(1) i^{3}=100 n$ 

